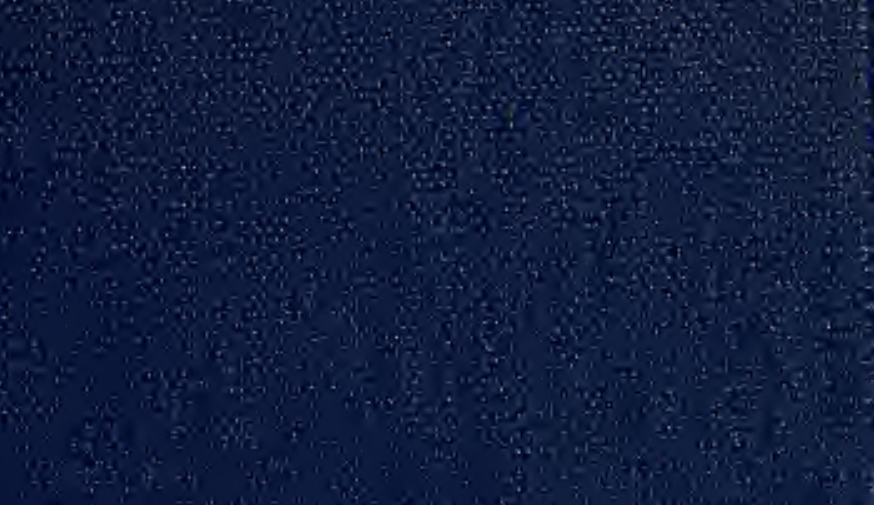


Cooper..' ... nibrary

2 Eas is ilieet

New Xork Lew York ion28 






\section{ARTS APPLIQUÉS}

ET

IDUSTRIES D'ART

AUX

EXPOSITIONS

Q 


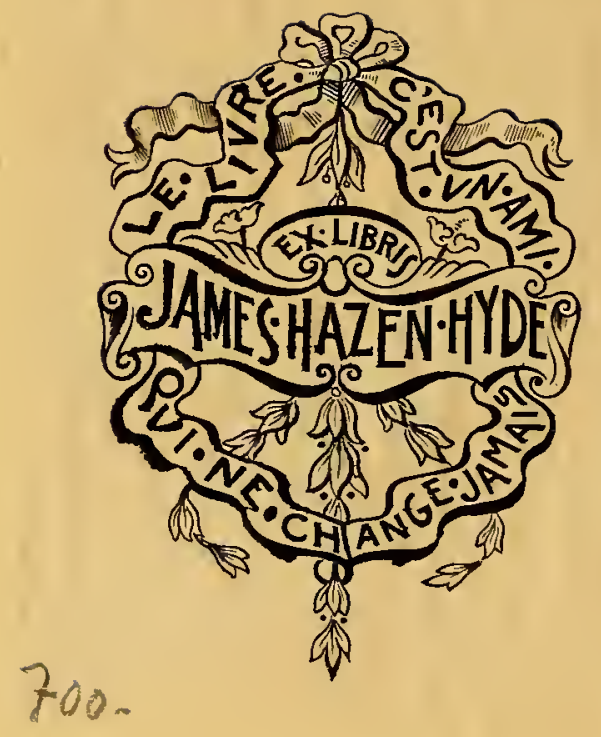




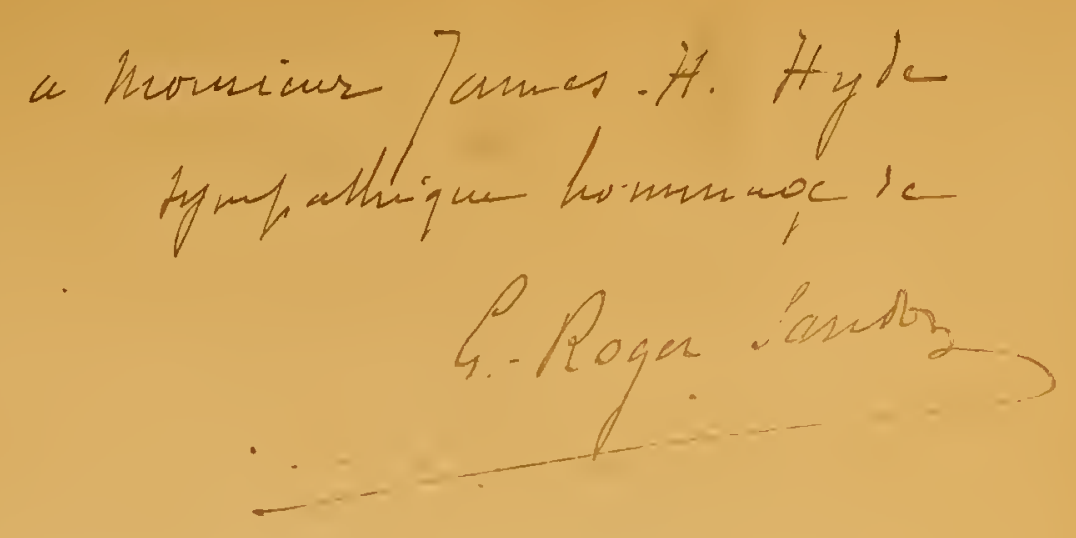

Arts appliqués et Industries d'Art

\author{
aux Expositions
}



1912

${ }^{{ }^{\prime+M} \text { ARTS APPLIQUÉS }}$

ET

\section{INDUSTRIES D'AR'T}

aux Expositions

PAR

G.-Roger SANDOZ et Jean GUIFFREY

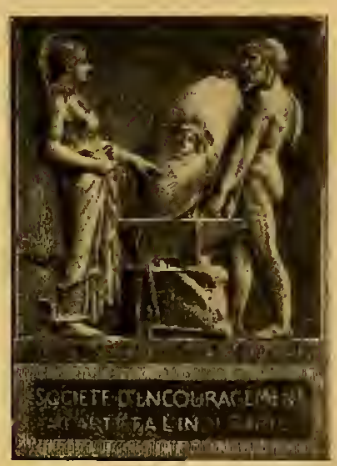

COMITÉ FRANÇAIS DES EXPOSITIONS A L'ÉTRANGER et

SOCIÉTÉ D'ENCOURAgEMENT A L'ART ET A L'INDUSTRIE

PARIS

1912 


$$
\text { - vly } 7.1900
$$

$$
329911
$$




\title{
Arts appliqués et Industries d'Art aux Expositions
}

\author{
Cañan - \\ I \\ Le Directoire, le Consulat, l'Empire
}

$1798-1815$

Oriniue des Expositions. - Les vieilles Fuires. - Szlons des peintres et sculpteurs. Arts libéraux el Arts utiles. - Corporations, Maillises ef Jurandes. - Louis . 111 londe une médaille dor annuelle de l'industrie. - François de Neufehâteau oryanise la premiere "Exposition publique des produits de l'Industrie française " eu l'an V1 (17998) - Exposilions de l'an IX (1801) et de l'an X (1802). - La Société d'Encouragement pour. l'Industrie nalionale. - Ce que comprement les Beaux-Arts à celte ipoque. - Succés des industries d'art à l'Exposition de $1866 .-$ Style Directoire et style Empire.

C'est l'art appliqué, semble-t-il, qui a eu le premier les honneurs d'une exposition. L'histoire rapporte qu'Assuérus aimait à montrer dans scs palais persans des collections d'objets de prix, et que Plolémée Philométor, un sicele avant Jésus-Christ, réunit, à l'occasion d'une fête, meubles rares, vases précieux, étofles magnifiques dont beaucoup " représentaient dans leur tissu même des figures d'animaux et divers objets (Alhénée, Deipnosophistesj ". On pourrait signaler dans l'antiquilé orientale ou classique, à Alhènes, à Capoue, à Rome, maints excmples de ees expositions. Si leur origine est lointaine, si au cours des siècles el à travers les peuples leur érolution s'affirme el, se précise, elles sont malgré tout une institution moderne. Les marehés locaux où les artisans élalent les produits de leur labeur, à côté de maints autres, annoncent les expositions; mais le commerce et l'appât du gain, seuls, entrent en jeu. Les foires sont un progirès: plus vastes, leur durée est plus longrue; marehands el ouvriers y viennent plus nombreux et de plus loin. L'ambition s'y mêle : chacun veut briller; il y a des concours, des récompenses. Mais tout s'y rencontre et s'y heurte pêle-mêle; le mot de "foire " d'ailleurs est appliqué parfois à nos expositions contemporaines, et en a gardé un sens quelque peu dédaigneux. 
Bazars orientaux où les caravanes apportent de la Meeque, de Perse ou d'Arménie, leurs cuitres, leurs soieries, leurs bibelots; vieilles foires de Champagne ou de Beaucaire, de Saint-Germain ou de Lendil, de Leipzig, de'Stourdbridge ou de Nijni-Novgorod, où l'or/ëurerie, les tissus, les porcelaines, les meubles, avađent leur éventaire el leur emplacement; groupements dans un même quartier, dans une même rue, des anciennes corporalions industrielles qui invilaient seigneurs et riches bourgeois à venir admirer leurs "pièces" les plus belles et les mieux choisies : loules ces manifestations sont les antécédents des Expositions modernes.

Et nous pourrions encore mentionner a V'enise l'usage quavaient les marchands de la "Mereeria " de décorer leurs étalages el de mettre en montre leurs plus riches marchandises, le jour de l'installation du doge.

Mais ce nétaient encore que des foires locales ou spéciales. Louis Xl, roi de France, est le premier qui eut l'idée de présenter officiellement à l'échange nos produits naturels et manufacturés : il chargea deux banquiers de Tours, les f'rères Briçonnet, de réaliser ce projet. Ils devaient exposer à Londres, sans les vendre, nos articles, "afun que les habitants du dict royaume d'Angleterre cogneussent par effect que les marchands de France estoient puissans pour fournir comme les aultres nations ". En mème temps devait se conelure un traité de libre échange avec Warwick; mais la gucre civile des Deux Roses recommençait : le ministre anglais se faisail livrer une partie de nos marchandises; le resle de la cargaison, réembarqué, étail pillé par les corsaires. La tentative échoua. Il n'en est resté que les lettres patentes, expédiées d'Amboise en 1471 , qui fixent J'indemnité due aux deux "commissaires royaux $"$.

Je leur côté, peintres et sculpteurs se réunissaient pour exposer leurs cuvres. L'usage des expositions particulières, réservées aux beaux-arts, apparaît à Rome au début du dix-septième siècle; elles ont lieu, deux fois l'an, à la Saint-Joseph (19 mars) et à la Saint-Jean (2/ juin). La France suivil l'exemple, el dès avril $\mathbf{1 6 6 7}$ l'Aeadémie de peinture el de seulpture inaugura ses expositions (1). Les "salons" se tinrent alors en plein air, au Jardin des Princes du Palais-Royal, puis en 1673 sur la place Dauphine. lls eurent lieu d'abord tous les deux ans jusqu'en 1683 , encore qu'il n'y eût pas d'exposition pendant les deux années 1677 et 1679 , à cause des dépenses qu'elles occasionnaient a l'Académie. La huitième exposition s'ourrit en septembre 1699 el occupa pour la première fois la Grande Galerie du Lourre. Un intervalle de cinq années s'écoula avant que n'ourrît la neuvième (170\&); dès lors la périodicité bisannuelle fut rétablie jusqu'en 1737 ; celte année-là l'exposition se lint dans le Grand Salon carré du Louvre. A parlir de 1737

(1) Collection des litrets des anciennes Expositions depuis 1673 jusqu'en 1800 . Príface de Jules Guillroy. . 
les "Salons" sont annuels jusqu“en 3751 (sauf les années 1714 et 1749 ), puis redeviennent bisannuels jusqu'ì la Révolution.

Mais les "Salons" sont des expositions restreintes et limitćcs aux sculs peintres el sculpteurs; les arlisans et les industricls en sont cxclus. Déjà il $y$ a séparalion très netle entre l'artiste, l'arlisan el l'industriel. Des groupes ennemis se constituent, jaloux de leurs prérogalives, creant dans l'art une hiérarchie : d'un côté les " arts libéraux ", de l'autre les "arts utiles ". lia suppression des " corporations, juraudes " et " maitrises", malgré tous les abus qu'on a pu légitimement leur reprocher, ne fera qua asraver ces dilticultés. Peu à peu a disparu a ce fonds d'anciennes familles dans lesquelles se trouvaient les artistes de chaque spécialité. Désormais un jeune homme né dans un mélier a-t-il quelques dispositions, il se croil du talent, il quilte son industrie; il la dédaigne pour transporter ses espérances et ses travaux dans une sphère qu'il croit plus élevée. L'industrie est livrée à des pratieiens sans iniliative, sans itlées, el si elle demande des modèles aux arlisles, il: les lui donnent, mais sans avoir la conseience de la destination des objets et des procédés employés à leur fabrication. Le créaleur est d'un cólé, le metteur en ocure de l'autre, et il s'élève des réclamations également justes des deux parts : les artistes sont mécontents de voir leurs modèles mal cxícutés, les labricants ou leurs ouvriers déclarent ces modeles incxéculables. Celte absenec d'entente produisit une scission depplorable el un dédain réciproque." "

C'est le comte de Laborde qui parle ainsi dans son rapport de Londres, 1851 (1), que nous aurons sourent à citer. En elfet, la scission était déja profonde. C'est à grand'peine que les tapisseries des Gobelius furent admises aux Salons; et le ciseleur-bronzier Gouthière, malgré l'appui et l'intervention dn duc d'Aumont, $y$ ril ses arures relusées.

Louis XVI, "voulant entretenir l'émulation par des molifs de grloire et dhonneur ", fonda, par édit lu 26 désembre $177 \%$, un prix amnel, "une médaille dor du poids de douze onces " qui devail être décernée á " loutes les persomes qui, en frayant de nouvelles roules ì l'industrie nationale, en la perfectionnant essentiellement, auront servi l'Etat et mérité une marque publique de l'approbation de Sa Majestc. " Mais nous n'arons pu savoir si cette médaille fut jamais décernée, car il n’en existe aucune trace ni it lat Monnaie ni au Cabinet des Médailles.

Puis la crise rérolutionnaire bouleverse le pars, arrêtant le commerce, entravant l'industric par les guerres; mais la coalition est raincue el lion songe a ranimer partout la vie économique, a améliorer les conditions du lravail, à stimuler lesprit de recherehe chez les inventeurs el les artisans. Déjà, en l'an III, sur un rapport de Grésoire. étail fondé le Conservatoire

(1) Voir, à la fin de cette étude, une bibliographie sommaire des liapports français consacrés à la Décoration cl anx Arts appliqués ì l'Industrie dins les Expositions. 
des arts et métiers; en l'an IV, Forliez écrivail au Comité de l'Instruction publique : "Les arts du dessin sont l'école où se puisent directement et indirectement tous les arts industriels... Il importe d'encourage ${ }^{\circ}$ l'industrie dont les ramificalions s'étendent à une suite de professions dans la société, telles que l'horlogerie, l'orfèverie, l'ébénisterie, la menuiserie... "

Deux ans plus tard, une circulaire du 9 fructidor an VI (26 aôt 1798 ) annonçait l'ouverture de la première "Exposilion publique des produits de l'Industric françaisen. C'est François de Neufchâteau, Ministre de l'Intérieur, qui mit en avant celte idée glorieuse el sut dignement la réaliser : il vantait la France républicaine "devenue l'asile des beaux-arts", et en méme temps il faisait l'éloge des arts utiles qui " contribuent si puissamment ì sa prospérité..., dont l'exercice fait l'occupation du peuple français et doit faire son bonheur.. Les arts ont été souvent oubliés et même avilis; la liberté doit les venger... Le gouvernement doit couvrir les arts utiles d'une protection particulière."

l'Exposition s'ouvril au Champ de Mars, sous soixante-huit arcades "à la greeque " dessinées par David. L'entrée en fut gratuite; cent dix exposauts y prirent part. Le catalogue les appelait " artistes et manufacturiers ". Le rapport du jury les qualifie lous égralement "d'artistes ", et désigne les produits exposés par celte périphrase nouvelle: "les arts associés aux lumières. "On y voit élever les "paisibles conquêtes de l'industrie à la hauteur de nos trophées héroį̈ues \#. Les récompenses furent réservées à tout ce qui représentait l'art, le goôt, la beautè.

Le discours d'inauguration prononcé par François de Neufchâleau, dans le style emplatique de l'époque, insiste sur la grandeur future des arts décoratifs: "L'lndustrie est fille de l'invention et sceur du génic et du goût. Si la main exécute, l'imagination invente. Ah! rendons enfu aux arlistes la justice qui leur est due! Que les arts nommés libéraux, bien loin d'aflecter sur les autres une injuste préminence, s'atlachent désormais à les faire valoir. "EL il conviait les artisans à donner aux produits français a le caractère simple, la beauté des formes anliques, un fini plus précieux, un lustre plus parfait encore que celui dont se vantent avec tant d'affectation les manul'actures anglaises $n$.

Si l'on feuillette le catalogue et le rapport, on y trouve :

Les porcelaines de Russinger, les aciers plaqués d'or el d'argent de Patoulet, Audry el Lebeau; les échantillons d'ébénisterie de Bruns; la slatue en pied du général Bonaparte fondue par Martin; les lapisseries d'Aubusson de Roby; les papiers peints "d'un nouveau goût " de Poller el de Daguet et $\mathrm{C}^{\text {in }}$; les tableaux en plumes colorées de Bonillard; les toiles peintes de Grémond et Barré et de Bazile; les draps reteints de Machault " artiste "; les verreries de Saget; les assortiments de " mesures républicaines" de "Cicéri, artiste "; les belles édilions de Didot jeune sur peau de vélin; les faïences de Villeroy; les porcelaines de Dilh el Guérard; les 
crislaux de Catoire et Besson; les produits de la Manufacture de Sèvres; les caractères d'imprimerie de Pierre Didot, Firmin Didot et Ilerhan, etc. (1).

Bien qu'annoncée trop tard, cette exposition, où s'étaient groupés les produits de seize départements, eut un grand succès. Aussi François de Neulchâteau, dès'le 24 vendémiaire an VII (15 octobre 1798 ), établissait les grandes lignes d'une seconde exposition el prescrivait à tous les commissaires du gouvernement et des administrations centrales d'encourager les artistes de leur arrondissement à $y$ participer. Chaque phrase était un dithyrambe en l'honneur des arts utiles, "les premiers de "tous chez un peuple qui a fait de leur étude une condition essentielle de l'excrcice de ses
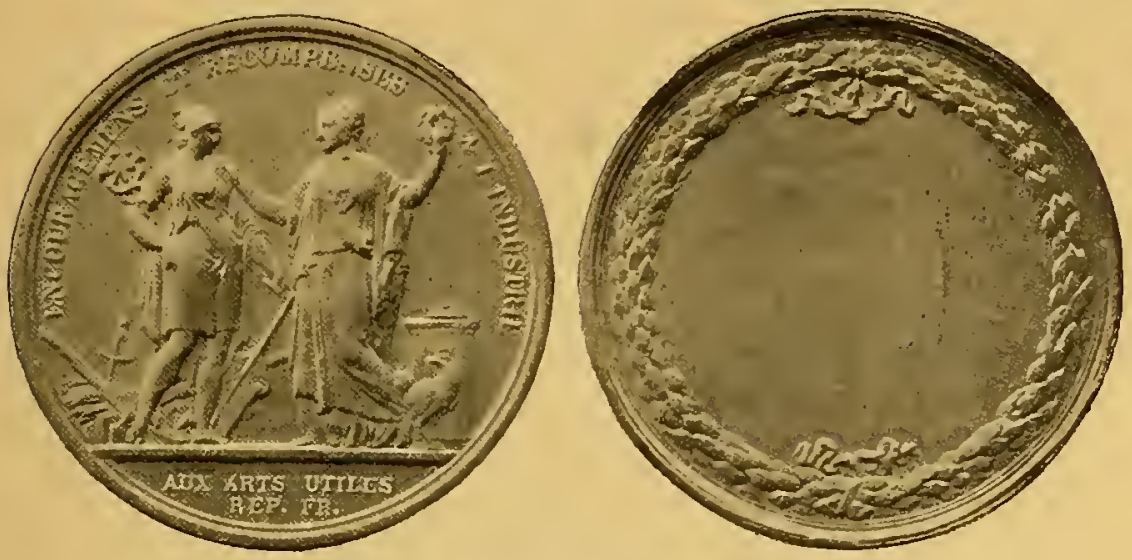

I et II. $-2^{\circ}$ et $3^{\circ}$ Expositions de Paris, an IX et an $X^{*}$. Médaille gravèc par Benjamin Duvivier.

(Il n'en acait pas été décerné pour la fro Lixposilion, an $\mathrm{VI.}$ )

droils... Tont ce qui tient aux arts utiles, tout ce qui sert aux besoins de la vie sera admis au concours". Il faut " nourrir le bon goût parce que les arts sont l'apanage, la gloire et la force d'un peuple libre".

Mais le coup d'Etat du 18 brumaire devait retarder ee projel. La seconde Exposition publique des produits de l'industrie française n'eut lieu qu'en l'an IX (1801); on aurait voulu réunir "arts libéraux " et "arts uliles", mais les peintres et les sculpteurs invités dédaignèrent de répondre à la convocation. Les 220 exposants furent installés dans la cour du Louvre, alors "Palais des Sciences el des Arts ", dans 104 portiques d'architecture romaine. David le peintre, qui avait ouvert en même temps et au même lieu, une exposilion particulière de ses ourres, fut dẻlaissé el s'en plaignit amè-

(1) Pour eet historique, ef. Comilé français des Exposilions à l'étranger, bulletin de mars 1909 : La première Exposilion publique des produils de lindustrie française ì Paris en lian $1 / 1798)$. 
rement dans les journaux. Les Consuls firent une visite officielle. Il y eut 77 médailles (19 en or, $28 \mathrm{en}$ argent, $30 \mathrm{en}$ bronze) et 3:3 mentions honorables. Le rapport du jury, signé du eitoyen Costaz, signale des progrèe dans la cérạmique, la lapisserie, le mobilier, l'impression des lives et des éto/fes. Citons parmi les nouveaux lauréats l'ébéniste Jacob et son concurrent Li"nnereux (médailles d'or), Bonvallet, inprimeur sur éloffes d? laine, et Jouvet, le marqueleur (médailles d'argent). Ni l'or/èrerie ni la bijoulerie ne figurent au palmarès.

L'annéc suivante, an X ( 1802$)$, s'ouvril encore, dans la grande cour du Louvre, la troisieme Exposition des produils de lindustrie française: 5 qo exposants y prirent part. Chaque fois le succès s'affirmait plus grand. W'ailleurs la situation étail brillante et la paix d'Amiens, mettant un terme

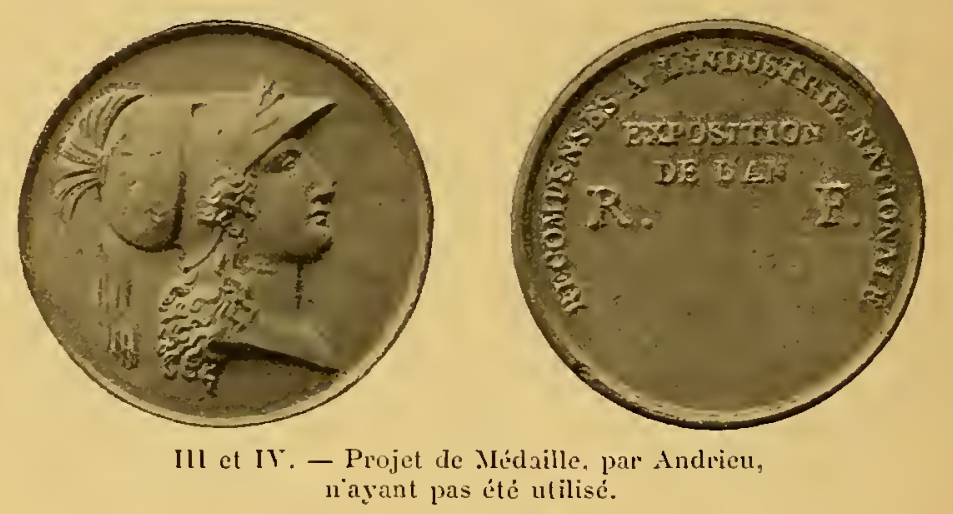

aux guerres puineuses, venait d’être signée. Chaplal, Ministre de l'Intérieur, avait fondé récemment la Sociélé d'encouragement pour l'inlustrie nationale, composéc de savants et d’industriels: Berthollet, Brillat-Savarin, Conté, les frères Costaz, les frères Delesser', François de Neulchâteau, Guvton-Alorveau, de Lasteyrie, Monge, Montgolfier, Parmentier, Scipion Périer, Ternaux, Vauquelin, Vilmorin, etc. Son but étail a d'exciter l'émulation ", "de répandre les lumières ", "de seconder les talents ", "de composer des manuels sur les diverses parties des arts, de rapprocher lous ceux qui prennent intérêt aux progrès des arts et de secourir les artistes dans le besoin $»$. Elle créail de nombreux prix, dont certains élaient réservés à la gravure sur bois, aux éloffes faconnées el brochées, aux meubles en bois indrqènes, aux plaqués d'or el d'argent, elc. C'est à celte société que fut confié le soin d'organiser la troisième exposition. Chaptal avait clemandé que tout produit français y pût figurer, le drap grossier de Lodève, comme la marquelerie la plus raffinée, car il fallait moins "présenter un pompeux étalage de chefs-d'ceurre qu'offrir le tableau ou la réunion de tous les objets qui se fabriquent en France" . 
Le premier Consul visita l'Exposition, accompagné de Joséphine; et deux hommes illustres, Fox et lord Cornwallis, vinrent spécialement d'Angleterre pour admirer nos produits. On décerna 151 médailles (38 en or, 53) en argent, 6o en bronze) et 103 mentions. Les manufactures nationales (classe XIV; obtinrent près du public un immense succès. Costaz, président du jury, ne fit aucune distinction entre artistes et industriels, et célébra dans les produits de l'industrie "le génie inventif et fécond des artistes français". Le palmarès nous a conserve l'écho des élogres décernés aux belles orfíreries d'Odiol et d'Auguste (médaille d'or), à la "calcographie " de Joubert el Masquelier, aux ébénistes lignnereux et Jacob, aux lerres cuites des frères Tra-
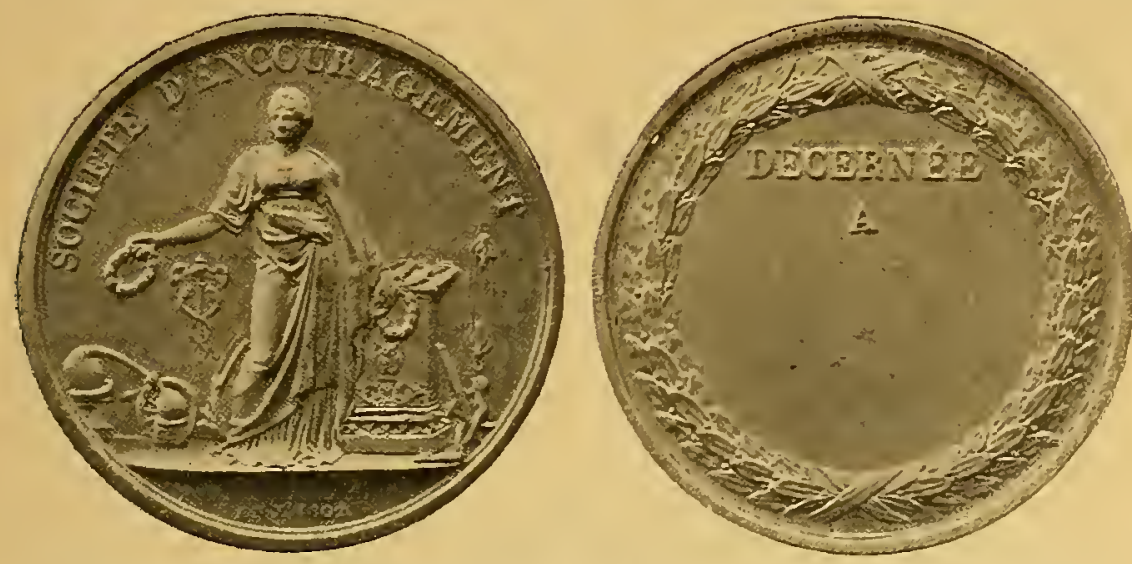

V et VI. - Médaille de la Sociélé d'enconragement pour lindustrie nationale. fondée en 1802, qui prit une grande part à l'organisation de la $3^{\circ}$ Exposition, an X.

buchi, aux nécessaires de Lemaire, aux tapis de Rourier et Sallandrouze (médaille d'argent), de Pial, de Lefèvre el fils, aux édilions de Pierre Didol l'aîné et Firmin Didot (fables de La Fontaine sur vélin), aux imilations de monuments antiques des frères Piranesi, à Jouvet, tabletier, à Olivier, graveur, aux papiers peinls de Jacquenard el Bénard, successeurs de Réveillon (médaille de bronze), à Simon pour ses papiers peints veloutés, à Esnault pour ses broderies, aux passementeries de Gobert, aux fleurs arlificielles de V'enzel, aux applications d'étofles d'Angrand, aux outrages en platine de Jeannety, elc.

Dans la classification, le mot : beaux-arts (Groupe XIII) eut alors une acception très large. Il comprenait, en effet, certaines professions qui plus tard en seront exclues, telles que la bijoulerie, l'orfëurerie, la joaillerie, l'ébénisterie, le bronze.

$1 l$ en est de même du mot " artiste ": il qualifie alors les plus éminents représentants de ces industries, il marque la supériorité intellectuelle d'un 
homme; c'est d'ailleurs un mot récent qui ne figure pas dans le premier dictionnaire de l'Académie française.

La quatrième Exposition publique des produils de l'industrie française fut inaugurée, le 25 septembre 1806 , sur l'Esplanade des Invalides; au centre, une fontaine portait le Lion de Saint-Marc pris à Venise; les industries d'art y figurèrent avec éclat, et pour la première fois on installa luxueusement les groupes dans de vastes locaux à portiques que décoraient les tapisseries des manufactures impériales de Beauvais, des Gobelins et de la Savonnerie. Des tables centrales entourées de meubles présentaient avec goût les objets exposés. On compta 1422 exposants répartis en 104 groupes. Le nombre des récompenses s’éleva à 610 , dont 54 médailles d'or, 97 d'argent et 80 de bronze. Le jury, présidé par Monge, avait été très sévère, et la simple admission à l'Exposition était considércéc comme "une première distinction $n$.

Le rapporteur Costaz mit de pair "falbricans et artistes"; il ajoutait : " notre attention s'est particulièrement et presque exclusivement fixée sur les productions qui peurent devenir un objet de comnerce $n$; on avait écarté les "ouvrages d'adresse " et les "tours de force " pour accepter surtout les objets pratiques d'usage courant.

Les arts utiles élaient brillamment représentés, el Costaz, dans son rapport, classe en 35 chapitres les produits envoyés, parmi lesquels ceux-ci nous intéressent plus spécialement:

IV, V: Soies, dentelles, blondes, brocarts, tissus imitant la peinture, lableanx de velours de Grégroire, tapis de Piat, Rogier et Sallandrouze, moquelles d'Abbeville;

XI: Toiles peintes d'Oberkampf, dont " la manufacture de Jouy tient le premier rang par le choix des tissus, par la beaté et la solidité des couleurs, par la variété et le bon goût des dessins ", toiles imprimées d'Hausmann, de Dollfus-Ilieg, chìles d'Augustin Périer, papiers peints de Jacquemard et Bénard, de Zuber;

XVI : Bijouterie d'acier poli du grand quincaillier Schey;

XX: Belles lypographies de Pierre el Firmin Didot, de Levrault (de Strasbourg) " qui imprima une relation cles fêtes données par la ville de Strasbourg á Leurs Majestés Impériales à leur retour d'Allemagne" ;

XXI : "Calcographies », gravures el ouvrages de Joubert et Masquelier, Baltard, des frères Piranesi, de Filhol;

XXII : Mosaïques, incrustations en relief de Belloni;

XXV : Verreries de Ladouepe-Dufougerais, exécutées dans les manufactures de cristanx de S. M. I'Impératrice, au Creusot;

XXVI : Poteries et grès de Sarreguemines; porcelaines de Dilh et Guérard;

XXVII : Orfévrerie : grandes pièces d'Auguste, exécutées par "la 
rétrainte et l'estampage présentant le maximum de difficultés "; enrois remarquables par "la magnificence, le goût et la perfection d'exécution ", d'Odiol, de Biennais "qui joint au talent de l'exécution un groût éclairé et pur " et "utilise les plus habiles statuaires de la capitale";

XXIX : Bronzes de Thomire; lustres et pendules de Ravrio el de Galle;

XXXI : Ebénisteries de Jacob, "qui sont au-dessus de ce qu'on a vu dans ce genre n; meubles de Burelle, IJeckel, Papsl, Baudon-Gaubau;

XXXII : Dans la tablellerie el l'ornement, les marqueteries et les cadres de Frichol; les nécessaires de Lemaire; les jais et "jayets " de Germain Autré, les coraux de Rémusal;

XXXIV : Elablissements impériaux; les envois de l'Imprimerie impériale dirigée par Marcel, de la Manufacture de Sécres dirigée par Bronsniart qui utilise le nourcau vert extrait du chrome par Vauquelin; des manufactures des Gobelins, de la Sabonnerie, de Beaurais que dirigent Guillaumot, Duvivier, IIuet. "I.e jury, dit le rapport, a donné une altention particulière aux produils des manufactures impériales; il pense que, chacune dans leur genre, elles doivent être un modèle de beau, el qu'elles sont principalement utiles par les exemples qu'elles donnent el par l'émulation qu'elles excitent parmi les fabricans parliculiers qui s'efforcent de les égaler."
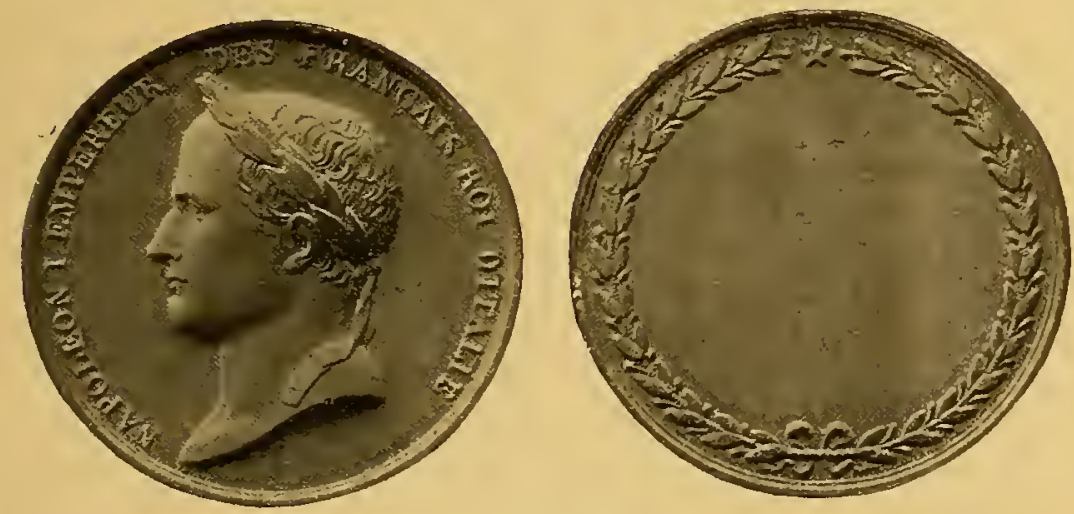

VII et VIII. - 4" Exposition de Paris, 1 Sot. Médaille gravéc par Dumarest.

Puis de nouveau les guerres vinrent arrêter ce grand essor ćconomique et industriel; on quitta l'atelier pour l'arméc, le fusil remplaça l'outil; et l'Empire s'acheva sans avoir pu ouvrir une nouvelle Exposilion. Nais le mouvement était donné, el les quatre premières Exposilions de l'an VII, de l'an IX, de l'an X, de $\mathbf{1} 806$ avaient accru puissamment la vie el le progrès des industries d'art. Quoique les rapports d'alors ne donnent aucun nom de créateur, l'artiste reste encore à côté de l'inclustriel; il travaille avec 
lui it la même aurre. Jes peintres comme David, Prudhon, " au talent délicat el fin, fécond et flexible ", Isabey, Laflitle donnent des modèles; les architectes Percier el Fonlaine, les modeleurs-ciseleurs Thomire père et Thiérel son élève, Pajou, Jeannest, Aubry sont des premiers à fournir des dessins ou à apporter leur concours.

Ce fut une période féconde en œurres d'art. Le style Directoire continue en quelque sorle le style Louis Xrt, parce qu'il s'inspire comme lui du gont classique el antique, des fouilles récentes d'Herculanum el de Pompéi. Puis l'expédilion d'Egyple crée un genre nouveau. On abandoune les modes qui brillerent à Versailles el at Trianon. On restaure les palais, on embellit les hôtels princiers. Arlistes, décorateurs, industriels d'arl, ébénistes, orfèvres, ciseleurs, arlisans de tout métier el de tout genre rivalisent à l'envi pour créer el inventer, pour salisfaire l'Empereur, les Impératrices et les grands de la cour. Ce sont les belles pièes d'orfèvrerie d'Auguste, d'Odiot, de Biennais el les riches créalions des Nitol " joailliers et bijouliers de LL. MJI. l'Empeseur et J'lmpératrice ", de Fonein el de son gendre Marguerilte, " joailliers de la Couronne ", d'Halbout, "joaillier de la Légion d'honneur ", et encore de Bapst, Devoix...

C'est la psyché el la loiletle de Marie-Lonise; c'est le berceau clu roi de liome offert par la Ville de Paris et exćculé par Odiol el par Thomire, enrichi de peintures par Prudhon; cest l'alelier du peiutre David décoré " ¿ı İa pompéienne " par Georges Jacob, " ancien menuisier du roy ", a vec l'aide de Percier el Fontaine, encore lout jeunes; ce sont les meubles de son fils lirançois Jacob-Desmalter, où la déesse égypliemne Isis foumissail une ornementalion curieuse; ce sont les travaux d'ébénisterie de Baudon-Gaubau, faits en orme noueux el chargés d'ornements en bronze doré. Tous inventent, tous collaborent. Nlais on n'a pas accueilli leurs innovations sans protester; on a ri de leurs efforts, témoin ce jugement de Roderer, entre cent autres, à propos de ce nouveau mobilier :

"On n'est pas assis, on n'est plus reposé. Pas un siège chand, fauteuil ou canapé, dont le bois ne soil à découvert ou ì vive arête. Si je m'appuie, je presse un dos de bois; si je veux m'accouder, je presse deux bras de bois; si je me remue, je rencontre des angles qui me coupent les bras ct les hanches. Il faut mille précaulions pour ne pas êlre meurtri par le plus tranquille usage de ces meubles. Dieu préserve aujourd'hui de la tentalion de se jeter dans un fauteuil : on risquerait de s'y briser..."

La crilique est amusantc. C'est celle qui altend toujours au début quiconque veut changer lia mode el crécr une nouveauté. Quoi qu'il en soil, la période est féconde: elle a peut-être délaissé les traditions de mesure el de bon goût qui avaient caractérisé l'ancien régime; elle n'en a pas moins élé vivante; elle a créé un slyle; on reconnail ses œuvres d'art parce qu'elles ont leur cmpreinte originale, leur cachet propre, et, s'il est vrai que la chanson populaire colportée aux carrefours est la meilleure 
preuve du succès el la marque de la gloire, nous n’en prendrons d'autre exemple que les couplets sur l'Exposition de 1806 dus à la muse d'un ciseleur célèbre en son temps, Ravrio, - du moins lui sont-ils altribués :

\section{LE CHIXSONTER ALX PORTIQLES}

$$
\text { (sur l'air de Fanchon). }
$$

Que de souverains sur terre

Qu'arec justice on vénère

Sont loin d'avoir un seul quart

Des chefs-d"ceurre de notie art.

Par notre ébénisterie

El tous ces meubles parfaits, En deux ans notre industrie Pourrail orner cent palais.

Aree raison l'on admire Ce Jacolb el ce Thomire, L'or moulé par Odiot, lit ce fameux lavrio... 


\title{
La Restauration
}

\author{
$1815-1830$
}

Exposition de 1819. - On y lícompense les eollaborateurs de "lindustrie manufacturière "française. - Le rapport du baron Costaz reste le document le plus complet sur l'histoire économique de celte période. - Insucés relatil des expositions de $1 \$ 23$ el de 1827 , quoique cette époque lùt une ère de prospérité pour lindustrie francaise. - Sityles de la Restauration. - Le bric à brac gothique el " moyen ageux " s'impose partutut. - Inlluence du romantisne en littérature, cn art, sur les modes.

Pendant treize années, de 1806 à $\mathbf{1 8} 8 \mathrm{~g}$, il y a un temps d'arrêt. Les ruerres successives où s’anéantissait la lorce du pays, l'invasion, la resIauration des Bourbons, laissent peu de temps pour penser í l'industrie el organiser une exposition nouvelle. Mais bientôt on se préoccupe en haut lieu de ranimer le zèle des travailleurs, et, à la suite d'un rapport de Decazes, Louis XVlll, par ordonnance du 15 janvier 1819 , prépare la cinquieme Exposition des produils de l'industrie el décide que désormais elle aura lieu tous les quatre ans. A celte occasion sont envoyées aux préfels des instructions détaillées et fort bien comprises.

"Faites-vous rendre comple des découvertes qui pourraient avoir amené depuis dix ans une amélioration notable dans une branche quelconque de l'industrie manufacturière de volre département, el signalez-moi les savants, les artistes, les ourrier's auxquels on en estredevable. Un mécanicien, un simple contremaitre ou nême un ourrier doué d'un esprit observateur, ont quelquelois, par d'heureuses découverles, élevé tout à coup des manufactures au plus haut degré de perfection. „ Le fail vaut d'ètre remarqué : e'est la première fois qu'on songe aux collaborateurs. C'est ainsi que des récompenses spéeiales furent altribuées ì quarante-sept ouvriers ou savants non exposants, tels d'Arcet, "inventeur du fourneau d'appel des doreurs ", qui reçut le cordon de Saint-Michel. En outre Oberkampf et Ternaux furent promus barons el d'aulres obtinrent la croix de la Légion d'honneur: Firmin Didot, Jacquard, Daniel licehlin, Roze Cartier, Denière, Mallié, Roux-Cardonnel, Utzschneider, elc. 
L'Exposition se tint dans les salles récemment terminées du Lourre, au rez-de-chaussée; il y eut 1662 exposants et plus de 6000 objets. C'est le baron Costaz qui fut, encore une fois, chargé du rapport : celui-ci est des plus remarquables et reste le document le plus intéressant sur l'histoire économique de celte période. On y trouve l'élude des progrès accomplis depuis 1806 dans les dilférentes industries, grince à la mécanique et à la vapeur,

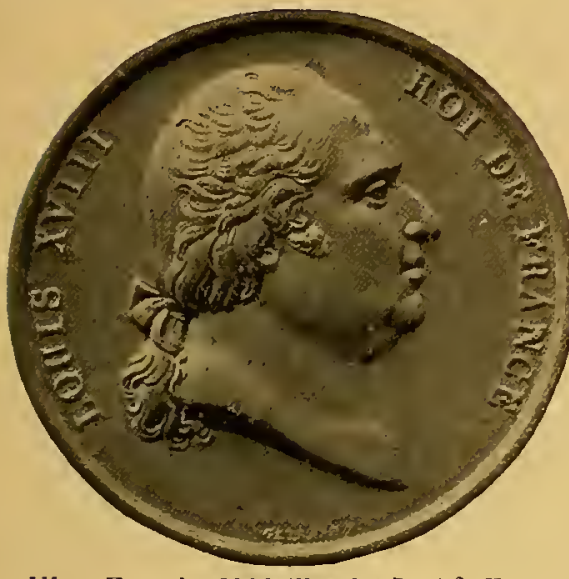

IX. - Face des Médailles des jo et $6^{\circ}$ Expositions de Paris, 1819 et $18 \% 3$, par Gayrard el de Puymaurin.

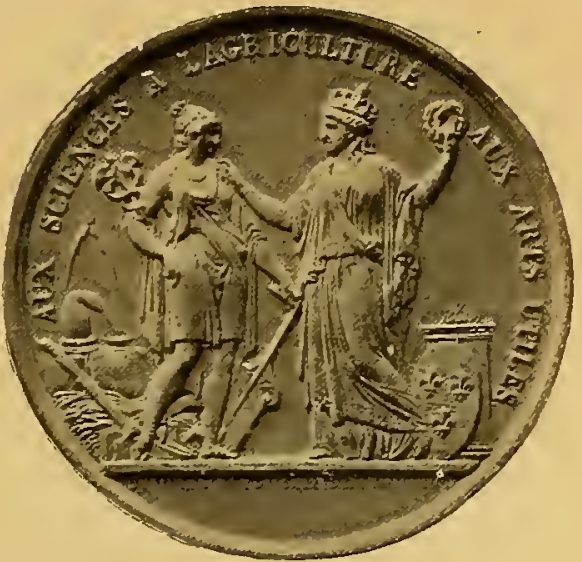

X. - Revers de la Medaille de la $5^{\circ}$ Exposition de Paris, 1819 .

Pour le revers de la mérlaille, on a utilisé el fait transformer par de Puymatrin la fase de la médaille

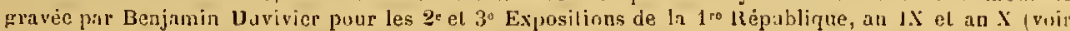
fig. let II). Le bonnet phrygien a été remplacé jar la couronue rovale, et le cog, par l"ecusson aux fleurs de lis. On a ajouté á ganthe une cornae sous lo enmpas. l."inseriplion de la médaille de la lre $R \dot{c}-$

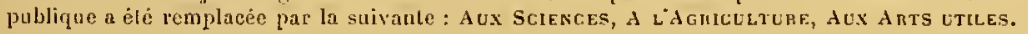

l’éloge parfois mêlé à la crilique, el de précicuses remarques sur la fabrication d'un objel ou son esthélique, ainsi que sur les moyens de simplifier cerlains procédés. Lui aussi n’oublie pas les créateurs:

" I.es progrès ne sont pas uniquement le résultat des lumières, du zèle et de la persévérance des manufacluriers. Ils sont dus aussi au génie inventif des artistes qui ont créé de nouvelles machines, simplifié la maind'icurre..."

L'Exposition nationale de 1819 ful un vrai triomphe; un journal anglais de l'époque le précise en ces termes : "Daus les arts d'agrément, les Français ont toujours occupé le premier rang parmi les nalions industrieuses, les voilit pour le moins au second dans les produils de choses usuelles. " l.art industriel était dignement représenté, el le rapport du baron Costaz en marque exactement le progrès; dentelles, blondes el broderies dont "les dessins sont d'un meilleur goût, mais dont l'abandon par la mode a ruiné beaucoup d'ouvrières; tapisseries el papiers peints parvenus à "un haut 
degré de perfection", parce qu'ils ont pour aides "limagination féconde des artistes et la délicalesse de leur goût "; orféwrerie en qui l'art du plaqué se développe; bijouterie qui est encore en pleine erise depuis $: 813$; bronze ciselé où il faut "que le bon gôut se montre dans la composition du sujel, dans le dessin el dans la finesse du travail "; porcelaines, pour lesquelles il faudrail "concilier la commodité el l'éléçance "; ébénisterie "remarquable par la décoration, le choix des formes el l'emploi ingénieux des bois exoliques". La lilhographie est encore dans l'enfance, et le comte de Lasteyrie qui l'a introduite en France, el Engelmann pour ses estampes n'oblienment que des mentions honorables.

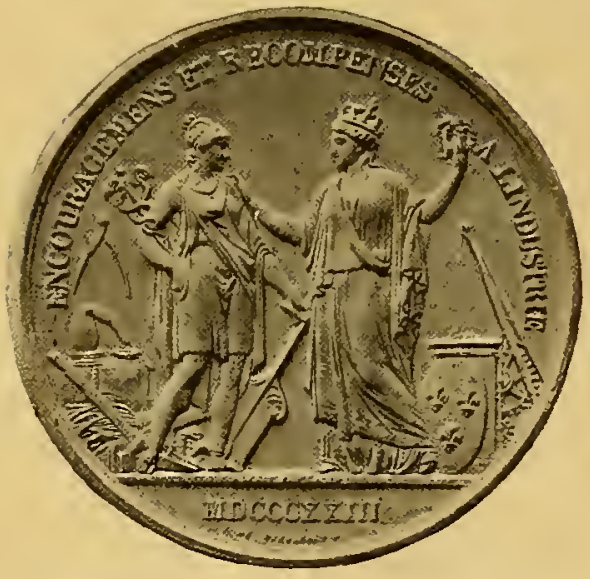

xl. - Premier état du revers de la Médaille de la to Exposition de Paris, 1823.

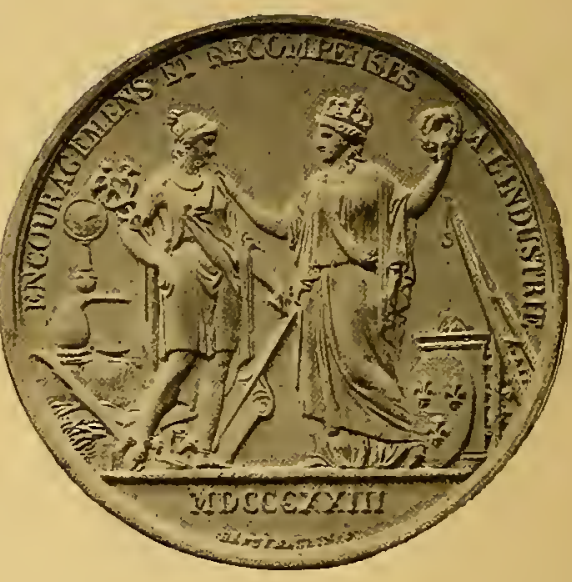

XII. - Deuxieme itat dı levers de la Mídaille de la $6^{\circ}$ Exposition de Paris, 1823.

Pour la $6^{\circ}$ Exposition, on utilise tajours la médaille gravée pay Benjamin Duvivier pour les $2^{\circ}$ et $3^{\circ}$ Expositions. an $1 . \mathrm{X}$ el an $X$. La signalure de Daviviec a disparu et a élé remplacée par celle de Puymarin

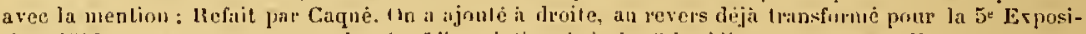

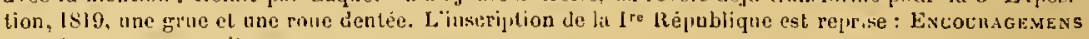
ET RÉCOMPEXSES A L'JNILSTHIE.

Paur je deuxième èlat de la méthille : le eompas de gauche a éłé remplacé par une horloge-concou.

La sixième Exposilion des Produils de l'Industrie française s'ouvrit le 25 août 1823. Il n'y eul que 1642 exposants au lieu de 1662 ; le nombre des récompenses seul augmenta : 1091 au lieu de 869 . Elle se tint au Louvre comme la suivante en 1827 ; mais elles n'eurent, l'une et l'autre, qu'un succès médiocre. En 1827 , le nombre des exposants augmenta un peu: 1695 ; les récompenses s'accrurent encore : 125 f. Le vicomte Iléricart de Thury el l'ingénienr Migneron rédigèrent un rapport d'ensemble pour chacune de ees expositions, dans lesquelles " le jury dut se préoceuper de l'ulilité des produits envoyés el non des difficultés vaincues ". L'abslention de nombreux exposants fut très remarquée; elle tenail à ce fait que certains industriels des départements avaient craint, en dévoilant 
leurs modèles, d'en favoriser les copies el de se voir ainsi distancés par leurs rivaux.

Au lendemain de l'Exposition de $18_{27}$, des manufacturiers, fabricants et artistes: Thomire, Roufflard, Denière, Firmin Didol, Denayrouze el Caussen, Schlumberger, Ravrio, etc., adressèrent au Ministre de l'Intérieur, comte de Corbière, une pétition collective pour demander la création d'un " Palais des manufactures ", réservé aux expositions générales. Le palais du Louvre où elles avaient licu jusqu'ì présent allait leur être enlevé; il leur fallait un monument pour les abriter, ou mieux un palais, puisque, depuis la kestauration, e'est dans un palais, et dans celui même de nos rois, que les "Expo-

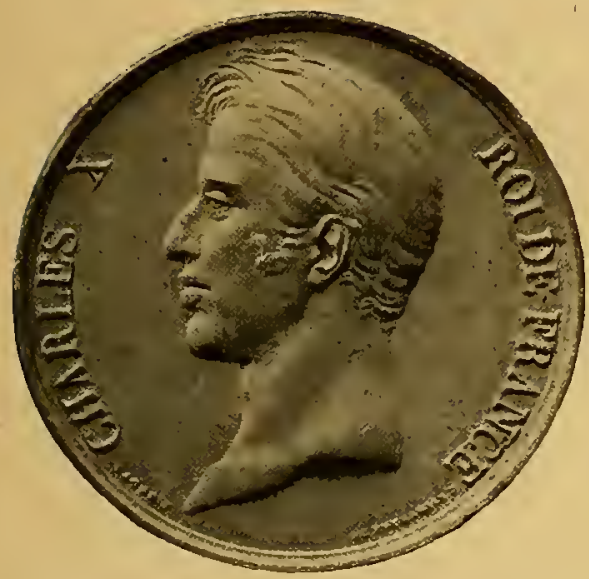

xIII. - Face de la Nédaille de la $7^{\mathrm{e}} \mathrm{Ex}-$ position de Paris, 1827 , par Caqué et cle Puymaurin.

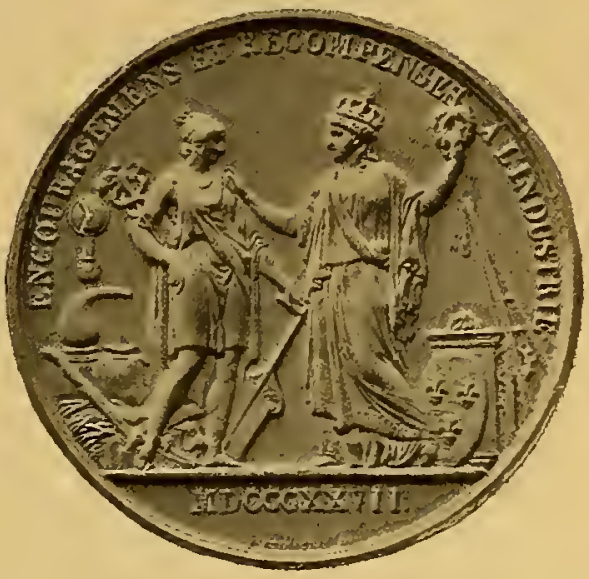

XIV. - Revers de la Médaille de la $7^{e}$ Exposition de Paris, 1827, semblable au deuxieme étal de 1823 .

sitions ont repris naissance et qu'elles ont toujours reçu une si lionorable hospitalité n. Le projet n'eut pas de suites, mais l'idée en sera reprise et réalisée plus tard avec le Palais de l'Industrie. Elle est rederenue d'aclualité encore aujourd'hui.

La Restauration fut une ère de grrande prospérité pour nos arts indus. triels. La mélallurgie fait d’ènormes progrès, l'acier commence à devenir courant; le " maillechort", alliage de cuivre, de nickel et de zinc imitant l'argent, est obtenu en 1819 par Maillet; le platine est purifié et très utilisé. Les faïences de Sarreguemines et de Creil se perfectionnent; à Baccarat, a Saint-Quirin (Neurthe), à Montbermé, à Cirey les cristalleries ont une immense renommée. La soierie de Jyon est rénovée par la découverte du métier Jacquard, plus lard amélioré par Depouilly, el des nouvelles teintares chimiques, notamment celles de Guimet. L'impression mécanique par le cylindre a remplacé l'impression à la planche dans la fabrication des toiles et fapiers peints; la papelerie d'Annonay devient cèlèbre; labaissement 
des prix de revient du lapis de pied en multiplie la consommation; la bijoulerie-joaillerie, un instant arrêtée, retrouve, depuis le sacre de Charłes X, toute sa magnificence de l'Empire: la lilhographie, inventée en $179^{3}$ par Senéfelder, se développe grâte aux arlistes qui l'utilisent, et promet déjà de "devenir, pour les arts du dessin, ce que l’imprimerie a été pour la propargation des sciences $"$.

Comme le conslatera Achille de Colmont en 1855 dans sa très complète IIistoire des Exposilions des produits de l'industrie française:

"On voit quels progrès immenses moins de quinze années avaient fait faire à l'industrie. A aucune époque de l'histoire le progrès n'avait élé aussi général, le quinzième siècle avait peut-être vu de plus grandes découvertes que celles de la vapeur et de la lithographie, mais jamais tous les arts industriels ne s'élaient avancés, en même temps, d'un pas aussi ferme et aussi rapide. "

Nous serions injustes si nous ne cilions les principaux lauréats des Expositions d'alors et les ceurres qu'ils y frent admirer: soieries, chiles el cachemires de Bellangeret et Dunas-Descourbes, 1)ollfus-Mię, Mallié, Bauzon, Poidebard, Roux-Cardonnel; étoffes lissées de soie, d'or el d'argent de lepouilly, Chuard, Seguin; Lapis de Roze-Carlier; impressions sur loile de Gros-Davilliers; toiles peinles de Daniel Kochlin et d'Oberkampf; élo/fes pour tentures et meubles de Pillet, Corderier et Lemire; beaux livres de Pierre, Firmin et Jules Dilol; "calcographie " de Laurent; fä̈ences d'Utzschneider; pianos d'Erard el de Pleyel; ébénisterie en hois indigénes de Jacob-Desmalter; bronzes ciselés de Thomire, Denière, Ganne; bijoulerie d'acier de Frichot et de $\|^{\text {we }} V^{*}$ Schey; pièces d'arfévrerie de Odiot, Biennais, Cahier, Fauconnier; lilhographies clu comte de Lasteyrie.

Le style de l'Empire avait marqué un retour à l'antiquité classique; le style de la Restauration, par réaction coutre lout ce qui rappelait le sourenir de la liérolution et de l'Empire, ne tarda pas à suive le goût nouveau que la lillérature et la peinture araient imposé par leurs chefs d'œurre. Un alınanach de la Révolution n’avait-il pas fait cetle prédiction amusante: " Nous arous tant épluché les modes, lant ralfiné sur les goûts, lant retourné les nieubies el les ajustenents que, rassasiés, excédés de jolies choses, nous redemanderons le gothique comme quelque chose de neuf. "On adopta les hauts dressoirs chargés d'orfévrerie et de fäiences anciennes, on voulut pour s'asseoir des chaises monumentales pareilles à des stalles de chanoine; le bric-à-brac gothique et romantique envahit tout; ou collectionua les armures, les vieilles chasubles. I.a mode est au moyen âge; Victor Hugo va ressusciter les vieilles églises arec Notre-Dame de Paris; Waiter Scoll, en Angleterre, popularise toute la chevalerie avec ses tournois, ses manoirs, ses pages, ses châtelaines. Viollet-le-Duc restaurera plus tard chìteaux et nonasteres en ruines. Partout e'est le même enthousiasme pour le moyen 
âge; les artistes prennent pour modèles ce qui subsiste de la vieille France. Le décor est partout gothique; la reliure se fait " it la cathédrale " comme les meubles se sculptent d'après les vicux balhuts de chêne et les crédences féodales. Les fabricants font d'étranges amal games au goût du jour; orfèvres, bijoutiers, ébénistes, tapissiers, bronziers u'ont d'admiration que pour l'ancienne France et suivent l'architecte Ilittorf dans celte évolution; on réagit contre la froideur immuable du classique qui relevait de la seule raison: cest en somme la lutte de l'art chrélien contre l'art païen.

En même temps il nous faut noter un réveil puissant du sentiment personnel; chaque cuvre reflète une individualité: Delacroix, Géricault, Ingres, Ary Scheffer donnent libre cours í leur fantaisie : ils peignent pour la première fois, au lieu des Grees et liomains de convention, des hommes. Les sculpteurs Rude et Barye suivent le mouvement, et l'on ne peut leur reprocher qu'un dédain trop voulu pour quiconque ne se consacre pas à l'art pur. Malgré la scission qui de nouveau se fait sentir entre l'artiste et l'industriel, le romantisme a sur toute l'industrie une inlluence heureuse; il secoue utilement le pays el rajeunit partout lactivité el lïnvention; il fut le libérateur du sentiment.

Il n'est pas jusquaux modes qui nंen subissent le contre-coup : il suffit de rappeler Gavarni, Eugène Lami, sansoublier La Mésangère et son fameux Juurnal des dames et des modes. Tout ce qui n'est pas gothique est arrićé, vulgaire, "bon pour le bourgeois, pompier el épicier"; la cravate énorme se porte "à la romantique"; les femmes savent l'art de disposer l'ècharpe, surchargent leurs robes de "bouillonnés" et portent à nouveau des bijoux; les cheveux, très à plat, sont retenus par une chainette d'or d'où pend sur le front une "ferronnière "; la coitfure est trìs haute, ombragée de " turbans ", comme ceux de $\mathrm{M}^{\text {me }}$ de Staël, ou de grands chapenux a fleurs. Fêtes et bals travestis sont occasions et prétextes pour étaler des joyaux garnis de pierres de fantaisic, améthystes, topazes, cristaux de toutes couleurs. D'Allemagne on importe de nouvelles danses : valse, polka, mazurka, remplacent la parane maniérée el la gavolte régenee. Iar duchesse de Berry règne sur la mode et pourrail être appeléc "l'arbitre des élégances".

Cependant à la fin de la liestauration, l'art industricl est arrivé à un point critique. L'accroissement du bien-être public commence à créer des besoins nouveaux : chacun veut sa part de luxe comme son lot de bonheur. Pour satisfaire à ces clemandes, l'art tend à se spécialiser, à se manulacturer. Mais, en revanche, le fabricant qui suit les prourès du goùt et les exigenecs artistiques du public cherche à rester à la hauteur de sa lâche : il veut redevenir artiste. Ce sont les deux tendances opposees qui, dans les expositions d'alors, se font jour, et cependant, comme l'écrira plus tard le comte de Laborde, il faut que "l'art dounc la main a l'industrie, non pas comme i une esclave qu'on relève de sa déchiance, mais comme à l'épouse qu'on est fier d'avoir à ses côtés". 


\title{
III
}

\section{Monarchie de Juillet et Deuxième République}

\author{
$1830 \cdot 1851$
}

Exposition de 1 S3 : nombre croissant des exposants; on $y$ recompense pour la preniere fois leurs collaborateurs. - Contusion des styles et dispersion du grout. Influence du peintre Chenavard. - Le dessinateur Couder, - Opinion de Stéphane Flachat sur les causes du manvais zoul de l'epoque. - Exposition de 1839. - L'orfëre Froment-Meurice: son influence: son projet d'art populaire. - Exposition de $18 \%\{$. Besoin de laux luxe à bon masche. - Exposition de $18 \%$. - Multiplication des réconpenses depuis cinquante ans. - La grande industric. - La mode bourgeoise. - Les Expositions à l'chtranger et en province.

C'est en 1831 qu'aurait dû s'ourrir la huitième Exposition, si l'on avait suivi l'ordonnance du 19 janvier 1819 . Mais la Révolution de juillet arait bouleversé le pars très profondément : on résolut de s'en rapporter aux Chambres de commerce, et l'ordonnance de Thiers, Ministre de l'Intérieur, en date du 7 octobre 1833 , décida que les Expositions de I'Industrie auraient lieu tous les cinq ans au printemps; en mème temps, les Salons des peintres et sculpteurs, qui se tenaient alors tous les trois ou quatre ans, devenaient annuels. La huitiène Exposition des Prodnits de l'In lustrie française s'ourrit donc en 183 ', le $1^{\text {cr }}$ mai, jour de la fête du roi, sur la place de la Concorde.

11 y arait 36 ans - un tiers de siècle - que le Directoire arait inauguri la première Exposition. Depuis, le nombre des exposants et leur valeur araient été sans cesse en crojssant. Jusquen 1830 , il arait fallu souvent stimuler le zèle des industriels, prodiguer les encouragements; désormais on sera obligé de nodérer leur alfluence el de recommander une extrème sévérité au jury.

Ln 183', l'art appliqué, alors encore classé dans les "Beaux-Arts", progresse et se perfectionne en proportion. Le beau rapport du baron Charles Dupin le constate éloquemment dans la rerue qu il passe de toutes les sections qui lui sont consacrées. - Ants restrunes: Tissus riches; dentelles; madras; broderies; blondes: draperies; teintures; gaze onduline; colons filés pour robes el monchoirs. etc. Arts nomcumanes : Meubles; 
bronze; appareils d'éclairage; vitraux; arts céramiques; faience; lapis; lentures; glaces; cristaux; papiers de tenture. - Ants sexsitrifs: Ornements de lable; orfèvrerie. - Ants trpograpunges : Edilions de luxe; gravures; lithographie; reliure.

Aclivité fébrile de recherches en tous sens, chaos d'idées contradictoires, dispersion du goût, confusion des styles, voila ce qui marque l'Exposition de 1834 , ce qui de plus en plus va caractériser le règne de LonisPhilippe. On bésite, on tâtonne. Victor Champier a très bien expriné l'incertitude de celte époque : Plus de doctrines ni de principes directeurs. Au despotisme des conventions du passé, qui avaient élé si longtemps salu-
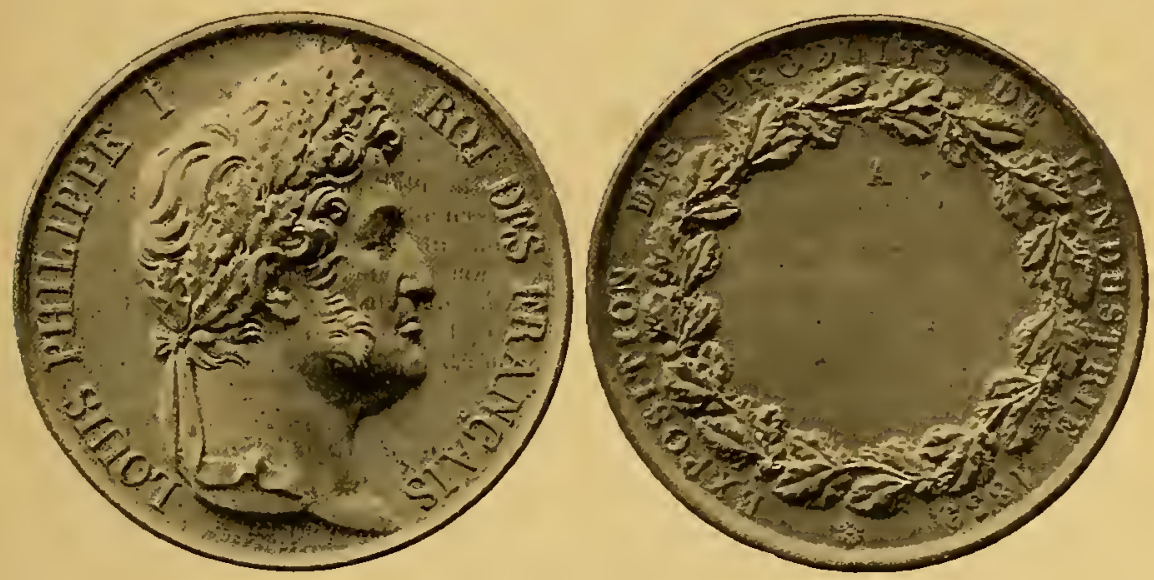

$\mathrm{XV}^{r}$ et XVI. - $\mathrm{S}^{\circ}, 9^{\circ}, 10^{\circ}$ Expositions de Paris, 1834, 1839, 1844. Midaille grave par Depaulis.

Laires, succédait le conflit de mille théories armées les unes contre les autres; c'était Je chaos dans la recherche d'un renouveau qu'on arait peine à dégarer et qui n’apparaissait qu'à l'élat de vague lueur. Tous les styles d'autrefois parurent se réveiller en même temps et s'échapper du sépulere, plus on moins défigurés, pour saluer d'une sarabande ironiquement macabre la société bourgeoise à son aurore. Au milieu de la cacophonie tumultueuse de la production industrielle de cette date, oú était le guide qu'auraient pu suivre les décorateurs?..."

Cependant, dans cette confusion, les talents et les goûts obéissent à deux courants. L'un est le style officiel "Louis-Philippe ", qui tend au classique el marque comme une évolution, une suite logique du style Empire; l'autre, le "romantique ", inauguré, comme nous l'avons vu, à la fin de la Restauration, entraine les esprits vers l'art national du moyen âge, puis vers la Renaissance. Parmi les partisans et les défenseurs de ces lendances, il faut rappeler les noms du peintre Chenavard et du dessinateur Couder. 
Aimé Chenavard, directeur artistique de la manulacture de Sèvres en 1830 , ful, "toutes proportions gardées, le Percier et le Fontaine de l'époque romantique ". 11 prit ses éléments un peu á tort et à travers dans les styles, comme " dans un bric-á-brac ", amalgamant en hâte, mélangeant les époques, pastichant le passé, surtout le quinzième et le seizième siècle, et contribua plus que tout autre à ruiner le style Empire. Le comte de Laborde a fait de lui ce portrait si vivant : "Cet artiste avait l'instinct du frelon qui sait trouver dans chaque fleur le suc qu'elle contient el qui ignore le secrel de l'abeille pour en faire du miel. Fureteur infatigable, il avait feuillelé les livres, calqué les gravures, copié les manuscrits, dessiné les monuments, et de tout cela il n'avait pas su se former une originalité propre, un style individuel. En dépit d'une exécution des plus habiles, malgré des détails très bien rendus, on aurail dû lui reprocher l'abus de toutes choses, la disproportion dominant partout, l'absence complète de calme, de pondération et de simplicité... Chenavard avait séduit quelques hommes de lettres qui faisaient alors les réputations, et il étail devenu l'artiste populaire, le prophète et l'homme-dieu d'une religion qu'on croyait nouvelle : l'art appliqué à l'industrie... Tout ce désordre, qui ressemblait fort à une orgie, marqua, dans l'art el l'industrie de la France, d'une manière déplorable (1)."

Quant i Couder, habile dessinateur autant que travailleur inlassable, il ne cessa de prodiguer ses plus riches dessins aux manulactures de châles, de lapis et d'impressions de toutes sortes. $11 \mathrm{fut}$, dit Achille de Colmont, " l'un des hommes qui ont le plus contribué au développement de notre industrie de luxe et à la faveur dont elle jouit à l'étranger."

D'autres noms seraient ì ciler, parmi les artistes de valeur dont les créations furent si précieuses alors pour les industriels. Pour les orfèvres, hijoutiers et joailliers, ce sont Vechte, Feuchères, Cavelier, Pradier, David d'Angers, Kílagmann, Triquely, Geoflroy de Chanmes, les frères Fannière, tout jeunes encore, qui exécutent figurines, mascarons, animaux, climères grotesques et crnemeuts et renouvellent le goût d'alors; ailleurs, Laroche, Liénard, Rousseau donnent des dessins de lapisseries, de meubles, de céramiques.

Balzac nous a conservé en maintes pages de ses romans: Une Fille d'Éve (1838); La Fille anx yeux d'or (1834); Béalrix (1838), el surlout Le Cousin Pons (1847), les descriptions minulieuses et précises des intérieurs bourgeois de celle époque. Il nole chaque pièce du mobilier, en indique jusqu'aux moindres ferrures, el ce sont là de précieux documents pour l'histoire de nos industries d'art.

(1) On trouvera sur eet arliste des renseignements intiressants dans Maurice Le Corbeiller, Rapporl centennal du Mobilier et de la Décoralion. Exp. univ. de 1900. - Cf. aussi A. Chenavard, Album de l'ornemaniste, Paris, 1836 ; Recueil de décoralions inlérieures (tapisseries, tapis exécutés dans les Manufactures lioyales), Paris, 1832-1835. 
Malgré ses lacunes, malgré la confusion des styles qui égare le goût, Exposition de 1834 obtint un vif succès qui s'est perpétué jusqu'à nous dans un ouvrage très complet de Stéphane Flachat: L'Industrie à l'Exposilion de 1834. On y trouve, après des plaintes sur le désordre qui a présidé ¿ son installation, ces justes critiques sur le mauvais goûl du jour : "... Où sont les genres, où sont les écoles, où sont les maîtres? Ėn sommesnous au grec, au romain, au gothique? Reprenons-nous le style de la Renaissance ou celui de Louis XIV, ou celui de J.ouis XV, ou celui de J'Empire? Avons-nous le nôtre? 1834 marquera-t-il, par des formes spéciales et neuves, indices d'un parti pris par un homme fort, suivi par d'intelligents el courageux élèves?... L'art en ee moment s'éparpille, l'inclustrie le sonmet à ses besoins, en attendant qu'elle reconnaisse ses lois... L'avènement politique de la "bourgeoisie" et la chute des classes privilégiées ont donne a l'industrie des beaux-arts une direction toute contraire. Ces classes, au moment de leur chute, avaient constitué.une école et, si détestable qu'elle fût, le luxe s'y logeait à l'aise, l'habileté des ouvriers pouvait s'y cléployer sans crainte. Un grand prix étail altaché à la perfection de leur travail. Mais aujourd'hui tous ces nouveaux élus aux bienfaits du bien-être, - tels que les ont suscités la Révolution, la division des propriétés et l'égalité devant la loi, - n'en sont pas encore à ce point de développement qui, bon ou mauvais, laisse sa trace dans l'histoire des arts, a sa forme el ses gon̂ts arrêtés."

"Dans ce larre cercle de nouveaux consommateurs, si rapidement tracé par un si soudain el si prolond ébranlement, les limites de l'utile, du confortable, ne sont pas atteintes; le beau n'est pas cncore un besoin. De lá cetle universelle hésitation, celle fatigante incertitude de formes, cette anarchie dans les arts du dessin. Ecoutez les meilleurs fabricants, ceux de l'intelligence la plus aclive, du sens le plus fin, ce qu'ils vous feront surtout remarquer à leur exposition, c'est qu'ils ont cherché à y satisfaire tous les goûts; ce n'est pas le leur qu'ils imposent; le consommateur, ce Protée aux mille lêtes, leur dicte tous les siens; la lortune est à qui l'aura le mieux deviné, à qui se sera trouvé prêt pour le jour du caprice..... »

Aussi dans cette confusion voit-on apparaitre un besoin de faux luxe en nême temps qu'un abus du confortable el du "bon marché n; la classe bourgeoise s'est enrichic, la foule des parvenus augmente. Chacun se précipile vers ce qui est, dans sa pensée, le symbole du bonheur : "le luxe "; il en veut sa part: les arts somptuaires en subissent le contre-coup; c'est l'avènement du clinquant, bijouterie à bon marché, meubles en plaqué. Tout est pour la parade. La pacotille triomphe partont.

Il ne faudrait pas cependant s'exagérer la laideur du style Louis-Philippe; pas plus que le style du second Empire, il ne mérite toutes les plaisanteries dont on l'a accablé. Il faut du recul pour jugrer les styles, comme pour apprécier les cuvres littéraires. A distance, on se rend mieux comple 
des "valeurs"; on voit sous un angle plus juste l'ensemble des lignes et le caractère général. En 1900, à l'Exposition rétrospective de l'Art décoratif, un intérieur Louis-Philippe reconstitué n'a-t-il pas su plaire aux yeux, parce qu'il s'en dégagreait un charme latent, un attrait insoupçonné?

Un important détail enfin vaut d'être remarqué à l'Exposition de 183 4 qui compla 2447 exposants : c'est la première fois que des récompenses sont accordées aux collaboraleurs mêmes des exposants.

La neuvième Exposilion des produils de l'Industrie s'ouvrit le $1^{\text {er }}$ mai $18 \% 9$; elle réunit 3281 exposants et occupa aux Champs-Elysées le Carré Marigny ou Carré des Fêtes ( 16500 niètres carrés) où sera plus tard construit le Palais de l'Industrie. Il élait à craindre dès lors que l'esprit mercantile ne s'emparât des expositions, que le jury, trop nombreux, ne dispersât ses efforts pour s'occuper d'intérêts personuels, et que les récompenses ne fussent recherchées " plutôt comme des enseignes de boutiques que comme des titres d'honneur industriels".

Le jury décerna 2305 récompenses, et sa sévérité fut telle qu'il en écarta " les efforts du génie lorsque les résultats sont purement scientifiques ".

Dans son jugement il examina surtout, comme plus importants :

$1^{\circ}$ L'invention el les perfectionnements utiles classés d'après l'importance manufacturière de leurs résultats;

$2^{0}$ L'étude des fabriques et leur situation topographique;

$3^{\circ}$ La qualité réelle et commerciale des produits;

$4^{\circ}$ Le bon marché acquis par les progrès de la fabricatiou.

Le succès fut très récl, et le baron Thénard, président du jury central, put dire avec orgueil : "I.es concours de 1819 à 1827 viennent révéler à l'Angleterre qu'elle aura bientôt une rivale dans les arts. De si liautes espérances sont justifiées par le concours de 1834 ; celui de $\mathbf{1} 839$ les réalise. "

Jusqu'à présent, il n'y avait qu'un rapport unique, donnant la synthèse de l'Exposition; la multiplicité des classes, le nombre des exposants, ont obligé, en 1839 , le jury à donner des rapports particuliers, partiels, qui fragmentent la vue d'ensemble, autorisent parfois un oubli d'impartialité, mais par contre fournissent plus de détails, plus de précision, plus de compétence dans l'étude de chaque profession.

Ici un nom glorieux apparait, en plein triomphe : celui du maitre orfẻve-bijontier, François Froment-Meurice, " argentier de la Ville de Paris ». Dans ces industries, il personnifie le style romantique. Il réalisa ce que Wagner avait tenté : il fit du bijou, non plus un banal objet de commerce, mais une cuvre parfaite ou délicate, capable de causer les mêmes joies esthétiques qu'une toile de maitre ou qu'un groupe imposant de sculpteur. "Son nom, éerit Ernest Chesneau avec raison, est célèbre à l'égal de ceux d'Eugène Delacroix, Théodore Rousseau, Rude, Barye, Berlioz, Lassus. Si ses ouvrages sont moins connus que ceux de l'architecte, du 
musicien, du statuaire et du peintre, cela lient uniquement a leur destination plus discrète, lout intime el personnelle. Comme ses contemporains, plus qu'eux peut-être, car son action s'exerçait sur le groùt de la femme, il concourut a dégager l'art moderne de la gaine étroite et rigide des conventions pseudo-classiques ou l'avait renfermé la génération précédente, et à lui rendre le mouvement, la couleur, le sens de l'histoire, le fen et l'imaginalion, la verve el l'invention dans la curiosité du rai, en un mol, la vie. "

On ne peut que souscrire à ce jugement. Froment-Meurice a exeret une influence énorme sur l'industrie des orfèrres-bijoutiers de son lemps. 11 I’a ranimée par son goût et ses eréations el lui a donné un vérilable essor. Ses relations amicales avec les écrivains et les arlistes le mirent encore en valeur. Nme de Girardin, Eugrene Suë, Th. Gautier en parlent avee enthousiasme; H. de Balzac le nomme dans ses lettres "son cher poète en actions et en mélaux " ou "son cher maitre aurifiber " et ne manque pas d'allacher au bras de ses hérö̈nes un bracelet signé de son nom. Victor llugo, enfin, lui clédie une ode.

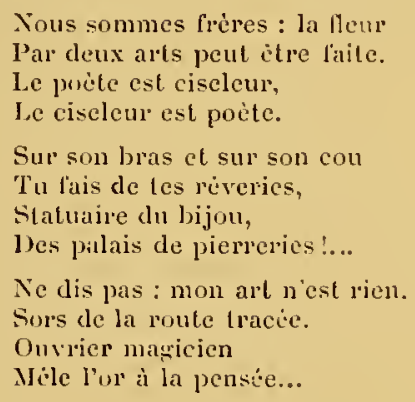

Froment-Meurice, s’il n'eul pas dans le maniement du crayon el de l'ébauchoir la virluosilé d'un Benvenuto Cellini, avec qui ses amis se plaisaient à le comparer, n’en montra pas moins toutes les qualités d'un créateur : it a la science, l'imagination, l'audace inventive, la volonté directrice, l'absolue maîtrise qui firent de lui un chef d'école. Il excelle à diriger un atelier, et, ainsi que le constatera Wolowski dans son Rapport sur lorfèverie à l'Exposition de 1849 , "comme tous les hommes d'un vrai mérite, Froment-Menrice s'altache avec scrupule à faire ressortir les services rendus par les collaborateurs qu'il a su s'adjoindre, peintres, sculpteurs, ciseleurs, ouviers habiles. Il a toujours eu soin, pour chacune des pièces remarquables de son exposition, d'indiquer ceux qui l'avaient secondé ".

Froment-Meurice, "amoureux de toute beaulé, épris de toute élégrance ", aurait voulu faire de l'art "national, c'est-i-dire populaire", el "forcer son arl si éminemment patricien it servir aux besoins des classes déshéritées" en " usant des moyens féconds que la scicnce moderne mel sans se lasser entre les mains des ouvriers intelligents... n. C'est Maxime du Camp qui 
nous l'apprend dans son élude sur Les Bealnx-Arls à l'Exposilion universolle de 1855, mais la mort est venue quand il allait réaliser ce beau projet, au moment même où il voulait ouvrir une boulique dans le populeux quartier Saint-Antoine.

Après sa disparition (1855), le critique de la Revue des Deux-1/ondes, Gustare Planche, essaya de ruiner sa réputation et l'appela un "metteur en ceuvre, un liabile négociant, dont tout le mérite fut de s'cntourer d'artistes pleins de talent el d'ouvriers excellents"; de partout on protesta ; ses collaborateurs furent les premiers à rendre justice à leur maître, et Th. Gautier lui consacra, dans la Presse du 4 arril 1855 , un bel article d'éloges.

Nous avons fait la place un peu large it Froment-Meurice, mais il représente loute une époque, el son nom s'est perpélué glorieusement jusqu'à

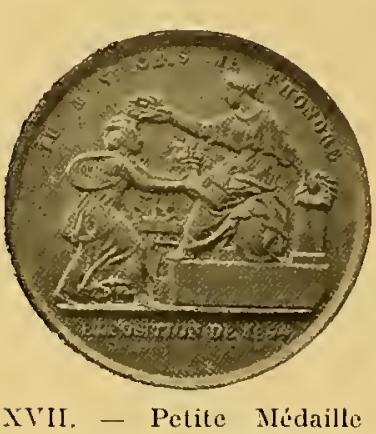

frappée à l'oecasion de la $10^{n}$ Exposition de $\mathrm{Pa}$ ris, 1844 . nous.

L'Exposition de 1844 se tint, comme la précédente, au Carré Narigny. La Commission des Beaux-Arts y joua un xôle important. Il y eut 3960 exposants. On remarque dès celle époque un besoin de distinction, un souci plus grand d'art, une tendance a lutter contre le laid qui envahit tout. Th. Gautier écrit dans la Presse du 17 juin : "La laideur" est un fait moderne contre lequel les artistes se débaltent tant quils peuvent; nos maisons, nos habits, nos meubles, nos voitures, nos attelages, nos ármes, nos ustensiles sont hideux; pour s'en convainere, il n'y a qu“à les faire sculpler."

El quelques années plus tard, le cluc de Luynes, dans son liapport sur les mélaux préeienx à l'Exposilion de Londres, 185 /, altribuera justement cette décadence à l'inlluence du public sur l'art. "Quand le public, dit-il, veut des produits de mauvais aloi sous les rapports de l'art, du travail el de la solidité, mais à bon marehé, le plus habile fabricant est obligé de renoncer à ses convictions el à ses ourres consciencieuses pour se prêler à des exigences aussi impérieuses et qui, si elles n'ćtaient pas obẻies, mettraient en péril sa situation commerciale."

L'Exposition de 1894 devait être la dernière de la Monarchie de Juillet. La périodicité quinquennale fixait l'Exposition suivante à l'annéc ${ }_{18} 89$. Malzré les dures journées de 1848 , l'Assemblée nationale tint à n'en pas changer la date, mais sans la Révolution qui renversait Louis-Philippe, el aussi sans l'opposition des Chambres de Commerce, il est probable que le ministre Tourret, suivant le désir déjá cxprimé par Boucher de Pcrthes en 1833 , aurail obtenu que l'année 18 49 vil à Paris la première Exposition internationale. L'Exposition s'ourrit le $1^{\text {er }}$ juin, au grand Carré des ChampsElysées. L’agriculture y figura pour la première fois el l'ancien titre 
Exposition des produits de l'Industrie française devint Exposition des produits agricoles el industriels. Les arts industriels y figurèrent avec éclat. Médailles, décorations, éloges officiels, places honorifiques, rien ne fut négligé pour stimuler les efforts, et les 4322 exposants oblinrent 3738 récompenses. Les collaborateurs reçurent des distinctions particulières.
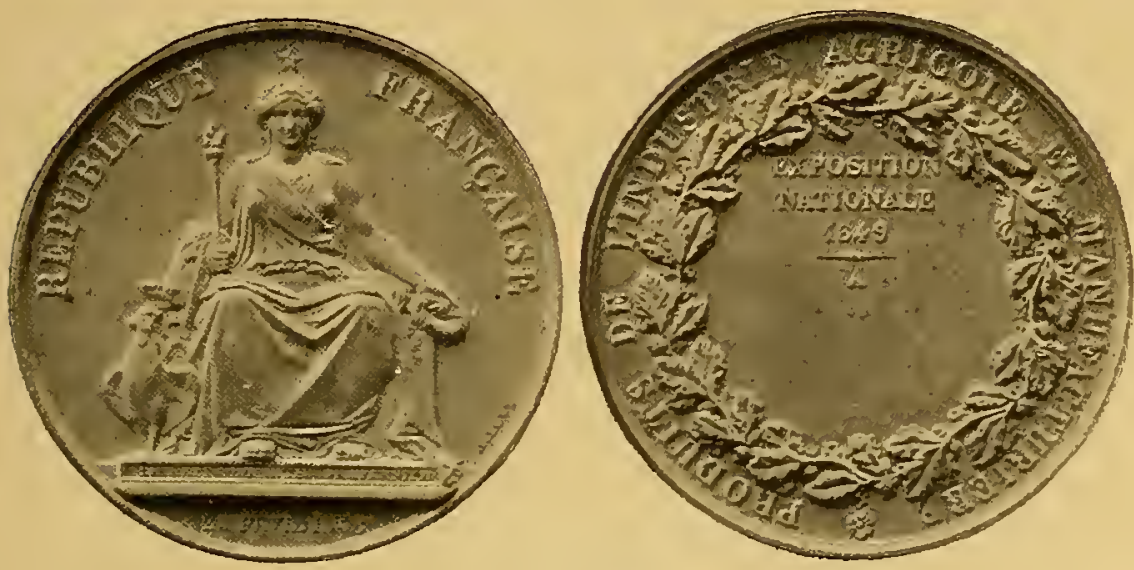

XVII et Xix. - $11^{\circ}$ et demiere Exposition nationale de Paris, 18fy. Médaille gravéc pal A. Bovy.

Qu'il est loin le temps où l'admission seule est " une première distinction ". Le mercantilisme a commencé à envahir les récompenses; le tableau ci-dessous permetlia d'en hien juger.

\section{Expositions nationales de Paris}

1798-1849

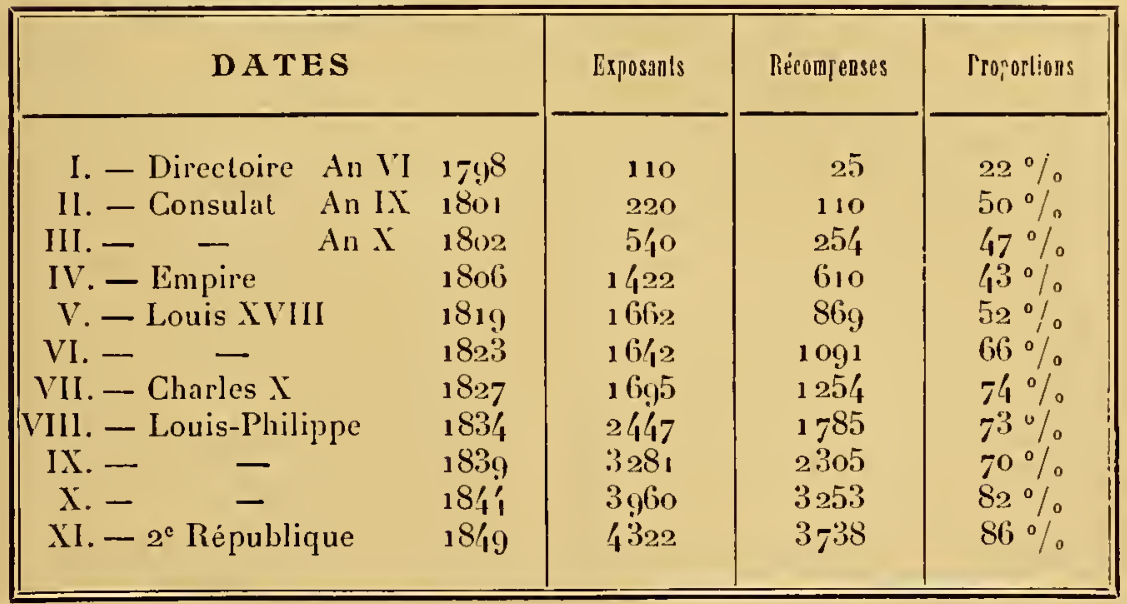


Parcourons rapidement les listes des lauréats aux expositions de celte période; parmi les principaux, nous trouvons :

Orfétrerie: Froment-Neurice, d'abord, puis Odiot fils qui s'est voué a l'orfèrerie " anglaise genre Louis XVI ", Faucomier, Wagner, Rudolphi, Lebrun, Morel el $\mathrm{C}^{\mathrm{ie}}$, Duponchel, A. Gueyton, Christofle, qui, après avoir laissé à son neveu Rouvenat sa maison de bijouterie, a introduit en France les procédés de Ruol\% el d'Elkinglon et houleversé tous les méliers qui concernent la dorure et l'argenture. Parmi leurs collaborateurs : le dessinateur Liénard, les seulpteurs Fannière el Obry, les ciseleurs Mulleret, Daubergne, Poux, l'émailleur Sellier, le grraveur Plouin.

Bijonterie : Frichot et ses objels d'acier, Dafrique, inventeur de la passementerie et de la dentelle d'or, Savard et ses bijoux dorés.

Orféves et bijonliers sont bien représentés aux expositions depuis $\mathbf{1 8 3 4}$, mais il nous faut cependant noter l'abstention de grandes maisons comme celles des frères Bapust, de Fossin, joaillier du Roi, de Mellerio, de Martial Bernard, de Muo Janisset pour laquelle travaillaient Alexis lalize, inventeur des bijoux en émanx cloisonnés, Jules Chaise, Jean-Paul Robin, Petileau, créateur du bijou genre mauresque en argent émaillé.

Tabletlerie : Aucoc, successeur de Lemaire.

Bronzes d'art: Thomire, Denière, Lacarière (ćclairage), les fondeurs Eck ol Durand.

Céramique : les fäences dures de Leboul et Thibault, les faïences fines de Geiger, les porcelaines du décorateur liousseau; les grès cérames de Sarreguemines. M. Saint-Amand rapporte d'Angluterre en 1834 des procédés nouveaux pour la fä̈ence el les étndie avec Brongniart à la manufaclure de Sèvres, où le coularge sera bientôt substilué au moulağe.

Verrerie, cristallerie : les grandes pièces élablies couramment à SaintLouis el Batcearal.

Typographie: Firmin Didot, Name, Paul Dupont, Plon, Silbermann (ypochromie).

Iléliographie : Fizeau.

Lithographie: Lemereier, Engelmann (chromolithographie).

Gravure sur bots : Best, Leloir el Cie qui font renaître "celte mère de l'Imprimerie ".

Tapisserie el tenture : rideaux brochés de Sainl-Quentin.

Trapis et moquettes : lilaissier frères, Sallandrouze.

Ebénisterie : Meynard, Chenavard, - mais on ne voil plus aux exposilions les Jacob auxquels va succéder la dynastie des Jeanselme, - A partir de 1834, a l'acajou longtemps à la mode succèdent les bois indigènes tels que fiêne rosé, orme, érable, cerisier, platane, saule; l'exécution est plus soignée, l'ornement plus sobre. le placage fait de grands progrès.

Papiers peints : Zuber fils, Etienne Delicourt. 
Toiletle: Jouvin et ses gants.

Brocarls d'or el d'argent : Nathevon ot Bouvard.

Teinture el impression sur lissus : Gros-Jean, liochlin, IIartmann, Godefroy, Caron-Langlois, Piol, Schlumberger, Japuis, Nichel; bleu d'outremer de Guimel; genre ombré el impressions réservées de Jourdan; doubles teintes de Broquette; nouveau jaune de Guinon.

Châles, echarpes indiennes, cachemires el lenrs imilations, devenus un art véritable se traduisant par le sentiment du coloris et l'harmonie des couleurs chez Deneirousse, Boisgrlary, Sabran el Gessé, Devèze, Duché, Crillet, Curnier, Egly el Roux, Bosquillon, IJébert, Girard.

Soieries el velours de Lyon : Potton et Crozier, Bonnel, Langrevin, Chartron, Reverehon, Maurier el A. Bernard, sans oublier Ollat de Nimes.

Dentelles, tulles, broderies : une reprise se fail seatir en 1844 dans la fibrication du point d'Alençon, de la Valenciennes, de la dentelle de Bayeux; Lelébure se fail particulièrement remarquer.

Tissus nouveaulés: ils se développent à Louviers, Sedan, Elbeuf; les lissus de laines el colons se fabriquent it Mullıouse, Roubaix el Rouen chez Blech, Krechlin, Schwartz, Terny'nck, Aubert.

Sculpture en carlon-pierre: Joseph Hubert.

Cette période, qui commence et s'achère par une révolution, fut une ère de liberté plus grande et de progrès économique; alors que la cour de Charles $\mathrm{X}$ limitait ses réceptions à un cercle étroit de royalistes convaincus, Louis-Philippe, "le roi ciloyen", ouvre ses salons ì la bourgeoisie, el le peuple même vient le saluer familièrement. On tranforme le chàteau de Versailles en un vaste musée dédié "à toutes les gloires de la France ". Le duc d'Orléans est l'ami d'Horace Vernet et le protecteur de Barye.

La grande industrie se développe; elle augmente le nombre de ses ouvriers, elle abaisse le prix de tous les objets manufacturés et met it la portée du consommateur modeste, non seulement le nécessaire, mais encore ce qui en̂t élé le luxe cent ans auparavant. Les mueurs industrielles transforment la société el modifient les conditions de la vie.

Au milieu de ces changements, la mode évolue el abandonne les extravagances. La redingote des hommes est fantaisiste el pincée à la iaille pour les élégants; le ministre Guizol la porte sévère el puritaine, tandis que Saint-Mare Girardin la laisse ample et longue. Les femmes ont la taille pincée, les corsages fermés devant par un réseau de lacels, les cheveux courls el bouclés; une petite "capote " enferme doucement le visage. C'est a la promenade de Longehamp ou au boulevard de Gand - d'où le nom de "gandin" - que l'on voit les toilettes des "lionnes" el des "loretles". Quant aux "dandys ", "fashionables" et "jeunes-frances ", ils se réunissent surtout an café Tortoni et à la Maison Dorée. On les retrouve dans les caricatures que Gavarni donne au Charivari, dans les dessins de Deveria 
et de Grevedon et dans les journaux de modes dalors : le Prolée, le bon goul, le l'andore, ou le Panorama fashionable.

Mais il nous est bien difticile encore de définir nettement cette époque. Elle ne se distingne pas, comme le Directoire ou l'Empire, par des caractères nets el tranchés. Elle a pourtant son style assez reconnaissable. On y voit labandon de la ligne droite, un air de nonchalance, de la grâce ; rien ne s'y lait remarquer de trop raide ni de trop brntal; en un mol nul excès en plus ou en moins ny attire le regard. Il flotte partout une certaine langueur, quelque chose de modéré, les romantiques auraient dit de "bourgeois"; on Yrespire un calme qui repose, un grand apaisement, et, lorsque l'ail s'est un peu habitué à ces tonalités simples et douces, on y goûte un vai charme.

Cependant les Expositions de l'Industrie qui śélaicnt succédé à Paris avaient donné l'idée d'en ourrir de semblables en province el à l'étranger. lin France, Caen, en 1803 , inangure la série des Expositions de province; yuatre autres Expositions devaient encore y aroir lieu. P'uis Nantes, Bordeatux, Lille, Amiens, Valenciennes, Toulouse, Dijon, Grenoble, Metz, avaient tenu de semblables assises, limitées soil à un département, soit à toute une région.

A l’étranger, les villes de Stockholm, Saint-Pétersbourg, Moscou, Gand, Bruxelles, Lausanne, Berne, Zurich, Berlin, Munich, Leipzig, Trieste. Vienne, Madrid, Barcelone, Lisbonne, Turin, Florence, New-lork, Washington, pour ne citer que les principales, suivent l'exemple: partout le mouvement se généralise.

Jusqu'à présent les Expositions, ces grandes revues de liudustrie franצaise, ont fourni des points de comparaison aux travaillcurs, vulgarisé les déconvertes et les perfeetionnements, et répandu sur toute leètendue du territoire l'espril d'initiative et le goût du beau. Celle de 18 qy est la derniere qui soit " uationale". Comme nous lavons vu plus haut, on avait pensé uu moment ì la laire internationale et universelle; la fraternité des peuples ¿lait une des jclées que la liévolution de lévrier avait rendnes populaires; mais elle était encore trop nouvelle. Eo lirance on hésita, el c'est à Londres, en 1851 , que cette idée grandiose devait pour la première fois être mise it exécution. 


\title{
Second Empire
}

\author{
$1851-1870$
}

La premiere Exposilion internationale a lieu à Londres en 1851. - Beau Rapport du Comle de Laborde sur l'applicalion des arls a l'indusluie. - L'Angletere ncus cnlève nos meilleurs artistes industriels : Vechle, Moucl, elc. - Exposition auiverselle el internationale de Paris, 1855 ; principaux lawials: recompenses anx collaboraleurs. - Exposition universelle el internalimale de Londres, 1862. - liap:port de P. Mérimée. - Fondalion, en 1863, de l'Union centrale des Beanx-Arts appliques a l'lndustrie; son programme; ses Exposilions. - Exposition universelle el interualionale de Paris, 1867 ; classilication de Le l'lay; les rapports: les déligations ourricres. - Style, modes et socicte du sceond linjpire.

Le triomphe du libre échangre, que l'Angleterre dut à IIuslisson el à Robert Peel, le rapprochement politique entre la France el l'Angleterre, les efforts du prinee Albert, lout eoncourut au sucès de la premiere Fixprosition Internationale lenue a Londres en 1851. L'architecte Joseph Paxton construisit, pour l'abriter, le fameux Palais de Cristal, au milieu des arbres de Ilyde Park. La Société Royale des Arts, des Manufactures et du Commerce fut chargée de l'ormanisation. Malrré la réunion dans son tilue des mots art el commerce, malgré l'existence d'une section des Beaux-Arls, elle aida mal a rapprocher les artistes el les industriels puisqu'elle excluait la peinture. Elle justifiail ainsi sa détermination : " I.a seulplure fournit ses arlistes ¿ l'industrie pour décorer une pendule, pour sculpler un menble; l'archilecture se combine avec l'industric du polier, du fondeur, el donne les profils et les dessins de loules décorations; la gravure s'exécule sur des cuivres el s'imprime avec une presse: ces arts sont industriels. Tout au contraire, la peinture transmet sur la toile un ordre d'études, de sujets, de passions qui sont étrangrers à l’industrie. " Elle ne firrura en effel quà̀ titre d'auxiliaire, avec les vitraux et les poreclaines peintes. Distinelion bizarre qui dénotait une cerlaine élroilesse de vues.

Il y eut 17 o62 exposants : la France y figura pour plus d'un dixième : 1756 exposants. Le jury décerna trois sortes de récompenses : les grandes médailles appelées Conncil medals, réservées aux inventions, les Prize medals pour les perfectionnements et les mentions honorables. La France 
obtint 57 médailles de conseil, 622 médailles de prix et 372 mentions, soit 1051 récompenses. C'était un immense succès.

Une innovation importante eut lieu. Tandis qu’à l'origine les exposants pouvaient rendre leurs produits, la Commission de 1851 , pour rendre à ce concours plus de dignité, interdit l'indication des prix. Le jugement du jury en fut un peu laussé : on metlait sur le même plan deux objets dont l'un était dix fois plus clıcr; la mention du prix de veute, sinon du prix de revient, est nécessaire pour une appréciation équitable. On récompensa parfois plus l'objet exposé et l'ensemble d'une installation que la valeur réelle de l'exposant; c'est ainsi que l'Imprimerie Impériale française n'eut qu'une médaille d’argent.

Parmi les principaux lauréats de la Section française, il faut citer : la Chambre de commerce de lyon (soieries); la manufacture de Sères; André (fonles du V'al d'Osne); Aubanel (bronze el fonle); Barbedienne (lironze el rédnclions); Delicourt (papiers peints); Deneirousse, Boisglavy et $C^{\text {ie }}$ (nouveaux procédés pour l'exéculion des dessins de fabrique compliqués): Fourdinois (meubles); Froment-Meurice, Gueyton (objels dart et galvanoplaslie); Gumet (teinlures); Lemonnier (parures et joaillerie de la reine d'Lspagne); Liénard (pendules en bois sculpté); Maës (rerrerie); Marrel frères (cachels el labalières); Rudolphi (bijoux); Pradier (stalue de "Phryné"), clc.

l.'Exposition de Iondres donna lieu à de rolumineux rapports qui signalèrent les résultats obtenus dans cliaque industric. Wolowski disait quils sulfisaieut ì eux seuls pour" "marquer d'une manière notable dans l'histoire ". Ceux de la Commission française, publiés de 185 a a 1873, sont mallieureusement inacherés. Le Rapport général, par Charles Dupin, comprend luit énormes tomes, véritable encyclopédie sur tous sujets. Parmi les rapports de classe, deux sont demeurés pour ainsi dire classiques et méritent, par les sujets qu'ils traitent et les conclusions qu'ils offrent, mieux qu'une simple mention : ec sont ceux du comte de Laborde et du duc de Luynes.

Le happort dn duc de Luynes étudie les mélaux précieux, passementerie, bijonlcrie, joallerie, orférerie, el, comparant les industries d'art des deux pays, explique nos fautes et nos erreurs. "l'Angleterre a de riches et puissantes maisons, dont presque aucune n'a d'ateliers; elles font traviller des fabricanls spéciaux; d'où le grrand développement commercial de cerlaines fabrications, nuisible cependant à des industries relevant du goout et de l'art. EIles cherehent toujours i faire mieux, prennent des artistes de talent partout où elles les trouvent, tels les grands artistes français Morel et Vechte, les récompensent libéralement et leur font produire des chefsd'aure. En France, tout autre est la physionomie de nos industries; peu de grands capitaux; le principal mérite apparlient en propre aux artistes ou aux fabricants qui ont exposé; ils ne peuvent faire de sacrifices d'argent, mais ils font d'énormes sacrifices de travail, d’intelligence et de temps et contre-balancent, par leur propre valeur, la puissance croissante du capital. " 
Rappelons iei ce que le sculpteur Klaymann, en 1852, écrivait dans un mémoire : "Les arlistes qui travaillent pour l'industrie forment une classe nombreuse; la société les connaît à peine el les ouljlie quand elle les a connus, el cependant l'industrie doit sa supériorité sur tous les marchés du monde au bon goût, à l'imagination, à l'art en un mot qui préside ì ses pro duits, el ses qualités... lui viennent des artistes qui se sont roués à celte carrière, earrière ingrate sil en fut, profession trompeuse, véritable impasse pour ceux qui l'embrassent, surtout s'ils sont poussés par une ardente vocalion. ")

Quant au Rapport du comle de Laborle, énorme ouvrage de plus de 900 pages, il traite de lapplication des ar/s à l'iudustrie dans le passé, dans le présent, dans l'avenir. Outre un historique très clair et très juste des progrès des arts au milieu des changements de style et des divers modes d'enseignement, on $y$ trouve, sur l'expansion et la démocratisation de l'art el du beau, plusieurs pages qui, encore qu'un peu utopiques, alteignent un véritable idéal el dénotent un esprit d'une rare hauteur de rues. Les historiens le signalent parfois, le démarquent souvent, mais oublient maintes fois de le citer. C'est un devoir pour nous d'en domner une analyse el quelques extraits.

En Angleterre, c'est le moment oủ liuslin impose à l'altention ses nobles théories sur l'art et dirige le goût du peuple vers lidéal. Le comte de Laborde a compris le danger qu il y a pour la France ì se laisser envahir par des praticiens sans initiative et sans idées, qui délormeront la "mode" et ruineront, par des copies habiles et prétentieuses, son originalité et sa suprématic arlistique. "L'art est un. Il est la source de tous les progrès; sa prospérité est une force pour l'Etat. "Aussi l'Etat a-t-jl le devoir de maintenir le goût public el de réformer l'enseignement du dessin, afin que celuici, "placé désormais daus l'éducation à égalité avec l'enseignement de l'écriture, fasse renaitre dans la nation entière l'unité de goût el de jugement qui est la base de l'art $"$.

Le rapport demandait que le dessin fut obligatoire ì tous les examens et que l'on réorganisât entièrement "l'apprentissage des ourriers che\% les maitres el l'éducation des artistes dans les écoles spéciales ". C’ist l’industrie qui doit former elle-même ses artistes el les spécialiser très :écunes.

Il voulait que l'Etat, " eomprenant ses deroirs envers la nutiun, dans les questions d'art et de goût, s'imposât pour programme la perfeclion en toutes choses, et la poursuivît, depuis les détails les plus infimes de petite et grande voirie, jusqu'ì l'exécution mannifique du monument national ". D'où la nécessité d’avoir en tout les modèles les plus parfaits et au plus bas prix possible.

Il reprochait aux chefs d'industrie de ne vire que par l'habileté de main, le talent d'imitation el quelques instincts de gôt, " copiant, amalgamant, modifiant les modèles du passé pour arriver ù une reproduction 
bâtarde.... La routine trône en France plus qu'on ne croil ; elle y trône en fermant les yeux sur tout ce qui se fait liors de nos lirontieres; clle y trône avec des airs de supériorité, des airs de novaleurs; avec tant d'airs connus qui n'empêcheraient pas la concurrence étrangère de nous supplanter dans l'opinion publique et surtout dans l'estime d'un public d'élite qui fait l'opinion. ")

Avec le même enthousiasme, il regretlail l'influence heureuse qu'exerçaient en Angleterre nos artistes français Vechte, Constant Sevin, CarrierBelleuse, Jeannest, Morel, méconnus chez nous, ot faisait ce bel éloge : Morel el V'eclıte "sont nés dans l'apprentissage de l'orlèvrerie el sont devenus artistes comme on le devenait dans l'antiquité, au treizième siècle et au seizième, le marteau à la main. Morel a traversé tous les degrés de l'apprenlissage; il a pratiqué tous les procédés connus; il en a relrouvé plusieurs qui étaient perdus et très regreltés et il est devenu le plus lıabile orfèvrebijontier-joaillier que la France ait jamais possédé."

Quant à V'echle, e'est un artiste autrement puissant, c'est lui qui fit vers 1835 et vendil aux brocantenrs " ces pièees d'orlèrrerie repoussée qui paraissaient trop belles pour être modernes, qui, comme ouvres de la Renaissauce, avaient un style si large, si plein, si vivant qu'il élait difficile de l'associer í des maitres connus; d'un autre côté, on ne s'expliquail pas l'apparition subite de pièces aussi imporlantes el lout à fait incommues $n$. Il ne les signa que plus lard. "A la fois honme d'imagination, artiste habile, ouvrier incomparable, Vechte est à Morel ce que Michel Ange est à Benvenuto Cellini, toutes proportions gardées d'un Michel-Ange orlèvre à un Benvenuto Cellini bijoutier... Qu'a-t-on fait pour ces deux lommes, qui avaient dans leurs mains supplianles l'avenir de l'art associé á l'industrie? On les a laissés vécéter, s’èpuiser clans une lulle commerciale qui lue le génie et avilit le goûl, el enfin porler à Londres leur talent avec loutes les bonnes traditions de ce premier des métiers. Est-ce faute d'avoir été averti? Xon, ni l'un ni l'autre de ces artistes n'a caché ses ouvrages: c'est au grand jour des Expositions qu'ils les présentaient aux sulfrages du public et du jury, mais ils devaient être repoussés par toutes les administrations el servir de prolestation vivante contre l'organisation des BeauxArts."

Enfin, le comte de Laborde rêvait " une grancle manufacture modèle qui, en même lemps qu’elle aiderail l’industrie à épurer toutes ses créations, reconstituerail dans les métiers l'apprentissage soumis el sludieux, le patronage dévoué et instruil, tout en respectant la liberté de la paresse et les franclises de l"ignorance....."

ll s'était posé en défenseur énerorique de l'art français; et, à ceux qui, d'après lui, le ruinaient depuis un demi-siècle, il adressait ces éloquentes paroles: "Comprenez-vous comment l'art n’a pas été tué sous deux générations de fossoyeurs qui se suceèdent lugubrement depuiş soixante ans, 
occupés exclusivement à fouiller les tombeaux des générations passées, à les copier aveuglément, servilement, sans choix, et comme poussés par un fétichisme fanatique... Quelle atmosphère sépulcrale plane sur ces hommes et combien est grande la nécessité d'aérer et de parfumer ces caves de l'art moderne; combien il est urgent de constituer des hommes pratiques dune grénération saine, vigroureuse, el qui sachent faire une distinction radicale entre l'art créateur et les monuments du passé, comme on distingue la vie réelle de l'hisloire."

Et pour défendre l'art, pour donner à l'industrie toute sa richesse dimagination, toute sa beauté, le comte de Laborde insistait á maintes reprises sur la nécessité de faire l'éducation du public, car l'industrie en est dépendante: "Ce n'est pas elle qui achète, c'est elle qui vend; ce n'est pas clle qui peut faire la loi, car elle sollicite la faveur de lout le monde; c'est elle qui obèil a la loi imposée par lous. "La même idée se relroure exprimée avec beaucoup de foree dans l'Introduction aux Rapports du jury de 1878 par Jules Simon. "Le véritable promoteur des progrès industriels, le meilleur jugre, e'est le consommateur. La clientèle est la récompense de lout progrès accompli. On dit que la popularité ne suit pas toujours le mérite. Cela est vrai, el cela tient presque toujours au défaut de publicité. Le grand service que reudent les exposilious, c'est précisément de donner de la publicité á tous les produits el de rendre les comparaisons faciles. Aller plus loin et prétendre dicter son choix au consommateur, c'est entreprendre une tâelie dont le premier défaut est d'être inutile, et le second d'être impossible."

L'Exposition de Londres, en 1851 , reste une date illustre dans l'histoire économique du monde. Elle inaugure une ère nouvelle où les Expositions s'étendront à travers les deux continents, el qui sera marquéc de plus en plus par les progrès de l"industrie et du commerce, la multiplication et la plus grande facilité des communications et des échanges.

Par l'Exposition de Paris, 1855, la France voulut donner un digne pendant à l'Exposition de Londres.

Le décret du 27 mars 1852 avait ordonné la construction d'un palais destiné à recevoir les expositions nationales : ce fut le Palais de l'Industric. Critiques et moqueries ne furent pas éparónées à cet "honnêle hangrar ", comme le qualifiail André Hallays. Ln second décret du 22 juin 1855 , " considérant que les perfectionnements de l'jndustrie sont étroitement liés à ceux des beaux-arts...; qu'il appartient ì la France, dont lindustrie doil tant aux beaux-arts, de leur assigner... la place qu'ils méritent ", réunit les beaux-arts et l'industrie dans celte même Exposition universelle et internationale qui s'ouvrit à Paris le 15 mai 1855.

Malogré le mot de l'Empereur à l'inauguration : "J'ouvre avec bonheur ce temple de la paix qui convie tous les peuples à la concorde n, la paix était loin de régner en Europe. L'Exposition fut cependant un triomphe. 


\section{- XXXIV -}

Bien que l'entréc, jusqu'alors gratuite, fût pour la première fois payante, i] y eut 5160000 visiteurs.

On compta 23954 exposants, dont 2175 pour les beaux-arts, el le jury mixte international décerna 11033 récompenses de cinq ordres différents: grande médaille d'honneur (or), médaille d'honncur (or), médaille de $1^{\text {re }}$ classe (argent), médaille de $2^{\text {e }}$ classe (bronze), el mention honorable. On pouvait les attribuer non seulement aux industriels exposants, mais encore " aux contremaîtres et ouvriers signalés pour services rendus a leur industrie ou pour leur participation a la production des objets
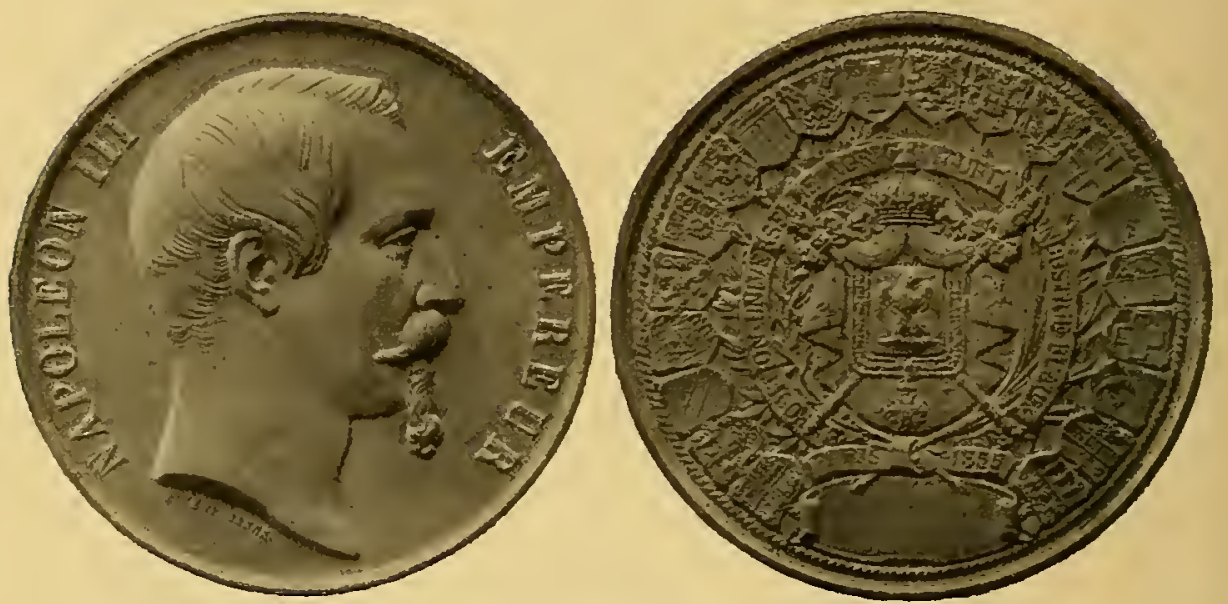

IX et XXI. - Exposition universelle et internationale de Paris, 1 S5̃. Médaille grave par Albert Barre.

exposés ". Le jury examina avec soin les mérites des coopérateurs et les divisa en trois classes : $1^{\circ}$ ceux " qui ont un mérite d’une notorićté si évidente que le jury a pu les désigner lui-même sur cette notoriété i); de ce nombre furent Vechte (grande médaille d'honneur), Cavelier, Geoffroy dc Chaumes, les frères Fannière, Jeannest, etc. (médailles de $1^{\text {re }}$ classe); $2^{0}$ artistes el ouvriers recommandés par les chefs d'industric; $3^{\circ}$ ccux qui sont signalés par les commissaires et patrons étrangers. Pour ces deux dernières classes, la tàche fut difficile : certains patrons refusèrent de désigner leurs bons ouvriers, dans la crainle qu'une maison rivale ne les leur enlevât; d'autres firent des propositions excessives.

Lindustric remportait un vif succès, el l'on se montrait comme un symbole heureux le groupe du sculpleur Elias Robert, qui surmontait l'arche d'entrée et représentait la France couronnant l'Art et l'Industric. Nous gardions le premier rang, mais l'Autriche et l'Angleterre avaient fait de rapides progrès. 
A Londres, en 1851 , les objets exposés we portaient pas leur prix de vente et cela avait enlevé un élément imporlant d’appréciation : à Paris, on laissa ì l'exposant toute liberté, à la condition que ce prix fit visé et reconnu sincere.

L'Exposition de 1855 a laissé une collection de rapports dont quelquesuns demeurent d'un très grand intérêt. La classification des huit groupes et des trente classes avait èté l'œurre de l'économiste Le Play, successeur du trénéral Iorin comme commissaire génèra]. Je prince Napolėon, président de la Commission impériale, avait pris une part très active dans l'organisation de l'Exposition; il rédigea un Rapport administratif où il préconisait des expositions spéciales el plus fréquentes, exigeait le prix de vente affiché,
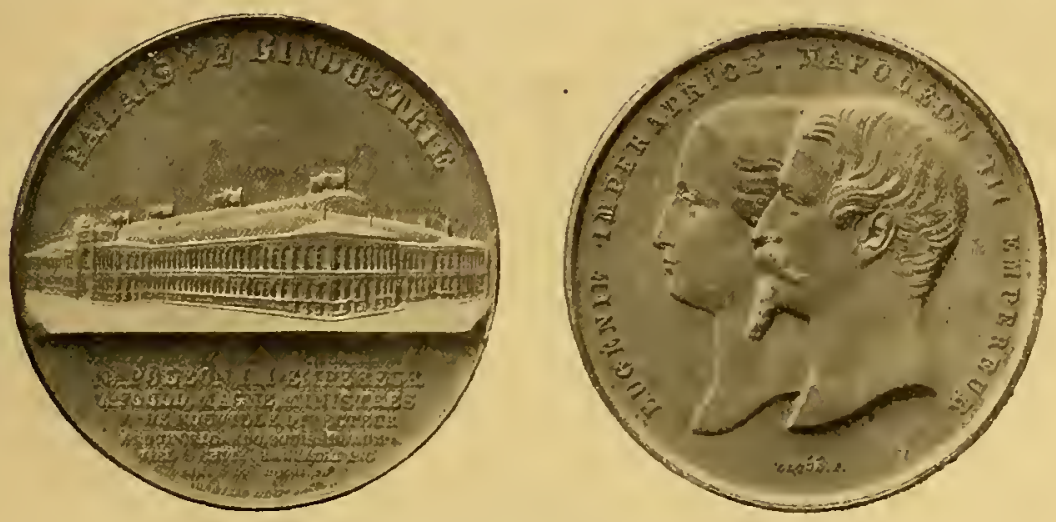

Xxil et xxIl1. - Medaille commémoralive du Palais de I'lndustrie, gravec pal Caqué.

et voulait substituer au jury, délordé et incapable de tout roir, de simples commissions d'ètnde.

I.e Rapporl général de . Wichel Chevalier est un beau travail d'économice sociale sur les moyens de réaliser le bon marclié; parlant de l'Angleterre industrielle, il dit entre autres : "Nous avons conduit les Anglais dans la voie du beau; par un échange mutuel et fort heureux, ils nous mènent vers l'utile. "L'éturle des classes nous entraincrait trop loin; les rapports qui sont consacrés à chacune d'entre elles sont des notices courtes, précises, très nettes, qui contiennent les observations générales sur l'ensemble de chaque profession, suivies de notes succinctes sur chaque exposant. Nous simnalerons :

Classe 17 : Orférerie, par Ledagre. Bijoulerie-joaillerie, par Fossin.

Classe 18 : Emanx, verrerie, /aïence, porcelaine, par Sainte-ClaircDeville.

Classe 24: Ameublement el décoration. Rapport très complet par du 
Sommerard. On y relève les noms de Fourdinois, qui dirige l'ameublement "dans la voie de l'art el des saines traditions du goutt"; Barbedienne, connu tant pour ses beaux meubles que par ses bronzes réduits suivant les procédés d'Achille Collas; Jeanselme père et fils, successeurs des Jacob; Beurdeley, J.-A. Quignon, ébénistes; Delicourt, Jules Desfossé et Zuber, dans les papiers peints; Poussielgue-Rusand, célèbre par ses décoralions d'édifices religieux; Baclielet, dont Viollet-le-Duc est le coopérateur.

Classe 26 : Imprimerie, pholographie, gravure, reliure, dessin, el plaslique appliquée à l'industrie. Le rapport de l'architecte Léon Feuchères contient un excellent historique du dessin de fabrique. Depuis la fondation, c11 1820, du premier "cabinet de dessin " par Amédée Couder, les dessinateurs luttent pour se faire admettre officiellensent aux Expositions; en 1834 ils $y$ sont parvenus, mais c'est en 1855 que la place leur est faite sans conteste. C'est Couder qui depuis trente-cinq ans créc tant de modèles et lournit tant d'idées, le projets et de dessius aux maisons d'orlevrerie-bijouterie-joaillerie, bronze, ébénisterie, tapis, papicr peint. De son alelier¿cole sont sortis tous les dessinateurs industriels du dix-neuvième siècle. Citons : Polerlet (dessins pour châles et papiers peints), Louis Laine (bijouterio), Laroclıe, "artiste de fantaisie ", les frères Berrus, dessinateurs et metleurs en carte du châle cachemire français, Chebeaux, F. Henry, Chabal Dussurgey, qui travaille pour Beatuvais et les Gobelins ; Liénard, l'éminent dessinateur pour bronzes, auteur de la fontaine monumentale de l'Exposition; Cavelier, le modeste auteur du berceau du Prince Inpérial, collaborateur d'Erard, Odiot, Denière, Thomire, Feuchères, FromentMeurice. Et, consécration officielle de cette justice rendue aux dessinateurs, la Chambre de Commerce de Paris recevait une grande Médaille en leur nom.

L'Exposition de 1855, surtout remarquable par l'extension du machinisme, mérite enfin l'attention par l'esprit de justice et d'équité qui inspira ses orranisateurs. C'est la première fois que l'on s'efforça vraiment de récompenser pleinement les collaborateurs et coopérateurs, artistes et ouvriers. Et ce juste hommage, trop souvent négligé depuis, pourrait derenir pour l'industric frauçaise la source d'un plus grand développement.

Le succès des deux grandes manifestations de 1851 et de 1855 incita la Grande-Bretagne à ouvril une nouvelle Exposition universelle el internationale en 1862. C'est la Société des Arts de Londres qui fut de nouveau chargée de l'organiser, et ce fut encore une entreprise privée. Le prince Albert, quoique malade, lui donna cependant tout son appui. En France, la Commission supérieurc était de nouveau présidée par le prince Napoléon: Le Play en fut le commissaire général. L'admission de nos produits fut décidée par des comités départementaux; mais le manque d'activité et d'indépendance dont ils firent preuve fut tel, que l'on décida à l'avenir de les remplacer par des délérués locaux accrédités à Paris. 
Le prince Abert mourait bientôt et l'Exposition s'ouvrit en 1862 , sous limpression de ce deuil, dans un palais élevé pour elle dans les jardins du South liensington. Les beaux-arts, exclus en 1851 , furent admis sans restriction, mais hors concours, parce que le but de l'Exposition était " non d'établir un concours entre les artistes des diverses nations, mais de faire constater les progrès et l'état de l'art moderne".

Le nombre des exposants, agricoles et industriels, atteignit 27500 , dont 8150 pour l'Angleterre el 5520 pour la France. Il n'y eut que deux ordres de récompenses: médaille et mention honorable. Sur les 12305 qui furent décernées, l'Angleterre en obtint 4141 et la France 2 658. C'était, pour l’industrie française, un véritable triomphe, car elle obtint à l'Exposition de Londres, 1862 , la plus forte proportion dans les médailles.

Comme en 1851 , des délégations de contremaîtres et d'ouvriers furent envoyées à Londres pour examiner les produits; elles firent preuve de zèle et d'intelligence, et plusieurs, en rendant compte de leur mandal, présentèrent de justes et utiles observations.

l.es Rapporls officiels de la Section française forment une collection de six volumes. Une savante introduction de Michel Chevalier - vue économique d'ensemble sur les progrès de chaque industrie - les précède. Chaque rapport de classe se termine par un tableau du commerce spécial de la France en 1860 , aree moyennes décennales de 1837 a a 1846 et de 1847 a 1856 .

Yous regrettons de ne pouvoir que signaler le magistral rapport sur l'enseignement industriel du général Morin el de Tresca, très documenté et toujours précicux à consulter.

La Classe 3o, ameublement el décorntion, seule nous retiendra, parce qu'elle a fourni au rapporteur P. Mérimée l'occasion d'écrire un chapitre intitulé Considérations sur les applications de l'art à l'industrie. Il constate limportance croissante de l'art industriel. L'Exposition de 1862 en est le meilleur témoignage, mais la France bientôt sera dépassée par l'Angleterre parce " qu'il existe une relation intime entre toutes les partics de l'art, et que, partout où surgit un grand artiste, se forment des ouvriers habiles et intelligents. Là, en effet, où coule un grand fleuve, il est facile de creuser des canaux d'irrigation, et le courant majestueux qui porte à la mer des vaisseaux de haut bord, alimente sans peine une infinité de rigoles, répandant partout la fécondité. De Raphaël et de Michel-Ange procède Benvenuto Cellini; le grand peintre, le grand sculpteur ont produit le grand orfèvre. "

Il remarque que nos produits d'alors sont surtout des imitations " témoignant de cette disposition fâcheuse pour l'art, à qui la passion est nécessaire et qui languit lorsqu'elle s'éteint $n$; ils manquent d'originalité : ils ne sont qu'ingénieux; ce sont pour la plupart " des combinaisons étranges de styles différents rapprochés au hasard, qui ne dénotent de la part de leurs auteurs 
qu'absence didée et faute de raisonnement ". Dès qu'un motif d'ornement est en rogue, il est reproduit par nos fabricants avec toutes les matières quils mettent en auvre : bois, métal, etc. Il faudrait qu'il existât un accord plus intime entre artiste et fabricant, et que le gouvernement, prenant exemple sur l'Angleterre, qui a créé l'Ecole de dessin du South liensington Museum, encourageàt darantage l'union de l'art arec toutes les branches de linclustrie.

On remarqua, par un contraste curieux, que " l'Angleterre aristociatique faisait, par sa production à bon marché, de l'industrie démocratique, tandis que la France democratique, par sa production de luxe, faisait de l'industrie aristocratique $"$.

C'est que, de plus en plus, on juge le degré de civilisation d'un peuple moins à ses objets de luxe et à son sentiment artistique, qu’à la diffusion du bien-être, à la puissance des machines créatrices, en un mot aux conditions matérielles de la vie. Un objet d'art ou de luxe peut ètre une rencontre fortuite, et des peuples peu arancés en fourniraient des modèles; tandis qu'il n’ a qu'une nation civilisée qui puisse présenter ce déreloppement harmonieux et parallèle de l'art et de l'industrie, ce bien-être général, ce triomphe constant de l'homme sur li nature au profit de tous.

L'art décoratif français, ou plutòt " les Beaux-trts appliqués à l'Industrie ", suivant l'expression alors en usage, ballottés entre tous les styles, loujours à la merci de la mode, se trouvaient privés de méthode et d'enseignement, sans bases solides comme sans but précis. Dẻjà, comme nous l'arons vu, d'éminents rapporteurs aux Expositions, surtout le comte de Iaborde. le duc de Luynes et P. Mérimée, avaient jeté le cri d'alarme. Eı 1863, sur linitiative de l'architecte-décorateur Guichard, onze industriels parisiens : Ph. Mourey, Lerolle, Ernest Lefébure fils, Turquetil, Chocqueel, Hermann, Lenfant, Mazaroz, Sajou, Schreller-Erard, Veyrat, Bergon, se réunissaient et décidaient, dans le but de favoriser le développement des industries artistiques, de fonder l'Union cenlrale des Beaux-Arts appliqués á l'Industrie. Parmi les considérations mises en avant, ils indiquaient : progrès de l'industrie en Europe; crainte de perdre notre suprématie; nécessité de perfectionner l'enscignement industriel par la création d'un conservatoire-musée d'art et d'écoles de dessin.

L'Union se proposait notamment " d'entretenir en France la culture des arts qui poursuivent la réalisation du beau dans l'utile, d'aider aux efforts des hommes qui se préoccupent des progrès du travail national, depuis l'école et l'apprentissage jusqu'à la maitrise..., d'exciter l'émulation des artistes dont les travaux, tout en rulgarisant le sentiment du beau et en améliorant le goût public, tendent à conserver à nos industries d'art, dans le monde entier, leur vieille et juste prééninence aujourd'hui menacéc. "

De tous côtés artistes et industricls s'empressèrent d’accorder leur aide et leur collaboration à l'œurre naissante: Barye, Klagnann, Davioud, 
Diéterle, Léon de Laborde, de Cardaillac, Champfleury, Paul Dalloz, Galichon, du Sommerard, puis Louvrier de Lajolais, Minoret, Racinet, Piat, Tillier, Lafenestre, Paul Mantz, René Ménard, Paul Lorain, Bartholdi, Chapu, Choiselat, Delagrave, Burly, les frères Fannière, Galland, Gérome, Lièvre, Riester, Roussel, Patrice Salin, Sauvageot, Paul Sédille, CarrierBelleuse, Eugène Muntz, Deck, Aimé Mlillet, etc. Leur nombre s'éleva aussitôt à 136 .

Le premier devoir de l'ouvre nourelle fut d'affirmer son existence par une Exposition, en /863, au Palais de l'Industrie, comportant des colleclions d'arl rétrospectif, des modèles de l'industrie d'art contemporain, et des traraux des écoles de dessin. L'année suivante, / 864, Eugène Guillaume exposa dans une grande conférence son plan complet des réformes de lenseignement du dessin et de ses applications a l'industrie, puis, en 1865 et 1869, deux autres Expositions, semblables à la première, eurent encore lieu; à celle de 1869 fut adjointe une Exposition rétrospective d'art oriental; en même temps, l'Únion convoquait un Congrès International présidé par Louvrier de Lajolais, pour y examiner ses théories et ses programmes en matière d'art et d'enseignement. L'unité de l'art y fut proclamée une fois de plus, et un plan de réforme de l'enseignement du dessin nettement arrêté.

Nous verrons plus loin, sous la troisième République, l'évolution de cette grande association, son ouvre et sa création du Musée des Arts décoratifs.

Dès leur retour de l'Exposition de I.ondres, 1862, les industriels a vaient demandé l'ouverture en France d'une nouvelle grande Exposition. Et le décret du 22 juin 1863 en fixait la date à l'année / 86 \%. Jamais Exposition ne se prépara sous de pires auspices, et c'est cependant celle dont le succès paraît avoir été le plus éclatant peut-être, el dont le souvenir est demeuré le plus vivant dans bien des mémoires. Elle marque l'apogée du régime impérial : clle eut pour cadre licureux l'immensité du Champ de Mars. Ce fut une fète, au milieu des tempêtes. Le prince Napoléon, chargé de l'organiser, se brouille avec l'Empereur; le Prince impérial, âgé de dix ans, le renplace, et Rouher, vice-président, devenu ministre, laisse enfin la direction et la mise en ouvre au Commissaire général Le Play.

A l'extérieur, l'Europe s'inquiète au lendemain de Sadowa; Maximilien empereur du Mexique, est à la merci de J'insurrection.

A l'intérieur, le duc de Morny, "l'âme de l'Empereur ", vient de suc. comber. L'opposition grandit au Corps législatif, et les mesures libérales de Napoléon III n'arrivent à salisfaire personne.

Cependant Paris, depuis douze ans, s'est métamorphosé. Le préfet Haussmann et le directeur Alphand ont créé le Bois de Boulogne et les ButtesChaumont, ouvert partout de larges boulevards et d'immenses avenues qui rayonnent autour de l'Are de Triomphe et bâti l'Hôtel-Dieu, le nouvel Opéra et Saint-Auguștiu. Peu à peu le malaise, comme par enchantement, se dis- 
sipe; la paix se fait, au dedans comme au dehors; et l'Exposition peut s'ouvrir le $1^{\text {er }}$ avril, réunissant, non compris les beaux-arts, 52200 exposants, dont 15969 pour la France.

La classification, due à Le Play, en est restée célèbre; elle était " basée sur des considérations philosophiques relatives aux divers besoins de l'homme». Quant ȧ la répartition même des produits de chaque groupe, elle était des plus remarquables. Les objets étaient groupés par ordre de matière en huit galeries concentriques : $1{ }^{\circ}$ au centre, histoire dn travail, puis succes-

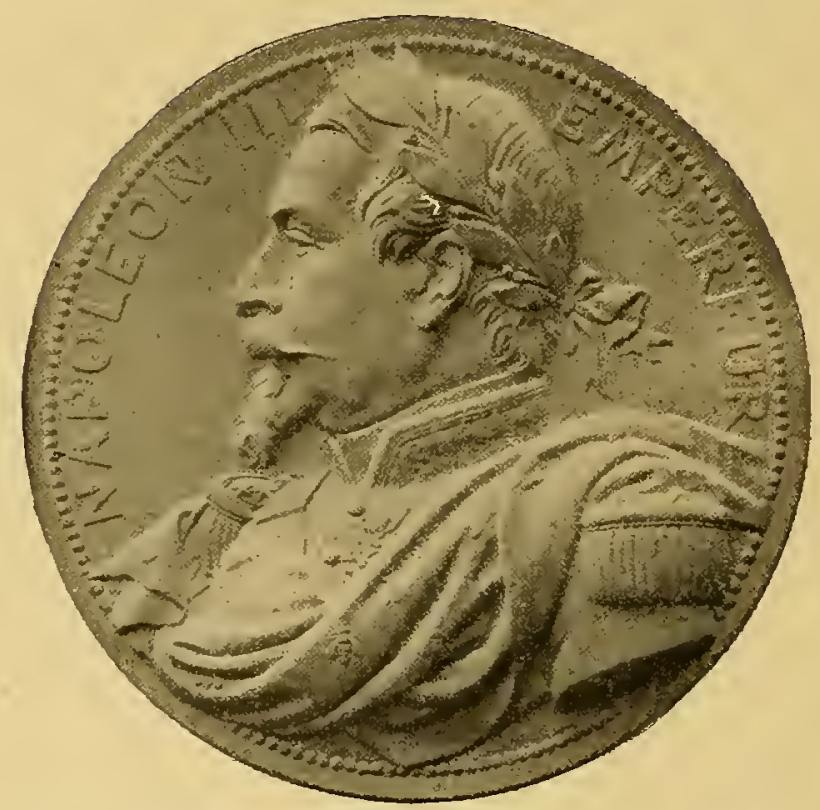

XXIV. - Exposition universelle et internationale de Paris, 1867. Grande Nedaille, gravée par J.-C. Chaplain.

sivement : $2^{\circ}$ cuvres d'art; $3^{\circ}$ arts libéran $x 4^{\circ}$ mobilier; $5^{\circ}$ vétements; $6^{\circ}$ matières premières; $7^{\circ}$ machines en monvemeut; $8^{\circ}$ aliments et boissons. Douze allées, six à droite, six à gauche, partaient du grand axe : les principales nations occupaient les secteurs limités par ces rayons. Ainsi, le visiteur pouvait, à son gré, étudier, par les galeries concentriques, l'état d'une industrie dans les différentes nations, ou, par les allées transversales, voir, pour chaque pays, l'ètat des différentes branches de l'industrie. Trois groupes, l'horticullure, l'agricullure et l'économie sociale, furent installés à part.

Trois empereurs, quatorze rois ou reines, le vice-roi d'Egypte, le sultan, le frère du Taïcoun du Japon, trente-trois princes ou princesses de familles régnantes vinrent la visiter. Ce fut un succès colossal, dont s'effraya Le Play lui-même, et le Rapport administratif qu'il rédigea insiste sur le 
danger de ces expositions de plus en plus gigantesques, impossibles à préparer en quelques mois, et dont la durée éphémère ne mérite pas les lrais énormes et le bouleversement économique qui en résultent : c'est une confusion des produits importants et secondaires; une crise de travail et de curiosité. Et, sagement, il préconise des expositions permanentes et restreintes sous le titre de "musées généranx ou musées commercianx".

Michel Chevalier écrivit l'Introduction anx Rapports du jury. Cette cuvre, oủ le savant se double d'un moraliste, est un exposé des rapports

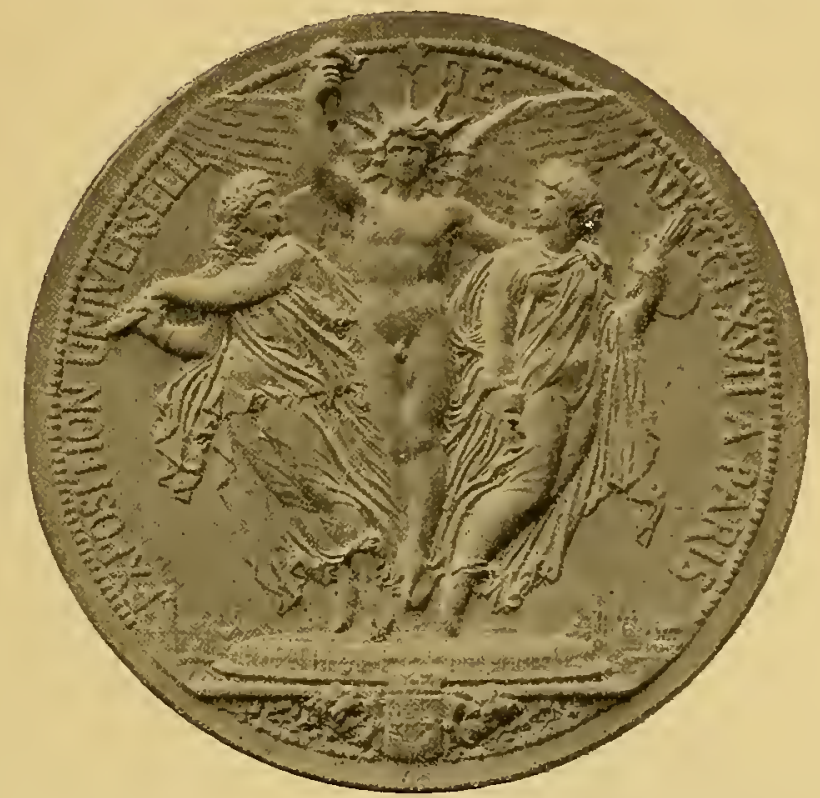

XXY. - Exposition universelle et internationale de Paris, 1867.

Revers de la grande Médaille, gravie par I.-C. Chaplain.

entre l'industrie, la science, le capital et la liberté, des perfectionnements de l'industrie et de la puissance de production des industriels et des sociétés.

Des rapports de classes, Irès complets et très étudiés, nous retiendrons parmi ceus qui intéressent directement l'art industriel :

Classe 8: application du dessin et de la plastique aux arts industriels. Rapport de Victor Baltard sur les procédés généraux el l'enseigmement de larl industriel. Rapport d'Edmond Tainny : applications diverses. Rapport de Barre: gravure en pierres fines. La classe posséclait en outre dessins el œuvres d'orfévrerie, ciselure, émaillerie, etc. La difficulté fut, pour le jury de cette classe, de départager les dessinateurs qui jettent leurs modèles sur le papier et les artisans qui sont créateurs à la fois par l'inspiration el par l'exécution, el ses rapporteurs insistent sur la nécessité de déve- 
Iopper chez nous le goût, l'invention, la variété, de lutter contre l'uniformité et la monotonie et d'établir des éeoles professionnelles de dessin pour toutes les branches de l'art industriel.

Classe 14: Rapport de E. Guichard sur les menbles de luxe; sauf de rares exeeptions, on y retrouve les reproches habituels.

$1^{\circ}$ Une habileté de main poussée à l'extrêne;

$2^{\circ}$ Des industries d'art puisant tout aux sources anciennes avec peu de discernement, et vivant sur le capital laissé par nos pères, sans y ajouter rien ou ì peu près;

3. L'absence d'invention et de style propre;

$4^{\circ}$ Des ourres conçues, en général, en dehors des convenances de leur destination et des lois harmoniques des ensembles.

"L'art est trop souvent dirigé, non par l'artiste, mais par la mode aveugle, par l'amour du faux luxe, par les goûts singuliers de clients volontaires et peu éelairés, et d'un autre côté par la nécessité de vendre qui entraîne et violente le fabricant, Iors même que e'est un habile homme et un homme de rnoût et qu'il n'ignore nullement que, en exéeutant la commande, il se place en dehors des conditions de l'art."

Et la conclusion s'impose d'elle-même : création d'écoles professionnelles, extension de l'enseignement des beaux-arts, rénovalion compléle de

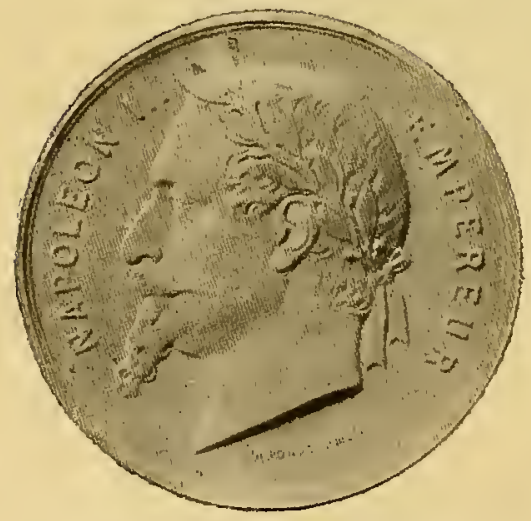

XXVI. - Exposition universelle el inlernalionale de Paris, 1867 . Face de la Iédaille des réeompenses, gravéc par H. Ponscarme. nos arls industriels et aussi " néressité de reconstituer une élite nombreuse de fins connaisseurs $"$.

Classe 21 : Paul Christofle : orfévrerie. Ia France y conserve le premier rang; l'orfèverie reste un art véritable, dans lequel il faut tenir compte non seulement de la commodité et. de l'usage auquel on destine l'objet, mais, encore de la pureté du style et de l'élégance de la forme et de la décoration.

Classe 26: Rapport de Fossin et Baugrand : joaillerie, bijouterie. On y copie moins, on tend à devenir original, mais si la France veut garder sa supériorilé, elle doit développer le জroût, faciliter l'exportation par une modification de la loi sur la garantie, créer des écoles de dessin pour les ouvriers bijoutiers, intéresser l'artiste a ux bénéfices, consacrer la propriété du dessin et a associer les ouvriers aux produits de leurs travaux en les rendant solidaires de la prospérité de leur industrie, sans entamer en rien le droit de propriété des patrons". 
Parmi les principaux lauréats des industries d'art, il nous faut signaler : Mame, Firmin Didot, l'Imprimcric Impćriale, pour la librairie; les frères Fannière avec leur famcuse "Chute des anges" en acier repoussé; FromentNeurice (Buste de l'Empereur sculpté dans une ainuc-marine et Berceau du Prince impérial), Christofle, Duponchel, pour l'or/èurerie, et Poussielgue et Amand-Calliat pour l'or/évrerie religieuse; pour la bijonlerie-joaillerie, Boucheron, qui donnait la liste de tous ses collabornteurs, Fontenay, Massin, qui rénovail la joaillerie française; Sallandrouze de Lamornaix, pour ses lapis; pour l'ébénisterie, Fourdinois ct aussi Itenri Lemoine qui avait fondé, en 1865 , la première école de dessin professionnel suivic l'année suivante par celle de la bijouterie, crééc par Alexis Falize, Massin, Fannière; dans le bronze, Denière et aussi Barbedienne: saluons cet illustre fabricant qui le premier, comme éditeur, s’est montré vraiment respectueux des droits de l'artiste et fut pratiquement le créateur de ce contral d'élition qui contribua tant au développement de la sculpture française.

Une importante innovation se manifesta pour le public par les récompenses spéciales que l'on décerna : clles furent "en faveur des personnes, établissements ou localités, qui, par une organisation ou des institutions spéciales, ont développé la bonne harmonie entre lous ceux qui coopérent aux mémes travaux of ont assuré aux outriers le bien-étre matériel, moral el inlellectuel ". Liidée fut quelque peu critiquée, laxée même de charlatanisme; on se moqua du tableau des mérites que la Commission avait dressé pour leur fixer un coelficsent; mais si, comme l'a dit plus tard Jules Simon, il y avait "générosité dans le principe el puérilité dans l'application ", l'cuvre n'en reste pas moins curieuse el belle, pour avoir fail, "dans cetle fête du travail, une place à la moralisation de louvrier, à sou instruction el à son bien-être ".

En même temps, une réelle importance fut donnéc aux délégations anvrières. Elues par leurs pairs, elles étaient chargées d'étudier la fabrication des objets exposés el de les apprécier dans des rapports adressés il la Commission d'encouragement. Leur mission fut remplie avec imparLialité; leurs Rapports illustrés sont en général très bien faits, el les vœux qu'ils formulent, pleins de sagesse et de sincérité, si l'expression n’en est pas toujours élégante, s'efforcent du moins d'être toujours justes et pratiques. On $y$ trouve des remarques utiles sur la fabrication lrançaise comparée \&́ celle de l'étranger, des roux pour l'amélioration de la dignité du travailleur, pour la création de syndicats patronaux et ouvriers, "afin d'y disculer froidement et de sauvegarder les intérêts des deux parties "; cnfin des critiques de la division du travail qui anéantit le goût de l'ouvrier. Travail, instruction, liberté, voilà brièvement l'utile conclusion qui se dégage de ces rapports.

L'Exposition de 1867 s'acheva dans les lêtes, mais au milieu de sombres présages. Michel Chevalier craignail, dans son rapport, qu’elle ne fût qu’un 
" météore lumineux, nais passager, sur un horizon destiné à s'obseurcir et ¿̀ ètre déchiré par les orages ". Quelques années allaient suffire pour que la crainte se justifiât. Ce fut le dernier rayon qui éclaire la fin d'un beau jour.

Le seeond Empire s’achève plein d'une eertaine futilité, mais aussi d'équitė; la sociétè, frivale et sérieuse, " y'affolant de divertissements et se pénétrant d'émotions ", usant, abusant de la vie, travailleuse et rieuse tour à tour, restera comme l'a dépeinte Pierre de la Gorce, "toute gracieuse arec des sourjres, des rires, des éclats de rire, des larmes aussi,

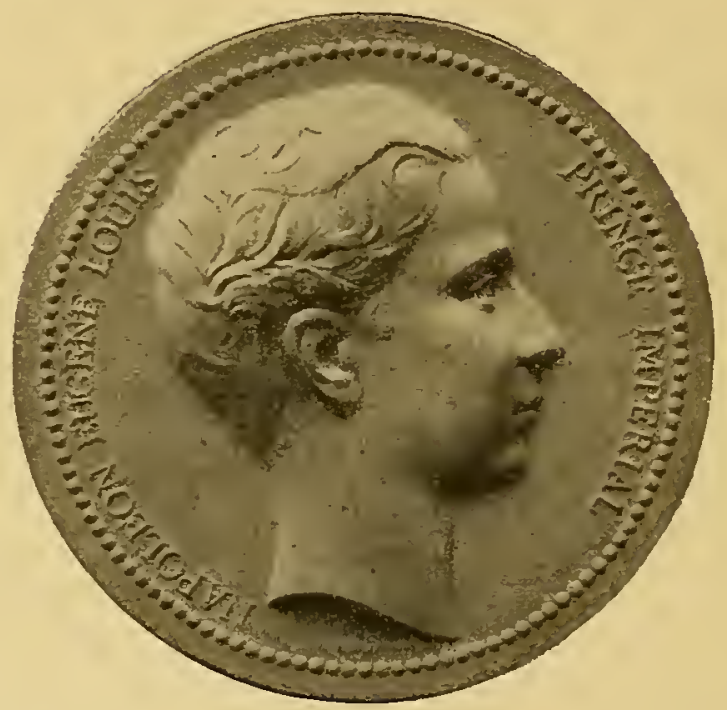

XXV11. - Exposition universelle et internationale de Paris, 1857.

Face sravée par Barre de la médaille frappée en $18: 39$.

mais qui se sèehent vite comme des gouttes de pluie sur les ailes d'un oiseaun.

L'Impératrıce Eugénie s’impose à la mode : son luxe, ses toilettes font loi. Elle devient le type officiel de l'élégance que chacun veut imiter; et sa couturière, $\mathrm{II}^{\text {me }}$ Yignon, est célèbre dans le monde entier. Le tableau de Winterhalter : "l'Impératrice Eugánie entourée de ses dames d"houneur ", nous montre bien cette société riche, élégante et joyeuse; cest une époque de fêtes offieielles ou partieulières, de galas, de revues, de réceptions. Les femmes en sont les reines : et que l'on parcoure bals, salons ou mémoires d'alors, ce sont toujours les mêmes que l'on admire passer : Frédéric Loliée, dans ses Femmes du second Empire, fait défiler devant nous $M^{\text {me }}$ de Metternich, surnommée "Madame Chiffon ", la duchesse de Mouchy, Mme Erazzu, Imo Walewslia, la duchesse de Morny, et puis aussi la Bellanger ou Mmo Iu- 
sard, la Païva ou la comtesse de Castiglione et enfin llortense Schneider, "grande-duchesse de Gérolstein ", Thérèsa, la chanteuse populaire, Cora Pearl et Léonide Leblanc, toutes plus belles et plus extravagantes les unes que les autres.

Dans les salons mondains, c'est une folie. Virre, c'est s'amuser. Les "rastas", les "petits crevés", les "fêtards " du Café Auglais sont les personnages de celle farandole effrénée. La Belle IIéléne, Orphée aux En/ers, les opérettes joyeuses où l'on déshabille les dieux de l'Olympe, les calembredaines folles, la musique endiablée d'olfenbach, voilà ce qui

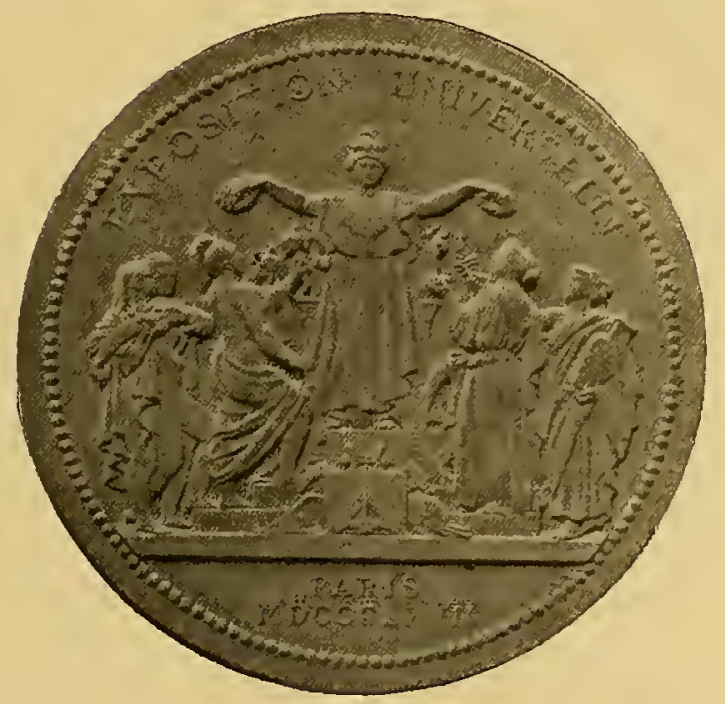

XXVlll. - Exposition universelle et internationale de l'aris, $186 j$.

Revers graré par Vauthier Galle de la Médaille frappe en isiog.

plaît ‘̀ cette demi-élite parisienne, et Vénus cascadeuse chante à Cupidon sans carquois :

Il nous faut de l'amour,

Nen fût-jl plus au monde.

Ce n est là qu'un des aspects du second Émpire, mais c'est celui que chacun a remarqué ct décrit, celui qui reste aux yeux du public le seul vrai, parce qu'il est fait de luxe lapageur, de bruit élourdissant, de rêtes perpétuelles el de parade. Cependant, l'on goute et l'on applandit en même temps les IInguenols, Fiust oll Mignon; rarement il y eut époque plus laborieuse, plus active, même plus moralisatriee, plus désireuse aussi de justice sociale dans ses dernières années. Au théâtre comme dans les romans s'agitent les grands problèmes de la vie el des maurs. Victor Duruy, par la loi de 1867 , erée des écoles graluiles dans 
toutes les communes, et bientôt réorganise l'ensergnement secondaire des Iycées.

Puis la mode obéit a la société; plus de crinolines énormes ni de ces jupes qu'on relève avec un cordon comme un store de fenêtre; plus de soicries chargées de dessins, plus de cachemires, mais une toilette légère, agile, alerte, beaucoup d'élégance et quelquefois du goût. l.e vêtement masculin, à part celui des jeunes élégants et des vieux qui les imitent, est

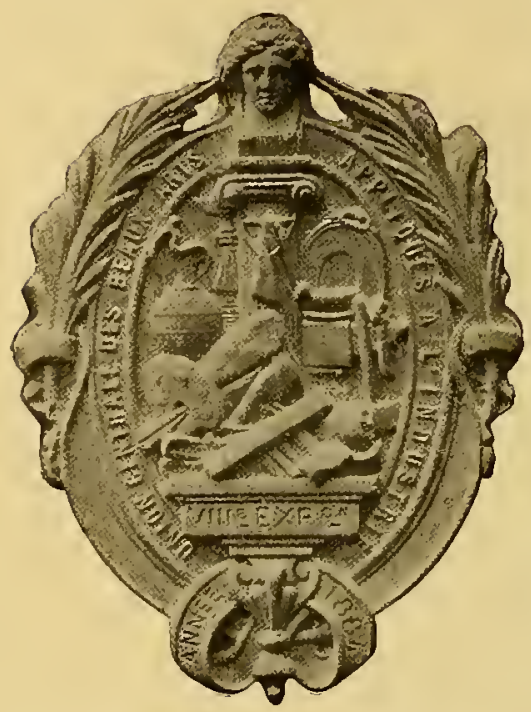

XXIX. - lace de la Plaquelle des Exposilions organiscies a Paris en 1865, ${ }_{1} 869,18_{7}+1876,1880,1882,1884,1887$, 1892, par l'Ĺnion centrale des Beauxirts appliqués à l'Indnstrie, fondéc en 1863 et fusionnéc en 1883 avec la Société du Musée des Irts décoralifs sous le nom actucl d'Lnion centrale des lrts decoralifs. bourgeois simplement. Quant ì la forme, elle est très inlluencée par l'entrée au musée du Louvre des bijoux étrusques de la collection Campana.

Nais, dans l'art, de plus en plus se sćparent les deux notions du beau et de l'utile. Pour l'ameublement ou la vaisselle, on ne vise plus qu'à l'utilité pure, au solide, au " cossu bourgeois", ou bien au bon marché, au factice sans yràce et sans fantaisie. On pastiche encore les vieux styles: on refait du Lonis $\mathrm{XIV}$, du Louis XV du Louis XVI. L'architecture, dont dèpendent les arts décoratifs, rahit la mème indécision. Elle construit sur des données disparates empruntées à d'autres âges. Býzantin et Pienaissance s'associent, et l'Opéra de Charles Garnier élève à Paris son assemblage fantasque de colonnes, de dômes, d'obélisques et de marbres multicolores, pendant que Viollet-leDuc et Duban procèdent à leurs savantes reconstitutions.

Les intérieurs sont luxueux, décorés par Fourlinois ou Lemoine, grandement tapissés, garnis d'Aubusson par Braquenié ou Ilamol, embellis par les portraits de Winterhalter, un tableau de Biard, une terre cuite de Carpeaux, une nymple de Chaplin.

Et c'est ainsi que le slyle du second Empire, si l'on peut appeler style cette indécision et ces contradictions de goût, est, comme sa société, très mélangé, très tapageur, montrant tantôt ce négligé des lendemains de fêtes et tantòt cette raicleur de l'élégant qui défile a la parade. 


\title{
Les premières années de la Troisième République
}

\author{
$1870-1889$
}

Expositions de Londres, $1871-72-73-7\}$ : de Vienne, $18-3$ : de Philadelplie, $18-6$. - Exposition de Paris, 18-8. - Son sueces et son importance. - Belle lntroduetion au Rapport général, par Jules Simon : ses eritiques du faux luxe el du manque doriginaliti de nos objets usuels. - Nécessité de créer d'urgence des écoles. - Trés intiressan rapport de E. Didron sur les Arts decoratifs.

lićlomes daus l'Enseignement du Dessin suivant la mithorle d'Eüune Guillaume. L'Ecole des Arts décoratifs et les Ecoles similaires de pruvinec, - L'Union eentrale des Arts dieoratil's; son róle et son action. - La France aux Expositions universelle's de l'etranger', de $18-8$ à 1859 .

Exposition de Paris, 1889 - Son suces malgré l'abstention des grandes nations. - $1 \mathfrak{x}^{\circ}$ fer détrône le bois el la pierre. - Les lndustries d'Art commeneent à manifester un réel besoin d'innover et une tendance plus saine vers une ornementation moderne, interprétant la nature. - Ice maitre Emile Gallé.

L'Lxposition de 1867 n'avait été, comme l'écrit, en 188,9 , le vicomte de Vogüe dans sas Remarques sur l'Exposition du Centenaire, que "la veillic. folle du grand deuil " qui devait aboutir à l'année terrible et aux ruines de $18 ; 1 \ldots$

Cependant, l'Angleterre avait inauguré á Londres, le $1^{\text {cr }}$ mai 1871 , dans les galeries du South Kensington, une série d'Expositions annuelles Internalionales, plus spécialement réservées aux beaux-arls et il l'enseignemenl. lesquelles devaient être en outre consacrées chaque année it un cerlain nombre d'industries. Il n'y avait pas de récompenses.

La France, dès 1870 , avait promis d'y participer. Nalgré les événements douloureux qui avaient paraly'sé nos industries et intercepté les communications, elle voulut montrer par sa vitalité que les malheurs n'avaient pas élouffé son génie. Le commissaire général, du Sommerard, aidé du prince de Galles el du ministre Gladstone, put momentanément remplir les galeries qui nous étaient réservées, avec des objets français empruntés aux collectionneurs de Londres, en attendant l'arrive de nos envois définitil's qui comprirent 1051 numéros. Du Sommerard créa un bureau qui servil 
d intermédiaire gratuit pour la vente entre l'artiste ou l'industriel el le public: cette innovalion fut très approuvée et aida à notre succès. Le règlement n'autorisait que l'exposition d'un seul spécimen de chaque objet, et en interdisait la vente immédiate. La France avait cependant obtenu, avec quelques autres nations, la faculté d'élever des annexes où l'on pourait vendre des objets semblables à ceux exposés.

Des rapports furent écrits par Viollet-le-Duc pour les beanx-ar/s, Gruyer pour les produits industriels présentés au point de vue de la forme el du dessin, le duc de Luynes pour la céramique, et Focillon pour l'enseignement et les inventions.

Lannèe suivante, 18;2, 1\%xposilion de Londres réunissait : colons, bijouterie, joaillerie, instrumenls de musique, appareils d'acoustique, papelerie, librairie, imprimerie. Nous y firurions avec honneur, mais nous n'y avions que 843 numéros: l'Exposition de Lyon, qui se tenail en même lemps, lui faisail concurrence. Le déclin ful encore plus grand en 1873 . I.e programme comportait : soie el velours, acier, ins/ruments de chirurgie, roilures et subslances alimentaires. L.a France et dautres pays s abstinrent, pour réserver tout leur effort à la grande Exposition de Vienne, qui arait lieu ì la même époque en Autriche. 11 y eut encore à Londres une Exposilion en 1874 comprenant : dentelle, genie civil, chanffage, cuirs, reliures, el rins étrangers. La lirance y présentait 972 numéros, mais l'insuccès fut lel partout, que la Commission anglaise déeida de ne pas continuer ces exposilions et de !e pas donner suite à celle qui élail prévue pour 1875 .

L.'Exposit on de Tienne s'ourrit le $1^{\mathrm{er}}$ mai 187.3 au Prater, dans des galeries construites sur les bords du Danube; aux beanx-arts et aux industries on joignnit pour la première fois (Classe 26) l'éducation, l'enseignemen/, l'instruction. D'autres classes méritent aussi d’être signnalèes par l’origrinalité de leur conception el leur nouveauté : la Classe 12 groupait les arls qraphiques el le dessin industriel; la Classe 19 montrail les lypes de l'habilalion bourgeoise, ses imérieurs, sa décoralion, son amenblement; la Classe 20 lui faisalit pendant avec lhabilation rurale. ses uslensiles et son mobilier. La Classe 22 off'ait la représentation de l'influence des musées des beaux-ar/s appliques a lindustrie.

La propriélé industrielle des objets exposés fut formellement protégée par une loi du Parlement autrichien, dont le Journal o/ficiel reproduisit une traduction ( $1^{\text {er }}$ décembre $18-2$ ). La question n'est pas nouvelle, puisque la première loi sur les brevels d'incention remonte à Mirabeau, 7 janvier 1791, el que d'autres lois vinrent y apporter d'utiles modificalions en 1836 , en 1844 , en 18668 (1), el depuis en 1909 . Mais c’est à Vienne que se lint, pendant

1) La loi da 23 mai 1 S6S rarantit plus spicialement les inventions suseeptibles delue brevelies et tes dessius de fabrique admis aux Exposilions publiques autorisces par l'administration. 
IExposition, le premier Congrès international à ce sujet. Celte question essentielle a été reprise depuis, en d’importants Congrès, à toutes les grandes Expositions.

Notre industrie et notre comnerce firent à Vienne un très remarquable et vraiment patriotique elfort, et sur 42000 exposants la france en présentait 3 g11 qui remportaient 2975 récompenses.

C'étaient les Chambres de commerce et les Comités consultatif's d'agriculture qui avaient décidé de l'admission des produits, et non pas des comités spéciaux. Un jury particulier s'occupait des ceuves d'art. Le bureau, créé à Londres en 18;1 par du Sommerard, fut réinstallé à Vienne et faci lita les relations du public avec les exposants. Il y eut des diplômes dilionneur décernés par le Conseil des présidents, vice-présidents et rapporteurs de jurys; des médailles d'honneur, des médailles de progrés, des médailles de mérile, des médailles de bon gouil et des diplômes de mérile. Les collaborateurs recevaient la médaille de coopération.

l'Exposition n'obtint pas tout le succès qu'on en attendait et aboutit même à un véritable désastre financier. Vienne était loin alors de toutes les capitales qui exposaient, et les visiteurs furent moins nombreux qu'on ne l'espérait. Mais la France avait montré que, malgré les mauvais jours, son industrie était redevenue florissante et que, chez elle, l'art et le goût n'avaient point périclité.

L'Assemblée nationale avait eu le tort de refuser des crédits pour nos délégations onvrières; les corporations envoyèrent cependant des délégués, grâce à une souscription de la presse qui produisit joooo francs.

Des rapports que nous a laissés l'Exposition de V'ienne plusieurs méritent encore d'être consultés. N. Bailly (Groupe XIX) s'occupa des appartements complètemenl meublés; Charles Rossigneux (Groupe V111), des bois lécorés. Victor de Luynes poursuivit les travaux qui lui étaient chers sur la céramique et la verrerie. Les objets d'arl pour services religieux firent l'objet d'un rapport spécial de boeswillwald; quant aux objets d'or et d'argent du Groupe Vl, comprenant joaillerie, orféurerie, bijouterie, ils furent très bien étudiés par Rourenat et Fontenay.

Pendant l'Exposition de Vienne, le Président Grant avait adressé i toutes les nations un appel les invitant à une Exposition pour célébrer le premier Centenaire de l'Indépendance des Etats-Unis. Ce fut le 10 mai 18; que s'ourrit l'Exposition de Philadelphie, dans le décor du "splendid Fairnount Park ». C’était une entreprise privée, placée sous les auspices de l'Etat. L'éloignement de Philadelphie n'empêcha pas la France d'y prendre une part active et d'y occuper le second rang, entre l'Angleterre et l'Allemagne. Le groupe 11I, éducation et sciences, constitué sur le modèle de celui de Vienne, lut des plus importants parce qu'il inaugurait dans sa classificalion des produits une méthode nouvelle. Jusqu'alors la science de l'homme était représentée éparse daus les branches diverses de l'industrie. A Phila- 
delphie, ce roupe de l'éducation réunit tout ce qui intéresse l'homme : commerce, politique, associalions cooperatives, écoles pro/essionnelles, instilutions fondées pour laccroissement et la propagalion des sciences, instruments scientifiques, systemes commercianx, hygiène, clc.

Mais grandes furent les difficultés pour les exposants non américains : évétion excessive des tarifs de douane, absence de garantie pour la propriété industrielle, jalousic commerciale.

Il n'y eut qu'une sorte de récompense : une médaille de bronze avec diplome et un rapport indiquant les motifs de celle distinction. On avait cru ainsi etre plus juste dans l'appréciation, mais beaucoup se plaignirent de celte uniformité sans apparal qui mettait tous les Jauréats sur le mime plan. Les récompenses l'urent décernées par un jury international; mais, les étrangers partis, un comité de revision, exclusirement américain, lut créé, qui lit additions et retranchements. Ce fut encore une occasion de 1) laintes. En définitive, la France remportail 653 médailles pour 1377 exposints, dont aso peintres et sculpteurs.

Plus généreuse que l'Assemblée nationale en 18-3, la Chambre des députés arait roté un crédit pour l'envoi de délégations ourriéres it l'Exposition de pluiladelphie, mais la Commission ouvrère voulut disposer de la somme à son gré et, sur le refus du ministre, une partie des corporations fit groupe a part, réunit de largent par souscription el organisa une exposition libre ì côlé de l'exposition officielle.

Il avait éte décide, après l'Exposition de $186 \%$, que l'on allendrait onze ans avant d'ourrir une nourelle Exposition à Paris. Notre jeune République mit son honneur à tenir les engagements de la France, et toutes les nations, sauf l'Allemagne, acceptèrent l'iuvitation qu'elle leur adressa pour l'Exposition universelle el internationale de Paris, 1878 , et encore le nouvel limpire Allemand participa-t-il à l'exposition des beaux-arts au dernier moment, mais hors conconrs. Aussi bien, si son industric n'y figura pas, ce fut moins à cause de trop récents sourenirs, qu'en raison des échecs ¿́prouvés par elle aux Expositions de Vienne et de l'hiladelplie.

Jamais peut-être il n'y eut plus d'ardeur, plus d'enthousiasme dans Jes groupes français. Lirantz élait commissaire général. L’admission des prortuits ful prononcée par des comités de classe, désinnés par les ministres de l'Agriculture el du Commerce et de l'Instruction publique : les Comites départementaux restaient chargés de signaler les artistes, agriculteurs et manufacturiers, et d'organiser, s'ils pouvaient, les groupements collectifs de certains produits d’une même classe. L'installation des produits français fut confièc à des comités mixtes composés moitié de membres choisis par le ministre dins les comités d'admission, moilié de membres élus par les expo. śunts de la classe. Il y eut 52835 exposants, dont 25872 pour la France. Les trois jurys - de classe, de groupe, de présidents, comme en $1867-$ distribuèrent ?!̣ sı récompenses de toutes sortes. 
L'Exposition s'ourrit au Champ-de-Mars le $1^{\text {er }}$ mai. Le maréchal de Mac-Mahon, président de la liépublique, entouré des princes étrangers et des ministres, l'inaugura solennellement. On s'ètait efforcé de conserver l'ordre de répartition de $\mathbf{1 8 6 7}$, dans un grand palais reclangulaire dú à l'archilecte Formigé, el remarquable par la polychromic de la décoration surtoul céramique.

Le palais du T'rocadéro, que les architectes Davioud el Bourdais avaient édifié pour abriter les expositions d'art ancien el d'ellinographie, el servir de Salles des congrés, a seul subsisté. Criliqué par beaucoup comme n'élant "d'aucun style ", appelé par d'autres "palais morne et pesant ", il il n'en est pas moins aujourd'hui un des monuments consacrés de Paris et fixe une date clans l'histoire de notre capitale.

Parmi les 76 rapporls qui restent de cette Exposition, certaius méritent de retenir notre allention. D'abord le Rapporl administratif de Krantz, mais surlout Introduction anx rapports du jury international par Jules Simon. C'est, de lous les rapports généraux, l'un des mieux compris, des plus justes et des plus intéressants; il n'est pas de proportions paradoxales : un seul volume in- $8^{0}$ de $5-6$ pages. Un historique précis et alerte des Expositions nationales de l'an VI (1798) i 1849 , el internalionales de 1851 a 1867 , sert de préface à la grande fêle de 1878 : au lieu d'une vue d'ensemble assez facile à écrire, au lieu d'un sec et froid comple rendu des groupes classe par classe, Jules Simon a esquissé des considérations sur les progrès de l'espril humain. Dans celle reuvre littéraire d'un altrait singulier el d'une haute portée philosopluique, il reconstitue, depuis les origines du monde, l'histoire des découvertes el des moindres travaux par lesquels l'homme vil, prospère, et se défend contre la nature; il montre " comment les lommes se rapprochent entre eux el échangent leurs pensées el leurs richesses, comment ils s'établissent chacun dans leur domicile, comment ils y pourroient à leurs besoins et à leur's plaisirs ", c'est-à-dire si nous prenons les têles de chapitre de celle ouvre qui résume un monde el syuthélise tant de connaissances à la fois : maison el mobilier, vélement, aliment, force productive, école; celte demì̀ e, est "l'arche sainte, l'aspiration vers l'idéal ".

Erudition qu1 n'ennuie jamais, détails d'histoire ou cilations qui précisent un fait et l'éclairent, se mêlent naturellement au récil. Qu'il y soit question de lindustrie des fleurs arlificielles, de l'archilectnre ou de l'imprimerie, on éprouve le méme intérêt à le lire parce qu'on y surprend toujours au passage quelque iclée nouvelle sur la transformalion progressive de l'objel, ou quelque considération humaine, sociale ou philosophique sur son avenir, et tout cela s'enchaîne, les classes de l'lxposition viennent d'elles-mêmes y figurer a leur ordre logique comme des preuves el comme dos exemples. Nous ne pourons mieux faire que de glaner au gré des pages quelques jugrements.

"Il y a un ellor't à faire pour donner plus d'élégance au mobilier et aux 
ustensiles du pauvre. Il ne peut avoir chez lui que du bois très commun, du fer ou du cuicre, de la poterie de faïence, des éto/fes à bas prix. Soit, il n'est question ni d'augmenter les frais de l'acheteur, ni de condamner le vendeur à vendre avec perte. Il serait absurde de demander plus de luxe; demander plus de goùt, e'est demander ce qu'on peut donner sans autre dépense qu'un peu plus d'art et de soin. Nous voyons dans nos musées des ustensiles de ménage qui remontent aux bonnes époques de l'antiquité; des lampes, des cruches, des chaudrons; ces objets n'ont pas plus de valcur

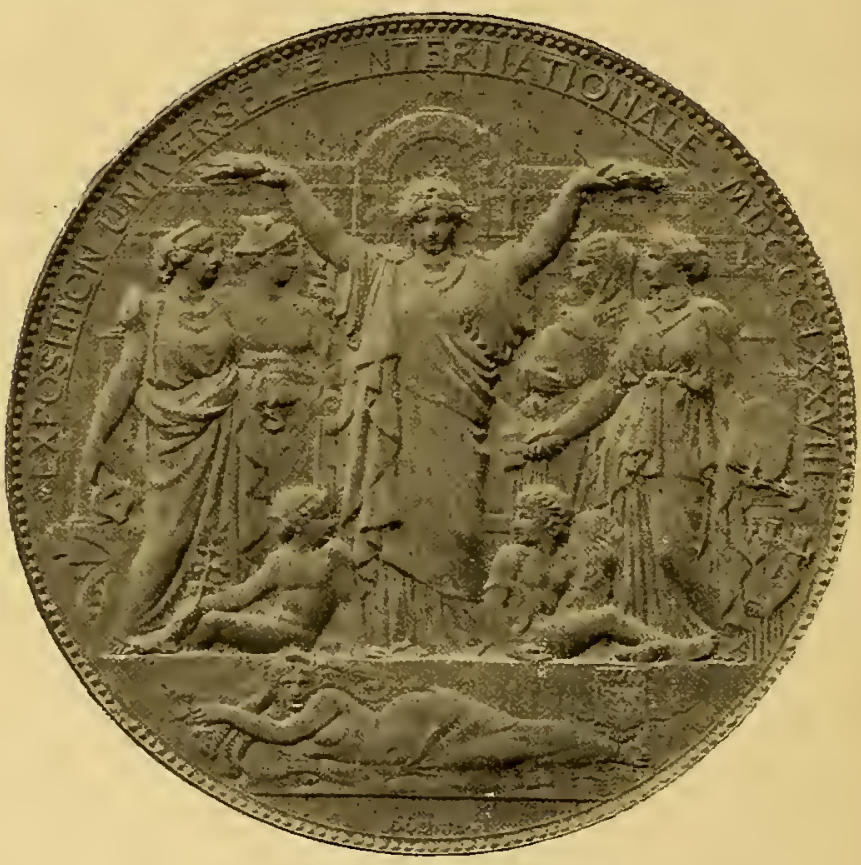

XXX. - Exposition universelle et internationale de Paris, $18-8$.

Face de la grande Médaille, gravéc par Oudiné.

intrinsèque que ceux dont nous nous servons : ce qui les distingue des nòtres, c'est la pureté, et même assez souvent la beauté de la forme. Nous pourrions faire cela, nous pourrions nous donner cela : il suffirait de vouloir."

Ailleurs, il démontre cette vérité " que l'homme qui trouve si difficilement l'utile atteint le beau du premier coup ", et en donne comme exemple la Grèce. Toujours l'homme a deviné le sublime avant de trouver le nécessaire. Le chef-d'œure est à l'origine des temps. "Le grand art est toujours près du rêve et de la jeunesse, et cela est aussi vrai dans la vie que Jans l'histoire. On commence par deviner, on finit par chereher. II est vrai que la seule possession solide est celle qui suit la recherche... Dans la 
marche de l'humanité, la science augrmente toujours, l'art décroit au lieu de progresser... Il y a deux courants : la poésie qui descend et la science qui monte..."

Et ceci à propos de l'architecture : "Quand un siècle ne peut pas s'élever jusqu'à la poésie, c'est quelque chose encore d'avoir une belle prose... il faut moins d'inspiration, il faut autant de génie architectural pour construire une halle que pour élever une é.lise. ”

Et qu'on ne s'y trompe point. Ce n'est là ni littérature vainc, ni phra-

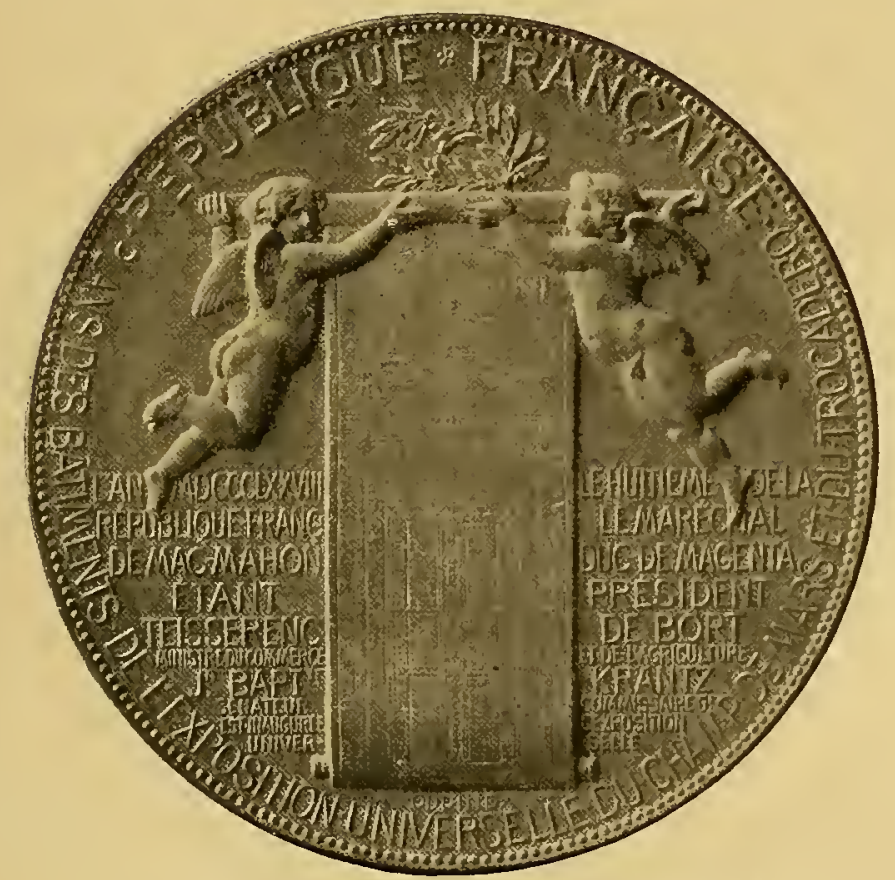

XXXI. - Exposition universelle et internationale de Paris, $18-8$. lievers de la grande Médaille, gravée par Oudiné.

séologie banale. Dans le mobilier il n'y a que changement d'imitatiou de style : copies ou réminiscences; partout la curiosité domıne. "On ne garde pas la royauté de la mode avec des imitations, même parfaites. Il faut inventer pour diriger. On peut, sans originalité, marcher à la tête de sa profession; on la précède, mais on ne la mène pas. "

Nos papiers peints en viennent à ressembler à de la tapisseric ou imitent, it s'y méprendre, les cuirs de Russic; " c'est un tort. Il semble qu'il y a pour les objets industriels, comme pour les actes de la vie humaine, une nécessité el un devoir de la franchise. Il faut être ce qu'on est. Ce papier, qui veut passer pour de la tapisserie, n'est qu'un faux luxe."

Enfin, le dernier chapitre, l'école, le plus neuf, le plus « actuel " encore, 
s'appuyant sur les conclusions des rapports particuliers de chaque classe, réclame pour toutes nos industries une éducition professionnelle el technique. " 11 y arait autrefois bien des causes de la domination dun peuple sur l'autre; le nombre, les ressources accumulées, même le préjugé. A présent, c'est la seienee qui gagne les batailles. Celui qui sait le plus, peut le plus. Celui qui peut le plus est le maitre. "Il faut étudier ou sombrer; notre orgueil de nous croire en tout, à la guerre comme dans lindustrie, la première nation du monde, est peut-être une des formes du patriotisme. C'est bien de travailler, mais avant tout il faut apprendre. "Non, ce n'est pas en nous volant nos dessins, nos artistes, nos contremaitres que les Anğlais réussissent, c'est en travaillant, en étudiant... Le travail, pour être productif, doit ètre fait au meilleur moment, dans le meilleur lieu, avec les meilleurs outils. Il doit être dirigé par la science. Celui qui ne sait pas, mettra dix jours à faire un travail qu'il aurait fait en un jour šil se tenait au courant des procédés nouveaux... Il ressemblera à ces condamnés aux travaux forcés qui font tourner, avec beaucoup de fatigue et de douleur, une roue qui elle-mème ne met aucune machine en mouvement."

La conclusion s'impose : il faut d'urgence fonder des écoles, et surtout améliorer et fréquenter celles qui existent. Jules Simon les passe en revue. A Paris, celles de l'ébénisteric et de la bijoulerie-joaillerie; la Chambre syndicale des horlogers, et son président Rodanet, s'efforcent d'en créer une; Chaix organise, dans ses ateliers mêmes, un embryon d'école pour les apprentis typographes; on comprend partout la nécessité d'étudier. A Lyon, Natalis Riondot a fondé en 1858 le Musée d'arl el d'industrie. Que de choses il reste a faire! Le travail ue vit " que par la science et la liberté ". Tout ce chapitre reste encore aujourd liui le programme tracé à nolre industrie nationale.

Nous arons tenu a faire ces citalions un peu longues, parce que beaucoup ignorent le rapport de Jules Simon. Pour d'autres, ce n'est qu'une introduction, dont on néglige de couper les pages. Il mérite mieux : sachons mettre à profit les sages conseils qu'il a donnés.

Voici encore un rapport d'ensemble : celui de Ed. Didron qui étudie les arts décoratifs, groupes I, II, III, IV et V, c'est-à-dire ceux qui intéressent plus particulièrement "le mobilier et la parnre, et sont soumis directement. à l'influence de nos mœurs, de nos hesoins, comme à nos convenanees et aux habiludes de notre vie ". Il distingue exactement l'imitation de l'interprétation, critique notre pauvrelé de conception dans les applications industrielles de l'art, par suite de l'oubli de "l'appropriation rationnelle et intelligente de la matière, du respect des convenances de la destination el de la simplicité des moyens mis en cuvre. "Il y a trop de copies du passé : c'est le jugement que répètent les rapporteurs d'expositions depuis quarante ans; on ne crée plus, on imite; avec adresse, avec ingéniosité, avec beauté parfois, mais on imite toujours. L'ouvrier est devenu une "machine animée :, 
qui, par la division du travail, reproduit à satiété le mème fragrment d'un mème modèle; le progrès mécanique diminue l'initialive; le laxe mis à lit portée de lou; est un faux luxe, le public n'y a acquis ni le groul, ennemi de la banalité, ni le sentiment vrai de l'art; " le doublé, le plaqué, le simulibronze el le simili-marbre, rimitation de la matière noble par le déguisement de la matière vulgaire, les plantes en carton et les fleurs en papier, n'ont en aucune façon élevé le niveau de l'éducation artistique du peuple, ni perfectionné les facultés de son âme par la nature des impressions qui ont élé excitées en elle."

Certes la vulgarisation de l'art industriel, sa diffusion à bon marché sont des nécessités actuelles, mais il faut lutter contre ce luxe apparent el dis-
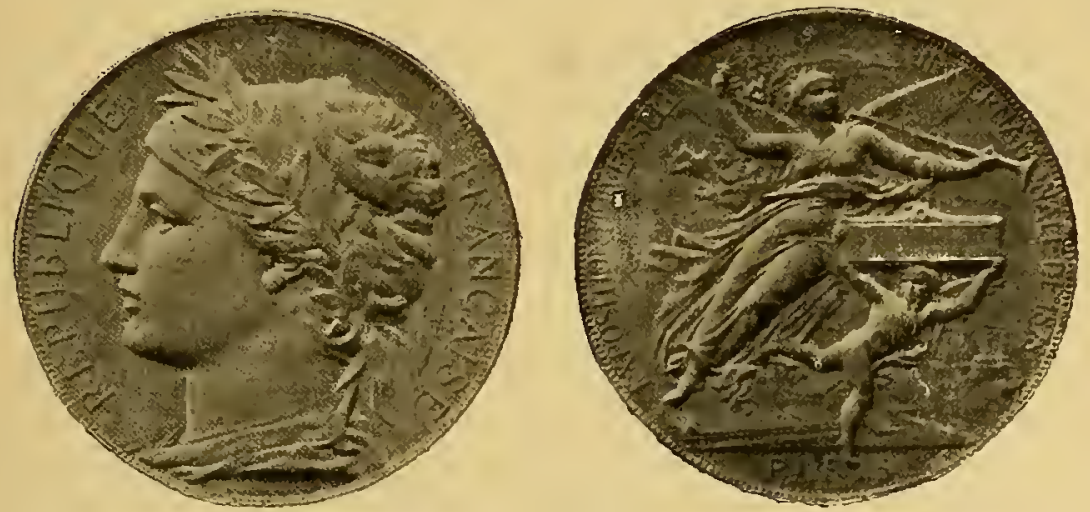

XXXIl et XXXII. - Exposition universelle et internationale de Puris, 18;8. Médaille des récompanses, gravie par J.-C. Chaplain.

proportionné, "contrefaçon misérable de la richesse ", et le diveloppement du mauvais goùt qui fait oublier la réelle beauté. C'est ainsi qu'on préfère par vanité un meuble en bois précieux incrusté de nacre el de mélal, mais laid, banal et fragile, à un meuble de bois vulgaire, sans décoration, mais pratique, solide el de belle forme, meuble qui d'ailleurs reste à créer. Dans chaque branche de lart industriel, il faudrait formuler les mêmes critiques. La peinture décorative devient un trompe-l'zil : dessus de portes, frises, corniches, simulent la sculpture; le papier veut jouer à la tapisserie; la tapisserie singe la peinture.

"L'arl appliqué à l'industrie est aflligé d'une hérésie esthèlique fort dangereuse : elle consiste ì employer tous les moyens, dont l'extrême habileté de la main-d'cuvre facilite singulièrement l'usage, pour déguiser la nature de la matière première, dissimuler les procédés de fahrication, et imprimer aux résultals oblenus une apparence absolument contraire ì la réalité. Liart de la décoration a besoin de celte sincérité rigoureuse, abso- 
lue, qui est sa dignité, pour expliquer les formes diverses qu'on lui fait revêtir et les fonctions précises qui lui sont départies. L'indécision du rôle de chacune de ces formes et les artifices de la fabrication amènent fatalement l'anarchie et le chaos."

Le fer, ne sachant plus conserver sa robustesse, usurpe la finesse et l'éléganee, privilège du cnivre. Le bois veut devenir métal; il n'est pas jusfu'au cristal qui ne cherche à s'épaissir ou à se rendre opaque pour imiter la porcelaine et plagier des formes qui ne lui appartiennent pas. C'est contre le mensonge qu'il faut rèagir. Là est la question vitale.

Londres a le South liensington Museum; il faut que Paris ait un établissement semblable, réunissant l'art rétrospectil et contemporain. Il faut une bibliothéque, des conférences pour les ouviers d'arl, des écoles de dessin. Il faut surtout, par ce musée, "faire l'éducation esthélique des masses ".

La place nous manque pour insister également sur tous ces rapports, dont beaucoup n'ont pas perdu de leur intérêt. Celui du duc de Luynes, avec Salvetat, Dubouché et Barriat, Classe 20, céramique, est un bel hommage rendu à nos manufactures de Sèvres, de Limoges, du Clier, aux poteries décoratives de Deck, aux panneaux genre persan de Parvilléc, ele.; la polychromie commence à peindre ses merveilles. Emile Gallé, de Naney, est loué

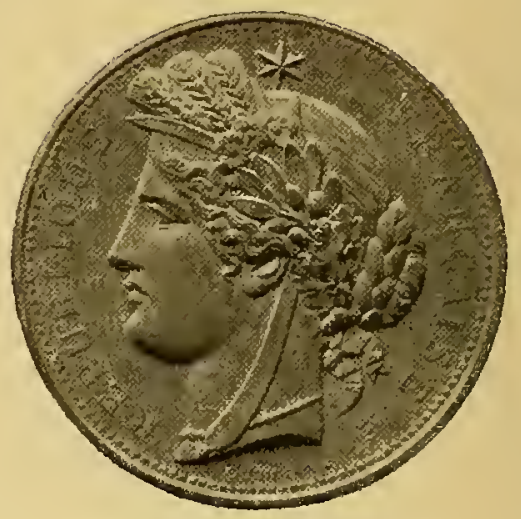

XXXIY - Exposition universelle et internationale de Paris, 1878 . Face des Médailles gravées par Oudiné, l'une pour la construction du Palais du Trocadéro, lautre en souvenir des Palais du Champ de Mars. en ces termes : "Ses modèles ont la saveur des châteaux de la vicille Allemagne, ils sont quelquefois d'un goût un peu brutal, mais singulièrement décoratifs, de formes bizarrement contournées, de couleurs violentes et curieusement opposées. N'importe, tout cela a l'aspect attrayant, la sareur piquante, le parfum mordant de la femme laide que l'on aime. "L'Exposition de 1889 mettra encore mieux en valeur le grand artiste. Danmouse, enfin, est appelé le "virtuose des grands feux du four ".

Le rapport de H. Mourceau sur la fabrication des tapis, lapisseries, Classe 21, Annexe, donne un historique important de cette classe depuis $\mathbf{1 7 9 8}$, les noms des lauréats, et note les évolutions et progrès de chaque branche de cette industrie. Dans la Classe 24, orférerie, rapport par L. Bachelel, on retrouve la maison Clrristofle qui a créé une école pour des apprentis et une institution pour les ouvriers malades el infirmes; ArmandCalliat, Poussielgue-Rusand, Froment-Meurice et Lucien Falize, etc.; la production augmente, la galvanoplastie est en pleine vogue. 
Le rapport de G. Servant, Classe 25 , bronzes d'art, fontes d'arl diverses, mélaux repoussés, donne un bref historique de cetle industrie el contient un éloge très étudié du fondeur Barbedienne à qui l'on doit le "frollé d'or ", décor qui algmente l'allrail des firgures, et de nouvelles palines qui nuancent ses métaux.

Les châles, Classe 35, délaissés par la mode, figurent à peine dans l'Exposition, el le rapporteur Gaussen en est réduit à faire l'histoire rétrospective de ce luxe bourgeois.

Bijouterie-joaillerie, Classe 39 , rapport de Martial Bernard : la France a dans celte branche une supériorité absolue, malgré le bijou doré et les perles

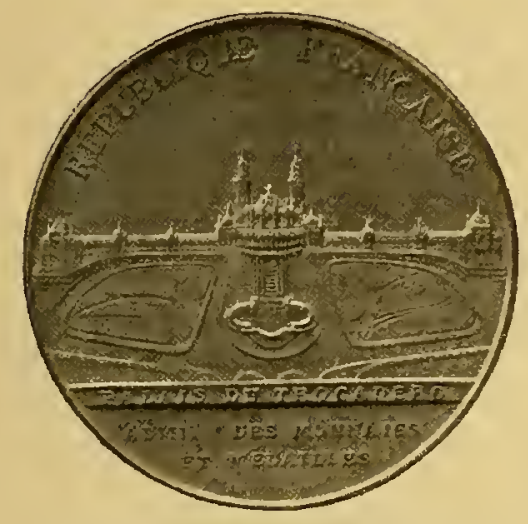

XXXV. - Exposition universelle de Paris, 1978. Revers de la Mílaille du Palais du Trocadíro, gravíe par Oudinc.

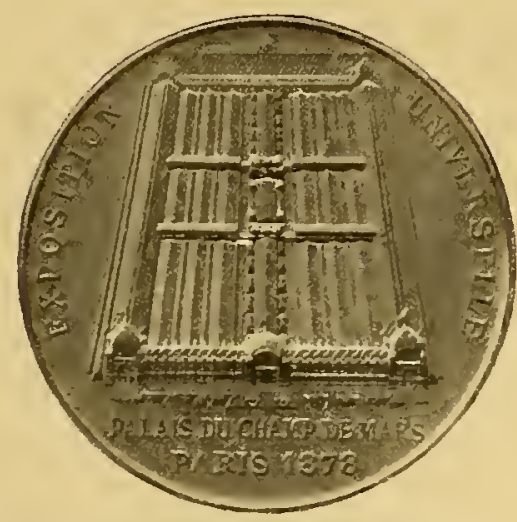

XXxv1. - Exposition universelle de Paris, 18-S. Revers de la Médaille des Palais du Champ de Mar's, gravie par Oudiné.

fausses qui prennent une extension considerable. Massin, Bouclıeron y obtenaient un réel succès el l'on pouvait admirer en maintes vitrines les travaux du ciseleur Rault. Comme Chrislofle, Boucheron présente plusiears objets d'art très japonais.

A noter enfin, - quelque regret que nous ayons ì ne pas le suivre dans ses délails, - le beau el complet rapport de Natalis-liondot sur les soies, Classe 34 .

N'oublions pas non plus les très inléressantes conférences qui eurent lieu el, nolamment, celles d'Emile Trélat, dont une consacrée au mobilier renferme enseignements el conseils qui n'ont rien perda de leur utilite.

Pendant l'Exposition, trois congrès sont plus spécialement consacrés aux arts industriels. L'enseignement visuel se complétait par lenseignement oral. L'un de ces congrès ratifia l'unification des fils de toute nature, déja disculée à Turin, à Vienne el à Bruxelles. Deux autres sur la propriété industrielle et la propriélé artistique votèrent d'importantes résolutions. 
Eufin, une large part des récompenses fut réservée aux cullaboraleurs. Yous avons vu que cette amélioration remonte assez loin : Jacquard, d'Arcet, sous la Restauration, avaient été ainsi l'objet d'une distinction spéciale. Luusage n'en fut vraiment établi officiellement qu'en 1855 . En 1867 , en 1878 , quelques fabricants marquèrent dans leurs vitrines les noms de leurs princijaux collaborateurs.

Dans son rapport, Jules Simon définit ainsi les collaboraleurs: ils " ne sont pas nécessairenient des ouvriers; on entend par ce mol les ingénieurs qui ont fourni les plans ou dirigé le travail, les contremaitres qui ont surveillé les ateliers, les artistes et les ouvriers d'èlite à qui très souvent revient la part priacipale du saccès n. Et il montre combien il est difficile d'ètre équitable, le patron s’attribuant parfois le mérite de l'invention ou la direclion et disant qu'il court seul tous les risques, tandis que son collaborateur pense qu'il a tout inventé, tout rectifié et qu'on n’aurait rien lait sans lui.

Il convient de signaler ici le désintéressement du grand bronzier Barbedienne qui préféra refuser la plaque de grand officies de la Lécrion d'honneur, afin d'obtenir la rosette d'officier qu'il avait demandée pour son collaborateur Constant Sevin. Chaque maison ne pouvait, en elfet, receroir qu'une nomination ou promotion dans notre ordre national. Barbedienne fut inébranlable, malgré l'insistance du ministre Teisserenc de Bor't lui rappelant que cétait la première fois que pareille distinction était offerte at un industriel.

I: Exposition de 1878 eut un réel succès économique et politique, sinon financier. Elle avait dignement montré au monde le relevement de la France. Peut-être n'avait-elle pas l'apparat el le faste des fêtes du second Empire, mais elle prouvait la force de notre pays et sa confiance en l'avenir. Des progrès considérables avaient été accomplis dans la techniqque de l'industrie, des écoles créées; partout on sétait mis avec ardeur à la tâche pour perfertionner l'instruction de nos ouvriers d'art.

Dans l'enseignement du dessin comme dans l'éducation professionnelle, plusieurs réformes avaient déjà abouti, dont les heureux résultats se feront surtout sentir à l'Exposition de 1889 . I,es conseils du comte de laborde commençaient à porter leurs fruits. Il avait démontré qu'en art une génération apprend et crée des chefs-d'ouvre, tandis que la suivante désapprend et ne laisse rien après elle : dans l'industrie, comme dans la science, au contraire, ce qu'une génération invente devient le patrimoine de la génération qui lui suecède. Devant le développement du machinisme, il faut former des ouviers capables, adroits el pleins de groût; et le meilleur moven de lutter, c'est le dessin.

A la suite du vote émis par le Conseil supérieur des Beaux-Arts en 1876 , Eugène Guillaume avait fait adopter sa réforme des méthodes d'enseignement du dessin, qu'avec Louvrier de Lajolais il ne cessait de préconiser dans 
de multiples conférences; l'élude du dessin est nécessaire aux artistes comme aux contremaîtres et aux ouvriers de la plupart des industries; le groût, l̈intelligence, le goût artistique sont des qualités vaines si elles ne sont pas cultivées par le dessin. C'est en somme ce que disait déjà sous la Rérolution le représentant du peuple Portiez: "Les arts du dessin sont l'école où se forment direclement ou indirectement presque tous les arts de l'industrie." Et Guillaume créait non pas l'art du dessin, mais la science Alu dessin; il roulait un dessin logique, linéaire et géométrique. Cette rigidité avait pour but "d'assurer aux esprits une forte discipline, de leur donner le respect de l"exactitude et de les habituer à réduire aux éléments fondamentaux les formes complexes de la nature $"$. En 18,8, la réforme fut appliquée à l'enseignement secondaire et primaire, où le dessin devint obligatoire. Ce programme devait, comme nous le verrons plus loin, rester en vigueur jusqu'à l'arrêté du 27 juillet 1908 . Celui-ci laissera à lélève plus le liberté de sentiment et d'interprctation, faisant du dessin nou un art d'agrément, mais un instrument général de culture; s'elforşant de prendre lil nature pour base et de la traduire directement et naïvement, il donnera un enseignement moins abstrait et plus pratique. Mais n'oublions pas que la méthode d'Eugène Guillaume créa un véritable mouvement, suscita partout des concours et des initiatives qui contribuèrent efficacement au déreloppement de l'instruction industrielle el artistique, avec l'aide el l'appui l'hommes comme Lajolais, Crost, Dutert, Chipiez, Paul Colin.

En même temps on réforma l'enseignement donné à l'Ecole des BeauxArts. L'école, jusqu'alors sous la dépendance directe de l'Académie des Beaux-Arts, avait élé, en $\mathbf{1 8 6 3}$, placée sous l'autorité de l'Administralion centrale, el plus de liberté commenşa à y régner. En 18,0 , c’ètaient les Beaux-Arts eux-mêmes qui prenaient le caractère de service public et étaient annexés au Ministère de l'Instruction publique: on reconnaissait "leur droil à la sollicitude de l'Etat... parce qu'ils répondent réellement à un besoin général, en tendant à développer dans le pays enlier le sentiment et l'amour lu beau... .. En 1875, M. de Chennevières, par décret, créait un Conseil supérieur des Beaux-Arts, dont le rôle fut si actil pour leur participation à l'Exposition de 1878 .

La situation des industries d'art avait fait l'objet, en 1874, d'une grande enquéte, sur l'initiative d'Antonin Proust, alors Ministre des Beaux-Arts, en même temps que cette même question était remarquablement traitée dans une plaquetle de l'architecte Davioud.

Enfin, l'Ecole de dessin et de mathématiques, fondée par. Bachelier en 1765 , pour les ouvriers de Paris, prenait, en 1877 , sous la direction de Louvrier de Lajolais, son titre actuel d'Ecole nationale des arts décoratifs. Ce nom nouveau contenait tout un programme et établissail distinctement la démarcation de l'école populaire avec l'école supérieure; les Ecoles d'arl décoratif de Limoges el d'Aubnsson étaient en.outre mises sous la même 
direction. En prorince, les écoles se multiplient, l'enseignement professionnel des jeunes filles s'élabore. lyon possède depuis 1856 son Musée d'arl el d'indrstrie, - peu à peu spécialisé aux soieries - fondé par la Chambre de commerce, sur le rapport de Natalis Rondot. Roubaix, qui avait des écoles industrielles depuis 1833 , obtenait en $\mathbf{1 8} ; \mathbf{6}$, de son conseil municipal, la création d'un enseignement du tissage el de la leinture et la réunion en un seul établissement des cours et collections artistiques disséminés dans la ville. Ce projet, en 1881, aboutissait à une Ecole nationale des Arts indusIriels, élevée ả frais communs par l'lítat et la V'ille, el ouverte le 30 juin 1889 . Lt se développaient en même temps vers l'art industriel : à Paris, les Ecoles municipales Bernard I'alissy et Germain Pilon, actuellement dirigées par John Labusquière; en province, les Ecoles d'arl décoralif ou des beauxarts de Lyon, Rennes, Nice, Marseille, Rouen, Reims, Nancy, Nanles, etc.

Quant à l'Ĺnio: centra!e des Beaux-Arls appliqués à l'Industrie, elle ne restail pas inactive el organisait : en $/ 87.4$ et en $/ 876$ des Exposilions des Beaux-Arts applirpués à l'Industrie, faisant suite à celles de 1865 et 1867 ; en $1880,1882,1884$ des Exposilions technologiques consacices successivement aux Arls du M:Lal, aux Arts du Bois et aux Arts du Fer; en 1887 une Exposilion récapilulative des Beaux-Arls appliqués à l'Industrie; en 1892 une lixposition moderne, retrospective el internationale les Arls de la Femme. Dirigée par des hommes du métier et énergiques, celte société prospèra et compta jusqu'à 800 membres, "unis dans une communion intime de grandes idées et de nobles ambitions ". Mais l'entretien d'une bibliothèque, lor granisation des concours, conférences et cours publics, les encouragements aux artistes et industriels, absorberent vite ses ressources, malgré la geénérosité de ses membres qui, par des contribulions personnelles, parvenaient à équilibrer son budget. La guerre de 1870 avait boulever'sé ses finances; aussi, en 1872 , elle se reforma sous le même nom, en société anonyme ì capital variable, dont toutes les actions étaient prises par les anciens souseripteurs de l'ceurre. Edouard André en était le président.

En 1877 , une association spéciale se formait sous la présidence du duc de Chaulnes et réunissail des amateurs, des artistes el quelques membres de l'Union centrale, dans le but de créer un Musée des Arts décoratis. Au bout de quatre années, un premier fonds de collections était formé, tant au moyen de souscriptions quà l'aide de dons généreux. Puis la jeune Association fusionnait avec l'Uuion centrale des Beaux-Arts appliqués à l'industrie, prenait le titre définitif d'Ĺnion centrale des Arts décoratifs et étail reconnue, le 15 mai 188 ., comme élablissement d'utilité publique. En même temps, Antonin Proust, devenu président, obtenait du gouvernement l'autorisation de lancer une vaste loterie qui laissait un bénéfice net de près de 6 millions, devant permeltre ultérieurement la création du Musée des Arts décoratifs, réclamé par tous. 
Elle se livrait en outre it une active propagande, aidée par la Revue des arls décoralifs, que dirigeait Victor Champier, auquel Roger Marx tien-

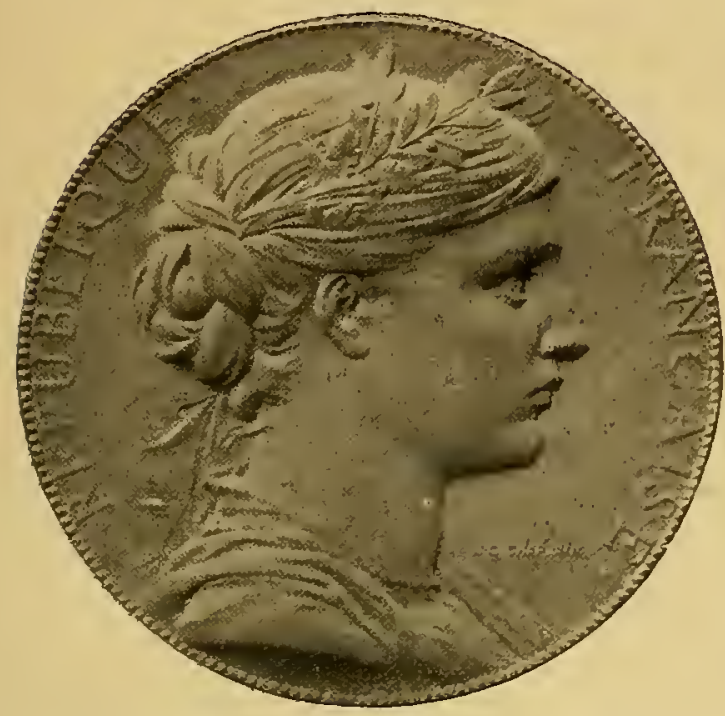

XxxyI. - Exposition internationale d'Élcctricité de Paris, ]881. Face de Ia Médaille, gravie par J.-C. Chaplain. dra, en 1889, à dédier son si intéressant ouvrage sur la Décoration, " en reconnaissance de son persistant et utile effort pour le développement des industries dart français $n$.

De $/ 879$ à $/ 8 \& s$, Ia France prit part aux diverses Exposilions universelles qui se tinrent it lítranger. D'abord en Australie, à Sydney, 1879, et à Melbourne, $1880 ;$ puis en llollande, it Amslerdam, 1883 , où nos industries d'art se firent tout particulierement remarquer. A Anvers, en 1885 , la France, dont Maurice Monthiers était le Commissaire général, occupait un emplacement presque égal ì celui de la Belgique, et elle obtenait près du tiers des récompenses. Bruxelles, en 1888 , ouvrit un " grand concours international des sciences et de l'industrie $n$, ceuvre privée à laquelle la France prit part, non officiellement, sous la direction d'Alexis Muzet.

LiExposition de Barcelone, ouverte cn même temps, absorbait toute l'attention et avait détourné à son profit les meilleurs des industriels. Un palais, en éventail ouvert, groupait les industries selon le plan logique et concentrique adopté à Paris en 1867 . Quoique les relations entre la France el l'Espagne fussent alors assez froides, Gustave Sandoz, aidé

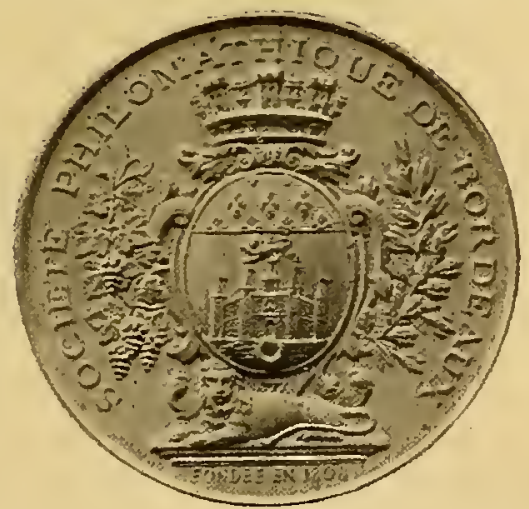

X.XYll, - Xll Exposition organisćc à Bordeaux en 1882 par la Societe philomathique. Face de la Nédaille (riduite d'un quart).

d'un groupe d'amis, industriels et commerçants, n'avait pas craint de pré- 
parer, dès 1885 , la participation française à cette Exposition el de la ga-

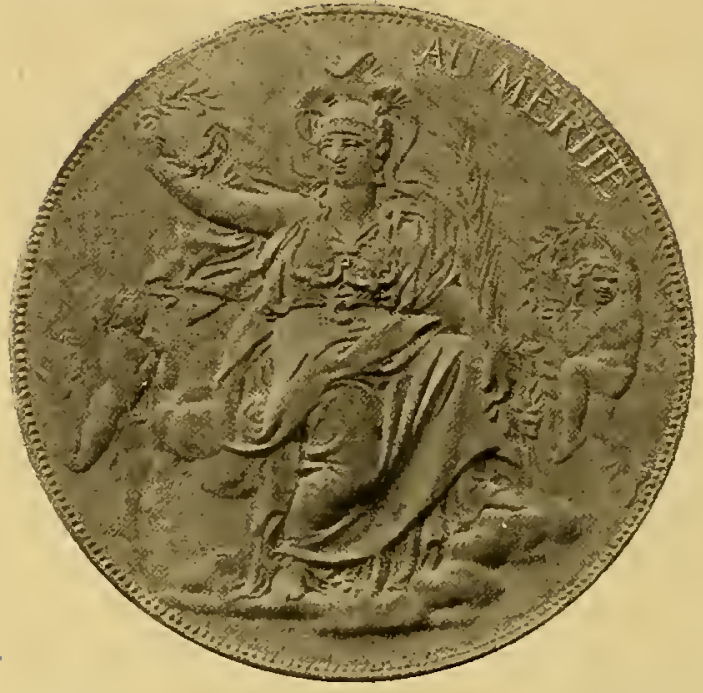

IXXIX. - Exposition universelle et internationale d'Anvers, 1885. Face de la Nédaille de la Section flançaise gravie par J.-C. Chaplain. rantir sur sa fortune personnelle. Le Comité français ainsi formé ne reçut aucune subvention du Parlement, mais, sur sa demande, le gouvernement nommait Charles Prevet, commissaire général, trois mois avant l'ouverture; la section française eut un grand succès et le Comité français de l'Exposition de Barcelone devait être l'origrine d'une association qui jouera ultérieurement un grand rôle dans les $\mathrm{Ex}-$ posilions : le Comilé francais des Exposilions it lélranger.

Bien que, dans la plupart de ces expositions, la

Jrance ait figuré toujours au premier rang, nous n'avons pas cru devoir $r$ insister, parce que leur importance est limilée el Jeur influence assez restreinte. Notre art industriel y était représenté avec honneur, mais rien de noureau ne le caractérise dans ces fêtes. Aussi bien la France est tout absorbée par sa procliaine grande Exposilion.

Annoncée par le déeret du 1/ novembre 188', qui en nommait la Commission d'organisation, préparée par le rapport d'Antonin Proust du 1' mars 1885 el la loi du 7 juillet 1886 qui réglait ses finances, l'Exnosition universelle et internationille de laris. 1889 , devait à la fois fêter le centenaire polilique de la Révolution française

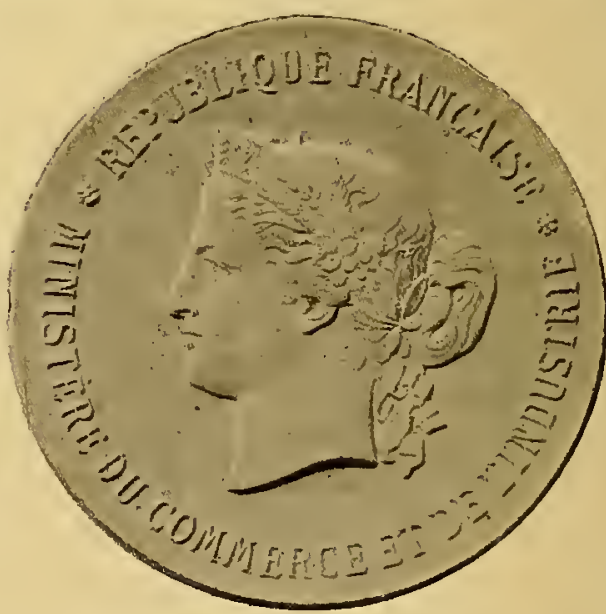

XL. - Exposition universelle et internationale de Barcelone, 1888. Face de la Midaille de la Section francaise. el le centenaire scientificiue et technique des grarces décourertes des 
Martelé ou forgé, il devient aussi un objet d'art el participe à l'embellissement intérieur de nos maisons. Il rivalise, par sa docilité, avec le zinc estampe chez Chennevières, avec les cnivres reponssés chez Gayet et Monduit; Formigé l'utilise à sertir la terre cuile, à encadrer la mosä̈que, à former sur une façade jolie des bas-relie/s polychromés, des frises et des portes: grilles, chenets, rampes, lustres sont autant de prétextes à assouplir le métal el à remettre en honneur la ferronnerie : c'est la grande nouveauté d'alors.

Si nous suivions à l'Exposition de $\mathbf{1 8 8 9}$ toutes les transformations de nos industries d'art, du bo:s, des tissus, du mélal, de la lerre et du verre, nous serions oblinés de répéter une fois de plus que la plupart de nos artisans et de nos industriels sont surtout des archéologues : dans ce genre, on n'y rencontre pas une défallance. "La science, écrit encore de roguë, n’a janais été plus sûre et plus générale, elle n’a jamais eu à son scrvice un travail plus habile. Nos meubles sont des initations si achevées des meubles Louis $\mathrm{IIV}$ et telles pièces d'orfèvrerie sont si sûrement ciselées que les Boule, Jes Germain, les lioitiers, signeraient sans hésitation ces œurres de leurs successeurs. L'ennui, c'est qu'ils nous offrent encore ee que d'autres nous ont déjà donné, c'est qu'ils reproduisent trop parfaitement ce que leurs devanciers ont créć; notre siècle a tous les styles dont il est la syntlıèse; il les reflète tous à la fois, el jamais il n'y mire son propre style. Le passé est le passé : admirons-le; inspirons-nous de ses neuvres pour apprendre d'elles comment leurs artistes travaillaient, et pour savoir surtout ce qu'il ne faut pas refaire. Les ceuves anciennes sont de bons modèles à consulter, non à copier. Lne copie, - c'est-à-dire tout ee qui procède servilement du pasés mort - est une curre mort-née; elle peut être une curiosité ou un amusement : elle n'appartient pas à l'art, elle est du métier. Elle ne remplacera jamais une création origninale; celle-ci peut avoir des défaillances, mais si elle se conforme à notre goût, si elle correspond à nos besoins esthétiyues, si elle tient compte des exigences de notre civilisation, de nos idées et de nos luabitudes, elle ne sera ni barale, ni insignifiante."

All'red Picard a laissé de l'Exposition de 1889 un magcistral Rapport général, précédé d'un historique très complet des précédentes Expositions; de très intéressants rapports, surtout techniques et économiques, ont été consacrés aux diverses industries d'art. Des Rapports spécjaux furent rédigés par les spécialistes les plus éminents. L'enscignement techniqne, Classes $6,7,8$, a son défenseur avec $\mathrm{B}$. Jacquenard, et l'application usuelle les arts du dessin el de la plastique, Classe 11, est mise en lumière par Champenois et Gemain Bapst. Les différentes classes sont longuement étudiées par $\mathrm{V}$. de Luynes (crislan.r, verrerie el vilranx); Lncien Falize (or/èrerie); E. Marret (bijonterie, joaillerie); Legriel (ouvrages du lapissicr el du decoratenr); V'ictor Legrand (tapis el lapisseries); Félix follot (pripiers peints); Lobnitz (céramique). Mais l'analyse de ces rapports nous entrainerait trop loin, et nous nous bornerons à noter les ouves caracté- 
ristiques, à dégager les tendances, à mettre en lumière les novateurs. Nous emprunterons beaucoup, pour les pages qui suivent, au travail de Roger Narx sur La Décoration et l'Art industriel à l'Exposition de 1889.

Et d'abord, après les Dutert et les Eiffel, nous ne pouvons passer sous silence, dans l'archilecture, les palais dus à Paul Sédille, Formigé, Ballu, les decorations de Paul Sédille, Frantz-Jourdain, Charles-A. Gautier, qui utilisent si intelligemment les grés de Lobnilz, de Muller, de Parvillée.

Dans le mobilier, après les styles lienaissance, Louis XV et Louis XVI, l'Empire est à la mode; on l'aceommode à notre goủt, on l'adapte ì nos
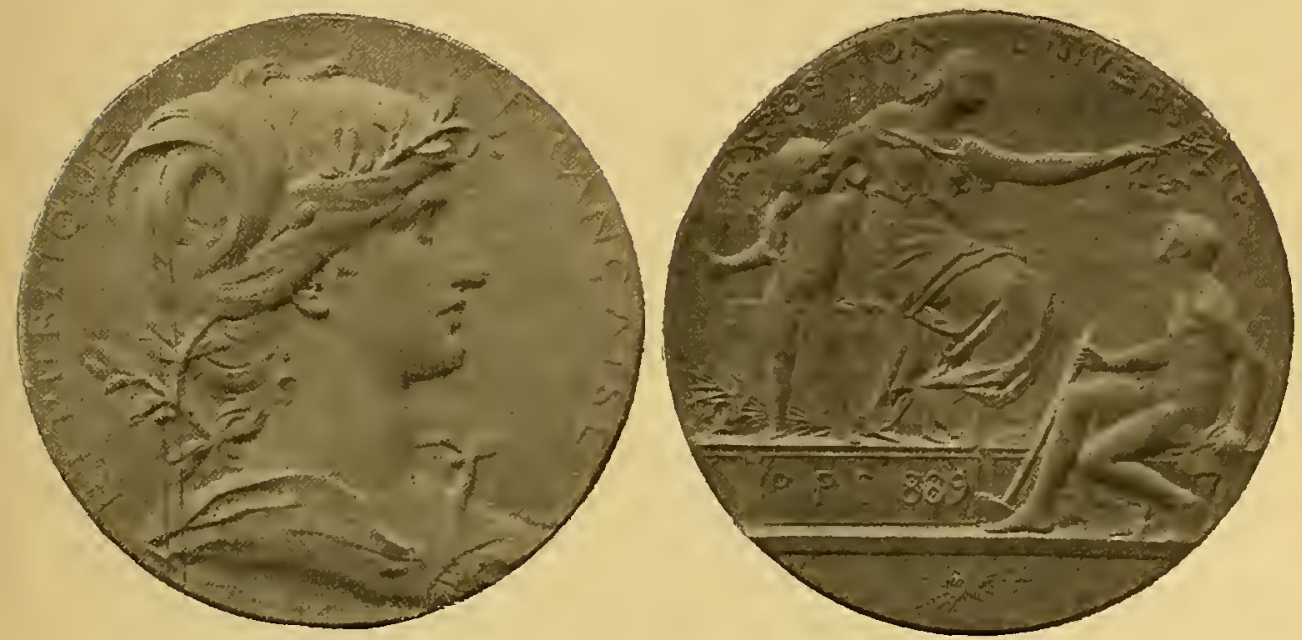

XLIII et XLIY. - Expositionn universelle de Paris, 188 (1.

Nédaille commémorative, gravéc par Inaniel Dnpuis.

progrès, mais eela reste du style Ėmpire. Cependant, quelques ébénistes recherchent les bois clairs simplement eirés ou teints, qui donnent plus de dessin aux veinures du bois et aux stries, et délaissent le plaqué, pièces rapportées, collées ou elouées.

Mais le triomphateur, e'est l'artiste lorrain Emile Gallé qui, tour à lour éhéniste, polier, céramiste on verrier, emprisonne sa chimère ou sa fantaisie dans tout ce qui lui tombe sous la main, tables, bahuts, verreries ou faïences. 11 ne travaille que le bois de sa province: " il demande aux motifs d'ornementation de devenir les emblèmes de la matière ou d'annoncer la destination de l'ouvrage. Sur les flanes et les dessus de ses tables, de ses commodes, ce ne sont que lleurs, plantes, herbes, oiseaux, ou papillons figurés dans le vrai de leur allure, de leur couleur et jetés en toute libertẻ le plus simplement du monde. "Mais Gallé est encore une exception.

Et l'industrie du mobilier, malgré l'extrême habileté qu'elle manifeste, est en décadence. Elle ne se renouvelle pas et elle influe par ses copies sur 
les autres industries qui concourent à ḷameublement: lentures el lapis. Les ateliers de Braquenie et de IIamot, comme nos Manufactures nationales, trop respectueux des traditions, ne font rien pour réagir. La tipisserie dimiune d'importance, cl ce luxe, éminemment décoratif, perfectiome le tissage, augmente la finesse du rendu, mais ne clange pas ses modèles. Ce qu'il laut en lapisseric, éest non plus l'érocation du passé, mais des curres adéquates el normales de nos peintres Puvis de Charannes, Gustave Moreau, Grassel, Besmard, Galland, Carrière, Cazin, Chéret, Willette, cic., qui seules représentent lidial moderne. Dans les tissus moins riches, la maladie d'imitation sévit sans pilie: lrocarls de lyon ou éloffes de Roubaix reproduisent d'eleruels modèles. Si les soieries et les damassés ont des arrangements noureaux de fleurs ou de palmes, e'est Je Japon qui en est eause : on a encore copié. Et il n’y a guere a signaler que les tentatives des lapissiers Damon et Jansen qui harmonisent si bien leurs tissus avec les tons le leurs meubles, ou du dentelier Miare qui orne ses travaux de passementeries el ses lires d'applications d'emaur.

I.es tapis eux aussi se ressentent de l'influence orientale : nos artisans refont à merveille, au point de s'y méprendre, les lapis de Madras el de liorassan, les moquelles de l'Inde et de la Perse, les carpelles adoucies de Smyrne. Naligré la parfaile fabrieation des Isidore Leroy, des Follot, les papiers peimls non! pas d'originalite, quoiqu'un papier en camaïen, roses trémières sur fond uni, fasse remarquer le nom de Jouanuy. Ce n'est pas que ce genre ue puisse lui anssi se renoureler el l'on peut admirer che\% Chaix les ceures du maitre a/fichier Jules Chéret qui, suivi de maints imitateurs, a lapissé les rues de Paris de ses fresques et de ses estampes, égayant la monolonie grise des édifices, décorant de frices et de bas-reliefs les espaees nus des murailles. Cest un " musée en plein vent ", une perpéluelle évocation capricieuse el joyeuse; la publicité lui est un prétexte pour inveuter des enchautemeuts.

Les bronzes et les cuirres, omements de nos salons, sont toujours des réductions dapris tel ou tel maitre surtout ancien, el cependant des procédés nouveaux riennent au secours de l'industriel, notamment la cire perdue et la lonte directe sans relouche du bon artisan Liard. La lumière électrique " n'a pas encore rencontré le mode de présentation spéciale qu elle exige impérieusement ", mais "les clains de Brateau, les cuirs mosaĭqués de Cazin, les montures d'écentail de Duvelleroy, les ferronneries de Marrou et les orf $\dot{e}$ rreries de Dionède, les relinres de Gruel et de Marius Michel sont des merveilles ». Parfois l'art se heurte à l'art appliqué: la vieille lulle reparaît; on envisagre la taille, la qualité du métal, la combinaison el le prix des matieres, iroire, email, or, argent; on oublie que les figures exposées par Lucien lialize. Christolle, Boueheron, portent cependant les signatures de Mercié, Barrias, Jacquemart, Falguière, Roty, Boltée, Joindy, "Orfères et joailliers affirment leur intention de ne demander qu’a la llore leur inspira- 
tion. "Les freres Vever repoussent dans l'argent des mimosas et des roses fraiches cueillies. Gustave Sandoz a demandé a Massin le modèle d'ur superbe devant de corsage en joaillerie. Lucien Falize polil son a vase sassanicle, beau comme une gemme du trésor de Saint-Marc ". Emile FromentMeurice nous lait admirer le beau vase de Paul Sédille. Eufin, le Ixyonnais Armand-Calliat renouvelle l'orfécrerie religieuse, art obstinément inmobile, enchainé par les traditions et par la routine de la clientèle qui le fait vivre. Son "Reliquaire de Saint-Louis de Carthage " est un chef-d'curre. Voici ce qu'en dit le vicomte E.-M. de Voguë : ".... Il a adopté un style, le roman, dont il ne s'écarte jamais. De patientes études l'ont armé de tnutes les ressources du métier; il a étendu el diversifié l’emploi des émaux,
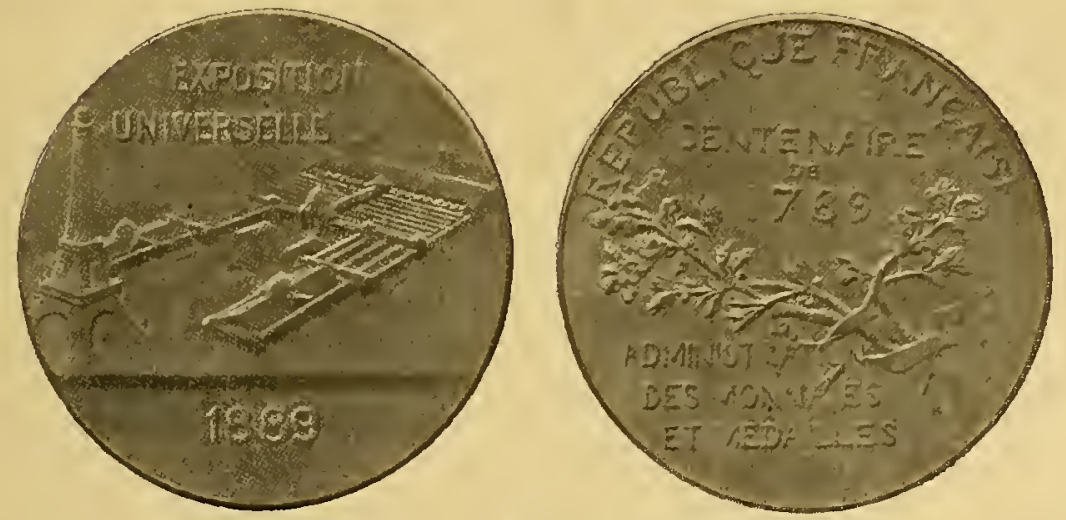

XLY et XlY'l. - Exposition uniserselle de Paris, $188 y$.

Médaille de la Tuur Eiffel et des Palais du Champ de Mars, grave par. Daniel Duruis.

des nielles, des ivoires. Mais surtout il est parti d'une idée bien simple: il s'est dit qu'au lieu de réduire l'oruementation des vases sacrés à quelques molifs reballus, loujours les mêmes, jl fallail ouvrir les vies des saints et puiser à celte source intarissable les merveilleuses histoires, les symboles particuliers qui se dérouleraient sur les reliquaires, les ostensoirs, les calices, racontant la gloire du bienheureux auquel l'objet est dédié."

Lindustrie française garde encore sa valeur el son origginaitité, bien que l'Américain Tíflany ail tenté de créer un style nouveau dil "saracénique "; celui-ci est trop composite, trop compliqué, mélange de japonais et d'indien, de français et d'angrais, et son succès au delà de l'Allantique n’est qu'une lantaisic passagère.

Mais la section des porcelaines, céramiques el verreries est un véritable triomphe. Les essais inaugurés par Salvetat ont entin abouti, et on troure dans les vitrines des spécimens de porcelaine flambée, "Lransformée en matière précieuse par la dissemblance des effets dus à des combinaisons de cuisson, a descourants d'oxygine faisant passer le rouge de cuirre par le 
violet, par le bleu, le vert, le lilas, en des nuances chatoyantes, voltigeantes 2 . Chaplet triomphe dans cel art; mais d'autres, d'une fantaisie moins capricieuse, se restreignent, comme Dammouse, aux teintes blondes et grises, ou décorent, comme Bracquemond, un service entier de fleurs des champs. Delaherche ornemente ses grés, $\mathrm{y}$ dispose des couleurs adoucies et sait toujours garder à la forme sa destiration el aux teintes leur convenance appropriée. Chez Haviland; Bracquemond renouvelle maints modèles. Et c'est enfin Gallé, faiencier, qui invente toujours et séduit, attire, conquiert par sa fantaisie. Roger Marx indique comme caractéristiques de sa manière " la mise en valeur constante de l'émail "slannifère", la superposition d'émaux d'opacités inégales, le rapprochement de lons sobres et discrets, parfois le contraste du raffiné avec le lrutal, puis l'application de la gravure à la terre molle ou sèche." l.es belles porcelaines de la manufacture de Copenhague, dirigée par lirog, sont seules, avec les ouvrages de Gallé, à trahir l'inspiration directe de la nature. La manufacture de Sèves a envoyé de belles pièces, mais toujours les mêmes. Quelques rases cependant s'y font remarquer par leurs délicieux bas-reliefs, qui sonł déjà dispulés par quelques amateurs; le grand public apprendra plus tard quils ont été modelés par le maitre Rodin, qui avait alors travaillé quelque temps à la ilanufacture, a trois francs l'heure.

Dans l'industrie verrière, notre supériorité est sans conteste. C'est en vain que Venise reproduit ses anciens modèles de vases à dauphins el ses coupes bleuâtres ou rosées, et que les manufactures de Bohême continuent à écouler laurs cristaux semblables et connus. Rousseau-Léveillé a compris l'art du cerrier; sans surcharger, comme d'autres, son crïstal de motils d'or, et sans le bigarrer au hasard, sans exiger de lui qu'il joue le rôle du marbre, ni qu'il déruise l’aspect du laqué, de la porcelaine ou du bronze, il veut que le cristal suffise à sa propre décoration; il sait "le jasper sous l'action localisée des oxydes ou tresser un réseau d'élincelantes craquelures par une projection d'eau froide entre deux feux ». Il excelle dans les saillies inattendues, les reliefs énergiques, les volutes capricieuses el fermes.

Mais c'est encore Emile Gallé qui reste ici le maitre, et éest à lui que notre verrerie doil son nouveau renom. Comme un alchimiste, il « métamorphose en pierres dures la substance vilreuse. Il sait façonner à son gré des sardoines, des onyx, simuler les fêlures des quarız, l'ambre cendré, le tachelage de l'écaille; puis l'envie l'aiguillome d'emprisonner dans le cristal, le fuyant, l'insaisissable : la vapeur des nuages, le suintement des buées, l'écho assourdi des reflets, les fumées ondoyantes, les clartés lunaires "). E.-M. de Voguë l'appelle non sans raison " un Japonais né à Naney "... "Quant aux plantes dont nous avions fini par faire une ornementation conventionnelle, il leur a rendu une personnalité, un langare, il a relrouvé les lois mystérieuses de leurs attitudes...; lout le monde des vivants y passe, les oiseaux, les poissons, les insectes, el des hommas aussi, des figurures el descorps d'au- 
jourd'hui... Après l'exacte réalité, ce sont des recompositions spirituelles, des larves d'êtres qui pourraient exister, qui luttent tragiquement pour arriver à la clarté de la vie, dans les demi-ténèbres de ses verres fumés... " El cependant tant d'originalité " s'accompagne d'un respect constant des lois d'appropriation. la forme ne cesse jamais de demeurer en rapport avec la convenance, el de la forme émane le décor" ".

Gallé a fondé et dirigre à Nancy une école vivante, originale, qui fait un contraste étrange avec nos manufactures officielles où l'Etat, gardien du goût, fait recuire fidèlement le biscuit qui plaisait à $\mathbf{M}^{\mathrm{me}}$ de Pompadour, repeindre arec adresse le berger dans le fond de l'assiette, et rebroder encore sur les métiers de haute lisse, en trompe-l'oil chromolithographique, les "saisons" et les "points cardinaux".

Bien que ringt et quelques annćes nous séparent déjá de l'Exposilion de 1889 , nous n'avons pas encore le recul nécessaire pour en juger froidement les résultats, et dans nos citations plusicurs oublis subsistent à côté d'exagérations certaines. Mais celte date restera dans l'histoire de l'art appliqué français. Décoration extérieure et intérieure, mobilier, parure, marquent une tendance plus franche à la gaieté : de même quen Anğleterre, les conseils des Ruskin et des William Morris ont préconisé des intérieurs joyeux et commodes, en France Emile Gallé a montré le bon chemin.

L'essor est donné; la nature, flore et faune, est devenue le thème d'une ornementation nouvelle qui, empruntant it l'Orient ses vives couleurs, va encore se développer, el les dernières années du dix-neuvième siècle vont donner naissance, quel que soil le titre qu'on lui donne, à un style réel, véritable, bien caractérisé, ayant ses cxagérations, mais présentant aussi ses beautés. 


\title{
La fin du $\operatorname{XIX}^{\mathrm{e}}$ siècle
}

\author{
$1890-1900$
}

L'Enseigneneat du Dessin : lEcole nationale des Arls décoratifs: Grasset et l'Feole de la rue Vavin: les Ecoles de province. - La Société à Encouragement à l'Art el à l'ludustric. - Campagne pour ladmission aux Salons des "Ouvriers d'art industricl "; elle réussit en 1891 à la Société nationale des Beaux-Arts, et partiellement en $189 a ̄$ à la Société des Artistes francais. - Projet d'une Exposition de la Plante. - L'Exposition des Arts de la Femme organisie en 1892 par l'Union centrale. Deuxième Congres des Arts déroratifs, à Paris, en 1894 . L'Evolution de la Décoration et des Arts appliqués s'acentue de plus en plus. - L' "Art noureau " en France et à l'etranger. - l.e Comile français des Expositions à létranger et la transformation des Expositions. - Expositions françaises de Londres, 1890 , et de Moscou, 1891. - Expositions universelles et internationales de Chicago, 1893 ; Anvers, 1S94: Amsterdam, 1895. - La Section française à lExposition de Bruxelles, 1897 . - L'Exposition universelle ef internationale de Paris, 19no. - Réel ellort des industries d'art franẹises pour se dégager des formes conventionnelles : Emile Gallé, René Lalique. - Jes Musées rétrospectifs montrent l'evolution de la mode ef du groùt pendant le dix-neuvième siècle.

L'Enseignement du dessin, comme nous l'avons v'u, avait été complètement transformé suivant les théories du grand sculpteur Eugène Guillaume, et son étude était devenue obligatoire en 1878 dans l'enseignement secondaire et dans l'enseignement primaire.

Celte méthode créait la "science du dessin " et elle était conçue dans un sens très noble et très élevé; la geéométrie en était la base, afin de donner aux esprits des élèves une forte discipline, le respect de l'exactitude, et de les habituer à réduire aux éléments fondamentaux les formes complexes de la nature. Si l'avenir devait prouver que ladite méthode était trop élevée pour la mentalité enfantine, elle n'en a pas moins donné d'excellents résultats grâce aux elforts d'Eugène Guillaume, de Louvrier de Lajolais, de Dutert, de Crost, de Paul Colin, de Chipiez, de Genuys. En même temps elle inaugurait entre l'Etat et les municipalités une union, grâce à laquelle se créaient ou se transformaient en province toute une série d'écoles de BeauxArts, qui recevaient, suivant leur importance, le titre de Nationales, de 
Régrionales ou de Municipales. A Paris, l'Eeole nationale des Arts décoratil's avec Lajolais el Genuys, les licoles muncipales Bernard-Palissy el GermainPilon développaient encore leur enseignement pendant qu’à l'licole particulière de la rue Vavin, londée courageusement par Guérin, le mâtre Grasset, aidé de L.-O. Nerson, voyail passer par ses classes la plupart de nos artistes décorateurs actuels et contribuait puissamment par ses cours et son ceurre il l'évolution de l'art moderne.

C'est en vue de montrer au public les résultats de l'enscignement que Gustave larroumel, alors directeur des Beaux-Arts, faisait créer après coup à l'Lxposition de 1889 la Classe 5 bis de l'enseignnement du dessin, qui eut pour président Eugène Guillaume, arec Paul Colin comme rapporteur. Guillaume, Larroumel et l'éminent chef de bureau léopold Crost avaient tenu pour la première fois a réserver, dans un jury d"art, une place aux grands industriels el aux grands collectionneurs, "à ceux pour qui l'art est la parure d'une existence luxueuse et à ceux qui cultivent en hui une branche de la richesse nationale ", el c'est ainsi que Lucien Falize, Félix Follot, Gustave Sindoz, furent appelés à faire partie du jury de la Classe 5 bis.

Gustave Sandoz fut alors tout particulierement lrappé, non seulement des résultats obtenus, mais aussi de l'inégalité des envois des ćcoles de province, el, pour remédier a ce grave délaut, il proposa l'organisation d'un wrand Concours général amnuel de composilion décoralive, qui serail suivi, a la demande de Crost, d'une Exposition circulanle des objets primés.

C'est dans ce but que se créait en 188 g la Sociélé dencouragemenl ¿' Mrl el a l'Industrie, présidée par Gustave Sandoz, assisté d'un groupe d'amis: Henry Maret, Félix Follot, Eugène Guillaume, Larroumet, Crost, louis Bonnier, Lueien Layus, le général liolland, lules llollande, Mühlbacher, Bordas, Descubes, Van Brock, Estieu, Chassaing, Yves Gurot, Pauliat, de Lanessan, lsidore Leroy, Chaplain, Chipiez, Roty, Dutert, Le Vasseur, Porles, Pierron, Thibouville-Lamy, Léon Dru, Jalla, André Guillaume, Roger Sandoz, Gaston Menier, Wickham, Wunderly, ele.

1) accord avee l'État et l'administration des Beaux-.Irts. la Société ajoutail peu ì peu ì son concours général anuuel de composition décorative, des Concours de bourses d'apprentissage, des Conconrs spécianx, des Concours de prines d'encouragement aux artisles décoraleurs des différents Salons, "donnant aussi par lous les moyens en son pouvoir aide, protection et encouragement aux artistes, artisans et ourriers dart, les soutenant auprès des pouvoirs publics et accordant son patronage à toutes les ceuvres de vulgarisalion arlislique ». A Gustave Sandoz, trop tôt disparu en 1891 , succédèrent comme présidents Henry Marel, Gustave Larroumel, Félix Follot, Henry Roujon, qui ont su développer l'uure, stimuler les iniliatives, faroriser les arts régionaux, forlifier les jeunes talents avec l'aide et J’appui de nouveaux collèrues tels que Charles Prevel, Ferdinand Périer, Emile Dupont, Pinard, Ancelot, Fernand Chapsal, Laquionie, Harant, 
James-II. Hyde, Dervillé, Jules el Jean Guiffrey, Léon Barbier, Jules et Rogel Bouvard, André Lebon, Ernest Levallois, Paul Simon, Leygues, Maciet, Roger Mlarx, Victor Champier, Emile Berr, Bessand, Bigard-Fabre, Boin, Albert Carré, Michel Lagrave, Chaumié, Jules Comte, Maurice Conyba, Jean Cruppi, David-Mennet, Domange, Dujardin-Beaumetz, Failliot, Jean Faure, Fenaille, Formentin, Gastinne-Renette, Geisler, Hetzel, Jeanselme, Mareel Jozon, Lahure, Leseur, Maguin, Manaut, de Montarnal, les frères Niclausse, Perdoux, Raymond Poincaré, Rau, Revillon, de RibesChristofle, Ricois, Charles-Roux, Savard, Susse, Trouillot, Valentino, Vaudremer, Emile Vernier, Guilleré, les frères Berlaut, Pierre Marcel, Pierre Arbel, Emile Bourgeois, Bouwens van der Boijen, Lèo Claretie, Bellan, Paul Dedet, Louis Dausset, Gabelle, Gustave Gelfroy, Javaux, Raoul Larche, Mezzara, Marotte, Armand-Calliat, Mesnil, Gottvalles, Megniez, etc.

La Société d'encouragement à l'Art et à l'Industrie a bea ucoup contribué à maintenir des liens plus étroits entre l'artiste, le patron, l'école et l'atelier; elle s'est eflorcée de rendre pratique cette grande vérilé de la civilisation si éloquemment définie par cette formule : "Le Beau est la splendeur du Bien ". Le maitre graveur Roty a tenu à résumer son but et son ceuvre dans la belle plaquette qu'il avait modelée et qu'il donna à la Société : Minerue doil conseiller perpétuellement T'ulcain.

Art appliqué, art industriel, indnstrie d'art, art décoralif, pour beaucoup ces quatre expressions paraissent désigner une même catégorie d'œurres; elles ont cependant un sens différent qu'il importe de préciser. L'ancien terme, art appliqué à l'industrie, bien juste cependant, a malheureusement élé quelque peu abandonné par l'usage. L'expression art industriel est plus fréquente; il semble y avoir dans la sonorité de ces syllabes, dans la banalité de cet adjectif qui réduit, diminue la valeur du noble mot «art», quelque chose de secondaire, de dédainneux même : expression inexacte et injuste qu'il vaut mieux, à notre aris, remplacer par celle d'industrie d'art. Quant à l'art décoratif, il s'oppose à l'industrie d'art. Ce sont, si l'on veut, deux formules qui correspondent à deux formes d'art. L'art décoratif, comme l'art appliqué, crée toute œuvre ou tout ensemble d'œuvre qui ne tend pas exclusivement à l'art pur et sait unir le beau à l'utile, landis que l'industrie d'art fabrique; l'un fournit les modèles que l'autre exécutera ; l'un conçoit, invente, construit le projet ou l'ouvre, dont l'autre fera les applications et les reproductions. Et notre administration les avait nettement classées : l'un dépend du Ministère des Benux-Arts, l'autre du Mlinis. tère du Cammerce.

Comme nous l'avons vu par les pages qui précèdent, tout en France semblait avoir conspiré depuis de longues années contre l'art décoratif : dislocation des corporalions, envahissement de la machine, vulgarisation de nos modèles, passion grandissante pour l'ancien, envalissement du faux 
luxe et de la camelote, division du travail, transformation de l'apprentis. sage. Mais l'Exposition de 1889 devait montrer ì ceux qui savent voir que notre Art décoratif commençait son évolution et, revenant à la nature, préparait l'éclosion d'un style nouveau.

D'ailleurs d'éminents critiques d'avant-garde mènent alors le bon combat qui aboutira à une de ces campagnes de presse si utiles pour la lutte des revendications el le progrès des idées.

Roger Marx, dans le premier article qu'il consacre au Salon de $\mathbf{1 8 8 9}$, montre combien est incomplet ce Salon annuel, alors unique, où l'on ne voit aucune des cuvres créées pour l'industrie par nos artistes les plus habiles; il écrit :

"Quant à l'observateur, il n'espère pas de renseignements complets, valables, d'une réunion d'où se trouvent exclus les travailleurs sans nombre qu'une appellation dédaigneuse qualifie d'ontriers d'art ind listriel... "

" Un Salon significalif sera celui qui montrera l'effort esthétique d'une annee, sans réticence d'aucune sorte, qui assemblera les travaux de tous les novateurs, en vue d'établir le développement logrique et un du gónie national. Il ne suffit pas que l'Union centrale des Arts décoratils permette de rencontrer a de rares intervalles les " ouvriers de lindustrie "; nous souhaitons suive, chaque printemps, l'évolution de leur talent; nous voulons que leurs œuvres dernières figurent à côté de celles des peintres, des sculpteurs, et nous revendiquons pour elles les mêmes lonneurs, la même goloire ou le même engouement. Puisque l'art est l'expression adéquate du milieu social, ce serait courir le risque de le mal connaitre que de manquer de l'étudier partout où se marque sa trace. Plus d'exclusion, plus de catégorie, plus de protestation indignée contre l'union intime de l'utile et du beau; un meuble, un bijou où le tempérament d'un maître s'est donné librement carrière, l'emportent mille fois par l'intérêt sur la statue ou le tableau exécuté sans instinet ni vocation, à l'aide de recettes apprises. "

"Comme s'ils ne s'étaient pas placés au rang des créateurs en donnant la forme et la vie à la matière ! Comme s'ils ne méritaient pas le titre d'artistes et la part d'applaudissements que la mode s'est accoutumée à réserver sans partage, en dépit de toute équité, aux exposants du Palais de l'lndustrie..."

Victor Champier dira de ces mêmes " ourriers d'art", dans la Revue des Arts décoratifs et dans Les Arts décoratifs a l'Exposition de 1889:

"Ce vœu, que nous ne cessons d'exprimer depuis plusieurs années, que nous espérons voir réalisé pour le Salon de 1890 , est conforme à l'inlérêt de la Société des artistes comme à celui du public. La presse quotidienne commence à sen tour à s'en faire l'écho, tant il se trouve, à lheure qu'il est, si bien compris et semble tellement justifié..."

Quant at Lueien Falize, qui aclsève alors son remarquable rapport sur

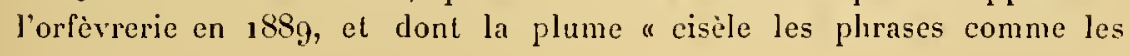


ouriers de ses ateliers cisèlent les métanx précieux ", il a conçu un magnilique service de table decoré d'herbes potagères dont il transmettra l'idée aux Christolle. Il propose alors à l'Ĺnion eentrale des Arts décoratifs un vaste projet d'Exposition de la plante: "La plante est infinie dans ses aspects. graciense dans sa fleur, fine et capricieuse en ses racines, altière el robuste par la solide architecture de ses grands arbres, délicate et souple en ses longues liges vertes, variée dans le dessin de ses feuilles. Les rraines, par leurs juxlapositions imprérues, constituent des jeux de fonds. Jes bulbes et les oignous donnent des profils de rases. I.es fruits ont prêté leurs formes a tous les besoins d'art de thomme... L'écorce de l'arbre est un

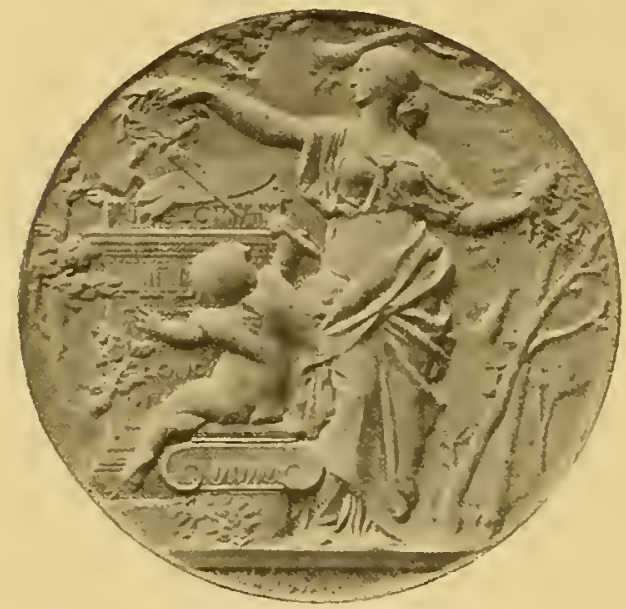

MLIII. - Socicté des Artistes franẹais, fonclée en 1883 .

Médaille grave par Danicl Dupuis. modèle pour les ciseleurs, les lleurs des jardins ont toutes les harmonies de la couleur, et Fon n'en finirait point soil fallait analyser toutes les beatés que nous offre le règne végétal et que l'art exploite sans arriver à les épuiser..."

Cette Exposition aurail etté classée en six parties : la planle vivante, les industries d'art, une exposition arlistique, les havaux des écoles, une scction rétrospective et lhisloire de larl des jardins.

Ce projel, d'abord accepté aree enthousiasme par les membres de l'[nion centrale des . Irts decoratifs, fut ensuite trouvé trop grandiose; il n'eut pas de suite. Mais l'Lnion centrale ourrit une très intéressante Exposition des Arts de la Femme au Palais de l'Industric en 189 , sous la direelion de Marius Vachon, qui avail particulièrement étudié en 1882 la Siluation des Industries d Art en France. In peu plus tard, en เ8gj, André Guillaume or granisait ì la galerie Georges Petit, avec l'aide de la Société d'encouragement à l'Art et á l'lndustrie et de son président Larroumet, une Exposilion de la Fleur, reduite, mais très choisic; inaugurée par Georges Leygues et IIenry Roujon, alors Ministre el Directeur des Beaux-Arts, elle fut très visitée el eut un réel succès.

La lutte continuait cependant. Lidiée lancée en 1889 par Roger Marx faisait son chemin : en 1891 , la Societé mationale des Beaur-. Irts admettait les artistes décorateurs it ses Salons annuels, suivie quatre ans après, en $18,5 \overline{5}$, par son añée, la Sociélé les arlistes français.

I.e principe de l'T nilé del' Irl est enfin reconnu. La desination ne suffit 
plus à classer les productions des artistes par eatégories; la pensée qui les a mises au jour en fait senle la valcur. Jes Salons annuels ouvrent leurs porles aux applications de l'art à l'inlustrie, et le Musée du Luxembourg leur réserve une place parmi les collections de l'art contemporain. Noublions pas que ce dernier projet remonte à M. de Chennevières, alors Direeteur des Beaux-Arts, qui, dès 1874, se préocenpa de eréer au Luxemboury. une section des objets d'art moderne qui serait comme la continuation du Iusée du Louvre. La tentative échoua, mais l'idée avail déja été émise ofliciellement, démontrant qu'il n'y avait ni grands arts ni arts mincurs et qu'i] 11'existail d'autre hiérarchie entre les artistes que celle qui était imposée par le talent. Il a fallu cependant près de vingt ans pour qu'un musée acceptâl, cle nos modernes artisans, vases de verre ou d'argile, ustensiles d'argent ou coupes de bronze, plaques d'émail ou bracelets d'or; et ces objets d'usage familier frappent l'imagination de quiconque les admire, au même degré qu'une aquarelle, qu'une toile de maitre ou qu'une statue, el concourent également ì renouveler en ehacun la source d'émotion qu'il vient y chercher.

Tous ceux qu'intéressait la renaissance des industries artistiques suivaient passionnément ees questions et prirent part au deuxième Congrés des Arts décoralifs qu'organisèrent en 1894 l'Lnion centrale el Georges Berger, son nouveau el actif président.

Eugène Guillaume présida ce Congrè̀s; deux ministres, Spuller et Georges Leygues (une crise ministérielle élant survenue pendant la durée des sessions), présidèrent, l'un la séance

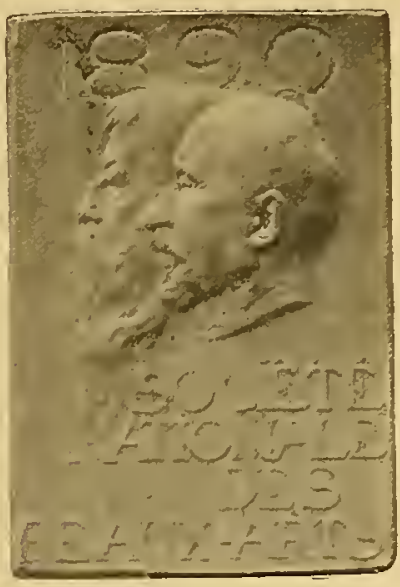

XIXYIII-Societé nationale des beaux-Arts, fondée en $1 \$ 90$. Plaquette gravée par Alexandre Charpentier. d'ourerture, l'autre le banquet de clôture, et lous deux déreloppèrent les mêmes idées. "Ce qui fait la valeur d'une ceuve d'art, c'est la conception et l'élévation ou la délicatesse de la pensée unie à la perfection de la forme. Ln objet qui remplit ces conditions, quelle que soit sa destination, quel que soit le nom qu'on lui donne, est un objet d'art. "Le Congrès, auquel assistèrent près de quatre cents délégués, artistes, savants, industriels, écrivains, fonctionnaires, se subdirisa en trois sections, dirigées chacune par Gustave Larroumet, le sénateur Bardoux et le vice-recteur Gréard : $1^{\circ} d e ́-$ veloppement des arls décoralifs en France; $2^{\circ}$ législation; $3^{\circ}$ enseignement du dessin el hisloire de l'art. Parmi les questions discutées, signalons notamment l'imilation en matiere d'art el d'industrie, l'obligation du dessin au certificat d'études primaires, le róle de la femme sur l'avenir artistique de notre pays, la création de Masées d'Arts décoratifs dans les départements, 
la fondation d'une chaire d'histoire de l'art appliqué aux métiers, l'organisation d'un service d'inspecteurs d'art décoratif, la refonte de la loi sur la propriété artistique et industrielle, la situation des ourriers d'art devant les dispenses militaires, ete. le Congrès de $\mathbf{1 8 9 4}$, comme le disail Eugène Guillaume, "aflirmait une fois de plus l'unité de l'art el conquérail pour l'art décoratif le droit de vie el de cité dans la grande fédération de l'art français."

Ce Congrès, si complet qu il fût, ne put malheureusement résoudre la question du Musée des Arts décoratifs, et notre pays devait en rester privé pendant encore plus de dix années.

Mais l'évolution de l'art moderne s'accentue de plus en plus. D'abord, très réalistes, nos arlistes, libérés des préjugés du grand art, se souviennent que les styles du Moyen Age et du dix-huitième siècle tirent leur charme, nnn pas de l'imitation rigoureuse de la nature, mais de sa libre interprétation; ils demandent á la flore et à la faune des formes nourelles, qu'ils parent d’une ornementation où la figure est présentée avec tout son agrément; ils savent harmoniser la ligne et le modelé et demander toute sa gaieté à la couleur et à la lumière.

Nous avons constaté, en 1889, l'wurre des Gallé, des Grasset, des Chéret, des Chaplet, des Dammouse, des Delaherehe.

En 1891, peu importante est la premièe section d'Art décoratif, acceptée au Salon de la Société nationale des Beaux-Arts; celle de 1892 roit pour la prenière fois les étains de Desbois, de Baffier, d'Alexandre Charpentier; lorsque la Sociélé des Artistes français, lout d'abord réfractaire, eède partiellement en $\mathbf{1 8 9 5}$, et accorde une sous-section aux "ouvriers d'art industriel ", c'est René Lalique qui apparaîl d'un coup dans toute sa splendeur, émerveillant les visiteurs par ses bijoux el joyaux, où se mélangent, de façon tout inaltendue, pierres précieuses, mélaux et émaux.

A la fin de celle même année 1895 , S. Bing inaugrure rue Chauchat un hôtel-magasin que l'archilecte Louis Bonnier a décoré suivant son titre: l'Art nouveau, pendant que dans la presse, spéciale ou non, discutent el combatlent Roger Marx, Victor Champier, Marius Vachon, Arsène Alexandre, Ilenry Havard, Frantz Jourdain, Maillet, Emile Berr, ThiébautSisson, et que le public intéressé suit les nouvelles créations arlistiques de Gallé, Grasset, Plumel, Selmersheim, de Feure, Eugène Gaillard, Colonna, ele.

Cette même rénovation artistique se fait jour à l'étranger el ses progrès n'y sont pas moins considérables. En Angleterre, où la statuaire na jamais existé, c'est dans la décoration intéricure et le mobilier que le mouvement se fail surtout sentir. Ruskin, dans ses Pierres de Tenise (1851-1853), a formulé son esthétique dans les trois prescriptions suivantes: " $1^{\circ}$ n'encouragez jamais la fabrication d'un objet dans la production duquel l'invention n'a pas de part ; $2^{\circ}$ n'exigez jamais un fini minulieux pour le fini lui-même, 
mais seulement s'il tend à un but pratique ou noble ; $3^{\circ}$ n'encouragezjamais une imitalion ni une copie d'aucune espèce... " La voie tracée par IRuskin est admirablement suivie par Burne-Jones, Walter Crane, William Morris; s'ils se sont d'abord trop inspirés de leur style national Marie Tudor, la logique et le bon sens anglo-saxon leur feront vite abandonner les formes inutiles ou vrament archaïques pour prendre à la nature tous les éléments dont ils ont besoin.

Industriels et commerçants britanniques savent suive de tels maitres, et les grandes firmes "Liberty" ou "Maple " créent d'importantes succursales dans toutes les graudes capitales.

En Imérique, Louis-C. Tilfany révolutionne l'art du vitrage, de la verreric et de l'ameublement en général.

En Danemarl, e’est dans la porcelaiue surtout que paraissent les nouveaux modèles déjà si admirés en $188 y$.

Et le mouvement général de rénovation se lait sentir en Italie, en AnWriche, en Iollande, en Suéde.

En Belgique, s'ourrent en 18g'i la première Exposition de la Libre Esthétique, où une large place est faite aux Arts décoratil's, el la Maison "'Art, qui, installée dans l'ancien hôtel du célèbre avocal Edmond Pieard, présente à l'arehilecture bruxelloise les eréations de l'A rt nouvean de tous les pays. L'architecte Van de Velde cherehe à satisfaire le goût flamand et son amour de l'ampleur el de la richesse par des boiseries, des étolles, des broderies, des cuivres aux courbes bien souvent imprévues.

Quant a l'. Hllemagne, patrie de Van de Velde, elle abuse alors d'une décoration graplique el d'une stylisation raiment exagérées.

Depuis leur origine, les Expositions se sont complètement transformées : elles sont d'abord nationales de l'ar. VI (1798) ì 1849 ; organisation, admission, installation, allribution des récompenses y appartiennent surtout à des fonctionnaires et à des savants. En 1851 , elles sont devenues de grandes manilestations internationales de l'activité mondiale, el peu í peu industriels et commerçants sont admis dans les divers comités et jurys.

Quand les Sections françaises à l'étranger sont organisées par l'Etat, elles coûtent des millions, et ses hauts fonctionnaires, malgré toute leur bonne volonté, ne peuvent connaître les véritables intérêts des exposants dont bien peu d'ailleurs songrent à sortir de France.

Quand l'Etat sabstient, e'est la plupart du temps une Société financière qui prend en maius la direction de la Section française et est obligèe de couvrir ses risques par une recherehe de bénéfices payés fatalement par l'exposant. Quant aux titres de membres des comités et jury's et aux hates distinetions, combien sont attribués ì des hommes qui ne sont même pas exposants. Comme nous l'avons indiqué plus haut, c'est alor's qu'un groupe d'industriels, ayant ì sa tête Gustave Sandoz, voulut que l'Exposition appartîut ì 
l'exposant, que l"̈nitiative privéc marehât d'accord avec la puissance de d'Litat, que les pouvoirs de l'entreprise fussent absolument séparés des droits de l'exposant et que ces manifestations devinssent rraiment pour la France un moyen de développer son exportation, de forcer les Français à voyager et ì faire micux connaitre leurs produits en les présentant eux-mêmes it leurs clients.

C'est ainsi que l'Exposition de Barcelone, 1888 , organisée et préparće depuis 1885 par ce groupe, n'entraina pas la moindre dépense pour l'Etat, quoiqu'clle ait été reconnue officiellement moins de trois mois seulement avant son ouverture.

Eu 18 g̣, sur un nouvel appel de Guslave Sandoz, les membres des Co-

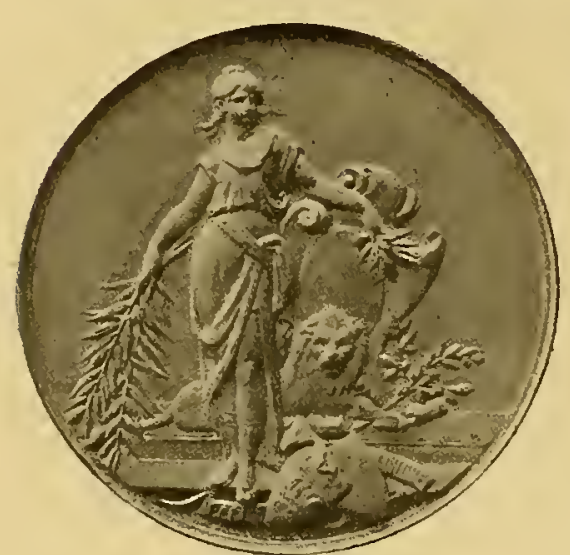

XIIX. - Exposition liançaise de Londres, 18 yo.

Médaill dessince par G. Fraipont. mités de Barcelone se constituajent en une Association permanente qui, sous le nom de Comilé d'inilialive des Expositions françaises it l'étranger, organisait une Exposilion française à Londres en 1890 et obtenait du Tsar l'ukase autorisant la grande Exposition /rançaise qui eut licu à Moscon en 1891 .

Puis le Comité, alors dirigé par Thibouville-Lamy, qui venait de remplacer Gustave Sandoz, prématurément cnlevé, se réunissait à la Sociélé d'Economie industrielle el commerciale pour préparer la participation de la lirance à l'Exposilion de Clicago, 1893 , par une

Commission spéciale que présidait Ernest Lourdelet, assiste de Georges Lamaille, secrétaire général, et llaurice Estieu, trésorier.

Mais l'impossibilité de prendre part aux Expositions internationales amena le Comité à élargir son clamp d'action; c'est ainsi qu’il se reconstituait en 1895 sous le nom définitif de Comilé français des Exposilions it l'étranger et appelait ì la présidence Allired Aneelot, qui venait d'appliquer avec un récl succès à Amsterdam, 1895 , ses théories fondamentales : séparation absolue des pourvirs de l'entrepreneur et de l'exposant, exclusion systématique des comités des bénéfices qui sont, quand ils existent, ristournés aux classes et à leurs participants.

Les anciens ministres du Commerce, Victor Lourties, André Lebon, Marty, Siegrried, Mesureur, roulurent bien accepter la présidence d'honneur, suivis depuis par ILenri Boucher, Maruéjouls, Paul Delombre, Millerand, Alfred Picard, Delaunay-Belleville, Dervillé, Trouillot, Dubief, Doumergue, Jean Cruppi, Alfred Massci. Ch.-II. Couyba. L.e bureau comprenait 
alors Alfred Aneelot, président; L. Courrenr, Emile Iupout, Fauré le Page, Georges Harlmann, Lucien Layus, Charles Lecrrand, vice-présidents; G.-Roger Sandoz, secrétaire général; Manrice Listieu, trésorier; Barbier, Blondel, Debain, Lamaille, Noirot-Biais, Walter, Luboulor, Jaul Simon, secrétaires.

Le Comite, dès son origine, avait compris de façon conerète el moderne que la "diplomatie du droit " commence a saffirmer devant la "diplomatie de la force " et que, daus les relations extérieures, la partie économique et commerciale est appelée á prédominer charjue jour darantage; a Barcelone,
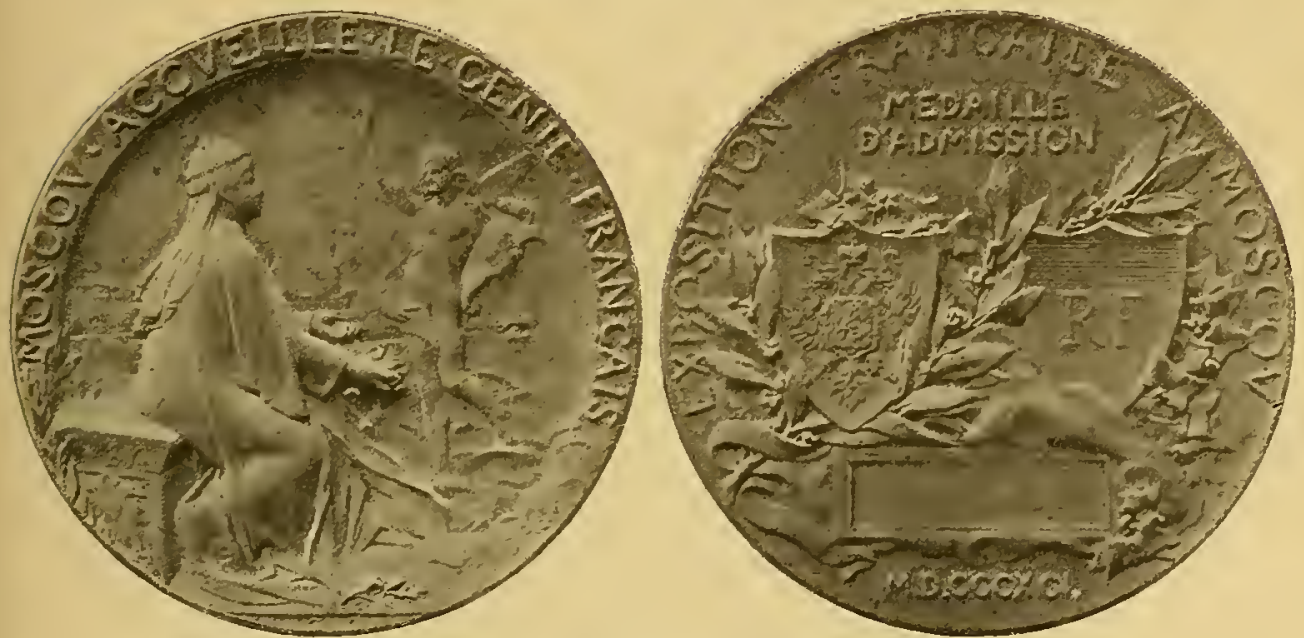

L el Ll. - Exposition française de Moseou, 1891. Medaille dadmission gravée par 0 . liuty.

1888, ¿ Chicaro, 18,3 , à Bruxelles, 1897 , il fait sortir notre gourernement de son inertie; il prend des initiatives prérieuses à Moscou, 18g̣, à Glasgrow, 1901, et quand, reconnu comme établissement d'utilité publique en 1 go1, il aura fusionné en 1903 avec l'ancienne Réunion des Comilis.s el Jurys. présidée par Georges Berger et Charles Prevet, nous verrons quelle fut sou ưure aux grandes Expositions qui commencent le vingtie ne sièele. Mais u'auticipons pas et constatons seulement des maintenant lat place que, des lorignine, le Comité français des Expositions à l'étranger a tenu à réserver aux Beaux-Arts, aux Arts décoratifs el aux Industries d'art.

J.Fxposition française de Moscou, 1891, fut particulièrement réussie: nos arts industriels $y$ eurent un réel succès; il ne reste malheureusement aucun rapport sur cette importante manifestation française qui préèéle de quelques anućes une alliance destincé à rétablir l'équilibre européen.

C"est à Chicago, en 189.3 , que devait avoir lieu la plus grande Exposi- 
lion de cette période pour fêter le quatrième centenaire de la découverte de l'Amérique par Christophe Colomb.

L'Exposition de Philadelphie, $18-6$, avait laissé un mauvais souvenir : l'élévation des droits de douane, l'absenee de garanties, les difficultés de toutes sortes, les agissements du jury contrôlant, augmentant ou supprimant les récompenses après le départ des étrangers, ne semblaient pas d'abord devoir encourager nos'industricls at prendre part en grand nombre aux fêtes de Chieago. C'esl sur les bords du lac Michigan, dans le JacksonPark, que s'élendit l'immense foire aux palais blancs : entreprise privée, subventionnée et patronnée par l'Etat et la ville : on avait copié, mais en plus colossal, notre Galerie des Machines. I'Exposition fut ouverte le
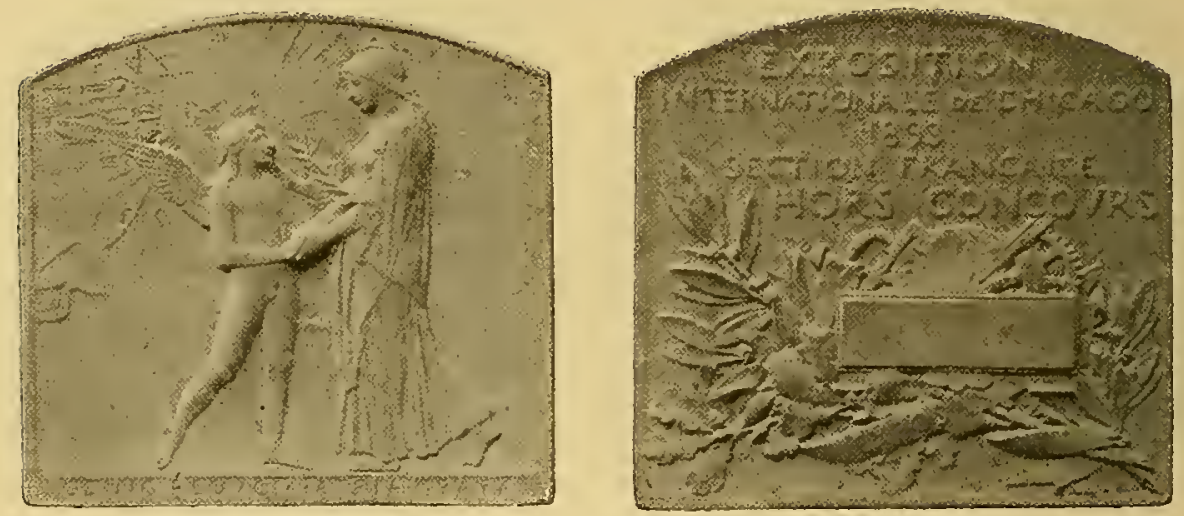

LII el LIII. - Exposition universelle et internationale de Chicago, 1893 . Plaquette de la Section l'rançaise, gravie par O. Ioly.

dimanche, ce que l'on n'avait pu obtenir à Philadelphie. Quant au nombre des exposants, notre Commissaire général, Camille Krantz, l’évalue à environ 45000 dout 2762 pour la France, mais nos expositions collectives ne comptaient que pour une nnité et cel usage ne fut pas général pour toutes les sections élrangères.

La France avait adhéré la première et roté près de 4 millions de subventions; son rôle $\mathrm{y}$ fut très brillant; notre section fit même quelque peu le succès de l'Exposition.

La classification élait d’une fantaisie bien souvent amusante : les tombcaux et mansolées voisinaient avec l'ameublement et les tapisseries. Comme i Philadelphie, le jury n'offrait aux élrangers aucune garantie, et le gouvernement français dut meltre notre section hors concours.

Si le succès matériel élait minime, les leçons rapportées étaient précieuses et prouvaient bien le but commercial des Etats-Unis : par des tarifs protecteurs élevés, obliger compatriotes ou étrangers ì créer chez eux les 
industries qui leur manquaient, meltre en valeur tout le sol et s"imposer ensuite au vieux monde. Nais comme chez les Américains tout est alors énorme, disproportionné el incohérent dans son faste même, à Chicago le goût français triomphe tout particulièrement; si ce succès ne se traduisit pas par des ventes immédiates, il eut, comme après Philadelphie, une véritable influence sur l'Américain du Nord et de l'Est el contribua à développer son groûl pour nos industries parisiennes et à lui rappeler le chemin de la France.

"Mais les raffinements du confortable ne constituent pas la civilisation. L.e peuple américain, obligé à l'origine d'être dur pour lui-même et pour les choses, a conservé une rudesse caractéristique dans ses goûts el dars ses
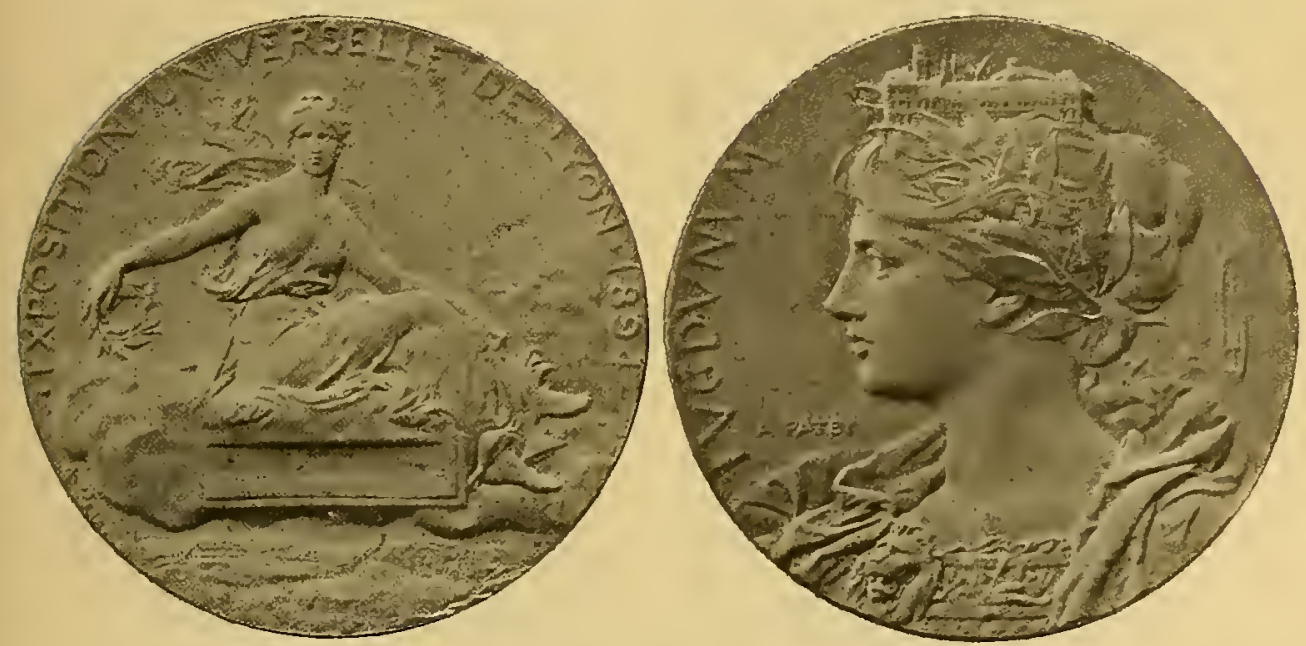

LIV et LV. - Exposilion universelle de Lyon, 1894.

Médaille gravie par A. Patey.

veuvres. Il considère comme des progrès incomparables le téléphone, la lumière électrique, le phonographe, et il jouil avec une évidente satisfaction du bien-être. mais il ne saurait soutenir aucune prétention au point de vue artistique. L'art est indépendant du luxe avec lequel l'Américain le confond sans cesse. Préoccupé avant lout de l'utile, il ne fait pas les choses pour le plaisir de les faire, il les fait uniquement pour le but qu'il se propose. Or, dans toute question dart el de goût, il $y$ a un élément désintéressé : l'ideal, que caressent avec amour aussi bien le public à qui l'ceuvre s'adresse que l'arliste qui l'exécute. Ce besoin d'idéal, la volonté ne suffit pas a le créer; il nât graduellement par une sorte de courant sympathique qui va du public à l'arliste inspiré, et de l'artiste a un public capable de partager ses impressions. "Ce jugement, extrait du rapport de Victor Legrand, marque bien la mentalité américaine de celte époque.

Les raisons qui font que les Américains mêlent "conforiable et artis- 
tique $"$ sont tres simples: ils ont des fabriques, nous avons des ateliers; leurs clients ne sont pas des collaborateurs, mais des acheteurs, tandis qu'en France, les amaleurs, plus nombreux el éclairés, sont des inspirateurs qui savent commander avec goûl, cerlains de trouver quelqu'un pour comprendre el exéculer.

Aussi les Elats-Lnis nous empruntent nos idées el nos wurres en même temps que nos artistes, nos artisans et nos ouvriers. Mais tous, dans celle vie fiévreuse, oublient leurs facultés d'invention, leur goût créaleur : ils ne s'acclimatent pas; el, s'ils ne viennent pas chaque annće se retremper en
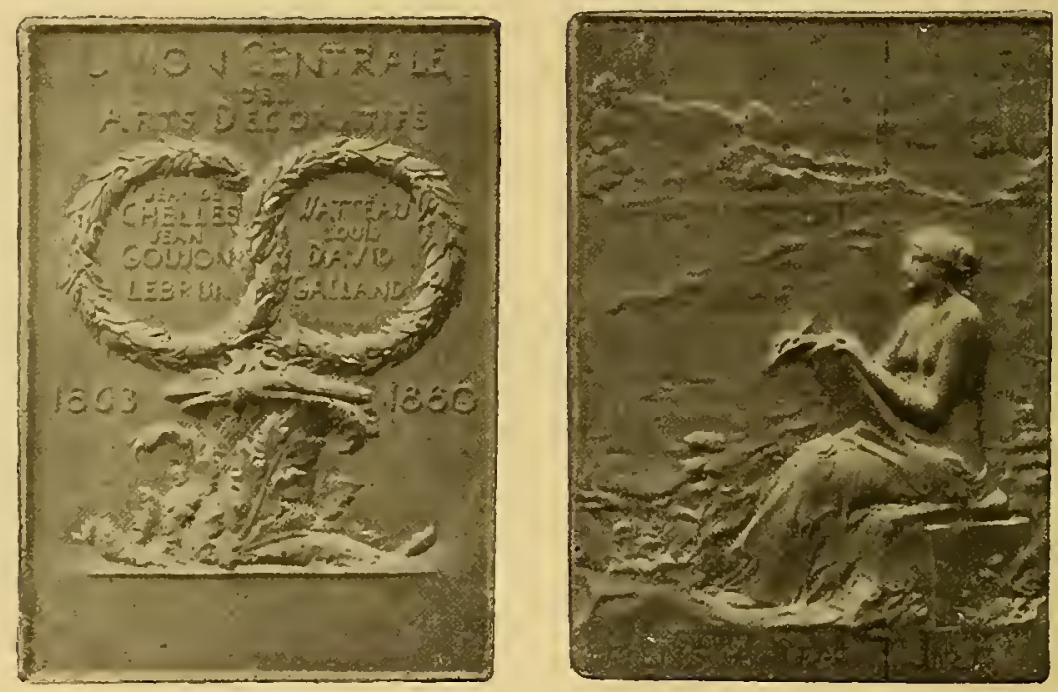

LVI et LYII. - Union centrale des Arts décoratifs, fondée en 1863. Plaquetle gravic par O. Roly.

France, leurs belles qualités sont perdues. Celte constatation est celle de plusieurs rapporleurs français de Chicago.

Totre céramique est la première, malgré les droits élevés qui entravent les marchés. Dans la verrerie, furent parliculièrement remarqués Emile Gallé, Lèveillé avec ses vases gravés en branches et fleurs, et les frères Daum avec leurs paysages d'hiver aux saules blancs de grésil.

Si nos hronzes d'art, avec Barbedienne, Thiébaut, Colin, soutiennent leur vieille réputation, il n'en est pas de même pour les bronzes d'ornement el d'ameublement : ici e'est encore le pastiche. Pour l'éclairage, Eugène Piat a modelé pour le bronzier Gagneau girandoles et appliques d'un beau mouvement. Le zinc d'arl, appelé " bronze d’imilation ", reste malgré IIoltol et Eugène Blot, "par rapport au bronze, ce que le carton-pâte est à la sculplure sur bois". 
Mais les Etats-Unis, par la contrefaçon de nos modeles, font alors un tort énorme à nos éditeurs d'art el surtoul déprécient nos ceurres. Déjì,
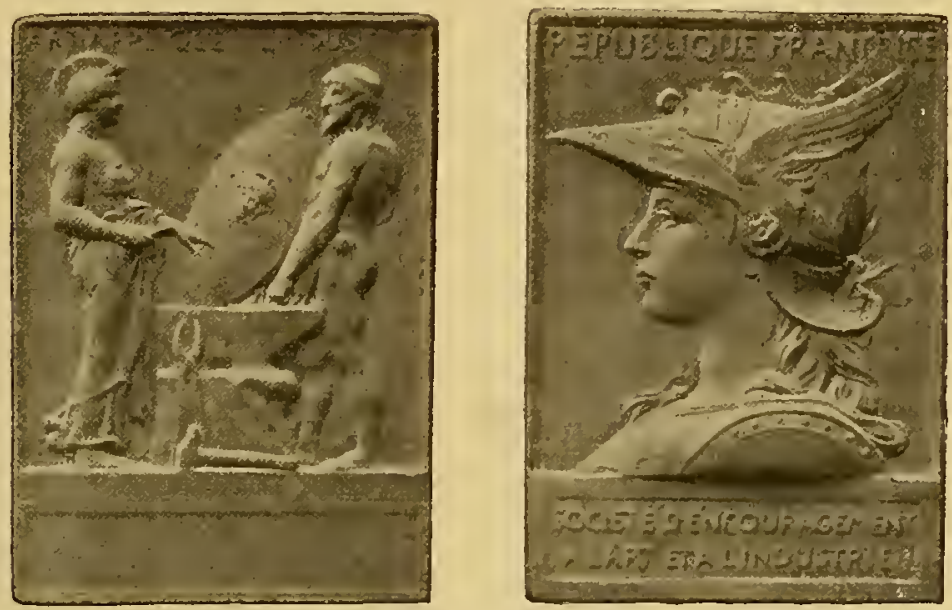

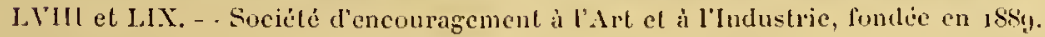
Plaquette grave par $O$. Roty.

en 1888 , Louis IIollol avail fondè une Ligne pour la protection de la pro-
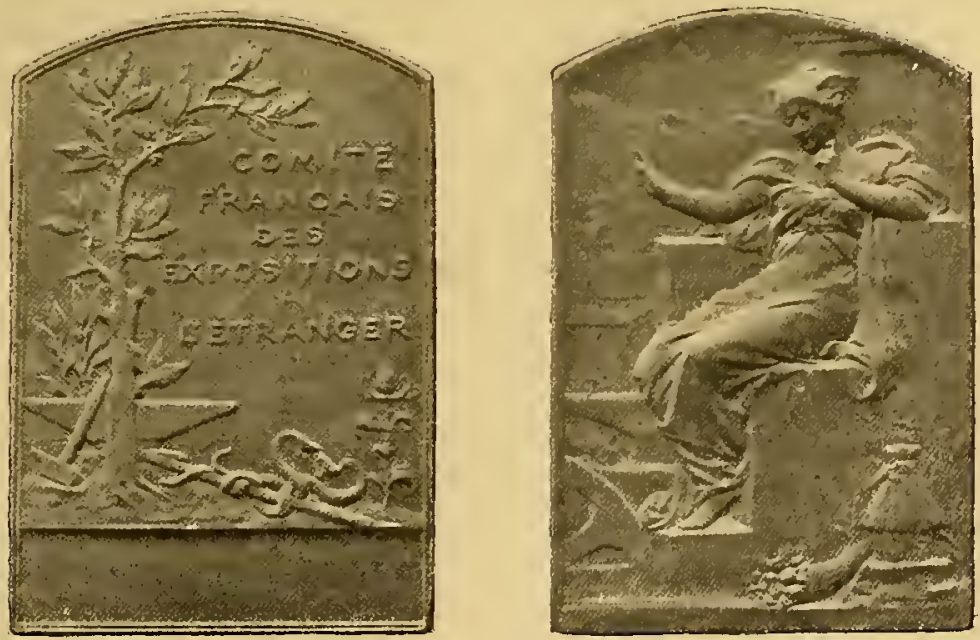

LX el LXI. - Comilé français des Expositions à l'ćtranger, fondé en 1 syo. Plaquette gravéc par Louis Botlice.

priélé arlistique anx Eilats-L'nis, el, en 1891 , une loi permellail de pour- 
suivre les contrefaçons lorsque deux modèles de l'original avaient été déposés à la bibliothèque du Congrès de Washington. Le rapporteur de la Classe 23, Albert Susse, a fail à l'Exposition un relevé des bronzes français surmoulés par les fabriques américaines.

En orfévreric el en bijouterie, les rapports d'André Bouilhel el d'Henri Vever sont très complets : en 1889 , nous avons commené la décolalion par la plante; ce n'est pas assez, il laul créer, el ì la théorio joindre la praltique. Nous n'avons fail que des essais, il faul faire de l'industrie d'art qui, clle, est loujours belle, et non de l'industrie de mode toute de convention el qui nous apparaîl ridicule dès que la vogue a cessé... Les rapports de la bijouterie el de l'orférerie sont illustrés, de même que le liapporl général administratif du Commissaire général hirantz; ils sont parmi les premiers qui aient accompagné le texle d'illustrations, complément indispensable pour bien faire voir et comprendre. Enfin, il nous faut signaler encore le rapport de Viclor Legrand dont un chapitre est consacré aux conditions du tracail aux États-Lnis, le rapport de Victor Champier où l'on trouve d'inléressants renseignements sur les écoles d’art créées en Amérique el sur les qualités décoratives de certaines des industries de ce pays, el le volumineux rapport des délégations outrières qui mérite d'être consulté.

A Chicago, nos industries d'art ont conservé leur suprémalic parce qu'elles ont pour elles le goùl que le comte de Laborde, en 1851, appelait de celte belle expression "le plus adroil des comnerces el le premier des méliers", parce quelles ne peuvent pas ase transplanter comme une industrie simple el mécanique, qui relève d'une consommation courante, el quait leur faut, pour virre el se developper, un ensemble de traditions que l'in. telligence la plus éveillée ne peut acquérir eu un jour."

11 en sera de même aux Exposilions d'Anvers, 189 ', d'Amsterdam, 1895 , el a celle de Bruxelles, 1897 , qui eul pour Commissaire géuéral Maurice Monthicrs. La section française ful décorée par Georges Rémon, el nos industries d’art s'y trouvèrent brillamment représentées; au centre, les bijoux el joyaux ainsi que l'orferrerie avec les vitrines des maisons Boucheron, Vever, Louis Aucoc, G.-Ihoger Sandoz, Chrislolle, André Aucoc, Boin-Taburet, Debain, Savard, Piel, Fornet, Murat; René Lalique y paraît pour la première fois dans une exposition universelie el internationale. Siol-Decauville, Soleau, Susse, représentent dignement le bronze. Et nous ne saurions oublier dans la Lrosserie, la tabletlerie el la maroquinerie, Emile Dupont, les frères Amson, Genty, les frères Leloir, Maurey-Deschamps; les papiers peints de Fèlix Follol, d'lsidore Leroy, de Jouanny; les menbles el lapisseries de Damon, Pérol, Soubrier, Blondet, Braquenié, Ilamot, Cornille, Ternisien, Poleau, P.-II. Rémon; les céramiques de Brault, Ilarant, Hache, Locbnilz; les verreries de Gallé, l)aum, le Rosey, llarant, Appert; les mosaíques de Guilbert Martin; les belles iditions de Delagrave, Doin, Ilelzel, Le Vasseur, Lucien Layus, Masson, Belin, ele. 
Il n'y a pas eu de rapports de Classes à l'Exposilion de Bruxelles, mais seulement un Rapport général écril par Charles Legrand, pour le Comilé français des Exposilions à l'étranger, comme devail l'être peu après le

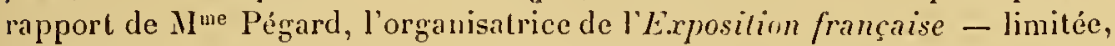
mais fort jolie, - de Saint-P'élersbourg, 1899 , cù se trouvaient réunies nos premières maisons dans les cinq groupes de l'L 1 meublemenl, des Arts du mélal, de la Céramique, de la Toilelle el des lrts graphiques.
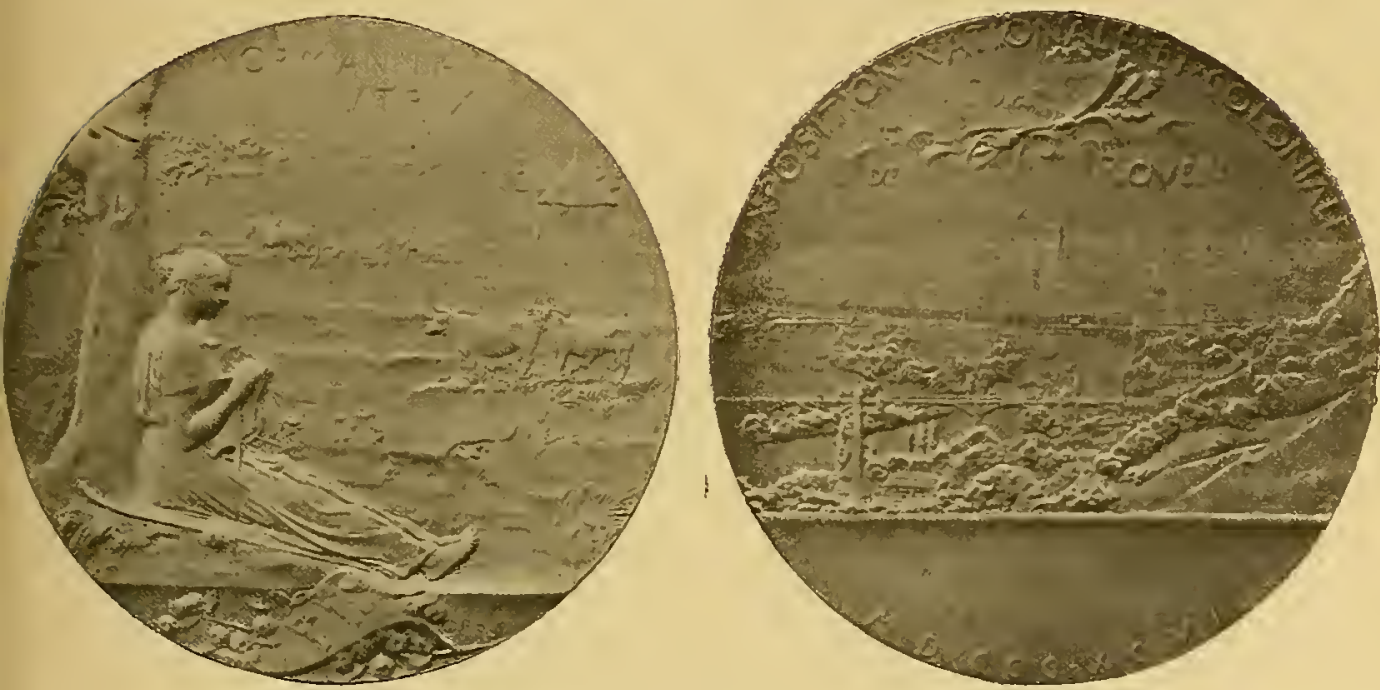

LXII et L.XIIl, - Exposition nationale el coloniale de Rouen, 1896. Médaille gravée par O. Roly.

Le monde entier se préparait alors à prendre part à l'Exposilion unicerselle el inlernationale de Paris, 1900 . Comme les précédentes, celle grande manifestation s'annonçail sous de sombres auspices : guerres sino-japonaise et hispano-américaine, malentendu franco-britannique, luttes intérieures politiques et sociales. Mais sous l'intelligente direction du Ministre du Commerce Nillerand et de ses chefs directs, le Commissaire général Alfred Picard, les Directeurs généraux Delaunay-Belleville, Stéphane Dervillé, Jules Bouvard, grâce au dévouement des Comités et des exposants, l'Lxposition de 1900 a montré la vitalité de cette "Grèce moderne ", la France, qui a su, après de si douloureux moments, reconquérir sa situation dans le monde, constituer un second empire colonial, marcher dans la voie du progrès el conserver la première place à la tête de la civilisation.

L'Exposition de 1900 a dote Paris d'une grande voie et embelli les Champs-Élysées de la magnifique perspective qui s'ourre sur le dôme des Invalides. Il en a subsisté le Pont Alexandre, ouvre des architectes CassienBernard et Cousin et des ingénieurs Résal et Alhy; le Grand el le Petit 
Palais, dus l'un aux architectes Deglane, Louvet el Thomas, et lautre a Girault.

La disparition de la plupart des monuments en carton-pâte, qui composent surtout les Expositions, ne doit pas cependant nous faire oublier la frande Porle de Binet sur la place de la Concorde, si bien comprise et si joliment polychromće; le superbe alignement des Palais des Nations, qui décoraient la rive gauche de la Seine et la rue de Paris, égayée par les fantaisies de Jean Veber, Albert Guillaume, Lncien Métivel, Bellery-Desfontaines, Lucien Gros, Jbels, Francis Jourdain; le Pavillon Bleu de Dulong; les Palais des Forets, Chasses et Péches, et le Cabarel de la Belle-_leunière, par Tronchet: les Serres el Passerelles de Ch.-A. Gautier; le Pavillon Roumain, de Fornigé el Lucien Magne; le Théitre de lin Lö̈e Fuller, par Ilenri Sauvage el Pierre Roche. Si la plupart de ces constructions étaient trop uniformément blanches, et manquaient de la jolie polychromie de 1889 , on a pu dire sans exaćration qu'elles avaient nécessité une véritable "orgie statuaire ". Rappelous parmi les meilleures curres de nos sculpteurs, les figures allégoriçues de Gustare Michel pour le pont . Mexandre; le "Travail ", haut-relief de Guillot, pour la porte de Binel; la jolic trise d'Allard pour le palais du Génie civil; le fronton de Théodore Rivière, les "Mineurs"; dans le palais des Forîts, " ha Chasse ", haut-relief de Jean Baftier.

La décoration des classes arait été mise sous l'heureuse direction de Louis Bonnier, qui sut admirablement stimuler l'imagination el linvention de chacun; et lon se souvient encore, entre autres, des installations gracieuses el très étudiées des architectes Sorel (papelerie), Bénonville el Félix Aubert (pharmacie el cuirs), Frantz Jourdain (par/umerie), Plumel (decoralion fixe, Arfvidson (bijonterie-joaillerie), Jacques Hermant (insIrumenls de musique). Quant aux Salons rélrospeclifs du costume et de la dentelle, ils étaient décorés par Grassel, de même que la lapisserie l'avait élé par Steinlen; un superbe panneau de Besnard garnissail le salon de la Parfumerie Piver: quant aux vilrines, elles étaient pour la plupart très modernes el exécutées en bois naturels.

Regrettons, cependant, que l'on n’ait pas fait appel, alors déjì, aux talents d'artistes comme Toulouse-Lautrec, Maurice Denis, Bonnart, ele.

De nombreux livres ont été écrits, sans compter les articles de presse el de revue, sur celte question primordiale de l'applicution des arts it l'industrie a l'Exposition de 1900; atcun de ceux qui sy intéressent n'ignore certainement le remarquable ourrage de Roger Marx : la Décoralion el les Industries diart a LExpsition miverselle de 1900: nous avions eu dejjà recours pour les pages précédentes à ce magistral travail, mais, comme rien de mieux na encore ćté fail, nous nous excusons par avance si, dans les lignes qui vant suire, nous lui faisous encore de nombreux emprunts. 
Dans la classification de 1900, les Arts appliqués el Industries d'art appartiennent aux groupes suivants :

Groups II : OEurres d'ART : Enseignement spécial, industriel et commercial (Cl. 6) ; Peinture, Cartons, Dessins (Cl. 7); Grarure et Lithographie (Cl. S); Sculpture el Gravure en médailles el sur pierres fines (Cl. 9); Architecture (Cl. 10).

Groupe III : Instrilaexts et p'rocídés géx Éraux des letrres, des sciences et DEs ants : Typographic, Impressions diverses (Cl. 11); Photographie (Cl. 12); Librairie, Edilions musicales, Reliure, Journaux, Affiches
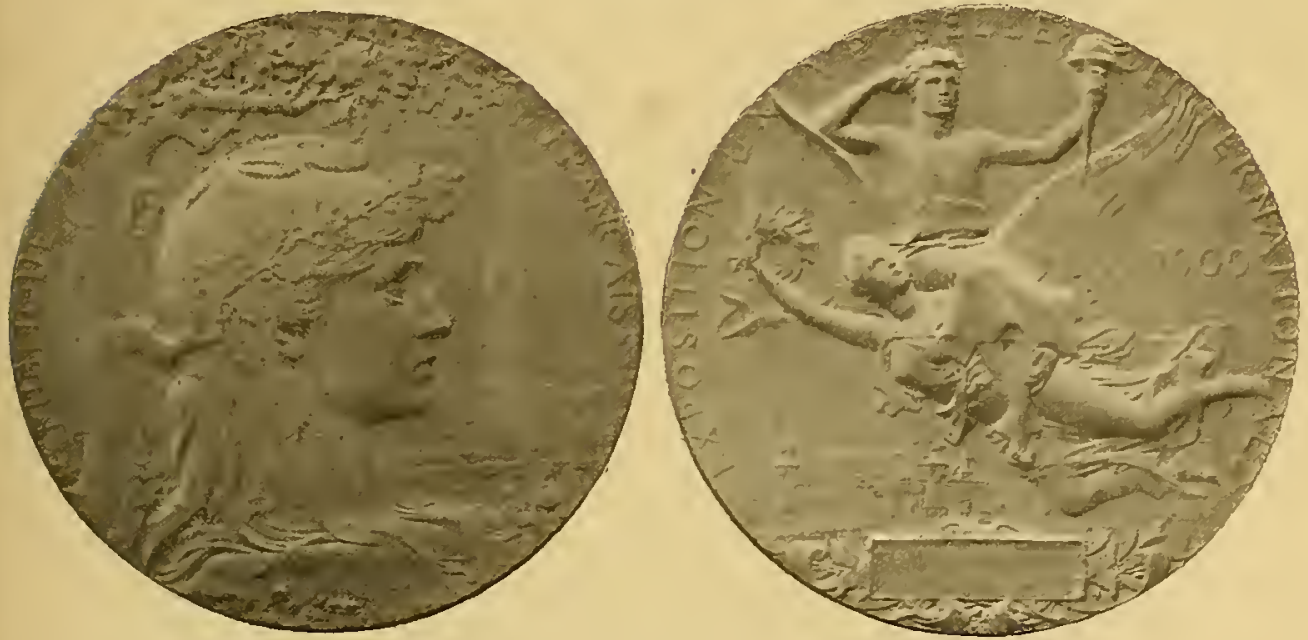

I.XIY et L.XY. - Exposition universelle el inlernationale de Paris, 1 gho. Médaille gravéc par J.-C. Chaplain.

(Cl. 13); Monnaies et Médailles (Cl. 15); Instruments de musique (Cl. 17); Matériel de l'Art théâtral (Cl. 18 ).

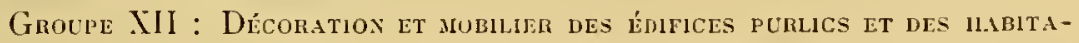
roxs: Décoration fixe des édifices publics el des habitations (Cl. 66); Vitraux (Cl. 67); Papiers peints (Cl. 68); Mleubles à bon marché et Meubles de luxe (Cl. 69); Tapis, Tapisseries el autres Tissus d'ameublement $(\mathrm{Cl} .70)$; Décoration mobile et Ouvrages du tapissier (Cl. 71); Céramique (Cl. 72); Cristaux, Terrerie (Cl. 73 ).

Groupe XIII : Flls, tissus, vêtemexts: Blanchiment, Teinture, Impression el Apprêt des matières textiles (Cl. 78); Fils et Tissus de coton (Cl. 8o); Lin, Chanvre (Cl. 81); Laines (Cl. 82); Soie (Cl. 83); Dentelles, Broderies et Passementerie (Cl. 84); Confeetion et Coulure (Cl. 85); Industries diverses du Vêtement (Cl. 86).

Groupe XV: INdrstries durerses: Papeterie (Cl. 92); Coutellerie (Cl. .9.3); 
Orfèverie (Cl. 94); Joaillerie, Bijouterie (Cl. 95); Horlogerie (Cl. 96); Bronze, Fontes et Ferronneric d'art, Métaux repoussés (Cl. 97); Brosserie, Maroquinerie, Tabletterie et Vanmerie (Cl. 98 ); Bimbeloterie (Cl. 10o).

La classification, très étudiéc, était duc ì Allred Picard qui s’ètait inspiré des principes de Le Play; mais l'affluence des exposants et le morcellement des emplacements empêchèrent qu'il y eût harmonie, comme en ${ }_{1867}$, entre la classification, l'installation et les nationalités : les produits exposés ne purent donc pas être groupés d'après le système rayonnant, par nature et par pay's d'origrine; en outre, chaque nation avait exigé
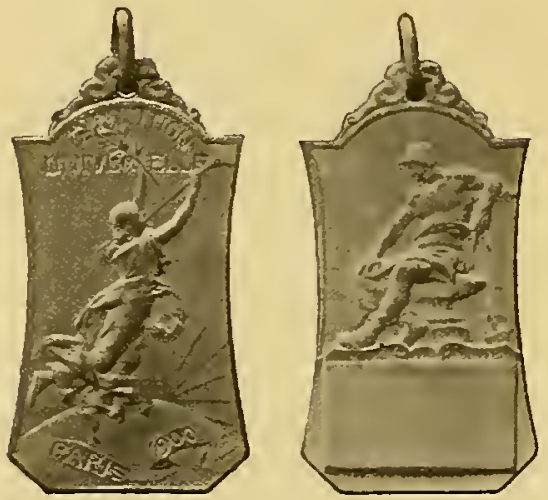

L.XVI et LXVII. - Exposition universelle et internationale de Paris. 1900.

Insigne commémoratif, gravé par Daniel Dupuis. d'avoir son palais particulier; de lì vint que les groupes disséminés et les nations séparées les unes des autres ne donnèrent plus l'impression d'un vaste ensemble; il $y$ eut exagération des forces, manque d'un véritable ensemble, et l'on eut trop sourent l'impression d'une multitude d'expositions particulières entre lesquelles la cohésion faisait défaut.

De l'Exposition de 1900 se dégage cependant cette impression générale que chaque industrie d’art fait alors un efforl ènorme pour se délivrer des formes conventionnelles el surannées; on veut s'arracher à lïmitation nostalgique du passé ; un désir se manifeste, d'innover et surtout de créer quelque chose de gai, de normal, de franchement vivant; comme le dit Roger Marx, "la convoitise de beauté est devenue un bcsoin social, chacun espère d'elle le souverain réconfort qui ćlève l'ùme, la distrait et la console ". C'est bien en somme la mise en pratique de la belle devise de l'historien Michelet: "Inventer ou périr ". Pour beaucoup, il n'y a plus antipathie entre l'objet et la matière; et de plus l'objet créé s'adapte souvent bien à l'usage auquel on le destine.

Le goût commence à reprendre sa place et un style nouveau d'art cherche à s"épanouir. On peul lui reprocher ses fautes, ses erreurs, ses défaillances. On peut trourẹ qu'il manque quelquefois de sobriété et de simplicilé el que par besoin de nouveauté il arrive à fatiguer l'cil ; les créateurs sont sujets a se tromper, mais micux raut encore une audace qu'on taxcra de révolutionnaire, que celle exubérance d'imitations auxquelles on nous avait trop longtemps habituès.

Pour mieux mettre en lunière l'effort tenté, les progrès accomplis, avec 
les noms de ceux qui furent les artistes de ces reures, nous ne saurions trouver de meilleurs guides que les rapporteurs des difrérentes classes.

Dans la Classe 11, lypographie el impressions diverses (A. Lahure, rapporteur). Peignol expose un nouveau type d'alphabel dî à Grasset, quelquefois trop oublié aujourd'hui par les disciples el élèves quil a formés; ce fut un novaleur bien intéressant avec son illustration étrange et puissante des Quatre Fils Aymon; son influence est alors "flagrante en toutes les classes de l'art décoratif " N'oublions pas son bel ouvrage, la Plante et ses applications ornementales, qui a donné à beaucoup de créations industrielles leur orientation nouvelle.

D'ailleurs, dans le domaine des Arts graphiques proprement dits, la fin du $x x^{\circ}$ siècle marque le point culminant des procédés photomécaniques. Cilons parmi ceux qui ont su en faire le meilleur usage artislique: le graveur Charles Gillol, qui a exćcuté les Quatre Fils: Aymon, de Grassel, les Dansenses, de Renouard, el encore Reymond, Ruckert, Victor Michel, Dujardin, Marolle.

Tout en uniformisant les productions, les procéclés mécaniques ont cependant poussé les garaveurs d'interprétation à assouplir leur facture; parmi ces derniers, les fières Florian savent traduire sur le bois une têle de Léonard de Vinci aussi bien qu'un croquis de Forain, el quelle pléiade d'arlistes originaux el d'illustrateurs qu’Auguste Lepère, Vallolton, Daniel Vierge, Renouard, Amiot, Pierre Roche, Victor Prouvé, Rochegrosse, L.-O. Merson, Raphaël Collin, Steiulen, Bellery-Desfonlaines, que Giraldon el

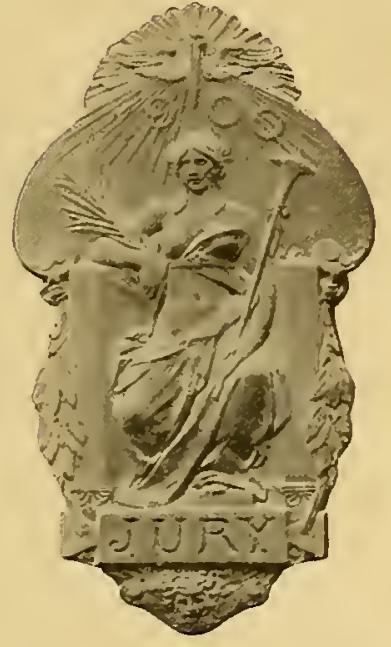

L.Xilll. - Exposition universelle et internationale de Paris, 1900.

Insigne du Jury, srave par Louis Botlice.

(Ce modr̉le. lëgèement réduit, servit d'insigne du Jurs": double, il en devial la plaquelle.)

Auriol, ces vignellistes charmants, que ces humoristes originaux qui s'appellent Chérel, Willelle, Léandre, Rivière, Morin, Maurice Neumont, Forain, Hermann Paul, Jean Veber, Ibels, Albert Truchel, Mélivel, Abel Faivre, Albert Guillaume, André Dewambez, Mesplès, Roubille, Sem, Poulbol, elc.

Dans la Classe 13, librairie (rapporteur Mainguel), les éditeurs continuent la tradilion des beaux livres; ce sont Manzi. Plon-Nourrit, FirminDidot, Larousse, Berger-Levrault, Name, le Vasseur el Layus, Lahure, Molteroz, Hérissey, Chaix, Ludovic Baschel, dont le fils René Baschet continuera l'curre à l'Illustration, Ferroud, Pelletan, Hachetle, Masson, Delagrave, Émile Lévy, Hetzel, Laurens, Gauthier-Villars, Conquet-Carteret. Doin, Champenois, Minot, Engelmann, Sirven, Floury, elc., et les éditeurs de musique IIeurrel, Enoch, Lemoine, Hartmann, Choudens. 
La reliure elje-même, ce vêtement du livre, doit ì ces praticiens : Gruel, Narius Michel, Engel, Carayon, Prouré, de beaux chefs-d'curre mosaïqués el colorés qui sont l'honneur d'une vitrine. La papelerie de luxe obtient un beau succès avec les maisons Stern, Weil, Dewambez. Quant aux affiches des Mnsées cenlemnaux, qui mirent leur éblouissant coloris el leur franche gaielé sur la tristesse de nos murailles, elles élaient dues à Jules Chèrel, à Carrière, à Grasset, à Léandre, à Willette, el avaient été éditées par Chaix el par de Malherbe.

Dans le Groupe Xil : décoralion el mobilier des édifices Arsène Alexandre, rapporteur de la classe 66), nous ne pourons oublier le bien curieux pavillon de Bing avec le salon et les affiches de de Feure, le panneau de José-Maria Sert el la salle à manger due à Eugène Gaillard; le joli pacillon du P'rintemps, orné par Marcel Ruty, el dont le plafond de Jules Chérel altirait tous les regards. N'oublions pas non plus le Pavillon de l'Linon centrale des Arts décoralifs, dont le grand panneau d'Abel liesnard, "l'Ile enchantée ", est actuellement au Musée des Arts décoralil's. Quant à sa décoration si bien entendue, elle avait élé dirigée par Georges Hoentschel.

Les papiers peints (CI. 68, rapporteur.J. Petiljean), dont la suprématie longtemps appartint à l'Angleterre, sont bien représentes en France depuis que les fabricants ont fait appel au concours de Ruepp, Couty et Bigaux; les papiers à couleurs tendres et larges frises a molifs allernés, l'emportent sur les tentures qui donnent l'apparence du cuir ancien ou de l'étolfe pelucheuse. L'artiste qui a le plus aidé ì ce succès, c'est Félix Aubert : papiers peints, tissus, tapis, broderies on dentelles, il a prodigué également partoul sa verve el son talent. Sa stylisation de la flore est élégante, simple et jolie. N'oublions pas enfin, parmi lant de labricants intéressants, les noms d'Isidore Leroy, de Félix et Charles Follot, de Jouanny, elc.

Dans la Classe du mobilier (Cl. 69, rapporteur Pol Neveux), le maître indiscuté est encore Emile Gallé. L'Exposition de 1889 nous a montré l'artiste lorrain remportant un fier succés, mais alors son cas était isolé el passa pour anormal, landis qu'en 1900 nous le retrourons entouré de disciples qui s'engagent résolument clans la voie qu'il a tracée, et nous n'aurons pas de meilleur guide ici que Gallè lui-même, qui écrivil dans le recueil de Victor Champier: les Industries d'art à l'Exposition de 1900, un arlicle sur le mobilier contemporain orné d'aprés la nature.

Le meuble d'art doit d'abord être construil logiquement, pratiquement d'après les exigences de la matière employée, le bois. Son décor doil a voir de l'expression, être sincère, joyeux puisque l'artisan qui le conçoil, l'interprète, ne copie pas, mais y traduit intelligemment sa pensée. Le meuble aura non pas un style, mais du caractère. "Le style n'est, comme l'a dit Gustave Geffroy, qu'une définition historique faite après coup lorsque les temps sont révolus, et lorsqu'il est possible d'envisager les résultats d'un long travail humain. "On a confondu hâtivement les meubles prélendus 
nouveaux, mais géométriques et conçus dans le silence du cabinet, et les meubles virants, francs, libres et artistiques; on a mis de pair le décor bizarre, mal pastiché, grossièrement démarqué el le décor sain, logrique, juste, d'un Gallé ou d'un Najorelle; el roici les principes, - non les excès - que conseille le maître lorrain : $1^{\circ}$ un meuble doil être fait pour servir, une chaise n'est point créée pour s'exhiber, mais pour procurer repos et assietle à une humanité qui a reins, jambes el dos; $2^{\circ}$ il faut que la construction réponde á la destination de l'ceure, au matériel d'exécution, et quelle soit aussi simple, aussi logique que possible; $3^{\circ}$ que cetle construction saine ne soil masquée par rien et qu'elle reste bien évidente; $i^{\circ}$ le
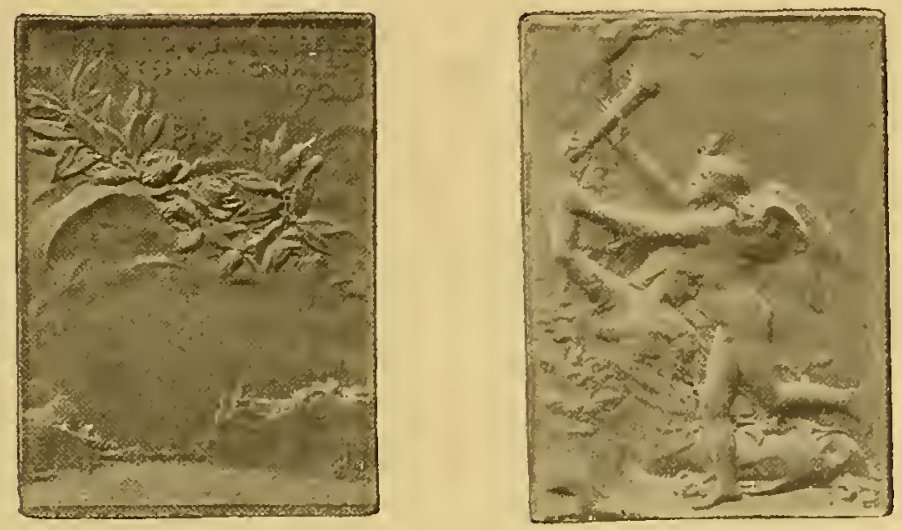

L.XIX et LXX. - Exposition universelle el internationale de Paris, agn. Plaquette commimorative, gravée par O. Roly.

décor de l'ourre peut s'inspirer des formes de la flore el quelquefois de la faune. Et ne dites pas que la nature olfre des assemblages sans variéte: tout se renouvelle sans cesse par la force des choses; il ne suffit que d'observer, de raisomer, d'adapter.

Et voici la conclusion que donne Gallé : "C'est la traduction pas à pas des artifices décoratifs de la nature elle-même... Notre style, c’est la mise eu beauté des organes utiles de nos muets servileurs, les menbles, les rases, les tentures, de la même laçon que nous voyons la charpente osseuse el les muscles de l'animal revêtu de chair... Le meuble traité comme un corps nu, orné du bon équilibre de sa structure, de ses organes épanonis comme ceux de l'animal ou du végétal, en leurs nerfs, en leur's chairs, pelages, plumarges, tissus, membranes, écorces, en leur bourgeomement, floraison, fructitication, voilà le labeur de statuaire, l'ourre d’intcllectualité, de vérité, de liberté, que nous préconisons... "

Gallé ajoute encore ì ses meubles, des ferrures el bronzes déduits de la plante : la frissonnante libellule, immobilisée un instant, a prêté ses ailes à 
la statique des consoles, l'entr'onvert de son corselet d'acier à des entrées de serrure en fer ciselé, incrusté, violacé ct bleui i la flamme: "Ln perceneigge devient un gland de tirois, unc pensée sert à végétaliser une clef de vitrine."

Que de modèles il faudrait citer, dus à Eugène Gaillard, de Feurc, Colonna! Cne bibliothèque de la maison Dumas emprunte encore à des applications d'ombellifères ses colonnes el rampes d'esealier, ses lambris, portes vitrécs el bureaux; un mobilier par Épeaux s"inspire des branelıes du pommier en theur; un buffet d'Alexandre Charpentier se couronne aux lambris de pampres de houblon el s'égaie sur ses volets de sarments de vigne et de gerlues d'épis.

I.es meubles de Majorelle, partieulièrement bien compris, altestent une originalité vraiment moderne el un heureux emploi de la sculpture sur bois; il n'est pas jusqua aux pianos, dessinés par liuper Carabin pour Herz, qui ne subissent l'influence nouvelle, bien quil y ail exagération dans la marqueterie et réel abus de sculpture. Enfin, si de grandes maisons, comme Jiégrer el Damon, Jemont, Schmit, Jansen, Mercier, Pérol, restent altachées aux anciens styles, elles n'en ont pas moins donné une preuve d'intérêt ẹ un gage de sympathie à celte transformalion de l'art, en créant, elles aussi, quelques meubles nouveaux.

Les lapis el lapisseries (Cl. zo, rapporteur F. Leborgne) délaissent la facile imitation de Smyrne; Jorrand se plaît à décorer la plus humble moquelte. Grâce à la compétence de son éminent administrateur Jules Guiffrey, la Manufacture des Gobelins n'hésite pas à denander des cartons à Gustave Moreau, Jean-Paul Laurens, René Binet, Félix Aubert et Jules Chéret. El cependant, il n'est pas de métier dans lequel la technique offre de plus grandes diffieultés. La tapisserie, rajeunie el rénovée par ces artistes, n'est donc pas une industrie morte, on peut la faire virre, et la preuve en est dans ces essais, mais à la condition de bien choisir des modèles conformes aux lois de son art.

La rénovation des Arts de la terre date d'avant 1889 , el nos pièces flammées que décorent le feu ou l'émail rivalisèrent avec celles d'ExtrêmeOrient. Chaplet, Delaherche, Carriès obtinrent des effets inallendus; la mode s'en mêla el des copistes reproduisirent à saliété leurs modèles ou šinspirèrent hâtivement de leurs procédés. Mais ils imitèrent plutòl qưils ne créèrent, sans compter que le feu a des caprices el que l'art en partagge le mérite arec la science. On se soucia souvent plus des couleurs que des formes, plus d'une jaspurc ou d'une eristallisation que de l'ordonnance de la composilion.

La céramique (Cl. 72 , rapporteur G. Vogl) n’a pas élé assez utilisée pour la décoration extérieure el l'embellissement de nos maisons, comme Formigé l'avait tenté en associant les terres cuites et les faïences émaillées sur certaines façades de l'Exposition de 1878 . On remarque cependant de 
curieux revêtements dus à l'babileté des techniciens Lœbnitz, Muller, Utzschneider. Alexandre Bigot se spécialise dans la céramique et parvient à égayer la monotonie de quelques maisons de pierre par des pilastres, colonnes, frises, balustres, cheminées ou briques émaillées.

Les grés flammés sont toujours aussi amusants de couleurs imprérues : Delaherche reste maitre en cel art avec Michel Cazin. Noublions pas Taxile Doat, qui associe le grès à la porcelaine el au hiscuil, el obtient ainsi de jolis contrastes de luisant et de mat. Albert Dammouse excelle à composer ces décors et à créer ces vases en pâte d'émail d'un charme prestiogicux. La fä̈ence enfin, longtemps dédaignée, est remise en honneur par Élienne Moreau-Nélaton, qui illustre ses vases d'une forme variée de feuillages champêtres, de branches et de lleurs.

Les pátes de verre sont restituées par lJenri Cros, Albert Lammouse et Ringel d'lllzach.

Les émanx, disséminés dans les Classes de la céramique (72) el des cristaax $(73)$, sont hautement appreciés; très beaux sont ceux d'Alfred Meyer, Grandhomme, Garnier, JJirtz el Georges Jean.

Thesmar est le restaurateur de l'émail translucide; mais c'est l'Américain Jouis Tillany qui remporte le plus franc succès; ses irisations opalines ou mates, ses colorations fuyantes simulent le frisson ocellé d'un plumage de paon, les nuages en fuile ou le rellet des caux argrentées. Il emploie les mêmes procédés pour le vilrail (Cl. 67, rapporteur L. Daumont-Tournel), et obtient une opulence de coloris que rehaussent encore les plissements et les froissements de la pâte. Le dessin s'exprime et sc figure par les sertissures du flomb ou les accidents du verre. Aussi bien, la lirance a toujours des peintres verriers qui defendent leur vicille réputation: Grasset collabore arec Gaudin, Besnard avec Carot, H.-J. Magne arec Leprérost, et nous pouvons regretter, comme Roger Marx, que Tillany, qui a rénoré l'art du vitrail, n'ait pas montré en 1900 les belles verrières du Salon de 1895 , qui avaient été exécutées d'après les cartons de Besnard, Toulouse-Lautrec, Maurice Denis, Roussel, Ibels, Vallollon, Serusier.

Dans la verrerie industrielle, Ernest Jeveillé s'altache à varier, par la trouvaille d'une forme neuve, l'aspert suranné des services de table el même des simples flacons.

Nais le plus extraordinaire artiste de cetle Classe des crislanx el verreries (Cl. 73, rapporteur Eugène IJoudart), c’est toujours Emile Gallé : émailleur, il a créé des camées el des intailles el produit des émax nacrés sur porcelaine de verre; il se renouvelle encore el cherche de nouveaux procédés de décors : en soumettant la pâte malléable au conlact des poussières sèches ou graisseuses, il a obtenu ces elfets de brouillard, ees teintes superficielles, neigeuses, opacifées, écumeuses, ou bien il incruste sur l'épiderme de ses vases des fragments ensuite repris el gravés, « véritable marqueterie où le robuste relief s'enclôt, se réchauffe el s'anime sous les 
nuances qui le jecouvent, assoupies et délicates. Le vase devient un vrai josan, par lequel un paysage translucide, une lleur symbolique traduisent un vers de poète ou une pensée ".

Faisons enfu une place à part à la . Manufacture de Sévres : avec son aldministrateur Emile Baumgart, et Alexandre Sandier, son directeur des travax, elle s'est déciclée à se libérer du passé : elle a fait appel à tous les artistes, même en dehors de son établissement. Ja fabrication s'est perfecLionnée, on y connaît maintenant la pâte tendre, et on y fabrique le grès pour l'architecture; on y sait l'art de "reprodure dans l'émail des cubes, des aiguilles, les arborescences fines et soyeuses du gire... n. Les biscuits otrent des figurines, des statuettes, des surtouts modelés par lirémiel, Iules Chéret, Lénard, Riviere, Desbois, Paul Roussel. Mais toute ceurre ne s'accommode pas de ces transpositions et telle statue est belle en marbre, qui n'est qu'enfantine en biscuit. Des rases, dont le profil et le décor dérivent de la flore, sont d'une coloralion et d'une vie nouvelles: une poliche de Bieuville anx ramures enchevêtrées: une urne de Fournier ou grimpe un leuillage de vigne vierge; un vase de Simas, formé de pétales juxtaposés en éventail, caractérisent cette rénovation. La Maunfacture de Coplenhague n'a pas été saus inlluence sur notre ellort ; elle aussi se renouvelle el fixe en décor sur ses porcelaines, dans des nuances gris-bleuâtres et mourantes, le charme des forêts danoises ou de sa mer lleurie de récils.

Les tissus imprimés de coton, lin et laine (Cl. 80-82; rapporteurs II. Déchelette, E. Faucher, Ch. Marrau) el ceux de soie (Cl. 83, rapporteur : J. M. Piotet) deviennent eux aussi plus modernes, et les fabriques de Duplan, à Jyon, el de Besselièrre, à Rouen, en offrent une abondanle variété. Fèlix Jubert présente une "stylisation de la plante, à la fois claire, sans sécheresse et élégante, sans redondance "; il a de jolis modèles puur cretonne, chez Scheurer el Jauth. Nos étoffes d'ameublement tissées ont it leur service des artistes qui renouvellent les modèles. Mais leurs dessiuateurs spéciaux sont trop fidèles au passé et prisonniers de la routine : aussi Crassel (pour Leclereq), Karbowsky (pour Ieborgne), Couly el Terneuil (pour Saurel), Sandier, M110 Rault, M ${ }^{\text {the }}$ Duprat (pour Cornille), Dufrêne et Paul Follot (pour Chatel el Tassinari), de Feure, Colomna, Gillet, enfin, sont parmi ceux auxquels on demande des idées neures, et voici des rideaux genre velours de Gènes sur fond de satin, dont les titres seuls suffisent it montrer la noureauté : " les Angéliques, les Tulipes, les Narcisses ", I] n'est pas jusqu'aux rubans et aux ta//etas, qui n'aient recours it la ngénćrosite des artistes. Ja ville de Sant-Étienne y demeure sans rivale arec les Maisons Béraud, Troyet, Brossy-Balouzet el Marcoux-Châteauneuf.

La broderie Cl. 8.; irapporteurs II. Hénon, G. Martin et G. Sébastien), abîmée el perrertie par l'abus du procédé mécanique, commence à virre de sa vie propre en redevenant simple, en retrouvant sa naïveté par le travail manuel; la machine a lavantage de produre beacoup el plus vite, mais 
elle se répète; seuls les doigts, habiles el délicats, peuvent exécuter ces berthes en point de France de la Maison Lefébure, ces dentelles de soie mèlée d'or, dessinćes par Félix Aubert, parce que chaque détail se précise, chaque point se auance. N'oublions pas de mentionner les broderies, rilleaux, tulles des Maisons Warée, David et Adhémar, Ancelot, Bellan.

Les splendides dioramas de la conlure (Cl. 85; rapporteur Léon Storch) maintiemnent sa vieille réputation d'élégance et de bon gaùt. Si l'honneur en revient í L. Perdoux, président de la Chambre syndicale, le succès est dû aussi aux maisons qui ont rivalisé de talent artistique : Bonnaire, Boué sexurs, Callot scurs, G. Douillet, Félix, Margaine-Lacroix, Ney sceurs, Paquin, Raudnitz, Aine Montaillé, Laferrière, Lebouvier, Redfern, Roulr, Worth...

Dans l'orféverie (Cl. 9'; rapport d'Armand-Calliat, terminé par llenri Bouilhel), le style nouveau a une place dhonneur chez Cardeithac et chez Debain; l'argenterie s'y inspire franchement de la nature et se revêt d'une curieuse originalité : le pavot ou le mimosa, le trèlle ou le chárdon, l'anémone ou l'ancolie sont les originaux d'où l'artiste déugage ses modèles. Chez Boin-Taburel, Falize, Boucheron, André Aucoe, Froment-Meurice, on remarque de belles pièees d'orlèrrerie de conception nouvelle quoique très classique.

Les frères lieller nous olfrent une belle orfèvrerie unie. Quant a la Maison Christolle, dirigée par Paul Christolle, Henri Bouilhet, F. de Ribes-Christolle et André Bouilhel, elle conserve ses suceès passés, s'inspirant particulièrement de la flore: un surtout de Rozet s'intitule "Air et Lau "; un autre de Larroux ollre une scène de "Vendanges"; un encore de Mallet reproduit simplement des belteraves. A côté, ce sont les plats de Jaindy, les couverts de Roly, les médailles de Vernon.

Jans la même Classe, nous rencontrons l'art religieux, qui continue à ctre dignement représenté par Poussielgue-Rusand et par les Lyonnais Armand-Calliat, père el fils : s'ils ont reeours á l'archéologie, c'est moins pour s'en inspirer que pour s'y instruire; ils rajeunissent et modernisent ce genre qui semble voué à d’éternelles répétitions du passé. PoussielgueRusand utilise les eréations des artistes Corroyer, Sauvageol, Génuys, Camille Lefèvre, Lelièrre l'rères. Les Armand-Calliat, de leur cùté, nous montrent un magnifique surtout de table, "la Curiosite ", lait spécialement pour le député Aynard; un calice modelé d'après un lis; une crosse en bois sculpté d'immortelles en aryent patiné; la erosse de Ngr de Tarbes, fleurie de roses symboliques, el des bureltes sacrées; des émaux couleur d'ivoire et de lurquoise; cilons enfin la superbe chasuble exposée par Biais et Noirot.

Dans la bijouterie-joaillerie (Cl. $9^{5}$; rapporteur Paul Soufllol), la France s"affirme au premier rang. "Dès qu'un art, a-t-on dit souvent, se consacre "I la femme, le Français est assuré d'y exceller ", mais jusqu'alors la fan- 
taisie de lartiste élail trop souvent exclue de la mise en valeur de la gemme; le prix de la pierre l'emportail sur lintérêt de la monture; on rapprochait les pierres les plus disparates, quitte à violer l'harmonie et à blesser la vue pourvu que l'objet coûtât cher. Dans son rapport spécial de 1889 , Massin avait démontré qu'il ètait urgent de transformer l'art de la joaillerie. C'est au maître René Lalique que devait revenir l'honneur de cette rénovation artistique. Ce fut sa gloire d'intervertir les rôles el d'obliger l'esprit à reprendre le pas sur la matière en utilisant les techniques des dilférents métiers. Sa connaissance du passé, sa culture, son savoir lechnique el professionnel sont venus s'ajouter à sa supériorité naturelle, et c’est ainsi qu'il est devenu le créateur poétique, coloriste el modeleur.

Fantaisiste, René Lalique a remis en honneur, en les modernisant, chimères, dragons et monstres marins, et tous ces profils de femmes légendaires dont le corps est insecte, poisson ou lleur : car, c'est un poète qui sail inearner dans ses curres lapparenee el la forme de ses lêves. Amoureux fervent de la nature, il a tiré de la laune et de la flore des paysages et des motil's qui deviennent d'eux-mêmes des joyaux : un coq debout dans un tourbillon de plumes, des hirondelles en plein vol, un corps nu de femme. 'Tour à tour peintre, médailleur, graveur, statuaire, il sait enchâsser les pierres précieuses ou banales, les perles, les émaux translucides ou peints, approprier les teintes au métal. Tout ce qu'il touche se métamorphose entre ses mains : les objets les plus usuels sont vivants, gais, agréables. Epingles ou boucles, bagues, broches, pendants, colliers, diadèmes, peignes lui appartiennent, et, comme si ces veurres ne suffisaicnt pas à distraire ses jours el à occuper son imagrination, il a, maitre orfève, eiselé dans l'argent des coupes, des surtouls, des cendriers oủ les chauves-souris volettent el où les poissons lumineux glissent sous un flot d'émail.

Comme Massin le fit pour la joaillerie en $\mathbf{1 8 6 7}$, Lalique a rénové complètement la bijoulerie a la fin du dis-neuvième siècle. Aussi, nombreux sont ses disciples, quoique beaucoup sachent garder leur originalité propre. Les parures cisclées par Georges Fouquet, daprès les dessins de Mucha, encore que trouvées un peu barbares, par leurs casques, chaînes el anneaux, témoignent d'un louable elfort de nouveauté; quant aux bijoux de Paul et Henri Vever, dont beaucoup dessinés par Grasset, ils sont d'un goût très moderne et méritent bien leur faveur : brillants qui se nuancent sur l'émail mat ou dépoli, diadème en plumes de paon ou pendentif à aneolie. Dans la joaillerie purc. l'ensemble le plus complet de modiles nouveaux inspirés de la flore se trouve chez les Vever : toujours la monture est li pour exalter la couleur el la forme dune gemme, et les pierres rares ue s'opposent ou ne s'associent que pour plaire au regard. Les objets prèsentés par Boucheron sont d'un goût très sûr el d'une fabrication merveilleuse. Coulon, les frères Falize, Chaumet, G,-Roger Sandoz obtiennent un 
franc succés, ainsi que Louis Aucoc, l'aul Templier, les frères Marret. Lucien Gaillard excelle dans le bibelot d'argent, dont il a rénové les patines. Citons parmi les principaux collaborateurs et créateurs de modèles de ces classes : Grasset, Vernon, Louis Boltée, Lucien llubert, Charles Marie, Menu, Lobin, Desbazeille, Nocq, Leture, Duval, Jacta, Bled, Ilirtz, Becker, Colonna, Dufrêne, Marcel Bing", Paul Follot, Liénard, Bourgeot, ete.

La ferronnerie (Cl. 97 ; rapprorteur 1I. Vian) suit le mouvement de rénovalion générale: les travaux de Bardin et Berogeotle, les balcons d'Emile Robert, la grille ornée de pavots "assouplie" par le Rouennais F. Marou, et surtout les lustres électriques de Jean Dampt pour la Maison Beau, retiennent l'attention. Fontaine utilise le talent d'Alexandre Charpentier pour créer dans un goùt nouveau et très moderne : serrures, plaques de propreté; boutons de portes el verrous. Le bronze d'éciairage forme dans celle classe une industrie nouvelle : plafonniers, lampes et appliques deviennent des ceuvres d'art auxquelles se consacrent les fabricants Gagneau, Soleau, Raingo, Guinier. Rien n'est plus gracieux que ces tiges ondulées et flexibles, à l'extrémité desquelles éclót, fleur lumineuse de cristal, une violetle ou une orchidèe.

Quant al l'étain, " ce Clair de lune de l'argent ", comme l'appelait liodenbach, remis en honneur depuis $\mathbf{1 8 8 9}$ par Brateau, il soutient sa nouvelle renommée avec Pierre Roche el Laporte Blairsy.

Les rapports des dilférentes classes que nous venons de voir si rapidement nous out montré un réel ellort pour se libérer du passé, un besoin d'innover. Mais on avait encore l'impression plus nette de ce progrès et de celte évolution quand l'ou s'arrêtait dans les .lusées rélrospectifs et centen. naux, qui formaient comme la préface de chaque profession et préparaient le visiteur à mieux comprendre l'industrie actuelle. Ces expositions spéciales étaient sous la direction de François Carnot; jointes à l'Exposition contemporaine, elles devaient surtout montrer les progris accomplis de 1789 à 1889 , dans chaque branche de production. L’idée n’était pas nouvelle, mais jamais elle ne ful réalisée sur un plan aussi vaste.

Sous le titre de mobilier et décoration (rapporteur Le Corbeiller), le Musée centennal des Classes 66 (décoralion fixe), 69 (meubles), 7o (tapis), I (décoralion mobile), 97 (bronzes) présentait à lui seul un résumé des industries d'art, une synthèse rapide de l'art décoratif pendant le dix-neuvième siècle. On y retrouvait, se suivant par époques - par styles peut-être, - des intérieurs Louis XV1, Directoire, Empire, Restauration, Louis-Philippe, second Empire. Reconstitutions amusantes et d'un charme singulier qui permettaient de mieux juger le passé, de comprendre la valeur d'un décor, ou la beauté ressuscitece d'une pendule, d'un tapis, d'une table ou d'un bibelot. Les chambres étaient neublées, parées pour une réception, vivantes en leur silence et leur demi-jour discret, et il semblait parfois que tout allait s'animer, qu'il ne manquait que les hôtes disparus dans ces 
demeures éphémères du souvenir. Portraits aux murs, livre ouvert sur un guéridon, lunettes sur un coin de cheminée ajoutaient ì l'illusion. Les objels familiers mis í leur place donnaient à l'ensemble des détails intimes et charmants; on regardait, on était étonné, séduit; on reconnaissait presque les choses... et l'ombre des gens qui araient été leurs lointains compagnons. Très complet, le beau rapport de Le Corbeiller consacre aux artistes du Mobilier du dix-neuvième siècle des notes d'une érudition tı̀ès sûre et altachante.

Le Muséc rétrospectif du costume el de ses accessoires: ombrelles, nauts, lorgnetles, èventails, chapeaux (Cl. 85 et 86 ), élail encore une reconstitution curieuse. Ces ajustements fanfreluchés, passementés, enrubannès aux couleurs claires, aux fleurs multicolores; ces costumes de théâtre au velours brodé d'or, portés par Napoléon ou Talleyrand; ees éventails à imagerie avec leurs petites branches divoire ou de bois sculptés sont le côté joli et féminin des industries d'art; le rapport qu'ont rẻdigné G. et Il. Cain, J. Claretie, L. Duchet, Fr. Flameno, H. Javedan, M. Leloir, et J. Robiquet, est une étude remarqualıle d’érudition pitloresque el de litléralure élérante.

J.es autres Classes tiennent plutôt de la collection. Ici (CI. 68), ce sont les papier's peints avec leur histoire reconstituée par Félix Follot, ì l'aide de panneaux, d'échantillons, d'arrêts du Conseil d'État, de médailles, ete. Sarriau nous raconte l'histoire de la céramique $(\mathrm{Cl} .72)$ et nous lait assister i la lente évolution de la porcelatine tendre on dure el de la fä̈ence fine, opaque ou stannifere; chaque manufacture y ressuscite avec quelque modèle ancien de rase, de lasse ou de bibelot; on $y$ suit les délaillanees artistiques de la Restauration el du règue de louis-Philippe, el on $y$ retrouve déji tous les grands noms de la céramique moderne: Chaplet, Dammouse, Delaherehe, Carriés.

La Classe 84 (mpporteur Li. l.efébure), avec les dentelles, les broderies, les soies, les lissus de soie, les fils, les lissus de laine, groupe des collections doeumentaires intéressantes : beaux chillons un peu finés aux teintes décolorées et jolies, qui sont, ayant subi le caprice des femmes el la fantaisie de la mode, de vieilles choses dans l'oubli et le passé.

Ia Classe 65, applications usuelles du mélal el produils de la petile mélallurgie, réunissait les collections les plus curieuses : serrures, clefs, verrous et targettes, marteaux de porte, enseignes, ustensiles servant au leu, plaques de cheminée, objets de cuivre, de bronze ou d'étain, sonnelles, clochettes, etc., et le rapport dû a P. Larivière, H. D'Allemagne, 1. Magne, et J. Doumergue, gardera longtemps son intérêt.

Pourquoi ne pouvons-nous que mentionner l'amusant rapport de Henry D'Allemagne sur les jouels d'autrefois (Cl. 100) que deux volumes sur les jenx complètent si heureusement? celui de Mathieu Planchon, sur l'horlogerie (Cl. g6); le rapport sur les monnaies et médailles (Cl. 15), de II. Sarriau; les trois beaux volumes de IJenri Boulhel sur l'or/éverie fran- 
çaise (CI. 94); la librairie, par Lucien Layus; bijoutiers-joailliers el exposilions, 1789-1870 (Cl. 95), par G.-lioger Sandoz.

Richement illustrée el très soigneusement imprimée par les frìres Belin, la collection des Rapports rélrospectifs el centenuaux de l'Exposition de Igoo constilue une série de précieuses monographies, qui a malheureusement été lirée à un trop pelit nombre d'exemplaires el que s'arrachent aujourd'hui les bibliothèques du monde entier.

C'est ainsi que l'Lxposilion de 1900 a donné la synthèse complète de l'activité humaine pendant le dix-neuvième sièele.

Elle en a vraiment marqué l'achèvement et l'apogée, mais il nous faut loyalement le reconnaitre : l'immensité même de cette foire du monde était presque paradoxale pour un peuple qui ne doil pas confondre quanlilé et qualilé.

Celle date marque donc un arrêt dans l'évolution des grandes Exposilions françaises, et la difticulté même de leur trouver un emplacement lore désormais les générations actuelles el futures à les limiter ou a les spécialiser. 


\section{VII}

\section{L aurore du $\mathrm{XX}^{*}$ sic̀cle}

$1901 \cdot 1912$

liagression des Arts appliqués à l'hudustrie apris l'Exposition de 19 o cl retour anx styles classiques. - La node et le suobisme. - La Socielie des Artistes dícorateurs et ses Salons annuels. - L'Union Centrale installe définitivement le Aluscie des Arts décoratit's au l’avillon de Marsan. - Le Comilé français des Expositions à l'étranorer et la Société d'encoura teurs aux Fxpositions de Saint-Louis, Igof; Liege, 1905 ; Milan, 1906 ; Londres, 1908. -L'Exposition l'rançaise d'Art décoratil'de Copenhague, igog, réunit pour la prenicre fois dans ane action commune artistes el industriels. - Expositions de Bruxelles, 1910 , et Turin, 1911. - Progriés des Aits décoratit's à l'étranger. - Le Salon d'Automne invite les Artistes dicorateurs munichois á son Exposition anumelle de 1910 . - L'Union provinciale des . Arts décoratil's. - Rólorme de l'Euscignement du Des-

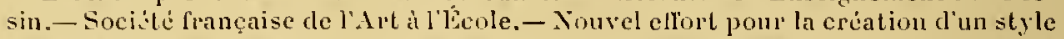
liançais contemporain. - la Secialisation de l'Art. - Núcessité de coordonner les ellorts de l'artiste, de l'industriel, de l'artisan, de l'ouvrier d'art. - Projet d'une Exposition internationale des Arts dicoratifs modernes i Paris. - Pour réussir il faut unir les Associations intéressées, les Syrndieats et tontes les bonues volontés en une vaste Fédération frinęaise des Arts appliquís à l'ludustrie, qui deva rouloir el agir, d'aceord arec l'títal.

Quel quail élé le réel désir d'un style vraiment adaplé aux besoins et aux aspiralions de la vie moderne, quelque succès quaient oblenu les grands promoleurs que furent les Gallé, les Lalique, l'Exposition de 1900 devait être suivie en France d'une véritable régression dans les Arts appliqués à l'Industric.

C'est que l'évolution du goùt public n'était malheureusement pas encore accomplie, quand les industriels choisirent leurs modèles pour l'Exposition de 1900 : beaucoup s'étaient adressés à des jeunes gens n'ayant qu'une éducalion artistique incomplete el manquant de tradition; ces derniers ne cherchèrent qưun gain immédial el dédaignèrent bien souvent le but el l'exéculion de l'objel qu'ils étaient chargés de créer, abusant de celle ornemenLation graphique si lacile, imporlée d'Allemagne el de Belgique. Combien de ces modèles, mal conçus, mal adaptés à la malière employéc, furent rapidement délaissés, r'autant plus que la plupart des exposants s’élaient trop limilés a l'exécution de bijoux, de bibelots, d'objets d'art uniques, de 
meubles, sans s'astreindre à composer les ensembles el les décors nouveaux nécessaires à des objels neuls.

En outre, aucun grand maîle is arls ne simpose, el, il part quelques exceptions, l'entente manqua entre arehitectes el décoratcurs comme entre décorateurs el industriels.

Les exagérations macaroniques, les excès même du molern slyle deraient porter un coup terrible au style moderne de la fin du dix-neuvieme siècle. Collectionneurs et marchands d'antiquités surent aussi prendre vivement leur revanche el ridiculiser les cuvres nouvelles; le snobisme s'en mếla, sans compter l'influence de la mode, si prépondérante en france. Elle y est plus
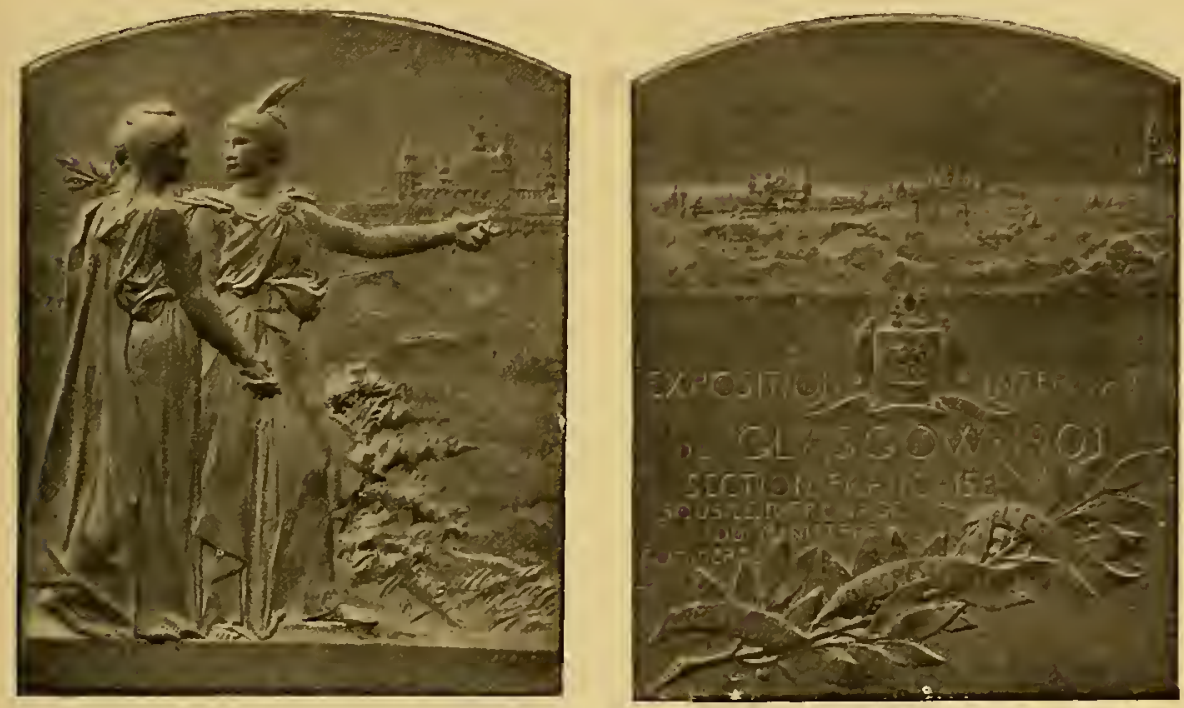

LXXI el IxXIl. - Exposition internationale de Glasgow, 1901. Plaquette de la Section trançaise, nravée par F’. de Vernon.

vive que nulle part ailleurs, puisque. pour beaucoup d'indestries de luxe, notre pays fournit les modèles que l'étranger achète el répand.

Mais cet arrêt dans la marehe de l'Art décoratif moderne, si malheureux fût-il, allail opérer une jusle sélection parmi les críateurs de modèles, rapprocher les vrais artistes rénovaleurs, el les faire soulenir par une élite.

A l'appel d'un jeune avoeal de valeur, René Guilleré, la Société des Artistes décomateurs se fonde en mars 1901 : elle a pour but:

$1^{\circ}$ L'organisation en France el it l'Etranger d'expositions de tendances neures;

$2^{\circ}$ Le relèvement des Arls appliqués;

$3^{\circ}$ La narticipation aclive ì toules les manifestalions el ì loutes les me- 
sures, publiques ou privées, intéressant, à quelque titre que ce soil, tout ce que l'on désigne habituellement sous les noms d'Art décoratif, d'Art industriel et d'Art appliqué;

$4^{\circ}$ L'étude de toutes les questions d’enseignement, de législation, de propriété artistique, de délense des intérêts collectifs ou privés.

Ses principaux membres sont, au début : liastard, Becker, Besnard, Bonvallet, Dammouse, Decœur, Dufrêne, Paul Follot, Eugrène Gaillard, Gèsuys, Grandhomme, Grasset, Guimard, Lambert, Marius-Michel, Mezzara, Sandier, Selmersheim, Tourette, Vernon,... etc.

Sous les présidences suecessives de Guillaume Dubufe, Edme Couty, Emile Vernier, puis de René Guilleré, nous la verrons figurer dans toutes les manifestations où sa présence est utile, participer aux Exposilions de la reliure, de l'ivoire, de la dentelle, du fer, du cuivre et de l'élain, de la soie, de la porcelaine, de la parure de la femme, du grés et de la faïence en ce Musée Galliera, que dirige si bien Eugène Delard, après Formentin, el enfin avoir claque année son Salon annnel au Musée des Arts décoralifs.

Car le Nusée des Arts décoratil's est enfin ouvert: en elfet, grâce il la ténacité des chels de l'Union centrale, Georges Berger, IIenri Bouilhet, Jules Maciel, si bien secondés par Raymond Kícehlin, Lefébure, Félix Follot, Sainsère, Georges Boin, Peytel, Léon Appert, Maurice Fenaille, Arthur Martin, Henri Vever, André Bouilhet, Metman, Mercier, Deshairs, etc., celle grande Association, ballottée de laneien Palais de l'Industrie à la place des Vosges, puis à la Chaneellerie d'Orléans, a puenfin installer définitivement au Pavilion de Marsan ses collections et sa bibliolhéque.

C'est le 27 mai 1905 qu'eut lieu l'inauguration du Mnsée des lrts décoratifs; il y avait un demi-siècle que le comte de Laborde en avait demandé la création; près de vingrt-cinq ans qu'Antonin Proust avait obtenu du Parlement une première convention; vingt ans qu'Lưrène Guillaume s'ćcriait au $\mathrm{Il}^{\mathrm{e}}$ Congrès des Arts décoratils : " La France est la seule nation qui soit privée d'un pareil instrument de travail." "

Nous nous étions laissé derancer daus cette voie par l'Angleterre el son South Fensington, devenu aujourd'hui le Musée Victoria and Ilbert, par "Allemagne et les Kunstgewerbemuseum de Berlin, de Hambourg, de Leipzir, de Munich, qui font une part si large aux productions du présent.

Dès son installation, le Musée des Arts décoralifs a su exposer les œuvres des styles anciens et modernes avec un goût et un raffinement qui lui attirent aujourd'hui legs el donations. Dans la grande nef ont lieu chaque année des exposilions spéciales, anciennes ou modernes, françaises ou élrangéres, très diverses, très éclectiques, dans un triple but d'émulation, d'édueation et de consécration.

Mais il est indispensable que l'Union centrale des Arts décoralifs persévère dans celte voie; il faut qu'elle ne se laisse pas déborder par l'amateur 
et par le collectionneur - comme cela faillit arriver, il y a quelques annces, au South liensington - et que le Musée des Mrls décoratil's ne risque pas de devenir un musée presque exclusivement consacré aux Arts el IIétiers du passé.

Et, avant de quitler le Palais da Lonre, émettons le varu que la troisième liépublique en élimine rapidement le Ninistère des Finances, comme elle a fail de la Préfecture de la Seine et du llinistère des Colonies, qu'elle adjoigne au Mlusée des Arts décoratifs un $1 /$ usée du Cos/ume, el fasse enfin de l'illustre demeure de nos anciens sourerains le Palais de l'Arl que réclame l'éducation du peuple français.

Cependant de grandes Expositions avaient lieu à l'étranger, et l'Italie avait l'honneur d'organiser a T'urin, en 1902, la première Exposition inlernationale des Arts décoralifs modernes; son règlement stipulait : "On
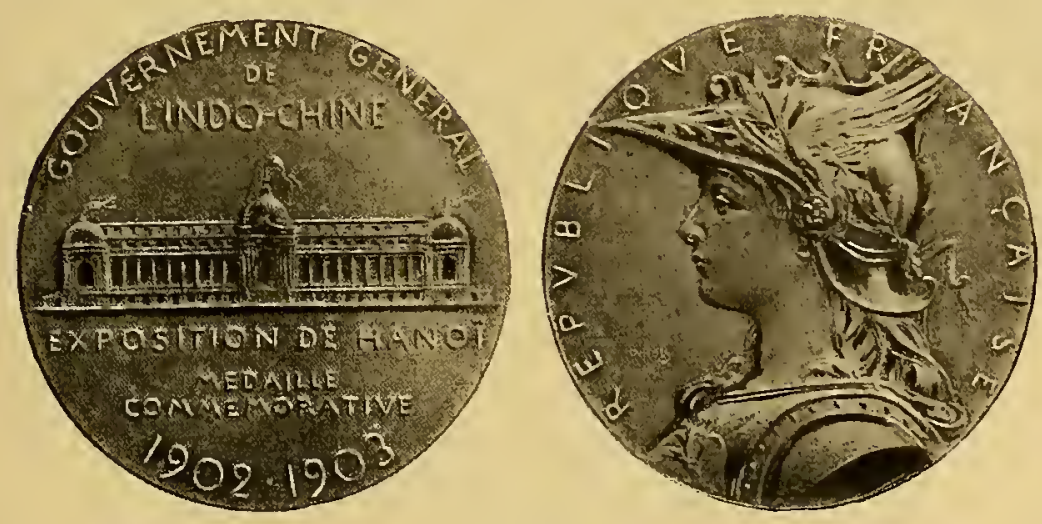

LXXIII el L.XXIV. - Exposition d'IIanoï, 1902-19o3. Midaille eommémorative, yrave par 0 . Ruly.

n'acceptera que les ouvrages originaux qui montreront une tendance tris unarquée au renouvellement esthétique de la forme. Les imitations d'anciens styles et les productions industrielles dénuées d'inspiration artislique ne seront pas admises. "Cette manifestation fut intéressante; mais la France y ful à peine représentée. La Commission spéciale qui s’ètait formée à Paris ne réussil pas à s'entendre avec les organisateurs turinois, et le Comité français des Expositions à l'étranger, qui n'avait pas voulu entrer en concurrence arec des compatrioles, fut prevenu trop tard quand celle Commission se relira.

Reconnu comme élablissement d'utilité publique en 1901, pendant qu’il participait a l'Exposition de Glasgow, accueiliant lannée suivante les membres de l'ancienne Réunion des Jurys el Comilés des Exposilions universelles présidée par MIII. Georges Berger el Charles Prevel, le Comilé 


\section{$-\mathrm{ClV}-$}

Irançats des Expositions à l'étranger, d'aceord avec l'lital, organisait successivement la parlicipalion françaisc aux Exposılions de Sainl-l'élersbourg,
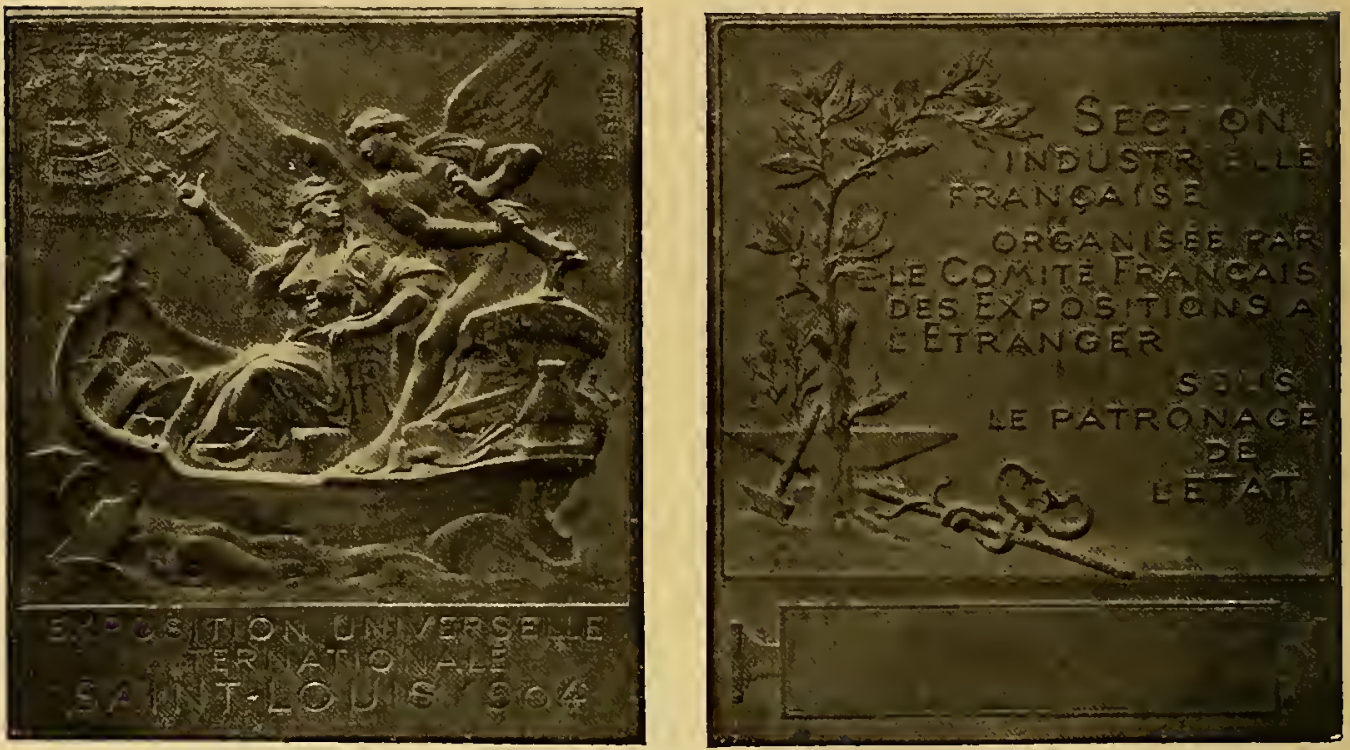

LXXV et LXXVI. - Exposition universelle et internationale de Saint-Louis, 1904 . Plaquette de la Section líançaise, gravéc par Louis Botléc.

19̣02; IIanoï, 1902-1903; Saml-Lonis, 190/; Liége, 1905; Milan, 1ço6;
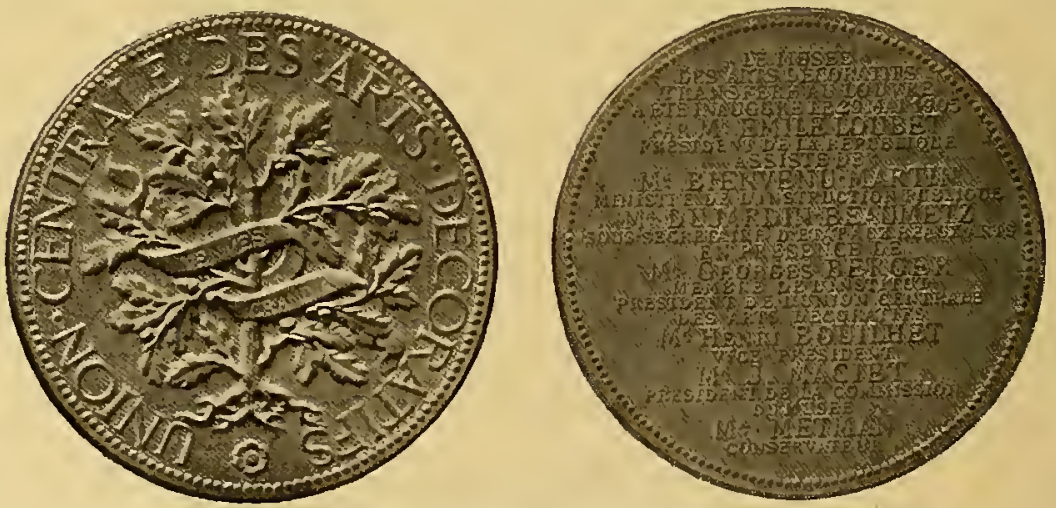

LXXvil el LXXÝrI. -- Médaille comménorative du transfert au Lourre du Nhsie des Arts décoratifs, le 29 mai 1 g̣os.

Bucaresl, 1906: Dnblin, 1907; Londres, 1908; Saragosse, 1908; Copenhague, 1909; Bruxslles, 1910; Buenos-Aires, 1910; Turin, 1911, elc. Nos 
sections y tinrent la première place, greâce à des directeurs et à des commissaires généraux comme Fernand Chapsal, Michel Lagrave, Marcel Jozon,

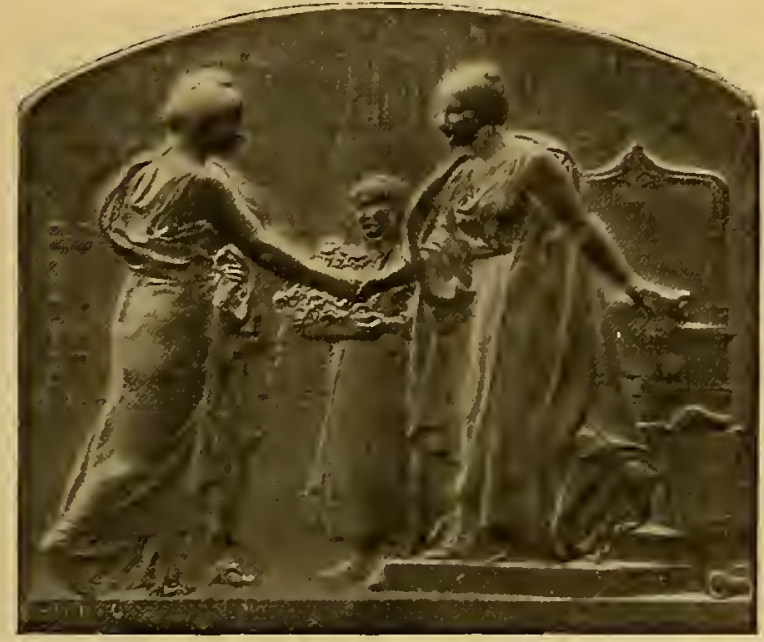

LXXIX. - Exposition universelle et internationale de Liége, 1905.

Face de la plaquette de la Section française, gravée par F. de Vernon.

Baudouin-Bugnet, Pierre Baudin, Stéphane Dervillé, grâce à des chefs

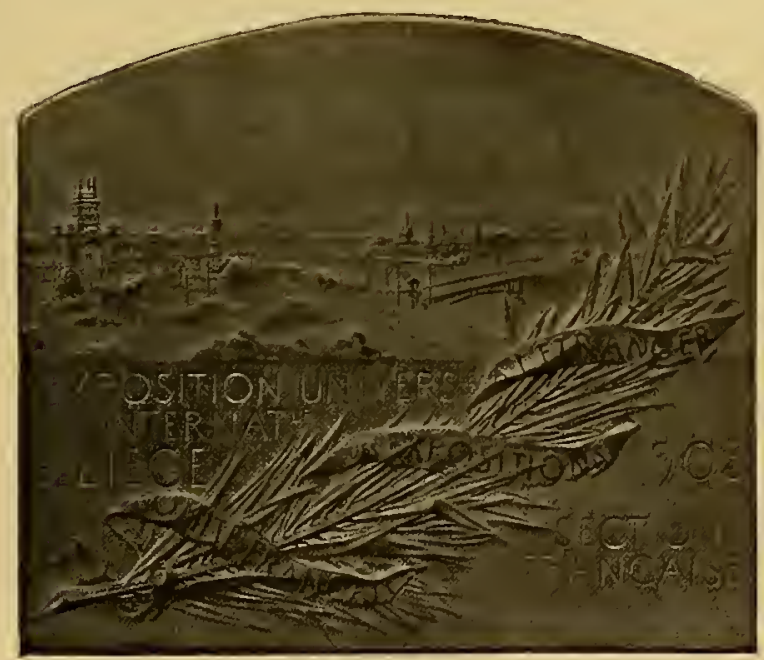

LXXX. - Exposition universelle et internationale de Liége, 1905. Revers de la plaquelte de la Section française, gravée par F. de Vernon.

et à des délégués comme Emile Dupont, Alfred Ancelot, A. Pinard, Alfred 
Maguin, Léon Barbier, Viger, Lucien Layus, J. Bouvard, Léopold Bellan, Jules Hetzel, G.-Roger Sando\%, Kester, Maurice Estieu, Mascuraud, Louis

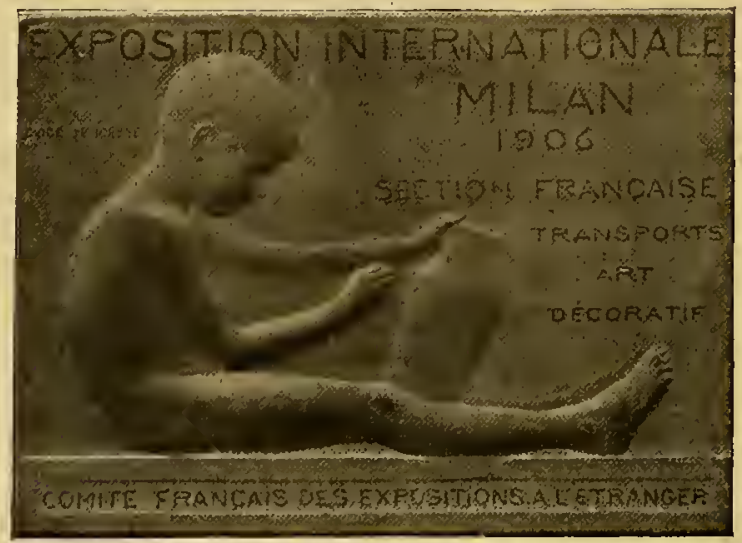

LXXXI. - Exposition internationale des Transports et des Arts décoratifs de Milan, ıgoG. Face de la plaquette de la Section française, gravée par $O$. Teneesse.

Aucoc, Manaut, J. Niclausse, de Pellerin de Latouche, de Montamal, Iéo Claretie, Ėmile Cère, de Brévans, etc.

Nous devons tout particulièrement isoler dans cette liste Fernand Chap-

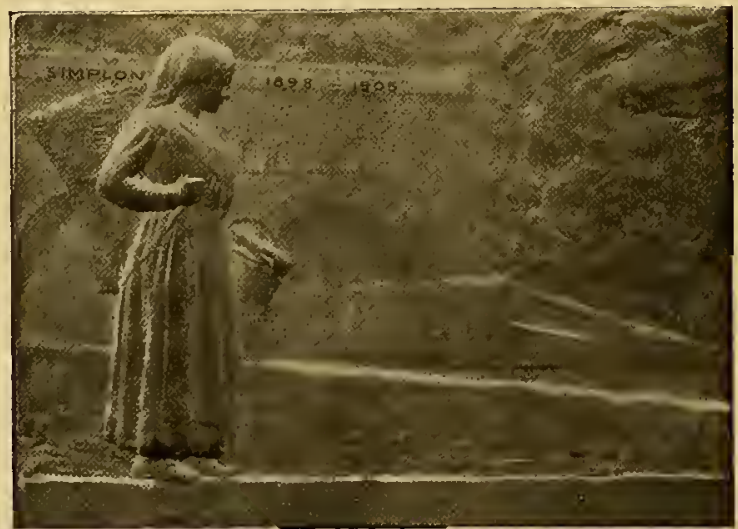

LXXXII.- Exposition internationale des Transports et des Arts décoratifs de Alilan, 1906. Revers de la plaquette de la Seetion française, gravée par O. lencesse.

sal,qui comprenant, a vec celte compétence si générale el loujours si averlie, l'importance économique et sociale de l'Art décoratif moderne, lui accorda des salons particuliers, à Liége, 1905, el à Bruxelles, 1910 ; Mlichel Lagrave 
et Emile Dupont qui, les premiers, réservèrent une place spéciale ì li. Irt décoralil moderue, at Sant-Louis, 19qo', à Turin, 1911; enfin, Stéphane Dervillé, qui toujours s'intéressa ì l'art décoralif avec un souci érudit et délicat d'amateur ralfíné.

Aussi bien, ee nous est un devoir, comme nous l'arons fail pour les diverses époques du sièele précédent, de rappeler ici les noms des principaux organisateurs - artistes el iudustriels - qui depuis 1900 maintiennent le renom français ì l'étranger.

\section{Grotre 11. - CEuvres dart.}

Guslaviz Larroumel, Ilenry Roujon, Roger Marx, Bigard-Fabre, Valentino, Paul Jćon, Caviole, Sagglio, Ilorteloup, Pol Neveux, liritsch-Estrangin; les peintres el dessinateurs: Léon Bonnat, Dawant, Guillaume Dubufe, Besnard, Cormon, Detaille, Iltermitte, Léandre, Forain, Maurice Nenmout, Truchel, lioussel; les sculpleurs el graveurs en médailles : liodin, Boisseau, Bourdelle, Alfred Boucher, Allar, Bartholomé, Gardet, Alfred Lenoir, Mereié,
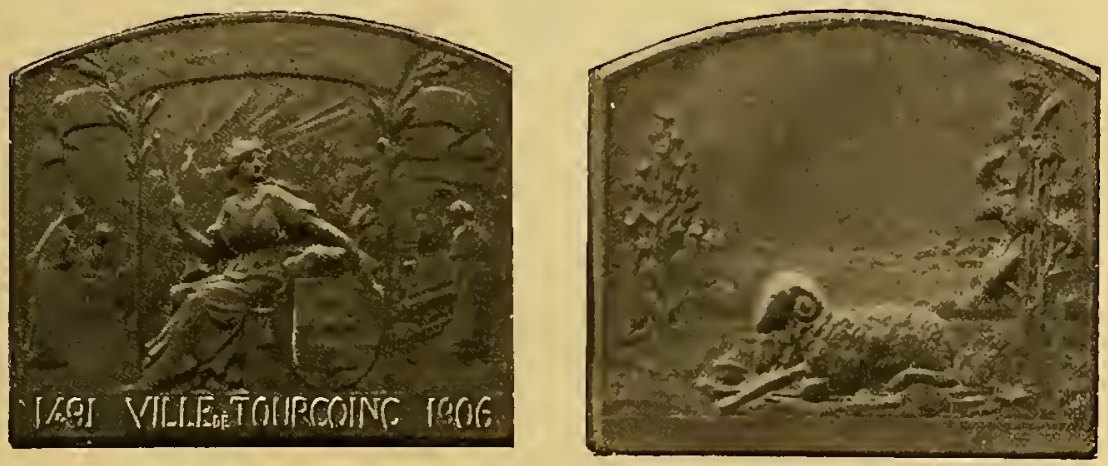

L.XXXII et LXXXIV. - Exposition internationale des Industries textiles de Toureoing, 19o6. Plaquette šravée par IIippolyte Lefebre.

Denys Puech, Chaplain, Roly, Louis Bottée, F. de Vernon, Emile Vernier, O. Vencesse, Charles Pillet, Pierre Dautel; les archilecles: Jules Bouvird, Louis Bonnier, lrantz.Jourdain, de Montarnal, Vaudremer, Paseal, de Baudot, Laloux, Chédanue, Lucien Magrne, Tronchet, Arnaud, Besdel, Bliault, Roger Bouvard, Constant-Bernard, Delrasse, Dezermeaux, Bouwens van der Boijen, Genuys, Girault, Guilbert, Ilbert Guillaume, Guimard, legriel, Narjoux, Charles Plumel, Redont, Pierre Selmersheim, Lonis Sorel, Toudoire, Umbdenstock, André Vineent; les administrateurs el directeurs de wos Manufaclures nationales : Jules Guitrey, Gustave Gelfroy, Peycelon, anx Gobelins: Badin, à Beauvais: Baumgart, Emile Bourreois, Sandier, Lecherallier-Cheviguard, à Sérres, ete. 
Groupe III. - Instruments et procédés généraux des lettres, des sciences et des arts.

Cusse 11.- Typographie, impressions diverses: Lahure, Chaix, Pichol, Louis de Bary, Bigo-Danel, Champenois, Gounouilhou, Chapon, Delmas, Dubouloz, Firmin-Didol, Ilérissey, Lortat-Jacob, Marolle, Porcabeuf, Stern, baron Louis Thénard, Voirin, Weil, Wiltmann, etc.

Chasse 12. - Pholographie : Paul Bourgeois, Belliéni, Paul Boyer, Davanue, Robert Demachy, Demaria, Gaumont, Gerschel, Jongla, Lumiere, Mendel, Nadar, Otto, Pirou, Jules lichard, ete.

Cuasse 13. - Librairie, reliure, éditions musicales: Masson, llelzel, Belin, Fourel, Doin, Lucien layus, IIainguet, René Baschel, J.-L. Bru-

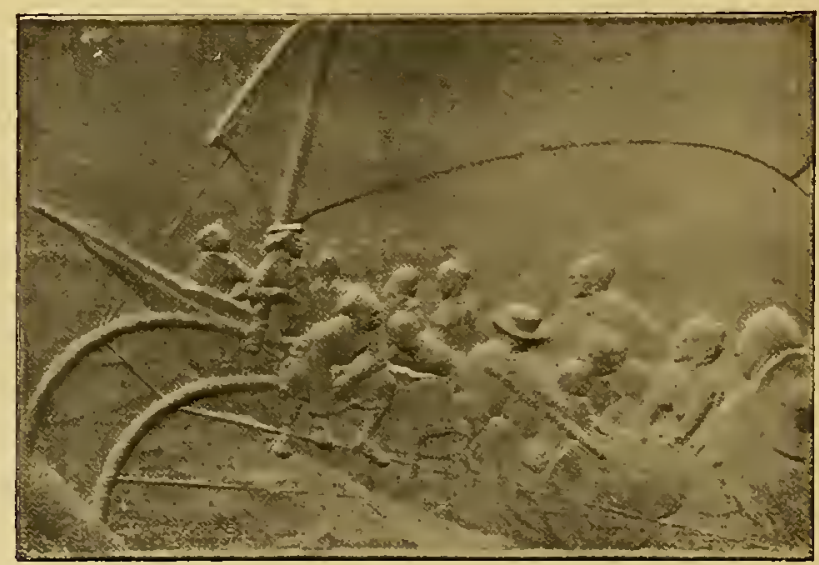

LXXXV. - Exposition coloniale de Marseille, 1906.

Plaquetle gravic par L. Patriarche, d'apris le tableau de D. Dellepiane.

net, Carlerel, Chevalier, Pierre Dauze, Delagrave, Enoch, Floury, GauthierVillars, Gillon, Jules Gleize, Peigné, Gruel, Louis IIachelle, IJeugel, JoretDesclozières, Pierre Laffitte, Laurens, Le Vasseur, Pelletan, Puel de Lobel, Roureyre, elc.

Chasse 17. - Instruments de musique: Gustave lyon, Acoulon, Ime F. Besson, Albert Blondel, Garessa, Evelte, Gaveau, Goultière, Mustel, Schœnaers-Millereau, elc.

Cuxsse 18. - Art théatral: Alberl Carré, Gailhard, etc.

\section{Groupe Xll. - Décoration et mobilier des édifices publics et des habitations.}

Cussse 66. - Décoration fixe des élifices publics el des habilations: Bergeolle, Alfred liesnard, Bigaux. Borderel, Brol, Fontaine, Charles 
Genuys, René Guilleré, Hoentschel, liaymond Kiechlin, Gaston Lecreux, Jules Maciel, Paul Mexzara, Eugène de Montarnal, Moriquand, Pellissier, livaud, Léou Riotor, Scheidecker, Maurice 'Testard, Georges Turck, Georyes Vinant; et encore les artistes décorateurs : Lalique, devenu verrier aussi merveilleux que bijoutier-joaillier exceptionnel, Ausseur, Barboteaux, Bastard, Becker, Albert Besnard, Bonvallel, Bourgeot, Brandl, Burnool, Coudyser, Dammouse, Dampt, Decour, Decorehemont, Delaherehe, Du-
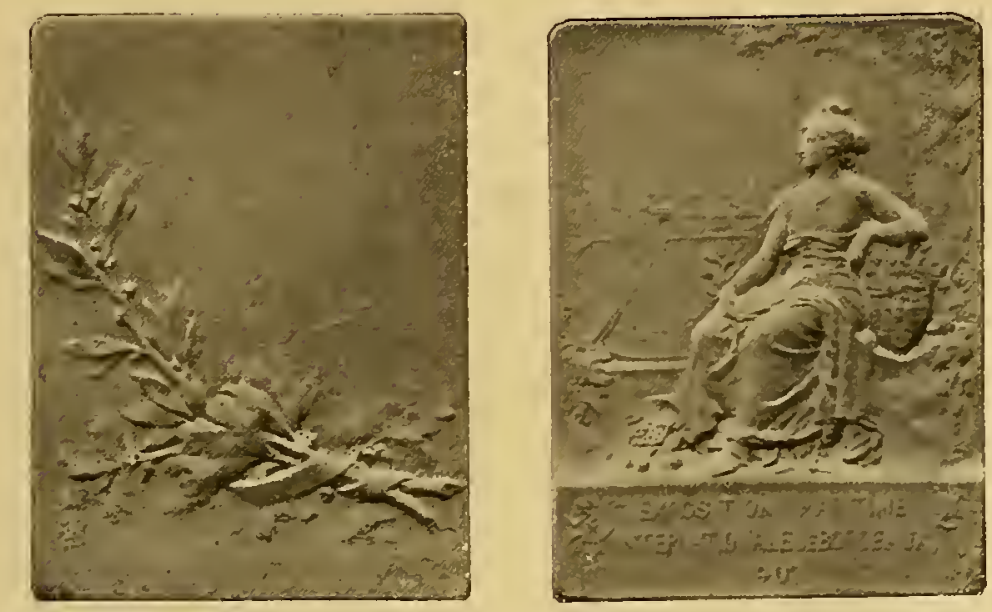

LXXXY et LXXXYH. - Exposition Maritime internationale de Bordeaux, 1907. Plaquette gravéc par IIcnri Dubois.

frène, Paul Follot, Eugène Gaillard, Grandhomme, Giraldon, Grassel, Ilairon, IJamm, Ilirtz, Gallot, Kieffer, Théodore Lambert, Le Bourgeois, Eugène Lelièrre, Lenoble, Majorelle, Marius Michel, Clément Mère, Mèthey, Rapin, Robert, Piere Roche, Szabo, Tourette, de Waroquier, etc.

Cuasse 67. - Vilraux: Gaudin, Picard, Trézel, elc.

Classe 68. - Papiers peinls : Félix Follol, Charles Follol, Isidore Leroy, Maurice Leroy, Desfossé, Jouanny, ele.

Classe 69. - Meubles: Alfred Damon, Charles Jeanselme, Mercier, les frères Pérol, Muller, Maxime Clair, Domange, Jemont, Linke, Schmidt, Soubrier, elc.

Chasse 70. -- Tapis, tapisseries el uulres lissus d'amenblement: Charles Legrand, V'iclor Legrand, Louis Blondel, Braquenié, Chanée, Chatel et Tassinari, Cornille frères, Hamol, Lorthiois, elc.

Cuasse 71. - Décoration mobile el ontrage du lapissier : Paul Belloir, Dantant, Poteau, P.-II. Rémon, Ternisien, etc. 
Classe 72. - Géramique : Alfred Hache, Louis Harant, Guignard, Laeroix, Landier, Jocbnit\%, Georges Mansard, Arlhur Metz, elc.

Cusse 73. - Cristaux, verrerie : Enile Galle, Appert, Barre\%, Daum, Georges Despret, Iloudaille, Georges Maes, Guilbert el René Martin, ele.

\section{Grotpl XIII. - Fils, tissus, vêtements.}

Classe 8o. - Fils el tissus de colon : David-Mennel, Casimir Berger, Esnault-Pelterie, Jalla, Langr, Roy, Seyrig, Wibaux-Florin, elc.

Cusse 81. - Fils et tissus de lin: Carmichael, Crespel, Mascré, Simonnot, ele.

Cusse 82. - Fils et tissus de laine : Ërnest Levallois, Balsan, Blin, Francisque Bonnier, Carissimo, Fraencliel, Glorieux, Charles Levent, Eugène Mathon, Michel-Cóle, Motle, Pollet, Prouvost, François Roussel, Paul Simon, Ternynck, elc.

Cusse 83. - Soies el lissus de swie : léon Perdoux, Lagnionie, Anlrie, Charles Bourgeois, Achille Brach, Kinsbourg, Victor Mandard, Raimon, Roubaudi, ete.

Cunsse 84. - Denlelles, broderies el passementeries : Henri llénon, Léopold Bellan, Ancelol, Béquel, Béraud, Biais, Cherron, David, Lescure, Marescot, Georges Martin, IJenri Noirol, Emile Sins, ele.

Chasse 85. - Industries de la confection el de la conture pour hommes, lemmes el enfants : Aine, Beer, Bessand, Bouruet-Aubertol, haudnil\%, Georges Brack, Chéruil, Cognacq, Douillet, Fillol, Honoré, Paul kahn, Laguionie, Margaine-Lacroix, J]we Paquin, Redlem, Reverdol, Ricois, Storch, Worth, elc.

Cu.ısse 86. - Industries diverses du vétement : Donchèle, l'éventailliste Duvelleroy, Mouilban, Benoiston, Blais-Mousseron, Brossard, Buissol, Chabanne, Charvel, Léon Cherreau, Dehesdin, Doll, Guyol, Pierre Imans. Louis lavey, Leprince, Lolliol, Lucet, Mermilliod, Talfonneau, Viallar, Villeminot, Léon Vimont, elc.

\section{Grotpe MT. - Industries diverses.}

Chasse yz. - Papelerie : Georges Pulois, Evelle, Fauchier-1)elavigne, Geismar, Hadrot-Binant, Maunoury, Louis Wollf, ete.

Classe 94-Orfèrrerie: Paul Christofle, Henri Bouilhet, Georges Boin, Armand-Calliat, Cardeilhac, de Ribes-Christolle, André Bouithel, André Aucoc, lieller frères, Poussielgue-liusand, llenry frères, Risler el Carré, Boulenger, elc. 


\section{- id -}

Cuasse 95. - Bijoulerre-joaillerie: Louis Aucoc, Mascuraud, Paul Templier, Boucheron, Lalique, Radius, Gustave-Roger Sandoz, Rouzé, Piel, les frères Vever, les frères Falize, Marlial-Bernard, Savard, Georges Fouquet, Gaillard, Beaudouin, Bourgey, Chaumet, Coulon, Félix Desprès, Ecalle, Féau, veuve Amédée Fornel, Lefebvre, Marret, Nurat, Nussbaum, Pinier, Quennessen, Ruteau, Téterger, Léon Vaguer, Duval el Janvier, elc.

Cuasse 96. - Iorlogerie : Hour, Leroy, duricoste, Favre-IJeinrich, Sidney Hébert, Paul Lévy, Lipmann, Georges Meyer, etc.

Classe 97. - Bronze, fonle el ferronnerie d'arl, mélaux repoussés: Soleau, Susse, Leblanc-Barbedienne, Siol-Decauville, Baguès, Bricard,
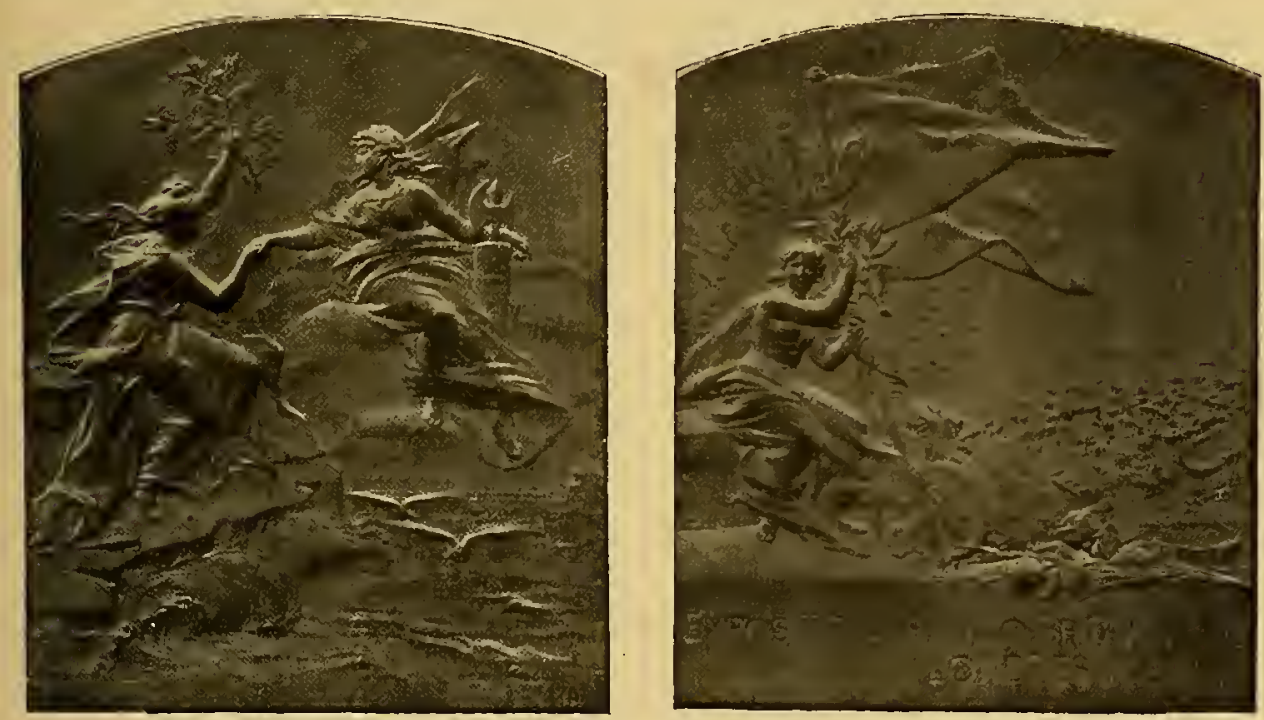

Ixxxvill el Lxx.Xx. - Exposilion Franeo-Britanique de Londres, jgos. Plaquetle de la Scetion fransaisc, gravéc par Ch. Pillet.

Eullinger, Jabouf, Paul Louchet, Raingo, Rouart, René Rozet, Mme IIenri Vian, elc.

Cuasse 98. - Brosserie, maroquinerie, lablelterie el lannerie : Emile Dupont, Amson, Genty, Lamaille, Leloir, Maurey-Deschan ps, Proffit.

Cuasse 100.- Bimbelolerie: Henry D'Allemagne, Léo Claretie, Fernand Martin, Amédée Prince, etc.

Comme nous l'avons pu constater dans toutes les Expositions qui ont eu lieu depuis 1900, le Comité français s'efforçail de réserver une place aux Arts appliqués, d'accord avec la Sociélé d'Encouragement à l'Art el à l'Industrie, la Société des Artistes décoraleurs, l'Ĺnion centrale des Arts décoratifs. 
Ce sont : a Hanoï, Roger Marx; à Saint-Louis, Guillaume Dubufe ; d Liége, Bellery-Desfontaines, qui sont plus parliculièrement chargés de ce soin. A Milan, nous sommes en pleine période de recul : le Parlement français refuse sa maigre subvention, habiluelle, mais, grâce à l'aide du Comité français, Frantz Jourdain el Monduil peuvent inslaller une Section des Arls décoralil's français - très modeste à côté de ce qu’ont fail Ilaliens, Allemands, Hongrois, - pour se conformer au programme lequel, comme à Turin, 19o2, posail en prineipe absolu l'affirmation d'une esthélique nouvelle. A l'Exposilion de Londres, 1908, la générosité de l'ancien député
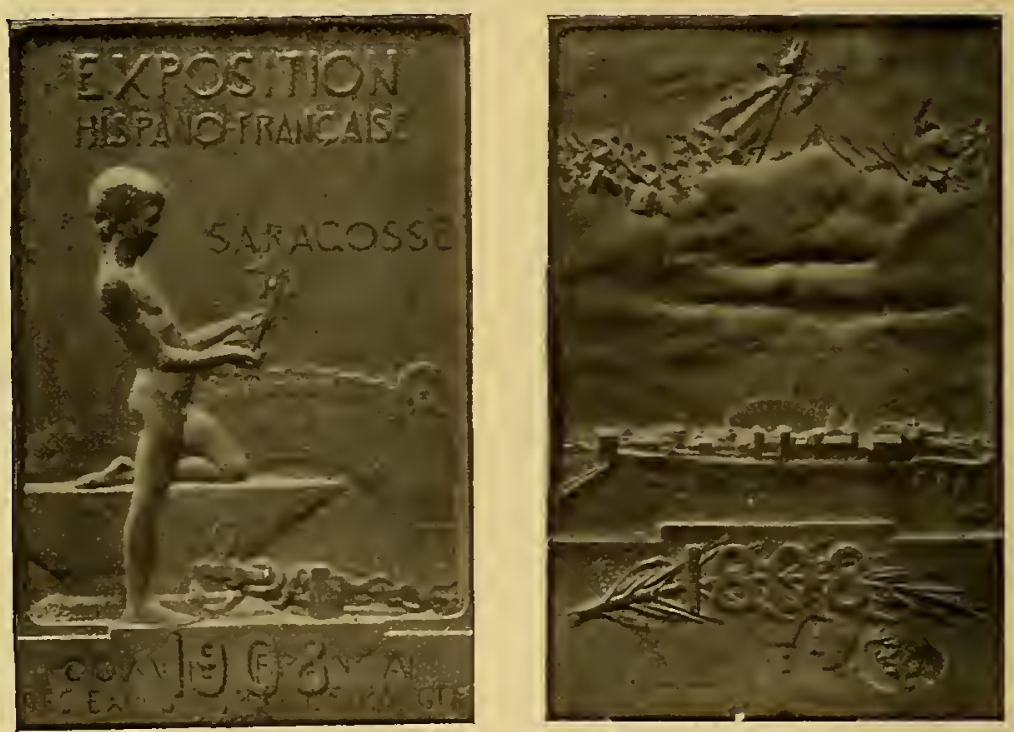

XC el XCI. - Exposilion II ispano-Franẹaise de Saragrosse, 1908. Plaquelte de la Section française, gravéc par Pierre DauteI

Délieux permel la construction d'un Pavillon spécial des Arts décoratil's français, qui eul beaucoup de succès.

Ces Expositions à l'étranger n'avaient pas été sans créer de nombreux points de contact entre les représentants de nos direrses Associations. Aussi, lorsque, au nom du Danemark, notre ministre, le comte Horrie de Beaucaire, présenta au secrétaire général du Comité français le projel d'une Exposilion française dirt décoralif à Copenhayue, pour 19oy, Emile Dupont, Layus, G.-Roger Sandoz, Emile Vernier, Jean Guilfrey, René Guilleré, erurent le moment venu de composer les divers Comilés de créaleurs el de fabricants el de les faire travailler ensemble à l'œuvre entreprise.

Malgré les déplorables malentendus qui empêchèrent quelques arlistes de comprendre l'importance du bul visé, l'Expositionde Copenhague réunit 
pour la premiere lois dans une action commune artistes, industriel setartisans. El cn terminant ce rapide historique, n'oublions pas de mentionner le
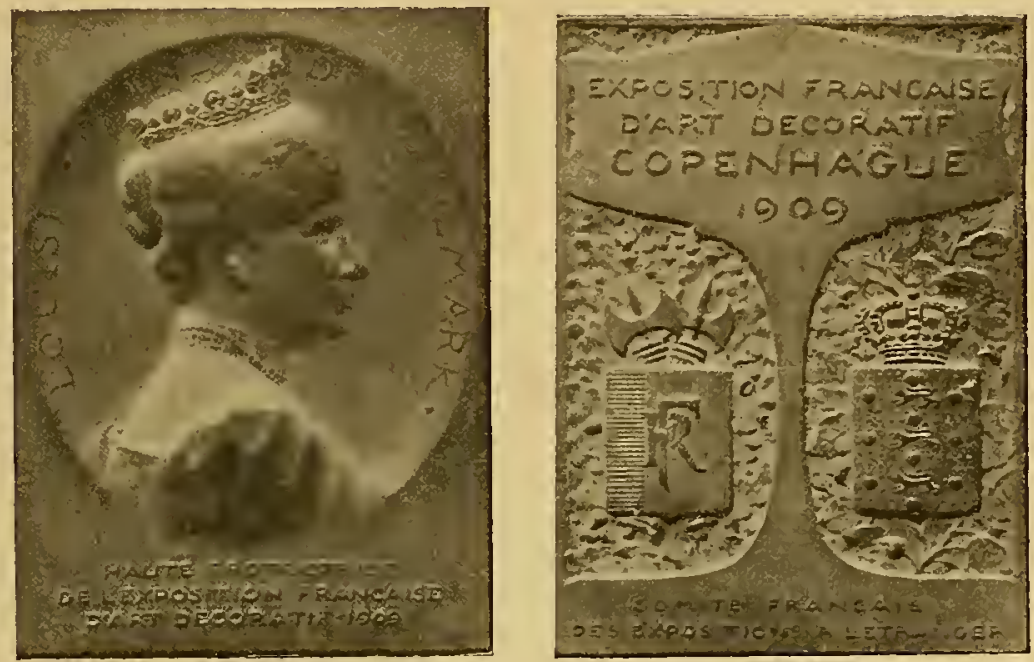

XCII et XCIII. - Exposition française d'All décoralil de Copeuhague, lyog Plaquelte gravie par ĺmile Vernier.

joli salon d'art, décoré avec beaucoup de goût par l'architecte Lambert, ¿̇ l'Exposition de Bruxelles, $\mathbf{1 9 1 0}$, et le très charmant pavillon de l'Art déco-
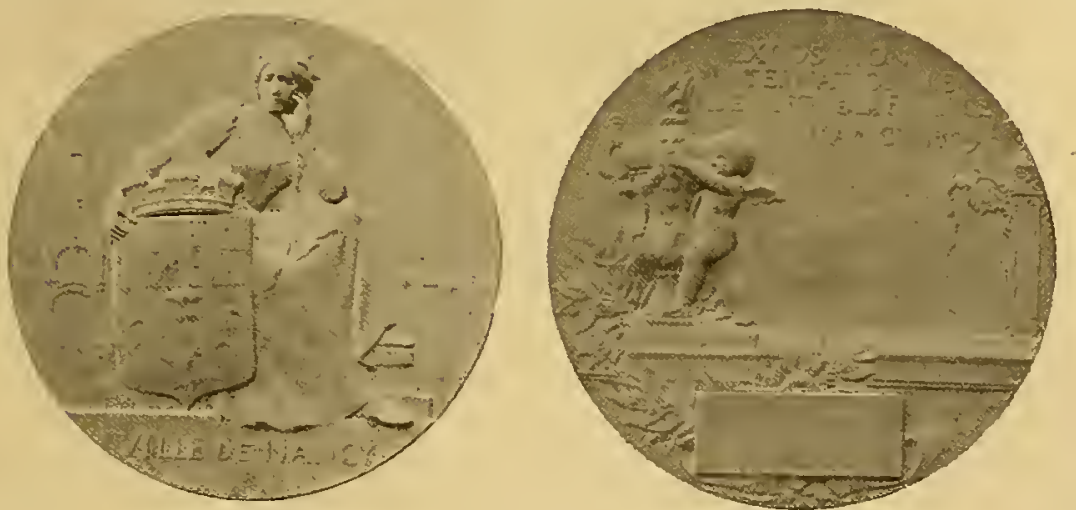

XCIV et $\mathrm{XCV}^{r}$. Exposition internationale de Nancȳ, 1909. Médaille gravée par Bussièrc.

ratif français, construil par Plumel à la toute récente Exposition de Turin, 1911, pour encadrer les objels demandés it nos déenrateurs par François 
Curnot et liaymond livelılin, actuellement président et premier vicePrésident de I'Union centrale des Arts décoratifs.

Dans ec pavillon oclogonal, était installé un cabinet d'amateur moderne, très réussi, el le seul regret que nous puissions exprimer est que le développement même de la participation française à l'Exposition de Turin n'ait pas permis de placer les envois de nos artistes décorateurs au milicu des vitrines de nos industriels d'art, pour montrer aux visiteurs, en un complet ensamble, tout ce que peuvent réaliser les Arts appliqués français.

Cependant, ¿̇ Paris, en 1902, 1905, 1908, 1911, d'importants Salons

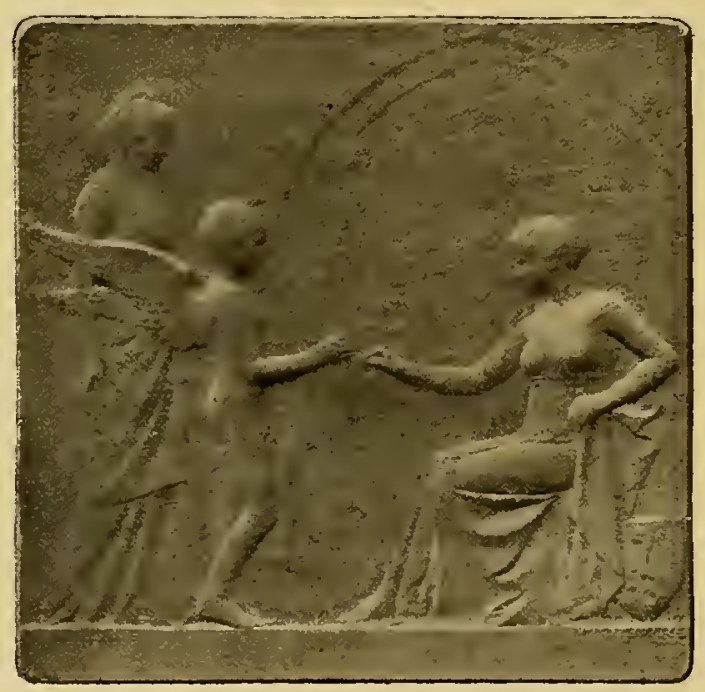

XCV1. - Exposition universelle et internationale de Bruxelles, 1910.

race de la plaquetle de la Section française, gravie par 0 . lencesse.

français da Mobilier étaieut organisés au Grand Palais par les présidents des grands Syndicats de l'ameublement, du bronze, de la bijouterie-orfívrerie, de la céramique : Perol, Louis Aucoc, Louis IIarant, Albert Susse, Soleau qui joua un si grand ròle dans la défense de la propriété industrielle.

Ces Salons aidèrent, par d'intéressants concours de mobilier à bon marché, au développement des Arts industriels.

De nombreuses Exposilions d'Arl modeme, exclusivement nationales, eurent aussi lieu à l'étranger dans ces dernières années; eitons, parmi les plus importantes, celles de Manich, Stullgarl, Vienne et Stockholm.

Celle de Munich devait faire éclater au grand jour la persévérance, la méthode, la discipline avec laquelle les artistes bavarois s'efforcent de créer un style bien personnel et de rivaliser arec la France et l'Angleterre dans les Arts appliqués. Les délégations envoyées par le Conseil muni- 
cipal de Paris el par de nombreuses Sociétés artistiques au congrès organisé par l'Union provinciale des Arls décoralis, londéc en août 1907 , ne purent s'empêcher de rédiger leurs rapports en termes quelque peu "aflolés " - le mol est de Clément Janin - R. Caralsin, charyé du rapport de la délégation du Conseil municipal, écrivail en elfel : "I.e Sedan commercial, dont depuis de longues années nous sommes menacés, n’est plus i craindre actuellement, c'est un fait accompli, et nous derons en prendre notre parti... Il faut considérer notre jeune génération acluclle comme absolument sacrifiéc..."

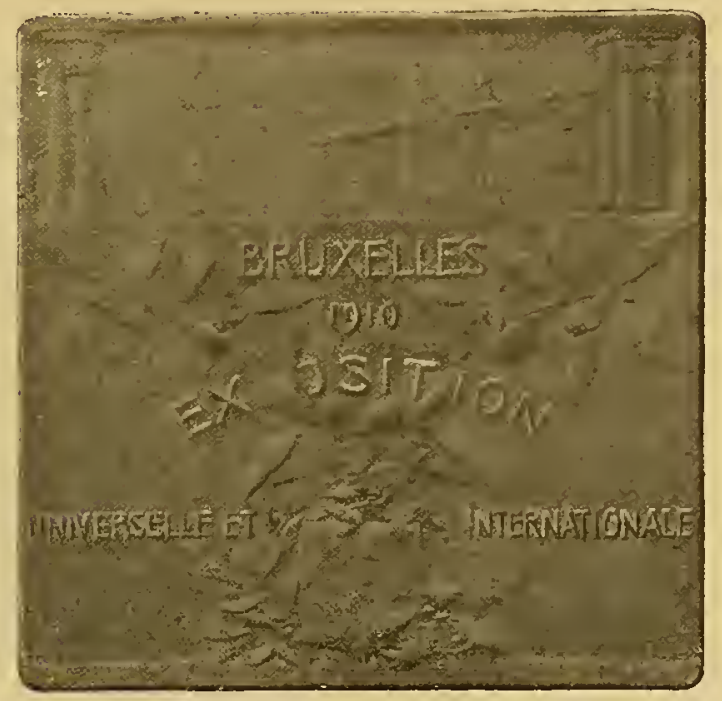

XCYll. - Exposition universelle et internationale de Bruxelles, jgio.

lievers de la plaquelte de la Section française, gravéc par O. Yencesse.

Mais, si exagérées qu'elles fussent, ces ligues, répétées el reproduites, ont obligé les plus optimistes à examiner sérieusement la siluation acluelle de nos industries d'art. J)'ailleurs, si l'Exposition organisée par les arlistes munichois au Salon d Aulomme de Paris, lyog, sur l'invilation de Frantz Jourdain, nous a fait mesurer le très grand chemin parcouru par nos voisins el concurrents, elle nous a rappelé aussi que les arlistes français possédaient ces grandes qualités qui sont le goût, la grâce, la délicalesse, l'harmonic des couleurs.

Comme on l'écrivait à propos du groupe allemand de "l'A.t de la Ilaison el de l'Industrie d'Arl ", a l'Exposition de Bruxelles, cependant si richement iustallé, si soigneusement exéculé : " Dans ces appartements noirs et blance, bleus el blancs, vert pomme et orangé, on peut imagiuer 
de loger un savant esthète ou un administrateur énergique : impossible dy installer une jolie femme..."

- Quelle différence avec les derniers Salons de nos artistes décorateurs et à quels résultats ces demiers arriveraient-ils s'ils trouvaient les mêmes appuis que leurs concurrents d'outre-Rhin? 'Toutefois, il n'est que juste de rappeler que si l'Arl décoratif moderne n'eut pas réeemment en France la faveur du wrand public, il trouva auprès de quelques amateurs un accueil généreux. C'est grâce aux encourag'ements de ces trop rares mécènes qu'il pul se développer.

Parmi cux, il convient de citer particulièrement la comtesse de Béarn, la comtesse Greffuhle, Maurice Fenaille, le marquis de Polignac, Bouwens
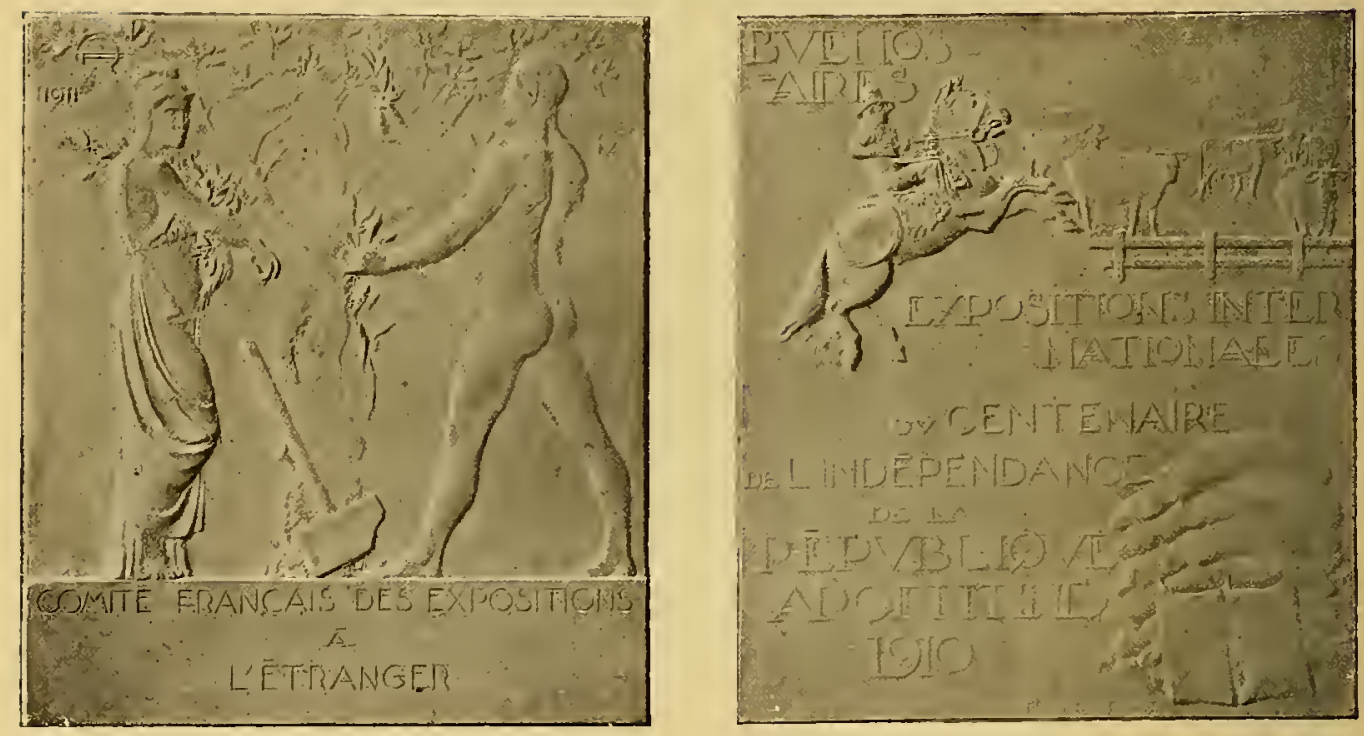

ICVIII el ICIX. - Expositions universelles et internationales de Bucnos-Aires, 1910. Plaquelle des Seclions françaises, gravéc par François Roques.

van der Boijen, Jaeques Rouché, Tlsomas, André Gide, Victor Lanson, Charles Stern, Ilirseh, Nozal.

L'Etat, malheureusement, resta trop longtemps insoucieux d'art décoratif. Bien peu nombreux étaient encore jusqu'i ces derniers temps les membres du Parlement qui s'y intéressaient; on en comptail pourtant quelques-uns. En plus des signataires (dont nous donnons plus loin les noms) du projet de loi concernant l'Exposition internationale projetie, il convient de ciler, ì la Chambre : Simyan, Leygues, Cruppi ,Etienue Rognon, Roblin, Beauquier, l'abbé Lemire, Maurice Barrès, Georges Berry, Sarraut, Jaurès, Denys Cochin, Jean Goujon; au Sénat: Couyba, Georgnes Trouillot, Emile Dupont, Pauliat, Maurice Faure, Gustave Rivet, etc. 
Les décorateurs trouvèrent moins d'indifférence auprès de la ville de Paris. Sous l'impulsion de quelques conscillers, amateurs d'art avertis, au nombre desquels nous derons mentionner : Deville, Rébeillard, le comte d'Andigné, Louis Aucoc, Galli, Bellan, Quentin-Baucharl, J.e Corbeillier, Lampué, Pelitjean, et très particulièrement l'ancien président Dausset qui a rédigcé le rapport présenté au Conseil municipal sur le projet d'Exposition internationale, le musée Galliéra fut ouvert aux décorateurs el des achats plus importants leur furent faits dans les Salons.

Aujourd'hui, le gouvernement et les municipalités donnent chaque jour aux artistes décorateurs les marques d'une sollicitude plus réelle. Ce n'est que justice. lls se sont assagis depuis dix ans : leurs ensembles mobiliers
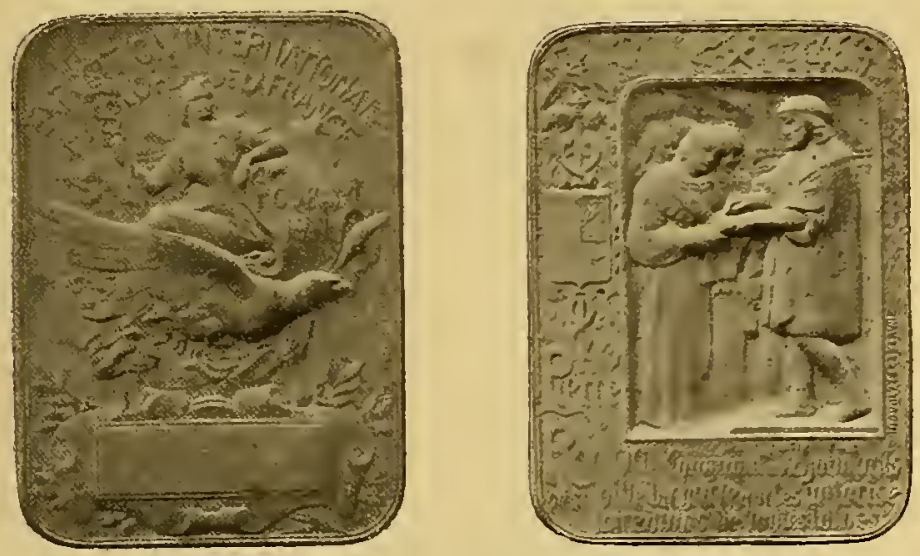

C ct Cl. - Exposition internationale de Roubaix, In11. Plaquelle gravée par IIippolyle Lefebre.

sont présentés avec groût et avec cette originalitis sobre, cette discrétion, celle mesure qui demeurent les dons imperissables de notre race.

Leur effort mérite d'autant plus d'être signalé que, s'ils ont su conserver leur individualité arlislique, ils commencent aujourd'hui ì s'entendre el ä montrer un véritable esprit de colnésion, grâce à l'action d'unjon exercée par la Société des Artistes décorateurs.

Quel que soit le grave malaise de notre Art décoratif, les progrès, les menaces même de l'étranger ont ouvert les yeux à de nombreux Français et répandu la bonne semence qui doit germer. Faut-il rappeler jei les éloquents cris d’ałarme jetés par Roger Marx, Émile Galté, Gustave Kahn, Jean Lahor, Lucien Magne, Henry Marcel, Itenri Noch, Clément Janin, Carabin, II. Dubret, Victor Prouvé, Grandigneaux, de Baudol, Sclmersheim, Albert Vaunois, Chudant, Jules Huret, Emile Berr, Fernand Ionmeja, du Bousquel, Léo Claretie, Steck, Gustave Geffroy, Pierre Mar- 
cel, Simyan, Saint-Sä̈ns, Bonnerot, Louis Lumet, Paul Brenot, ete, et l'énergique campagne menée par Gaston Quénioux, Edmond Pottier, Alfred

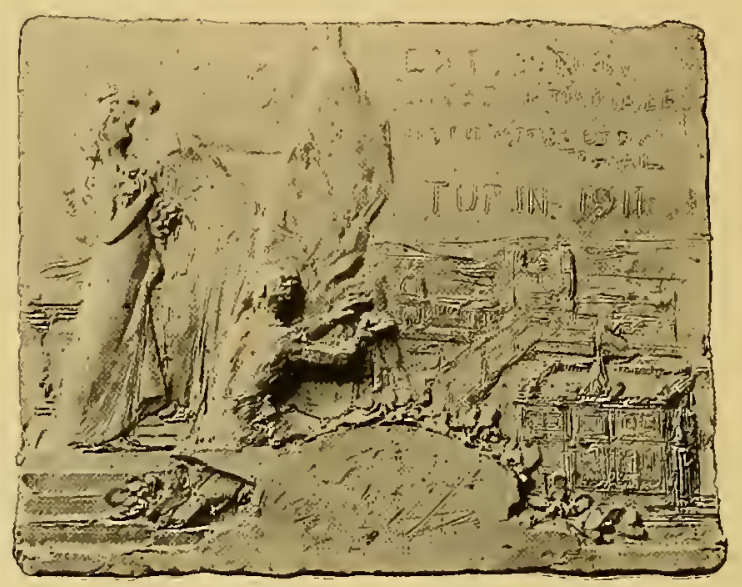

Cll. - Exposition interuationale de Turin, 19ı.

Face de la plaquette de la Section franeaise, d'après l'ébauche de Pierre Dautel.

Lenoir, Guébin, Liard, IIte Perrier, pour la transformation de l'enseignement. du dessin et son adaptation plus logique aux besoins de l'henre

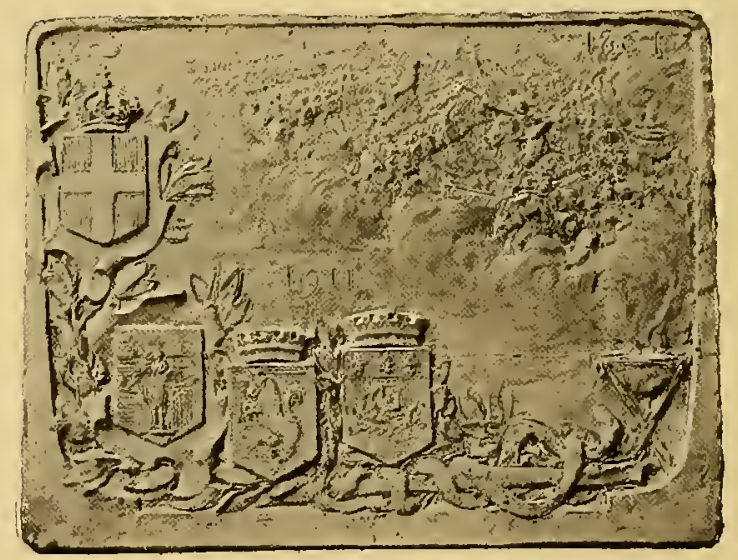

CIII. - Exposition internationale de Turin, 1911.

lievers de la plaquette de la Section française, d'après l'ébauche de Pierre Dantel.

présente, dans un but aussi utilitaire qu'esthélique. Les rénovateurs ont compris qu'il fallait s'adresser d'abord à l'enfant, lui apprendre à dessiner, à modeler, comme on lui apprend à écrire. 
L'ancienne méthode avait fait son temps, quelques services qu'elle eût rendus. Désormais, ì professeur jouit d'une grande liberté pour le ehoix des modèles, à la condition qu'ils soicnt pris dans la réalité. L'enfant n'aura sous les yeux que des modèles vrais, cmpruntés à tous les aspects de la vie et de la nature. Une grande variélé est en outre donnée au professeur pour les procédés techniques : non seulement la couleur riest pas exclue, mais il est recommandé de laisser un libre cours, en les dirigeant, aux instincts des enfants naturellement coloristes. On les excree aussi au modelage, afin de leur faire comprendre la superposition des plans et de leur permettre de reproduire plus réellement les objets qu'ils copient. linfin, cet enseignement, et éest lá peut-être le côté capital de la réforme, est lié désormais à l'enseignement général; il exhorte les professeurs, et notamment eeux des seiences naturelles, à encourager leurs élèves ì illustrer el décorer leurs travaux et devoirs, suivant leur sens naturel de la forme el de la coulcur.

Par là, cette grande rél'orme de 1909 prend une importance très large, et elle peut se résumer en trois principes; d'abord la liberté : liberté du suntiment et même de l'interprétation chez l'élève, et liberté d’action chez le maître; ensuite " le dessin moins étudié pour lui-même que pour les fins totales de l'éducation ", ce n'est plus un art d'agrément, e'est un instrument de culture générale; enfin " la nature prise pour base, aiméc pour elle-mème, traduite directement et naïvement".

Le problème de l'Arl à l'École avait déjà été posé dans de nombreux congrès, dont le premier, qui avait pour président le regrelté Beurdeley et pour vice-président Rogrer Marx, fut tenu au Cercle de la Librairie, en 1904; il avait amené Ch.-M. Couyba, alors député et rapporteur général du budget des Beaux-Arts, et léon Riotor, qui avait étudié ces questions en plusieurs missions à l'étranger, à fonder, en 19o7, la Sociélé française de l'Art à l'ĺcole. A eux se joignirent Roger Marx, Frantz Jourdain, Edmond Pottier, Van Brock, lous ceux qui s'inquictaient du renouveáu de nos industries d'art. Cette association a adoplé les principes suivants: "L'école saine, aérée, rationnellement construite el meublée, altrayante el ornée ; formation du goût de l'enfant par son initiation à la beauté des lignes, des couleurs, des formes, des mouvements et des sons. "Quoique bien jeune encore, elle a réuni, en quatre ans, 80 sections métropolitaines el coloniales, comprenant près de 1 / 000 membres.

Aidée des grandes maisons de librairic Larousse et llachette, elle a propagé son action par de nombreuses brochures, par des conférences, par des éditions d'estampes, des fabrications d'objets el de décors d'écoles, par des concours, des récompenses, des cxpositions, des congrès.

"Entre l'école manssade et l'école buissonnière, écrivait son président Couyba, il y a place pour l'école flenrie... "Celle gracieuse formule est tout un progranme dont l'application suivie peut contribuer puissamment 
à régénérer notre antique suprématie par l'école el par le penple. Peut-être verrons-nous alors le moment, prédit en 1851 par le comle de Laborde, " où il sera honteux de ne pas savoir dessiner, où on en rougira comme on rougit aujourd'hui de ne pas savoir écrire..."

Nous ne devons pas oublier non plus les travaux de l'Ĺnion provinciale des Arts décoratifs ayant à sa Lête Victor Prouvé, Nlbert Vaunois, Ad. Chudant, Grandigneaux, G. Quénioux, 11. Dubrel, Coudyser, Claude Couhin, Constant-Bernard, Dubief, Feuillatre, Mainié, Gérault-Carion, ele.

Au cours de ses Congrès tenus successivement à Besançon en 1907 , Munich, 1908, Nancy, 1909, Toulouse, 1910, et enfin à la Conférence technique des Arts décoratifs organisée par elle à Paris en novembre-décembre 1911, celte Union étudia non seulement toutes les questions relatives ì l'enseignement professionnel, mais encore les moyens de rénover les métiers et indnstries diart de province. Elle indiqua, en outre, la nature des améliorations à apporter aux conditions sociales actuellement imposées al'artisan créateur de modèles.

A celte grande question de l'enscignement du dessin est inexorablement liée la crise de l'apprentissage et de l'enseignement technique et professionnel : ce mal remonte à l'abolition des corporations, mais la crise ellemème est en somme toute récente. On ne fait plus d'apprentis, parce que les conditions du travail se sont modifiées, parce quentre le travail el l'ourrier s'est interposée la machine el que celle-ci se perfectionne de plus en plus et spécialise l'ouvrier. Ce dernier bien souvent exécule le même morceau toute sa vie : il est lui-même devenu machine. Le patron de son côlé, pour soutenir la concurrence, est obligé de décupler sa production tout en vendant au meilleur prix; l'ourrier se désintéresse alors de ce qu'il fait. Dans certaines maisons où les ouvriers travaillent aux pièces, ceux-ci ne se soucient nullement de perdre leur temps à former des apprentis, et le patron, prisonnier des lois de 1892 et de 1900 sur l'apprentissage, ne se risque pas à prendre des jeunes gens; les familles elles-mêmes veulent que leurs enfants rapportent tout de suite; à leur relour du service militaire, les ouvriers veulent gagner davantage et ne s'occupent nullement de se perfectionner dans leur métier.

Les industriels se sont vivement émus. Dans de remarquables rapports, documentés par des enquêtes poursuivies en France et à l'étranger, Fernand de Ribes-Christofle a su exprimer leurs doléances et examiner, avec un sens très profond de l'économie sociale, les causes de ces malaises et les remèdes a $y$ apporter.

Des ministres, des membres du Parlement: Astier, Siegfried, Doumergue, Dubief, Millerand, Cruppi, Jean Dupuy, Massé, Paul-Boncour, Couyba, Mascuraud, Sarraut, Étienne Rognon. Dron, Modeste Leroy, 
Buisson, se sont tout particulièrement attachés à l'étude et à la solution de eette grave question; comme l'établit une statistique récemment publicee, sur une population globale de gooooo apprentis, dont 110000 pour. Paris et 790000 pour la provinec, 95000 sculement fréquentent les écoles et les cours. "Il y a donc une armée - le mot n'est pas trop fort -- de 805000 enfants de 13 à 18 ans qui ne reçoivent aucune instruction professionnelle. Pour Paris seulement, 18 ooo jeunes gens sont inserits aux cours officiels ; le nombre de ceux qui ne fréquentent aucun cours est done de 92000 , et, si l'on tient compte que 50 pour 100 des apprentis inscrits ont une fréquentation irrégulière, on peut avaneer que plus de 100000 enfants ne reçoirent pas l'instruction professiounclle." "

“En province, oủ la fréquentation est un peu meilleure, il n'en faut pas moins compler sur un déchet de 25 pour 100 , si bien quau total, on trouve que 67000 enfants seulement sur 900000 reçoivent une instruction professionnelle....."

Si nous voulons préparer pour l'avenir de bons ouvriers d'art, il faut, dès son entrée à l'atelier, inculquer à l'apprenti la science de son métier, par la combinaison de l'enseignement pralique et de l'enseignement théorique au cours de la même journée de travail, et c'est aux associations syndicales que doivent être laissées l'organisation et la surveillance des cours prolessionnels, d'accord avee l'État, les Municipalités et les Chambres de Commerce. D'excellents résultats ont déjà été obtenus dans ce sens : notamment à Paris par les corporations de la bijouterie-joaillerie-orfèvrerie, du bronze, de la bijonteric-fantaisie, de l'ébénisterie, de l'horlogerie, de la menuiserie; à Tourcoing, par la création de l'École modèle d'apprentissagc due au député Dron; à limoges, par la Chambre des métiers; à Lyon, par l'École de bijouterie et d'horlogerie; ¿̀ Issoire, par l'École de dentelle, due ¿ Alfred Lescure, et encore à Roubaix, grâce au soin avec lequel Victor Champier s'est eflorcé de diriger l'École des Beaux-Arts vers un enseignement pratique adapté aux industries du tissage.

Une loi actuellement à l'étude doit bientôt réglementer le contrat d'apprentissage; nous souhaiton qu'elle aboutisse pleinement, mais, pour réussir, il faut que les professeurs, que les contremaîtres de nos apprentis et de nos jeunes ouvriers n'abandonnent pas de nouveau l'atelier pour un enseignement purement théorique; il laut enfin que le but à atteindre soit poursuivi de très haut, dans toute son ampleur, et qüil $y$ ait un parfait aceord entre les Ministères de l'Instruction publique et des Beaux-Arts, du Commerce et de l'Industrie, du Travail, et les Syndicats qui ont déjà rendu tant de signalés services.

Chacun doit aujourd'hui collaborer à cette grande ouvre qu'est en France la Rénovation des Arts appliqués anx Industries: "Le Prince, a écrit Montesquicu, imprime son esprit à la Cour, la Cour ì la Ville, la Ville aux Provinces. L'âme du Souverain est un monde qui donne Ia force à tous les autres. " 
Le Souverain n'existe plus; e'est l'État qui l'a remplacé. S'il n'en a ni la rolonté ni l'autorité uniques, sa puissance n'en est pas moins très réelle; cependant qu'a-t-il fail pour faciliter l'éclosion d'un style contemporain quand ont été construits ou installés récemment le Ministère des Colonies, le Ministère du Travail, la Cour des Comptes? L'État n’a rien tenté et l'architecture comme le mobilier de ces nouveaux palais ne sont que des pastiches du passé.

La faute, il convient de l'avouer, n'en est pas seulement à nos administrations, el e'est là que l'on peut plus particulièrement toucher du doigt le manque d'entente qui existe entre le créateur du modèle el lindustriel : rappelons à ce sujet une anecdole souvent répétée, et de très diverses façons : le Président Fallières, après le marouflage des peintures d'IIenri Martin dans le cabinel occupé par le secrétaire général de la Présidence à l'Ély'sée, avait été choqué du déplorable effet produit par la réunion de celle décoration nouvelle et d'un mobilier très classique. Il désira un ensemble tout moderne, el l'Administration des Beaux-Arts s'adressa dans ce but à l'excellent artiste, trop tôt disparu, que fut Bellery-Desfontaines. Très enthousiaste, ce dernier présenta des dessins complets : malheureusement, ils étaient pratiquement inexécutables el l'idée fut abandonnée; il est probable qu'il en aurait été tout autrement si Bellery-Desfontaines avait au préalable étudié ses projets avee un de nos bons fabricants ébénistes, comme le faisaient Percier et Fontaine avec Jacob ou Ravrio, un siècle auparavant.

Artistes, rendez-vous mieux comple des difficultés que rencontrent chaque jour industriels el commerçants ; sachez quelles sont leurs luttes, leurs crises; ne les considérez pas comme des intermédiaires, n'ayant d'autre valeur que celle du capital plus ou moins important qu'ils ont à leur disposition, souvent bien minime pour l'elforl engagé.

S'ils vous demandent un projet, un dessin, n'oubliez pas qu'ils ont une clientèle à satisfaire, très exigeante, très pressce, et qu'il leur faut présenter en temps voulu un modèle pratique, exécutable, adapté à son but, construit suivant la matière qui sera employée.

Quant í vous, fabricants et édileurs, négociants et commercanls, quelles que soient les facilités que vous donne la copie des modèles et des styles du passé, voyez, tandis qu'il en est temps encore, les dangers économiques de l'avenir, si vous persistez à suivre ces mêmes voies si souvent parcourues. Regardez ces maisons étrangères qui viennent vous faire concurrence ¿ Paris même, dans le meuble, l'orfèvrerie, les tissus, la céramique; lisez dans les statistiques la diminution des exportations el l'augmentation des importations dans la bijouterie de fantaisie, la maroquinerie, la tabletterie, le mobilier, le papier peint. Combien d'achats nos grands magasins sont-ils obligés de faire au delà de nos frontières: en Allenagne, services de table, vases, petite orfèvrerie, bijoux, cuirres, étains, verrerie, broderies, bimbe- 
loteric; en Autriche, services de toiletle, cristallerie, bois vernis, bibelots; en Ilalie, ébénisterie, majolique, cl cncore : tissus et porcelaines d'Anglcterre, broderies de Suisse, elc.

Quels que soient les stoclis considérables que le développement des grands magasins vous foree à posséder en réserve, rendez-vous comple que ce n'est pas du jour au lendemain que vos clients changeront leurs goûts, leurs habitudes, leurs traditione.

Le rapprochement du créaleur el du producleur, l'éducation nécessaire du vendeur el du consommaleur, doivent être aujourd hui réalisés, et il a semblé à plusieurs qu'un des meilleurs moyens d'y arriver serait d'oráaniser a Paris une Exposilion internationale des Arts décoralifs modernes.

Clı.-M. Couyba en émet l'idée dans son rapport sur le budget des BeauxArls de 1907 .

En 1909, Roger Marx développe l'économic du projet dans son délail quand il éludic tout particulièrement l'Art social el la nécessiléd'en assnrer les progres par une Exposition, ct nous ne pouvons mieux que ciler ses propres lignes: "Qu'aurions-nous á faire désormais de ces termes surannés, equiroques ou restriclifs d'Art somptuaire, d'Art décoratif! Quand un art se mêle intimement à l'existence de l'individu el de la colleclivité, la désignation d'Art social est seule pour lui convenir; on ne saurait limiler à une classe le bénéfice de ses inventions; il se dédie libéralement à lous sans distinction de rang ou de caste : c'est l'art du foyer el de la cilé-jardin, l'art du château el de l'école, l'arl du bijou précicux et de l'humble poterie populaire; c'est aussi l'art du sol, de la race el de la nalion; l'importance s'en alleste par le feu de son action sur le progrès des industries, sur la prospérilé commerciale du pays; - si bien qu'en somme ses destinées se trouvent intéresser à la fois l'esthétique, la sociologie el l'économie politique....."

"S'hypnoliser dans l'adulation des âges disparus, c'est entretenir le nuage d'un rêve, c'est perdre contact arec le réel el se disqualifier dans le concours ouvert entre les nations."

"Loin de demeurer oisives, durant notre long sommeil, elles s'étajent éclairées sur le principe de l'Art social, sur les conditions de son existence el de son progriès."

"En ce qui le concerne, la loj fondamentale est la loi du renouvellement nécessaire. Il ne remplit sa mission que sil évolue en accord arec l’époque dont il exprime les meurs, les idées, Jes besoins. Toute dérogation à la règle rompt l'équilibre et l'harmonie. Chez nous l'Art social n'est sorli de sa léthargie qu'à parlir de l'instant où il a tenté de se soustraire aux suggestions du passé el où il s'est retrempé aux sources du libre instinct el de la nalure."

N'hésitons pas à le répéler : Michelel avait déjà dit de l'Art qu'il doit "inventer ou périr" ". Et lioger Marx constate avec regrel combien de trop nombreux archilectes ont favorisé a la prolongation de cet anachronisme 
qui se perpétue comme un défi au bon sens el à la raison ", alors que l’architecture " est l'art social par excellence".

Et plus loin : " En 1900, on s'est trouvé en présence d'initiatives émanant parfois d'individualités glorieuses, mais sans lien entre elles, parce qu'il n'y avait ni unité de vues, ni même orientation des activités dans un sens déterminé..... "

“ On sait les atteintes portées à notre esprit d'initiative, à nos facultés d’invention laissées en friche, à notre goût qui végète el s'atrophie, faute de s'employer utilement....."

"Pour nous guider celte fois, nous avons les jalons d'une expérience dırement acquise; plutôt que d'assister, complices impassibles à notre amoindrissement, le mieux est de se remeltre à la lâche, de reprendre l'ouvre de régénération au point où elle étail restée, mais en s'imposant d'en réğler la conduite, selon la logique d'un plan prémédité, mûri et qui préserve l'entreprise de tout risque d'avortement. "

A la suite de ce travail, un débat s’institua dans la presse et dans les revues par les articles de Paul Ginisty, Vauxcelles, Pierre Gauthiez, A. Liesse, Grandigneaux, Alphonse Germain, Pierre Hepp, Pascal Forthuny, Yron, Joseph Lenot, Henri Duhem, etc. En outre, maints correspondants prenaient soin de formuler à Roger Marx les raisons pour lesquelles ils acceptaient ou refusaient de s'associer à sa conclusion. François de Curel, Paul Desjardins, Maurice Poltecher, André Chevrillon, Christian Cherfils, II. Bergson, Francis Jammes, Emile Verhaeren, Auguste Roclin, René Lalique, la princesse Marie Tenicheff, E.-M. de Vogué, Vaudremer, Charles Plumet, Maurice Materlinck, Albert Besuard, Maurice Denis, Bourdelle, Le Chatellier, Charles Gide, Edmond Picard, Destrées, Louis Bonnier, le pasteur Charles Wagner, Lucien Magne, Sézille, Chedanne, Bodin, étudiaient dans leurs lettres l'évolution de l'Art social en France et à l'étranger et recherchaient les conditions de son renouvellement et de son progrès.

Celte grande idée d'une Exposition internationale d'Art décoralif moderne avait, entre autres, lout particulièrement frappé G.-Roger Sandoz, secrétaire général de la Société d'Encouragement à l'Art el à l'Industrie, René Guilleré, Mezzara, Guimard et Paul Follot, alors président, viceprésidents el trésorier de la Société des Artistes décorateurs, et, au cours de longues conversations, ils cherchèrent les divers moyens de la faire aboutir.

Le moment était d’autant plus propice que le sénateur Émile Dupont, pour secouer l'indilférence générale, venait de prendre l'initiative de soumettre au Parlement el au pays l'important probleme des Expositions en France, el notamment la question éventuelle d'une grande Exposition internationale à Paris, en 1920.

Le 28 mars 1911, sur la proposition de G.-Roger Sandoz el de Jucien Layus, le Conseil de la Sociélé d'Enconragement à l'Arl el à l'Indnstrie, - si éminemment présidée aujourd'hui par Ilenry Roujon, après Gustave 
Larroumet el Félix Follot - donnait sa pleine adhésion au projet d'une Exposition internationale d'Art décoralif et ouvrail immédiatement un premier crédit pour le cas où une avance de fonds serait nécessaire, élant bien entendu que la Socièté n'agirail que d'accord el solidairement avec I'Union centrale des Arts décoralifs el la Sociélè des Artistes décoraleur's, et que l'organisation ultérieure de celle Exposition devait, le moment venu, passer à un Comité spécial.

Mis au courant de cette décision au cours de la réunion amicale des membres de la Sociélé d'Encouragement qui suivait celle séance de son Conseil, le sous-secrétaire d'Elal des Beaux-Arts, Dujardin-Beaumetz, adoptait immédiatement ce projel dans un chaleureux discours.

Quelques grands journaux en comprenaient bien vite l'importance et publiaient la lettre remise par les trois Sociétés au sous-secrélaire d'lital des Beaux-Arts, en même temps que des interviews des ministres Sleeñ, Alfred Massé, Paul-Boncour, Dujardin-Beaumelz, alors à la tête de l'InsIruction publique el des Beaux-Arls, du Commerce el de ITulustrie el du Tracall, el de Maurice Sarraul, rapporteur du budgel des Beaux-Arts.

Mais il fallail eréer un grand mourement en faveur de ec projet d'Exposition internationale des Arls décoralifs modernes : l'Union centrale, la Socićlé d'Encouragement, la Sociélé des Arlistes décorateurs constiluaient, sous la présidence de François Carnot, une Commission d'élude qui faisail appel aux Associations inléressées el íloules les bonnes volontés el condensail son travail en un Rapporl rédigé par René Guilleré, rapport qui

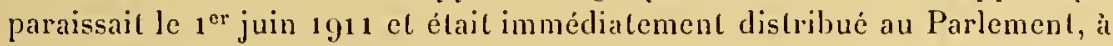
l'Administration, aux Municipalités, aux Chambres de commerce, aux grands gronpements artistiques el industriels.

La discussion est encore ouverte sur ce rapport qui a élé signé par les délégućs de toules les grandes Associalions s'intéressant à l'Art, soil par ordre alphahélique: Sociéle des Artistes décoraleurs, Sociélé des Artistes français, Société d'Encouragemenl à l'Art el à l'Industrie, Sociélé française de l'Arl à l'école, Sociélé nationale des Beaux-Arts, Salon d Iutomne, Ĺnion centrale des Arts dicoratifs, L'nion procinciale des Arts decoralifs.

L.es vorux suivants y ont èté adoplés :

\section{Les Associalions soussignées,}

l'réoccupées du développemenl de nos Arls décuralifs, litre d'une gloire séculaire pour la France,

Après avvir conslaté que les condiliuns économiques acluelles rendent nécessaires pour nos Industries d'arl, sunrce considérable de richesse nationale, l'élablissement de modéles nouceaux el leur diffusion,

Estimenl indispensable, pour stimuler les e/forts des arlistes, des industriels el des ouvriers d'art, une manifestation internationale, spécialisée à lous les Arls lécoralif's, appliqués à l'archileclure, au mobilierel à la parure, 
résercée ì des auvres d'une inspiration nouvelle, ḋ l'exclusion de luus pastuche ou copie du passé.

Et, en conséquence, émeltent le vœu que le Parlement et le Gouvernement, s'inspirant de ces considérations, decident l'organisation el l'oucerture à Paris, en 1915, d'une Exposilion internationale des Arts décoralifs modernes.

Le mouvement élait créé : Couyba déposait au Sénat un projel de résolution favorable; Maurice Sarraut, Étienne Rognon, entre autres, portaient le débat à la tribune de la Chambre.

Depuis, le 6 février 1912, la Chambre a renvoyé à sa Commission du Commerce el de l'Industrie la proposition de loi tendanl à oryaniser, a Paris, une Exposition inlernalionale des Arts décoralifs modernes, présentée par les députés François Carnol, Paul-Boncour, Henry Cochin (Nord), Charles Dumont (Jura): Alfred Massé, Noulens, Puech, Joseph Reinach, Sembat, Sebille, J. Thierry, Aynard. Nul doute que son rapporteur, le député Roblin, ne conclue dans un sens favorable.

Quant à la presse, elle avait fait le neilleur accueil à ce travail, el nous ne saurions trop remercier entre autres : de Jouvenel, Emile berr, Graudigneaux, Thiébaut-Sisson, de Fourcaud, Pascal Forthuny, Vauxcelles, Roches, Saunier, Paul Steck, Clément Janin, dont Floury éditait en même lemps les arlicles si complets sur le "Déclin el la Renaissance des Industries d'art el de l'Arl décoratif en France ". Exprimons aussi notre gratitude ì nos journaux d'art : la Gazelle des Beaux-Arts, la Revue de l'Art ancien el moderne, Art el Décoration, l'Art décoratif, la Revue des Beaux-Arts.

Nous n'avons pas cru devoir entrer ici dans les détails très complels que le Rapport donne sur le projel d'Exposition internationale des Arts décoratifs nodernes, el notamment sur son organisation alministrative el financière el sur sa classification qui parait devoir être faite suivant la destination des cenres: Groupes de l'Archiledure, du Mohilier, de la Parure el des industries qui s'y rallachent, ance classes spéciale's pour les Irts du Théatre, de la Rue, des Jardins el pour l'Enseignement.

Iais il fiut que restent inlangibles son objel et son hnl, la composition de ses comilés, la présenlation des centes.

\section{$1^{\circ}$ Son objel el son but:}

Par la collaboration de lartisle, de l'industriel el de l'artisan, réunir en une Lixposition internationale tous les Arts décoratifs : archilecture, arts du bois, de la pierre, du mélal, de la céramique, du verre, du papier, des lissus, elc...; sous loules leurs formes, qu'ils s'ippliquent à des ohjets d'utilité on à des aures purement sompluaires; dans loules leurs destinations : décoration extérieme el intérieure des édifices publics el privés, ameublement, parure de la personne. 
Celle Exposition doil ètre exclusivement d" "Arl moderne n. Aucuns pasticlte on copie des slyles anciens n'y seront admis.

$2^{\prime \prime}$ La composition de ses comilés.

Ils devront comprendre par tiers :

a) Des artisles, archilectes el décoraleurs de loules techniques;

b) Des industriels, fabricants, édileurs, entrepreneurs de traliax auxquels devront être adjoinls quelques ingémieurs, des ouvriers el contremaities de fabricalion;

c) Des écrivains, anteurs de livres trailant de l'Arl décoralif, des fonctionnaires el personnalilés sélanl occupés de questions d'arl décoralif moderne.

$3^{\circ}$ La présentalion des cutres:

Les reuves exposées seront disposées en chsembles harmonieux, mais de ficson pourlaul ì ne pas sacrifier cntièrement an pilloresque leur portée d'enseignement artistique el lechnique ou de documentition commerciale.

Tonle ouvve devra èlre exposée sous les noms de larlisle créaleur, de Iindustriel éditeur, el de leurs collaborateurs principaux, acec indication de la parl de chacun.

Une grave question est celle de l'emplacement. Mais ne confoudons pas de nouveau qualilé el quantilé: les terrains nécessaires ne doivent pas dépasser une trentaine d'hectares et leur exiguïlé relative facilitera même la tâche des Comilés d'admission et d'installation el les forcera ì être d'autant plus sévères.

N'oublions pas non plus que si le caraclère de l'Exposition est arlislique, son bul est surtout ulile el pralique : son organisalion générale doit done logiquement appartenir au ministère du Commerce et de l'Industrie, avec lequel, bien entendu, devront collaborer le ministère des Beaux-Arts, le ministère du Travai! et la Ville de Paris. Aussi bien les ministres Fernand David, Guist'hau, Léon Bourgeois, Bérard savent qu'ils peuvent compler sur le dévouement de ces hauts fonctionnaires et de ces chefs de services qui s'ippellent Fermand Chapsal, Albert Tirman, Gabelle, Louis Bonnier, Aulaure, Maurice Reclus, Paul Léon, Valentino, Mareadel, Iedet, Dumonthier, d'Estournelles de Constant, Fighiera, Caviole, Nicolle...

Le Parlement, le Gouvernement, la Ville de Paris out examiné ce projel avec la bienveillance la plus altentive, mais il a élé maiutenant assez parlé, assez disculé, assez écrit à son sujel; il faut aujourd'luui vouloir, décider et agir : acla non verba.

Quelle que soil la puissance de l'ḱtal, elle a besoin d'être soutenue par l'opinion publique et par l'iniliative privée.

Il y a quelques mois, les délégués des Sociétés arlistiques ont pu s'entendre dans nu but commun : c'étaient plus spécialement Roger Marx, François Carnot, Couyba, Henry Roujon, Layus, G.-Roger Sandoz, Rané Guilleré, Bausset, Louis Bonnier, Frantz Jourdain, liaymond liøechlin, 
Georges Lecomte, Lhermilte, Vielor Prouve, Van Brock, Georges Boin, André Bouilhet, Henri Vever, Edmond Poltier, Quénioux, Léon Riolor, Fẻlix Aubert, Chudant, Vaunois, Mezzara, etc...

Cet accord, celle entente, alors provisoires, doivent devenir permanents : assez, des questions de personnes; assez, des lulles d'écoles, de petites chapelles ou d'administrations. Quel noble but pour les diverses Associalions parisiennes et provinciales, pour les grands Syndicals intéressés, pour toutes les bonnes volontés, que de s'unir en une vaste Fédération française des Arts ippliqués à l'Industrie, qui ferail aboulir ce projel d'Exposition internationale el qui voudrait la solution pralique de ces questions vilales, à savoir : l'amélioration de l'appreutissagre, la réorganisation de l'euseignement lechnique el professionnel, la rénovalion des industries provinciales, l'exteusion du contrat d'édition, la transformation pratique de nos Écoles d'Art, el notamamcnl la reconstruetion de l'École nationale d'Art décoratif de Paris, si souvent réclamée, si souvent promise!

Vous tous qui voulez voir notre cher pays garder sa place a la têle des nalions dans le domaine du Beau, serrez les rangs! I.e combal en ordre dispersé est terminé, serrez les rangs $\ldots . .$.

Voilà quelle fut durant un long siècle l'évolution lente, roulinière ou capricieuse de nos Arts industriels; nous roulions, at Lravers les Expositions, indiquer seulement leur bisloire, ressusciler quelque peu leur vie; mais, en feuilletant noles el rapports, nous nous sommes laissé entrainer a écrire au courant de la plume des pages el des pages; nous avous trouvé à les rédiger un vérilable profil qui fera excuser la longueur démesurée de celle Elude : elle devail se réduire à quelques feuillels, elle a presque pris les proportions d'un livre.

Ce n'est lá, d'ailleurs, qu'une ébauche toute documentaire, qu'un plan esquissé à grands traits.

Nous laissons à d’autres, plus compélents, le soin d'écrire cel essai, de le parfaire el de nous clonner un jour celle IIistoire de la Décoration el des Arls appliqués à l'ludustrie qui manque à nos jeunes générations.

IIai 1912.

Au moment oí est dommé le "bon a tirer" de ces dernières linnes, nous sommes heureux dapprendre que le députe Iinblin vient, an nom de la Commission du Commerce et de l'Industrie, de dépuser son Rapporl (dont un résumé figure daus les Documents concernant l'Exposition internationale des Arts Décoralifs modernes projetée it Paris, imprinis a la suite de la présente Elude et de la Liste sommaire des Rapports officiels français consacrés aux Industries d Art dans les Expositions', el qu'en outre, le 1.2 juillet 1912. la Chambre des Díputés, d'aecord avec le Gouvernement, le rappoiteur et les auteurs de la proposition de loi, a adopté le projed de résolutiun suivant:

La Chambre invile le Gouvernement à nommer sans délai une Commission interministerielle chargée détablir les voies et moyens pour la réalisalion d'une Exposition internatiunale des Arts décoralifs modernes qui aurail lieu a Paris en $19 / 6$, sous la direction du Ministére du Ciommerce.

Juillet 1912. 


\title{
LISTE SOMMAIRE
}

des

\section{Rapports officiels Français consacrés \\ a ux Industries d'Art dans les Expositions. \\ I 798 - I9II}

\begin{abstract}
GENÉR ALITÉS
Achille De Cur.uoxt. - Histoire des Expositions des prouluits de Industric francaise $[1798-18301]$.

Comte Cusptal. - De IIndustrie funcuise, 1819, 2 vol.

Jules Sisos. - Introrluction au Rapport de lExposition le Puis, 1878, eh. Ier et 11, Ilistorique des Expositions [1798-1878..

Alfred Picaro. - Lapport genciral de l'Exposition de Puris, 1889 , tome Ier, 11istorique des Expositions [179S-1889].

G.-Ruger Saxnoz el Jean Gejfankx. - Arts appliquis et Industries d'Ant aux Expositions, litude dueumentaire [1 798-J9J?].
\end{abstract}

\section{I'atis, an II (1798), Exposition publique des produits de Industrie française.}

Catalogue des produits qui ont été exposés an Champ de Iars pendant les trois dernicers jours complémentaires de l’an VT, aree les noms, dipartements et demeures les arlistes et manufactuliers, qui ont concouru à l’Exposition, suivi du Procèsverust du jury nommé pour l'examen de ces produits.

\section{'al ris, an IX (IS0I), Seconde Exposition publique des produits} de lunustrie franceaise.

C.ıtangue des productions industriclles exposées dans la grande cour du Louvre pendant les einq jours complémentaires de l'an 1.X.

Pnocis-yerbu, des opérations du jury nommé pour examiner les produits de l'1ndustrie frunçaise. 


\section{Paris, an X (180:2), Exposition publique des produits de londustrie linangaise.}

Catrunge des productions industrielles exposées dans la grande cour du Lonve. Procis-Yratur des opérations du Jury.

\section{l'aris, I806, Lxposilion publique des prodtuits de lludustrie franuaise.}

Notire sur les objets exposes [dans la grande cour du Lourre], rédigíe et imprimée par oride de S. Exi. M. ne Chumparr.

Liappont dn Jury sur les produits de lludustrie française, présenté par S. Exe.

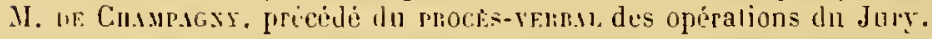

\section{Paris, ISIG, Exposition problique des produits de Inulustrie franģaise.}

C.statogre indinnant le nom des fabritans, aree la designalion sommaire des mouluits de leur industrie [expusis au Palais du Louré].

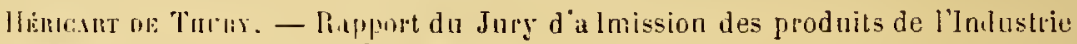
du départen'nt de la sine à l'Esposition.

M.-L. Costaz. - Riupport du Jury central sur les proluits de I'Industrie fran-

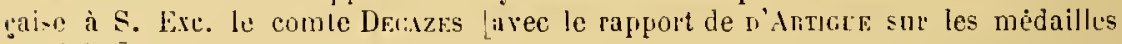
spinciales].

\section{Paris, 18:3, Fxposition publique des produits de lindustrie finngaise.}

Cuxaloger des produits de l'Industrie française admis a l'Exposition publique dans le Palais du Lourre.

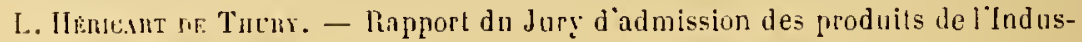
trie da departement de la Silur. 
$\mathrm{V}^{\mathrm{t}_{3}}$ Héncant de 'JuLn el M. Mignenon. - Rapport sur les produits de l'Industric française, présenté au nom dı Jury central à S. Exc. N. le comte ne Corbièr., apl:rouré par S.S. M, le duc ne Dorneaurlle.

A.-M. IIthos Je Vildufosse, - Ripport fait au Jury central sue les objets relatifs ì la métallurgic.

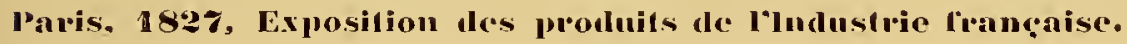

Catalogur des produits de l'Industrie francaise admis à l'Exposition publique dans le Palais du Lunve.

P.rfen. - Rapport du Jury départemental de la Seine sur les produits admis atl cuncours de l'Exiosition. 2 rol.

Vie Héruche de Then el M. Migneron. - liapport sur les produils de l'Industrie francaise présentés au nom du Jury central à S. Exc. M. le comte de Saris-Cajco, ministre, secrétaire d'Eıal dı Commerce et des Manufactures.

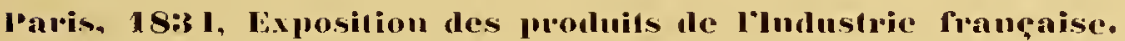

Baron Charles Dera. - Rapport du Jury central sur les produits de l'Industrie française [exposés sur la Place de la Concorde]. 3 vol.

Stéplıane Fucırs. - L'lndustrie à l'Exposilion de 183' (planches hors texte graves au trail).

\section{paris, I 839, Exposilion des produils de Pludustuie l'mencaise.}

Rappont ne Jlis cexthis [sur l'Exposition qui eut licu au Caré Marigny, aux Champs-Elyséc: ]. $3 \mathrm{rol}$.

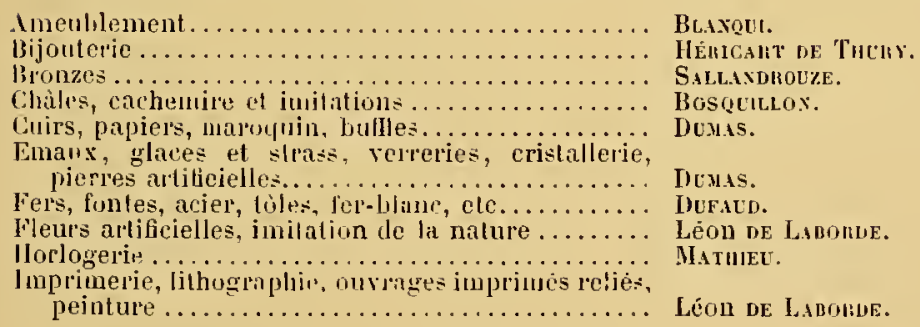


Instruments de musique.

Metaux divers et alliages ..........................

Orfèvrerie, ciselure, plaque...

Soieries, rubans, tissus de crin, etc.

Tapis, tissus de verre, dentelle ..........................

Terre cuite, faience, porcelainc, poterie en grès,

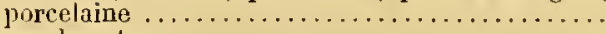

Tissus de coton.

Tissus de cotou, de conleur, et blancs ..........

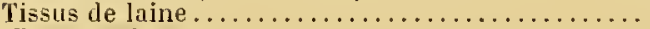

Vitraux peints.
SaVArT.

Belrther el jocchel.

BEUDIX.

CALEz.

BLANQU1.

Cuevieul.

BroNGXIART

KOECHLIX.

BALBBET.

LEGENTIL.

BROXG.XINT

\section{Paris, 1811, Exposition des prodnits de l'Industrie française.}

Rappolti du Julu centrat. [Eul l'Exposition qui eut lieu au Carré Marigny, aux Champs-Elysées]. 3 vol.

Dessins de fubrique.

Bijoulerie, stucs, etc.

Bronzes, ornements dorés, moulés, sculptés, cuivres

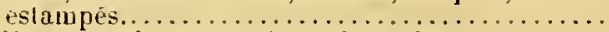

Chales de cachetuire el leurs imitatiuns............

Cuir's et peaux, cuir's vernis, maroquins..........

Ebénisterie, minqueterie, tabletterie............

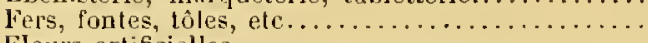

Fleurs artificielles.......................

Fonderie de caracteres, gravure sur bois, piejre, métaux, imprimerie, librairie, reliure.........

Galvanoplastie, dorure, argenture par les proceddes

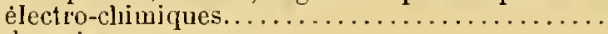

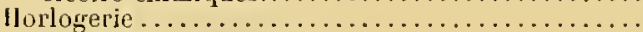

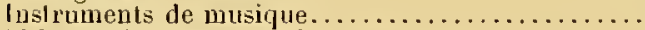

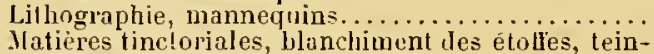

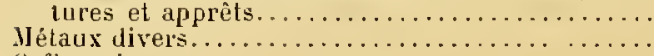

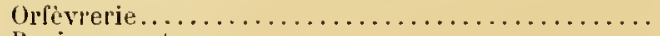

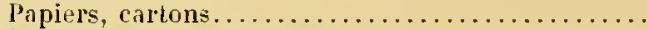

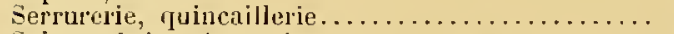

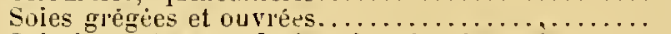

Soieries, rubans, peluches de suie, ti-sus de crul .. Tapis, dentelles, broderies, tapisseries, etc.........
Terre cuite, gres, fajences, poredinines. decor sur porcelitine, émaillage, vilpux peints.........

Ti-sus de coton blancs et coulemr, etc............ 't'issus de laine.

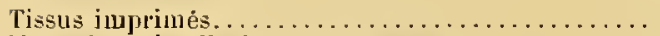
Verrerie, cristallerie, glaces, éman..............
SaLLAXDROCZE DE LATIOMXaIX.

iléligart ue Tulrr.

Lèon leutriline:

DENEHOESSE Ul LEGENTIL.

DIMAS.

BEUDIX.

Michel Cuevalier.

V'te Héricart le Tucry.

Fแแมเx-Didot.

Duin.s.

Baron Séguier.

Savalt et Delayorixière.

l'ICoT.

Chevinevl.

Beistilek et Moschel.

BEXYĖEE.

Dinis et Dinot

Chevieul.

Amédée Dur.ino.

Merisard.

Arlès-Dufour et Revelicirox.

Blangu.

Bhosginart.

Keittisgen.

Legentil, Legros, Gulba,-.IXXE-

Vente el Mlmerel (Nord).

B.HBet et SCHLUMbergeli.

Dimss. 


\section{Paris, I8 19, Exposition Nalionale des produits de I'Industrie agrieole et manufachurière.}

\section{C.sTAlogle officiel.}

Rappont ne Jun central sur les produils de l'Agricullure et de l'Inclustrie, exposés en 1849 [aux Champs-Ëlysées]. 3 rol.

Dessins de fabridjue

dificles de Saiut-Ouentin et broderies de Tarire.

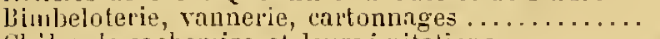

Ghales de cachemire et leurs imitalions ........... Conlenrs et matiores tinctoriales, teintures et im-

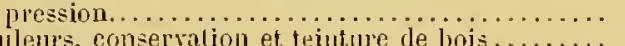

Conleurs, conservalion et teinture de bois.........
Cuin's et peanx, cuis's vernis, repoussés, hongroyes

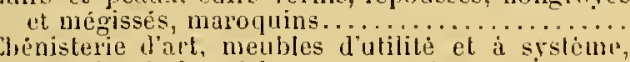
menbles de fonlaisie, marqueteris.............

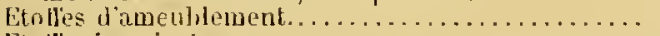

Elolles imprimies ..............................

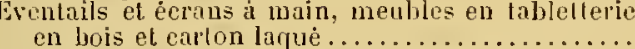
nience fine et gres cérame, faience brune ei blanche ì èmait slaunifère, poteries..........

Flenr's artillcielles, de parure. d'ornemenl........

Fonte, fonte mallèable, moulèc, fer-blanc.........

lilaces, cristaux, verres .....................

Granre el fonte le caracléres d'imprimerie... intprimerie en taille-tnuce... reliure............

llorlogerie de précision et civile ............... Industrie du cotrn...................................

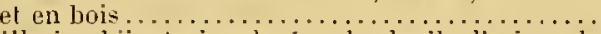

Jonillerie, bijouterie, lnrẻe, de deuil, d'acier, de strass, de corail, imitations du diamant........

lèlaus (or faux, doches et sonnettes, étain, maillechort, mélal anglais, cuivre, fonte de cuivre).

Miroiterie, hélingraphie sur plaques de métil, sur

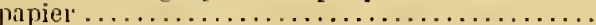

Orfivrerie, joailerie, bijonterie, plaque maillechort,

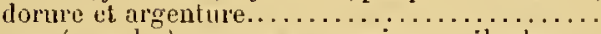

Orgues (grandes), orgues expressives, mélophones.

Ourrages en ivoire, fonderies de brouzes dial, bronze d'art el d'ameublement, hronze d'éclai-

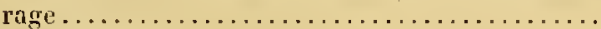

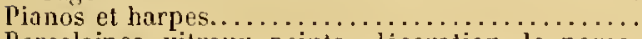

Porcelaines, vitraux peints, decorntion de porcelaine ef cristaux, émaillige sur émanx........

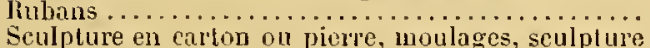
sur bois . con

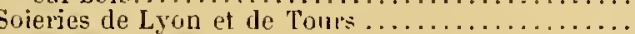

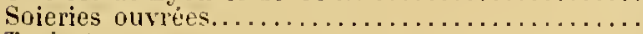

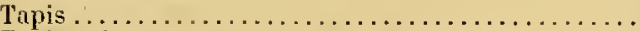

Tipisserie au mélier, hroderic, chasublerje.......
Sillaxdrovze de LaMoritix.

Fẻlix \свит.

Natalis-RosDOT.

Maxinte Guvsex.

J. Persoz.

Dus.s.

DUMAs.

Buaroul.

Justin Dumas et Germain Timbatet .

J. $\Gamma$ ERs $0 \%$

Nitalis-liomot.

Bovgox.

HÉRICART ve THUKY

Michel Cnevalouels.

Dinis.

A. Finix-Didot

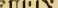

A. Mistires et E. DoLfit's.

M MiLote.

Héricint de Thuni.

Le Play.

Léon de Laborde.

WoLowski.

A. Séguier.

\section{Léon Feuchibes.}

P. Erard.

\section{Ebeliex.}

WOLOW'SKI.

\section{Bolgon.}

ArLés-Difour.

Max. Gicsses et Roux-Cinuoxier.

Blaxqui.

Natalis-Roxdot. 


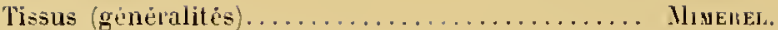

Tissus de coton blanc et écru................ E. Dolters.

Tissus de colon iunprines .................. H. BALBET.

Tissus de laine non foules de thoubaix et de lille. Iax. Giussex et Germain Thurert.

Tulles, dentelles et brolleries............... Félix Aenn.

Typochronie, lithographic, chromolithographie, pa-

piers peints . . . . P................. J. Penso\%.

\section{I,ondres, I8̄̄ 1, Ixposilion Lniverselle et Intcmalionale.}

Thayaux be la Counisson franciuse sur l'Industrie des nations, publiés par ordie de l'Empereur. 8 vol., $183 \ddot{3}-1873$.

Michel Cinevalter. - L'Exposition universelle de Londres, considérée sous les rapports philosophinue, technique, commercial et administratif au point de vue francais.

Exhibition of the Works of lndustry of all Nations 1851. Reponts uy tae Junirs on the sulujetcs in the thirty classes into which the exhibition was divided.

Tubleau statistique cmbrussant les progrés comparcis des industries francuises du coton, de la laine et de la soie. Cl. so. - Baron Cluarles Dupıx.

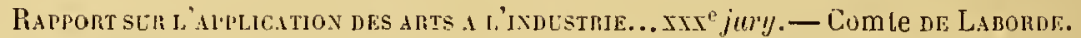

Arls céramiques

Blondes, tulles et broderies . . . . . . . . . . . .

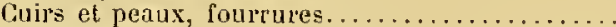

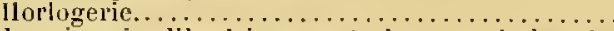

lmprimerie. librairic, papeterie, etc, industries

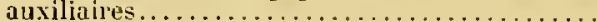

Impressions et teintures..................... Industrie des chàles el des lissus mèlange......... Inilustrie du chanrre et du Jin................

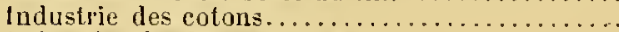

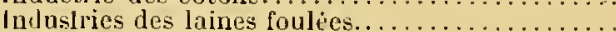

Industrie des laines peiguées................

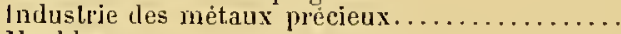

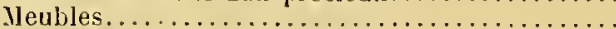

Objets de parture et de fantaisie...............

Ouvrages en fer, acier, cuivre, bronze, zinc......

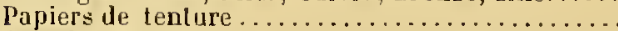

Soieries et rubans ............................

Substances vègélales et iniujales, matières premières des manufactures, des ameublements et des décors.............................

Tapisseries et tapis des manufactures nationales. 't"issns appliqués aux arts vestiairos............

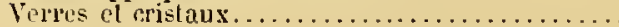

Cl. 67 Ereinex et Salietar.

8. Félix Aobny.

89 lítules.

96 Baron SEGGLER.

11 Fin.

78 PERSOY.

82 Jaxille Gicssex.

9 \& LEGENTII.

so MIMEREL.

82 Raxborra.

83 BERTOFILLE.

SI Duc ne Lulives.

69 WOLOWSKI.

8' Natalis-fionoot.

97 Goldexbeng.

$6 \mathrm{~S}$ WrLOWSKl.

83 MliLHS-DEFOUR.

S1 PAIEN.

70 CHEviteil.

S't Benxovili.e.

i3 P'́ligor.

\section{Paris, 1855, Exposilion Lniverselle el Internationale.}

Trataux ne la Conmission fraxigase sur l'Industrie des rations, publiés par ordite de l'Empereur. 3 vol., $18377-1838$. 


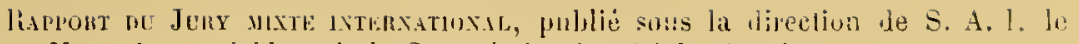

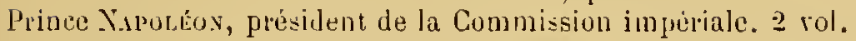

L. P.svis. - Recueil des picices it documents offoriels concernunt l'Expositivit unicersclle de 1 sòว

bonomie domeslipue; considiralions grénemales sur le but el l'ensemble de lexposiliun.

Dessius intustriels.....................

Imenlilement.

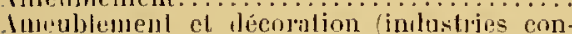

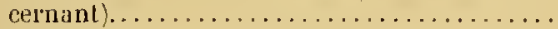

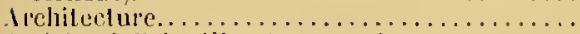

irlicles il baiguile et au crochut...........

Brouleries [an colon] pour ameublement .....

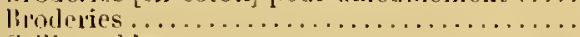

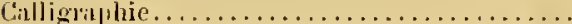

thiles broches de (hise, liancilis el bitringers.

(bilons (lissus de) el broderies de roton pour

l'amınhlencut .......................

progres el développennol de lindustrie colnn-

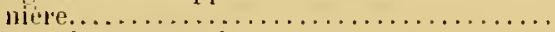

l'issus de cotun mélangé.................

Cisulenrs vituliables el cuans ............

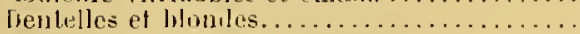

Eloffes nour ancublement ...............

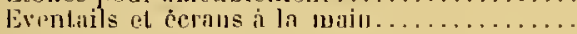

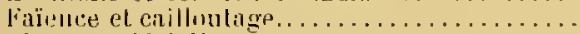

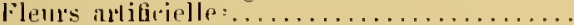

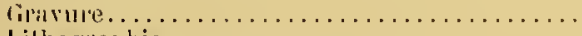

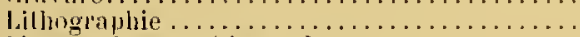

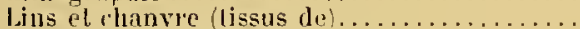

Moulage, estaupige $\ldots \ldots \ldots \ldots \ldots \ldots \ldots$

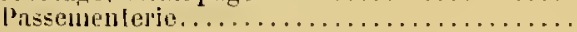

Peinlıre, gravure, lithograplue ...........

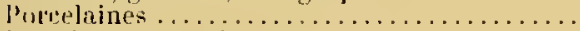

polrites el verrerie .......................

Ritlime .........................

sculpture ef gravure en undialles..........

Soje lissuls lie) el luhans...................

soies foulées, moviees, filature des dichels...

Tapis et lapi sirvirs il l'aiguille ............

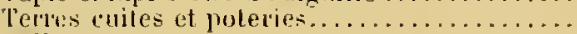

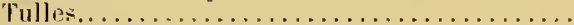

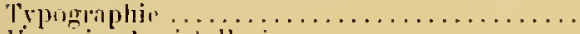

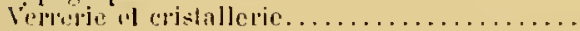

Vitraux............................

Gi. 31 Nichel CMeval.ter.

26 Léon l'Euluéres.

Cl. 31 limuteswit..

2i MU SOMUEKa

30 Anomyme.

2 ii LEGESTHL.

29) Lacr-Simrins.

23 lielix foms.

96 .ll:m.

20 Gacsers.

29 LrCY-S̈EDLI. 0 \%

29 SELIIHKE.

29 KuLLE:

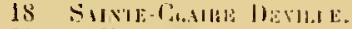

23 Fílix lums.

30 Cialises.

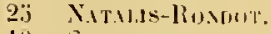

is SAlTEITT.

2.) Titilis-Ronem.

26 Mrki,

26 I.onis linastan.

22 CHETHET.

26 I.ECMESTE.

28 Pates.

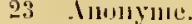

18 Rrginilit.t.

31 lianiesnili.

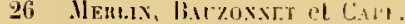

29) Anourw\%.

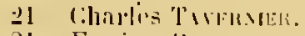

21 Engine liubst.

2.3 LIINIE.

23 DE BHot CKËRE.

28 LIETS DELILIYE.

26 Rimuret.

is Jiaigot.

28 DE GWWONT

\section{Iondres, I 862, Exposilion Iniverselle el Intemalionalu.}

Ri.repont de liAdministralion de la Commission impúriale sur la Seclion franenise de l'Exposilion unirerselle de 1862 .

Ipllicalion de l'dil a l'Industrie ..........

les brevels dinvention.................

Dessins industriels.

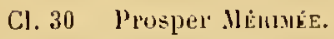

7 Arllur Llitikixo.

2 i Fix AuBr. 
Enseignemenl industriel.

Enseignement du dessin artistique et clu madetage, en vou de leis application à lïndustrie.

Ameublement et recoralion............... Arts céramique........................

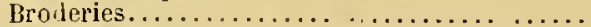
Bronzes d'art, zincs, cuirres, Jontes............ Bronzes d'art et d'ameublement. Siluilion de cetle industrie. Prompes. . . . . . . . . . . .

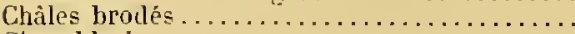

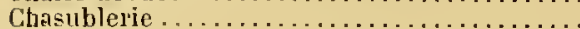

Cristaux................................

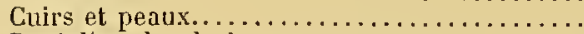

Denteltes, brederies, passementeries et tinpisseries...........................................

Etoffes d'ameublement en tissus mélangés, laines, soie, velours d'Utrecht..............

Horlogerie .........................

Joaillerie, bijonterie et orfevrerie............. Mtaroquinerie, vanuerie tahlefterie et eventails Objets fabriqués en bois el en iroire........ os, cornes, sabots, iroires. imalles, perw.... Papiers .............................

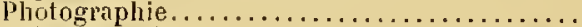
theliure des lirres, alhums of maropninerie..

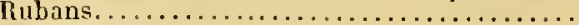

Serrurerie (grosse et pelite et ferronnerie...

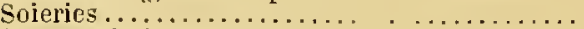
Soies, soieries el rubans................... Tapisseries et tapis...................... Tapisseries, ouvrages dirors all rorohet, au tricot et a l'aiguille ....................

Teintures et impressious..................

Tulte et dentelle à la mécanique............ Verrerie en gẻnẻral, vitranx..............
C1. 29

Charles Rionent.

30

\section{Pan'is, 1867, Exposilion Universelle et lnteruationale.}

Risport sur l'Exposition universelle de 1867, Paris. Prícis Des opératuns fit LISTES uES COLCa Bor.tTetrs, avec un appendice sur l'avenir des Exposilions, la statistique des opérations, les documen Is officiels et le plan de l'Exposition.

Gatalogue officiet, des Exposants récompensés par le Jury internalional pagination par groupes].

Michel Cievalier, - Introduction au recueil des lapports du Jury international.

Ripports de Jum intfricitronat publiés sous la direction de Michel Cil:VALITIS.

Alfred Le Roux. - Exposition universelle de 1867, à Paris. Jury spécial. Nonvel ordre de récompenses inslitué en faveur des établissements et des localitís 


\section{- CXXXYI -}

qui ont développé la bonne harmonie eutre les personnes coopéranl aux mêmes travaux et qui ont assuré aux ouvriers le hien-être matériel, intellectucl et moral. Rapport.

Applications de l'art i lindustrie........... Cunsidirations sur l'irt dons ses rapports avee

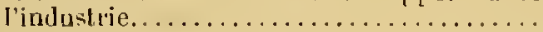
De l'enseignement du dessin en $1867 \ldots \ldots \ldots$ Enseignemat technifue, agliculture, inilus-

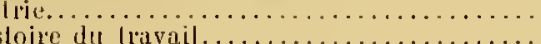

Ilistoire du lavail........................ aux ouviciers, chefs de ućliers............

peinture, dessio, sculpture, architecture, gravure et lithographie................

proceles et enseiguement de lint industricl. prouluits de toute sorle fahrifmés par des ortvlues chefs die ulitier's..................

Acier en $1867 .$.

Blanchiment, teintime. des matieres textiles.. . . . . . . . . . . . . .

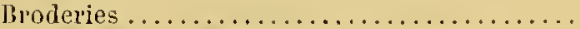
broderies et passementeries orientales...... Bronz: d'art, lontes d'art diwpes...........

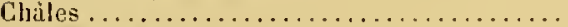

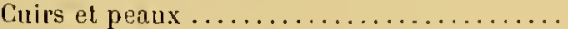

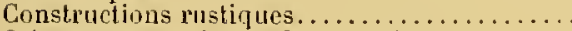
Cristaux, verperies de lixe et vilraux .......

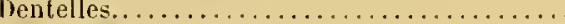

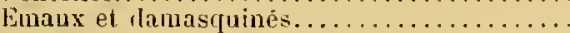

Eventials (fabrication des).

Faience dure, faience dicolative et porcelaine

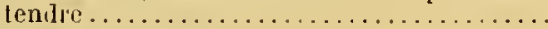

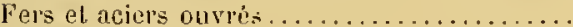

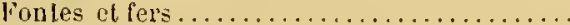

Galvanoplastie.

Application en frimd de la galvamolastie el te

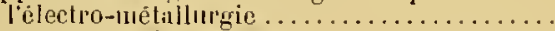
Grinvure sur pierres dures.................

Ilabitations caractérisées par le bon marche uni aux condilions d'hrgiune el de lien-être.

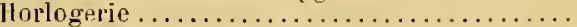

Industries accessoires [bimbeloteri $]$.......... Imprimerie et libraj rie .................. Joatlerie et bijouterie...................

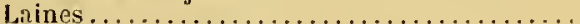

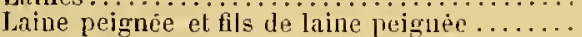

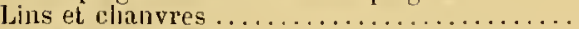

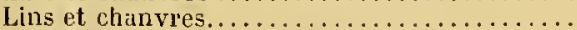

Maroquinerie, tahlettrie et vannerie, objels divers............................

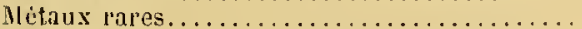

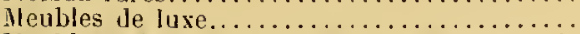

Meubles, vêtements el alimeuts de toule origine, distingués par les qualités uliles mnies

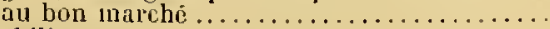

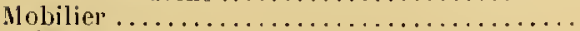

Orfèvrerie. . . . . . .

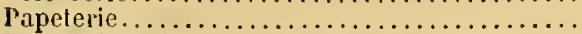
Papeterie, teinture et impressions (materiel et

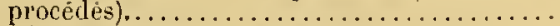

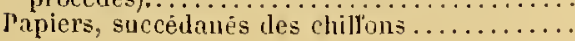

Cl. 8 Eidmonel T.ugxy.

If E. Guicuino.

89-90 Edmond Bnoxgivintit.

89.90 Phil PoบคÉE.

Gi. 1 E. de Sommerian.

Cl.93 Dumum el Vax Bu.hexaenank.

Gir. I Ernest Cuesseni.

CL. S H.LTHBD.

9' Suxt-lies el luguste Vill.

Cl. 40 E. Fineny.

4:) Nime bouratec.

33 Tiox rater.

33 DE LALXAY

9-2 BuRHEMIENล.

32 Davill Gasisux.

46 FatLEO

If Albert LE PLAY.

16 E. Peligor it G. Boxtemps.

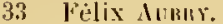

21 Philipue Mranocul.

3i Di rustar (piate).

17: limé Gustio.

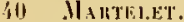

40 Edmond Frens el P'. Wonys de Bomus.t.

i7 DE JACUB!.

47 Orens.

8 Baline.

E. Degkaso et Dr J. Fulfheh.

BrÉgevt.

Fred. Jolndons.

l'anil Bortesu.

Fossix el Baccimixn.

Ilow.

li.-E.-Charles SEvorx.

CASSE.

MoL...

Louis Aucoc pite).

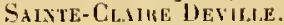

Diéteale et l'ollex.

91 \. Cocms.

91 SelLutilie.

2f Paul Cumstolite.

7 Roulatac.

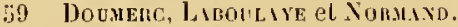
7 Anselme lityex. 
Papiers peiuts.

CI. 19 Aldiorif.

lapiers pe

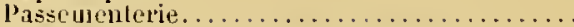

Pholographie, epreures el apparoils.........

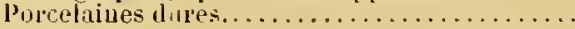

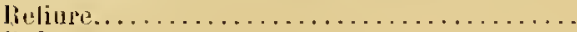

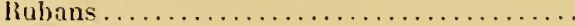

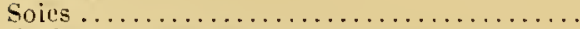

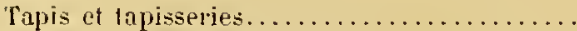

Tapis d'un nsage ordinaire ..............

Oovrages du tapissier et du décoralenr......

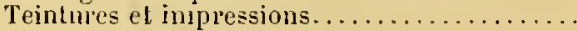

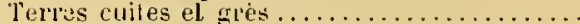

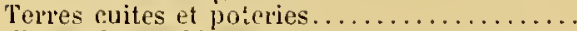

Tissus d'ameublement.

Tissus de pul'e linine peignée, de laine mélangéc, cardée ......................

Tissus de liu, chanve, jute et coton ..........

Tissus de colon..........................

Tissus de colon imprimés. ................... du chauve, chiuagrass et textiles divers...

Thisus de libine peiruce, nou foolée... do lil ct eoton, chiles......................

Tisius, elliluchages de laines...............

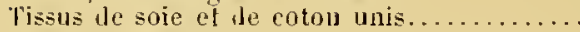

Tissus et soies.

Vètiment (coulection do) pour honnues,

femmes et enfank...................

Vèrentient d'homme et de lemme..............

Vêtement, malériel et procédés de la conture

el de la coufection ....................

Vêlcment, costumes des jiverses contres

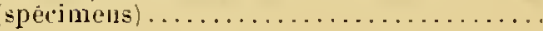

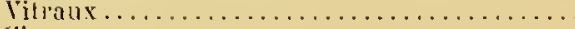

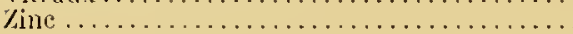

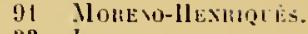 \\ 33 Lowver. \\ 9 1)+waxe. \\ 17 Denmontis. \\ 17 Paul borteat. \\ 31 Girovos. \\ 31 Jules Rismbert. \\ 18 Bidin. \\ is W. CHoceueel. \\ 1:) DiÉTERLE et DIGHY-WYATT. \\ 4. J. Prinsoz [6]:). \\ 17 ('HACUELOY \\ (ii.) L. B.ICUE. \\ 18 CAliLHIAX. \\ 29 LAHsoxxiEn. \\ 91 F. becoive. \\ 91 A. SEILIIËIE. \\ 27 Jules liofestix. \\ 2S A.-F. LegextiL. \\ 91 BOCFFARD. \\ g) V. Dabmourel Monexo-lJexiogcis. \\ 33 Deluate. \\ 31 Iphonse Psirx. \\ 91 Monexo-llixhocis. \\ 33 Alignste licsiltos. \\ i7 F.-Q. Jenry v'Iturixy. \\ 92 AMMIXI-])('MALESO

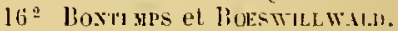 \\ î Edmunt licens.
}

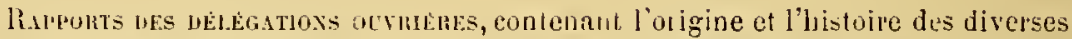
professions, l'appréciation des ohjets exposi's, la comparaison des arts et des iudus. tries en France ct à l'étranger. 3 tumes illusllés; [cllaque rapport paginé ia part].

libutrier's.

Balanciers, bilances el poids de précision.

Balances de haute précision..............

Bijouliers..............................

Cintonniers de fantaisie...............

bécoupeurs-marqueteurs...............

Dessinateurs d'ameublemenl............

Dessinaleurs en chảles.................

Horemrs sur hois....................

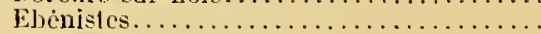

Frentaillistes

Feur's artificielles.......................

Fondeurs en cuive...................

Fourreurs et apprêteur's en peitux....... Horlogers..

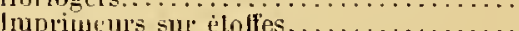

luprinculs en papiers peints.............

Imprimems en taille-douce.............
DIECUORIE et F. SULIS.

leh. Cirocher.

Avily.

Colpat, llemgor, Missox uf Pherotene.

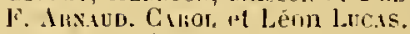

Ginent, A. Levaloos et E. Ponuel.

Bruxet el C. Nivilifa.

Canties, P. Dentr, E. Jixix, E. Meren, A. MoxNET el Rabrautr.

ENtieselt el LabahUe.

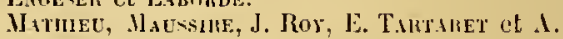
Vorm.

A. Batoe et A, JoIzlaL.

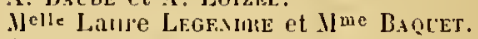

MVALLe, Gompunke.

IIFian, Jom, Lababie el Tolbin.

F. $-V$. Alexa vine.

Bulamb, E. Dosbotra et II. Mercien.

II. Deboss, li. Sinox et li. Sox.

Desiors, L. bonvitr el C. SIINestrie. 
Jualliers

A. L.LCHOLX at E. PLESSIEli.

Laqueurs

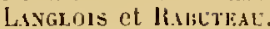

lillographe

A. Nutus, Cilleanel., P.-C. Dushy el E. I:0METTE.

Uarbriers

Jules Sicher ef 1 . Wilimotre.

en menble anticine

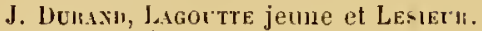

Menuisiers en siegres.................. Destries el SPOE'LER,

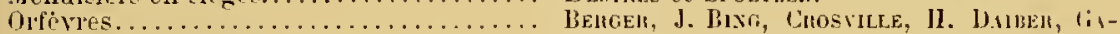

BHFLLE, GLFUELET EL GULLAUMONT.

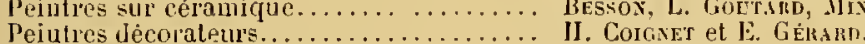

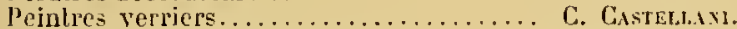

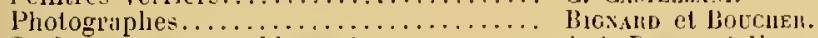

Seulp eurs en ameubiements ............. Ant. Denox et Vrgoureux.

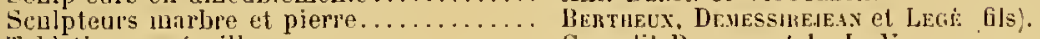

Tabletiers en écaille................. Cuf alit Rovome 4 L. - L. Viano.

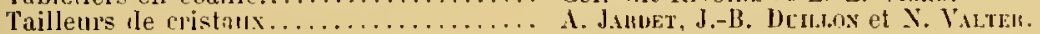

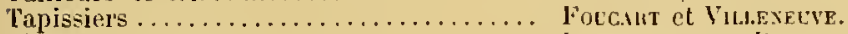

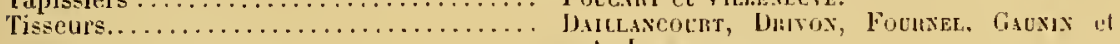
A. LECBHE.

Tourneurs sur bois................. Plévost et STOERKEl.

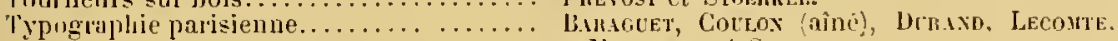
Joclist el SOHEIL.

\section{Londyes, 1891 , Exposition Intenuationale.}

France. Conmissiox supéheure. Rapports.

OEvvers D'Ant et produits industriels. Commissariat général.

Ipplication de lart ì lindustrie.

Dr: Leries.

lieaux-Arts.

VIOT.LET-Le-DCL.

Ceranique

1. rintern.

\section{Londres, 1872, Expositions Internationales.}

France. Cumission scpériecte, Rapports.

Leaux-Irts ef Beaux-Arts appliqués a l'industrie ........ Octave Lachor.

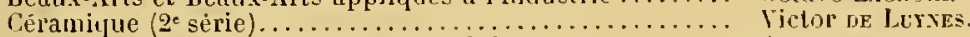

Cotons, ses transformations, ses produits ............ ALC.A.

lmprimerie el librairie ....................... Feürges .I

instruments de musique et appareils d'acouslique...... focmox.

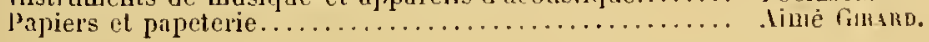

\section{V'ienne, 1873, Exposition Universelle et Internationale.}

France. OEcrres D'AnT el manufactures nationales. Commissariat général.

RAfPort n'Exseuble de li méligatiox ocviake française à l'Exposition universelle de Vienne. 
R.sponts. Exposition universelle de Vienne, 1873. France. Commission supërieure. วั vol.

Appartements complètement menţ'és........

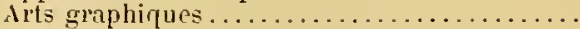

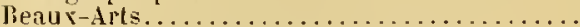

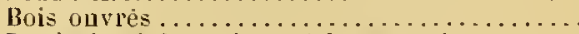

Broderies à la main et à la mérinirue......

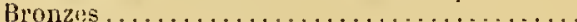

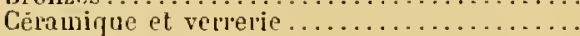

Cuir et caoutchonc . . . . . . . . . . . . . . . . . . .

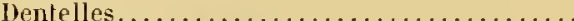

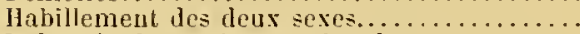

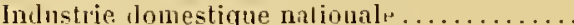

Joallerie, bijouleric, orlivrrite............

Ohjets d'art pour les services religieu.........

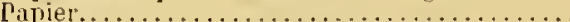

Passementerie, lieurs. pluures.............

Photographie, procédés, application, appareils.

Soie et tissus de soie...................

Tabletterie, maroquinerie, bimbeloterie.....

Tissus de coton unis, faconnés, mélangès....

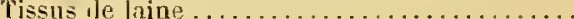

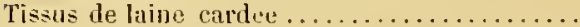

Tulles et dentelles i la micanique..........
Gr. 19 X. BBALLY.

12 F. Mlissox.

$2: 3$ Maurice Cortren

8 Charles liossininetx.

") B.soux.

7 Gustave Dreirles.

9 Victor de Lirives.

6 Charl's Sorris.

f) Félix Aubry.

3 J. Calkinits.

20 S. RONDElet.

7 Rouresat at Foxitexir.

23 BOESWILLWMII.

11 Clarles Bècoviart.

5 Paniot-LiUnext.

12 A. Diraxix.

ij Nitalis-losoot.

10 DEVELIEIRY

:3 Adolphe Deintie.

5) Densti.

ï Daliutisot.

5 Adolphe Disustr.

\section{Londres, I87., Exposilion Internationale.}

France. Commssion supéneche. Rapports.

France. OEuvnis dint et produits indusiriels. Commissariat général.

Beaux-trts

Exposition de la ville ile Paj

Industrie

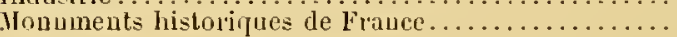

G. L.fFETESTLE.

Michatx.

G. Lix.

Brusigilit.

\section{Philadelphie, Isg6, Exposition Universelle ch Internationale.}

J. Ozexxe et E. pu Sommrrard. - Rapport de la Commission supérieure.

Arls̀ décoratil's.

\section{A. B.irtiolol.}

Imeublement et objets d’un usage général dans les constructions et les appartements................

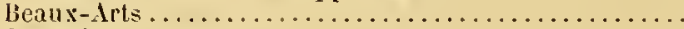

Cèramique et verreric

Fer et acier.

Marquis A. DE RocunMberl. S.lixtix.

Ch. Ds Bussr.

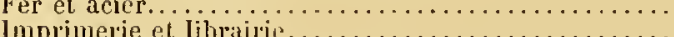

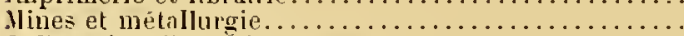

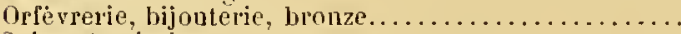

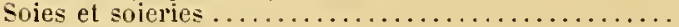

Vètuments, parures, allicles de fautiosic ..............
ALTOX.

R. Founet.

L. Sivosix.

G. Roulleatx-Dlgage.

l. Chatel.

DieTz-IIOXIIS. 


\title{
Paris, 1878, Exposition Lniverselle et Internationale.
}

\author{
J.-B. Kisntz. - Rappolt adminislralif. $2 \mathrm{rol.}$
}

Jutes Sumon. - Inlpoduction an Rapport du July, avec un Historique des Explopositions [1798 1878 .

E. Dunnox. - Arls dicoralifs (rappolt d'ensemble). 1. Arelitecture el decoralion fixe. 2. Nobilier et accessoires.

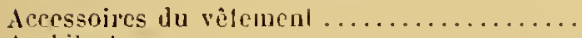

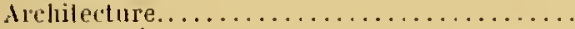

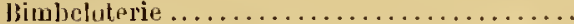

B'onzes d'art, fontes d'art, uélanc lepousses.

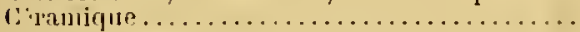

Chiles, spouliués, broclués, lancẻs, tc.......

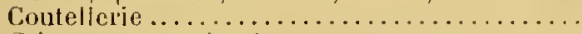

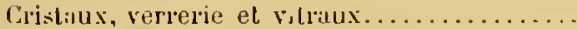

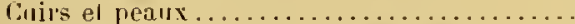

Dentelles, tulles, broderie, pissementic....

lits el. tissus de laine peignie...............

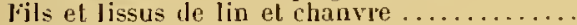

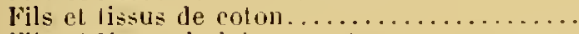

liils et lissus de laine carret. ...............

Fabricalion des lipis, tapisserir, lissus da-

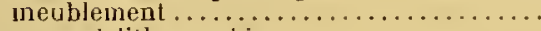

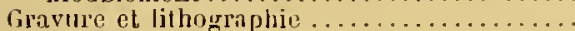

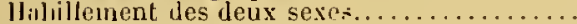

llorlogerie . . . . . . . . . . . . . . . . . .

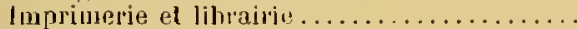

Joaillerie et bijouterie. .

Meubles i bon marche el de luxe, ouvrages du tapissicr et du decorateus.............

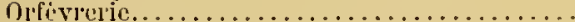

Papiers peinls, de tantilisie el stortes........

Photugraphic (épreuves de)..

Produits des exploilations el des industries forestieres thois, vannerie, elr.t........

produits de l'exploitalion des nines et de lit mélaliargie fmillechort, choches, löle imprimée? : Seclion 1, substances minèrales,

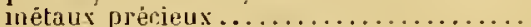
Section Ill, mèlaux usıels..............

Procédés chimigups de blanchincut, de teinture. d'impression, d'apprût.............

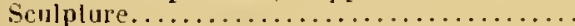

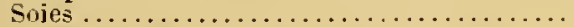

Tapis, tapisserie et tissus dameublement....
C1. \& VIUUREner.

II.1350.0.

limsoli.i.

f. SEnVANT

I. DE LAIYMES.

Pinirot.

Dinkos et Ciananont.

linost Jercien.

GilesER.

Inamor.

KOECHI.IX-SGHWAITZ

J. L.F. BLAV.

Ii. CaItCENAC.

bLIX.

II. NOLLISEAY.

V'icomile os Linoubs.

LEVOIS.

Clinulins Sarier.

Ein. Il untret.

M.ARTIa-Heraikd (picie!.

17-18 Thosogors et H. LEMorx.

I. JiACHELET.

1:. LEHOY

A. DAvAXME.

G.-li. ExNer.

11. \%:1LI.Eก.

LEBASTELL:

SCHTthexbenger.

11. Cirtipe.

VATLLA-RONDOT.

il. CHove.

\section{Imstendau, 1883, Exposition Luiverselle et Internalionale.}

Lnuis Canum et Charles Gunnfr. - Délégalion nationale ouvrière à l'Expusilion internationale d'Amsterdam. Raplort d'ensemble. 2 rol.

Imeublencut, menuiserie, ébéuisteric....

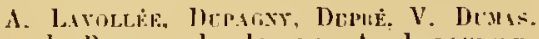
J. PAGIVD, L. JOFHRE, I. LABOLIGSE,

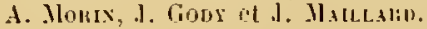


tuir's el peaux ourréc............... Jean Barnet, Eugi-ne Manus, Paul Mublix el Bonger.

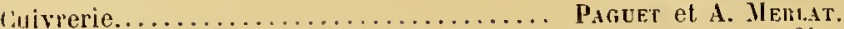

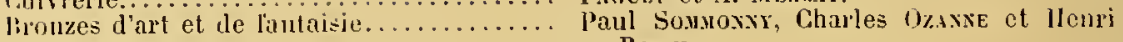

Boms.

Bijouterie de deuil, doré el acier.......... Martr.

lijouterie, joaillerie ef serti de Piris...... M. Mr.me-Tresel.

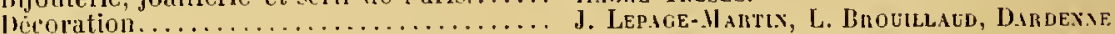
et. C.-L. DITT

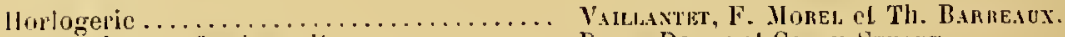

Instruction professiunnelle ............. Dexrs-Dovex el Cones-Stcalit.

Jualle rie ....................... Julez Besson el T. Cant.

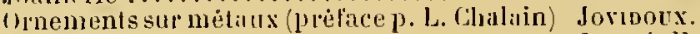

bapiers peinls ....................... Josepis lichter.

Gerurerie .

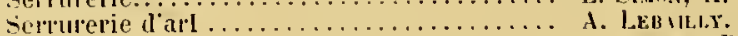

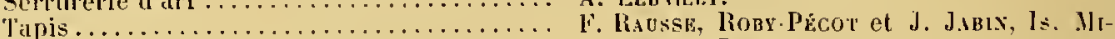

lissus de laine, colon, lin, clanvre. riJel et Boulaxo.

lissus, soie: ies, passementuries..........

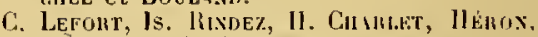
Durolrisy, A. Pelletien et Sexegis.

Derour, P. likel, Bongey, Gunon, Jlatuí atini, Besson. d. Dexrroux et Vachintr.

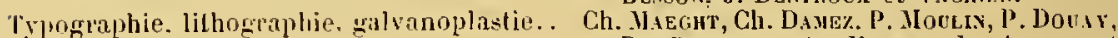
P. Rocssir, A. l'eliti, J. Aluar el L. DiCESNE.

Verrerie...................... F. B.t et Ch. Zet..En.

\section{Invers, 185.5, Exposition Lniverselle et Internationale.}

Rapports des membres du Jury inlenational des récompenses, publies par le Commissariat général du gouvernement. 6 vol.

lieaux-lils.

lijouterie et joaillerie.................. bronzes d'art, fontes diart diverses, mélaux

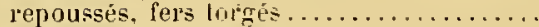

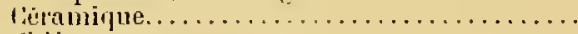

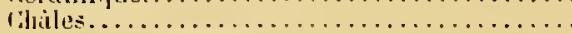

Cistaux, verreries et ritraux.............

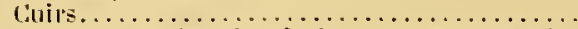
Dentelles, tulles, broderies el passementeric. liils ol lissus de coton....................

Pils et tissus de laine peigreec................

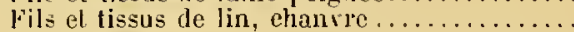

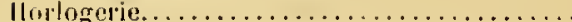
Meubles a bon marché el menbles de luxe,

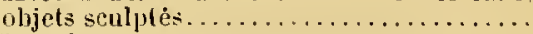

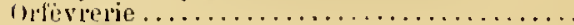
Jurrages du lapissier el du décoriatent...... liapeterie, reliure, molericl des arts et de ia

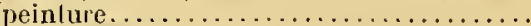

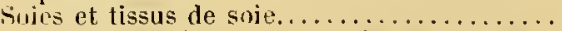
Tapis, tapisserie, et nutres lissis dimeubli:ment..........................

\author{
Gir. IX E. Fútrs. \\ Ci.3' Chanoine liecsiss. \\ 20 Ch. Vax ueli Stappex. \\ Ij Cam. Revanu, et Gustave Turan.

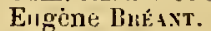 \\ I' Ein. Seitix. \\ 4 S.-B. VEUBOHCKHOVE. \\ 31 Camille Wв веп. \\ 2.j Paul Vax Acker. \\ 27 VALI.ET. \\ 26 Vennet-Pandinevinil. \\ 21 A.-ll. RODANer. \\ 12 G. DE SAvOY: \\ 3 t H. Vax Cilester. \\ 13 Devilte-Cirilix. \\ ; Bieitiof. \\ 29 Ch. Reboen. \\ 16 Ed. Dirous?.
}

Rapports des ourriers dèlėgués à l'Exposilion Internaiionale d'Anrers. 2 vul.

Art du marbrier................... Givormus.

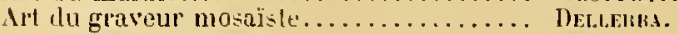


Art du lapidaire.................. Bessox.

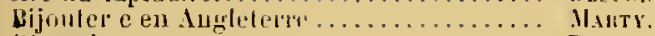

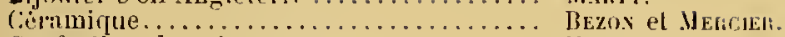

Confeclion des viblement ............. Ilonex.

bivtelles...................... lintle.

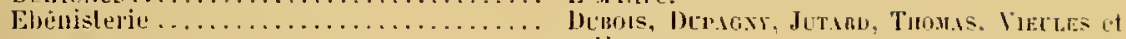

Elyenisterie ciu clonises......

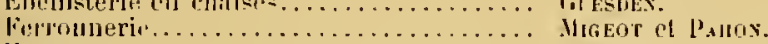

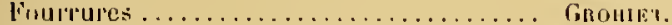

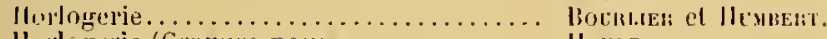

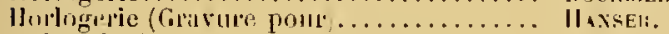

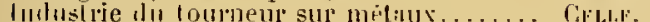

limprimerie blanlin.................. Parports.

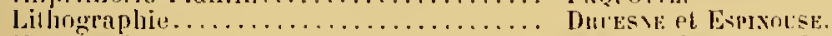

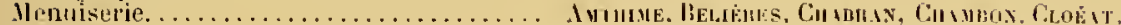

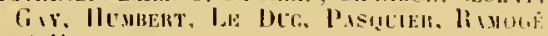
1.1 VIL.S.

Meubles.......................... Thuми.

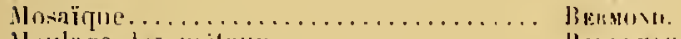

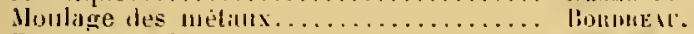

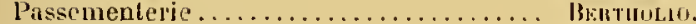

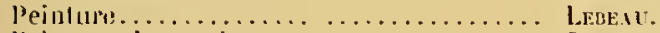

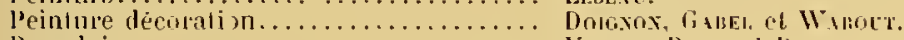

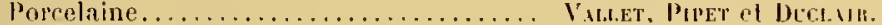

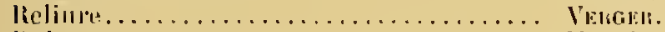

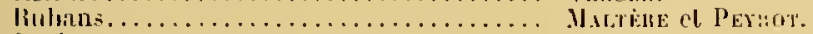

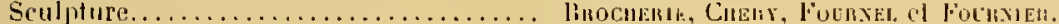

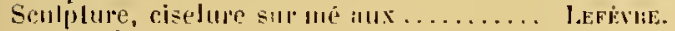

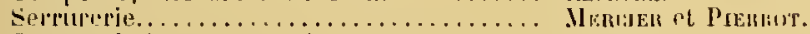

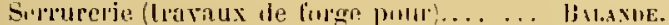

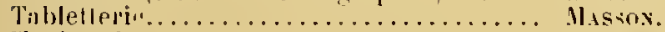

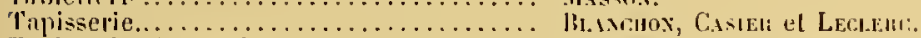

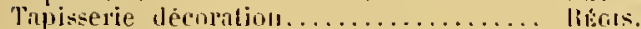

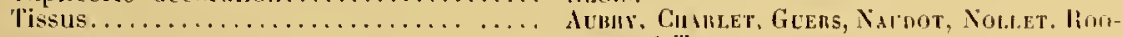
SEX el TELHES.

Tissus de colon.................... Bormuon.

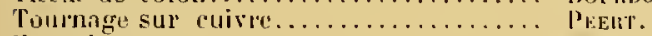

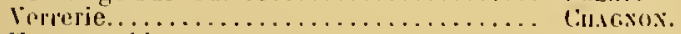

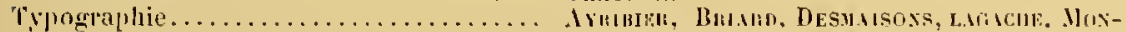

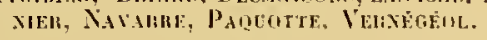

\section{l'aris, I899, Exposition Cniverselle el Internationale.}

Alfred Prcsib. - Rapport général. 8 rul.

Tome Ier. - Historique des Exposilions [1798-1889..

Tome W. - Beaux-Arts, Education el Enseignement. Matíriel et procéde: des Arls libéraux [imprinerie, librairie, lapelerie, reliure....

Tome T. - Mobilier, tissus, vètements.

Enspignenent technipue.

Enseignement des atls de desiu .......
Cl. 6. ief 8 P J liceremalid.

ï bis Paul Cols. 
Application usuelle des aris du dessin et de la pla-lique................... . Brouzes d'art, fontes, feromnerie.......

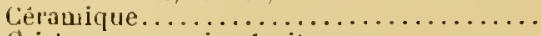
Cistaux, verrerie el vilraux............

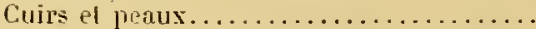
Dentelles, lulles, passementeric, Jivileris. fils el lissus de $\cot 0 \mathrm{n} . . . \ldots \ldots \ldots \ldots \ldots$.

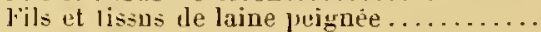
pils et tissus de lin. chinvie, jute .......

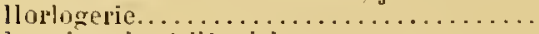
luprinerie et librairje............... Inilustries accessoires du vitement .......

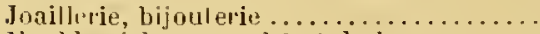
Jeubles it hon marche et de luxi..........

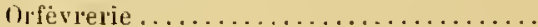
Ourrages du tapes er et du decurateur..

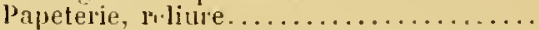

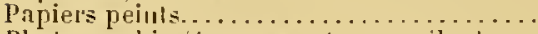
Pliutographie épreares el appareils de... Soles et tissus rle soie................. Tipis, tapisserie el tissus d imseublentrnl.

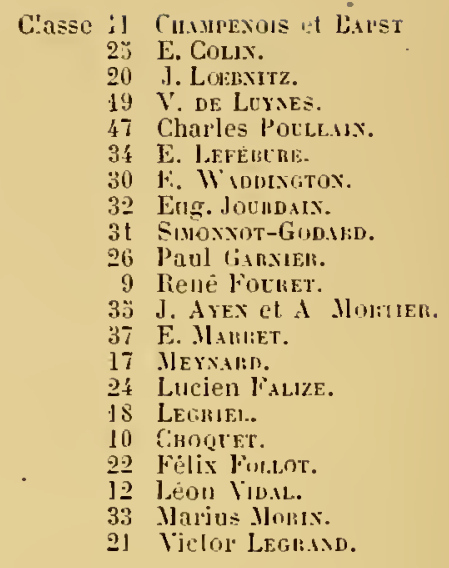

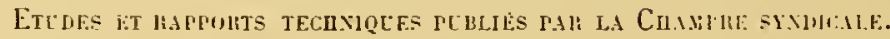

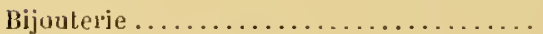

lijouterie en or duuble...............

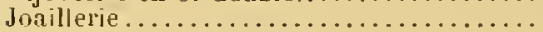

Orfërerie ..............................
Cl. 37 JACT.

37 PLII:ISTY

37 M!assix.

2; Hexis.

\title{
Chieago, I 893, Exposition Lniverselle et Internationale.
}

\author{
Camille Lisuryz. - Rapport administralif.
}

Enseignement in lustriel let commercial...

Archilecture et les imlustries qui en dé-

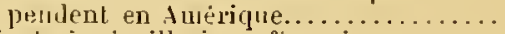
Rijouterie, joaillerie, orfevrerie ........... Broderies, passementeries, ete........... bronzes d'att, d'ameublement, d’ulairage.

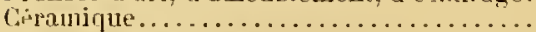
Cristaux el verrerie.................. Dentelles raies.................... lils et tissus de liı. chanre, jute. coton. Ilahillements des deux sexes............. llorlogerie.................. rilpport spécial

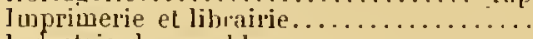
ludustrie du meuble..................

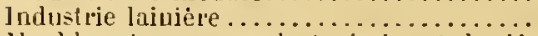
lleubles et ourrages du tipissier el du

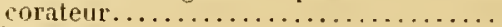

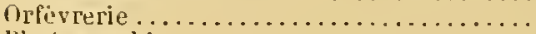
Photographie .....................

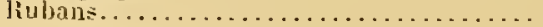

Cl. 33 L.-4i. HAVETE.

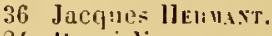

2 t llenri Vever.

26 Henti NoInor-biss.

23 Albert Scsse.

22 Alfred ll tcus.

22 Jizues libie.

26 Adrien WA ĖE.

Pilul LE Rlis.

26 Eugine Simos.

Chirles-Emile Tissot.

3 ' le SOtOIFis.

2] Gustave Qungux.

2a Challes lititent.

2] G. L.OUCHET-Beirati.

2 Andre binchlat.

3.) Ant. loviente.

gi Alexamlpe Cocromer. 


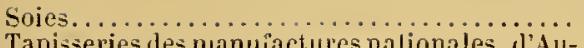

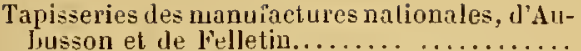

Jusson et de relletin...................

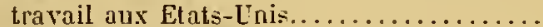

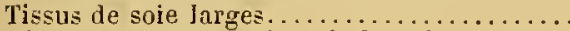

Vètements el accessoires de la toiletle; intro-
Cl. 2: Auguste CIIABriénes.

21 Georges Hниот.

21 Viclor LegRtXo.

2.̈ Joseph Guxer.

26 Julien HArEy.

Rapports de la Delégatjun outrabea à l'Exposilion de Chicago.

Ametblement bijouterie, horlogerie, urtiveric, juillieric.

Bronzes

Céramique et verrerie

Curirs et peaux.

Juppimerie.

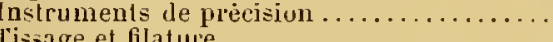

Tissage et filature........................
BiẺoxt, Gallatrd el GlèGy.

BuÉcy, Cotundever, Ileller, JACQLem, MoROGE, MULakB el VaUTIER.

MaSSENET et Gistox.

Rose.

Ciroleter, Cuthelet el Tillet.

B.MrROl et DEBÉs.

BOITE.A.

Grexier, Leyilire, Jisudot, Pichox, Selgyie/ et SrMoxid.

\section{Imsterdam, 1895 , Exposition Interualionale.}

Lucien Larus. - Rapport général de la Section française.

Sànt-Pélersbourọ, I 899, Exposilion Franeo-Russe.

N1 ${ }^{\text {me }}$ Pégaro. - Rapport général de la Section françai:e.

\section{Paris, 1900, Exposilion Universelle el Internationale.}

Allred Picard. - Liapport général, administralif et technique. 7 vol. plus 1 de plans et 1 d'annexe.

Alfrell Picind. - Bilan d'un siècle. 1801-1900:

Tome $]^{\text {er. }}$ - Education et enscignement, letlres, sciences, arts.

Tome IV. - Mines el mélallurgie, inılustrie de la décoration el du mobilier, lils, tissus, vêlements.

Enseignemenl spécial arlislique, far Paul Coux, Groupe ler, seconde partie, Cl. '́. 


\section{- CXILI -}

Enseignement technique, par Paul Jacoursoxt, Groupe ier, cinquième partie, Cl.ti : $1^{\circ}$ France; $2^{\circ}$ Etranger.

Introduction générale, tome ${ }^{\text {er }}$, seconde parlie : Beaux-Arts, par L. Bexterre. Introduction générale, tome II, quatrième partie : Industrie, par Michel Lisy.

\section{RATPOHTS DE ETTLSSES}

Bronze, foule, ferronnerie d'arl, el"........ 1 losserie, marntuinerie, tabletterit..........

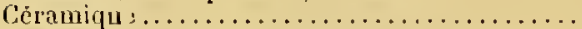

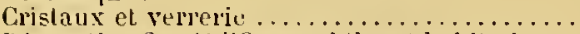
Dècoration fixe (élifices publics et habitations. Décoralion mobile et ouvrages dn tapissier, décoratiou extérieure de la rue.......... Deutelles, broderies, passementeriı......... Dentelles it la main. .................. Fils el tissus de cotou................... Fils et tissus de chanvi' $(. . \ldots \ldots \ldots \ldots \ldots \ldots \ldots$

Fls et tissus de laine vardè.............. Industrie de la contection et contur......... Industries diver'ses lu vêlement............

Instruments de précision, monnaies et mé-

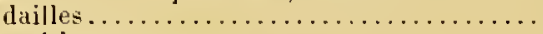
Jenx et jouels . . . . . . . . . . . . . . . . Joaillerie el bijouterie................. Librairie, reliure, athiches .............. Jeubles de luxe et meubles a lwon narchi... Orfèverie........................

Papiers peint

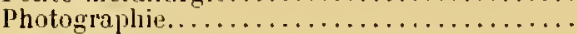

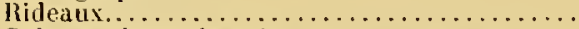
Soips et tissus te suic.................. Tapis, tapisseries et tissus l'ameublemunt... Tulles et dentelles à la mécanique... ....... Typonraphie, impressions diversin. .......

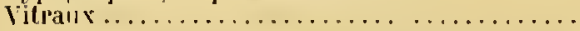

Cl. 97 Il. Vis.

ys Georges Ausox,

it lieoriges logr.

72 Engene Hondint.

73 Arsène Alexixoue.

66 Ch. Jeaxseluk.

7 llenli lléxox.

8 Georgres Marrix.

SO H. ЏËCHEL.ETTE.

81 Eid. Finchelu.

S2 Ch. Marteal:

8.3 Léon Srokch.

86 ll. HAYEM C.t A. MonTich.

1 J̈ llenri l'ELLAT.

100 léo CLAiETIE.

93 Paul SovfrLat.

13 M.ANGUE?.

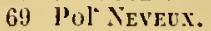

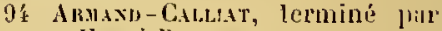
Ilenri BouilıEt.

68 J. Petirjeas.

63 DuFrÉxE.

12 Léon Viuat.

S: G. SÉBASTIEX.

83 J.-N. P1OTET.

50 Fejd. linnirgxe.

84 Heni llsxo.s.

II A. LAllulle.

bi Léoll Dicmoxt, Torrixi.

\section{Husées rétrospectifs et centemnaus.}

\section{R.IPPONTS}

Ipplientions usnelles lu métal el de lil petite mètallurgie.......................

Bijouliers-Joailliers ef Exposilions (1789-

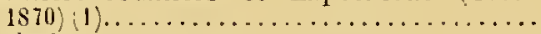
Broderie.

Brosserie, miroguinerie, tabletteric, vanuerie.

Céramique .........................

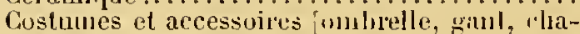
pıau, lorgnette, éveutaili...............

Coutellerie.

Cuirs et pe $11 \times \ldots \ldots \ldots \ldots \ldots \ldots \ldots \ldots \ldots \ldots \ldots$

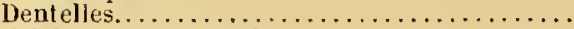

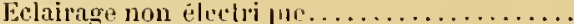

Fils et tissus de lain.'..................
Cl. 6.j Pierre Lamvithe, II. TJ ILIFHAGNE, L. MAGNE, J. D)NERGUE.

93 fi.-lioger Saxno\%.

SE II. Notliot.

98 H. STEETTISER?

72 11. SARRIAU.

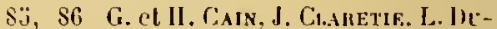
chet, Fr. Flumexf, II. IAle-

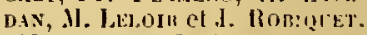

93 G. Inamest et C. Page.

89 Placile Pertereat.

8. E. LEFíbURe.

7:5 Henry D'Al.L.M.IGX.

82 A. Sernoux.

(1) Voy. aussi : Bijouterie franeaise at dix-neurieme siocle, IJenri Veren. i vol. 


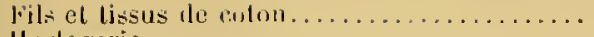
llorlogerie

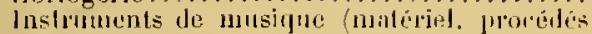
et produit. $\ldots \ldots \ldots \ldots \ldots \ldots \ldots \ldots \ldots \ldots \ldots$

Iouts $\ldots \ldots \ldots \ldots \ldots \ldots \ldots \ldots \ldots \ldots \ldots \ldots \ldots$

Librairie, journatux, il liclses, relimm.........

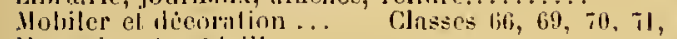

Ilsmuaies et mélailles. . . . . . . . . . . .

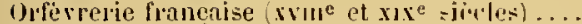

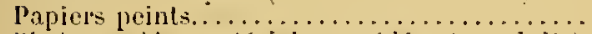

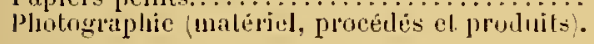

Soics et tissus de soir $\ldots \ldots \ldots \ldots \ldots \ldots \ldots \ldots$

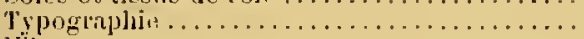

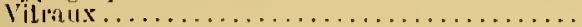

Ci. 80 Consite.

96 Mallieu Petronos:

17 Allorer Jicolots.

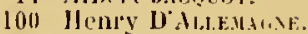

13 Litcin lites.

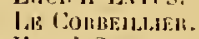

Il:I11'i S.IIIIIIE.

II"IIII BuvILIIE".

8 livix lind.ot.

12 D.tixise, Nimico licerati el 1. V'ivil.

83 Rizymothl Ciss.

11 DEI. 11. IIX.

(jT L. IIGIE.

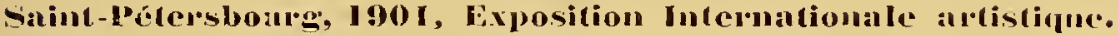

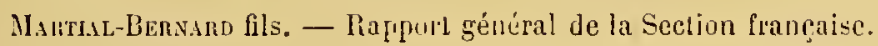

\section{Ilanoï, 1902-1903, Jxposilion Internationale ce Cuiversellı.}

Paul Boongrors et G.-Roger Sixuoz. - Rapport général de la Section françase.

\section{Saint-Louis, 190 I, Exposilion Luternationale el I niucrsella.}

Henry II metLe, J.-II. G.sxe, et P.-II. Renon. - Rapporl général de la Section fraturaise. 2 rol.

Arossoires dı vêloment [chapellerie, Inules, fleur's, jlunes, lingurie, bomnelerie, riumes, ousluelles, eveutails, ex:als]...........

Imeublement de bureaux ef l'babialions...

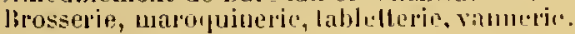

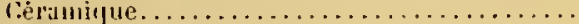

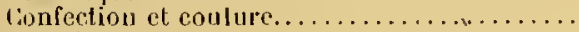

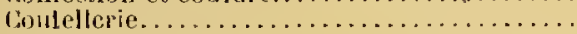

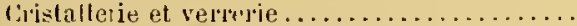

bécoration et mabiljer des editices publics et les babitatiuns...

becolition du tapissier..................

Denlolles, larulcrites, passementeries, lessios

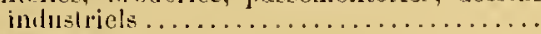

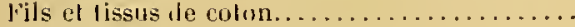

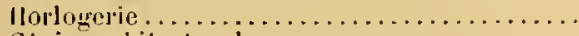

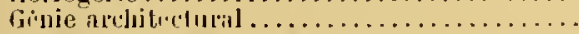

Induslrie du cujr, de la pelletiss 1 ...........

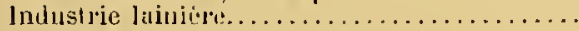

Inclustrie du lin ef ،lı chanrre............

Jonillerje, bijoulrrie .................
Cl. Gl Fugcile MEnmu,10n.

38 Pail Sochanik.

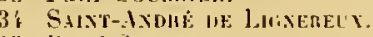

4.j liené Sachor.

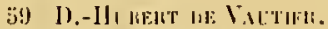

29 Georgess IImisis.

47 Lempold IPreitr.

37 Geologes lluext-GIË.

14 A. VIAET.

:8 Einile Siss.

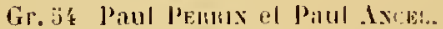

CI. 32 Silney llenfir.

27 Alluelt lizstok.

60 Mlluert DuM.urfe.

¿6 P:Iul II asse el lianoisqua liuNuEll.

j) Elicume I Iscat.

31 Elie II E:I.I. 


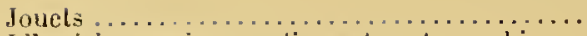
Lil,rairie, musique, reliure et carlographie ...

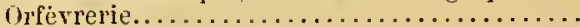

Papeterie

l'apiers peiuls

Photographie.

Quincaillerie, matẻriel, procèdés et produils [ferronnerie dart, serrurerie?.

Soiles et tissus de soie...................

Tapis, tapisseries, lapis d'ameublement.......

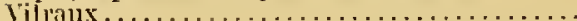

Cl. 36 Henry Dillemagie.

17, 18 Henri l.E Sovditi.

30 G. HeNRY.

28 John-F. Joses.

42 E. Descossis.

16 Jules Denania.

41 Louis Marson.

57 Emile Canaria et Etienne Cun BIx.

43 Paul Consilite.

39 Jlenri DE LUZE.

\section{Jiége, lons, Exposition Internationale el Luiverselle.}

Fernand Chrssal et A. Pixalid. - Rappolt général de la Seclion française.

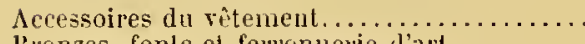
lironzes, fonle et ferronmerie d'art..........

brosserie, maroquinerie, tabletterie.........

Gisslaux et verreric......................

Cinir's et peaux ..........................

becoration fixe lles édifices publies et des lia-

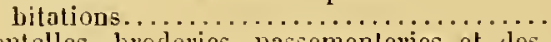
Dentelles, broderies, passementeries et des-

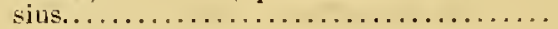
bicoration mobile et ourrages du tapissier... Fils, tissus et vêtements.................

lils et tissus de laine....................

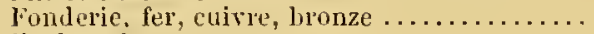
Horlogerie ............................... Industrie de la confection el coulur.......... Instrumeuts de musique.................. Jouets et jeux......................... Meubles a bon marché et de luxe ..........

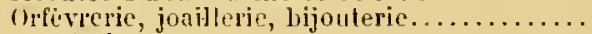
papeterie..............................

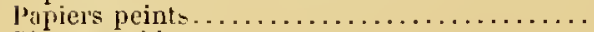
Pholographie.

Proluits de la chisse (fourrures) 'Tapis, tapisseries, étıllus d'ameublement.... Typographic, impressions diverses ..........

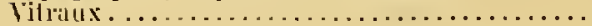

Cl. 36 Léon Curveau.

97 'Th. MILLET.

98 Gustave Litoccie.

73 Eugine 1Jontatr.

89 Gustave CaEx.

$66 \Lambda$. Bespel.

S' H. BÉQUET.

il Eugene Teusisies.

76, 79 Albert Ricboriti.

82 Henry Glonisix.

603 Ilenri Paumiterte.

96 Francois lisixty.

S. E. Ricots.

17 G. Detienit.

100 Alexis Cuarvix.

69 Fr. LINKE.

95 Paul Piel.

92 Pierre Lasdrix.

68 liẻlix G.Avdx.

12 Charles Mlexoer.

52 B. PrelFFer.

70 11. Pamison.

it llenri Pichot.

67 pélix Gaddis.

\section{Milan, Igti, Exposition Internationale et Cniverselle.}

Paul Drexres-Bryg et G.-Roger S.rvooz. - Rapport général de la Section française, arec une préface de A. Genvals.

Arls décoratifs [artistes lecorateurs] ....... Irls decoratifs verrerie, crislallerie, vi-

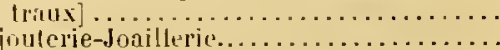
firosserie, maroquincrie, tablelterie, valnunclie
C]. 66, Secl. C. Pierre Seliensilelu.

Cl. 67 el i3 René 11 antix.

9 G. lovquer.

98 Gieorges Lelori. 
Confection et couture................

Cuil's el peaux.......................

lialeries du travail [art graphicue, papiers, travail des métaux, đu bois, céramique, verre, soie, coton, Injnel............

Décoralion fixe des édifices publics et ha-

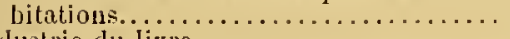

Imdustrie du livre....................

Industries d'art [er lorgé, meubles, cériwique, verres déenleês, lirises] ......... Industrie du vêlement................

Papiers peints, tapis, decoration mobile.

CI. $: 38$

13

CI. 66, Seet. A. Albert Besoel.

CI. 13 et lít R. Desclosiéres.

CI. 66, SecL.D. 86

Gl. 68 à 71
A. Hilimbolrig el A. Datio.

Cls. Mancusivo.

L.XXES.

Georges Conxille.

Georges Deliesnix.

Elonard Poteau.

\section{Buearest, 1906, Exposilion Universelle et Internationale.}

Léo Cíaketie. - Rapport général de la Seclion française.

\section{Dublin, 1907, Exposition Lniverselle et Internalionale.}

G. Mlıssard. - Rapport général de la Section française.

\section{Saragosse, 1908, Exposilion Hispano-Française.}

Joseph Stetren. - Rapporl général de la Section franẹaisc.

\section{Londres, 1908, Exposilion liranco-brilannique.}

Yves Guyot et G.-Roger S.ındoz, rapporteurs généranx; Paul Bocrgeors, Charles Jeanselme et Léo Cuaretie, rapporteurs généraux adjoinls. - Rapport général de la Section francaise.

\footnotetext{
Bijouterie, joaillerie

$\ldots \ldots \ldots \ldots \ldots \ldots \ldots$

bimbeloterie ..........................

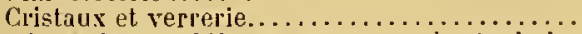

Dicoration mobile et ouviares du iapissies

(meubles i bon marché et de luxe, tapis,

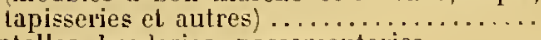

bentelles, broderies, passenienteries..........

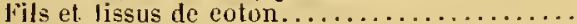

Fils et tissus de lia, chanve...............

fils e tissus de laine...................

Industrie de la confection et de la couture...

Librairie, reliure, aftiehes, cartes et appareils de géographie.

Photoraphic.....

Produits de la chasse, fourrures, pelleteries...

Soies et tissus de soie, Lyon et Saiut-Etienne.

soies et tissus de soie, Paris.
}

\section{Cl. 9:; 11. Terenger. \\ 100 DU SERTE-TELYITY. \\ 83 DEVawLIX.}

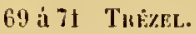

84 Ch. TutibitT.

so WiBaU.

81 SIм0NאOT.

82 Buix.

8ว Canette.

13, tí Trengen.

12 Ch. MExdel.

2 A.-E. Ru\%.

83 E. Ricilaks.

83 lininox.

\section{Copenhague, 1909, Exposilion française d'Mrt bécoratif,}

G.-Roger Sandoz et Jean Gulfrey. - Rappor général, précédé d'une Etude documen!aire sur les Arts appliqués et les Industries didrt dans les Expositions. 


\section{IBruxelles, 19 I O, Frposition Luiverselle et Interuationale (1).}

Fernand Chapsıt et A. Pıxıßr. - Rapport général dı la Section françai

limbelinterie.

lironze, fonte et ferrunneric d'arl, zinc d'art,

metamx rejoussés.....................

ls'osscrie, matoquincrie, tablel terie et vannerie.

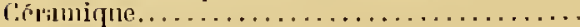

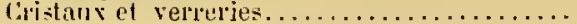

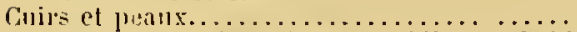

décoration lise des éditices publies el habi-

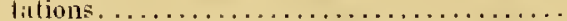

Dinoralion mobile et ouvages du tapissicr. lécorration exlérieure de la rue.............

bentelles, broderies et passementerie........

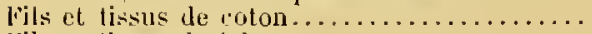

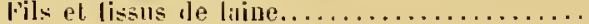

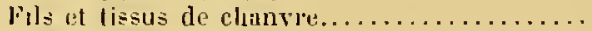

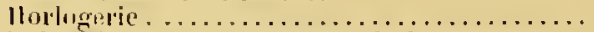

Indinstrie de lis confection et de la coulure...

lumlustries diverses du vètement.............

duailliurs-bijontiers et Expositions $(1870-1911)$.

l.ilnirire, reliure, aftiches................

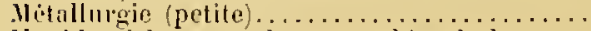

Menbles i loon marche el meubles de lise...

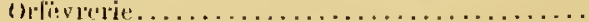

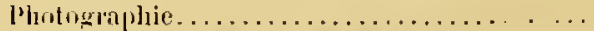

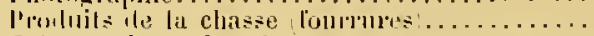

suins ul lissus de soic....................

Tapis, l ipissclies es autros lissus d ameuble-

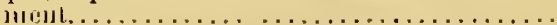

Tylogliplie, impressions diverses..........
Cl. 100 Alexis Cuncrs.

97 Jacques Susse.

ys Georges LeIoHi.

T2 DE GEIGEIS.

73 BARBE\%

89 Povi.Lis.

fi6 Duritho.

it Louis Bn nQuexié.

S't Alphonse Bris.

So René LaEDEMra.

82 Jules Rousseat.

SI Cavil.Lox.

96 Georges Mrina.

8.i KinIEGGK.

86 Piliext.

93 R.-Loger S.xum.

1:3 Charles MENDEL.

fii: B.ic.

fi) Pilul Socuinelt.

9 ' IIExily.

12 TAILAXDIBn.

:3 Vintor lieviri.us.

83 Tissti.1I:I.

70 LokTHiors.

11 L. DE B.MYY.

'Turin, I9) I I, Exposilion Interuationale (1).

Émile Berr et G.-Roger Saxnoz, rapporteurs généraux; Paul Dreyris Brifi, rapporteur général arjoint. - Rapport général de la Seclion française.

\begin{tabular}{|c|c|c|}
\hline lcessoiles du vêtement. & C.1. $133 \mathrm{D}$. & llenıi Deroc. \\
\hline Amcublements. . . . . . . . & 72 & Mlexandre Councren. \\
\hline Alts grapliques. & 143 a 131, t 33 et lä6 & LORTAT-JACOL. \\
\hline ditistes décoruteurs... . . . . . . . . . & Tl B. . & Raymond koeculs. \\
\hline lijouteric................ & $13 ; j$ & André FaLI\%:. \\
\hline limbeloterie et bijonteric lantaisie.... & 137 & Paul Piel. \\
\hline Bionze..... $\ldots \ldots \ldots \ldots \ldots \ldots \ldots$ & i3 $\mathrm{B}$. & Iuslin Bocisox. \\
\hline$\ldots \ldots \ldots \ldots \ldots$ & it & Jules LoEmXIT\%. \\
\hline Couture... & $133 \mathrm{C}$. & P'ichre Laguroxul. \\
\hline Décoritiou (matériaux ............. & $71 \mathrm{~A}$. & André Narjoux. \\
\hline bentelles......................... & $133 \mathrm{lli.}$ & PaUl DOLEY. \\
\hline Editices jublics et prives............ & 69. 70 & Charles Duper. \\
\hline fourrures....................... & $133 \AA$ & Charles IIxar. \\
\hline$\ldots \ldots \ldots \ldots \ldots \ldots$, & 136 & Fernand Diterfi's. \\
\hline . $\cdots \cdots \cdots$ & 14.4 & Penhgot-MIstue. \\
\hline$\ldots \ldots \ldots \ldots \ldots \ldots$ & 13 i 18 & Challes Mexuel. \\
\hline licliure el jonrnal................. & $151,132,1.33$ & Jules T.ILLANDIEI: \\
\hline Soieries.......... . . . . . . . . . & $130,131 \mathrm{~A}$ & Paul Consilue. \\
\hline$\cdots \ldots \ldots \ldots \ldots \ldots \ldots$ & $130,13111$. & Francisque Bmti.ixlr. \\
\hline$\cdots \cdots \cdots \cdots \cdots \cdots \cdots$ & 73.. & LOUIS THÉ\%EL. \\
\hline Verreric.......................... & T.'. & Léon HOUDAILI.F. \\
\hline
\end{tabular}

(1 La plupart les rapports de elasses des Exposilions de Bruxelles et de Turin u'ayant pas cincure éti deposís, nous donnons ici la liste des rapporteurs proposis. 


\section{EXPOSITION INTERNATIONALE DES ARTS DÉCORATIFS MODERNES projetée à Paris.}

\section{DOCUMENTS}

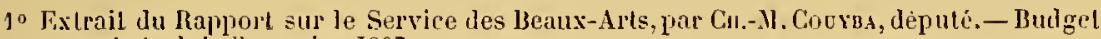
général de l'exercice In07.

20 "De l'Arl social el de la nécessilè d'en assurer le progrís par une Expósition ", par Rogen Mlakx (Idées Modernes, janvier 1909).

3" " Lilrt décoratil s'atrophie en lrauce. Pour le rivifier, il faut faire une Exposition

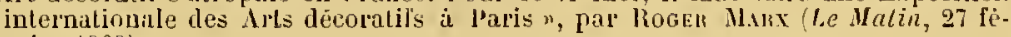
vrier 1909 ;

4" Rèponses aux propositions de Rogfn M.nx (Le Musée, décembre 1909).

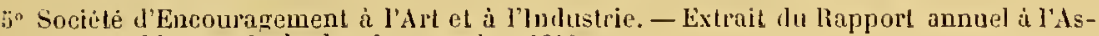
semblée générale du 16 novembre 1910.

6" Société d'Encouragenent à l'drt et à l'Industric. - Extrait du procès-verbal de la séance du Conseil de direction du 28 mars 1911.

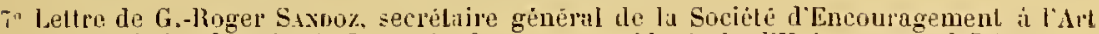
el a l'Industrie, a François Cusxor, président de l'Union centrale,des Arts decoratifs (28 mars 1911).

8० "Uue Exposition en 1913 ", par Emile Benn (Le Figara, 29 mars 1911 .

go brojet d'Exposition internalionale des Arts décoratils tnudernes. - Sẻnnce des dèlégués de 1 Cnion Cenlrale des Arts decoratils. de la Sociele d'Encouragement á l'Art et á I'Industrie el de la Société des Artistes Décorateur's (29 uar's 1911$)$.

$10^{\circ}$ Chambue des Députés. - Ir" sẻauce łu 30 mars 1911. Discussion générale du budget des Benux-Arts. Discuurs de M. Albert Salindr, rapportem. (Jourwal Officiel du 31 thars 1911).

$11^{\circ}$ Leltre adressée a 11 . Dumanx-Besumet\%, sous-secrétaire d'Etal des Beaux-1rts, par l'Union Centrale des Arts lécoratifs, par la Socièté d'Encouragement à l'Art et à l'Industrie et par la Sociélé des Artistes décurateurs (10 avril 1911).

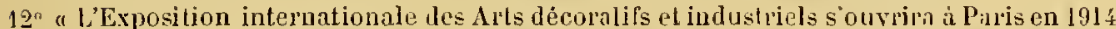
ou 1915 \%. Interviews de MM. SreEti, ministre de l'Instruction publique; Massí, ministre du Commerce; Paur-Bovcout, ministre du Travail; Dojalido-Bearametz, sous-secrétaire d'Etat aux Beaux-Irts, par Henry de Jouvenel Le Malim, 11 avril 1911).

13" Conseil municipal de Paris. - Séance du 13 avril 1911. Alloption dun vou de 11. Lampue en fareur de l'organisalion d'ute Exposilion internalionale d'Art décoratif i Paris.

140 Sénat. - Séance du 13 avril 1911. Proposition par Car-Ml. Cocrba, sénateur, d’un projel de résolution, en vae de l'organisalion d'une Exposition Internationale des Arts décoralifs el industriels à Paris en 1914 (Le. Matin, 16 avril 1911).

1:\% Commission d'étude composée des délégués des $A$ ssocialions artisliques francaises et présidée par François Gakior. -- Kapport sur une Exposition internationale des Arls décornlifs modernes à Paris en 1915 (rédigé par Rene Gurbentè el paru le 1er juin 1911).

$16^{\circ}$ Société d'Encouragement id l'Art el a l'Indastrie. - Assemblée générale du 20 juin 1911 ; extrait dı Rapport gétrẻral anuuel.

170 Chambre des Députés. - Jre séance du 6 décembre I91l. Discussion gẻnérale du Budget des Beaux-Arts. Discours de M. Elienue Rogxos. (Joumal Officiel du 7 décembre $191 \mathrm{t}$. 
180 Chambre des Dépulés. - Séance du 6 férrier 1912. Proposition de loi tendant á organiser à Paris, en $191 \%$, une Exposition internationale des Arts décoratifs modernes, présentée par Froncois Cariot, PAvL-Boxcocn, flenry Cocur (Nord, Charles Dunoxt (Jura), Jassé, Nollexs, Puecii, Joseph Reryaci, Sembat, Sibilie, J. THIERry, A riand.

190 Commissiou d'ètude : sous-commission financière présiclèe par G.-Roger S.ıтo\%; rapport de Paul iIezzara (28 mars 1912).

200 Conseil municipal cle Paris. - Séance du 2 avril 1912. Disconrs de Louis Duusser et roen relatif à l'orgauisation à Paris, en 1915 , d'une Exposition iuternationale des Arts décoratifs modernes.

210 Lnion Cenlrale des Arts décoratifs. - Assemblée générale du 30 avril 1912. Extrait du Rapport annuel de Francois Cinvor, président.

$22^{\circ}$ Chambre des Députès. - Rẻsumé du Rapport de Ml. Rosurx, sur la proposition de foi présentée en vue d'une Exposition internationale des Arts décoratifs modernes (déposé le Jer juillet 1912 et pubłié au Journal Officiel du 2I aonit 1912).

230 Chambre des Députés. - 2० séance du 12 juillet 1912 . Adoplion d'un projel de résolution tendant à organiser en 1915 , ̀ Paris, zene Exposition Internalionale des Arts décuratifs modernes. (Journal o/ficiel du $\mathrm{j} 3$ juillet 1912.)

\section{CHAMBRE DES DÉPUTÉS}

Budget général de l'Exercice 1907.

Rapport sur le service des Beaux-Arts

par M. COUYBA, Député

\section{Une Exposition Internationale d'Art Décoratif et une École nationale du Mobilier.}

Ainsi, comme on vient de le voir, nous sommes fortement battus en brèche dans les pays du Nord et en Italie, au point de vue du progrès de l'Art Décoratif. L'Etat a le très grave tort de ne pas se renseigner :

$1^{\circ}$ Sur les Expositions étrangères;

20 Sur les tendances et la personnalité des artistes par rafport aux tendances et à la personnalité de nos producteurs nationaux;

$3^{\circ}$ Sur les conditions normales de la production, du marché, etc.;

$\dot{4}^{\circ}$ Sur ce qu'on pense à l'étranger des Français et de l'Art français.

Nous nous présentons souvent aux Expositions du dehors avec une étonnante ignorance des terrains. Il arrive à certaines de nos manifestations d'ètre à peu près 
exactement le contraire de ce qu'il faudrait. Ajoutons que de regreltables conltils peuvent se produire entre le Commerce et les Beaux-Arts en matière d'exposilion hors frontières. Tout s'en ressent. Ni l'Exposition de Turin, naguère, ni celles de Liége, de Saint-Louis et de Milan hier n'ont étẻ des succès complets pour nous.

lin conséquence et en présence du mouvement qui ramène tous les arts à leur destination première, celle du décor, devant le développement remarquable de l'art appliqué à l'étranger, et en vue d'encourager nos architectes et quelques-uns de nos décócateurs à la créalion d'un style vraiment noderne "n rapport avec nos goûts et arec les cunquêtes les plus récentes de la science et de l'lyygiène, il partit utile soit de prépurer officicllement une Exposition internationale d'Architecture ct d'A $r t$ Decoratif, soit d'encourager l'initiative privce en vue d'une organisution de ce gemre.

L'architecture, le mobilier, les objets usuels dans leur expression décorative reflètent manifestement les arłs et les goùts de leur époque. Aujourd hui la maison d'Jabitation, bàtisse à loyers, petit JôteJ ou villa, est devenue la principale préoccupation des constructeurs. Autour de nous, on s'efforce d'en agrémenter Irs aspects, d'y rendre la vie plus com mode, plus saine, plus agréahle. Partout s'élèrent des essais de maisons populaires, de maisons ouvrieres, le naisons à bon marclıe. Partout la nécessité se fail sentir d un ameublement ì la fois esthétique et ncu coủteux. le développement des notions d'hygiène a contribué à répandre à lous les degrés de la population des besoins nouveaux auxquels la science et le machinisme devraient répondre par des eréations simples, mais lıarmonieuses, à la porlée des hourses modiques. Il fant montrer an peuple comnent on peut décorer à peu de frais le logis, ']uel qu'il soit, et inciler les fabricants à produire des mobiliers harmonieux dont le prix de revicnt ne soit pis supúcieur à celui des horreurs que l'on rencontre dans tant de logis ouvriers et bourgeois. Les meubles peuvent ètre en bois conmun; cela ne doit pas eınpècler leur forme d'ètre pratique et équilibréc, c'est-à-dire belle. Le papier des murailles peut coûter quatre sous le rouleau et n'en être pas moius agriable. Le vilain " chromo " pendu dans maints logis peut être jemplacé par des estampes murales dont le prix n'est pas filus élevé.

Il liut encourager nos artistes dans cette voie du décor pratipue et populaire. A dire toute la vérité, nous sommes encore les premiers au milieu de la concurrence mondiale, lorsqu'il s'agit de la création des objets de luxe. Nu! payss ne sanrait nons opposer un Majorelle on un Lalique, par exemple; mais il faut arouer que les étrangers commercialisent nos modèles de haul prix avec une activilè qui nous menace de plus en plus. Pourquoi l’initiative de nos commereants et de nos décorateurs, si ingénieuse lorsqu'il s'agit de l'invention et de la fabricalion d une picce unique, ne se porterait-t-elle pas vers une rénovation des modèles de vente courante répandus à un nombre d'exemplaires illimité? Une Exposation Internationale d'Art Décoratif bien préparée serait pleine d'enseignements à cet ígard (1). Elle mettrait en valeur les ressources d'imagination, de gout, de conscience dans le travail et d'labileté dans le savoir de nos artistes et de nos ouvriers, et l'annonce même du projet déterminerail dans certains milieux une féconde ardeur et une émulation certainement riclıe en résultats. En outre, il importe de créer une école nationale du mobiliel dans une ville où les inlluences artistiques extérieures viennent se greffer sur un tempérament de race originale et créatrice; et parmi d'autres il est un centre d'art uui semble tout désigné à l'attention de l'Etat: ¿'est la patrie de Jean Lahor, de Daum et de Gallé, c'est Nancy....

(1) Nous croyous devoil roppeler ici l'arlicle consaré par Roger Marx a l'Exposilion de Milan (Gazetle des Beaux-Arts, 1906, 1. ]H), où il dit : "Le projet de commimorer par une Exposition le cinquantenaire de la Troisieme lépublique ne s'aduet che\% nous qu'a la condilion de réduire le ptan à de justes proportions, el d'eviter la mégalomanie par quoi la portée des enseignements se trouva en 1900 si regrettableurent cowpronise." 


\title{
DE L'ART SOCIAL
}

\section{et de la nécessité d'en assurer le progrès par une Exposition}

\author{
par ROGER MARX
}

$\Lambda$ mesure que le cours des siècles se poursuit, que la civilisation évolue et que la suciété se transforme, l'esprit distingue mieux quels mobiles régissent l'activité humaine et selon quelles lois ses manifeslations se groupent et se complètent. L'ordre généra! s'en véréle peu à peu comme l'borizon se dévoile par degré au terme dune ascension lente; en rase campagne la succession des plans écliappe à l'observateur; la colline, la vallée, le lac apparaissent isolés, sans dépendance mutuelle; il faut le recul et la vision rayonnante pour découvrí l'enchainement 'lui lie chaque partie an tout et qui confëre à l'ensemble son caractère et son unité. Les entreprises de l'homme jrêtent aux mèmes remarques que l'euvre de la nature dont il süinspire. Malgrú la dispersion apparente de l'effort, un instant vient où se higgage le but vers lequel lendaient, en s'ignorant parfois, les volontés parallèles.

Longtemps on a pu se méprendre sur l'origine et la portée da sentiment qui exige la parure de la beaté pour tout ce qui nous sert et nous entoure; pareille convoitise semblait fantaisie pure ou dilettantisme; beaucoup la tenaient pour un luse que légitiment seules l'oisivetí ou la richesse ; il est acquis maintenant que ce besoin de beauté est le signe par où saffirment l'instinct du mieux, le désir d'adoucir la condition humaine et de hât’er un bien-être auquel tous aspirent, selon des nuvens diffèrents, mais avec des lloits égaux (1). Qu'aurions-nous à faire désormais de ces termes surannés, équivoutues ou restriclifs d'art somptuaire, d'art décuratif! Quand un art se mèle intimement à l'existence de l'individu et de la collectivité, la désignation d'art social est seule pour lui convenir; on ne saurait limiter à une classe le bénéfice de ses inventions; il se dédie libéralement à tous, sans distinction de rang on de caste; c'est l'art iu foyer et de la cité-jardin, l'art du chàteau et de l'érole, l'art du bijou précieux el de l'humble poterie populaire; e'est aussi l'art du sol, de la race et de la nation; l'importance s'en atteste par le jeu de son action sur le progrès des industries, sur la prospérité commerciale du pays; - si bien qu'en somme ses destinées se trouvent intéresser ì la fois l'esthétique, la sociologie et l'économie politique.

Les philosuphes de l'école positiviste et les Saint-Simoniens, Ruskin et William

1) En ce qui concerne te quatriène ètal, ce besoin semble la conséquence rigoureuse les satisfactions prérẻdemment accorlées aux bezoins primordiaux d'assistance, l'hrgiene et de conlont. Los questions dhyoiene of de confort sont, d'ailleurs, a tout instant conuexes aux questions esthétiques. "La joie des reux est un des élèments de la santé "), constatera Clarles Gide. (Economic saciale, ull vot. in-18, 1907, Jarose et Tenin, t. 233.$)$ 
Morris, Proudhon et Guyan, Destrées et Ldmond Picard, Jean Lahor (1), entre autres, ont eu l'intuition de l'avènenent prochain l'unc ère sociologique de l'art; les uns se sont complu au rève de l'utopie; dautres ont réduit le problène et spécialisé la question, par un séparatisme inopportun, en considérant l’art exelusivement dans ses relalions avec le quatrième état et non aree la société entière. Nous trouvons plus de générosité dans l"idéal qui réclame " de toul et pour tous le bien. fait de la beauté ". Un départ ne serait-il pas olseux d'ailleurs, quand à la seule sensibilité de chacun se mesure la fuculté de la jorrissanee esthétique ? Il l'arait compris, le précurseur et l'initiateur auquel revint de frédire le rôle grandissant dérolu à l'art et l'ordre de ses conséquences multiples. Dans son Rapport sur' l'Exposition de Londres de 18 ÏI (2), vèritalıle monument d'une vaste intelligence, ornée et lucide, Lion de Laborde a tout examiné, tout ealculé, tout préru. Parmi les penseurs uni sont intervenus depuis, il n'en est ancun - pils mẻme Nérimée rui se soit èleví à une telle hautcul de rues. S'en rencontre-t-il mème pour avoil apporté à l'étude de la question quelque contribution inélite d'un prix essentiel. Je ne sais trop, en conscience, tant se retrouvent, suns la plaraséologie vieillie de jałis, la plupart des idées dont notre génération s'altribue la mise au jour. Léon de I.aborde ne s'est dérobé en au une façno ì la sucislisation de l'art (3); il en a préconisé le relèvement, pour le bien génical, par le maintien du goût public ; puis, en patriole averti et sans lougir de se montrer pratique, il a envisagé l'alternative. de souveraineté ou de servitude proposéc par la suprématic ou l'abaissement de ec yue l'on nonmait alors l'art ulile, de ee que nous appelons l'art social aujnurd'luui.

Ainsi, dès $18 \ddot{0} 6$, un eritique a poussé le eri d’alarme, signalé le pécil et dénoncé "les elfurts réalisés de toutes jarts, atjn de ravil à la Frilluce une ilomination qu' elle a cxercée à plusicurs leprises depuis Charlenagne ct sins interruption comme sans conteste depuis Lonis XlV (4) $)$. Les raisons le cut ascendant ont étc maintes lois rappelées; il tient à la politesse des meurs, à ce sens ingénienx el aflini de la gráce, de l'élégance, de la mesure, que la France recut en partage avec d'autres pay's de petite étendue et le climat tempéré, la Grèce et le Japon. Deux siëcles et plus, lunivers eivilisé ne connut pas d'autres rérles que eelles de notre gout, pas C"antres styles que ces styles Louis XIV, Louis XV, Lonis XVl et mėme Premier Limpirc où nos dous fonciers s'étaient marqués avee une sincérité et une convenance parfaites. Glorieu-e mais reloulable conquète. Comment wiruler cet empire mondial? Comment ne pas concevoir d'une aussi triomphale avenlure l'urgueil immodéré qui avcingle et paralyse? De fait, l'esprrit d'initiative s'abdique jusyu'aı:x premières annèes de la Truisieme Rípolblique; notre paresse imprévoyante s'altalde dans l'érocalion stírile d'un passé aboli ; les 'morts retiennent plus la penséc que les vivants (3);

(1) Ct. Le systeme de politique josilive (1830-1842) et ha fin de la dernière lecon da

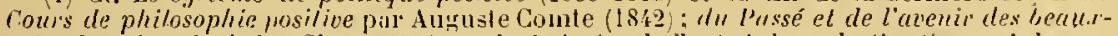
arts, doctrine de Silint-Simon (1830); du l'rincipe de lar el de sa destination sociale, par. Proulhon (1863); l'drt au point de vue sociologique, pal'Gurau (I890: : Ia Socialisation de

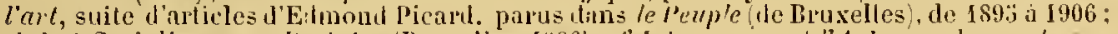

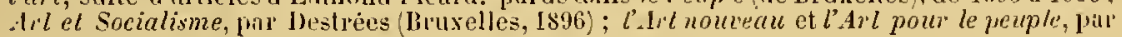
Jean Lahol' 190 I et 1902).

(2) Paris, Lmprinterie impériale. 2 vol. in-8o. Mt)CCCLIT.

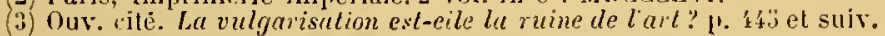

(4) II/., Avant-propos, p. 2.

(i) "Comprenez-vous, séciera Léon de Laburde, comment l'art ña pas élé lué sons deux générationsile fossoyeurs qui se succèdent fugubrement lepuis soixinle aus, occupé:cxelusirement i fouiller les tombeaux des gènératıons passees, á les copier aveliglément, servilement, sans choix cl coume poussés par un fétichisme fanatique... Comprenez-vous: ifuelle atmosphère sépulcrale plilıe sur ces hommes et combien est grande la nécessití l'aćrel et de parfnuer ces caves de l'al't moderne; combieu il est urgent de constituer des: hommas pratiques d'une généralion saine, vigoureuse et qui sache faire une distinclion ladicate entre lart créiteur et les monuments du prassé, comme on distingue la vie réel'́c. te lhisloile " (p. 400. 
on n'invente plus, on invenloric; on ne crie plus, on fait œuvre de critique et d'archéologue; ce ne sont partout qu'imitations déloyales et que pasticlies ridicules: Napoléon $~^{\text {er }}$ avait ressuscité Rome, la Grèce et l'Egypte ; le romantisme s'engoue du gothique et, sous Louis-Philippe, la Renaissance n'est pas l'ubjet d'une prédilection moins fervente; la curiosité du Sccond Émpire, qui se pique d'éclectisme, va rle l'art pompéien et néo-gree à l'art de llarie-Antoinette et de la Pompadour... S'hypnotiser dans l'adulation des àges disparus, c'est entretenir le mirage d'un rère, c'est perdre contact avec le réel et se disqualifier dans le concours ouvert entre les nations. Loin de demenrer oisives, durant notre long sommeil, elles s'étaient éclairées sur le principe de l'art social, sur les conditions de son existence et de son progrès.

En ce qui le concerne, la loi fondamentale est la loi du renouvellement nécessaire (1). Il ne remplit sa mission que s'il évolue en accord avec l'époque ảnnt il exprime les meurs, les idécs, les besoins. Tunte dérogation à la règle rompt l'éluilibre et l’larmonic. Chez nous l’art social noest surti de sa léthargie quä partir de l’instant où il a lenté de se sonstraire aux sugrestions du passé et oì il s'est relrempi anx sources du lihre instincl et de la nature $2 \%$. On peut placer au léclin du dis-neuvième siècle la période initiale de ce réveil dont porteront témoignage, en 1889, la Galerie des Machines, les palais de Formigé el dexceptionnelles contributions (3) ; dans la suite le mourement se continue, se jropage, el l'Exposition universelle de 1900 surprend les esprits en mal de décourerte; "c"est une phase d'èlaboration plutôt que de délinitif aboutissement, mais combien passionnante à raison des inquiètudes qu'elle déèle et des résultals dunt clle établit la progression " (4); on augure que notre ancienne prééminence nous sera bientùt rendue; on prononce le mot de renaissance; en réalité il ı en est rien; ce n'est quo'un laux départ.

D'ò̀ vient, et pourquoi le monremenl areéli Jans son essor en lirance a-i-il pl se poursuivre, sans entrave, à l'étranger? La vérité est que l'alfranchissement n'était qu'apparent; la hantise du passé n’a pas cessé de nous obsèıler; l'opinion reste à désabuser ; et, sans égard pour ses intérèts et son renom, la France persiste à professer l'effroi de l'originalitè et en mème temps une dévotion excessive à ses styles classiques qui n'ont cependant mérité de prévaloir que par leur adaptation judicieuse au milieu. D'aulre part on doit faire état de l'hostilité à tout changement, fréquente, sinon constante, chez les fabricants, chez les industriels; esclaves de leurs habitudes, ils s'y complaisent; une mérente possible des modèles existants ne les effraye pas moins que le sureruît de dépenses auquel obligerai l'établissement de modèles nouveaux : lant il est vrai que l'immédial seol les préoccupe et que de l'avenir ils n'ont cure. L’avis le plus commun rendait surtout responsable

(1) Michelet dira de lui qu'il coit "lurenter ou pirir n.- Jiuskiu de son côté, dans les Pierres de tenise ( $1831-1853$ ), a turmule son csthètique dans lestrois prescriptions suivintos: $1^{\circ}$ N'eucourigez jamais la fabrienlion d'un objet dans ta production duquel l'invention n'a pas de palt : '20 N'exigez jamais un lini minutieus pour le funi luj-mème, mais seulement s'il tend à un but pratique ou noble; $3^{\circ}$ " "encourngez jamais ube imitation nj une copie d'aucune cspèce...

2) C'cst la voie desalut recommandé, des 1573, par l'èducatem unique que fut Lccoq le Boisbaudran. "Au lieu d"inposer à la jeunesse l'étude prématurée, la répétition continue du passé, ne serait-il pas mieux de la placer le plus tỏt possible en face de la nature, atin qu'elle y cherche, avec un esprit sincére, une imagination fraiche et indépendante, des élèments nouveaux pour de nonvelles conceptions? Elle pourrait parvenir ainsi à rompro le cercle snus issue dans lequel l'art décoratif moderne tourne sans cesse et se trouve enfermé."

(3) Voir notre livre la Décoration et l'tit industriel à ll Exposition unirerselle de 1889 , l'aris, ancienne maison Quautin, in-80, 1890.

i) La Decoration et les Industries dítil à l'Exposilion universelle de 1900, par loger Marx, in-fo, Delagrave, èlitrut, 190l, préface, p. vir. 
de la réaction le goût encore incertain des inventions parues en 1900 ; qu un clroix s'imposàt parmi tant de recherches fiévreuses, personne ne s'avise de le contester ; mais, faule de satisfaice à l'effort d'accontumance, on a peut-être apporté trop de parti pris ou trop de hâte à censurer, dans leur ensemble, des ouvrages qui attestaient un desir l'émancipation on d'appropriation toujours estimable en sai ; car la plus pauve création est moins réprélıensible que la contrefarnn falote où l’impuissance se trahil et se confesse.

Le copiste rappelle sourent l'enfant qui trace avec peine des caractères sans connaître le sens caulıé sous les signes qu'il transerit. Ce parallèle se présente à l'esprit larsque l'on roit tant d'artisans repraduire docilement le soleil auréolé de reyons qui constitue l'emblème de la majesté du grand roi ; sans plus d'à-propos nos meubles s'orneront de cuives figurant des personnages de la Comédie italienne, tout comme à l'époque de la Régence el de Warteau; pas de médecin de village qui n'hésite à proscrire les lourdes draperies flothintes dont s'encombre ce lit du Coucher de la mariée que nos tapissices réditent sans arrèt, au mépris des règles de la plus élémentaire hygriène; n'est-il pas détoncertant encore de rencontrer, sous tous prétextes, parni les attributs du decor fanilier, les glaives, les boucljers, les trophées, détachés de la panoplic napoléonienue, qui semblent quelyue peu drsuets iprè: quarante années de paix el si contradictoires avec les aspirations humanitaires le la pensée moderne?

Les architcctes n'ont pas éti, semble-t-il, sans faroriser la prolongation de cet anachronisme ijui se perpètuc comme un défi au hon sens et à la raison. Il leur appartenait de proclamer, arant tons autres, les modifications survenues dans l'ètat de la civilisation; on est réduit à compter les êlifices uì l'auteur s'est sonsilait à la tutelle de l'antiquité et des styles morts. Vuilà bien le syınptôme qui aurait dủ mettre l'altention en éveil et inspircr le donte suc la viabilitè de la prétendue renaissance. L'art de butir u'autolisail il l'Exposition de 1900, et pour la lirance du moins, aucune conclusion réconfortanle ; or, l'archilecture scule peut déterminer et annoncer un nogrès durable; elle est l'art social par cxcellcnce; a son sort se tronve attacliée la fortune de mainte industrie; enfin s'il lui arrive de faire cuvre valable arec quelque continuilé, son succis implique l'accorl des roluntes qui a précisciment fait Jéfant en 1900 . On s'est trouvé en prèsence d’initiativas émanant parfois d’individualités glorieuses, mais sans lien entre elles parce qu il ñ ${ }^{2}$ avait ni unité de vues, ni mème nrientalion des aclivités dans un sens déterminé.

Des Etals soumis au régime monarchique, l'Angleterce, l'Allemagne, les Flandres, certains pays du nocd, ont prouvé dans cetlc rénovation un sens social mieux a verti et des qualités plus propres à en assurer la poursuite (1). lis n'ont pas èté tenus en lisière par le passé; leur tracition, moins illustre peut-ètrc, n'a pas été pour enx une entrave; s'ils ne possédaient jas notre gout inné, ils se sont mis en mesure de l'acquérir artificiellement par les suggestions de l'exumple, voire méme par l'emplunnt d'artistes francais ; ils ont multiplié les écoles, les musćes ; ils ont dévelopıè l'enseignement technique; ils unt - les Allemands surlout (2) — utilisé

(1) Au print de vue gégraphique, l'isolement de l'Angleterre ne manque pas de lui ctre favimible, et on retiendra iussi que, dans le petits pays tels rue li Belgique, la Hollaude, le binemirk, f'unité el la concorriance des ellorts sont plus faciles á ohleuir. En Allemagne, elles sont secondés par la trntince des anciennes copilales á former des "colonies" d'art distinctes. Jeut-ìtre derrait-on viser pareillement ehez nous à tat reconstitution des anciens centres. Les services rendus a Nancy par l'Association provinciale des Industri"s d"urt ifondée par Mi. Emi!c Galle) et à Besaneon par l'Union protincirale des Arts Decoralif; fondée par M. A. Clusılaul sont bien pour couseiller une actiou dans ce sens.

(2) Sur le dermier état de l'ar'l social en dllemagne, consuller le Rapport préspré au

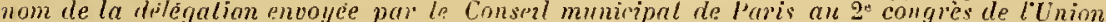

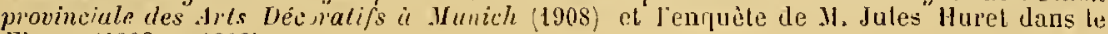
Figar (1908 et 1909). 
la fréquence des rapporls et la facilité des communications pour s'assinuler au jour le joul les plus récentes inventions les arlisans eurnpéens; d’intelligence libre ct positive, ils ont tiré parti et profit sans délai des découvertes de la mécanịue, de la chimie, de l'électricité, et la fabricalion indusirielle n'a jas lenu, dans leur príocupation, une moindre jlace que la céaiion de l'objet de luxe, édité à nombre restruiut.

Quand un problème est aussi complexe que eclui de l'alt social, la spontanëití, la promptitude d'esprit te suffisent jas à l'éclaircir, et on peut se demancler si l'espoir d'une solution lıeuremse n'est pasplutôt méuagé par la lenteur, le calıne et la réllexion où incline vuluntiers le tempérament septentrional. Sans nul doute, t'est une conscience nelte du hut à atteindre, éest l'esprit de suite, la coordination des efforts et surtout la méthude et la discipline qui ont permis ì d'artres l'aboutir et de tenir la France en éclıec. On connaîl de quel préjudice celle iulériorilé est levenue la cause; on sait les alleintes jorties à notre esprit d’initialive, à nus

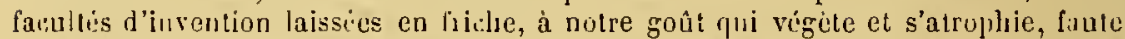
de s'employer utilemen!; on sait d'autre part l'abaissement du chiffire de telles exportations, l'invasion grandissante de tels produits manufacturés hors de Frauce (1), l'émigration à l'étranger de certaines industries séculaires et: jour d'autres, la menase d'une disjarition prochaine, enirainaut afr'is elle le désouvrement, le chimage... Ny a-t-il rien i tenter atin le conjurer celte déchéance, et toute possibilité de relèrement est-elle interdite quanu déjà on arait cru en discerner les premisses? Pour nous guiler, celte fuis, nous arons les jalons d'une expérience durement acqui-e; plutot que d'assister, complices impassible:s, à notre amoindrissement, le miens est de se remetıre à ia táclie, de reprendre l'cuvre de rigénération au point aì elle était restée, mais en s impusant d’en régler la conduite selon la logrique dun plan próméditè, mûtri et qui préserve de tout risqute d'avortement.

Par l'émulation qu'elle jrovoque, par le déploiement d'énergie qu'elle com mande, une exposition soule peut surexcier les aclivités et leur impluner l'élan salutaire. Mais que l'on ne s'ahuse point. D'exposition universelle, il ne saurait en étre question; l'ère en semble pour jamais close. La manifestation de 1900 s'est chargie d'útablir la vanitó uu plutût le danger des conceptions chimériques hors de relation arec l’échelle lımaine; la portée didactique en a été comprumise par le iésordre et la confusiou dont saccompagnent fatalement un plan démesuré et une ambitiın jalunse de trop embrasser; on eût dit l'elle un luazar ou une foire. La raison n'udueltruil guèrı que le préteste d'un eaprice fulile renourulit un amusemeat unéreus uju ne va p.ıs sans causer quelque perturbation dans les habitudes du pays. Il hut l'oxeuse de l'intérèt scientifique et le bénéfice d’un enseignement cerlain, pour justilier un tel branle has, et ce bónéfice, on ne le doit attendre que d'une exposition spéciale, an programme restreint, neltenient defini.

Puisque l'on nous prète l'intention de célébrer, selon un tel mode, le cinifuantenaire le la truisieme ripublique, il y aurait honneur el profit à ne pas laissel d'autre projet égarer la pensée et à nontrer sons ıfuelles espèces siest lraduite au vinglieme siècle la socialisition de la beauté. Cello exposition, muss la vourlriuns inleruationaie, parce que le concours est un stimulant actil; parce que plus dune suggestion heurense peut venir du dehors; parce qu"un exemple tout proche est li, et que de l'exposition de 'ourin (2) late la resurrection artistique de i’ltalie; uous

(1) Meubles, tissus, cuives el papiers puints anglais; hijomteric en fanx, dinanderic el ètains attemauds; sièges en bois courbé el verreries d'luiliche ; porcelaiues du Dinemark, elc...

(2) L' "Exposilion internationale des Arls Décoratifs moderues " de Turin a été ouverte

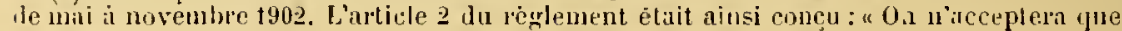
les ourrages originaux qui montreront une teutance bien marque a: renouvellement 
voudrions aussi qu'elle fùt moderne, que toute ríminiscence du prassé s'en trourit cxclue sans pitié, les inventions de l'arl social n'ayant d'intérèt et de raison d'ètrét que dans la mesure où elles s’alaptent rigonreusement au temp̧s qui les roil Haraître.

Mainlenan, quelle en serait l'économie générale? Le clıamp ne laisse pas d'être trí: élendu. Il nes'agil rien moius que deréréler l'art dans l expression de ses rapporlsavec la vie publique et privée, à la rillo el au village, en France el dans nos colonies: d'élablir comment l'industrie et le gotı̀t. s'accordent à transformer les ćlements, la malière pour le plaisir des yeux, l'agretment de l'usage, l'embellissement de l'exi:lence, conment aussi la dignité de l'homme s'accroit à parer les tímoignages du son libeur manuel et mèmeses loisirs, ses diverlissements, ses joies. Mais la démonstratiou n'aura de valeur convaineante qu’à force de précision, de clar'é. En pareille oc'ur'rence tant raut la classification, tant vaut l'eneiguement recueilli (1); elle deva se ıléduire du but mème le l'exposition et se baser sur l'ordre nalure!. C'est affuire aux économisles de la dresser avec le sonci prédominanl de dégager des lecons aecessibles a lous. Sans en délerminer par arance le lexte, u'est-on pas en druit d: présumer qu'une telle exposition unilail toules les forees vives en leur proposant un seul el même objet et yu'elle saurait eonsacrer la solidarilé de l'art et le la nature, de l'art et de la vie, de l'art et de la science? Du meme coup prenılraient lin les préjugés qui ont pesé lourdement sur les demières générations; au lieu d’ètre rouée à l'anathème, la machioc apparaîlıait comme un auxiliaire el un agent de diffusion rapidu et fidèle; rien ne subsisterait jlus de l'antagonisme d'hier cntre l’ingénicur el l'architecte réconciliés dans le culte utilitaire de la beauté. Cal. la préminence apparliendrait celte fois aux bâtisseurs de la cité future, à cenx qui édifient le palais et l'babitation ouvrière, l'usine et le musie, le pont el l'hôntilal, les thermes el l'asile de nuil; la peinture al la sculpture, qui prétendaient naruért absorber seules l'altention, inlerviendraient uans la limite de leurs fonclions dicoratives; le groupement technologique (2) assurerait aux industries de l'ornement, du mobilier et de la vie domestique la présentation normale qui leur fut trop sonvent refuséc; on apprendrait aussi dans quelic large mesure reslent 1ributaires lle l'art, la mode puis les moyens auxquels il nous faut recontrir pour transperter notre corps el répandre notre pensée; an dehors c'est encore l'art pui égayera la rue, qui

esthélique de la forme. Les intitations d'anciens styes at les produclions industritle: dézuées d'inspiration allislique ne seront pals aduisess. a Les clfuls propices de ces dispositions ont été hientòt mis en lumière par l'Exposilion de Hilan. Voir, sur l'ätat conjpatritif de l'art italien i ces dewx Expositions, mos arlicles de la fazelle des Beanx-lils:

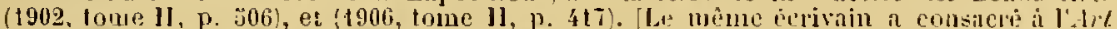
social ì l'Erpoxition Universelle de Bruxelles dans le mème pecueil hiazelte des BeruxA.l. 1910, t. II, p. 492) une élude postérieure il la pullication da minifeste des Idees modernes.]

(1) La rassifieati m rayonnate de Je Pliy, en 1867, reste mantenant oncore cxemplaire. "Elle elail divise a lit fois en sectuil's col'respondaut aux dillerents pays el en zunes concentriques correspondant aux diverses catégories le produits. Si on allait de lit circonférence ver's le centre, on passait en rưue tous les prorinits t'un mème pays; ; sin

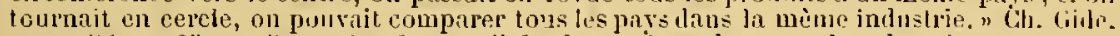
ouv. cite, p. 25. - De toutes facon - il fiudra eviter de retomber lims fos rereur:ul: de 1900. Jes monnaies et les mẻdailles étaient rangées lans la mêne classe que les instruments de précision; on relpouvait contondus pète-mêle, dans fe troupe Xl, la bijouterie-joaillerie st les produits en caontrhouc, la ferronneris d'art ef les olijels d. campenent.

(2) C'est celui qui a été suivi : par J'Union ccntrale pour'ses Expositions dn métal (1881. du bois, du lissu et du papier (tSS2), des ar's du feu 1S83), el pour l'Exposition généal.

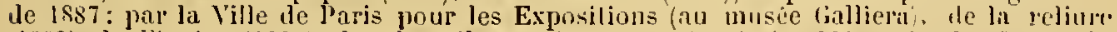
(1902), de l'ivoire (1903), des dentelles, guipures et houberte 1907), du fer foreri, du

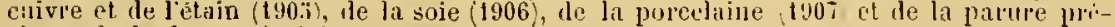
cieuse tle la femme $(1908)$. 
saura pourroir de prestige les cortèges, les fètes publiques (1); de son domaine relèveronı enfin le théâtre, la musique, la danse qui farorisent la transmission directe el l'extension immédiale de l'émotion esthétique... (2).

Mais à cntrer davantage dans le délail, alors qu'il s'agil d'un exposé succinct, forcément incomplet, on risquerail d'obscurcir l'idée qu'il faut se former d'un pareil dessein. 11 suffit d'ailleurs pour linstant d'avoir soumis à la réflexion des esprits édifiés sur la situation présente la chance de progrès olferte par une exposition d'art social, vision harmoniense el rationnellement ordonnèe de l'humanité en marche vers les destinées meilleures.

Rogrir Malix.

\title{
L'ART DÉGORATIF S'ATROPHIE EN FRANGE
}

\author{
Pour le vivifier, il faut faire une Exposition internationale \\ des Arts Décoratifs à Paris.
}

Totre ipoque consacre son effort à améliorer la condition humaine. Un sentiment tout molerne - la solidarité - a mis en éveil des aspirations généreuses et imposé la conscience de devoirs auparavant inconnus; mais les satistactions jusyu’a présent accurlées à des besoilıs élémentaires d'assistance signalent aue orientation, indiquent un acheminement et non un terme. Par une poursuite Jogique de nos revendications, l'accomplissement d'un progrès suscite tout aussitòt la convoitise d'un progrès nourean; nous arons voulu l'hygiène pour Lous; puis l hygiène a inslitú lo désil du confort; et maintenant les économistes en vienneut á recunnaitre ¡ue a la juie des yeux constitue un des éléments de la santé ». Voilà pourquoi l'art, appulé à orner ce qui nous sert et ce qui nous enloure, apparaît à cetce heure conme la recherchedu bien-ètre sous an forme la plus noble.

Cet art, on le nommait hier l'art somptuaire, l'art décoratif, et ces désignations poturaient s'a Imettue alors qu'ulles visaient pour le jassé des objuts de collection et

(1) Cr. L'Esthótique de ln rup, par Gustave Kahn (1901) : l'Esthétique des villes, pal' E:nile Jlague 190s. Se reporter igaloment aux trasaux des Congres (briges) et de

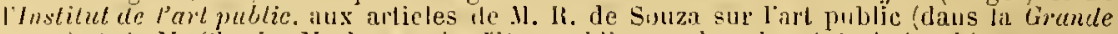
rerue) et re M. Chith's Morice sar les lüh's puhliques (dius les Ails de la rie), elc...

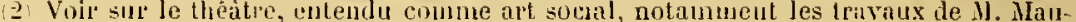
rice Poltecher et les Oburres de salnt sncial en Allemagme, par le professeur Albrecht

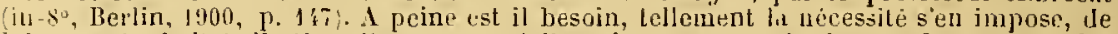
laisser provolr l'allubution d'un groupe á Jenseignement, puis des eouférences et dis "ungres dest nes à ètmlier les questions qui concernent l'art soeial, l'enseignement du lesin, l'enseignement lechuique on professionnel, el l'apprentissage. 
jour le pressent une production exclusirement icscrve à ume élite fortunéc; l'accession à l'art du quatıiène état met hor's d'usage ces désignations restriclives; envisagè dans ses rapports avec la vie de l'individu et de la collectirité, cet art est l'art de la nation entière, c'est l'Art sucial. liépond-il à sa mission, nous voyons en lui l'expl'ession fidèle de la civilisation ambiante; cesserait-il d'óroluer arec la société lont il émane, il se dérobe ì son obligation la plus imperrieuse et sa dicalence est. certaine.

lnstruils les causes qui associent laccruissement de la lichesse à la prospérité le l'ult social et guidés pal" un souci bien entendu de leurs intérèts économiques, des pays moins artistes que la France, mais d'esprit plus positif - l'Angleterre, l'Sllemagne par exemple - ont compris cette loi tondamentale du renouvellement nécessaire; ils se sont mis en mesure d'y satisfaire en suppléant à linsuffisance de lenl gout natil par les suggestions de lexemple et les lienfaits de l'enseignement. Pendant ce temps, nutre génie est resté inféodé aux styles illustres qui lui ont valu depuis deux sićcles une suplématie mondiale; au lieu d"inuover, selon l'esprit de la race, il languil et s'atrophie dans l'éracation stérile d'un passé aboli. Les mceurs, les usages, tunt a pu clianger autour de nous; les constructeurs n'en continueni pas muins de bîlir selon les modes d'autrefuis; le danger d'un pareil anaclınnisme rst d'autant plus inquietant que l'arihitecture est l'art so:ial par excellence et que l'elle dépend, pour une boune partie, le sort des industrics d'art - n'est-ce pas dire liblat le nos exportatiuns? On soccupe it bon druit de réformer l'enseisnement du dessin, de madilier l'enseignement teıhnique, de parer aus inconvenients de la crise de l'apprentissage, et il faut applaudir à toutes les initiatives qui prépareront une génération dartisans micus alnée pour l'exercice intelligent et loyal des métiers; mais par-dessus tout on doi l'épandre la notion de l'effort à accomplir en vue d'arlapter les dons fonciers de notre invention et de notre goût à l'expression harmouieuse d'idées et de besoins nouveaux.

Comment parvenil à ce résultat? Cumment exercer une action décisive sur l'opinion et sır la proluction, sur le rublic qui juge, qui comnande, qui clıoisil, et sur le créateur qui exécute, qui réalise? Et d'abord quelle est, au rai, la situatiun? Alires 1889, un mourement semblait prèt à se produire. Dutert renait d'üdifier cette Galerie lles Machines qu'on se deshonorera. denain à détruire, tandis qu"il siérait de la classer au nombre des monuments listorịues du dix-neuviène siècle; Formigé avait suscité le rève éphémère de ses palais de fer et de terre, aux tons le turquoise et de corail pilli ; l'un après l'autre, sur nos instances, les Salons s'etaient ouverts indistinctement aux ar's purs on appliqués... Ce fut pour les activités une occasion rare de se donner libre carricre; elles le firent avec quelque hitc, comme il arrive pour un début, sans coodination des efforts et peut-être sans un souvenir assez présent le la tralition nationale. D'oì l'avortement de tant d'essais et d'intentions souvent louables en soi. Tout est à rejrenire; mais il ne parait pas malaisé de découvrir les roies propres a faroliser me renaissance, pour peu que l'on tienne conpte des inclinations du tempérament français, lequnel n'aime point. a peiner de façon incertaine, dans lomble et sans hunnrur. Seule une Expositiun speciale, ut programme restreint ct nuttement défini, peut provoquer l'ilan utile, stimuler les énerries, rallier les voluntés élurses aujourd hui mieux disciplinées et idifiées par l'expérience sur les moyens à adopter et le but à atteindre.

Cette exposition d'art social, on la roudrait internationale, afin de mettre ì protit les leçons de l'ètranger'; on la roud'ait moderne, c'est-à-dire prèvenant les retour's sur le passé et proscrivant, aux turmes de son règlement, toute imitation de l'ancien. Si la printure et la statuaile n'y intervenaient dans lit limite de leul's applications ornenentales, l'architecture an contraire y tiendrait un rôle prér.ondèrant. La matière y apparaitrait transformée par l'industrie hunaine selon les aspirations et les ressoulces particulięres a charue classe; l'lumble poteric ne s'y 
vertail pas accueillie avec moins ı’’̇gards que le bijou précieux. Lne telle exposition libérerail le l'entrave du préjugé: elle narquerait la fin du mépris voué à la nachine; elle ferait cesser l'antagonisme siculaire entre l'ingènieur et larchitecte; elle gromperait, selon une classitication néthodique ct d'après la même idée d'ensemble, des manilestatinns jusqu'alors arbitrairement diseéminées dans la rohute des expositions muiverselles; $n i$ le théatre, ni la musique, ni la danse n'en seraient exclus; l'art de la cilé, l'art de la rue, l'art des jardins, l'art des fètes popmlitires lui deraient l.ul renise en honneur.

Si la troisiène Républịue persiste dans son projet de célébrer par unc exposition le einquantenaire de sa fonilation, il ne semble guère que l'un puisse souhailer une conmémoralion plus aple à rijonir notre illial humanitaire et à scconıler notre amour du progrès; par elle sonuvirait dignement une ère nouvelle - l'ère sociolıgiuge de lart yu'ont depuis lungtemos annoncée les uhilosoples de l'école posiliviste, Aug!iste Comte, Prull llon el, aprés eux, Guyau.

Iiogren Minx.

LE MUSÉE. — Décembre 1909.

\section{Réponses aux propositions de ROGER MARX}

l.es propositions émises par Rnger Marx daus les Iltes Modernes de janvier 1 gut el le Matin du 27 févice 1909 suscitaient immédialement lattention fui duit sattuclice à toute question d'orilre vital pour le pays.

Un debat s'instituait dans lit presse et dans les revues : nous signalerons plus specialement dans la presse quotidienne, les articles de Vauxcelles (La Crise des A'ts dicoralits en France, Gil Blus du 3 février), de Paul Ginisty (l'Art social, Petit rurisicn du 4 février), de Pierre Gauthiez (Pour la beauté, Echo de P'uris llu 16 février), de A. Liesse (l'Alt social, Journal des Débats iln 21 février), de Grandigneaux (le Railicul), de Luciphar (le Figaro, le Siecle), ctc. ; dans les rerues, les Ctudes d'Alphonse Germain (l'Ochilent, janvier 1909), de Pierre Ilepp (la Grande hovue, 2; mars), d'Anclé Fontainas (Mercure de Frunce, 16 avril), de Pascal Forthuny (l'Architecturc moderne, $f^{\text {er }}$ mai), de II. A. Y'on (l'A rehitceture, $f^{\text {ee }}$ el \& mai), de Josepli Lenot (Rerue des Lettres et des Arts, juin), de Henri Duhem (le Musce, novembre 1909 , etc...).

D'autre part, Roger Marx recevait de nombreuses lettres acceptant ou refusant de s'associer à ses conclusions.

Dans la revue le Musie, de lécembre 1909, il remercie de leur bienveillant intérèt ses corresprondants : Boutroux, Fouillé, Charles Gide, Sthuré, Beaiquier. Edmonıl liuard, Dsstrées, Bonnier, Lucien Magne, Sézille, Chedanne, Bodin, ainsi que le pasteur Cliarles IVagner.....

Parmi les lettres repues, le Musie publiait celles, approbalives ou non, qui pouvaient inviler à lètude du problème et en hàter la solution, notamment celles de Frangois de Curel, Paul Dssjardins, Maurice Pottecher, André Chevrillon, Christian Cherfils, H. Bergion, Prancis Jammes, Emile Verhaeren, Augusie Rodin, 
René Lalique, la Princesse Marie Tenicheff, E.-M. de Vogïė, Vaudremer, Charles Plumet, Maurice Mreterlinck, Albert Resnard, Maurice Denis, E.-A. Bourdelle, A. Le Chatelier.

Roger Marr, pour la publication de ces lettres, les a " sériées selon l"idée doninante, inspiratrice de l'opinion exprimée ".

\section{Y a-t-il un Art social, et quelles sont les conditions de son évolution \\ en France?}

Je suis en complète conformité de pensée avec rous. Si la condition matérielle du plus grand nombre est allée en s'améliorant, il est certain que l'alimentation spirituelle n'a jas suivi la mème progression. Thut ce qui pourra servir ì combler ce vide ou à supplèer ce qui ne peut plus exister fournit la matière d'une cuvre infiniment féconde. Vous indiquez un commencement de mise en pratique qui semble séduisant...

François ne Curet.

Autant que je puis, après une lecture, dégager les propositions essentielles de votre article, ce sont celles-ci :

$1^{\circ}$ L'art ne doit pas étre considéré comme un luxe qui se superpose à la vit', mais bien comme une manifestation de la vie mème, qui s'y inclut, de sorte que l'œuve d'art soit empceinte al'un carautèce de nícssite autant que les productions de la nature;

$2^{\circ}$ La vic qui se manileste clans l'cuvre d'art, qui la commande ct l'anime, est une vie socitle; toute la socièté y coopère, toute la suciété doit en pouroir jouj, et si ceux qu'on appelle jnexactement "les hommes du peuple " en paraissent aujourd'hui exolus, c'est qu'il sont exclus aussi du peuple, je veux dice de la communion des esprits par où une collection llinilividus se fond en une réelle unité, et cettc question ne relève déjà plus de la suciulogic estlıétique, mais simplement de la justice ;

$3^{\circ}$ La société dont la vie s'exprime par l'ceuvre d'art avec un caractère le nécessité est la société immélliate actuelle, celle qui moule notrc scnsibilité comme notre aclivité ; - et l'art rétruspectif, avec ses musées, ses mobiliers " de style ", ses ressouvenirs et ses "simili ", ne sera jamais qu'un artifice auquel la beauté manquera parce qu’y manque l'empreinte ile nécossité. Il faut donc que la civilisation présente se replie sur elle-même pour enfanter, dans la conscience de l'artisan sincère, l'art irréalisé encore qui lui correspond.

Si telles sont bien ros theses, je ne crois pas qu'on puisse les contester : quant à l'opportunité d'une Exposition internationale d' "Art social ", quelques-uns feront les réserves; une exposition n'a pas en soi la vertu de promouvuir un art original : elle ne peut que le constater ; il est rrai qu'elle le consacre et donne, par l'exumple, aux germes latents, l'audace de poindre.

Paul Desandins. 
L'idée d'une Exposition telle que vous la limitez me paraît intéressante et bonne : celte exposition servirait à déterminer les étapes de l'art en son évolution sociale; elle pour'ait donner anx producteurs, avec la conscience de l'effort collectif, .ne hardiesse et une confiance qui leur manquent parfois, - peut-être aussi une discipline.

Ces mots un jeu barbares, "la Socialisation de l’Art", inspirent de la méfiance et de l'antipathie à de vrais arti-tes que je sais; cependant cest un fait et qui ne signifie rien contre l'individualité nécessaice de l'artiste dont la riensét restera tuujuurs indépendante, et même en réaction contre le milien social qui tend à la comprimer, comme sa vie restera toujours à quelque degré solitaire.....

Puur l'imitation, je suis d'avis, comme vous, qu'elle n'est à allcun degré un facteur de l'art, et qu'elle est la négation de l'artiste, - bien que la piupart des artistes professionnels ne vivent que d'imitation. L'imitation formelle du passé est d'autant plus vaine qu'elle s'applique à des clioses mortes. Mais l'imitation d'un objet d'art ou d'une furme d'art présent, c'est-à-dire né depuis peu et encore tout chaud de la mole, n'est pas moins répugnante. L'art étant sinon une imitation, du moins une transposition de la nature, qu'est-ce que l'imitation d'une chose déjà imilie ou transposée?

Par contre, vous admettez ceriainement que le lien entre le passé et l'arenir ne peut se romple, qu'il n'y a pas en réalité de brusques sants dans l'Art, non plus que dans la Nature, et que l'étude consciencieuse, réfléchie et rraiment aimanto du passé, pour en pénétrer l'esprit, en revivifier, en qıelque sorte, en soi toutes les inventions, peut ètre aussi féconde pour l'intelligence, que i'est pour les sens l'ohservation directe de la vic, de la nature, du monde, qui nous entoure.

Et à mon sens, le désir d'une trop grande originalité, qui étonne et qui s impose, mème par le scandale, est aussi néfaste à la solidité et à la durée d'une œuvre, d'une forme d'art, d'un style, que l'hostilité des conservateurs et la résistance intéressée des marehands.

En somme, tout se ramène à un patient équilibre, à cette sage et difficile mesure dont les Grecs avaient le sentiment si ferme et rotre dix-septième siècle le goǹt nn peu étroit ; cette mesure que les étourdis dédaignent parce qu'ils la confondent avec la médiocrité.

Etant d'aceord sur ces points, nous nons entendrons sur l'utilité d'élargir, de plus en fluss, l'art dans la vie et dans le peuple, en essayant d'éveiller ou de réveiller, dans le penple, le goût d'une beauté non distincte de l'utile et d'une grandeur śalliant arec la simplicité.

Maurice Pottech fr.

\section{Que le renouvellement de l'Art social est la condition de son progrès.}

Toujours, ou du moins depuis trois siècles, la France, grâce à son goût sùr entre tous, a tixé les styles. Il faut donc que ce soit chez elle, dans une Exposition faite à Paris, que tous les novateurs soumettent leur travail à l'attention publique. Cumme elle l'a fait jadis, elle éliminera, adoptera, choisira et enfin composera.

Emile Venh.ıfreis. 
Je sens qu'il y a une erreur initiale. Il n'y a pas aujourd hui de mode qui ne soit inspirée du passé, pas de produit qui ne soit une cojie, tićessairement infélieure, d'un style antérieur. Après les plagials du grec et du Moyen Age, volui anjourd'lui les pillards du japonais, du persan.

Rien de personnel, rien que faiblesse. Al ! si nous avions la force, si nous savions regarder et ètulier la nature! Alol's un cordonnier siturait suivre la forme d'un pied, le modeler avec son cuir. Ur, montrez-moi un soulier, même de "bonne maison ", ıui ne soit iuspiré seulensent de la convention de la mode? Encore est-il a parier que l'amateur, l'acheteur de ce produit rationnel, lravail intelligent et artistique, serait à.trouver. Cherchez l'imateur.

1) faudrait que les artisans d'aujourd'hui, comme ceux d'autrefois, fussent les juges, les seuls " arbitres de nos élégances". Mais, pour commeneer, i] faudrait qu'ils en fussent capables. Pour en ètre digne, il faudrait que l'ourrier rederiut l'inventeur d'autrefois.

Or', les faits démontrent et une exposition ne pourra que témoigner le néant de ee genre d'inrention.

Est-ce la faute du machinisme ? C'est possible, mème probable. Cette grave question de la déchéance de nos industries d'art est-elle liée à tous nos frroblèmes et nos soucis politiques et économịues? C'est à redouter.

A supposer qu'une Exposition révèle l'étendue et la gravité du mal, elle n'en apportera pas le remède.

Auguste Ronx.

Dans un texte restreint, vous avez embrassé la question si complexe de la détresse de l'Art décoratif en France avec la sérénité d'un noble esprit qui ne reut envisager les choses que dans lenrs grandes ligues, dejdaignant de s'atlarder aux détails. El cependant vous avez tout dit.

Les causes de l'état de choses que nous rléplorons ensemble sont bien celles que vous signalez: les producteurs ont perdu l'habitude de l'effort. Il est plus aisé le copier un fautenil Louis XIV que d'en eréer un d'une égale heauté. plus en accoril avec notre temps.

Que serait-il advenu pourtant si les ateliers dans lesquels, depuis vingt ans, s'exècutent sans relìche des pastiches des styles anejens, avaient eu à leur tête, au lieu de spéculateurs oecupés de leurs intérèts, des artistes convaincus et acant töut souticux de bulles formes? Peut-êtro l'Art social cût-il repris déjà en France son éclat de jaılis :

Mais il est dans notle socjété une classe qui veille soigneusement à ce qu'un semblable progrès ne se puisse accomplir : les collectionneurs d'ubjets et de meubles anciens, pour la plupart marchands. Trafiquants impudents et snobs, ils s'érigent en éducateurs de la riche bourgeoisie, pour le plus grand profit de leurs affaires, sans se soucier de l'arenir le l'Art, dans ce pays dont ils élouffent sans scrupules toutes les énergies créatrices - inconscients, semble-t-il, de l'auvre abominable qu'ils poursuivent, ignorants souvent et incapables de reconnaitre la beauté si elle n'est pas cataloguée dans quelque collection fameuse ou si une date anthentirue ne leur pernet pas d'orienter leur jugement.

Espérons pourtant que, malgré le tart qu'ils lui out causé déjà, l'Al't social moderne aftrmera avec éclat sa réelle valeur, dès que, selon votre væu, on lui en donnera les moyens par l'Exposition dont, pour ma part, je souhaite lorganisation prochaine.

Les artistes de notre pays et des autres nations, résolument secondés jar vous et, je n'en puis douter, jar tous les véritables amaleurs diat, concourront ardemment à prouver qu'ils pourraient, pour peu qu“ils y soient encouragés, égaler les maîtres d'autrelois et doter leur siècle d'un Art oì la France retrouverait son prestige passé.

\section{René Lam.rQee.}




\section{De la prééminence de l'Architecture dans l'Art social.}

Je recois votre article, aimable rappel du bon combat que nous combattions cìte ì côte il y a vingt ans! Quelques-unes de nos espeérances ont été trompées. L'Architecture, comme vous le marquez fortement, est génératriee et régulatrice de toute grande pousséc artistique; il ne ma point paru qu'elle ait continue on renonvelé, à l'Exposition de 1900 , les tentatives pleines de promesses des Dutert et des Formigé. L'une façon générale, il me semble que l'effort de 1889 a margué le point 'ulminant d'une courbe, plutôt que le point de départ d'une échelle ascendante. Vous êtes un peu plus optimiste ; puissiez-vous avoir raison!

Vutre projet d'Exposition internationaie, limitée à l'Art social, pent ètre fécond : cela dépendra pour beaucoup les hommes qui lui donneront vie et forme. L'expérience nous a montré qu'une Exposition c'est un homme, une pensée heureusement ou maladroitement réalisée.

Combien vous avez raison de lappeler nos contemporains à la souree-mère, ì cel incomparable travail de Léon de Labor.le ! Il vous eùt approuvé, encouragé; et ce suffrage postlume a un bien autre prix que le mien...

E.-N. nl: Vogül:

Depuis longtemps, nous summes dans un grand trouble, gràce à l'application irraisonnée de formules toutes faites, an manque d'initiative, à l'asservissement aux styles du prassé, lesquels. venus à leur heure, avaient leur raison d'ètre et sont aujourd'hui sans objet. Ainsi que vous le dites fort bien, ce serait aux architectes de réagir. Nalheureusemont, les efforts réalisés sont demeurés trop isolès pour avoir une action efficace, et nous assisterons à des exhibitiuns surannées et incohérentes, tant que nous ne mettrons pas d'accord la forme arec la fonction, avec la structure et la uature des matériaux employés. Tuute tentative dans le sens rationnel ne peut donc qu'ètre suuhaitée.

Une Exposition d'art appliqué, en réunissant tous les efforts avec le concours des étrangers, provoquerait certainement un mourement sérieux, et l'on ne saurait trop tendre à le voir se réaliser, pourvu, comme vous le dites avec grande raison, qu'il s'agisse, non d'une Exposition universelle, mais bien d'une exposition d'un caractère tout spésial et bien déterniné. Vous ruppelez à propos les spéciméns enroyés en 1900 par les étrangers, meubles, ferronnerie, peinture décorative, verrerie, etc., etc., qui avaient vivement intéressé par leur originalité, par leur rationalisme, et dont nous n'avons jas assez profité. Puissions-nous ne pas diffèrer indéfiniment la solution et réaliser enfin une Exposition d'Art approprièe à notre milieu, baséct sur la logiyue et la raison. Il n'est que temps d'aboutir.

Vaunreuer.

Notre rôle aujourd'hui est donc de nous débarrasser tout d'abord de l'influence qu'exerega sur nous l'étude des anciennes époques, dont, du roste, nous n'avons su voir que les manifestations extérieures, sans avoir pu nous élever jusqu'aux idèes générales, si pleines de qualités de vie et d'adaptation.

Ensuite, nous devrons étudier les matériaux nouveaux et les plus récents moles de production mis à notre disposition par le maclinisme. 
C'est avee cos seules basus que l'artisan mudurne - architecte, ingénieur et artiste tout a la fuis - léa ouvre utile et eréera lugiquement un style modernc.

Iais l'évolution est lente, si elle est logique, un sṭlle ne peut ètre créé ni par un individu, ni nème par une génćration, peut-être; il improrte de déterminer aujourd hui des idées gènéralcs.

Certes, on n'arrivera à un résultat qu'après bien des títonnements; les styles anciens aussi s'élaborèrent lentement; nais les artistes doivent avoir la ló et rroire que, si incomplets que soient leurs efforts, - si ces iılées ginćrales sont furtement ancrées en eux, - quelque chnse rustera de leur labeur affranchi ef qu'on n'a pas le droit de dire que ce labeur lut inutile.

Charles Pi.cur.t.

\section{L'Art social en France et à l'Etranger.}

Je viens de lire rot le ètude sur l'Art social. Vuns arez magistralement et définitivement exprimé ce que nous pensons tous sur ce sujet. ll est tempis que la France n'ignore plus les efforts merveilleux, mais snmvent desordonnis, qui se funt autou" d'elle. C'est elle qui sanca mettre toutes chuses an puint. Mlais qu'elle se làte. Les iléments qui doivent former la beautí quic nous attendons ne demenreront pas longlemps malléables. Votre appel était nécessaire; joignons-y tous notre voir.

\section{Maurice MIfratick.}

J'ai lu avec bien de l'intérêt rotre étu le sur la nésessité, pour notre Alt national, le réagir devant lënergie le cenx qui nous regardent sans doute avec ansiété. Je veux parler de nos voisins d'outre-Manche ou d'outre-Rhin, ou encore d'au dela des Alpes. Une grande clıose m'inquiete four le relivement que rous souluaitez: cest la multiplicité des aspirations qui, on non pourrait louter, gènent les réalisations. D'autre part, je suis sùr, et cela est réconfortant, que le liançais ne perdra janais le guût de la chose bien faite sur larjuelle le guide son clair ccrveau.

Nous sommes un peu dans lialternative des lils d'hommes le génie. On a tant et si magnifiquement ploduit dans les temps passes, nous arons lant vu de réalisations, nous nous souvenons de tant de choses, on nuus a tant enseigné! Seul un berger de génie pourrait faire oublier tout cela, ou plutót le recommencer. Mais yuand ee ne serait que pour steonel cette satisfaction irritante on vit le producteur français, l’Exposition, dont vous indiqnez la néces-ití, derrait ê're décrétẻe.

\section{Albert Bessinu.}

Contralisation à outrance, étatisme el surtout timilité des capitalistes français, lepuis lungtemps connue, mais aetuellement augmenté lı malaise politique. En A!lemagne, les sommes consacrées à la création des líunsigevurbesehüle et dues à l'initiative privée sont considérables.....

On s`illusiunne sur la généralité de l'effort allemand. Ce qui domine cncore là-bas dians le peuple, e'est le goùt que Barrès di.nit dans Colette Baudoche. - Mais il y a une aristocratie audacieuse : allez à Weimar et laites-vous montrer l'établis-

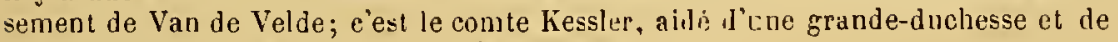
quelques grands seigneur's, qui est l'auleur de tout cela. 
Et le résult at est hin d'èlre social, eneore moins pupuluire.

Toutes les écules l'art du passé ont débuté ainsi; cest une éliıe qui les a imposées au pe'uple - emmne e'est le gont de deux ou trois grandes mondaines et d'un conturier qui dicte la unode des robes pl des chapeaux.

La supériorité de la France, autrefois, dans les arts apjliqués et maintenant encol'e dans les arts majeurs, tient à la qualité de notre sensibilité. Là où le machinisme est possible ('n Allemagne nu ailleurs). la sensibilité de l'artisan est presque sans valeur: on peut la sacrifier. Chez nous, pas! De li l"impossibilité de concilier la fabrication industrielle el lart en France.

Maurice Dexis.

Il faul le dire, la plupart du temps le bien sérieux est obtenu [en Aliemagne] et quel enseignement! La plupart des arehitectes ont des maisons d'exposition it eux: ils ont lá des meubles au dessin eréé par eux, en harmonie avec la maison tout entière; tous les ameublements et tous les objets usuels sont dessinés, construits par eux, dans l'ordre d'ensemble du tout, avee un soin digne de tous les éloges. On n'y dedaigne rien, pas plus l'antichambre que la euisine; tout oljet d'utilité est mis en harmonie; tout est de formes renouvelées.

J'ai plus que de l'espoir pour la France; le génie de la race est très fort. Elle médite plus longtemps, et surtout elle était déjà si belle qu'elle a grand'peine it l'oublier. Elle est comme la femme belle qui se détourne avee peine de son miroir d'hicr pour sourire au miroir d'aujourd'hui. Mais je la sais bien capable d'éblonir d'une autre beauté d'elle son miroir de demain.

\section{E.-A. Borknetif.}

Grâces rous soient rendues, a rous, monsieur, qui, ailin droit au but, nous arez dit: "Maîtres jadis des marchés étrangers du déeor, de la forme et de la matière. par tous ceux qui, élèves de nos doctrines, apprentis de nos métiers, attendaient de nos exemples un rayonnement d'idéal dans les réalisations de la vie, nous nous sommes reposís pendant qu’jls se dérouaicnt au labeul. Voici maintenant qu’ils vont seuls et nous précèdent. Resterons-nons en arrière, essonfflés d'avoir trop admiré nolre aurre ancienne, ou montrerons-nous qu il est encore en nous des énergies intelligentes, pour la délense d'un patrimoine de maitrise et de génie?"

Vous nous conviez ainsi au meilleur emploi qui puisse ètre des deux grandes lois sociologiques d'Imitation et d'Opposition, en nous proposant l'effort pratique d'une Exposition internationale d'Art social. Pourons-nous hésiter à nous mettre en présence des progrès accomplis ailleurs et des mérites par lesquels nos coneurrents surent nons devancer, afin de nous préparer à défendre fermement notre rang.

La question est de celles qui, par un jugement mérité, ne souffrent point l'inclécision. Nul ne se dispensera de répundre: "L'heure est renue ", qui n'a poill abdiqué le mépris de la laideur el l'espoir de la Beauté.

LE Ch.itelier, 


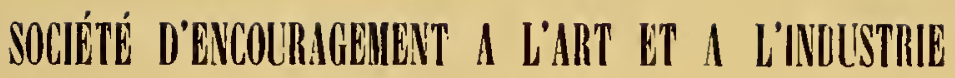

\author{
ASSEMBLÉE GENÉRALF DU 16 NOVFMBRE 1910
}

\section{Extrait du Rapport annuel.}

* . . . Si l'on observe l'évolution le l'Art décoralif moderne, on constate qu'il y a en France, depuis quelque vingt ans, le réel désir d'un stỵle adapté aux besoins et aux aspiratinns de la vie moderne. Les promoteurs en furent les Gallé, les Grasset, les Lalique.

Cotte évolution n'était pas encore achevée, malheureusement, quand les industriels commandèrent leurs modèles jour l'Exposition de 1900; ils s'adressérent à des jeunes gens u’ayant qu'une éducation artistique incomplite, manquant le tradition et dédaigneux du but de l'nbjet qu'ils étaient chargès de eréer. Ces modèles trop souvent mal conẹus, mal réalisés, furent rapidement délaissés, et on revint arec une nouvelle faveur aux styles classiques. L'influence de la Mode est en outre prępondérante en France, elle est plus vive que nulle part aitleurs, puisque, pour beaucoup d'industries de luxe, notre pays fournit les modèles que l'étranger achète et répand. Ce constant changement de formes nouvelles a longtemps plongé l'opinion publique dans l'incertitude el l'a confirmée dans l'admiration exclusive des styles anciens. Nais il se produit bien des signes précurseurs, comme nous le disions au conmencement de ce rapport, qui nous permettent d aftirmer ifue l'opinicn publique s'éveille de noureau à la compréltension d'un Art décoratil' moderue. Nous arons le lerme espoir que nous verrons très prochainement revenir une période de marche en avant dans l'évolution de l'Art décoratif qui s'est twp restreint en France dans l'exécution de bijoux, de bibelots, l'objets d'art, de meubles, sans s'astreindre assez à composer des ensembles, des cadres pour des objets treufs, élégants et bien adaptés aur b̧escins d'aujourd'hui.

Nons suirrons avec intérét cette évolution aux prochaines Expositions internationales de Bruxelles et de 'Turin, et nous espérons bien voir se réaliser un jour le projet d'une grandiose Exposition internationale d Art dicoratif à Paris, dont la conception est due à notre collègue Roger Mars.

Mais il ne faut pas nous le dissimuler: que de luttes encore il fauda soutenir pour arriver à unir comme nous le désirons, le créateur, le fabricant, l'ouvrier, pour faire sentir à notre commerce, comme à sa clientèle, quel intérét vital il y a pour la France à créer des modèles vraiment nouveaux et à quitter les voies dı passé, si lielles qu'elles aient íté.

Comprenons enfin que cet accord de l'artiste, de l'industricl et de l'artisan est absolument nécessaire si notre époque veut laisser des cuvres sobres, bien cons- 
truites, ni banales, ni exiravagantes, respcctuenses de leur but et de leur milien comme de leur matière. T'el est le nunveau style, harmonieux dans ses lignes cemme rans ses conleurs, ne confondant pas furmules el théolies arec traditions, mais logique et confurme ì la vie contemporaine, que nous espérons voir sortir définitirement, en notre cher pays, du gout, de l'intelligence et du travail cles gineratius modernes.

\title{
G.-Roger Sannoz et Jean Gujfray.
}

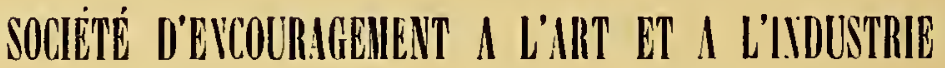

\author{
Consejl de Direction \\ SWANCF DU 28 MARS 1911 \\ Extrait du Procès-Verbal
}

\section{Projet d'Exposition internationale d'Art décoratif moderne.}

M. G.-Roger Sandoz, secrétaire général, met le Conseil au courant des eonversations qu'il a eues avec MM. Guilleré, Mezzara et Paul Fullot, président, ricoprésident et tréserier de la Soeiété des drtistes Décoraleurs, au sujet dı grand intérèt qu'il y aurait d'organiser à Puris une Exposition internationale d'Art técoratif modeme sur le programme indiqué, en 1909 , par notre éminent eolligue M. Roger Mars dans ilfférents artieles de journanx et revues.

Cette Exposition antrait pour but l'union pius étroite de l'artisle, le l'industriel, de l'artisan, et toute copie des stryles du passé y serait rigenreuscment relusée.

Elle pourrait être organisće sous le contrôle de l'Etal, sur l'initiative des trois grandes Assueiations que sont l'Union centrale des .Irts Décoratil's, la Société d'Encouragement à l'Art et à l'In lustrie et la Suciété des Artistes Décorateurs.

Toutes les Commissions, quelles qu'elles soient, seraient composées d'artistes exposants, d'industriels exposants et de personnalités s'intéressant à l'Art décoratif molerne.

Des subventions pourcaient ètre demandies au l'arlenent, à la Vilie de Paris et aux Mlunicipalités.

Le recrutement serait fait par in ritation, et l'admission ne serait définitive qu'après examen de l'objet ou de l'ensemble présenté à l'Exposition.

L'installation devrait tenilre autant que passible à eréer des groupements harmonieux, el les artistes comme les industriels seraient tenus de donner les noms de leurs principaux collaborateurs avec indieation de leur part de cullaboration.

L.es sections étrangères seraient autonomes. 
Le secrétaire gínéral ajoute que le moment somble venu do discuter celle importante question. En effet, notre dévoué collègue, M. Je sénaleur Emile Dupont, a pris l'initiative de soumettre al Gonvernement un projet eventuel d'Exposition internationale et universelle, en 1920 , a Paris; nous devons renercier M. Emile Dupont d'avoir eréc le mouvensent d'ujinion gràce aujucl les pouvoirs publics et le pays se rendent compte aujourd'hui que la France doit plendre une dicision tant au sujet des Expositions unirerselles que ıles Expositions spéciales.

Le Conseil, sur la proposition de M. Lucien Layus, dévlaru aprouver ce projet 1'Exposition internatiunale d'srt decoratif moderne; il donne [3eins pouroirs pour le suivre a MII. Henry Roujon, président, Lucien Layus, premier vice-président, et G.-Roger Sandoz, sterétaile général. Une somme de j̃000 fraucs est mise éventurllement à leur disposition, au eas où une avance serait nécessaire pour obtenir le Grand Palais, par exemple; mais il est bien entendı que la Société d'Encouragement à l'Art et à l'Indusirie n'agira que d'accord et solidairement avec J'Union centrale des Arts Décoratifs, présidée par M. François Carnot, et la Société des Artistı:s Décorateurs, présidée jar M. Guilleré.....

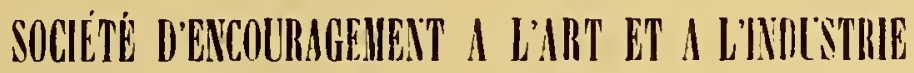

\author{
Lettre à l'Union centrale des Arts décoratifs.
}

Paris, le 28 mars 1911.

Non cher Pitesidfat,

Lilée dune Exposition interuationale d Art décoratif ou applique paraissant faire son chemin depuis quelque temps, nous en avions causé avec MIM. Guilleré, Nezzara et Paul Follot, de Ja Société des Artistes decorateul's. Ces messieur's devaient mème se rúunir ehez moi demain soir, etcomme nous pensionsque la dite Exposition ne pourrait ètre pratiquement réalisée, que, d'accord avec l'Lial, sur l'initiative de l'Union centrale des Arts décor.itifs, de la Société d'Encouragement à l'Art et à l'Industrie et de la Société des Artistes décorateurs, j'avais proposé qu'en votre absence nous convoquions votre dévoué premier viee-président, M. Raymond Kóchlin, à cette amicale conversation.

Dans une séance du Conseil de direction de la Société d'Eneouragement à l'Art et à l'Industrie, qui a eu lieu ce matin, sous la présidence de M. Laỹus en l'absence de notre Président, pleins pouvoirs ont été donnés à MM. Ilenry Roujon, Lueien Layus et à moi-même, pour étudier cette question avec I'Union centrale et la Société des Artistes décorateurs et retenir au besoin offieieusement dès maintenant, 
auprès du Sons.Seerélariat d'Elat des Beaux-Alts, le Grand Palais des ChampsElysées, pour 1913, date qui paraitrait indiquée ponr diverses raisons.

Au déjeuner dle notre Sociéte, qui suivit ce Conseil, il a èté parlé de ee projet. II. Dujardin-Beaumetz, dans son diseours, s'y est déclaré tout à fait farorable, et l’idée a eu un véritalıle succès auprès des assistants et notamment de nos collègues MM. Tranillot, Courba, Bellan, Tournade, Emile Berr, Van Brock, G. Boiu, Fenaille, elc., qui ètaient prisents.

Devant la rapilité avee laquelle a marché le projot de ríalisation de refte Exposition, j’ai tenu, en rotre absence, à prévenir de suite $\mathbf{M}$. Raymonıl hixehlin, et la conversation qui devait avoir lieu chez moi a été transformée en une réunion qui se tiendra mercredi soir, chez notre grande sœur aînée l'Union centlale des Arts décoratifs, et à laquelle assisteront M.M. Rarnond kæechlin et Metman pour l'Union, Laỵus et moi-mème pour la Société d’ Éncouragement à l'Art et à l"Industrie, Guilleré, Mezzara et Paul Follot pour la Société des Artistes décorateurs.

D'aceord avec MIM. Kinechlin et Layus, je rons avise de suite de ce qui précéde, sachant tout l'intérèt que rous portez au déreloppement des Arts appliqués.

En aftendant lhonnewr et le plaisir de vous voir, veuillez eroire, mon elier Président et ami, à mes bien dévoués sentiments.

Le Secrettuire generul,

G.-Roger S.ıvooz.

$8^{\circ}$

LE FIGARO. - Mercredi 29 Mars 1911.

Une Exposition en 1913.

Voici une intéressante nourelle:

Au moment même où la Chambre de Conmerce de Paris repoussait l'idée d'une Exposition unirerselle en 1920, déjà condamnée par la plupart des Chambres des départements, et où le Conseil Muricipal de Paris se déclarait, de mème, hostile à ce dangerenx projet, une autre idée s'ébauchait, prenait corp̣s. Elle est lancée depuis hier. Elle sera réalisée dans deux ans.

Rappelons les termes de la motion que volait avant-hier, sur la proposition de Mu. Chassaigne-Goyon et Aucoc, le Conseil Municipal de Paris:

"Le Conseil émet le rau que les pouroirs publics ne s'arrètent pas à l'idée "d'une Exposition universelle en 1920, mais créent une commission extraparle" Inentaire en vue de réaliser pratiquement, le plus rapidement possible, une série ") d'Expositions internationales successires et spcciales pour chaque genre d'in"dustries. D

C'est le régime nourean que nous navons cessé de préconiser, depuis le jour oì il fut officiellement question d'entreprendre à Paris - c'est-à-dire dans la banlieue de Paris, puisque la place eùt manqué dans Paris mème - une Exposition uniccrselle; et c'est í cette mème solution qu'ont successivement adhéré, depuis 
trois mois, presque toutes les Chambres de Commerce à qui Je gouvernement posait la question, et la plupart des grands syndicat:, rt de nombreuses municipalités.

Or, l'expérience va être tentée. On cst prèt. Eit c'est l'une des plus chalmantes et des plus glorienses " spécialités" de notre industrie, celle de lint décoratif, qui aura lhonneur d"inaugurer la série de ees grandes expositions, cunẹtes suirant !a formule nouvelle.

Une Exposition internutionale de l'Art décoratif s'ouvrira à Paris en 1913.

Sans duute l'Erposition "spéciale " n'est pas une nouveauté chez nous; depuis longtemps, les arts, la musiqque, le mobilier, l'automobilisme, hier l'aéronautique ont eu dans Paris leurs expositions particulières. Nais ce neitaient la que des entreprises privées où l’étranger n'était pas officicllement conroqué, et vì l'État n'interrenait point.

L'Exposition de 1913 auta un caractère tout diffërent. On voudrait en confier Jorganisation à une sorte de consortion d'associations qui seraient l'Union centrale des Arts lécoratifs, la Suciété d'Encouragement a l'Alt ut à I'Industrie, et la Société des Artistes décorateurs.

M. Frangois Carnot, président de l’Union Centrale, itait, hier, alısent de Paris. On attend son retour four lui soumettre le projet d'une combinaison à laquelle on ne croit pas run'il refuse son concuurs.

L'Etat, en tnut cas, y appurtera le sien. C'est en son nom que les étrangers seront co: Ivoqués à la première de nos grandes Expositions spéciules: c'est sous son patronage, son contròle, que celle Exposition sorganisera.

Dès hior, Ml. Dujarilin-Beaumetz en apportait joyeusement la promesse au déjeuner de la Société d'Encouragement ì l'Arl et à l'Industrie, où ce projet tout neuf éc:Iauffait dèà les esprits.

La date de 1913 semble la phus commade; d'abord parce qu'ulle est rapprochée de nous; ensuite, parce qu'en 1914, le Grand Palais sera réserví a une Lxposition dı Mobilier; entin parce que deux graudes Expositions seront, immediatement apres, sur le point de souvir : S.un Francisco en 1913 ; en 1917 , Tokio.

Le clinix de l'emplacement n'est pas arrèté encors. Quelques-nns des promoteurs dı projet souhaiteraient que l'Exposition ne fùt p.ss trop èloigrnée du eentre de Paris; ju'elle orcupat le Grand Palais, le Coul's-la-Reine et l'Esplanade des Invalides. Mais M. Dujardin-Beaumetz a dẹja fait un antre rève; it voit la première Exposition internationale d'Art décoratif s'elever entre le bois de Boulugne et les Champs-Elysies, sur le terrain tout neuf des fortitications abattues.....

Tuut ecla sera discuté plus tard. 


\section{PROJET O'EXPOSITION INTERNATIONALE DES ARTS DECORATIFS MODERNES}

\section{Séance, le 29 Mars 1911, des délégués de l'Union centrale des Arts décoratifs, de la Société d'Encouragement à l'Art et à l'Industrie, et de la Société des Artistes décorateurs.}

MA. Koechus el Metnax, pour l'Union centrale des Arts décoratifs : Lucien L.tres et G.-Roger SAxdoz, pour la Société d'Encouragement à l'Art et à l'Industrie; Gulineré et Mezzara, pour la Société des Artistes décorateurs, se mettent d'accord sur l'avant-projet suivant, proposé par MII. G.-Roger Saxdoz el Gumlent́.

\section{AVANT - PROJET}

But de l'Exposition. - Par la collaboration de l'artiste, de l'industriel et de l'artisan, réunir en une Exposition internationale tous les arts décoratifs : archirecture, arts dı bois, de la pierre, du métal, de la céramique, dı verre, du papier, etc..., sous tontes leurs formes, qu'ils s'appliquent à ules objets d'utilité ou à des aenvies pureneut sompluaires; dans toules leurs destinations : parure de la personne, déroration extérieure et intètieure des édifices r.ublics, de la maison, de la rue, du théîtwe, du jardin....

Tous pastiche ou copie des słyles ù passé seraient rignureusement refusés à celte Exposition.

Place serait faite aussi à l'Enseignement artistique, technique et professionnel, et à des sections ouvrières.

Enilucement. - Le Grand Palais parait ètre l'endroit le plus pratique, í condition, toutefois, que l'un puisse y adjoindre érentuellement le Cours-la-Reine el l'lisplanade des Invalisles.

Date. - L'année 1913 paraît èlre la plus indiquée, le Grand Palais des Champs-Elysées étant retenu en 1914 pour le Salon dı Mobilier et deux grandes Expositions itant projelées, en 1910̃, à San-Francisco, el à Tokio en $19 t \overline{7}$.

Orgrnisution. - L'Exposition serait organisée sous le contrôle de l'Etat, sur l'initiative de l'Union Centralc sles Arts décoratifs, đe la Sociélé d'Encouragement à l'Art et à l'Industrie el de la Société des Artistes décorateurs, par les soins d'un Commissaile sénéral et d'un Comité supérieur d'organisation. Ce Comité serait autonome; il nommerait dans son sein une Commission exécutive.

Les Comités d'almission el d'installation, et éventuellement les Jury̧s des récompenses, seraient nommés par le Commissaire général et la Commission exécutive d'aceor'd avec l'Etal. 
Toutes les commissions, quelles qu’elles soient, seraient composées frar tiers, dartistes exposants, d'industriels exposants et de personnalites s'intéressant á l'Art décoratif morlerne.

Budyet. - Les frais de l'Expo:ition pourraient être assurés par les versements des exposants pour leur emplacement, et par des subventions avec affectations spéciales, qui seraient demandées an Gourernement, au Parlement, à la Ville de P'aris et anx Municipalités.

Les bénéfices, sil en existait, pourraient ètre en partic attribués à des sociétés ou œuvres s’intéressant à l'Art décoratif el en partie ristonmés aux exposants.

Recrutement et admission des exposunts. - Le reerutement des exposants serait fait par invitation.

L'admission ne serait définitire qu'après examan de l'objet on de l'ensemble présentès à l'Lxposition.

Instullation. - E!le devrait tendre, autant que possible, à ereer des groupements luarmonieux.

Les artistes, cumme les industriels, seraient tenus de donner les noms de leurs principaus cullaboratenrs, avee indication de leur part de collaboration.

Seetimns ctrangeres. - Les imvitations aus divers pays leur selaient allressées par lintermédiaire dı Gunserumeut franęais. Chaeune des Sertions étrangères serail autonome.

Iicompenses. - Il y antait lieu d'examiner ultérieurement s'il serait attribué Jes récoumens's aux exposants.

\title{
CIIIHRRE DES DEEPTES
}

\author{
$f^{\text {re }}$ SFAICE DU 30 MARS 1911
}

\section{Discussion générale du budget des Beaux-Arts. Discours d'Albert Sarraut, Rapporteur.}

(Journal officiel du 31 mars 1911)

Je ne connais pas, présentement, dans le inmaine des arts, de question yjui, au double point de vue des intérêts moranx et matèriels d'un pays comue le nòtre, mérite davantage d’appeler l'altention et ıle relenir la sollicitule de ses rẹrésentants [que eelle du rôle et de limportance des Arts décoratifs].

J'exprime ainsi une conviction très profonde et je serais heurenx de la voir partager par tons mes collègues. (Très bicu! tres bien!)

Voici bien iles années, Messieurs, que nous assistons à ce speełacle, moralement, économiquement et socialement très inleressint, d'un vaste mourement de rénovation, d'une large renaissance des arts dı foger et le la vie, qui suscite partout, is l'̈̈ranger comme en France, les efforts les plus renarquables, les initialires les filus harilies, et, l'on peut le dire désormais, les manifestations les plus féeondes. 
D乞 tous les côtés, dans tous les pays, une pleiade claque jour plus nombreuse d'artintes décurateurs, d’indu-triels, d’artisins, d'ouvrier's d'art, à la rectıerche de formules et de styles qui apportent l'expression esthélique de leur temps, s'iugirjient et s'emploient à régénúrer notre sens modecne de l'art, à afliner, à accioîl'e notre goút soit des visions extérieures, des grandes surfạes décoratives, des monuments prblics, des ornements de la rue, soit des ambiances familieres de la maison, du fuyer et le la vie intime.

Ce n'est le lieu ni le moment de rappeler ici, en ce qui concerne la France, les origines, les étapes. les lustes, les errem's ou les succès de cette évolution, qui a été désignè des noms les plus divers, quelıuefois les plus mal choisis - art nouveau, art moderne, art propulaire, etc., - et qui est tout simplement... ce que M. Rogel Marx appelle excellemment la renaissance des Arts de la vie par la nature ct selon la tradiiton nationale. (Tries bicn! tres bien!)

Ce mouvement, qui était déjà sensible à l’Exposition de 1889 , devait dègager une très puis:anle aftimation dans celle de $1900 \ldots$

M. Dijardin-Beaumetz, en 1900 [dans son rapport sur le budget des BeauxArt: ], soulignait arec juie les riches promosses (pue l'on ponvait d'ul'es et dijà recueillir dans ce grand mourement de rénovation, dans la renaissance de cet art appliqué et décoratif, par lequel, attestant l'éternclle vitalité du gènie créalenr de notre race, l'effort de nes artistes et de nos décorateur's renouait la chaine trop longtemps interrompue le cette admirable tradition qui, pendant des siècles, tit la gloirc incomparable du goûl trançais. (Trés Lien! très Lien!)

Est-ce que ces espurances se snnt réalisées? Ces belles promesses de l'Exposition de 1900 sur l’avenir de notre Art Décoratif ont-elles élé tenues?

Messieurs, je réponds catégoriquement : oui. Certains ont faru en douter et peut-ètre trouverait-on encore l'expression et l'écho de ce doute dans certains documents qui vous ont été soumis.

Je regrette pour ceux qui ont formulé cet injuste sentiment qu'ils n'aient pas frris la peine, ou julutôt le plaisir, de parcourir et d'examiner arec soin les Expositions d'Art décol'atif qui sont périodiquement organisées daus ce pars, et notamment celle qui était ouverte, il y a quelques jours encore, dans cet admirable Mlusée des Irts décoratil's du pavillon de Marsan, dont il est impossible dè parler sans évouuer et saluer en jassant d'un juste hnmmage la mémoire de notre distingué et regretté collegue, M. Georges Berger. (Appluulissements.)

Cette Exposition rèvente de la Société des Artistes lécorateurs, si cnmplète, si instructive, si harmonieuse et si française, vraiment, comme íl f.ut renercier ses urginisateurs den aroir montré non seulement au public francais, mais aux visiteurs étrangers, la magrifique leson et le très haut enseignement!

Nuts pouvons ètre profondément fiers de l'ieurre ainsi accomplie par nos artistes, nos artisaus, nos ouvriers dart, nos techniciens. Je tiens à le délarer à cette tribune, afin que cette admirable pléiale de travailleurs en reçoive l'encouragement qui permet de poursuive aves plus de con fiance et al'aluleur la grande ceuvre entreprise.

Et combien faut-il les arlmirer, en vérité. quand on sait a travers quelles dillicultés et puels obsticles, au prix de quels sacritices et de quelles abnégations, avec quels trop faibles encouragements ils ont pu obtenir des résultats tels que ceux qu'ils nous ont montrés! Car c'est lí ce qu'il faut dire et c'est là ce qu'il faut roir, atin d'y tronver la leçon de l'effort de demain, atin l'y chercher la nesure et la forme de lappui que ces artistes sont en droit d'attendre d'un pays dont ils defen lent la glorieuse tradition et dont ils accroissent la richesse. Les obstacles, ils les rencontrent partout! Au sein mème de la Cité des Arts, où pourtant lout derrait être harmonie et où le culte de la méme beautè devrait ouvrí vers eux le geste solidaire de toutes les mains fraternelles, que de résistances opposées encore à ces décorateurs par certains artistes purs obstinés au prèjugé suranné de l'antique hiérarchie des Arts! 
De la part des pouvoirs publies, que d'hésitations à leur consentir de généreux et nécessaires encouragrements...

M. Etienne Rogron. - Ils ne regoivent que 4 p. 100 des fonds d'encouragement.

M. L. RappontelK. - Quelle parcimonie el quelle négligence á leur égard arant l'arrivèe du nisistre qui, fidète à l'opinion du rajportenr de 1900 , s'efforce aulant qu'il le peut, avec des ressources, hélas! trop modestes, d'encourager la production et le goút de ces œuvres nouvelles, comme il a été le premier, par une témérité heureuse et dont je le félicite, à imposer dans les achats de l'Etat les expressions hardies des esthétiques indépendantes! (Trés lien! tris bien!)

Mais chez les industriels surtout, qui sont pourlant les collaborateurs tout indiqués, qui devraient ètre les auxiliaires les plus énergriques de nos artistes décorateurs - à côté de trìs nobles et clairvoyantes exceptions qu il faut saluer d'un juste hommage, que dinerties, que de routines, quelie méconnaissance encore trop grande de l'ouvre et de l'effort de ces artistes! Méconnaissance, d ailleurs, qui n'a d’égale pour ces iudustriels que la méconnaissance profonde de leurs intérèts. (Trés bien! trés tien!) Car, ceux dont je parle n'ajerçoivent pas, dans la concurptuce étrangère qui se fait de joul en jour jlus hardie et qui ne devrait aroir qu'une valeur d'èmulation et de comparaison, le danger qui vieut, qui menace et qui grandira chaque jour josıu'à l'heure cù la rague qui monte sans cesse aura entouré et submergé, sans qu'ils aient levé la tète, les copistes attardés au pläiat stérile des vieux styles! (Appluudissements.)

En rain ces industriel; essaient-ils de prétendre qu'ils sont obligés de tenir compte de la résistince du public, de son ćlucation, de ses préjugés, de son engonement pour les tormnles du passé. La répouse est, en vérité, trop lacile. Car si notre public français, si accessible à toutes les lormes dı plogres, à toutes les manifestations et à toutes les révélations de l'art el du goùt, est anssi rebelle que les industriels le prétendent aux conceptions nouvelles le l'Art appliqué et décoratif, comment expliquer alors que lant de maisons étrangères, que tant d'industries étrangères de la décoration envahissent nos boulevards et les grandes arières de notre eupirale, surgissent et s'implantent, thaque jour: plus nonbreuses, au cœur de Paris et de nos grandes villes et viennent ravir, fresque sans effort, une elientele que nos industrie!s n'unt pas su ou n'ont pas voulu garder?

Et alors, voici disormais posé devant l'Etat le probleme, la grave question qu'il ne peut pas éluder. Son devoir politique, son devuir d'élucateur, comme son intérêt écononique et son intérèt financicr lui commandent avec la mème force d'encourager l'action de nos artisans, de nos ouvriers d'art. Je dis que c'est pour l’Etat un deroir pulitique.

Or, dans la cité moderne, dans la société moilerne, toute runplic des runeul's de l'évulution sociale, remuée des aspirutions chanue jour plus ardentes et plus vastes d'une foule qui veut plus de bonheur, plus de clarté, plus de justice, qui sans cesse a plus de lésils, jilus de besuins, pius d'idéal aussi, le mouvement d'Art dunt je parle vient répondre a l'un de ces besuins qui se fait chaque jour plus sensible sinon plus impérieux : le desir dune vie meilleure et plus ornée, le désir de la beauté lans la vie de chaque jour, le désir, à côté d’un plus grand hien être matériel, d'un bien-ètre esthétique sans leyuel l'autre ue serait que l'humble et l'insuffisante satiffaction des instincts. (Très bien! trés bien! Applaudisements.)

Oui, Messienrs, c'est là un grand ren social de notre temps, une revendication profonde de notre époque, et qui l'honore! ìt n'y eût-il que celte raison, l'Etat, celui qui représente la Cité, qui recueille et doit réaliser les aspirations, aurait le devoir d'encourager ces artisies qui embellissent la vie ct la font plus donce à 
vivre, de les traiter comme des collaborateurs utiles de sa tiche. Car leur Art n'est plus aujourdhui la chose dont on peut se passer, il n'est pas le superflu, il est le nécessaire, il est une partie essentielle de l'action humaine en essor de progıs et la satisfaction d'un besoia profond qui traduit et qui exprime la dianitè sans cesse accrue de l'ètre humain.

Ainsi, an point de vue politique comme au point de rue ceonomique, c'est le devoir ćtroit, ligoureux, impèrieux le l'Elat de soutenir celte renaissance d'Art el ces artistes, de lutter arec cux, jar eux, pour Jui comme pour eux, contre la double invasion qui menace à la fois le guìt francais et la richesse nationale.

Que faut-ji faire dans ce Lut? Je nai pas besoin de vous le dire, Monsicur le Sous-Secretaire d'litat; rous le savez mieux que moi, puisque vous rous ellorcez chaque jour de l'accomplir. Vous savez quelle jart plus large il faut accorder aux arlistes décorateurs dans les commandes, dans les achats, dans les subventions, dans les bourses le voyage, dans les constructions, daus l'ameublement et l'ornementatiun des futurs édifices publics; vous savez anssi quelle part plus grande voit leur ètre réservece lans la constitution de ces grands conseils et de ces cumitis qui prési.lent aux destinées des arts français et où il faut également faire une place, à côté des artistes, à lenrs collabarateurs les ourriers, les artisans, les tecliniciens.

$\mathrm{M}$ is lorsque l'Eiat aura ainsi préché d'exemple et agi pour son compte personnel, je considère qu'il n’aura pas ternuné sa tâche. Je parlais tout à l'heure des indusiriels. Il faut, à mon sens, que l'Etat se retourne vers eux, qưil les stimule, qu'il les presse, qu'il les sollici e, qu'il les engage à imiter son propre exemple. Il peut inlluer sur eux; et, s'il le peut, il le iloit.

Hier, jai recueilli avec plaisir, de la bouche du Ministre du Travail, la promesse et l'espricance qu'une triple collahoration de son ministère, du vótle et de celui du Commerce, canjuguerait et unirait les effurts nécessaires pour l'encouragement et le developpement des Arts décoratifs. Mais, en attendant que cette action biunfaisante puisse s'exercer, ne pensez-rous pas, Monsieur le Sous-Secrétaire d'Etal, puisquc nous arnus un Ninistère de l'lnd sstrie et du Commerce, et que son titulaire sympathique nous parait accessible à des suggestions comme celle que nous formulons, qu'un pourait lui demander, au nom de l'iutérét national, soa intercession auprès d'industriels qui ne peurent plus ignorer anjourd'hui que lesormais assagi, éøuilibré, épuré ales elreurs et des extraragances primitives, notre Alt décoratif et appliųué, notre Art national est tout prèt à subtenir contre quiconque la belle lutte frour les droits du groùt et du génie français? (Applauclissoments.)

Et, lor'sque cela sera fait, la tảche ne sera pas cncore terminée; car à ces créiteurs, à ces artistes décorateurs, il faut que chaque jour sajuatent de nouveaux críateurs, et à cóté d'eur des ouvriers, des artisans, des techniciens : il faut renouveler, èlarfrí la source où s'alimenteront les besoins de l'Industrie nouvelle, préjrarer le recruiement des travaillen's manuels qui collaboreront à cette renaissance décoratire... 
Lettre adressée à M. Dujardin-Beaumetz, sous-secrétaire d'État des Beaux-Arts, par l'Union centrale des Arts décoratifs, la Société d'Encouragement à l'Art et à l'Industrie, et la Société des Artistes décorateurs

Jaris, le 10 arril $19 t t$.

Monsieur le Ministre,

Lols de la dernière discussion du budget des Beanx-Arts, M. le Rapporteur ch rous, dislariez à la Chambre, dans des discours qui furent applaudis aree un senıment unanime de patriotique ferveur, que l'Etat derait aujourd'hui considerer cumme un devoir urgent de se préoccuper actirement de nos Arts décolalils 1 d'assurer le maintien menacé de leur ancienne suprènalie.

C'est à ees fins, Monsieur le Ministre, et encourages par l'aceueil bienveillant que rous nous arez dejji mar.jue lans ce projet, qu'au num de nos trois Assuciations: I'Union centrale cles Arts décoratils, la Sociéle d Encouragement à l'Jrt et i l'Industrie, la Sociélé des Artistes néeorateurs, nous avons l'honneur de rous prier de rouloir bien demander au Parlement de voter le principe d'une Exposition internationale d'Art décoratif, qui aurait lieu à Paris en 1914.

Ce moment rous semblerait particulièrement opportun. Une plus longue attentr. et quoi que l'ameuns ulijectent, risquelail d'énerrer des forces justement implatientes et dont nous pouvons vous assurer qu'elles sont dés à présent très prêtes. Ajouteruns-nous que nous estimons que, par le concours indispensable de l'Etal, avec la cullaboration de nos trois Associations solilaires, de tons les iléments, ilu toutes les competences, de toutes les bonnes rolontes que nous aijuellerons et saurons '„r.ouper', le succès se trouverait assuré.

Celte Expositiun vicndrait à sun leure pour stimuler, par l'ümulation de la présince itrangère, tous les lalents, tous les effurts et réaliser liuniun nécessaire de l'artiste, de l’industriel et de l'altisan. En manifestant dans son harmonieuse latalice un Art dont lexpression neuve répondrait aux aspirations et aux besoins ile notle éporine, c'est dans lou tes les formes, à tous les derrés rle la vie sociale qu cile l'erait pénétrer avec plus de bien-étre une plus glianule somme de branté.

Veuillez agrécr, elc.

Puur lu Societe d'Fneouranement il lirt et ì l'Inclustrie

Le Secretrime gineral G. - Roger SAsno\%
Poul' l'Union centrale des Avts decoratifs If president l'. Cillinor

Pour la Sociele des Artistes dicordicurs

L: Prisilent Ii. GuILI.F:! 
LE MATIN. - Mardi 11 Aviril 1911.

\section{L'Exposition internationale des Arts décoratifs et industriels s'ouvrira à Paris en 1914 ou 1915.}

\section{Quatre membres du gouvernement se dèclarent prèts à en prendre l'initiative.}

M. Steeg, Mlinistre de l'Instruction Publique, la considere comme une nicessiti: II. Missi, Ministre du Commerce, y voit le moven de résoudre le problème de l'Enseignement technique et la crise de l'Applentissare; M. P.un-Boxcoun, Ministre du 'ravail, surritre l'idée de comoquer, à celle occasion, une Conférenee des gourcmenents pour la limitation internationale des heures ile.

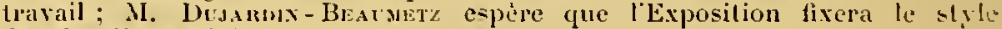
du vingtiéme siécle.

Quelques heures à peine etaient passées depuis la publication de notre arlicle sur la nécessité d'une Exposition internationalc des Arts décoratifs et industriels it l'ar'is, et déjà l’idéc était à demi réaliséc.

Quatre membres du gourcrnenent en effet la faisaient leur. Et justement ceux auxquels, de par leur lonction, revient la charge d'organiser cette grande rencontre de peuples.

Il laut pour le succés de cotte Exposition, qui doit réaliser l'accord des artistes, des arlisans et des industriels, le eoncours de trois Mlinistėres : celui de l'lnstruction l'ublique, celui du Commerce et celui du Travail. La logique veut que le sonssecrétariut aus Beaux-Arts, qui derrait dailleurs, dans une demvcratie bien ordunnée, "ùlre rattaché à ces trois dlinistères à la fois, réilise, en cclte vccasion dı moins, l'unilé et l'accord des services.

Yuus avons été voir les trois ministres et Il. Dujarılin-Buaumetz. Tuus sont d'aceord pour proclamer que ce projet doit ètre exicuté à Paris et dans la furme méme qui fut indiquée hier par le lutirl.

II. Steeg, Ministre de l'Instinction l'ublique et des Bcaux-Arts. - " Je considere cette Exposition comme une nécessité, nous dit $\mathrm{Ml}$. Stceg. Les besoins nièmes de notre vie nationale l'exigent. Notre population ne se developpe pas, et par conséquent notre main-d'œuvre ne peut pas se multiplier. Nons ne pouvons pas rélıandre sur les marchés du monde des masses éuormes d'ol.jets ; ce n’est pas par la quantité que nous pourons triompher, éest par la qlialité.

"Une Exposition comme celle-li fera valuir loutes les qualilés frantaises. Elle montrera que le sens de la periection est nutre réritable sens natiunil ; que, si ailleur's on fabrique les mèmes objjets, chez nons on ne les fabrique pas de la même manière; que, si on veul sortir du médiocre et du banal, il faut venir en lirance, parce que tout, mème l'objet le plus humble, y revêt, gràce aux talents de no: artistes, une forne préciense.

"Et puis, en mème temps que nous montrerons cette espèce d'élération de 
l'Indıstrie franıaise, nous donnerons enfin a l'Art un caractère démocratique. Nous ne sommes plus au temps ui la lortune des altistes dépeudait des èlites. C'en est fait les aristocraties. Il faut donc étendre le nombre des consommatenrs; il faut que chaıue sitoyen puisse acheter sa palt de beauli, que chaque foyer puisse avoir sa parure.

"Créer de nouveaux besoins et lés satisfaire aussitòt erées, e'est la formule mème du progrès. Le besoin d'Art est conme les autres, il esi aujourd'hui plus ripandu que jamais. Mais pal'e que les artistes et les artisans sont séjarés, paree yuion en est demeuré encore à lia mode de l'art elier, les matestes demeurent rondamnes au logis triste dont les murs sont nus et les nueubles sans grice.

"Une Exposition des Arts decoratifs et inilustriels nous pernettrit de ehanger tout cela : elle nous donnera l'Art à meilleur marché, le fera eontribuer ainsi à l'éducation de notre démocratie, à son bien-ètre et à sa dignité. Oui, il laut faire l'Exposition internationale des At's décolatifs à Paris. Et nous la ferons ! "

II. Massé, Ministre du Commerce. - Le Ministre du Commerce esi daceord avec son collègue de l'Instruction Publigue et des Beaux-Arts. Ce qui le préoccupe plus partieulièrement, lui, c'est le développement de l'enseignement technique.

"Je suis profondément partisan de celte Exposilion, nous declare-t-il dès l'alıord. Sans doute, toutes les grandes écoles professionnelles du monde y enverront l'exposé de leurs méthoules. Ce sera pour nous un précieux résumé, aù nous trouverons plus d'un enseignement.

) En secend lieu, un merveilleux effort se poursnit en ce monent dans nos instiluts spéciaux, dans nos éeoles régionales. Cet plíut n'est pas assez connu, encouragé. On en verra toute la portée quand l'Lxposition lui permetta de se díployer à tous les regards.

1) Enfin nous en finirons avee le préfugé rnineux des Arts supérieurs, de ceux qu'on appelle les Beaux-Arts, pour les distinguer des autres, comme s'il pouvait y avoir des arts qui ne soient pas beaux. On ne saura jamais tout cu que soûte à notru commerce, à notre exportation cette conceptio' funeste i' in art aristocratique, au nom de la juelle les artistes se défendent de lonner des modèles à l'Industrie. Bexucoup d'entre eux se eroil'aient déshonorés si leurs nuvres étaient reproiluites. Quelle erreur! Créer des modèles, éest donner du travail aux artisans, permettre aux inlustriels le progrè̉s. Rien de plus nécessaire. Uu l'̉at, surtout un État répıblicain, n'a pas accompli sa mission d'art quand il a entr'ouvert à la fomle la porte hes musées. Il faut qu'il ait fait sortir l'Art des musées, convaincu les artistes qu'ils ne doivent pas réserver leur talent pour la statue de marbre ou pour la toile uniqus, orgueil du cullectionneur; mais que, plus généreux de leurs dons, ils doivent les faire servir à embellir les objets les plus humbles et les demeures les plus pauvres, afin le frire mieux comprendre à tous le prix de l'existence.

"Ajoutez à tous les avanlayes de l'Exposition, eelui-ci. C'est qu'elle offrira un vasie terrain d'étude à tuus ceux que préoccupe la crise de l'Apprentissage. "

Iéi, II. Massé se reneontre avec

II. P.ut-Boscour, Ministre du Travail. - " Cutte Esposition internationale des Arts décoratil's et industriels à Paris s'impose, nous dit celui-ci.

"Oulre qu'elle permettra de créer des types modernes de maisons auvrières, qu'clle réveillera dans les organisation- profissionnelles l'amour des métiers, ellı, nous seru une occasion nécassaire de portur l'euè.le à la crise de l'Apprentissage, si menagante pour ce pays.

"Depuis les lois qui ont limité les lieures de travail dans les ateliers où les apprentis travaillent pré; de; adultes, les apprentis ont élé mis hors l'usine, rejetés it la rue.

"Peut-on revenil sur ces lois, les defaire ? Non certes! 
1Quelle est dons la solution? Limiter lez heures de trarail hes adultes. 1.a France peut-elle le faire seule? Je compren Is que cette expécience lui semble difficile et dangereuse. La concurrence internationale nous guette. Iiuiuer nos industriels, ce n'est pas le moyen de donner du travail à nos ouviers. Il faut adopter une autre taclitue. La milleure, et celle qui honolerait le pius le Gonvernement flaneıis, consisterait à inviler lous les Gourernements, en nème temps qu’a participer it une Exposition des Arts decoratils, à se faire représenter dans une mande Conférence où ils étudieraient en commun les moyens de limiter les heures de trarail dans tous les pars.

"S ils aceeptaient, cetie Exposition pourait ètre une grande late dans l'llistnire, inaugurer pour tous les proletariats une ère meilleure, où ils connaitraient de plus près le bonheur et la beauté. 1

Ainsi parla M. Paitr-Boxcoun.

11. Dedardx-Bruluftz, sous-sccretuive d'Etut aus Berux-Arts, n'est pas moins enthousiaste.

"L'Erposition dont vous roulez bien me parler, nous dit-il, qui réunirait l'effort de nos artistes, de nos artisans d'Art décoratif, de nos ingénieurs et de nos industriels, aurait ce premier résultat de renouer la tradition qui a fait la force et 1 gloire de l'ésole française daus le passé, en rítablissant ponr notre démocratie maderne l'unité de l'Art.

"C'est, en effet, l'alliance intime de l'artiste et de l'artisan, de l'idée créatrice et de l'outil qui la rialise, qui a donnè à notre Art français son caractère el sa purtée.

„En reprenant celle mé.houle nationale, nous effacerons la fameuse distinction entre les arts majeurs et les arts mineurs, qui a pesé si lourdement sur l'art décoratil du dix-neurième siecle. Est-il besoin de rappeler qu'au dix-septième sicele, dans notle beau Versailles, les maîtres de la jeinture, de la sculpture élaient en mème temps les créatenrs de tous les molits dornementatiun, et que dans notre dixhuitième siècle, dont de tous cutés actuellement liat moderne s'inspire, des lommes comme Waltun, Boucher et tant d'autres éraient à la fois les inspirateurs, les soutiens et les gruides des lecorateurs.

" Celte Exposition aura encore uue autre conséquence. En élevant jusqu'à l'Art le nivean de tous les metiers, elle inspirera à tous le sertiment de la recherelıe, lu caractère, du goùt et de la grice. Elle contribucru a risondre le problème de l'apprentissare, sans la sulution luquel les induslries dicoratives périroni; elle montrera la nécessité d'isssocier, lans lë̉lueation des apprentis, l'étude artistique des formes el des colorations à l'étude pratique de toutes les réssonres dı métier, au milieu de l'atmosphèe:te mème de l'atelier.

"D'autre palt, il importe que l'esprit moderne, yni s'affirme depuis vingt an!ées par tant d'initiatives lardies et d'inventions marnifiques dans toutes le: branches de l'activité industrielle el scientifque, trouve un moyen d'alfirmer aussi 3a personnalité dans le domaine de la créarion artistique.

1) En un not, après yue nos artistes et nos artisans ont donné à travers l'Histoire toute cette admirable succession de styles frangais où s'exprimait si bien la pensée des époques direrses, il est nécessaire qu'ils formulent, pour notre dimocratie modurne, le stṛle du ringlième siècle.

) Noublions pas non plus que l'art est un grand créateur de richesse. Si la France, jar la beauté de ses sites et la splendeur de ses monuments, attire sans cesse el de plis en plus l'ètranger, elle peut aussi, par se; créations d'art, par le gaù de ses modèies, par la forme élégante qu'clle sait donner anx olijets les plus modestes, étendre le prestigge de notre inlustrie et augmenter notre fortune nationale. Enfin, à l'lence oì nous voulons implanter défnitivement dans notre pašs les institution: de liberté, il est bon, il est nécessaire de créer pour tous le 
beau dans l'utile et dapprendre à la démocratie tout entière cette " joic de vivre " que le dix-huitième siélc réservait à une aristocratic."

Ainsi tous les membres du Gouvernement que nous arons vus, c'est-à-dirc cenx que leurs fonctions appellent à organisel l' kxposition internationale des Arts décoratifs et industriels, se sont déclarés prèts à en prendre l'initiative.

D'autre part, dans la soirée l'hier, les trois grandes Saciélés d'Art décoratif ont adressé à M. Dujaldin-Beaumetz la leltre suivante :

\section{A M. Dujarlin-Beametz, sous-secritaire d'Etat aux Beaux-Aits.}

\section{Munsieur le Ministre,}

"Lors de la dernière discussiun du budgot dos Beaux-Arts, M. le Rapportenr et vous, declariez à la Chambre, dans des discours qui furent applaulis avec un sentiment unanime de patriotique ferveur, que l'Etat devail aujourd'luui considérer comme un devoir urgent de se préaccuper activement de nos Arts décoratils el d'assurer le maintien menacé de leur ancienne suprématie.

"C'est à ces fius, Monsicur le Ministre, et cncouragés pac l'accueil bienreillant que rous nous arez dỉjà maryué dans ce projel, quau nom de pos trois Associations, l'Union centrale des Arts décoralifs, la Snciété d'Encummgencnt i l'Art el à l'Indıstrie, la Société des Altistes décoraleurs, nous avuns l'honneur de rous prier ale vouloir bien demarder au Parlement de roler le principe d'une Exposition internationale d'Art décoratif qui anrail lieu à Paris en $19 t \dot{4}$.

"Ce moment nous semblerait particulièrement opportua. Une ulus longue attente, et quoi que daucuns objectent. risquerail d'énerver des fnices justement impatientes et dont nous pouvons vous assurer qu'elles sout dès à présent trís prètes. Ajouterons-nous que nous estimons que par le concours indispensable de l'Etat avec la collaboration de nos trois Assaciations solidaires, de tous les éléments, de toutes les compétences, de toutes les bonnes volontés que nous appellerons et saurons grouper, le succès se trouverait assuri.

» Cetle Exyosition viendrait à son heure pour stimuler par l'émulation de la présence étrangère tous les talents, tous les cfforts, et ríaliser l'union nécessaire de lariste, de l'inclustriel et de l'artisan. En manifestant dans son liarmonicuse totalité un Art dont l'expression neuve répondrait atux aspirations et aux besoin: de notre époque, éest dans lautes les lurmes, a tous les degrés de la ric socialc: qu'elle ferait pénétrer, avec plus de bien-ètre, une plus grande somme de beauté.

" Veuillez agréec, Monsieul le Ministre, l'assurance de notre haule considération."

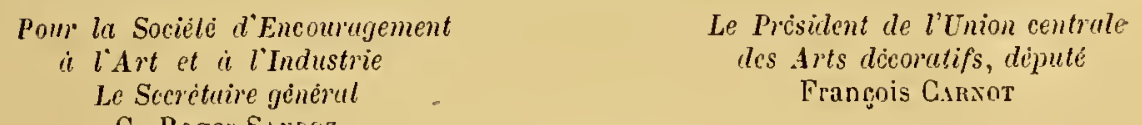
Le Pisident de la Sacieti tes Irtisles dicoriteurs lienć Geulteís

Ce dacument prouve que le monde des Arts et de l'Industcie réclame arec nous cette granile manifestation de l'énergie el de la grice françaises. Maintenant il ne reste plus qu'à agir. 


\title{
CONSEIL MUNICIPAL DE PARIS
}

Séance du Jeudi 13 Avril 1911.

(Bulletin municipal officiel du Vendredi 14 Avril 1911.)

\author{
$\longrightarrow$ \\ 17. - Adoption d'un rau en fueur de l'organisation d'une Exposition d'Art decoratif \\ i Puris.
}

M. LaMptik. - Messieurs, des consultations fuites dans les milieux les plus différents il semble résulter que, pour des raisons séricuses, toute idée d'une vaste Exposition universelic en 1920 soit définitivement écartée.

Par contre, il semble d'autant plus nécessaire d'encuurager toutes les manifestations devant avoir prour résultat de provoquer un essor de notre Art et de notre Industrie, d'établit' et de mieux faire apparaître leur supériorité dans le monde, de favoriser leurétroite union.

Le Conseil municipal, toujours soucieux du prestige et de la prospérité de laris, s'intéresse plus que jamais à ces questions.

Lin effet, ces questions d'Art décoratif, d'Art industriel, préoecupent tous les pays. Partout on multiplie les effurts pour aceélèrer leur développement. Dans les grandes villes de l'étranger, on erée des musées, on enrichit ceux qui existent déjà. On ouvre des éeoles pour former avec méthode des apprentis, puis des artisans. On organise des expositions pour éduquer le goût public, pour déterminer chez les artistes un effurt de recherches et de créations, pour attirer les visiteur's étrangel's et leur faire connaitre la production nationale.

Il y a deux ans, èètait Munich qui onviait le monde à une Exposition d'Art lécoratif et suscitait dans toute l'Allemagne un effort don t nous avons ressenti jusqu'it Paris le retentissement.

Cette année, c'est 'Turin qui a pris cette initiative.

Alors que les autres prays s'ingenient à encourager et à mettre en valeur les créations de leurs artistes, à renouveler leur Industrie par des mo.lèles nouveaux, à attirer la clientèle internationale, la France n'a encore rien fait pour lífendre, dans celte lutte, sa supériorité, plus ancienne et jusquà présent indiscutée.

Mais les progrès réıliscis par les autres nations, la méthode qu'elles apportent dans l'enseignement des Arts décoratifs, l'énergie persistante qu'elles montrent pour la diffusion de leurs produits, nous lont un devoir, non seulement d'apporter tous nos soins á l'éducatioil professionnelle de nos artistes et de nos artisans, mais aussi d'encourager toutes les mianifestations qui doivent avoir pour résulıat de maintenir, au dedans comme au dehors, la supériorité de l'Art décoratif français.

C'est dans ee but et pour oes raisons que j'ai, l'honneur de vous proposer l'adoption du rœu suivant : 
Lo: Conseil,

Reconnaissant combien il serait utile de provoquer un nouvel essor de nolre Art et de notre Industrie el de faire connaître au monde les créations magnifiques résultant de leur étroite collahoration,

Emet le vœu qu'une Exposition inter'nationale d'Art décoralif soit organisée à Paris pour 1914 ou 1915, el se déclare prêt à s'associer à lonte initialive qui pourrail ètre prise à cel effel.

\section{Signé : Lampole, Rebeiclard, Devilles, Robagla, Chlacsse, Rolux, Henti Galu, Frédéric Brunet, P. Quevtin-Bicchart, lioger Lanbelin, Paul Fleurot, Petitukan.}

M. Louis Dutsset. - Messieurs, je me rallie pleinement à la proposition de mon collègue M. Lampué. Jc suis en effet convaincu qu après s'ètlé prononcí très nettement contle le projet d'Exposition unirerstle internationale en 1920, le Conseil ne saurait Ionner trup dencouragemen!s aux projets d'organisation d'Expositions internationales spécialisées. Celte dont il s'agit est intéressante au premier chef. Le guut se prerfectionne clıaque jour et toutes les industries, même les plus pratiques, les plus terre ì terre, tendent à se rapprocher de l'Art dicoralif.

M. Ambroise liexdu. - Ne confondez pas l'Art ancien a vec l'Art nouveau.

M. Lonis D.usser. - Bien entendu. Nais vuus avez pu constater par vousmèmes l'effirt réalisé, l'année dernière, à Bruxelles, par d aulıes pays.

Il esi de tuute nécessité de ne pas nous laissel distancer fiar les nations concurrentes.

Une Exposition qua comprendruit l'Art industrial sous toutes ses formes, depuis le bijou jusqu'à la façade ot la décoration intérieure de la maison, serait d'un excellent enseignemeıt pou: nos artistes, nos artisans et nos écoles professionnelles qu'il ne faut surtout pas onblier.

Elle en :ouragerait leur's effurts et, à l'henre oì l'útranger ne recule derant aucun sacrifice pour s'assurer la suprématie, notre indlustrie y trouverait un nouvel élément d'activité et de perfection.

Je m'assacie donc pleinement a lidèe de M. Lampué. Je crois que le Conseil doit l'étudier le trè́; près et cheruher, a vee les pouvoir's publics, les moyens fiuanciers de la réaliser a vec toute l'amplenr qu'elle méritc.

Il y aura lieu den reparler et je deman le le renvoi de la pruposition de notre collègue avec avis tris favorable anx Conmissions compitentes.

M. Ambroise Rexnu. - Noublious pas que nus styles du dix-septiène et du tix-huitième siècle sont encore les modèles du monde entier.

M. Aucoc. - J'appuie également la proposition de M. Lampué, car je suis un de ceux qui ont prééonisé les Expositions internationales spécialisées qui, seules, peuvent rendre des services a l'Industrie Irancaise et aux Arts industriels.

Je fais, toutefois, une réserve en ce qui concerne la date de 191't, car je sais qu'il y a déjà, pour cette année, une Exposition spėcialisée qui doit se tenir an Grand Palisis.

M. le Puesident. - Je mets aur voix le projet de vou dépissí par notro collégue M. Lampué.

Le projet de vou est adopté. 


\section{S É N A T}

\section{Séance du 15 Avril 1911.}

M. Couyba, sénateur, dejose un projet de résolulion invitant le Gouvernement is itudier l'organisation d'une Exposition internutionale des Arts decoratifs et industriels it Paris en 1914.

Ce projet, sur la demande de M. Couyba, et après avis farorable de M. Steer. Ministre de l'Instruction Publique et des Beaux-Arts, a étí renroyé à la Commission d'iniliative dı Sénat.

(Le Matin, du 16 avril 1911 ).

\section{COMMISSION D'ÉTUDE}

\section{COMPOSÉE DES DÉLÉGUES DES ASSOCIATIONS ARTISTIQUES FRANÇAISES}

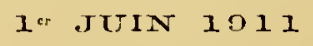

RAPPORT

rédigé par René GuILLEnÉ

sur nne Exposition internationale des Arts Déconatifs Hoder'nes

PARIS 1915

C'est par une regrettable défaillance à sa légitime renommée d'initiatrice dı progrès dans le domaine des arts comme dans celui des idées, que la France a laissé à l'Jtalie l'lonneur d'avoir organisé la jremière Exposition internationale des Arts décoratifs modernes.

Le riglement de l'Exposition de Turin en 1902 stipulait: "On n'acceptera que les ouvrages originaux qui montreront uno tendance bien marqueje au renouvellement esthélique de la forme. Les imitations d'anciens styles, et les productions industrielles dénuées d'inspiration artistique, ne seront pas aumises." 
Ce programme, qui faisait un princife absolu de l'affirmation diune estlinfigue nourclle, l'Italie le reprenait il l'Exposition de Mlilan en $190 \mathrm{~b}$, fuis en $19 \mathrm{tt}$, il celle de Rome, où cllp a tenté de réaliser une Exposition d'Arcliferture exclusirensent morlerne.

Comme l'Italic, tous les autres pays orit organisé, et arec quelle remarqualile mćthode el quelle continuite daus l'eflort, le grandes Expositions, mais maliunales, d'Art décoratif moderne. Parmi les plus importantes, citons cellı.s de MInnich, Stuttgard, Stockholm, Vienue...

En France, en 1906 , M. le liapporteur du Budget des Beaux-Arts devaru la Chambrc réclama unc Exyosition internationale d'Art décoratil.

Sans vouloir citer tous les cerivains que ce projet préaccupa vivement, rapfelons que l'un d'eux, qui en avait plus palticulièrement éludié l'économie, tixail alors l'ouverturc le cette Exposition à 1920 .

Cette éclıcance aujourd'hui a semblé trop lointaine. A altendre, on yeut craindrc, en eflet, de léconıger les talents trés prèts, ou de laisser l'èlranger nous divancer à noureau. Au reste, l’honncur français, en mènc temps que les conditions économiques ct commereiales acturlles, nuus en funt un besuin pressant.

C'est pourquui, an momunt mème où, dans la Presse, un organe imporlant proclamait la nécussilé nrgente de celle manifestation, les l'ésidents des truis Sucjélés, l'Union centrale des Arls décoratils, la Socjplé des Artistes Decoraleurs, la Sociét:

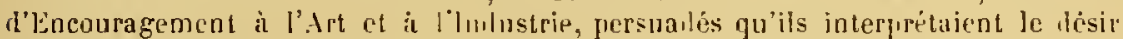
de toutes les Sociéti's s'intëressant i I Art Dicoratif, exprimaitnl le vou que le Gouvernement réalisât cefte Exposition des 191 \%̈.

Examinons l'objet de cette Exposition, les ruisons qui la nécessitent, les résultats ceonomityes et artistigues quon en peut allemlre. Nons étudierons ensuite: son organisation artistique dans ses lins et ses movens; son arganisation administrative; son oreanisation funciere.

Objet. - "Par la collaboralion de l'artiste, de l’industriel el de l'artisan, réunir en une Esposition internationale tous les Arts décoralifs: architerture, arts du bois, de la pierre, du mélal, de la ríramiqur, du verre, du papiel', des tissus, eic...; sous routes leurs formes, qu'ils s'appliqguent à des olijets d'ulilité ou ì des ceures purement somptuaires; duns toutcs leurs destinations : décoration extiricure et intérieurc des édilices publics et prives, ameublement, prarure de la persounc... n

Celte Exposition doil être exclusirement d'irt moderne. Aucun pasticlıc ou copie des styles anciens n'y seluient admir.

Une Exposition in deux scctions, l'une de style uncéne, l'sutie de slyles anciens, est absolument impossible.

Raisons. - D'abord, trourelait-on un emplaccment assez vaste pour priscnter une Exposition qui, si clle n'ètait pas réservée aux ourres d'une esthétique moderne, prendrait iresque, par l'apport des industries nombreuses qu'on y pourrait ratlacher sous prétexle d'art décoratif, des proportions d'Exposilion inirerselle?

Les èrangers, quant à eux, enverront uniquement des ceuvies d'Art moderne ainsi qu'ils l'ont toujours fait dans les Expositions, à Bruxelles romme à T'urin. Pour nous, diviser nos forces, ne serait-ce pas assurer notre infériorité?

Si on laissait aux fabricants le moven trop facile de jarliciper à l'Exposition arce des ceuvres de styles anciens, ils saisiraicnt vite l'occasion d'y coroyer leur stork do malchandises, el ne réaliscraient aucun eflort puur eréer des modelis modernes. Lrs obligerait-on à n'exposer dans la seconde scction que s'ils ligurent dans la première? lls respecteraient la lettre du réglement en présentant une ceuve inodertie insigni- 
fiante. Et ne serait-ce pas s'enfermer dans la routine dont on veut justement sortir, aller contre les fins mème de cette Expositinn, qui sont en effet : de proroquer lı rérulisation et la difficsion des styles modernes francais.

Mais quelles raisons de ces fins?

liaison d'honneur d'abord!

N'appellerons-nous a Paris un si grand concours de peuples que nour leur montrer des mauvais pastiches des nurres qu'ils peuvent admirer, au Louvre, à Versailles, à l'ontaincbleau... ou chez eux dans leurs propres musées?

Depuis quarante ans, nous faisons commerce de tontes les richesses de notre mobilier national; nous débitons des surmoulages des commodes, des tabies et des fautenils, des ehenets et des pendules, des bronzes et les girandoles; nous vendons des copies de toutes ces merveilles décoratives entassées par les dynasties royales dans leurs palais, que nous avons trourés comme des greniers d'abondance. Cés répliques furent d'abord traities on perfection, far l'emploi des mêmes moyens qui avaient servi à l'exécution des originaux. Les bronzes étaient alors fondus et ciselés. Aujourd'hui ils sont reproduits par la galvanoplastie! Nos beaux modèles anciens sont galvaudès, vilipendés. Bien flus, certains marchands estimant la main-d 'œuvre frangaise trop coûteuse font venir d'Italie, d'Espagne, de Belgique, les bois tout ouvrés, tout sculptés (:éance du Sènat du 24 mars 1910); ils sc contentent de les assembler et de les revendre comme produits français!

Pínibles constatations! Pendant des siècles, depuis le muyen âge, la lienaissance italienne exceptée, la France a imposé son goùt au monde. Aujourd hui, nous ne sarons plus que nous faire gloire du talent qu'ont en nos ancêtres. Tomberons-nous à n'être plus qu'un jeujle de mouleurs et de copistes?

Il faut réagir courageusement, nous relever. Nous nous derons de renouer avec notre tradition et de rester des créatenrs. II est d'un devoir promier pour la République d'aider à la réalisation des stỵles modernes.

Et hâtons-nous devant la menace ćtrangère. Les étrangers sont très en avance sur nous. L'Angleterre, l'Allemagne, l'ltalie, I'Autriche, la Hollande, la Belgique, les pays Scandinaves ont leurs styles modernes, et dès à présent sont outillés pour leur exécution à bon marchı̇. Bien plus, ils comnencent à en importer de grandes quantités chez nous. On comple à Paris, comme maisons étrangères de décoration cxclusirement moderne:

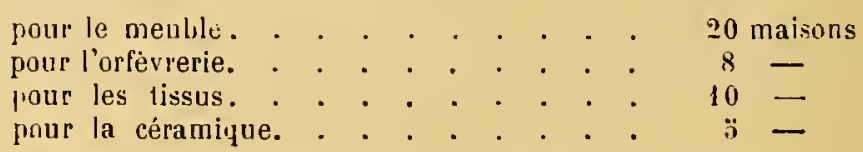

Et combien de fabriques itrangères n'ont pas en France de maiscns de vente a leur nom, mais y possèdent des dipôts importants. C'est près d'elles que se fournissent tous nos grands magrasins de wowveautés, sans en excepter un, en articies modernes:

Services de tables, de toilette (Autriche, Allenagne);

Vases, majuliques (Allemagne, Ilalie, Danemark);

Bois vernis (Angleterre, Autriche, Italie);

Petite or'èvrerie, cuirre, ètains (Allemagne, Hollande);

Verrerie (Allemagne, Bohème);

Bijoux (Allemague);

Broderie (Suisse, Allemagne);

Bimbeloterie (Angleterre, Autriche, Japon, Allemagne);

'Tissus (Angleterre);

Ete., etc... 
Mais cest également sur ces fameux styles anciens que nous pensons si frangais, que les étrangers aujourd'hui nous battent en brèche. Puisqu'il suffit de copier des pièces de musées, il leur est tout aussi facile yu'à nous d'exécuter du Louis XV ou du Louis XVI. Ils ont maintenant dexcellenIs ouvriers, de parfaits artisans, un outillage plus important que le nôtre. Comme ils fabriquent à bas prix, la main-d'œuvie n'étant nulle part aussi chère qu'en France, leur coneurrence devient des plus dangereuses. Le chiffre de leurs importations augmente chaque jour.

En voici quelques exemples (Rapport sur la modification des tarif's douaniers. Documents du Sénat, 1910).

\section{M.IROQLINERIE}

\begin{tabular}{|c|c|c|c|}
\hline \multirow{3}{*}{$\begin{array}{l}1892 \\
1908\end{array}$} & Importation & & Exportation \\
\hline & 3.390 .090 & . & 7.937 .968 \\
\hline & 6.620 .820 & . &.$\quad 6.308 .192$ \\
\hline & Balance en perte: & 1.880.508 $\mathrm{fl}^{\circ}$. & \\
\hline
\end{tabular}

\section{BIJOUTERIE JE FINTAISIE}

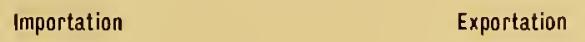

TABLETTENIE

Importation Exportation

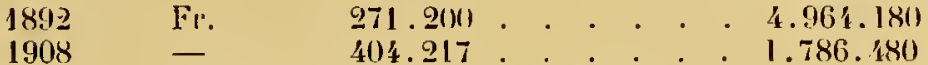

Balance en perte: $3.421 .717 \mathrm{lr}$.

\section{METBLES}

1899

Importation Exportation

Kilogs 1.853.000 . . . . . 11.804.000

$1908 \quad-\quad 6.5335 .000$. . . . . . 12.781.0001

Bilance en perle : 3.685 .000 kilogs

\section{PAPIERS PEINTS}


Sur tous les chapitres, ae sont parcilles constatations. En tapis, limportation dOrient passe de 143.376 kilogrammes en 1892 a $330 . \$ 36$ en 1908. L Allemagne nous inonde de porcelaines, et de biscuits Louis XVI. Et que de produits nous recerons de l'étranger dont les nomenclatures des donanes ne nous rérélent jas le caractéte dubjct lécoratif !

Un exemple? La dinanderie allemande cutre comme "ouvrages en coirre "; on se contente de l’argenter à Paris pour éclıpjicr au tarif du cuivre argenté. Qui cherchera sous celte rubrique les corbeilles a pain, jardinières, surtuuts de table, scaux à ı̆lace, ete..., d orfèverie à bon marché tunt uous somnes submergés.

Comment lutter?

C'est en créaut des cuves de style moderne qui ne soient pas tombées dans le domaine public et restent protigées par les lois de la propriété artistique et les conventions internationales; c'est par ce fui est proprement francais, notre gunt et notre esprit d"iuvention, que nous pouvons reconquérir notre ancienne suprématic sur ces marelıcs.

Puur ces raisons artistiques et économiques, cette Exposition doit ètre exclusivement réservée à l'Art Décoratif moderne.

Exposition sélectionnée. - Arant dèlre une Ėiposition où l'on vende, une Lxposition marcliande, elle doit èrre unc Exposition d'esthétique. Aux Expositions universelles en l'runce ou à l'Etranger, aux Expositions jndustrielles spéciales peuvent prendre part tous les industriels, les marchands, les arristes, en un mot quiconque loue une place pour présenter ses pruburts. La lajdeur voisine avec la beanté. En raison de la lin qu'elle poursuit, l'Exposition projetée ne doit présunter au contraire qu'une sélection d'auvres. (Voil Commission de récejtion.)

Il faut mème que les moindres détrils de cette Esposition (oriflamme, màt, prospectus, prisenlation des salles) aient un caractere dart. (Voir Commission d'installation.)

Résultats. - Les résultats de cette Exposition dans lordre économique comme daus !ordre altisliciue seraient consilerables.

$1^{\circ}$ Résultats iconomiques: Nos industries, que nous auriuns rajrielées à l"attention de l'illunger, prenılraient à ce renonveau d'Art un 'ssol' nouveau. Aujourd'hui $t_{1} m s$ les faljricants vendent les mèmes objets Renaissance. Louis XVl, Empire. Les corbeilles à pain des or"èves ou des bazars sunt diffírentes dans la valeur de leur nétal on la qualité de lenr fabrication, mais se ressemblent par lenr décor de style. Cela vient de ce que le modéle est lombe dans le domaine public. l. industriel sélicux tıourera donc un avonlage immédiat à ćlablir des modèles d'Art moderne, afin de protiger ses criations conlre le dimarquage tet limitation en simili de ses propres coneurrenls français. Par lá, il donnera à sa production un caractere hien personnel. C'est aiusi seutement que nous jourrons recon-tituer, en rumline sorte recréer nos maisons, nos anciennes maisons industriclles, comme elles libient autrefois, ayant clacune une individualite particulière, un gout propre ct dont le nom jadis, la funse suflisait a garantir dans le monde entier la qualite artistique dine curre.

Qu'on ne dise puint arec certains que lancer des styles modernes serait rendre impossible l'écoulement du stock considérable d'auvres de styles anciens que notre commerce lient cu magasin. On ne saurait, du jour au lendemain, renverser le f assé, changap le goùl, les habilules, les tralitions, mais il faut savoir luréparer l'arenir, un avenir jeut-ètre prochain.

L'organisatiun sociale de l'Art Décoratif se trouverait nécessairement modifíc par cette Exposition, dans un sens de riformes utiles aussi bien pour les industriels yue pour les artistes, les ouvriers, les artisans. 
La production des artistes deriendrait personnelle, puisqüils ne se contenteraient plus d'associer les èlements des styles jassés dans unc ceuvre qui doit garder san anonymat poul paraitre ancienne et qu'ils seraient vraiment des créaleurs.

Ce caraclère mème de la produclion ferait adopter, comme base des rapports entre industrieis et arlistes, te contrat d'idition(I).

Avantage pour l'industriel qui n'aurait pas i exposer les frajs dacquisition d'urs mo léle; l'artiste, d'autre part, serait rémunéré suivant le succès de snn wuvre. Enfin, ces milliers d'èlèves sortis de nos écoles d'Art Décoralif et occujés acluellement à des besognes serviles, arrangements ou margotagr's, suivant le terme d'atelier, d'éternels rubans, rosaces et raies re cour Louis XVl, trouveruient par la une tàche plus digne de l'enseignement artistique qu'ils recoivent.

Les conditions du travail des arlisans et des ourriers seraient anéliotées. La crise de l'applentissage recerrait une solutinn peut-être plus facile. Aujourd hui, à quoi servirait aux ouvriers d'ètre de parfaits techniciens, puisqu'on laisserait lıur talent sans emploi. Sont-ils sculpteurs sur hois? Pendant cinquante ans de leur vie, ils auront à "pousser» la même baguelle d'uves ou de raies de cour. Lart moderne, au contrice, leur proeurerait des travax nouveaux quileur permettraient le montrer l:urs qualitis l'exéculants, et proportionneraient leur $\neq$ ain à leur talent. Actuellement on leur fait exéculer des meubles lienaissance, Louis XV, Louis $\mathbf{X} V^{\prime}$ éest-à-dire des meub!es qui ont été crées à unéénoque uù la maı:hine élait inconnue, et pour être exécutés entièrement à la main. Poul fabriogucr ces meulıes à bon marché, on est obligè d'employer l'homme comme une machine. L'urtisan se spicialise afin de cébiter le plus possible. Une baguette de rajes de cour nasse dans $3, \dot{4}$ ż mains ; chacune donne son coup d'outil toujours pareil, antomatique.

Est-il besuin pour cela d'un parfait apprenlissage? Il ríen scra pulus de même avec un Art moderne. Les artistes, qui ne créunt pas seulement des pieces uniques, concerront leur mo ièle le tulle façon que la machine fuisse l'cxćcuter et réserveront à l'artisan les points ỏe sculpture où celui-ci pourra alors exercer son talent dans toute sa verve.

Arracher l'artisan au scrvage d'une besogne de machine, pour lui donner une tikche qui jöntèresse, c'est exciter son labeur, c'est aussi relever sa moralité. Si l'alcoolisme fait tint de ravages shez les nuvriers d'art, cela tient à leur degroût des travaux qu'un leur doune.

Enlince serait la main-d'vuvre francaise qui profiterait de cette renaissance d'art. Nos meubles de style sont, nous l'avons dit, fabriqués en grande quartile dans les villes du nord de l'Italie et de l'Esparne. Puisque la tache demandie reste servile et mécanique, ces paysans étrangers peu salariés y suffisent. Ėn $188 \pm$, on employait à Paris 3000 sculpteurs sur buis; en 1910 , on n'en comptait plus que 1300 avec chomage de 50 poul 100 , soit 730 . En $188 \%$ travaillaieut 3000 menuisiers en funteuils, en 1910 il en reste 300 . Parmi les élères sortis de nos écoles professionnelles, 57 pour 100 sont obligés de renoncer à leur mótier d art. (Séance (lu Senat du 2q mars 19t0.)

L'exécution des curres medernes, réclamant plus d'habileté et al’inlelligence. ne pourlait ètre contiée qu'à les artisans frangais sous la direction iumèliate des ar listes créateurs.

20 Résultuts artistiques : Nous avons plusieurs fois parlé de renaissance d'Art. C'est, en effet, une véritable renaissance yue jeut provoquer cetle Exposiliun. Par elle, nous parviendrons a réuliser des styles modernes qui répondent anx aspirations de notre époque, à créur un Art Jécoralif qui satisfasse aussi bien les besoius les plus modestes que les caprices du luxe, par là a faire pénétrer à lous les degrés, sous toutes les formes de la vie sociale, avec plus de bien-ètre, une plus grande

(1) Ce contrat n'est à peu pries employé aujouri'hui que dans le bonze statuaire. 
somme de beauté. Nous chercherons à ajouter vraiment l'Art à l'Utile et non plus par l'Art à rendre inutilisable un objet utile! On a trop considéré l'Art Décocatif comme l'art des industries de luxe. Coneeption fausse ! Les objets les plus simples de nos usages peuvent ètre artistiques. L'Art décoratif, ou, pour l'alpeler plus exactement, l'Art appliqué à l'lndustrie ne doit pas èrre envisagé seulement sous sa forme somptuaire, avec ses tapisseries, ses émaux, ses orfèvreries. ll faut aussi que le verre, l'assiette, le bol, la table de l'écolier, la suspension fantiliale aient été dessinès, ornés par l'artiste. N゙en était-il pas ainsi au meyen àge, seule époque oủ la Erance ait eu veritablement un Art populaire. Lit ce ne sont pas seulement les Industries d’art proprement dites qui auraient à bénéficier de ce renouveau, mais bien toutes les Inilustries qui demandent qu'on ajoute à la qualité d un objet par l'élégance de sa forme ou de son décor (exemple : automobile, brosserie). 1l faut justement que tous les oljjets nécessaires à nos usages et uju sont susceptibles d’ètre lécorés, soient réalisés dans cette Exposition (exemple: plaque d’égout, bouchous d'auto, moules à biscuits, porte-trollt:y, etc...).

Le prix jusqu'iei trop élevé des ouvres de style moderne vient de ce qu'elles sonl presque toujours des piẻces uniques. Industrililisées, fabriquées en séries, elles se vendıaient mểme moins cher que n'importe quelle cuvre le sty̆le ancien. Grâce à cette Exposition, nous arrirerons à créer un art à bon marché, un art vraiment lémocratique, à la portée de tous, et qui metıra un peu de joie, de claire propreté, de la beauté enfin jusque dans les plus modestes foyers.

Organisation artistique. - Nous arons à en étudier les fins et moyens, c'est-à-dire à définir ee que comprendra cette Exposition, le mode de classement, de présentation des ceures, et à examiner par quels concours artistiques nous la pourrons réaliser.

Classification. - Il y a trois systèmes de classitication :

u) technique suivant les procédés le fabrication des ceuvres (exemple: dans les etoffes, tissage et impression).

b) par matiere (exemple: bois, meital...).

c) d'apres $l \iota$ destination des aures (exemple : architecture, mobilier).

1) Classification technique : Ecartons ce mode très utile seulement dans un musée pédagogị!ue.

B) Classification par mative : Elle eomprend :

$1^{\circ}$ Les arts de la pierre;

$2^{\circ} \quad-\quad$ lu bois ;

$3^{\circ} \quad-$ dil métal :

$\dot{\Psi}^{0} \quad$ - de la cérani ${ }^{\circ}$ ue :

$\dddot{\partial}^{\circ} \quad-$ du vere ;

$6^{\circ} \quad$ - ru papier:

$7^{\circ} \quad$ - des tissus;

$8^{\circ}$ - des matières animales cuir, nacre, corne, corail, iroire, ambre, ćcaille...).

Nous ferons à la classitication "par matière " quelques critiques.

Oủ rentremait la joaillerie qui emploie les pierres précieuses, use du métal le moins possible, seulement pour la cliarpente du bijou et comme aceessoire. Dans la sectiun de la jierre? L’èmail est une matière vitreuse. Le mettrons-nous dans les arts du verre on de la céramique, alors quil se range nalurellement par ses destinations habituelles avee l'orfevierie ou le bijou? A quoi rattacher la coutellerie ? Si la lam a de couteau est de métal, le manclie peut être de pierre dure, de 


\section{- C.SCII -}

bois, de eristal, de poreelaine, de euir, de corne, d'ivoire... Le manche comme la lame peuvent ètre des pièces d’art. On ne saurait done à quelle section exposer le couteau.

Ces exemples pourraient ètre multipliés. Dans bien des cas, nous ne saurions distinguer le principal de l'accessoire, et quelle matière doit l'emporter sur l'autre. La classification par matière pourrait présenter dans un musée d'enseignement des avantages incontestables. Ici nous voulons nous adresser surtout au grand public. Il ne cherche pas pour ses besoins un objet de métal ou de pierre, mais bien un modèle de chaise ıle jardin, de couteau, d'escalier, de revêtement de muraille. Et, en plus, quelle léroute pour sou esprit quand sont confondus dans une méme section, comme en 1900, les pieces d'arelitecture et les objets d'art, la tuilerie et les grès d’étagcere. Quel désagrément aussi pour l'artiste que ce voisinage. Les industriels, enfin, aimeraient-ils à ventiler leur prouluction dans tontes les sections; un bijoutier, par exemple, consentirait-il à présenter ses broches dans les diverses elasses du métal (médaille), de la pierre (lapis), du bois (ébène sculplé), de la nacre, lu corail, de l'ivoire, de l'cuilie...

Ces abjections à la classification par matière peuvent se résumer :

$1^{\circ}$ Difficulté, lorsqu'un objet est composé de deux ou plusieurs matières, de fixer celle qui servira de base de discrimination;

$2^{\circ}$ Conlusion d'objets disparates par leur usage, leur forme, leurs proportions ;

$3^{\circ}$ Trop grande dispersion des créations d'un mème artiste on industriel.

C! Classificution par destination : C'est celle que nous adopterons en principe, mais nous ne saurions, sans éliblir la plus grande confusion, en raisun te la inultiplicité des destinations, suivre uniquement cctle classification. Nous la combinelons dune avec les classifications " teclinique " et "par matière ".

Classification proposée. - Nous proposerons la elassification suivante:

$1^{\circ}$ Groupe de l'Architecture;

$2^{\circ}$ Groupe du Mobilice ;

$3^{\circ}$ Groupe de lu Parure.

\section{Sections spèciales :}

1. Les Arts dlu Thealre;

$2^{\circ}$ Les Arts de la Rue;

$3^{\circ}$ Les Arts du Jardin;

$4^{\circ} L^{\prime}$ Enseignement.

Toutes les productions sont dunc ratlacheses à trois groupes qui répondent it Irois destinations bien différentes : architecture, mobilier, parure de la personne; Dans ces groupes, on classe les ceuvres suirant leur matiële, "métal, bois..." ; lans ces classes de matières, on distribue les æuvres en salles séparées soit suivant la qualité de la matière " or et fer », soit snivant leurs procédés techniques, "ćloffes tissćes, ctuffes imprimées; fer forgé, fonte de fer $n$.

NOTA. - Les entmerations qui suirent ne sont pas limitatires, mais interviennont is tilve l'excmiple.

\section{I. - GliOLPE DE LARCHITECTLRE}

\section{Chasse A. - Exsenbles b'irgittectile}

$1^{\circ}$ Architecture ríalisée.

$2^{\circ}$ Maqueites ( lispositions et dézorations exterieures et intérieures). 


\section{Architecture PLbique}

Plan de ville, place publique.

Mairic, maison du peuple, hôtel de ville, musée, bourse, églises et temples, halles el narchés, caserne, muséum, observatoire, lycée, école, tour.

Hôpital, asile, crèche.

Columbarium, monuments funéraires...

Poste, gare, pont, aqueduc (1).

Palais, installations d'expositions.

\section{ARCHITECTCHF TRIVEE (2)}

Architecture des villes.

Maisons de grandes industries, banque, usine, maison de bains, hûtel de voyageurs, boutiques.

Hòtels particuliers, immeubles de rapport, maisons ouvrières.

Arehitecture des campagnes.

Villas, chalets, cottage, ferme (et voir section "Arts des jardins ").

Rentreraient dans cette classe toutes maquettes de paquebot, yacht, tramway, wagon, automobile th moyens de transport.

Viendraient ensuitc tous les éléments de construction (matèriaux déjà ourrés et ornés) et de décoration (éléments soit décoratifs, soit servant à l'usage, parties fixes de l'architecture) pour toutes destinations architecturales, planes ou plastiques, dans toutes matières.

Ils seraient répartis comme suit :

\section{Ceisse B. - L.A DÉCORATION DE L.A PIERRE}

Toutes désorations peintes on sculptées de la muraille (fresque, statuaire décorative...).

\section{Matieres :}

$1^{\circ}$ Pierre, grès, granit, lave.

$2^{\circ}$ Marbre, albâtre.

$3^{\circ}$ Ciment (ciment armé, coloré), sluc.

$4^{\circ}$ Matériaux artificiels (pierre armèe, marbres reconstilués, composés du ciment et du liẻse, stall).

bestinations : Revètement du mur, du sol ou du plafond, cheminées, escaliers, vases, vasques, piélcstaux, monuments funéraires.

\section{Classe C. - Ld dÉCoration du hols}

Mutières : Tous bois, sculptès, menuisés, dẻroupés.

Destinations : Tuus traraux de chappente el menuiscrie ourragíe; lambris, solives, escaiier, parquet, deranture, huisserie, rersienne, palissade, auvent, treillage, menuiserie de batean.

(t) Les lravaux d'ingénieur terront aroir un calactèle architectural ut dicoralif.

(2) Tous ess immeubles diversifiés pour tous besoins, hótel avec atelier d'artisle, hùt 1 po n' curcle, toutes contitions de climat ou de lisu (mer, montagne, nord, midi, colonies!. 
Classe D. - LA DÉCorattoN D'́ MÉTAL

Matières: $t^{\circ} \mathrm{Fer}$, cuive, acier, flomb.

$2^{\circ}$ Fonte de fer, tôle, zinc.

'lous procédés : martelé, fondu, découpè, estampé, embouti.

Destinations: Sommier, grilles, balcons, rampe, tuyaux de descente, lucarne, chêneaux, crète, èpi, giroutte, ancre, marquise, iéverbère, vespasienne, cage d'ascenseur, enseigne, serrureric, crémones et espagnolettes, fumistcrie, poẻle, radiateur.

\section{CLAsse E. - LA DÉCORATHON DE LA CÉR.MMQLE}

Mutiëres : Terre cuite, fuÏence, grès, porcelaine.

Destinations : Revêtement et pavement, cheminécs, épi, antefixe, tuiles et briques décorées.

lnstallation de salles de bains.

\section{Cussse F. - LA DÉCortition de velire}

Vitraux neints, émaillés. IIosaïrues de verre.

(liattachíes : armatures et résilles). Verrear'né, imprimé pour portes et fenétres. Vitrifications nour revêtement et plavemsut (ex. chṛ̣socérame).

\section{II. - GROUPE DE MOBILIER}

\section{Classe A. -- LES EXSEMBLES DE MOBILIEt}

$1^{\circ}$ Ensembles réalisés.

$2^{\circ}$ Naquettes.

Ensembles mobiliers réunissant tous les arts divers; pièces d'habitation pour toutes destinations, calıines téléphoniqnues, instıllalion dé salle d'usine, cantiue, asile de nuit, salon, cuisine, bibliothèque, chambre l'ourrier, cabine de bateau, salle de classe, etc.

\section{CaAsse B. - LA DÉCORATION DE BOIS}

Matieres : Tous bois y compris les joncs et rotins, dans tous procédi(y compris bois coulbès, écrasés, filis).

Rattachis : l'osier, la paille, fibres de palmier, raffia, abacג.

Annexe : Section du cuir pour l'ameublement et tenture.

Destinations: Meubles, menbles spéciaux (billard, casier, billiothèque), moulures, cadres, baguettes, vannerie, stores de bois filés.

\section{CLasse C. - L.A DÉCORATION DU MÉT.LL}

Matieres : $1^{\circ}$ Or, argent, acier, platine, élain.

$2^{\circ}$ Bronze, fer, aluminium.

$3^{\circ}$ 'Tỏle, fer lualtu, fonte de fer, zinc. 
Iestinations : Orfèrrerie religiense ou civile, monnaies et médailles, grosseric et menuiserie d'or et d'argeat, émaillerie sur métal.

Dinanderie.

Luminaire.

Coutellerie.

Horlogeric.

Armurerie.

Quincaillerie, literie de métal, articles de ménage de fer battu et tôle peints ou émaillés.

\section{Classe D. - L.I DÉCORATIOS DE IA CÉRAuIQLEE}

Mutièrcs : Terre cuite, faïence, biscuit, porcelaine, gròs.

Destinations : Service de table, de toilette, accessoires de salle de baias.

Luminaire.

Céramique de décoratiun.

Emaillerie sur céramigue.

\section{CaAsse E. - LA DECOR.ATION DU VERTE}

Verre el cristal.

Pites de rerre. Emaux sur verre.

Gobeleterie, flacons, boutellles.

Service de table et toilette.

Verreries d'éclairage.

Miroiterie.

Vitrifications, perles, courounes mortuaires.

\section{Clase F. - L.I DEGORATION UES TISSLS}

Mutives: Soie, laine, coton, chanvre, lin, ficelle, jute, abaca, tissus de poils, tissus de fibres, toiles cirées.

llattachés : feutre, linoléum.

Destinations :

$1^{\circ}$ Citoffes d'umculilement et de tenture:

i) tissées; brochées; lamées ;

b) imprimées ;

Passementerie, broderie, dentelles d'ameublenent.

$2^{\circ}$ Lingerie de table et de tenture.

Toiles cirées.

$3^{\circ}$ Tapis: a) Tapis de laine. Point noué et Jacquard ;

b) Sparterie, tapis de corde, linoléun, feutre, tapis imprimis.

$4^{\circ}$ Tupisseric : a) Cobulios, Aubusson, Beauvais ;

b) Mécanique.

\section{Clssse G. - LA DÉCOR.ITION DU PAPIEt}

'lous papiers, chiffons, bois, paille, etc...

$1^{\circ}$ Les Prquers pcints : Tous procédés (gaufrés, satinés, métallisés, initalion de :ilir, etc.). 
$2^{\circ}$ Le Livere : Papiers, caractères, dispositions typographiques.

Jllustrations et tous ornements destinés à la décoration du livre.

Reliure, couvertures de livres el partitions.

Papiers et éroffes de garde.

Publications d'art.

$3^{\circ}$ L'Estampe : estampes décoratives.

千 La Papeterie :

a) Menus, faire-part, actions de Compagnies, prospectus, cartes à jouce ;

b) Pupier à lettres ;

Rattachée: tabletterie spécialc pour la papeterie (articles de bureaux).

$\ddot{\jmath}^{\circ}$ Le Cartomage :

(t) Boîtes à parfumerie, modes, etc..., éliquettes;

b) Oljjeis en papier màché.

\section{1. - GROUPE DE LA PARURE}

\section{Chasse A. - LE VÊTEMENT}

$1^{\circ}$ Vètements de femme.

Vètements d'homme, y compris chasublerie, uniformcs, livreses.

Vètements d'enfant.

$2^{\circ}$ lingerie et bonncterie.

$3^{\circ}$ Broderies et dentelles, tissus perlés et décorés pour vètements.

$4^{\circ}$ Passementeric, rubanerie, boutons et accessoires.

\section{Classe B. - Les MOdes}

$1{ }^{\circ}$ Chapeaux et coiffures.

$2^{\circ}$ Maquettes de disposition et d'ornementation de la chevelure.

\section{Classe C. - LA tiLELTR}

Fleurs naturelles, stérilisées, artificieltes en toutes matières (satin, porcelaine, celluloïd).

Arrangements en vases.

Fleur pour la toilette et les modes.

\section{Classe D. - Bljouterie}

to Bijoulerie et joaillerie. Mśtaux et pierres précieuses.

$2^{\circ}$ Bijouterie de fantaisie el d'imitation (perles et pierres vitriliées, métaux doublés, bijoux de devil).

\section{Classe E. - tabletterie}

Eventails, laques, tous objets de liroire, corne, nac:e pour la toilette et la parure, étuis, fume-cigare, etc.

Brosserie.

Jouets.

$$
\text { Claše F. - Maroquinerie }
$$

Rattachés: articles de voyage. 


\section{SECTIONS SPÉGIALES}

a) Les Arts du Théatre: $1^{\circ}$ Architecture : Salle de théàtre; on ne pourrail y présenter que des mises en stène modernos ; tous les théîtres piarisiens scraient invités à y donner àes représentations (littérature, nusique, danse).

Maquettes d'architecture extéricule et intérieure, disposition el décoration des théâtres (salle: dégagements, tribunes, fuyers, vestiaire); théitre en Illein air, cirque, lippodrome, vélo et aérodrome.

Maquettes de décors et de mise en scène, maquettes de féeries, maquettes clıorégraphiques, dispositions d'éclairage...

$2^{\circ}$ Molilier: Sièges, luminaire, décoration et ameublement de loge, de spectateur et d'acteur. Accessoires is théilre.

$3^{\circ}$ Hurure : Vìlements de scène, des gens de service (ouvrenses). Etoffes, bijouterie, fleurs.

Rattachés: instruments do: musique.

b) Les Arts de lu rue: $1^{\circ}$ Arclitecture : maquettes d'alignement d'immeubles, refuges, dispositions des rues et trottoirs.

$2^{\circ}$ Objets d'utilité puhlique ou deslinés au décor de la rue; lampadères, réver bères, foutaines Vallace, plaque d'égonts, lavatorics, baraq̨ue, kinsq̣ıe, mât et potence de trolley, devanture, plaque indicalrice, entrées sonterraines.

$3^{\circ}$ Publicité : affiches de papier, métul, verre, plàtre peint et galvanisé, enseignes lumineuses...

Parte-affiche, voilures-affiches, prospectus.

$4^{\circ}$ Fètes mubliques : maquettes de corlèges, ares de triomphe, arrangements de tribunes, voitures fleuries, feux d'artifice.

Lampions, mits, oriltammes, binnières, guirlandes.

c) Les Arts des jardins: Architecture (jardins réalisés et maquetten!.

Cités-jardins, pares, squares, ares de verdure, portiques, disposition des massifs, mosaïques, fontaine, buffet d'eau, belvéllère, kiosque, serres, treillages, bacs, cages d'animaux, volière.

Mobilier : hancs, sièges, vases, caisses.

De l'enseignement : $1^{\circ}$ Travaux des élèves ;

$2{ }^{\circ}$ Section de l'Art a l'Ecole (estampes, bons points, livres, molilier).

Nous estimons que l'on ne doit pas ouvrir de section ouvrière spéciale; les objets les plus simples seraient présentés avec ceux du luxe. Il serait inutile de n'avair affirmé le principe de l'unité de l'art que pour y apporter une dérogation regreltable en établissant une hiérarchie dans ces arts mémes en faveur desquels on avait supprimé toute hiérarchie, en distinguant un art populaire d'un autre art qui serait alors un art noble, un art de riche et un art pour les paurres.

\section{MODE DE PRÉSENTATION}

$1^{\circ}$ Présentation rayonnante : Le Play a inventé on mode dit "rayonnant " qui fut appliqué à l'Exposition de 1867.

"Cette Exposition était divisée à la fuis en secteurs correspondant aux différents " pays et en zones concentriques correspondant aux diverses catégories de produits. "Si on allait de la cilconférence vers le centre, on passait en revue tous les " produits d'un même pays; si on tournait en cercle, on pouvait comparer tous les " pays dans la même industrie." (Ch. Gide, Economie socinle.) 
Ce mode de présentation nous parait difficilement praticable. On peut déterminer la largeur des fuseaux ou sectemrs suivant l'importance de participation des nations, mais chaque nation ne saurait avoir une contribution exactement proportionnclle daus chaque brancle d'industrie.

Supposons que la zone 1 soit attribuée à la pierre, la zone 2 aux tissus, le fuseau A à l'Angleterre. L'espace réservé à l'Angleterre pour les tissus serait insuflisant alors qu'elle ne pourrait remplir celui qu'on lui attribuerait pour la pierre.

$2^{\circ}$ Présentation proposée : Il faut éviter une présentation monotone, froide, purement didactique. Pour faire comprendre l'Art décoratif, il faut le faire aimer, le montrer séduisant et comme il doit être, une parure nécessaire de la vie.

Il convient done de présenter autant que possible toutes les productions d'Art décoratif en fonction de la vie, c'est-à-dire comme elles le sont dans la réalité suivant leur destination, leur emploi, en fonctions les unes des autres, en ensemble, créant le décor de notre vie.

Ce sera done d'abord en fonction de l'Architecture. On montrera les architectures d'un décor extérieur et intérieur moderne entièrement inslallées et meublées (1).

Les boutiques des immeubles seraient concédies à des pâtissiers, cafés, restaurants, fleuristes.

'Tous ces immeubles seraient groupés ensemble. Ce serait ainsi résumer, ou mieux synthétiser par quelques exemples choisis, unc ville moderne qui formerait le centre, le coeur mèmc de l'Exposition.

Mais toutes les proluctions ne pourtont tronver place dans des architectures réalisées. Elles seraient réparties suivant l'ordle de classification indiqué.

Chacune des classes prévues pourrail comprendre :

to Une salle centrale, cù seraient réunies en un ensenuble les couvres les plus artistiques ;

$2^{\circ}$ Une salle de maquettes et projets;

$3^{\circ}$ Une salle des procédés tuchniques et di la fabrication.

On clıcruherait à présenter les œuv'res le plus possible en ensembles harmonieux, mais le façon pourtant ì ne pas sucrifier entièrement au pittoresque leur portée d'enseignement artistique et technique ou de documentation commerciale.

Toute cuvre devrait être exposée sous les noms de l'artiste créateur, de l'industriel éditeur, et de leurs collaborateur's principaux, avec indication de la part de chacun.

\section{PARTICIPATIONS ÉTRANGÈRES}

Chaque nation serait autonome et présenterait son exposition à sa convenance.

\section{CONGLits}

Des Congrès mettraient à l'étude toutes les questions d'organisation de l'Art décoratif.

(1) Les architectures réalisées en matériaux définitifs ne figureront qu'en nombre forcément restreint à cette Exposition. Un fonctionuaire éminent, lui-même architecte renommé, signalait jnstement qu'on pourrait faire concouril aux prix qui seraient ¿lécernés à l'architecture á l'occasion de cette Exposition - par une henreuse extension du concours des facades - lous les immeubles et détaits (magasins, boutiques, ete.) qui anraieut été constrnits à Paris dans les trois ans qui précéderont l'Exposition. Ce serait, en effet, donner un stimutant actif à la production d'Art moderne. 
Législation. Gonventions internationales.

Réglementation de la production. Ententes intersyndicales.

Décentralisation artistique.

Enseignement de la décoration plane et plastique.

Apprentissage.

Art à l'École, etc.

\section{MOYENS}

Producteurs: L'Exposition sera faite grâce à l'entente de l'artiste, de l'industriel et de l'artisan. C'est cette entente qu'il faut réaliser, et les efforts solidaires de ces trois groupes qu'il faut provoquer. Les amateurs d'art aussi doiventêtresollicités. Beaucoup, nous n'en doutons pas, seraient disposés, en raison du but patriotique de cette Exposition, à faire des commandes speciales. On pourrait, en outre, trouver une utile main-d'euvre chez les élèves des écoles d'Art décoratif et des écoles professionnelles (130) (techniques diverses), des lycées (42) et des cullèges (44) de jeunes filles, des écoles primaires publiques et supérieures, des écoles normales d'institutrices (broderie, dentelles, perles), des écoles indigènes (Algérie et Colonies).

Enfin a Paris ou dans nos provinces francaises que d'artisans intelligents, que d'ouvrières habiles, que de fabricants actifs el animés de très bonne volonté, nous pourrions intéresser à cette cuvre de renouveau artistique. C'est d'ahord le recensement de nos forces qu'il convient de iaire. Au fond des campagnes, il y a des ressources ignorées. Ce sont des potiers à Thuir, près Perpignan, dans tous les environs de Quimper, à Rohan, près Lorient, à Cussac (Charente-Inférieure), à Treigny-en-Puisaye (Yonne) et cent autres dans le Var, le Berry; des verriers dans le Gard, le Var; des vanniers dans la Neuse; des brodeuses dans les Vosges et mille autres petits centres industriels pay'sans dont il faut appeler le concour's.

Propagande : C'est d'abord par des conférences qu'on éveillera le zèle de tous ces productenrs et qu'on préparera le public à aimer l'Art décoratil', à comprendre la nècessité l'un Art moderne, par lì à faire le succès de cette lixposition.

Ces conférences doivent être faites à Paris dans tous les milienx, dans les Universités populaires comme dans les grandes Societés, dans les ș̣ndicats ouvriers comme dans les syndicats patronaux, dans les grands centres, a Lyon, Marseille, Toulouse, Bordeaux, Lille, Roubaix, Nancy, dans les petites villes, jusque dans les campagnes.

Pour soutenir tout ce mouvement, pour le réaliser, nous avons des Sociétés artistiques à Paris.

Ce sont, sans que cette liste marque une hiérarchie entre elles dans leur valeur, par ordre d'ancienneté : a) Sociétés s'occupant exclusivement d'Art dècoratif:

$1^{\circ}$ L'Union Centrale des Arts dicoratifs;

$2^{\circ}$ La Societè d'Encouragement ì l'Art et à l'Industric;

$3^{\circ} \mathrm{L} n$ Societè des Artistcs décorateurs ;

trois Sociétés qui ort pris l'initiative du présent Rapport;

$4^{\circ} L^{\prime}$ Union provinciale des Arts decoratifs, qui par ses Congrès travaille à faire la synthèse des efforts des artistes et artisans de province.

Par órdre d'ancienneté : $b$ ) Sociétés comprenant une section d'Art decorctif :

$1^{\circ}$ Saciete des Artistes français (une sous-section d'Art décoratif);

$2^{\circ}$ Socièté Nationale des Beaux-Arts, le premier Salon qui dès 1891 ait donné un mouvement impurtant à l'Art décoratif moderne, en lui créant une section spéciale; 
$3^{\circ}$ Socite du Sulon d'Automne, qui par ses dernières expositions a provoqué un essor noureau le l'Art décoratif et a contribué, en présentant les ceuvres des artistes munichois, à éreiller l'altention publique sur la nécessitè d'une renaissance française;

\section{(t) Sociétés de Propagunde:}

Suciété nationale de l'Art à l'Éeole, pour ne eiter que la jlus importante.

Dans les départements:

Des Sociétès artistiques, acalémies, Soriétés d'encouragement aux Arts, qui trouveraient dans eette propagande une fin utile à leur activité sonvent inemployée.

Direction artistique : Elle serait confiée a la Commission de réception.

Celle Commissiun nagirait pas seulement au moment de la réception délinitive des neuvres en 1913 , le jour le l'ouvertme de l'Exposition.

C'est dès maintenant qu'elle devrait fonetionner, en diligeant les travaux prilares pour cette Exposition. Nous ne derons fas nous dissimuler qu'en France, si nous possédons des artisans, des fabricants, des artistes qui sont habiles, d'une habileté trọ grande parlois mème, dans leurs métiers, car ils visent an tour de foree, nous avons quelque peu perdu les traditions de goût qui ont fait la fortune des styles anciens, du gothigue an Lonis XVl.

Les élèves des écoles, les arlisans de l'aris on de province présentent dans tes Expositions des travaux parfaitement exécutés mais dont la composition est souvent de l'imagination la moins élegante. laut-il en aceuser les styles Louis-Phitippe et Napoléon 11I, qui ont alımé lés yeux francais?

Lit tâche de cette Commission de r'écetion (commission esthétique, jury supéricur) serait :

$1^{\circ}$ D'accepter les projets et maqueltes de toutes architectures on aurres destinées ì cette Exposition;

$2^{\circ}$ De mettre en rapport, à la demande, les artistes et les industriels élitenrs, d'aider à la formation d'équipes d'artistes, d’indusiriels, d'artisans, travaillant en vue des ensembles;

$3^{\circ}$ De provaquer la eréation d'auvres, afin de ríaliser, dans son ensemble et ses détails, le programme de cette Lxposition;

$4^{\circ}$ De conseilier, de diriger tous les artistes, industriels, arlisans, ouvriers d'art qui réclaneraient ses avis.

Il serait indispensable de confier à cette Commission des pouvoirs absolus.

Organisation administrative. - L'Exposition serait organisée pal ın Comité supérieur et les Commissiuns déléguées, sous le contrile de l'Elat (Instruction Publique, Sous-Secrétariat, d'Etat des Beaux-Arts, Commerce, Trarail) et de la Ville de Paris, représentés par un Cummissaire gẻnéral.

Comité supérieur : Le Comité supérieur serait composé par tiers :

$1^{\circ}$ d'artistes, architectes el décorateursile toutes techniques;

$2^{\circ}$ d'industriels, fabricants, editcurs, entrepreneurs de travaux, auxquels devraicnt ètre adjoints quelques ingénieurs, des ourriers ut contremaitres de fahrieation;

$3^{\circ}$ d'écrivains, auteurs de livres traitant de l'Art décuratif, fonctionnaires et personnalités s'étant oceupés de questions d'Art décoralif modernt.

Ce Comité devrait étre nombreux, afin d'intéresser à l'Exposition le plus grand nombre de compétences et de bonnes volontés.

Le Comité supérieu étudielait toutes les questions de principe.

Seraient nommées dans le sein de ee Comité supérieur : 
$1^{\circ}$ Lne commission excutice: Elle serait elırgée de la réalisation pratique de l'kxposition, dans tous ses détails administratifs et financiers;

$2^{\circ}$ The commission de reception (Voir ci-lessus, partie artistique);

$3^{\circ}$ The commission dinstallation (1).

Organisation financière. - Budget: Les frais de l'Exp̣osition pourraient etre assures par' les versements des exposants, pour leur emplacement, et par des subventions avec affeetations spéciales, du Parlement, de la Ville de Paris, drs ununicipalités.

Les bénéfices, s'il en existait, pourraient être en partie attribués à des Sociétés ou curres s'intéressant à l'Al't décoratif et en partie ristuurnés aux exposants.

II serait créé un syndicat de garantie.

Emplucement: L'emplacement devrait ètre distribué pour les études de plan, au moins trois ans, et pour les travaux, au moins deux ans avant l'ouverture de l'Exposition. Cette Exposition aurait une durée de six mois, de mai à octobre inclus: les démolitions exigeraientégalement six mois : l'oceupation serait done de trois ans.

Le Grand-Palais et ses entorrs ne pourraient ètre occupés aussi longtemps. Retirer à la jouissance du public, pendant trois ans, l'Esplanade des Invalides scmble également impcssihle.

Restent les fortifications dont la dèmolition est projetèe, soit de la porte Maillot à la porte Daupline, soil de la porte Maillot à la porte Cluamperret.

La question devrait être résolue rapidement. Les travaux de démolitions seraient en effet assez longs, si leur adjudication est mise à bas prix, car il faudra laisser aux démolisseurs tous délais pour vendre les matériaux sur place. D'autre part, les talus ne sauraient suffire à combler les fostés; des apports de décharéc seraient nécessailes.

On peut envisager comme emplacements possibles et, dirons-nous, préferables, le champ d'entruînement de Bagatelle ou cclui d'Issy-les-Monlineaux, suit l'espacc ites foltifications compris entre la Muette et la polte du Point-du-Jour, soit même le pare de Saint-Cloud.

Signalerons-nous que nous avons de rastes hip'podromes à Lnngchamp, duteuil, Vineennes, Saint-Cloud, Champigny, Maisons-Laffitte, Enghien, Saint-Ouen, pour faire courir des ehevaux, et qu'il serait profondément attristant de ne pouvoir trourer un emplacement pour montrer les productions de nos Arts et de nos Industries françaises !

Nous ne doutons pas, d'ailleurs, que le Gonvernement et la Ville de Paris n'étudient ì question qui nous préoccupe avec la bienveillance la plus attentire. Elle ne concerne pas seulement l'Exposition projetée, mais en€ore toutes les Expcsitions spéciales ou universelles que la France pcut organiser dans l'avenir.

Conclusions: Comme on a pu le voip par la leeture de ce rapport, c'est la France entière que cette Exposition intélesse. Paris d'abord, et très immédiatement sa prospérité. Aussi, le Conseil municipal doit-il lui apporter son attention la plus zélée. Toutes nos provinces ensuite, tous nos grands centres de production, de lille ì Marseille, de Nancy à Bordeaux, Lyon, Toulouse, Roubaix.....

Pur la multiplieité des intèrêts qu'elle enveloppe, nombreux sont les départements ministériels auxquels elle vient se rattacher. Le Ministère de l'Instruction Publique et le sous-secrétariat des Beaux-Arts, le Ministère du Commerce, le

(1) Les sections étrangères auraient leur organisation administrative propre, fonctionnant sous le contròte de tuntoritẻ francaise. 
Mlinistère du Travial doivent la patronner directement. Les Ministères des 'l'araux publics et des Colonies y partieipent. Le Mlinistère des Affaires Étrangèeres est appelé à inviter les nations. Le Mlinistère des Finances ne pent en être désintérussé. Le Gonvernement tout entier' lui donncra done ses prèoccupalions attentives.

C'est pourquoi nous ne dontons pas que cette Exposition ne soit organisée avee le mème enthousiasme unanime dont a été saluée l'annonce de son projel.

Elle vienılra à son heure, et son plus grand suecès aura été de réaliser l'unité de l'Art el de la vie, en déreloppant un Art issu de la vie comme son expression immédiate, et qui, par un retour fécond, fera la vie plus harmonieuse, plus belle, meilleure à ètre vécue.

Vœux : Les Associations soussignées,

Préoccupées du développement de nos Arts décoratifs, titre d'une gloire séculaire pout la France,

Après avoil constaté que les conditions économiques acluelles renilent nécessaires pour nos Industries d'Ar't, source considérable de richesse nationale, l'élabılissement de modèles nouveanx et leur diffusion,

Estiment indispensable, pour stimuler les efforts des artistes, des industriels et des ouvriers d'Art, une manifestation internationale,

Spécialísée à tous les Arts décoratifs, appliqqués à l'arehitecture, au molilier et à la parure,

Réservée à des æuvres d'une inspiration nouvelle, à l'exelusion de tout jastiche on copie du passé.

Et, en consíquence, émettent lo sen que le Pallement et le Gouvernement, s'inspirant de ces considérations, décident l'organisation et l'ouverture à Paris, en 1913 , d'une Exposition internutionale des Arts decoratifs modernes.

\author{
Sociélé des Artistes lècoratcurs. \\ Sociètè des Artistes Francais. \\ Société d'Encouragement ì l'Art tet il l'Industric. \\ Socicté nationale des Beaur-Lits. \\ Société du Sulon d'A utomme. \\ Union centrale des Arts decorutifs. \\ Union provinciule des Arts dicorutifs.
}

Ont signé comme membres des bureaux ou délégnès des Sociétris ci-dessus énumérées, et sans que le nombre de reprèsentants de chaque Société soit proprortionnel à son importance :

Mn. Félix Aubfrir, membre de la Délégalion de la Sociélé nationale des Beaux-Arls. Henci-G. Benger, trésuriur adjoint de l'Union centrale des Arts décoratils.

Georges Boıs, trèsorier de l'Union centrale des Arts décoratifs.

Louis Bonnen, secrétaire-rapporteur de la Société des Artistes franegais, délégué de cette Société, directeur des Travaur de la Ville de Paris.

André Bourr.her, secrélaire de l'Union centrale des Arts décoratifs.

Ferdinand Bussson, député, viee-président de la Société nationale de l'Art à l'Ecole.

Van Brock, více-président de la Société d'Encouragementà l'Art et à l'Industrie et de la Société de l'Art ì l'Erole.

François C.triot, député, président de l'Union centrale des Arts décoratifs.

Chudist, secrétaire général de l'Union provineiale des Arts décoratifs.

Cocybı, sénateur, président d'honneur de l'Union provinciale des Arts décoratifs, président de la Société française de l'Art à l'École. 
Dswnouse, membre de la Délégation de la Société nationale des Beaux-Arts. Georges Desvalltires, vice-président du Salon d'Automne.

Max Defromas, membre du bureau du Salon d'Automne.

DсвиET, vice-président de l'Union provinciale des Atts décoratifs.

Maurice Dufnene, secrélaire de la Socièté des Artistes décoratenrs.

Tictor Dupus, directenr de l'lmprimerie Nationale, vice-président de la Sociélé de l'Art à l'lícole.

Paul Follot, trésorier de la Société des Artistes décorateurs.

Fintz-Jousbis, président do Salon d'Automne.

Gasouft, dirceteur de l'Enseignement au Ministère de l'Instruction publique, rice-présillent de la Société nationale de l'Art à l'École.

Giandigneiux, secrètaire délégué de l'Union provinciale des Arts décoratifs.

Clarles Gurns, membre du Bureau du Salon d'Automue.

René Gur.trus, président de la Société des drtistes décorateurs.

llector Gumsan, vice-président du la Sıciété des Artistes décorateurs.

Henri H.im, plésident Je la section des Arts décoratifs du Salon d'Automne.

Louis Hahant, trésovier de la Société d'Encouragement à l'Art et à l'Industrie.

Raymond liccillix, premicr vice president de l'Union centrale des Arts ilécoratils.

Géo Lamothl: secrétaire de la Société des Artisles décorateurs.

Lucien Liyus, premier vice-président de la Sociẻlé d'Encouragement à l'Aut et à l'Industrie.

Georges Lecomte, membre du Conseil supérieur des Beaux-Arts, nembre du Conseil d'Alministration de la Suciété nationale de l'Art à l'Ecole.

LEF'sure, secrétaile de l'Union centrale des Arts Décoratifs.

Camille l.fic̀vue, vice-président du Salun d'Automne.

Lhғылттк, vice-président de la Sociéte Nationale des Beaıx-Arts, président de la section des objets d'Al't.

Pierre Mancei, secrétaice de la Société d'Encouragement à l'A ‘t et à l'Industrie. Abert Marque, membre du burean du Salon d'Automne.

Roger M.srx, inspecteur général des musées.

Paul Mrzzari, vice-président de la Société des Artistos décorateurs.

Charles Pruset, vice-président du Salon d'Automne.

Perricion, membre du Bureau du Salon d'Automne.

Peytel, vice-président de l'Uaion centrale des Arte déeoratifs.

Edmond l'otrien, vice-présilent de la Société nationale de l'Art à l'École.

Victor Prouve, président de l'Union provinciale des Arts décoratifs.

Quevolx, vice-président de l'Union provinciale des Arts Hécoratifs.

Léon l’ioton, secrétaire géuéral de la Société nationale de l'Art à l'Écule.

Henry Rouson, président de la société d'Encouragement à l'Art et à l'Industrie.

G.-Finger Sandoz, secrétaire génélal de la Société l'lincouragement à l'Art it à l'lndustrie.

Olivier Sancère, vice-président de l'Union centrale des Aits décoratifs.

Henri Sauvage, membre du Burean du Saion d'Automne.

Fernand 'l'ussusk, membre de la Délégation de la Socićté nationale des Beaux-Arts.

Varinus, premier vice-président de l'Ĺnion provinciale des Arts décoratifs.

Emile Vrinirn, président d'honneur de la Socièté des Artistes décorateur's, membre de la Délégation de la Sosiété nationale des Beaux-Arts.

Henri Vever, vice-président de l'Union centrale des Arts décoratifs.

de IV sioovuen, secrétaire de la Socièté des Artistes décorateurs. 


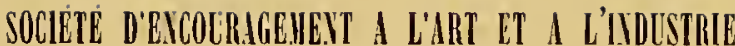

\author{
Assemblée Générale du 20 Juin 1911.
}

FX'PRAIT DU TAPTORT ANNUTL

Le souei de l'année qui vient ne nous empéche pas de songer à un avenir plus éloigné. Si tant d'elforts divers se produisent maintenant, si les initiatives les plus variées se manifestent, si les artistes et le publie sont d'accord pour sortir de la routine, il est nécessaire de gronper toutes les bonnes volontés, d unifier les effurts, pour éviter les pertes de foree qui naissent de la dispersion et pour hater une renaissance si importante pour le renom et pour la prospérité artistique de notre pays. Du moins quelques-uns de nous l'ont eru, et rutre seerétaire général au eourart de conversations qu'il a eues avee MNJ. Guilleré, Mezzara et Paul Follot, président, vice-président et trésorier de la Soeiélé des Artistes décorateurs, a envisagé avec ces Messieurs le projet d'organisar à Paris, vers 1913 , cette Exposition internutionale d'Art dicorati moderne dejà réelamée en 1906 par notre ami M. Couyba dans son Rapport sur Je budgel des Beaux-Arts, et si étudiée à plusieurs reprises en 1909 par notre éminent eollègue NJ. Roger Marx.

Il semble que eetie importanre question d'une Exposition internationale d'Art décoratif s’inpose plus que jamais à notre attention, en ce moment où notre distingué collègue M. le sénateur Emile Dupont a pris l'initiative de soumettre au gouvernement un projet éventuel d’Exposition universelle en 1920 à Paris. Nous avons ici le devoir de remereier H. Emile Dupont d'avoir eréé le mouvement d'opinion grice auquel les pouroirs publics et le pays se rendent enmpte, aujourd'hui, que la Franee doit prendre une décision, tant au sujet des Expositions unirerselles que des Expositions spéciales.

Dans sa séance du 28 mars, votre Conseil, sur la proposilion de NJ.J. L. Layus et G.-Roger Sandoz, a donné sa pleine adlıession au projet d Exposition internationale d'Art decoratif. Il a accordé tuns pouvoirs pour le suivre à MMI. II. Roujon, président ; L. Layıs, premier vice-président, ot G.-Roger Sandoz, secrétaire généra]. Une somme de 3000 franes a été mise à leur disposition au eas où une avanre de fonds serait nécessaire, étant bien entendu que la Société d'Encouragement à l'Ant et à l'Industrie n'agirait que d'aceord et solid.airement avee l'Union centrale et la Société des Artistes décorateurs, et que l'organisation éventuelle de ectto kxposition derrait passer, le moment v'enu, à un Cumité spécial d'organisation.

El vous vous rappelez, ehers Collègues, avec quel enthousilisme vous avez acrueilli, a la réunion qui suirit, le discunss de notre distingue sous-secrétaire d'Etat aux Beaux-Arts, M. Dujardin-Beaumetz, lequel, mis au courant, adoptait immédiatement ee projet.

Quelques grands journaux en comprenaient bien vite l'importanee et publiaient 
la lettre adressée par les trois Sociélés à M. Dujardin-Beaumelz en même temps que des interviews de nos Ministres de l'Instruction Publique, des Beaus-Arts, du Commerce et de l'Industrie, du Travail et du Rapporteur du budget des BeauxArts au Parlement. En outre, notre cher collègue M. Couyba laisait adopter par le Sénat un rœu favorable à ce projet.

Mais il fallait créer un grand monvement en faveur de ce projet d'Exposition internationale des Arts diccrutifs modernes. L'Union centrale, la Suciécé d'Encouragement, la Société des Arlistes décorateurs conslituaient, sous la présidence de M. Franģois Carnot, une Commission d'ctude qui faisait appel a toutes les bonnes volontés et condensait son travail en an Rrpport dù surtout à la plıme de MI. Guilleré, rapport qui vient de paraître et a élé distribué au Parlenıcn, à l'Administration, aux Municipalités, aux Chambres de Commelce, aux grands groupements syndicaux, à toutes les Associations et à toutes les personnalités intéresséts.

La discussion est aujourulhui ourerte sur ce rapport qui a éte signé par les délégués de toutes les grandes Associalions s'intéressant à l'Art, soit par ordre alphabétique :

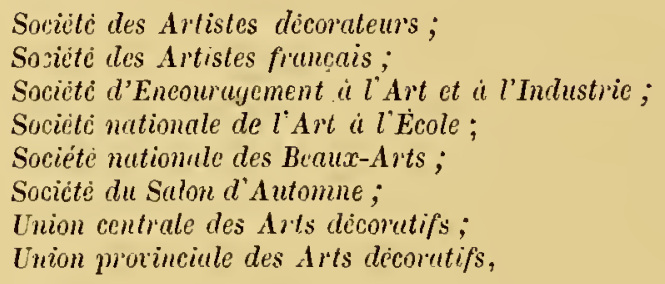

lesqueiles ont adopté les veux suivints :

"Les Associations soussignées,

"Préocupées du développement de nos Arts décoratifs, tilre d'une gloire séculaile pour la France,

) Après avoir constaté que les conditions économiques actuelles rendent nácessaires pour nos lndustries d'Art, soulce cousidérable de richesse nationale, l'élal,issement de modeles nouveaux et leur diffusion.

" Estiment indispensable, pou' stimuler les elforts des artistes, des industriels et des ouviers d'Alt, une manifestation internationale,

"Spécialisée ì tous les Arls décoratifs, appliqués à l'architecture, au mobilier et à la parure,

"Réservée à des cuvres d'une inspiration nouvelle, à l'exclusion de toule copie ou pastiche du pas: $\dot{c}$.

„E, en conséquence, émettent le væu qü le Parlement et le Gonrernement, s'inspirant de ces considérations, lécident l'organisation et l'owverture à Paris, en 1913 , dune Exposition internationale des Arts dicoratifs modernes. "

Ėu terminant notre rapport, l'an Alerticu, chers Cullègues et Amis, nous vous hisions combien nous désirions voir aboutir un jour te graniliose projet, et voici que sa réalisation s'annonce plus prochaiue que nous ne l'espérions. Soyons persévirants et tenaces dans notre effort ; restun: unis arec toutes les grandes As:ociations iutéressées; nul doute alors que nous n'atteignions notre but et que nous n'arrivions enfiı à réaliser dans notre chère l'rance cette collaboration si nécessaire de l'artiste, le linilustriel et de l’artisan.

G.-Roger Sandoz et Pierre Mancf.L. 


\title{
CHAMBRE DES DÉPUTÉS
}

\author{
$1^{\text {re }}$ séance du 6 dècembre 1911.
}

\section{Discussion générale du Budget des Beaux-Arts, Discours de M. Étienme Rognon.}

(Joumal Officiel du 7 dscembre 1911)

M. Etienne Rognon, - Nlessicurs, comme je l'ai fait l'année dernière, comme je serai probablement obligé de le faire l'année jroelıaine, je suis obligé de revenir encore sur la même question; je vais rous rechanter eetle vieille ehanson; si ell. ne vous amuse pas, je la rccommencerai quand mème, jusqu à ce que nous ayon: abouti enfin à revivificr un Art essentiellement francais qui, depuis le moyen âge jusqu'à nos jours, étaiı considéré comme l'apanage artistiłue de la Franee, je veux parler de l'Art décoratif. (Trés bien! Trés bien!)

L'annéc dernière, j'ai signalé eette situation lamentable. Elle n'a pas varie. Nous avons entendu de belles promesses.

Nous arnos tous recounu yu'il y arait quelque elıose à faire ct là se sont buirnié: nos manifestations. 11 est vaai que dans le rapport de cette année de M. Simyan il y a des propositions nouveiles en ce qui concerne la méthude d'enscignement général, appliquèe à ce que l'on dínomme le grand Art.

Pour mon compte, si je trourc intéressante son idéc d'introduire dans l'enseignement des Beaux-Arts des atelicrs indéjendants, je erois que nous ne pourons pas attendre de cette mesure le relèvement de l'irt décoratif en France; je crains fort - e'est un peu par expérience et par observation - que ectle pénétration des atelier's indérendants à eưté de l'enseignement offieicl de l'École nationale des BeauxArts n'ait pour conséquence sumvent d'exagérer tet de faire dévier dans une vois fausse des jeunes gens qui auront la pré:ention de se eroire plus forts que leurs pro-

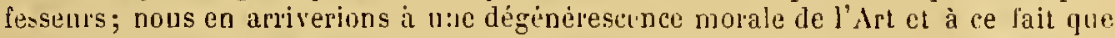
nous constatons aujourd'luui, trop sourent, ı) des élèves, qui auraieıt peut-être fait de trés bons ouvricrs de méliel, ne font que de maurais altistes produisant des axurres phiènoménales comme celles que nous avons vues aux lndépendants el à l'Exposition du Salon d'Automne (Trés bien! trés bien! sur dicers bancs. - Mourements divers.)...

Je considere que tout est à refaire au noint de vie lo l'enseignement de l'Art, comme dins l'euseignement en général.

On se tromje ètrangement el c'est sonvent parce que ceux qui disculent de cas. guestions n'unt malheureusement pas récu assoz de la vie de métier.

Si on arrirait à ce résnltat que le professcur s'en tienne purement et simplement il l'euseirs ement de l'Art, s'il reslait professeur dans son ceale, ec serait plus desalstreux eneore, à mon avis.

L'Allemagne a fait l'cxpéricnce - et elle la fait tuus lés jour's - que l'enseiguement artistique ne peut être séparé de l'enseignement pratique quotidien. Dans 
les admirables écoles d'Allemagne, dans les étales de Munich où l'on donne un enseignement de métier, un cnseignement artistique, les professeurs, les contremaîtres sont eu mẻme temps obligés de fournir un travail dans les ateliers, afin qu'ils ne perdent pas contact arec la prouluetion journalière.

M. Jarrès. - C'est ce contact arec le métier qui a fait la grandeur des artistes dans le passé. (Trés bien! très bien!)

M. Etienni Rogion. - Autrement, l'enseignement devient ce que rous constatez, un enseignemeut de classe. tie sont toujours les mènes jrofesseurs qui forment les mèmes èlèves, et ces élèves, à leur tour, en formant d'autres, cet enseignement retourbe ì l'enseignement ancien.

Vous voulez mnderniser lenseignement des Beaux-Arts. Il faudrail pour cela le prprendre tout entier à la base.

Il ne faudrait pas ecée cette division qui existe non seulement dans les esprits, mais dans les matières, dans les programmes.

II ne faudrait pas déclarer que l'Art décoratif est un Art inlérieur : on l'a préfendu el on le prètend encore. (Trés bien! Trés bien! a l'extréme gauclee.) Ét il ne futudrait pas que les prólesseur's, membles de l'Institut, qui consaerent de liaut l'Art français, et qui n'admettent que l'Art conforme à leurs doctrines, séparent l'Art décoratif de ce qu'ils appellent le grand Art. (Tres tien! trés bien!)

Pour nous, je le déclare nettement, nous sommes partisans de l'Unitéd'Art. Il ne jeut y avoir deux Arts, il n'y en a yn'un seul... Et ceux qui prétendent que l'Art decoralif est un Art infierieur, ignorent précisement qu'il a permis aux architectes auciens de construire des monuments carrespondant aux besoins et aux nécessités de la vic de leur époque. Aujourd'hui, au contraire, nous assistons à ce spectacle limentable que des architectes ne connaissant que la décoralion estérieure, ne connaissant que le dessin, ne sachant pas, comme je le disais l'an dernier, utiliser les matériaus qu ils ont à leuc disposition, ne sarhant pas tirer parti des inventions modernes et des dernières découvertes, et négligeant les ressources qu'elles leur fourniraient, funt des constructions qui sont en contradiction flagrante avec le bon sens architectural et qui heurtent la logique décorative...

Si l'enseignement était donné dans un sens pratique, nous naurions pas á faire de ces constalations lamentables, nous n'en serions plas aujourd ’hui à déplorer que l'Art décoratif soit en France dans une situation inférieure à celle où jl deviait être. Yous avons d'autant plus it nous en préoceuper que, sourent, ici, on vante aree ruison l'action merveilleuse du gónie flancais. Mais lorsqu'on a eu l'occasion de se Iromener hors de France, lor'squ'on a constaié ce qui se fait à l'étranger, on est obligé de le signaler afin que notre pays ne reste pas plus longtemps indifférent, qu'il réagisse el sorte de sa torpeur. Ceux qui, en France, ont la direction et le contrible de l'adanistration de l'Alt, ceux qui peurent agir par leur puissance administrative et par l'autorilé de lenr fonction, doivent nous entendre.

L'Allemagne a lait des ellorts considérables en matière d'Art décoratif. J'ai, il y 'quelqnes années, visité ane Lxposition très intéressante d'Alt décoralif à Municlı'. On y voyail réunis un ensemble de documents des plus curieux, depuis le mobilier de cuisine jusqua'au mobilier de Iuxe et mème des reures de ce qu'on est conrenu d'appeler le grand $\mathrm{Art}$; on y voyait aussi comnent l'enseignement du dessin est donné depuis les classes enlantiiies de l'école prinuaire, dans un sens rationnel et fratigue, basé, nor sur les vieux systèmes, mais sur lobservation de la vie quolidienne, des ohjets usuels, sur la reproduction des choses réenes, des choses vues.

Cela a une importance consiılérible, parce que cela permet à l'enfunt de développer ses facultés, de clıercher autour de lui ce qu’il y a d’intéressant, de grouper les ducuments qui lui premetront plus tard de decorer son inlérieur et de reposer zes yeux sul des objets de bon guòt. Si, dès ses jeunıs annérs, vous donnez à l'enfunt une éducation artistique, rous développez en lui le désir de recliercher et de 
comprendre le bearr, de fuir et de détester le laid. C'est ainsi que l'on forme l'údueation artisligue ef morale d'un peuple.

Je sais que l'on prépare pour 1913 une grande manifestation artistique, une Exposition d'Art décoratif. Nais comme toujours - et j'en eausais dernièrement avee M. le sous-secrétaire d'Etal - celte manifestation va avoir lieu à Paris. Nous nous sommes plaints maintes fois, et nous nous plaindrons longtemps encore sans doute, de eette centralisalion à outrance, qui se produit dans toutes les branches de l'activitc nationale et qui se manifeste d'une façon toule particulière dans le damaine artistique. Nous regrettons et nous regretterons eneore qu'on ne suive pas l'exemple des ltaliens et des Allemanls, arec leurs Expositions de 'Turin et de Municls.

la première objection que vous allez me faire, e'est que les rilles de Munich, de 'l'urin sont des capitales d'A't et que Rome, par exemple, n'est pas essentiellement une capitale d'Art comme l'est Paris pour la l'rance.

Maisenfin, il y a, dans ce pays de France, des cités, des villes, des centres artistiques qui, depuis des siècles, ont donné la preıve de leur atlachement ì l'Art décoralif.

Je ne rondrais pas parler plus particulièrement de celle que j'ai l'honneur de représenter; mais il y a tout de mème des villes comme Nancy, Lyon, Toulouse...

M. Cimarles Benorst. - Et Rnuen!

M. Ėturne Rogran. - ... et liouen, qui ont été, depuis des siècles, le berceau de manifestations artistiques et qui ont conservé un patrinone d'Art déearatif qui leur est prapre.

Ėt si vous vouliez faire réellement la grande manifestation d'Art que vous plojelez, si vous vouliez rénover l'Art déeoratil en France, il ne faudra pas organiser un grand bazar internalional. (Trés bien! tres bien! sur direr's bancs.)

Daus tous les cas, monsieur le Ministre, permettez-moi do rous le dire, il est nécessaire de prendre ros précantions fıour que l'Exposition des Arts décoratils, si vous la faites à Paris, ne sorte pas de son cadre et pour qu'elle soit nettement délimitée.

II ne faut absolument pas que celte manifestation soit pour les entrepreneurs une occasion de faire tout autre chose qu'une Erposition l'At't decoratif. (Trés bien : trés bicn!)

Certes nous sommes partisan de l'ouverture de cette Exposition, mais je sais qu'en insistant pour obtenir le bénéfice de celte manifestation en faveur de ma ville natale et que j’ai l'honneur de représenter, je soulèverais immédiatcment les protestations de représentants d’autres régions. (Dèncigutions sur dicers bancs.)

M. Junnìs. - Non; nous sommes prèis à appugyer Lyon, pour le bon exemple.

M. Etienne Rogron. - Il vous est loisible, monsien le sous-secretaire d'Etat, d'examiner la question.

Dans tous les eas, je garde sur ce point mes idées et mon opinion.

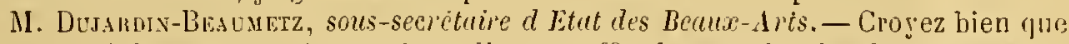
nous ne nigligeons pras la province. il me suffit de rappeler les Expositions de 'Touresing el de Roubaix, pour vous donner la preuve que l'Art décoratif n'a pas éfé négligé. Je serais très heureux qu'il pùt y aruir des expositions de ce geure à Lyon, à Toulouse, à Lille, dans tous ces grands centres artisliyues et dans bien d'autres enco:c. (Tris lien! trés bien!)

M. Enouaro Ninon. - Ar Puy, par exemple, célèbre par sez dentelles.

M. Le Sors-Sechersike n'Etat. - On jourrait y faire, en elfet, une admirable exposition de la dentelle.

N. Ethenve lingson. - S'il est intéressant de soulerer le point de savoir quelle sera la rille qui hénéficiera de la grande Exposition de 1913 et si l'on tient compte de la réponse que rous m’arez faite, Monsieur le sous secrétaire d'Etat, de ne pas 
négliger les rilles de provinee, il n'en ressort pas moins que cette grande manifustation d'Art, l'unique en ce genre, et la première qui se fera, aura comme théâtre, comme centre d'action, Paris. Vuus renez de vous engager en laissant entendre clairement que la première mani!'estation artistique, la grande Exposition de $1913 \mathrm{~J}$ iura lieu à Paris.

11. Le Socs-Sichitane n'Erat aux Beaux-Arts. — Le Gouvernement n'a rien décidé encore quant à l'Exposition de $191 \ddot{3}$.

M. Etienne liognon. - Monsieur le ministre, permettez-moi justement d'attirer tout particulièrement votre attention sul ce point. Paris est le centre indiscutable les grandes manifestations d'Art franęilis; il y a lans nos musées des collections admirables. Mais le but que vous visez, cn faisant une Exposition d'Art décoratif, n'est pas simplement de démuntrer que Paris est une capitale d'Art, e'est aussi de prouver que la France entière est une capitale d'Art. que, dans toutes nos régions, lans les coins les plus recules de la France, dans ces pay's montagneux de l'Est, il y a iles centres où l'Art n'est pas né:-ligé.

Il y a des villes admilables, comme Besanȩon, Moret, qui sont perlues dans le Jura, où on fait des elıoses extrèmement intéressuntes. Il y a Ies régious, comme la région lyonnaise, qui, depuis des siècles, ont une production artistique des pius remarquables, où tout un monde très intéressant vit de la produetion des tissus.

Si done rous fai:iez ectle premièrc manifestation d'Art en province, rous auriez accompli ce qu'ont fait les Allemands : un peı de décentralisation artistique. Vous permettriez à ces villes, à ces régions, de se reconstituer. Vous clonneriez un nouvel essor à cet Art régional qui a disparu. (Trés bien! trés bien!)

L'admirable Art lorrain, qui ne vivait plus que dans ses musées, a été rclevé, on peut le dire, grâce au conrage et à l'ardeur des Gallé, des Prouvé; mais enfin ce sont des manifestations isolíes qui ne pourraient sc fortitier, s'augmenter qu'à la condition que lion essaye de faire de la décentralisation, et les seules manifestations qui puissent faroriser cette décentralisation, ce sont los Expositions d'Art décorati dans les centres provinciaux. (Trés bien! trés bien!)

Voilà ce qu'il faudrait faire, et non pas toujours grouper et réunir à Paris toutes res expositions.

Que ronlez-rous? Je ne puis que rester et je resterai un provineial, considérant Iue e'est par la province que Par'is est devenu liche, que Paris s'est développé.

M. Cualles Bfyorst. - Il y a tout de même bien eu quelques Parisiens de Paris.

M. Etiexse Rogxox. - Je ne dis pas que ec sont uniquement des provinciaus qui ont formé le cuntingent intellectuel de la ville do Paris, mais je dis que souvent des Francais sont considćrés el consacrés commc étant des Parisiens qui n'ont que d'humbles origines provinciales.

Il n'est pas nécessaire de démontrer davantage combien il scrait intéressant pour l'Art décoratif, de faire cette première grande manifestation de l'Art décoratif que fera la prochaine Exposition, en province plutôt qu'à Paris....

[II. Etienne Rognon cite alırs plusienrs lettres à lui adressées, notamment de Mx. le Baudot, au nom de l'Union syndieale des Architectes francais, Lucien T'issié, secrélairc général de la Soeiété libre des Artistes français, René Guilleré, président de la Société des Artistes décorateurs, Frantz Joulduin, président du Salon d'Automne, qui approurent les eritiques qu'il a faites de l'enseignement officiel des Beaux- $\boldsymbol{\Lambda} \cdot \mathrm{ts}$.]

Il faut faire l'unité dans l'Art, il fant surtout que les hommes qui seront pilus tard des peintres, des architcctes, des sculpteur's, soient bien des hommes aptes à faire leur méticr, que cos hommes ne soient pas dirigès vers tel ou tel métier parce que la situation de leurs parents le leur permet nu paree qu'jls ont été poussís par un désir personnel; ce n'est pas ainsi q̨u'on fait des artistes; c'cst en procédant à 
une refonte de l'enseignement à la base, c'est en obligeant les gens à connaître leur profession, c'est en obligeant l'architecte à être un ouvrier de métier, mais c'est surtout en mettant la profession d'architecte - je l'ai déjà dit l'année dernière - à la base de toutes autres pour faire des hommes d'art...

... Il est indispensable que l'on approfondisse d'une facon plus terre à terre la situation lamentable qui résulte de la division du grand Art et de l'Art décoratif.

Vous ne réaliserez aucun progrès, tant que vous n'aurez pas réuni ces deux branches de l'Art, tant que vous ne vous serez pas rappelé que ce qui a fait la puissance de la production artistique du pays au moyen âge, c'est que les hommes qui contribuèrent à la construction des monuments étaient des ourriers de métier qui connaissaient la pratiqne et la matière, tandis qu'à l'heure actuelle, dans les écoles des Beaux-Arts, on n'apprend presque jamais le travail de la matière, la pratique des métiers. (Trés bien! trés bienl)

Véritablement, cette situation est angoissante, elle ne peut durer. Ce n'est pas tout de venir manifester, de Jéplurer la situation lamentable dans laquelle se trouve l'Art décoratif, il ne suffit pas de faire des déclamations à une tribune; il faudrait qu'enfin le pouvoil responsable prît un peu en mains les doléances de ceux qui signalent cette situation, qu'on essayât de réagir et qu'on fit un effolt dans ce sens.

Messieurs, il y a un point sur lequel l'année dernière j'avais appelé l'attention de M. le sous-secrétaire d'Etat les Beaux-Arts. J'avais demandė où en t́taient les travaux du conseil supérieur ıles Arts décoratifs. MI. le sons-secrétaire d'Etat m'a répondu que le conseil supérieur ne s'était pas encore réuni. Je ne sais pas s'il s'est réuni ou s'il se réunira; en tout cas il ne fonctioune pas... 


\title{
CHAMBRE DES DÉPUTÉS
}

\author{
DIXIÈME LÉGISLATURE
}

SIISSION DE 1012

Annexe au procìs-verbal de la séance du 6 Février 1912.

\section{PROPOSITION DE LOI}

\author{
tendant à organiser en 1915, à Paris, une Exposition internationale \\ des Arts décoratifs modernes. \\ Présentée par MM. François Carxot, Pabl-Boscorr, Henry Cocuns (Nord), \\ Charles Demoxt (Jura), Massé, Noulexs, Puegh, Joseph Rieracil, \\ Sembat, Sibille, J. Tulerry, Arxard, Dépulés.
}

(Renvayce à la Commission du Commerce el de l'Industrie)

\section{EXPOSE DES MOTIFS}

Mrssiecrs,

Depuis plus d’un demi-siècle, la tradition sétait établic d'avoir à Paris, tous les onze ans, une Exposition universelle internationale. Nous navons à rappeler ici ni les splendeurs de 1889 et de 1400 , ni les vives critiques ansquelles donnèrent lieu ces gigantesques kermesses, où l'effort de toutes les industries du monte entier veuait se présenter dans une multiplicité de productions qui dépassait les limites de l'imagrination el excédait la force d'attention de l'esprit humain.

Cette tradition aurait appelé une nouvelle manitestation en 1911. Mais, lorsque, devant le Pallement et devant l'opinion publique, la question fut posée de savoir s’il fallait la réaliser, la presque unanimité des personnes ou des collectiritís consultées se prononẹ: pour la négativs. Lassitule des visiteurs, dépenses excessives; augmentation continuelle de la sulface nécessaire s'aggravant encore du fait de la diminution des espaces libres, tous les arguments porlaient a celle conclusion : " Te faisons plus d'Expositions universelles, qui ont cessé d'étre réalisables, t't pollons désormais lous nos efforts vers des Expositions sélectionnées et spicialisé. 
Or, il est iacontestable que, pour inaugurer à Paris ce nouveau type d'Exposition, la sprécialité dans laquelle peut el duit s'aftimer encore la supériorité traditionnelle de la France, e'est l'Art décoratif dans toutes ses apulications, c'est l'ennoblissement ducadre et des accessoires de la vie individuelie ou collectivemoderne.

C'est done une Exposition internationale des Arts décoratifs modernes dunt nous renons demander au Parlement de décider l'organisation à Paris en 1915 .

Pourquoi cette spécification: Arts décoratifs modernes? Pourquoi cette date : $1910 ̈$ ?

Nous voulons les justifier.

Quelque admiration protonde et légitime que méritent les Arts décoratifs francais du dix-septieme et du dix-lıuitieme siecle, quelque gloire que notre pays en ait tirée, il serait absurde et injuste de prétendre que les formules diverses fournies par eux sont l'explession définitive répondant dans le jrésent et même dans l'arenir à tous les besoins artistiques de la vie. Dans les Beaux-drts proprement dits, dans la peinture, la sculpture, la musique, ne rovons-nous pas apparaitre constamment, dans une entraìnante évolution qui est à l'honneur de l'Art francais, des artistes dont l'reuvre vient à son heure pour répondreà des aspirations sans cesse évoluant elles-mêmes? Les Arts ne vivent pas de plagiat $\epsilon 1$ de copie, et ce n'est pas méconnaître et oublier les gloires des siẻcles passés quo d'applaudir ¿ des œurres neuves; notre admiration pour Rodin, pour d'Indy, pour Besnard, n'est pas une injure pour Houdon, pour Beethoven ou pour Wratteau.

Pourquoi en serait-il autlement en Art appliqué à l'Industrie? Ne voyons-nous pas laut ce qu'il y a d'incuhérent à vouloir enfermer l'existen:e individuelle on sociale moderne, si transformée nar l'évolution de la science, dans un cadre créé pour un grand seigneur du dix-lutième siècle? Ne sentans-nous pas tout ce qu'il y a de dangereux et d'injuste lans l'espèce de suspicion jetée sur tout ce que notre pays renferme d'artistes décurateurs et d'ouvriers d'art, lorsque nous laissons affirmer que l'Arl ancien seul existe, qu'il n'y a ras d'Alt moderne, que la source de la puissance créatrice est tarie et qu'il nous faut vivre désormais de pastiches et de copies?

Une telle injustice serait imméritée. L'lıeure est venue d'en faire la démonstration, et toute une gínération nourelle d'artistes attend avee impatience que vous lui fuurnissiez l'occasion de faire sos preuves aux yeux de toute l'Europe.

Prenons garde, d'ailleurs, cu'en attendant trop longtemps, nous laissions les autres nations s'emparer de ce qui fut si longtomps note monopole artistique. Nous avons déjà laissé à l'Italiu l'honneur d'avoir organisé en 1902 la première Exposition internationale des Aris décoratifs mo lernes, bannissant les imitations d'anciens atyles et les productions dénuées da varactere artistique. A la suite de I'Italie, tous les autres pays ont organisé de grandes Expositions nationales d'Art décoratif moderne; à Munich, à Sluttgard, à Stockholn, à Copenhague, à Vienne, avec méthode et continuité, les diverses nations out montré les l'ésultats menacants de leurs efforts de création. L'Angleterre, l'Allemagne, l'Autriche, la Hollande, la Belgique, les pays scandinaves on l leurs styles madernes, et dès à présent sont outiliés pour leur production à bon marché; ils nous envahissent, atteignent notre clientèle, importent mème ehez nous des quantités consilérahles de produits de leur Art décoratif nouveau, et ils prennent sur notre propre marché le monopole de l'Art moderne.

Il faut réagir énergiquement et sans perdre une heure, et c'est la raison pour laquelle nous insistons auprès du Parlement, pour que cette manifestation dont nous attendons le salut de notre $A r t$ décoratif moderne et de nos industries d'Art, ne soit pas retardée au delà de $191 \ddot{\text { ż. }}$

Tuutes les sociétés s'accupant exclusivement d'Art décoratif, ainsi que nos trois grands Salons annuels, se sont émues de cette grave situation. 
Leurs représentants qualifiés, réunis au mois de juin 1911 an Pavillon de Marsan, adoptaient à l'unanimité un rapport qu ils adressaient aux pouvoirs publics.

Ce rapport se résumait dans le vœu ci-après, sur lequel nous appelons toute l'attention du Parlement:

"Les Associations soussignées,

) Préoccupées du développement de nos Arts décoratifs, titre d'une gloire séculaire pour la France,

"Après avoir constaté que los conditions économiques actuelles rendent nécessailes pour nos industries d'art, solirce considérable de richesse nationale, l'établissement de modèles nouveaux et leuı diffusion,

) Estiment indispensable, pour stimuler les efforts des artistes, des industriels et des ouvriers d'art, une manifestation internationale,

"Spécialisée à tous les Arts décoratifs, appliqués à l'architecture, au mobiliel et à la parure,

1) Réservée à des œuvres d'une inspiration nouvelle, à l'exclusion de loute copie ou pastiche du passé, et, en conséquence, émettent le vœu que le Parlement et le Gouvernement, s'inspirant de ces considérations, décident l'organisation et l"ouverture à Paris, en 191 ö, d'une Exposition internationale des Arts décoratifs modornes.

") Sociète des Artistes décorateurs ;

"Sociëti des Artistes franẹis;

"Socièté d'Encouragement à l'Art et à l'Industrie ;

") Socièté nationale de l'Art à l'École;

) Socicte nationale des Beaux Arts;

"Socièté du Sulon d'Automne;

"Union centrale des Arts décoratifs :

1) Union provinciale des Arts decorutifs."

Nous faisons nôtre la conclusion de ce vou.

Et, on conséquence, nous vous demandons de voter la proposition de loi suivante:

\section{Proposition de Loi}

Article unique. - Une Exposition internationale des Arts décoratifs modernes sera organisée à Paris en 1915. 


\title{
EXPOSTITOI INTERIITIDELLE DES IBTS DECORITIFS HODERIES
}

\author{
projetée à Paris.
}

\section{COMMISSION D'ÉTUDE}

\section{Rapport présenté le 28 mars 1912 par la sous-commission financière.}

\author{
Munsteuli la: Présinfint,
}

Messieuns,

Votre sous-commission financière a tenu deux séanees les 13 ct 20 mars 1912 , sous la présidence de M. G.-Roger Sinnoz.

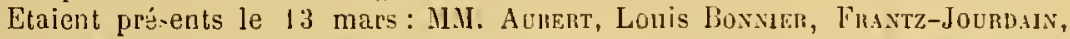

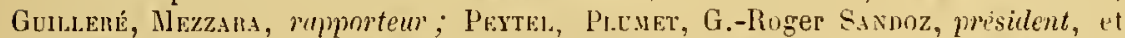

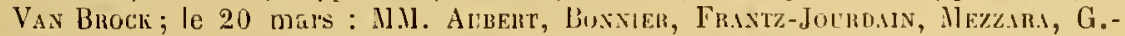
Roger Sandoz et Van Buock. Ml. Robran, député, rapporteur du projet de lui présentí par M. Francois Canrot et ses colleggues, a bien ruulu ussister i cette seconde scance.

M. Pifri remplissait les functions de secrétaire.

Des idées échangées et des inlormations reçnes il résulte que l'état actuel de la question, sous ses différents aspects, est aujourd'hui le suivant :

Marche des études préparatoires. - Le rappurt de M. le député Roblin sera déposé à la rentrée des Cbambres. Il espère que le projet pourra ètre adopté avant la clôture de la session. Le Parlement ne peut voter que le principe de l'Exposition. Il appartiendra au Gourernement de présenter ensuite un autre projet de loi relatif aux voies et moyens. Le rapporteur doit se borner à suggérer des solutions et à faire voter to principe (M. Roblin).

Date. - Il fandıait adopter la date de 1916 , caren 19130 aura lieu l"Exposition de San-Francisco (M. G.-Roger Sandoz). Si la seconde loi est votée avant la fin de l'année, on aurait le temps nécessaire pour l'exécution des travaux (M. Bonnier).

Emplacement. - ll faut un emplacement de 20 hectares environ avec des acces faciles. Si lon adopte les fortifications, le terrain proposé entre les portes d'Auteuil et de Saint-Cloud, avec la partie de la zone militaire entre les portes Molitor et de Saint-Cloud, parait être l'emplacement le plus favorable. Aucun autre ne présente les mêmes avantages. Mais l'occupation de ce terrain dépendra de la réussite des négociations en cours entre la Ville et l'Etat. La question fuit des progrès et une solution favorable peıt êtl'e espérée avant la fin de l'annéce, tant pour les fortifications que paur la transformation de la servitude militaire en servitude sanitaire (M. Bonnier). Au reste, on pourrait pent-être obtenir, dès la solution des négociations, un arrangement à l'amiable permettant ì la Ville de prendre possession de la partie des terrains nécessaire à l'Exposition, ainsi que de celle destinée à l'agrandissement des Abattoirs. 
Iais il ne fant pas nous dissimuler l'importance de celle question d'emplacement. C'est d'elle que dípend la rúussite de I'Exposition projetée, ct la Commission d'étude préférerait que la Ville revint sur ses premiéros idées et nous accordảt un cmplacenent tont prè̀, tel que le Champ d'Entraioement de Bagatelle que viendrait compléter l'île de Puleaux.

Importance de l'Exposition. - Elle parait intéresser trente-trois industries rui ont été reprisentées chacune par une elasse à l'Exposition de 1900 (M. Nezzara). Il faudra naturellement tixer une limite à l'espace réservé aux sections étrangères (M. F'antz-Jourdain). L'Expasition doit servir d'ensoignement ct d'ellcouragement pour l'avenir, et réveiller l'osprit I'initiative et d'entente des artistes, des industriels, des arlisans el des ourrier's d'art (MM. Guilleré, Van Brock, etc.).

Construction. - On ne pourruit èlever des palais définitifs devant servir aux Expositions futures (II. Plumet, MI. Bonnier). Il faudrait, en effet, des erédits trop élevés; ce serait engager l'avenir et répondre mal à l'intention des promoleurs qui s'efforcent de ranimer l'évolution artistique française.

Lien moral avec l'Exposition de 1920. - Peut-ìtre serait-il bon. surtout si l'Exposition des Atts decoralifs modernes a lieu sur les terrains des fortifications, yu'un lien moral existat entre le projet qui nous occupe et celui de l'Exposition d'Economic suciale proposée pour 1920 a l'occasion du Cinyuantenaire de la République (N. G.-lioger Sandoz). Une partie des travaux (terrassements, halls) pourrait servir, mais il ne faudrait pas construire les palais en vue de leur utilisation ultérieure (NI. Plumet et M. Aubert). La large place accordée aux industries rurales fournirait une excellente préparation aus Expositions régionales projetées aussi pour 1920 (.I. Roblin). Ce lien noral peut, cn ellet, intéresser le Parlement et les municipalités.

Organisation administrative. - La direction générale appartiendrait au Mioistère du Commerce, d'accord avec la Ville de Paris et les Ministères des BeauxArts et du 'T'ravail. Les autres Ministères : Instruetion publique, Finances, Affaires Etrangères, Colonies, Travaux Publics, ete., y seraient inléressès, clracun en ce qui le concerne.

L'Exposition serait a la fois officielle et en partie autonome, utilisant cette union de l'Etat et de l'Initiative privée qui a si bien réussi prour l'organisation des Sections francaises dans les Expositions à l'Etranger.

L'Administration supérieure de l'Exposition serait confiée à un commissaine général ou à un directeur général assisté d'un haut Conité de patronage, comprenant toutes les notabilités intéressées, et d'une Conmission supérieure exécutive de nombre limité qui assurerait la rigoureuse exécution du programme. Cette Commission exécutive se composerait par tier's d'industriels, d'artistes et de personnes competentes.

Chaque groupement aurait à sa tête un comité spécial composé par tiers des mèmes éléments.

Projet de budget. - Il ne pent ètre que très approximatif. On peut calculer l|u’il s'élèverait it environ $13 \ddot{3} 00000 \mathrm{fr}$.

En dépenses. - Administration : 9000000 fr. - Installation générale : $1710000 \mathrm{fr}$. - Constructions : $3800000 \mathrm{fr}$. - Aménagement et décoration : $830000 \mathrm{fr}$. - Exploitation : $1520000 \mathrm{fr}$. - Publicité et attractions : $1813000 \mathrm{fr}$. - Encouragements el sulventions : $1873000 \mathrm{fr}$. - Imprévus : 1000000.

En recettcs. - Concessions : 1200000 fr. - Entrées : 3000000 fr. Subvention de l'Etat : $8000000 \mathrm{fr}$. - Subvention de la Ville de Paris : $1250000 \mathrm{fr}$. (MN. G.-Roger Sandoz et Mezzara). 
Ce projet de budget vise surtout l'emplacement des fortifications. Ciest pourquoi la somme demandée à la Ville de Paris est trés minime, car ıl semble qu'elle doive prendre d'abord à sa charge les premiel's travaux de mise au point des terrains, des fortifications et do la zone, beaucoup de ces travaux étant déjà prévus dans le jrojet général de la Ville.

Si l'Exposition avait lieu dans un autre enclroit, tel que Bagatelle et Puteaux, la subrention de la Ville derrait naturellement ètre plus importante.

Les travaux devraient être exécutés sous la direction des hants fonetionnaires de la Ville (M. Frantz-Jourdain, ete.).

Considérations financières. - Une kxposition largement eonegue dans un but d'intérèt général cluit être faite principalement aux frais des pouvoirs publies, qui en recueilleront ultérieurement les bénéfices.

Quant aux exposants, il faıt leur donner le tertain gratnitement, comme dans les précédentes grandes Expusitions, d'autant plus que leurs l'ais, déjà très grus d'habitude, scro:at eneore plus ćlevés cette fois-ei.

La sous-commission a.examiné aussi les combinaisons financieres précéclemment empluyées, mais il semlile que les loteries et émissions de bons doirent èlre éeartées, les dernières expérienees ayant été défavorables (MII. Peytel et Vau Brock).

Il $\mathrm{y}$ an rait Jien cependant d étudier une combinaison avec les nntabilités finaneières et les grands établissenents, notamment pour l'ashat immédiat et la revente ultérieure des terrains si l'emplacement choisi était aux fortifications (M. Peytcl).

Rapports avec les Syndicats industriels. - La Commission a actuellement obtenu l'accord complet entre les dillél'enles Sueiétés arlistiques. Eille doit maintenant réaliser l'entente des Associations artistiques avec les Chambres syndieales, en s'adressant à leurs présidents et aux chefs des industries d'art.

M.M.G.-Roger Sindoz, André Bouilluet et Guilleré ont en un long entrelien aree M. Pérol, président de la Chambje syndicale de l'Ameublement et présilent des Salons du Nobilier. D'après cette conversation très cordiale, il semble que l'aecord cherché sera beancoup plus facile que d'aueuns le croient. Le Président de la Glıambre syndicale de l'Ameublement est loin de se montrer hostile au prajet. If aurait cependant préféré voir les comités et jurys componsés par moitié d'industriels et d'arlistes sous l'adjonction d'autres personnalités. Nous espérons que les noms proposés le rassureront puisqu'ils représentent un gage d'impartialité.

Aussi bien, il existe de la part de certains industriels un malentendu sur le mot " moderne " qui pour eux s'applique au style en partie démodé de la fin du dixnenvième siècle. Mais il a bien été stipulé que le programme de l'Exposition veut l'évolution de la Décoration et des Arts appliqués à l'Industrie et non l'imposition d'un style officiel (MM. G,-Roger Sandoz, Guilleré et André Bouilhet). Quant à l'inspiration du passé, on ne peut jamais l'écarter complètement; seuls, derront ètre rejetés la copie ou le pasticise des styles anciens. Sur ce point, aucune concession ne doit être faite (MM. Aubert, Frantz-Jourdain, ete...).

La Clambre syndicale de l'Ebénisterie va ctre eonvoquée par son Président pour lui transmettre sa conversation arec les délégués de rotre Commission. Il en est de mème de la Chamble syndicale de l'Orfèvrerie-Bijouterie-Juaillerie, dont le Présideni, M. Paui Templier, a longuement causé arec M. G.-Roger Sandoz. M. Tenplier adhère d'autant plus au prineipe de notre projet, que, eomme uons, il approuve complètement la suppression des Expositions internationales universelles de Paris et leur remplacement par des lixpositions spéeiales internationales ayant lieu tous les quatre ou einq ans. Il ne fait de réserves que sur les question; de détail et d'organisation.

Quant aux autres Syndicats, nuus n'arons pas enrore pu les consulter. 
Pour résumer, il parait à rotre sous-commission qu'il y a lieu aujourd'hui :

$1^{\circ}$ De demander à M. le député lioblin, suivant son aimable intention, de déposer le plus rapidement possible son rapport concluant à l'adoption par le Parllement du projet de loi cléposé par M. François Carnot et ses collègucs, en faveur l'une Exposition internationale des Arts clecoratifs modernes à Puris en 1916;

$2^{\circ}$ De prier la Ville de Paris de réioudre la si importante question de l'emplacement, qu'il soit pris soit sur les terrains des fortifications, soit dans un autre endroit tel que le champ d'entraînement de Bagatelle;

$3^{\circ}$ De demander au Gouvernement d'étudier le plus tôt possible la proposition le votre Commission d'itude sur l'organisation génèrale proposée par elle;

$4^{\circ}$ De continuer les négociations avec les principales corporations intéressées et J'inviter leurs ehefs à une jrochaine conversation arce les dẻlégucis de votre Commission, pour arriver arec eux à l'entente et à l'accnrd díjict réalieés entre nos direrses Associations artistiques.

\section{Lc Rapporteur,} P. Mezzara.

\section{CONSEIL MUNICIPAL DE PARIS}

\section{Compte rendu de la séance du Mardi 2 Avril 1912.}

\section{3. - Vœu relatif à l'organisation, à Paris, en 1915, d’une Exposition internationale des Arts décoratifs modernes.}

M. Louis Dausset. - Nessieurs, s’il est une Jranche de l'activité artistique où la France doive conserver le prenier rang, c'est, sans contredit, l'Art décoratif.

Le passé glorieux qu'a notre pay's dans ee domaine lni fait une obligation d'y maintenir tout son renom sous peine ie déchoir. Or, il nous fant bien l'avouer, depuis plusieurs années la production artistique française dans l'Art décoratif n'est plus l'objet de la mème faveur. Les rapports des gliundes associations d'art sont unanimes sur ce point; depuis vingt ans notre production artistique a subi à l'extérieur une trop réelle dépréciation. L'étranger ne nous achète peut-être pas moins qu'avant, mais il ne nous achète certainement pas davantage, et, dans cette matière surtout, une nation qui n'arance pas est une nation qui est bien près te reculer.

De plus, les statistiques les nlus sủres montrent que depnis vingt ans nos importations en meubles, en papiers peints, en maroquinerie, en bijouterie, de fantaisie, en tabletterie, ont augmenté dans des proportions consilérables.

Les grandes manufactures étrangères ont, ì Paris et dans toute la France, des magasins qui font concurrence aux nêtres.

Les meuhles allemands et autrichiens ont des dépôts dans le faubourg SaintAntoine.

Les cristalleries allemandes ou de Bohême rivalisent avec celles de Baccarat. Les porcelaines d'Allemagne, de Hollande ou de Danemark ont une vogue peut-ètre 
supérieure a nos porcclaines de Sèvres, de Limoges ou de Nevers. Les tissus anglais finiront bientôt, si nous n'y prenons garde, par avoir raison de nos draps d'Elbeuf ou de Sedan. Les soieries de Lyon sont délaissées pour les soies allemandes d'Essen ou d'Elberfeld.

Quand, dans l'Art ou dans l'Industrie, un pays ne se fournit plus exclusivement chez lui, et qu'il va rechercher à l'étranger do quoi salisfaire ses lıesoins et ses goûts, il est peut être pernis d'entrevoir lôt ou tard sa décadence artistique et industrielle.

Paurquoi donc marquons-nous un temps d'arrêt dans les progrès de l'Art décoratif? Il y a à cela des causes multiples. Je ne veux en signaler qu'une, parce que tout le monde aujourd hui est d'accord sur ce point.

C'est que dans toutes ces branches de notre activité artistique, industrielle et commerciale, qui se réunissent et se pénètrent de plus en plus, nos astisles et no: artisans en sont restés ou á peu près à l'imitation le l'ancien. Certes, le rayonncment artistique de la Fiance de Louis XlV, de Louis $X V$, de Louis XVI et même de l'Empire, a été tel qu'on concoit aisément quc notre dix-neuvième siècle $y$ ait puis's son inspiration; mais l'uxcés na pas tarlé à se produire, et, pendant trop longtemps, nous nous sommes bornés, et nous nous bornons anjourd hui cncore à lil simple copie. Un tres remarquable raploolt que j’ai sous les yeux et qui cst signé de tous les noms qui comptent en matière d'Art décoratif, dit très justement :

"Depuis quarante ans nous faisons commerce de toutes les richesses de notre mobilier national, nuus débitons des surmoulages des commodes, des tables et des fauteuils, des chenets et des pendules, des bronzes et des girandoles; nous vendons des copies de toutes ces merreilles décoratives entassées jar les dynasties ruyales dans leurs palais que nous arons 1 rouves comme des greniers d'abondance. Ces répliques furcnt d'abord traitée.s en perfection par l'emploi des mênes mojens qui avaient servi à l'exécution des originaux. Les bronzes étaient alors fondus ct ciselés. Aujourd hui ils sont reproduits par la galvanoplastie! nos bcaux modèles sont galvaudés, vilipendés. Bien plus, ccrtains marchands, estimant la maind'ceuvre françisu trop coùteuse, font venir d'lıalie. d'Espagne ou de Bclgir]ue, les bois tout ourrés, lout sculptés; ils se contentent de les assembler et de les revendre comme produits français...

) Puisqu“il su'fit de copier, il devient, à nos rivaux, tout aussi facile qüì nous, d exécuter du Louis XV ou du Louis XVl; ils ont maintcnant d'excellents ouvriers, le parfaits artisans, un outillage plus important que le nótre, et leur concurrence est devenue plus dangereuse.

"Pénibles constatations! - Pendant des sičcles, depuis le moyen àge, la Renaissance italienne exceptée, la France a imposé son goủt au monde. Aujourd"hui, nous ne savons plus que nous faire glvire du tulent qu'ont eu nos ancètres. Tomberons-nous à n'être plus qu'un peuple de mouleurs et de copistes ?"

Sous une forme un peu vive, ce jugement porté sur notre époque par les hommes les plus compétents et les plus autorisés, conticnt une grande part de vérité, et est bien fait pour nous remplir d’inquiétude. Sans doute, nos artistes et nos al'tisans ne doirent jamais oublier les traditions classiques; la grande règle, et peut-être aussi le grand secret, est de s'inspirer des purs chefs-d'cuvre admirables des siècles où l'art du mobilier el de la décoration atteignit sun apogée : mais s'inspirer n'est pas copier; on peut prendre d'un vieux style ce qu'il a d'ćlégant, de noble, d'harmonieux, de bien francais, tout en l'adaptant aux idëes et aux goùts modernes. Malheurensement, des ouvriers d'une babiletć extrême se contentent aujourd'bui de reproduire le plus exactenent possible les dessins anciens; on calque ou lon imitc servilement: on ne crie plus. Et cependant la concurrence formidable des peuples voisins nous fait une loi de trouver du nouvcau.

Il importe donc de réagir. Comment? Les mèmes hommes qui nous ont signalé 
le langer, nous ont indiqué des remèdes. Il en est, Messieurs, dont nous nous sommes préoccupés depuis quelifue temps déjả, comme la réforme profonde de nos écoles professionnelles et la rénovation de l'apprentissatge.

Mais, à côté de ces réformes de longue lıaleine, naus pouvons espérer beaucoup également d'une autre manifestatıo à laquelle les principaux groupements d'Ari décoratif ont donné utue adhésion unanime. Nous voulons parler d'une Exposition internationale d'Art ilécoratif moderne qui se tiendrait à Paris.

Certes, la vogue des grandes Expositions internationales et universelles est passée. Pendant le dernier demi-siẻcle, ce fut presque une tradition de réunir tous les onze ans, à Paris, dans une grande Exposition, tous les produils et toutes les manifestations de l'activité lumaine. Après le formidable elfort de 1900, son succès grandiose et aussi les déborres nombreux qui en résultèrent, l’immense majorité des personnalités et des collectivités intéressíes à l'avenir des arts, du commerce et de lin lustrie, se prononcerent contre ces lixpositions " unirerselles », marquant leur préférence pour une série d'Expositions internationales «spécialisées ». C'est une Exposition de ce genre, "spécialisée » à l'Art décoratif, qui s'impose aujourd'hui.

L’objet doue pareille manifestation a été défini d'une façon précise dans-le rapport auquel je viens d'emprunter une importante citation :

" Par la collaboration de l'artiste, de l'industriel et de l'artisan, dit ce rapport, réunir en une Exposition internationale tous les Arts décratifs, architecture, arts du bois, de la pierre, dı métal, de la céramiipue, du verre, du papier, des tissus, ete., sous toutes leurs Tormes, qu'ils s'appliquent à des objets d'utilité ou à des ouvres purement somptuaires; dans toutes leurs destiuations : décorations extérieures et intérieures des édifices publics et privés, ameublement, parure de la personne, etc."

Mais nous irions sans donte contre le but que nous nuus proposons d'atteindre si nous faisions simplement une Exposition d'Art décoratif; il faut que cette Lxposition soit exclusivement une Exposition d'Art décoralif moderne. Si nous n imposons pas formellement cette condition, nous resterons dans les sentiers dèjà battus, dans la copic de l'ancien, dans la reproduction du passé oì se fige un peu trop l'Art décoratif français contemporain, alors que nos concurrents et nos rivaux s'en affranchissent, créent des modèles et des styles nouveaux, s'adaptent au présent et marchent vers l'avenir.

En opposant directement nos productions aux leurs, nous les obligerons à lutter ouvertenient arec nous, et, si cette lutte s'ouvre, nous sarons d'arance que nous pouvons compter sur la victoire éclatante du travail et du goùt français.

Mais ce travail et ce goût, il faut que nous le stimulions, que nous le réveillions chez nos artisans, chez nos artistes, clıez nos industriels. Seule l'Exposition internationale d'Art dísoratif moderne, es cxcitant l'émulation, en for ant la création d ouvres nouvelles, en donnant à nos artistes la garanıie que ces mödèles nouveaux seront protégés contre le démaıquage et l'imitation, en lappelant nos indusiries à l'attention de l'itranger, domnerait à l'Art décoratif l'rançais cet essor, ce renouveau dont il a tant besoin.

Socialement, l's résultats que nous pouvons attenılre d'une telle Exposition doivent nous la faire désirer. Les cenves de style moderne sont, à l'heure actuelle, d'un prix relativement élevé parce que généralement elles sont uniques. Industrialisées, elles se vendraient à les prix modiques; accessibles au plus grand nombre, " elles créeraient, comme on l'a dit très justement, un Art à bon marché, un Art vraiment démocratique, à la portée de tous et yui mettrait un peu de joie, de claire propreté, de la beauté enfin jusque dans les plus modestes foyers ".

L'idèe d une telle Exprosition a été préconiséc dans de nombreux congrès; elle a été présentée récemment au Parlement par un groupe de députés :

MI. Erangois Carnot, Paul-Boncour, Henri Cochin, Ciharles Dumont, Massé, Noulens, Puech, Joseph lieinach, Mrcel Sembat, Sibille, Joseph Thierry, Aynard. 
La proposition déposée par ces honorables parlementaires comprend un article unique: "Une Exposition internalionale des Arts décoratifs modernes sera organisée à Paris en 191 ö. "

Les grandes nations - celles qui précisément nous font concurrence aujourd'hui - nous ont devancés déji daıs cette voie. Et, peut-ètre, doivent-elles leur progrès actuel inconlestable à l'initiative qu'elles ont su prendre à tenjps.

Dès 1902 , l'Italie organisait i 'T'urin une grande Exposition internationale oì elle déclarail naccepter que les ouvrages originaux qui montrent une tendance bien maryuée lu renouvellement estljétique de la forme a bannissant les imitations des anciens styles ". C'est le mê:ne principe qu elle reprenait en 1906 pour l'Exposition de Milan et, (1)ut récemment encore, pour celle de Rome.

Les autres pays ont suivi: Munich, Stutigard, Sto:kholm, Vienne, ont en leurs Expositions d'Art décoratif moderne, nationales, celles-là : seule lia France a nėgligé ces grandes manifusatiuns. Il scmble cependant que maintenant un revirement se produise peu à peu.

Ah! sans doute, nous tenons encore le premier rang: les dernières lixpusitions de Bruxelles et de Turin eu sont la preure éclatante; à Turin aucune autre nation ne parvint à rivaliser, dans les productions de l'At dicuratif, avec les merveilles de goút et de pure élígance rassemblees dans le fravillon françis. Mais, néanmoins, nous pùmes constater que nus rivoux ivaient fait des progrès immenses. Défendons-nous, el pour cela convions-les í renir se mesurer, dans notre capitale, avev nos artisans, nos uuviers, nos inlustriels et nos artistr's.

Le Cunseil Municipal, fui consacre ì l'enseignement professionnel un budget plus éleré que n'importe quelle ville du monde, et qui a tant lát dans ces dernières années pour l'Art décoratif, en rendant possibles les belles Expositions de Galliéra, se doit à lui mème dapporter son appui morul et matériel au prnjet d'une ganade Exposition internationale d'Art décoratif moderne à P'aris.

Il y aura lieu de mettie un vaste emplacement is la disposition du Conite d'organisation, et du Alnistère du Commeree, í qui incrmbera certainement le soin de pré|rarer cette grande manilestatiou. Le moment venu, nous ferons à ce sujet des propositions précises qui derront ètre étudiées par les Commissions compétcntes.

Pour anjourcl'bui, je vous deman lerai simplement démettre le vau suirant, dont les considérants sont ưcux-là mémes qui ont été adoptés à l'unanimité frar les représenlants qualifies de tautes les sociétés d'Art décuratif et qui ont été repris daus la proposition de loi prisenlie au larlement.

\section{“Le Couscil,}

"Préoccupé du déveioppenent de nos Arts técoratifs;

"Constatant que les conditions économiques actuelles rendent nécessaires pou nos industries d'art l'établissement de modèles mouvcaux et leur diffusion;

"Estimant indispensable pour stimuler les efforts des arlistes, des industriels et des ouvriers d'art, me manifeslation internatiomale spécialisée à tous les Arts décoratil's et réservée à des ceurres d'une inspiration nouvelle, à l'exclusion de loute copie ou pastiche du passé,

\section{"Emet le rreu :}

"Qưne Expositio: internatioaale des Arls déeoratifs modernes. soit organis ée. ourerte à Paris en 191\%̈." 
M. Aucoc. - Messieurs, je ne viens pas diseuter le projet de vou déposé par II. Dausset.

Je reconnais çu'une Exposition internationale des Arts décoratifs à Paris en $19 t$ ò aura le grand avantage de stimuler nos fabricants et indıstriels, mais je ne comprends pas la raison qui a engagé les promoteurs de cette Exposition à rouloir exelure les produits qui s'inspireraient des anciens stỵles que nous ne saurions jamais répudier, parce qu'ils sont une des gloires de notre pays.

Je demande done qu'on supprime du projet de vœu le mot "moderne " et que cette Exposition comprenne tous les produits de l'Art décoratif, mème ceux qui s"inspireraient de styles anciens.

Le projet de rœu présenté par M. Dausset est mis aux voix et adopté.

\title{
UNION CENTRALE DES ARTS DÉCORATIFS
}

\author{
Assemblée générale du 30 avril 1912.
}

\section{EXTRAIT DU RAPPORT ANNUEL DE M. FRANCQOIS CARNOT, PRÉSIDENT}

..... Au mois de mai dernier, les représentants attitrés de deux Suciétés, avee lesquelles uous sommes toujours heureux de collaborer dans l'intérèt des Arts Décoratifs : la Société d'Encouragement à l'Art et à l'Industrie et la Société des Artistes décorateurs, vinent trouver votre Président pour examiner avec lui l'íventualité d'urıe Exposition iıternationale d'A:t décoratif moderne. Ce projet, lancé lepuis plusieurs années dans des artieles de eritiques d'art, n'avait pas encore trouvé son heure; : i quelques esprits informés pressentaient l'importance qu'une semblable manifestation poulrait aroir pour nos Industries d'Art, cependant les groupenents les plus directement intéressés dans l'Industrie romme dans les Sociétẻs d'artistes, n'en avaient pas encore perçu clairement la nécessité.

Les yeux commençaient pourtant à souvrip, sous la menace de la concurrence étrangùre, de la lutte économique chaque jour plus àple, de l'évolution indéniable des besoins de la clientèle individuelle on collective. Industriels, artisans et artistes comprennent enfin la nécessité d'une union pour la création de modèles nouveaux, mais cette union ne se réalisera que si on lui donne un but inımédiat, si on lui assigne un délai fixe, si les événements viennent l'imposer, en plą̧ant, à date déterninée, les producteur's français face à face avec leur's concurrents étrangers, sous les yeux du monde entier.

Dans ces conditions, oui, nous qui connaissons les ressources profondes du tempérament et du gẻnie français, toujours stimulẻs par l'orgueil national, autant et plus que par l'intérêt, nous sommes certains de leur voir réaliser un effort sans lequel les Industries d'Art de notre pays risqueraient de voir leur échapper la suprématie que nutre fierté ne pourrait se résoudre à abdiquer. (Applaudissements.)

C'est pour cette raison que votre Président, fort de l'assentiment de votre 
Conseil, signail, avec les Présidents de la Société d'Lncouragement à l'Alt et à l'lndustrie et de la Société des Artistes décorateurs, une lettre ouverte deunandant au Gonvernement de réaliser à Paris, en 1913̈, une Exposiıion Internationale des Arts Décorarifs Modernes.

En mème temps, les bureaux de ces trois Sociétés prenaient l'initiative de constituer une Commission d'Eude, chargée d'élaborer un rapport sur celte question complexe et iélicale.

Gelte Commission, conroquée au Parilion de Marsan, appela la collaburation de toutes les Sociétés s'vecupant exclusivement ou partiellement d'Art décoratif. Nous sommes heureux de dire que toutes répondirent à notre appel, et que, lientôt, I'Union Provinciale ces Arts décoratifs, la Société des Arlistes Fran jais, la Sociélé nationale des Beaux-Arts, la Société du Salon d'Aulonne, la Société francaise de l'Art à l'Ecole, étaient olficiellement représentées à nos síances aù lles critiques d'Art, des menubres les plus qualifiés du Conseil muricipal de Paris c.t de l'Administration municipale, venaient nous apporter corilialemeat le coneours précieux de leur expérience et de lenr avis.

Un rapport, aussi documenté qu'intéressant, élabli au nom de cette Commission par M. Guilleré, approuvé et signè des représentants de tontes les Sociétés réunies. fut adressé aux pouvoirs pululies vers la fin du mois le juin. La gravité de la crise extérieure empècha le dépôt d’une propusition de loi an mois doctobre, mais dès que la situation diplomatique permit de proposer à l'examen du Pallement une question dexposition internationale, votre Pı́sident déposa à la tribune de la Ghambre une proposition de loi, conuresignic par des représentants de rous les groupes politipues sans distinction d'opinion, terdant à décidel l'organisation, à Paris, d'une Exposition internationale des Arts décnratifs modernes, en 191 כ̈.

La Commission lu Commerce, saisie de cette proposition le loi, a désigné, comme sons-rapporteur, M. Roblin; eelui-ci s'acquitte avec zèle de la mission qui lui est confiée, et son rapport sera déposé et mis en discussion lès la rentrée de la Chambre. Il m'est permis le rons dire, des maintenant, que l'opinion du rapporteur est nettement lavorab.e à notre projosition, et que la grande majorite de la Cammission semble tout acuuise à son priacipre.

Nous ignorons assurément çuel rôle l'Union centrale pourra ètre appelée à jouer dans l'organisation de l'Exposition projetée; en tous cas, celui qu'elle a rempli jusqu ì ce jour, en groupant autour d'elle, dans un mẻme esprit de dévonement à une eause nationale, les Sociétés artistiques les plus adrerses untre elles, et en réillisant lunion de tous leurs eflorts, ce rôle est un horueur pour l'union centrale, ear il témaigne des sentiments qu'elie inspile et dont nous avons le droit d'êlre fier's. 


\title{
CHAMBRE DES DÉPUTÉS
}

DIXIÈNE I.ÉGISLATLRE

SESSION DE 1912

Amexe au procés-verbal de la $2^{\mathrm{e}}$ séunce du $1^{\mathrm{cr}}$ juillet 1912.

\section{RAPPORT(1)}

\author{
FSIT \\ AU xoy de la Commssiox du Comerce et de l'Industrae \\ chargete 'D Examser la propositiox de LOl de M. François Carsot \\ ET Plisieuns de ses collekgles, texdaxt a ORgaxiser Ex 1915 , a PARIS, \\ une Exposition Internationale des Arts décoratifs modernes \\ PAR
}

M. ROBLIN, député.

Plusieurs esprits avisés araieut projetè đ'urganiser à Paris une grande "foire internationale ". Mais l'opinion s'est montrée aussitôt hostile à celte idée; on a crainı de renonveler l'Exposition de 1900 sans ses résultats mais avec tous ses dangers : mẻlange hétéroclite par suite du manq̧ue demplacement, afllux à Paris de travailleurs provinciaux qui s'y étahlissent el qui, l'Exposition fermée, sont condamnés au chômage, centralisation dans la capitale de toutes les énergies an détriment de nos provinces. Les Expositions ne sont done en ce momeut possibles que spécialisées.

Limitées à un genre délerminé de production, obligatoirement classées et ordonnces, elles permellent par un coup-d'œil d'ensemble de se documenter méthodiquement. Elles forment comme l'encyclopédie réelle et acluelle de toute une branche d'activité. Elles excitent l'émulation, altirent l'altention, liappent l'opinion.

(1) Le très complet Rapport de M. Rohlin a élé déposé à la Chambre des Députés pendant limprcssion de celle Etude. Vous ne fouvions songer it remoduire les 118 pages qu'il componte, maix" nous sommes heureux de puzwoir en lonner ici un Résumé cilant les passuges les plus caraclèristiques et riunissant as exlraits cnlve eur par de courtes analyses. 
Telles on telles villes de province, cenlres régionaux d'activité, seraient les cadres appropriés et utiles de ces Expositions.

Et voici surtout le grand avantage qu'on en pourrait retirer :

Nous possédons épar's dans loule ln France des lalenls et des initialives que nous ne lentons pas suffisamment d'uliliser, de mellre en valeur. Dans tous les coins de nos provinees sommeillent, régèłent, meurent de vieilles industries originales, almirables, à peine connues. Llieure va venir de les secouer, de les réveiller, de les rendre prospères en les faisant connaître. C'est seulement par l'Exposition locale spécialisée que l'on y arrivera.

Déjà une proprosition de loi a été léposée tendant à organiser une Exposition internationale des Arts décoratifs à Paris en 1913 , et la Commission du Cnmmerce à la Chambre des députés en a décidé l'extrême urgence.

A l'unanimilé, elle a déeidé que l'institution d'une Exposition d'Art décoratif conlemporain s"imposait et qu'il élail de toule nécessité de l'organiser le plus tót possible : il y va de l'exislence de toule une branche de notre aclivité nalionale. C'est pour loule une parlie de notre production une question de vie ou de mort.

Dans une première partie - les pares précedentes formant comme une préface, une introduction nécessaire au rapport - M. Roblin montre d'une facon très nette, mais très précise en sa grande brièveté, quelle place a été faite à l'Art dẻcoratif dans les Expositions antérieures à 1900. Nous ne reviendrons pas sur cet historique, dont nous avons déjà fait une esquisse.

Arrivant enfin à l'Exposition de 1900, M. Roblin montre bien qu'il s'est produit alors "une éclosion tout a fait extraordinaire dans l'histoire des Arts eontemporains " et que dans heaucoup de cas " il s'est manifesté une supériorité incontestée sur les résultats obtenus dans les Expositions antérieures ". Il étudie dans ses grandes lignes le mouvement de l'Art décoratil dans les arts du feu ou le mobilier, définit et juge ce que l'on a appelè le modern style qui avait alors cette gualité d'ètre neuf et de vouloir surtont ètı'e neuf : mais il n'était pas dans la tradition française, excessif dans son originalite de recluerches, il dépassait dès l'origine son but au lieu de l’atteindre. Attaqué par les pulistes des styles établis, abandonné et eritiqué mème par ses anciens défenseurs, il devait succomber; il y avait effort à se dégager lı passé, e’était une tentative, ce n'était pas un "faux départ ".

Depuis 1900, comment a évolué l'Al't décoratil moderne, nor seulement en France, mais encore à l'étranger? Il n'y a pas eu chez nous depuis cette époque d'Exposition universelle. Mais chaqque grande nation l'Europe on d'Amérique en a organisé au moins une importante; sourent l'Art lécoratif a occupé la place prépondé:ante et mème l'Expinsition tout entière lui était exclusivement consacrée. Passons-les rapidement en rerue.

Tums, 1902. - L'Italie ourrait en 1902 , ì Turin, une Exposition internationale où l'on nacceptait " que les ourvages originaux montrant une tendance très marquée a!l renouvcllerrent esthétịne de la forme ». Un défaut d'entente empècha nos décorateurs d'y participer avec tout l'éclat qu'ils auraient pu y déployer.

SaInT-Lous, 1904. - Arec section d'Art décoratif organisée par Guillaume Dubufe.

LIEGE, 1903. - Bellery-Desfontaines y installe un salon entier avec la collaboration des artistes nouveaux en renom. 
MiLis, 1906. - Avec section d'Art déeoralif organisée par MM. Frantz Jourdain et Mlonduit.

Loxines, 1908. - Un pavillon y fut aménagé spécialement pour les décorateurs far un amateur, M. Delieux. Notro suecès y est tiès vif.

Copranugue, 1909. - Pour la première fois artistes, industriels et artisans furent groujós ensemble plar le Comité frauçais des Expositions et la Société iłencouragement ct collaborèrent à l'œuvre conimune, et $\mathrm{M}$. Roblin veut bien citer à cette accasion le Rapp mit de MII. G.-lunger Sandoz et Jean Guiffrey et son introduction sur les Arts apmliqués at les Industrics d'Art aux Expositions.

Buxxl:Li.f, 1910. - Le mème effort d'unilè se poursuit dans le salon d'art a ménagé par t'artuitecte Lambert.

Tumis, 19t1. - Un pavitlon y est réservé aux artistes décoraleurs modernes. Dans ta prólace du catulogue, M. li. Tixehlin, que cite M. Robtin, s'exprime ainsi :

“L'Luion centrale des Arts décuratifs n'a admis dans ses vitrines que des ourrages d'un curictere franchement moderne, et toutes Jes copies, tous les pastiches ll's styles anciens en onl été délibérément exc]us. Non j:oinl qu'elle ne professe pour les vieux slyles dr. France une arlmiralion passionuée, mais elle sent non moins passionnément la nécessilé de les renouveler, le ne pas se complaire à des rediles el c’est pourquoi elle s'est adresséc uniquement aux antistes et anx artisans qui prétendent voir et penser par eux mêmes, non d'après les formules convemues... Nous continuerons d'a voir dans le saug ces formes que nous avons créécs et qui demeurent familières, el toute noureauté dérange nos labiludes. Nos arlisans onl eu moins d'occasions de manifester leurs talents et de créer de grands ensembles clécoratifs que ceux d'aulres pays, uì l'absence de tralitions laissail le clamp plus libre aux innoraleurs; mais il semble que le préjugé contre l'Arl décoralif molerne tende à disparaître, chez les jeunes généritions surtoul, et qu'un prochain avenir doive jermell re à nos décorateurs français le donner toute leur mesure. On reconnaît, en effet, eliaque jour diranliage en France combicu les prétendus rćvolutionnaires demeurcut au fond dans la grande tradition frinçaise et avec quelle ingéuieuse logique ils s'appliquent, surtout inconsciemnenı, à la dévelopfer...

" La qualité première de rolre Art décoralif de jadis élait, plutôt que la foree, une certaine grâce mesurée et charmaule que nol n’a jamais su nous preudre, même en sappropriant uos formes: c'est encore cc caractère qu'on distingue chez nos modernes artisans, ils recherchent J'aimable plus que le puissint et prétendeut continuer l'art sociable qui est dans notre tempérament et dians notre tridilion."

C'est ce fil perdu de la saine tralition francaise qu'it s'agit de retrouver : c'està-dire convenance, à-propos, ordre et ehois, et comme le dit très justement M. Robtin :

I] paraît de plus en plus cerlain que sur toute l'agilation antérieure a passé un souffle de sigesse, de raison, de modération portiut avec lui "de légers effluves d'élégince el de goùt".

Malgré quelques hésitalions, quilques inquièludes ou même des erreurs, un sent désormais le souci diune d icor..tion de meilleur aloi, un retour vers ce 
sentiment que le meuble est le serviteur et le compagion de l'homme, quil doil être fait à sa mesure, qu'il doit grandir par les devoirs de sa fonclion, à des besoins matérjels qu'jl est teru de salisfaire exactement, mais aussi à des goûts nouveaux. "Car, dans la maison, il est un lémoin discret de la vie qui doit garder avec réserve son loole de comparse ou de figurant, sans prétendre se bausser à celui d'acleur principal. "

Si ces constatations sont encore consolantes pour notre amour-propre el si nous avons le droit de ne pas désespérer, it ne faudrait pas en conclure que nous triomplons et sans plus de souci de notre preslige nous cnilormir simplement sur des lauriers bien fragiles encore. Un coup d'œil sur l'état actuel de l'Art décoralil à l'étranger suffira pour montrer que nous arons à lutter, beaucoup à apprendre, et que plus d'un peuple nous a déjà derantés dans fa roie diun style décốratif moilerne.

D'abord I'Angleterre: ce n'est pas d'aujourd'hui que date l'action d'un William Morris ou d'un Walter Crane. Il y a en des errements ; mais la période en est ctose, et des norateurs, hardis et icnacis comme Mackintosch, produisent des cuvres qui sont la marque d'un véritable Art moderne nonveau; ct l'Angleterre les accepte aujourd hui sans discussion.

La Belgique, depuis longtemps, s'tfforce de se créer un style ; en vain s'est-on moqué de l'art "belge "; en vain a-t-on lénigré les "produits brabançons". Les recherches n'en demeurent pas moins infiniment lécondes.

En Hollande, il existe une impressionnante émulation tle bons vouloirs qui, naguère encore, aloutissait, à l'llleal Home Exhibition de Londres, à la présentalion d'une section moderne albsolument lool's pair. Des emprunls ingénieux furent fails a l'arl colonial; puisant dans ces trésors, les Nćerlandais, comne ies Anglais, ont su y découvrir des éléments décoralifs dont ils ont su, avec un tacl et une mesure exquis, rajeunir, dans l'oljet usuel de chez eux, un certiin nombre de formes et de décor's.

Autriche-Hongrie. - Les ironies élevées jadis contre l'art dit "belge " étaient iuséparables des lazzis décernés à liart viennois. Les menbles en " boîles à cigares ", pour reprendre une expression qui eut du succès, ne furent point, alors, dı guût des tradilionnalistes français, obstinés dans leur adniralion pour les slyles de clıez nous ou les pastiches habilemenl déguisés. Il n'en subsiste pas moins que l'arl moderne aulrichien suit une route des plus intéressantes, el qu'il y a trois aus, lors de l'Exposition de Vienne, on vit des ensembles dignes d'être tenus̀ pour mieux que d'hésitanls efforts.

L'Allemagne : On se rappelle en 1909 , au Salon d'Antomne, IExposition curieuse d'Art munichois : encore un peu lourd, et heurtant par ses violences notre goût afliné. Mais les artistes de Munich se sont essayés au contact de notre art et l'Exposition qui se tient là-bas en ce moment même, montre qu'ils ont su corriger leurs fantes et attenuer certaines bizarreries. His sont en plein prugrès 
et, à la nouvelle que Paris convierail, avant 1920, les nations étrangères à faire une démonstration solennelle, Munich a immédiatement centralisé ses forces, et en un accord parfait, artistes, artisans, industriels, fabricants, municipalités, amaleurs, mécènes " marchent " pour renouveler à celte occasion, et sur une bien plus vaste échelle, le groupement qui fut tant remarqué à la dernière exposition bruxelloise.

La Sujde n'est pas restée en dehors du mouvement. Et l'Exposition récente de Stockholm en a été la preıve manifeste. Pour ne dater que de 1870 , la rénovation n'en est pas moins significative et à force de volonté, de travail, la Suède a fini par dépasser beaueoup d'autres nations. La tisseranderie fut restaurée, le docteur Haselias créa le "Nordiska Museet " (musée du Nord) pour y jecueillir les objets usuels rappelant les traditions artistiques du pays. Lart de la dentelle au fuseau, abandonné, fut remis en honneur ; les meubles furent Suédois ; la porcelaine prit une extension considérable; des a r'tistes eumme Venneberg ou Wallander inven. tèrent des motifs pour décorer vases et pots ; la verrerie de hosta, la poterie de Hoganaïs, l'orfèvrerie, la fonderie, tous les arts, rajeunis et vivifiés, s'épanouirent comme dans un splendile printemps.

En Italie les arts décoratifs commencent à renaître et à se développer suivant une méthode inteltigente.

La Russie s'éveille doucement et la Finlande a peut-ètre des architectes dignes de Sarinen, qui nous émerveilla par son pavillon Finlandais en 1900.

Telle est, à l'étranger, la situation de l'Art décoratif moderne et M. Roblin a raison de conclure :

Comment, devant cel assaut presque unanime, ne pas mettre avant toute autre préoccupation, chez nous, celle de donner aux artistes décorateurs toutes facilités pour affirmer dignement l'indéfectible vitalité du génie français? Peut-on accepter sans douleur l'hypothèse que, dans dix ans, notre public acheteur se refusera encore à aider l'art moderne et s'obstinera à gaspiller dans de folles enclıères, sur des bibelots anciens, des fortunes dont la vingtième partie suffirait à assurer le triomphe de la France sur le terrain de l'ar't moderne?

En présence de cette situation, l'évidence éclate de la nécessité pour la France de faire plus qu'elle n'a fait encore et, en organisant à son tour une Exposition d'Arl décoratif, suscite à la fois l'effort de ses nationanx et démontre à l'étranger qu'elle ne consent pas à déchoir du rang qu'elle a loujours tenu.

Or, une Exposition de ce genre peut comprendre, soit à la fois, soit exclusivement :

Ou des cuvres anciennes;

Ou des æuvres copiées ou inspirées de modèles anciens ;

Ou des œuvres résolument modernes.

Mais de quelle utilité scrail aujourd'hui une Exposition d'œuvres anciennes? La prééminence de nos décorateurs dans les siècles passés n'est plus à 
démontrer. La Centennale de 1900 l'a fiit avec éclat. Nos musées du Louvre, de Cluny, du Pavillon de Narsan, de Versailles, de Fontaineblean (pour n'en citer que quelques-uns), en constituent la rétrospective permanente, facilement accessible. Qu'y ajouterions-nous? S'agil-il, d'ailleurs, de faire lriller une fois de plus le génie des Boulle, des Riesener, des Jacoh? Il n’est pas en cause. C'est de notre production actuelle qu'il est question, de notre production inenacée par la concurrence étrangère. C'est d'elle qu'il faut firire aflirmer, faire constater la prééminence.

Dira-t-on que le génie de ces artistes était tel, qu'ils ont fixé pour toujours les formes de décoration intérieure ot que nous ne devons plus nous contenter que d'exceller dans leur copie ou leur pastiche?

L'idée ne vaudrait pas même qu'on s'y arrête, si la déplorable production de copies dans laquelle se sont, depuis un sjècle, confinées la plupart des industries du décor, n'avait déterminé dins le public un étal d'esprit qui donne à celte idée au moins l'apparence de l'étendue.

If y a d'abord là une erreur csthétique. Aucune formule d'Art, si parfaite qu'on la suppose, ne peut durer éternellement. Les chefs-d'œuvre ne se succèdent en art qu'en se différenciant les uns des autres ; les styles pour s'élablir ont besoin de contredire entièrement les règles de composition des styles précédents. Persister dans le passé, c'est s'opposer à une loi, c'est nier l'évolntion. Littérature, modes, coupe des vêtements, tout change, touta besoin de changer. Que l'on garde les beaux vieux meubles par respech, comme souvenirs de fanilfe, soit! Mais qu' on les imite; non. Qu'on tes démargue au point de reproduire les crevasses du bois, les piquures des insectes et la patine des ans, c'est un contresens, c'est "l'apothéose du truquage ".

Nais il y a pire :

Il y a là l'indice d'un danger qui, même si nous n'étions pas inquiétés par la concurrence de l'étranger, serait menaçant pour l'avenir de nos Arts décoratifs. Si nous laissons s'anémier, par un tel aluus de la copie, leur's facultés créatrices, si nous ne les excitons pas au contraire à considérel l'originalité, la nouveauté, l'accord avec notre temps, comme des conditions nécessaires de la perfeetion, c'est la déchéance à bref délai - et pour combien de temps?

C'est pourquoi, à la question qui se pose des limites à fixer à l'élendue de l'Exposition future des Arts décoratifs, nous répondons calégoriquement: "Non seulement il est sans intérét d'y produire des ceuvres anciennes el des copies ou interprétations de modèles anciens, mais il est indispensable de n'y admettre que des cuvres modernes, rigoureusement modernes. "

Ainsi l'Etat reprendra l'initialive que, depuis plus de dix ans, sous une forme ou sous une autre, tous les rapporteurs du budget des Beaux-Arts l'ont adjuré d'assumer; nos Arts décoralifs, libérés eniin des entraves que les exagérations du mercantilisme opposaient à leur développement naturcl, retrouveront une suprématie que malheureusement - selon les paroles mèmes de M. Guist'hau, Ministre de l'Instruction publique - "ils n'ont plus intégrale " et il sera permis d'espérer que la démocralie ne demeurera pas, de tous les 
régimes qui se sont succédé sur la terre de France, le seul qui n’ait pas trouvé à s'exprimer d'une manière origin tle dans ses façons de bàlir et d'ordonner' nos demeures.

E sonomiquement, le danger qui menace estaussi pressant; la filveur des æuvres anciennes atteindra un point culminant ; les rècentes rentes et les enchèrts fintastiques auxquuelles certains amateurs se sont laissés aller pour acı̣néril telle étagère ou tel paravent, en sont la preuve. Les industriels se bornent it produire des copirs de l'ancien; des stocks consillérables s'entassent. Si la mode tourne (et elle tournera fatalement), ce sera la débaicle : les cuvriers inaptes à prodıite autre chose, l'industriel manquant de modéles nouveaux, manquant d'artistes habiles pour en créer. Le jour viendra où la dépréciation des copies de style pousscra l.s amateurs rers les meubles eréés par des artistes modernes. Le snobisme s'en mèlera et chacun suivant la mode voudra aussi des meubles modurnes.

Notre réulutation eurnjéenne n’est pas entaınée; nous conservons encore le goùt, l'ilégance, mais l'ètranger est à nos portes et nous-mẻmes nous élargissons un peu plus chaque jou: la brèche pour laisser passer le flot de l'inrasiun.

Il n'est pas, en effet, dì copie qu'on ne puisse, gràce aux moyens mécaniques mis en œuvre, exéculer au dehors aussi bien que chez nous; el, comme dans beaucoup de pays les matières premières el lit main-d'œuvre sont moins coûleuses, il en résulte que mime pour les oljjels " de style " nous ne conservons plus sur les marchés de l'él’anger notre preéminence; bien mieux nous sommes obligés de nous défendre en France contre des importalions menaçantes.

Là n'est pas tout le danger. A vec lit belle témérité qui est une des iormes de notre caraclère, nous répétons volontiers que c'est notre gon̂l, que ce sont nos modes qui régissent le monde. Cela fiıl vrai. Cela l'est peul-ĉtre encore. On ne peut pas affirmer que celi le sera longlemps. Beaucoup de pays nous envient celle supériorilé, et là, les industriels rencontrent un engovemeut d'autanl plus vif pour les créalions modernes qu'ils font de leur succès une question de vitalité natiouale.

A considérer l'ensemble de ces recherches extérieures, un fail s'impose avec une inquiélaule évidence. Si nous ne nous décidons pas à unir loutes nos énergies ol à les sagement coordonner pour créer un Al't moderne français, avant deux ans, dans le domaine artistique comme sur le terrain économique, nous sur. ns dépassís au point qu'il nous faudra peul-être un demi-siècle el plus pour reconquérir le premier rang. Il $n$ بs suffit point en effel de se bercer à la musique des mots, et de décerıer de flalteurs éloges, d'assurer urbi et orbi que la France ne saurail se laisser arracher par quiconque le seeptre du goût, de ce goût dont elle est el reste aujourd'hui la conseillère unirerselle. 11 faut être singulièrement inconséquent pour ne pas se rendre comple que, sur notre marché même, à l'inlérieur de notré lerritoire au cœur de la capilale, des firmes étrangères se sont installées, on t pignon sur rue, lont anuuellement de très importants chiffres d'affaires, en arounant avec une franchise qui d'ailleurs les honore, la pruvenance lointaine des objets qu'elles offrent à leur clientèle... françitise. Ici n'est point la place d'appayer les faits par des désignations de 
personnes, mais chacun pourra aisément se convaincre qu’à Paris, dans lés industries du meuble, de la porcelaine, du bronze, el quelques autres, un gros chiffre d'affiires se fiit an bénéfice exclusif de maisons importantes, succursilles de grandes raisons sociales ins'allées à Londres, à Copenhague, à Vienne et autres lieux.

Aussi bien, l'avenglemenl de ceux qui prétendent que "la palrie n'esl pas en danger " est-il inqualifiable et sans excuses. Ceux-là assurément n'ont pas voyagé, de saison en saison, en Europe, n’ont pas visilé les Expositions d'Aıt décoratif moderne qui, excellemment présentées, s'ouvrent avec régularité en Allemagne, en Angleterr', en Hollande, en Suède, en Italie, en Autriclie, en Hongrie. Pour ne ciler que les plus récentes, rappelons les manifestations de Stockholm, de Mlunich, de Turin, l'Ideal Ilome Exhibition de Londres, où la Hollande présenta une section de loule première importance. Il existe à Bud.1pestl, à Vienne, des Écoles d'Art décoratifqui exposent leurs travaux et innćdiatement les voient transposés de la théorie à la pratique par des industritls justement avisés. Il y a un tffort considérable à Glasgow, à Bruxelles, à Amstrr'dam. Ici et là, on ne pense, on ne crée que pour la modernisation des arts de l'industrie. $1 l$ y a un mouvement américain. Il y a un mourement japouais. Et sitôl passée la barrière de Deutsch-Arricourt, on ne peut faire un pas daus l'empire allemand sans trouver à Carlsı́ube, à Stuttgart, à Mannheim, à Francfort, en Bavière, à Berlin, à Drusde, à Leipzig, à Weimar el dans le Nurd, avec une activité significative, à Dusseldorf, à Crefeld, à Elberfeld, des groupements lenaces, déterninés à innover, à faire jaillir des ténèbres el, à flots, une vérité trop longlemps enfouie sur l'inféconde imitalion des arts llu passé.

Ce n'est pas que mainl's " paroles prévoyantes " n’aient déjà dénoncé ce danger immanent. - M. Roblin cite à l'appui jlusieurs passares de rapports signés des noms les plus autorisés. - " Le Sedan commercial, icrit l'un d'enx, dont depuis de longues annces nous sommes menacés, n'est plus à crain.l.e actuellement; c'est un fait accompli et nous devons en frendre notre parti. " Un' autre constate :

"J'ai mu mapercevoir que nos imitations du style ancien sont battues en brèche et qu'elles perdent du terrain. Je crois que le momcnt n'est pas très éloigné où sur la plupart des marchés le moderne sera presque exclusivement demandé. L'Exposition de 1916 peut montrer à tous que nos artisans, aussi bien que ceux d'Allemagne, clierclient et que mieux qu'eux, peulêtre, ils ont trouvé; mais il faut pour cela que tout l'effort soit dirige sur le moderne. Une Exposilion d'Art moderne - voilà lia conclusion ì laquelle uboutissent tous les esprits soucieux de notre avenir artistique. ('ítil celie déjà que M. Couyba émettait en $\mathbf{1 9 0 7}$ dans son rapport sur le londgel des BeauxArts. C'étail celle que, deux ans après, dans un arlic'e sur l'A $\cdot$ l social qui cut beaucoup de relentissement, reprenail MI. Roger Mil'x. Tuute lit presse s'en empara...

Cependant, comme précisément venait d'échouer le projel d'une vaste Expo- 
sition universelle et que l'opinion se prononçait presque unamimement pour une Exposition à programme linité, la Société d'Encouragement à l'Art et à l'Industric se déclarait, le 21 mars 1911, prête à soutenir de ses deniers le projet d'une Exposition réservée à l'Art décoratif. Une "Commission d'étucle " fut constituée, qui comprenait à la foìs des délégués de sociétés de décorateurs, comme celle des Artistes décoraleurs el l'Union provinciale des Arts Décoralifs; des salons Artistes Français, Société Nalionale, Salon d'Aulomne, el des sociétés vonées depuis longtemps au développenent de nos arts industriels, rom ne la Sociétć d'Encouragement à l'Art el à l'Industrie et l'Union centrale des Arts Décoratifs. Un remarquable rapport résumait bientôt les travaux de cette Commission et s'achevait par le vœu suivant, signé au nom des Associations que nous avons énumérées et de la Sociélé de l'Art à l'Ecole par ;2 artisles, industriels, amateurs, etc.

\section{VOEU}

"Les associations soussignées,

"Préoccupées du développement de nos Arts décoratifs, titre d'une gloire nécessaire pour la France,

:A Après avoir constaté que les conditions écononiques actuelles rendent nécessaires, pour nos Industries d'art, source considérable de richesse nationale, l'établissement de modèles nouveaux et leur diffusion,

"Estiment indispensable, pour stimuler les efforts des artistes, des industriels et des ouvriers d'art, une manifestation internationale,

"Spécialisée à tous les Arts décoralifs, appliqués à l'architecture, au mobilier et à la parure,

„Réservée ì des æuvres d'une inspiration nouvelle, à l'exclusion de toute copie ou pastiche du passé,

"Et, en conséquence, émettent le vœu que le Parlenıent et le Gouvernement, s'inspirant de cts considérations, décident l'organisation et l'ouverture, à Pitris, en 1915, d'une Exposition internationale des Arts decoratifs modernes."

Et M. Roblin conclut par ces mots :

"C'est ce vœu, rappelant une proposition déjà soumise au Sénat par M. Couyba, qui a été repris dans la proposition de loi que nous avons citée en tête du présent rapport. Notre Commission l' a fait sicn. Non seulement en effet elle estime, pour' les raisons que nous venons d'exposer, que cetle manifestation en faveur de l'Art décoratif moderne est nécessuire, mais elle pense, pour les raisons qu'il nous reste à développer, qu'elle sera toule à l'houneur de la production française.

La renaissance des Arts modernes est de la plus haute importance au point de rue économique et social. 
Depuis l'Exposition de Turin, l'opinion, qui s'était détournéc des décorateurs modernes après 1900, semble s'être reprise et à nouveau on sent, à des signes certains, que le pulblic est prêt à rendre aux novateur's toutes ses synpathies.

... Ne pas entrelenir, ne pas amplifier de pareils courants de sympatbie... ce serail, pour reprendre le mol de M. IIenry Marcel, ancien directeur des Beaux-Arts, " un déni de justice, une absence complète de solidarité lıumaine, un manque de patriolisme".

Est-ce à dire que nous ayons la prétention, qu'on nous prête, que d'aucuns peut-être se donnent, de erèer um style? Nullement. Il n'est pas question d'inslaurer quelque esthétique officielle que ce soil. Nous savons 1 rop que la notion d'un style est une notion pour ainsi dire rélrospecive; que c'est en faire abus que de l'appliquer aux œuvres du présent, dont nous ne pouvons pas, faule de recul, spécifier les éléments durables, délerminer exactement les origines, prévoir les résultats. Un style ne peut être concerté. Il ne se commande, ni ne s'impose. Toul ce que l'Etal, ou les amatcurs peuvent faire, c'esl d'en faciliter l'éclosion, en suscitant des recherches nouvelles, tandis que les producteurs, de leur côté, s’efforceront de soumettre leur pensée à cetle discipline qui, donnant aux cuvres l'unité, caractérise les grandes époqucs d'ar'.

Il n'y aura pas un style, une senle discipline qui donnera le ton, réglera tout comme une loi unique et souveraine : et comme l'a observé M. E. Vernier :

"Il ne faut pas nous allendre à la révélation d'une formule tyrannique, qui régira lout. I] y aura de l'ẻlasticité dins le style nouveau. Le public nïa pas vers un genre: il ira rers tous les genres, pourvu qu'ils soient beaux. "

A toutes les objections que l'on formule en fareur d'un Art décoratif moderne et contre le pastiche éternel des vieux styles,

Les industriels répondent de diverses manières. Les uns prétendent que la rogue des anciens styles est telle qu'ils n'osent la contrecarrer par des modèles nouveaux dont l'établissenıent et la production leur coùteraient cher, sans débil assuré. Observons que si celle rogue est tenace, c'est bien en grande partic gràce aux industriels eux-mênes, qui l'entretiennent et l'accroissent en ne donnant jamais au public l'occasion de modifier son goûl.

Un jour viendra cependant où le public, à force de voir aux vitrines des meubles nouveaux, et influencé par un snobisme naissant, ne demandera que du nouveau.

- Nais, répliquent encore les fabricants, c'est bien ce que nous craignons. Nous avous des slocks de meubles de style qu'il nous faut écouler, el, d'autre part, nous ne pouvons jamais les remplacer par des stocks de meublesmodernes produits dans les mèmes conditions; car l'ancien ne nécessite pas de frais de 
création, il se débile par séries qui, l'une dans l'autre, reviennent à un bon marcbé extcème, landis que, pour aroir des meubles moderncs, il faudra payer le créaleur très clier. C'esl tourner dins ce cercle vicieux : pour débiler le meuble moderne en sćlie, il faudrait que le fubricant soil sùr de la clientèle, et, pour avoir celle clientèle, il faudrail que celle-ci soil déjà allirée par le bon marchć des séries ćlabli ss. E I résumé, ce qui est nécessaire, c’esl un gros effort pécuniaire de la part des fabricants.

Enfin, ajoutent cerlains industriels, nous ne pourons pas faire clez nous la révolution à laquelle vous nous invilez. Nous n'avons plus d'ouvriers. Il n'est pas dans notre rôle de recluercher ì qui incombe la responsabilité de celte déchéance de la main-d'uurre el d'éludier si précisément les fabricants ne sout pas viclimes de leur propre imprívoyauce : en accentuant, comme ils l'ont fait, durant lout le cours du dix-neuvième siècle, l'industrialisation à outrance des méliers arlistiques, en substiluant la copie à la production origginale, l'ourrier' spécialisé el nểme la machine, à l'ouvrier arlisan donl le travail lent, appliqué, les connaissances élendues à toules les ressources du mélier élaient une garantie de parfuite exéculion... La dispariion de la mâ̂lrise est alu même tilre que celle de l'apprenlissage le témoignage éclatant de la décadence des industries d'art. Notre espérance est précisément que le relèrement de l'art moderne, ra obligeant l'industrie à une aclivité conlinue de production originale, facilitera le relour au développement des compétences techniques appropriées aux formes présenles de notre production.

N'oublions pas non plus parmi les causes de cet état de choses, l'état des rapports entre industriels $t$ t artistes fournisseurs de modèles. T'andis que ces derniers par leur ténacité obtenaient droit de cité dans la famille artistique et leur admission comme exposants aux salons én 1890 , le fossé se creusait filus profond entre le décorateur el l'industriel; celui-ci, considérant celui-là comme son collaborateur anonyme, oubliait sourent de faire figurer son num dans les concour's : d'où conflit; l'industricl utili:a des copistes et démarqueurs plus morltetes; le décorateur pur ne connut plus que céramique, émail, verrerie ou bijou, ne créant que des objets susceptibles d'être colluctionnés ou nils dans un musèe.

Vuilà un des écueils principaux qui retardent le progrès de nos arts du décor. Pour le surmonter, il ne suffit pas d'attendre que les nícissitćs écunomiques de nolse produclion aient rapproch: arlisles et industricls : il fitul résolument prévoir les événements el, tant d'une part que de l'aul'e, faire les concessious qui abouticont à l'entente. Si les Anglais, les Allemands, les Viennois ont pu produire des efforts considérables en art moderne dans les Expositions récentes, c'est parcc qu'ils ont réalisé cel accord. Qu'allend-on pour faire de mêne dans notre pays, où le passé nous offre, dans cel ordre d’idées, de si glorieux exemples?

Les industriels ont un gros effort matériel à produire: il leur faul sacrifier les sommes nécessnires à la créalion de modèles nouveaux, à la publicilé qui les répandra dans le monde entier, à l’outillage mécanique moderne qui les mul- 
Liplirra selon les nécessilés de la vente. De son côté, il est nécessaire que l'arlisle soil "soutenu, encouragé, alimenté; qu’il ait l'émulalion el une parl de profits : qu'il soil intéressé en un mol à trouver du nouveau, de l'inédit, lant moralement par le succès personnel que pécuniairement par la vente fruclueuse des produils de son imaginition $n$. (Grandigneaux.)

Une entente est don; nécessaire.

Comme l'it dil le grand décoraleur Eugène Gaillard : " L'ocuvre d'art appliqué doit être susceplible de répélition indéfinie sans déperdition appréciable d: ses qualités essentielles. "C'est à l'artiste pt ì l'industriel, associés, de lriani'ler du concert à donner l'un aux modèles, lautre à ses répétitions, ce caratctère nécessaire.

Aussi la grande exposition projetíe doit ètre

une manifestalion d'oldre industriel el commercial aussi bien que d'ordre artislique. Nous désirons qu`elle soit ouverte à lout fibricant, pourru que les cuvres porlent, avec le cachel d'une création originale, la désignation de leurs auteurs.

Longtemps il y a eu une hiérarchie des arts; et l'Art décoratif, l'Art du fuyer était un peu "le parent pauvre "; les Arts mineurs par contraste avec les Arts nobles et riches, les Arts majeurs, c'est-à-dire Peinture et Sculpture. Et MI. Roblin dit excellemment :

Manier un pinceau, modeler une silhouetle dans l'argile : voilà de l'Arl! Pousser un outil dans la malière, ce n'ı'sl que du mélier d'arlisan...

L'arislocratie de l'Art, ainsi envisa gée, n’est qu'un déni de justice. Forl heureusement, el de jour en jour dćsormais, certains, dont le rombre va toujours croissanl, recommencent à croire en France que ces licérachies sont aussi vaines qu'orgueilleuses et qu'un ouvrier d'art peut mettre, dans le moindre bibelot usuel, plus de beaulé que n'en enfermera jamais dans son colossal cadre doré, un peiutre de " grandes machines ".

Le premier art e'cst l'Arehitecture et il serait à désirer de voir la Peinture et la Sculpture revenir à leurs traditions décoratircs; un jour est proche où tous les Arts collaborcront à la parure de l'habitation. Alors l'Art décoratif sera reconstitué dans son unité; alors on rerra le mème souci commun d'lıarmoniser dans la matière un idéal bien défini.

Ainsi, parłant d'Art décoratif, c'est-à-dire en un mot, de tout ce qui pcut contribuer, dans le détail de norre vie, à rendre cette vie plus confortable, plus souriante et micux parée, - l'A rchileclure commande et réglentente toul. G'est par elle qu'il faut aborder la question lu renouveau arlistique el tant désiré. Si elle est bâlarde, les éléments de décor, qui y prendrout place, s'y trouveron heurtés, contrariés, dénalurés souvent par l'imperfection du cadre bâli. Si elie est franchement de style ancien, rien de moderne ne pourra s'y trouver à l'aiso. Si elle est résolument moderne, toutes les recherches acluelles y fleuriront sans peine. 
Done, aussi bien l'Exposilion projelée sera moderne dans lous ses délails, aussi bien son architecture doit-clle être elle aussi moderne absolument. Pas une pierre posée sur une autre pierre, pas un percement dans le mur, pas un couronnement aụ toit, pas un délail dans tout ce qui sera construit à l'Exposilion, sans que, résolument, l'archilecte, rompant avec toule forme copiée d'après le passé, ne se soil imposé l'obligation de créer, selon une oplique contemporaine en ulilisunt el mariant au micux lous les matériaux dont jl dispose en notre lemps. Aucune imitation ne pent ĉtre toléréc dans celle enceinte à la la porte de laquelle les styles, rappels d'esthéliques périmées, doivent êlre lormellement consignés. Seule, escorlée par la multilude des idées modernes qui parliciperont à celte fêle de l'Ar', la lradition aura le droil d'entrer.

La question se pose done d'un contrôle extrêmentent sévère sur les arehileclures le l'Exposition des Arts décoralifs el, avant loule chose, d'un choix entre deux partis contradietoires :

$1^{\circ}$ Construire un énorme palais pour abriler toutes les seclions exposantes ;

$2^{\circ}$ Morceler l'Exposition en pelites habitalions bâties selon des destinations multiples el constiluant des types variés de demeures privées ou publiques: villas, hôtel's parliculiers, hôlels à voyageurs, maisons de campagne, logis uuvrier's, elc., elc.

Ia République, en protégeant l'Exposition des Aris décoralifs modernes, en lui attribuant, pour qu'elle soil digne de notre pays, d’inportanls crédits, ne doil pas commeltre la faute d'aventurer des sommes émormes sur un seul risque. Le budget de construction ne pourra qu'êl'e réparli entre les archilectes de qui l'on peut allendre des solutions à ce grand problème d'un style architectonique acluel, el l'Exposition, à cet égard, portera effet dans la plus large mesure, si l'on ne pent présenter au public, côte à côte, des types de demeures modernes, variées, de earaclère personnel, el ne conservant, dans leur discrédil, qu'un seul lien: celui d'être conçues loules dans l'intention nettenent résolue de satisfitre aux besoins acluels - lant esthétiques, que matérjels - en metlant logiquement à prolit loutes les r'essources que l'industrie contemporaine apporte à l'architecte.

Dans ces habititions, les Ä'ts appliqués de toute nature trouveront naturellement un cadre excellent el approprié au mieux pour la mise en valeur les efforts qui dans tous les méliers concourent à la réalisation d'un Art moderne. Ce seront là autant de foyers, offerts en exemple au public, foyers dont lintimilé s'apparentera avec celle de nos demeures privées el nù le visileur, s'avançant de pièce en pièce, reconnaîtra l'ordonnance des lieux où lui-même al l'babilude de se venir reposer, parmi les siens, après les journées du labeur. La démonstralion ainsi se fera plus éloquente el plus direcle, que si, dans un vaste palais, tous les arts décoratifs étaient rassemblés, fûl-ce en un ordre parfail. Rien ne pourra êlre plus édifianl, rien ne pourra mieux convaincre les incrédules, décider les liésilants, assurer la vicloire de l'idéal moderne dans 


\section{- ccxisuil -}

les esprits réfractaires encore, que ces réalisalions vivantes de homes tout aménagés, tout prêts pour recevoir leurs hôtes, vivants, en un mot. Dès le seuil, la ferronnerie de la porte sollicilera l'allention, el déjà la parure des murailles intérieures, le vilrail qui là-bas égaye l'escalitr'r, la mosä̈que du sol incileront à pousser plus loin la visite, à rérifier si l'Art moderne ćquivaut e॥ confort, en charme, les Arts qu'il prétend détrôner. Et silòt une autre porte ouverle, ce sera le salon ivee ses meubles, avee ses tentures, ses tapis, sa peinture ineorporée à l'arehiteeture, l'originalité de ses baies par où afluera la lumière. El partout, sous la main, la curiosité du bibelot inédit.

Arts du vètement et de la parure, Art du théitre, al'rangements de nos intérieurs el de nos vitements, Art de la rue, Alt des jardins, M. Roblin etudie rapidement les différents aspects de l'Art décoratif, et aloptaul la classification jroposéc par la Commission d'étude des delégués des Associations artistiques françaises, il la reproduit duns son entier et en fait, pour ainsi dire par arance, le programme de la future Exprosilion.

Au moment oì il paraîl si nécessaire d'encourager l'aclion de nos arlistes décorateurs, de nos arlisans, de nos ouvriers et de nos industriels d'arl, l'opportunité d'une Exposition d'Art décoratif moderne ne peut être diseutée. Mais ne serait-il pas possible à les parliculiers, à des inilialives indiıiduelles, à des groupements libres de dirigel l'œurre à accomplir? Nous le croyons pas. Evidemment, des tentatives ont dû ĉlre laites çì el là, mais leur portée a élé restreinte, leur action linitée, leur résultat incertain. Ce que nous roulons, e'est un effort d'ensemble, large el fécond. Comme l'a si b'en résumé M. Mezzara, il est nécessaire "que l'Exposition ait un caractère officiel".

It est certain que l'Exposition projetce devra être sincèrement imprégnée d'art, mais, avant toul, elle aura, comme jréoccupation première, la sauregarde des grands intérêls économiques français : c’est dire que le Ministre du Commerce est olligigatoirement appelé à y jouer un rôle de premier plan.

Il serail contraire ì toutes nos vues et à toutes nos idées de prélendre que le Département des Benux-Arts loive être tenu à l'écart. Bien loin de là : par son organisalion même, par ses relations,journalières, le Département des Beaux-Ar's est particulièremenl qualifié poul' diriger l'orientation arlistique de nolre pays.

Ceux qu'il faut alleindre, entrainer, ce sont les industriels, et le Ilinistire du Commerce seul peut avoir une action sur eux. Seul, il a sur eux une influence et une influence considirable. En liaison directe avec tous les grands groupements économiques qui ont quotidiennement besoin de son intervention ou de sa collaboration, il est qualifé pour prendre la divectiond'une Exposition d'Art decoratif, ne serait-elle que française.

L'organisation a une importance capitale, et M. Rohlin y insiste arec raison.

Le Ministere du Commerce nous parail désigné pour prendre la tête de l'organisation de l'Exposition. 
C'est, du reste, le seul qui possède un service des Expositions. ll est armé pour réaliser administrativement le projet qui nous occupe. $\mathrm{J}$ a une personnalité propre qui lui est définitivement acquise. C'est le Ministère de la " production nationale". A ce tilre, il devrait être parmi les premiers, alors qu'il n'est considéré que comme secondaire et que les grands intérĉts dont il a la garde ne disposent clıc lui que d'organismes pour la plupart insuffisants : le service des Expositions en est un exemple frappant.

Quoique filible dans ses rcssources et n'ayant que pen de moyens, il a su toujours être à la hauleur de sa lâche. Mais, en raison du nombre croissint des Expositions et de J'importance de plus en plus grande des intèrêts qui y sont engingés, il apparait comme indispensable de renforcer ce service en le complitant et en le rendant aulonome.

l] llerrail pouvoil assurer une direction d'ensemble à l'uccasion de tontes les Exposilions qui ont lieu aussi bien en France qu'à l'étranger. Il devrail être à même de renseigner le public à claque instant et très rapidement sur toules ces manifestations.

Dans un avenir prochain, la nécessité nous amènera à modifier complètement ce service et à le mettre en concordance a sec nos besoins.

Presque tous nos Minislères, d'itilleurs, sont intéressés par une Exposition d'Art décoratif: l'Instruction publique pour l'Enseimnemenl, les Finances pour les intérêts du Trísor public, le Travail pour lont ce qui concerne les ouvriers, les Colonies pour faire cunnaitre les productions locales, les Affaires élrangères pour les relations atrec toules les nations, bref, chacun de nos Départements aura à produire son effort el sa collaboration.

Il appartiendra au Commissarial général, sous la baute autorité du Ministre du Commerce, de grouper loutes les bonnes volontés.

A côté de l'ślal, la ville de Parris se doil à elle-même d'apporter son concours a l'œurire prnjelée. Edlle ne sampait y manquer, étant donués les intérêts considérables que r'présentent pour elle les Arls décoratifs. Dans toutes les branches de ces Arts, c'est par milliers qu'elle compte les patrons, les ourriers, les artisans. Paris est le centre, le foyer de notre produclion qu'il résume à l'étranger. De nombreux visiteurs seront altirés par l'Exposition de 1916 et apporteront un profit immédiat à notre capilale. Au point de vue moral et au point de vue malciriel, on n'aurail pu comprendre que Paris n'apportâ pas son concours à I'Élal.

Il y aura lieu de mettre un vaste emplacement à la disposition du Comilé d'orgatnisation et du llinistère du Commerce, à qui incombera cel'tainement le soin de préparer retle grande manifestation. Le moment venu, nuus ferons à ce sujet des propositions précises qui devront être éludiées par les Commissions compélentes.

Pour arjourdhui, je vous demanderai simplement d'émettre le vou suivant dont les considérants sunt ceux-là mômes qui ont été adoplés à l'unanimité par les représentauts qualifiés de toules les Sociétés d'Arts décoratifs et qui ont élé repris d:uns la proposition de loi présentée au Parlement: 
« Le Conseil,

" Préoccupé du développement de nos Arts décoratifs;

" Constatant que les conditions économiques actuelies rendent uŕcessaires pour nos industries d'Art l'établissentent de modèles nouveaux ct leur diffusion ;

"Estimant indispensable pour stimuler les efforts des artistes, des industriels el des ouvriers d'art, une manilestation internationale spécialisće à tous les Arts décoraifs el réserrée à des curres d'une insplitalion nourelle, à l'exclusion de loute copie ou pasticlıe du passé,

"Émel le vœu :

"Qu'une Exposition internationale des Arts dícoralifs modernes soil organisée el onverte ì P'il'is en 191ว."

A la séance du Conseil municipal de Paris, une diseussion s'engagea, et M. Aucoc demanda la suppression du mot moderne dans le reu.

Malgré l’intervention de M. Aueoc, le vou de N. Daussel ful adopté.

Le vole dn Conseil municipal esl des plus jrécieux.

Le choix d'un einplacement est primordial pour une Exposition. La surface nécessaire est de $20 \ddot{~ a ̀ ~} 30$ liectares dans un cadre appropriẻ, point trop loin du centre, d'accès facile et rapide, de communications conmodes. Plnsieurs combinaisons ont dijà élé suggrérées, qui toul's nous semblent devoir répondre de façon salisfaisulule aux nécessités envisagées. Toul le monde comircindra que nous ne pouvons pas nous expliquer davantage sur ce point, cap i] appartieud au Gouvernement de prendre à cet égard des initiatives nécessaires. Toul ce que nous pouvons dire, e'ust que lit question d'emplacentent stra aisément résolue ou mieux d'accord av'c lia Viile de P'aris.

D’après le vole llu projel de résolution que nous avons rapporté, il est cerlain que la Ville de l'aris ne nous mar ehandera pas son concours financier. Les frais d'une Exposition internationale d'Art décoratif moderne ne saurajent être très éleví, eu f́gard aux intérêts eu jeu. Il nous est toutefois difficile, au point de vue bulgétaire, d’ap:orter des précisions qu'il ne nous appartient pas de donner. Toutefois, nous uslimons que toules les ipéritions finaneiòres qu'occasionnera l'Exposition devront être soumises à un contrôle très sírienx organisé sous la surveillince d'un fonctionuaire responsab'e el d'après des règles précises el délerminées.

Construira-t-on plusicurs pelits pavillons ou édifiera-t-on un immenze palais ? Tout en roulant laisser la question entière, il nous semble qu'il serait peul être prélérable d'avoir recours au premier systène, qui permeltrait de créer pour un groupe d'arlistes des eadres appropriés à leur conception. Les petils pavillons aluraient l'avantage d'olfrip au public " moyen " des modèles qui pourtuient se répandre.

Le prix d’un grand palais serait plus élevé. 
Si les ressources financières ne le défendent point, il nous scmble désiralle que l'Exposition vienne en aide, par des subventions, à des artistes, à des petils artisans, de façon à leur permeltre la réalisation de leur œurre.

Le Gouvernement et la Commission auront le devoir de se mettre d'accord avec les industriels et avec les divers groupements, pour dissiper les malentendus, pour amener un accord fécond. L'Exposition internationale d’art décoratif moderne n'est dirigée contre personne, nest faile au profil de personne. Son but est l'intérêt général.

\section{GONGLUSION}

Votre Commission du Commerce, pour les multinles raisons que nous arons exposcies, est done d'acis, conformement $\dot{a}$ la proposition qui nous e:t soumise, qu'il y a lien d'n'yanist?' une Exposition d'Art decoratif mo'terne.

Cette Exposition derra etre fuite le plus tit possible.

L'amée 1913̈, a laquelle on arait songi tont ciubord, est une dute un pon mpprochee et le dilai qui sernit ainsi imparti aux exposuts seicait trop court. D'ailleurs, en 1913, whe Exposition internationale doit s'ouvrir a San-Frantiseo. Dis raisons d'utiliti et de courtoisie ont poussé votre Commission la Commerce it s'urriter. à lamée 1916.

Yous rous demundons done de voter la proposition de loi suivante:

\section{PROPOSITION DE LOI}

\section{ARTICLE UNIQUE}

Une Exposition internationale d'Art décoratif moderne sera organisée à Paris en 1916. 


\section{CHAMBRE DES DÉPUTÉS}

2" séance du 12 juillet 1912

Adoption d'un projet de résolution tendant à organiser en 1915 , a Paris, une Exposition Internationale des Arts Décoratifs Modernes.

(Jounal officiel du 13 juillet 1912.)

14. - Adoption d'un projet de résolution.

\section{M. le Président.}

Lordre du jour appelle la premièc délibération sur la proposition de loi de M. Francois Carnot et plusieurs de ses colligues, tendant à organiser en 1915, à Paris, une Exposition Internationale des Arts Décoratifs Iodernes.

M. le Rapporteur de la Commission du Commerce me fail connaitre que, d'accord avee les auteurs de la proposition de Joi et arre le Gouvernement, la Commission substitue au texte de l'article unique primitivement présenté par elle un projet de résolution ainsi concu :

" La Chambre invite le Gouvernement à nommer sans délai une Commission interministérielle chargée d'établir les voies et. moyens pour la réalisation d'une Exposition internationale des Arts décoratifs modernes, qui aurait lieu à Paris sous la direction du Ministre du Commerce."

Personne ne demande la parole?

Le projet de résolution mis aux voix est adopté. 



\section{ARTS APPLIQUES ET INDUSTRIES D'ART AUX EXPOSITIONS}

\section{INDEX ALPHABÉTIQUE des noms cités}

A

Acoulon, crill.

dilim, cxxivis.

Allemal, xcr, cx.

Ainc, xcr, cx.

Nisly (J.), cxLll.

Alsert (Prince), xxix, xxxi, xxxil.

Albrecht, $\mathrm{Cl} x$.

Ally, Lxxxy.

Ilean, cxxxix.

Aldrophe, cxxxrill.

Mlexandre (drsine), Lxxir, cxsir.

Alexandre (F.-V.), cxxxun.

Aliguy (Ienry di), cxxivu.

Allar, cril.

Nllard, s.xxxis.

Illewagne (llenry D'), xcru, dxi, cxul. cxLVH, ExLIII.

Mpliand, xxxix, Lxill.

Amiot, Lxxxis.

Amson (lícies), Lxxri, cxi, cxly.

Ancel (1'. c. cruru.

Ancelot (Alfied), Lxx, Lxirif, t.xix, xcr: i:v, $\mathrm{cx}$.

Audigne $\left(\mathrm{J}^{\circ}\right)$, cxrut.

Andre lioutes alu Vial dosise

Andlé (Ellunarl), Lx.

Andriell, vi.

Inlipe, cr.

Inglatul, vir.

Innonay (Papeterie) xi.

Iuthime, cxum.

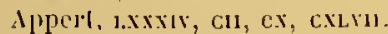

Arbel (Pierre), s.xxir.

Iroet (l), xit, Lvill.

lifvilsoll, Lxixl.

dres-Dufour, cxxxu, cxxin, cxxxr, cxxxr.

Alwan l-Culliat, xı,11, Lri, txrif, xсr, cx, CXLri.

Armand-Dmmaresq, cxxrsul.

Aruaud, crit, cxxxyut

Art el décoration, cxxir.

Alt decoratif (1), cxis.

irligue $\left(d^{\prime}\right)$, cxxs.

dotus (A.), cxxхr.
Astier', ixx.

Aubillel, xxx.

Auberl, xwr.

Aubert (felix), Lxxiv, xo, xc11, xcr, xix,

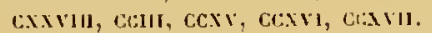

Auble, $x$.

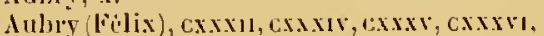

cxxist, cxi.

Jubry, cxulit.

Aubusson (Tapisserie d") $\mathbb{r}$, xcl1.

Aucoc pere Louis), xxir.

Aucoc fils (Louis), Ixxir, xcril, Cri, cal,

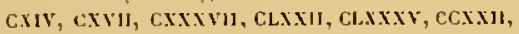
coxisix.

.lucose (Indré), $\mathrm{xcr}, \mathrm{cx}$.

Audry, IV.

Suliture, cxxyl.

dugusli, w, $1 x, x$.

Aumont (dive d'), 111

Auricoste, cxi.

luriol, txxxix.

lusseur, cix.

dutré (Gerusain), Ix.

fralle fallpiere, exxмm.

dyen (J.), CXLIX.

lyuad, xcy, cxxri, cir, ccrs.

Asribier, cxll1.

\section{B}

Bac, cl..

Bacriral Cristallerie de, xy, xxw.

Bachelet, xxir.

bachelet (L.), LI, cxL.

Bachelier, Lıx.

Badin, cru, cxxxy, cxxxin.

bifticr (Jean), I.xxy, l.xxxr.

Baguès. cxi.

Bailly (N.), xLIX, Cxt.

lialaude, cxinl.

Ballu, Lxv.

lialsan, cx.

Ballard, vill.

bisltard ('lictor), xus, cxxxvis.

bilzale, xx, xxill.

liapst, $x$, xxy. 
Bapisl (Germain), Lxiv, CxLIY.

Baijuet ( $\mathrm{Mmc}$, cixxym.

Bal', cxLII.

liaraguet, cxxix.

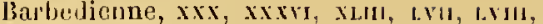
Lxxxh, cxxivll.

larbet, exxxu, cxixis.

Barbier (Léou), ו xxu. Lxтx, Cут.

Barbot, CxLo

Barhotenux, cix.

liard (F.), cxlit.

lialdin, xcru.

Bardoux, Lxxv.

Barral, cxixur.

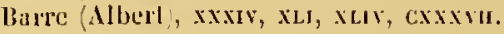

Barre, IY.

Bareaux Th.! cxtil.

Barres Daurice', cxri, Clxir.

Barreswill, cxxxr.

barsed (J.), cxill.

Barrez, Gx, Ch.

Barrias, t.xง.

bitrial, wh.

Bartholdi . L., xxxix, cxi.

bistholone, crul.

Bary (Louis de), crin, ca.

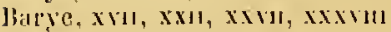

Baschel Luduvie, L.Xxxix.

Baschet (Rene), Lxxxix, toul,

bistuluit, CaL.

bastaj, cu, $\mathrm{Cl}$.

Baule (A.), crxxiul.

baude li. coxivin.

Batudin (Pierre), cx.

Baudon-Gaubdu, Ix, x.

Baudot $\left(\mathrm{d}_{1}\right\rangle$, cris, cxill, cex.

liatudouin-Bugnet, cr.

Baugrand. xы1, cxxхm.

liaudratrl, x:1s, cro, cxl.

liauzon, xvr.

bauzunnet, cxxxy.

bayeux Deutelle de, siru.

Bazile, $1 \mathrm{x}$.

Bèarn countesse de), Gxu.

Beau, xcril.

Beaudouin. Gxr.

Beasuquer, Cxvi, CLxir

Beauvais Manufacture de, vin, $\mathbb{x}$.

becker, xcriI, CII, Cix.

becoulet (Ch.), cxl.

beer, $\mathrm{cx}$.

Bcethoven, ccxin.

Belieres, cxilll.

Beliı, Lxxiy, xcex, crilı.

bellau (Léopole), xcr, Cri, cr, cxri, Caxxu.

Bellanger, xus.

Bellangerel, xus.

lieltery-Defoutanes, txxxy, Lxxxix, cxu, caxil, ecxis.
Ballieni, crilı.

Belloir (Paul), Gax.

Belluni, vili.

Bènari, vis, rir.

Béréilile I.) cxist.

Beuoist (Charles), corx, dix.

Benoiston, tix.

Béuguville, Lxxxr.

Béruct, cx, cxisult.

Berand, cxiriol.

Béraud, xciv, cx.

Bergeulle, xcris, aris.

lierger, Gixix.

Berger (Casimir), cx.

Berger (titorges), watt, Lxxy, ixxix, Gu, C111. CLXXYit.

Berger (llenri-fi.), ccrrr.

Berger-Levraull, ixxxix.

bergon, xxxist.

liergson Il. , cxxil, cLXII.

Berlioz, xxis.

bermoul, cxilli.

Bernared / $\mathrm{d}$ ), xisur.

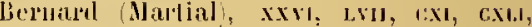
Cxtsil.

bermusille, cxisus.

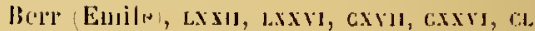
ci.1, Cixxil, Gixxill.

bertus hires, xxxi.

berry Georges, cxrr.

lierly (duchesse de, xin.

Berlaut (frès), l.xxil.

Berthier, exxxul.

Burthollal, vi.

Bertholio, calir.

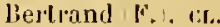

Berlucux, cxxxix.

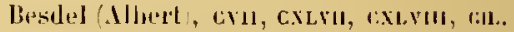

liesuard (Allielt), 1.xu, l.xxvi, xc, rchi, 1:1,

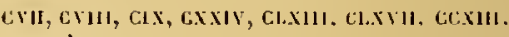

licssind, Lxxil, cx.

Besselievere, xar.

Besson, Cxxxix.

Bcssoll (J), CxLII, GxLIJ,

Besson, $Y$.

Bessoll (IIme Ji), Crith.

besl, xiry.

beudiu. cxixir.

butudeley, xxxv, cxis.

bezon, cxlin.

Biais, Lxxtx, xcy, cx, a.

Biald, Xlvi.

Biémout, cxis:

Bienmais, $1 x, x, x$,

Bieuville, xcis.

bigard-labre, Ixxi, cru,

bigratux, $\mathrm{xc}$, cvill,

biguild, cxхxтx.

bigry-l)illol, crill. 
bigot Nexandre, xom.

binet liene: rxxirt, xcar.

bing (S.) Lxxit, xi.

ling (Jareel), xerll.

bing (J.), cxxxix.

Blais.llousseron, $\mathrm{cx}$.

Blanchon, cxtul,

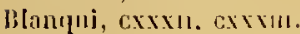

blech, xxill.

bled, xerur.

Plinull, covil.

Plin, cx, cxt.1, cxt.11, cil..

Blonilel Albert, critl.

Blondet, ז.xxix, i.xxis, ex.

blol Etupene, txryll.

Bohin 11. , r.s.1.

bodin, cxxis, cisu.

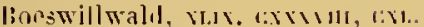

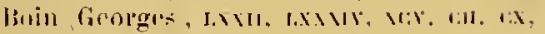
cxivil, coxili, r.all.

Boistrlivy, xwri, xxx.

lioisseall, Crul.

Boitonu, Gxiv.

lioitrail Pajul, cxxxur, cxxxull.

lhonilparte (Géniolab), iv.

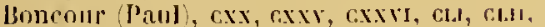

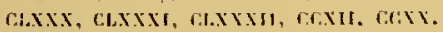

Bonliarit.

Bounaire, xcy.

Bonnial, Lxxry.

llonnal (leon), cr:1.

Bonnerot, critu.

Bonnet, xxvil.

Bounier bouis), cxxi, Lxxy, Lxxxu,

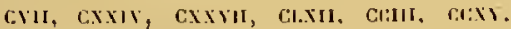
caxvi.

lionnich Franrisque), cx, cxisu.

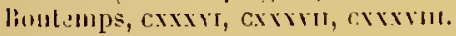

loonvallet, 6:11, 1:1x.

lionvallet, ir.

diolilas lidnani, t.xxi.

butderel, cull.

Dorilinal, cxle!r.

loiggey, cxlit.

bosqtillon, xxyi, cxxxi.

boltèe (Louis), Lxil, Lxil, t.xxmil, t.xxix, XCVIt, CIY, CYII.

Bouche? (llcory), Lxxyul.

linucher, cxxxix, clxxxul.

lioucher (Alfred), wir.

Bowher ale Perlhes, xxis.

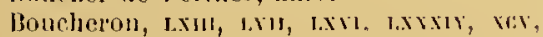
Xi:ir, cxi.

Boue, rax.

Bouffird, cxxryll.

Bougon, cxxxilt.

Boubor (J.), CL.

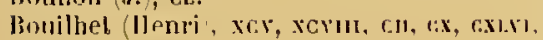
cxisil.

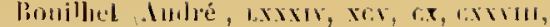
cistr, cсHI, сехин.

Bunillatril, $\mathbf{x}$.

Boulitat, cxulı.

liublenger, cx.

lioulle, ixir, caxix.

lionrulisis, t.I.

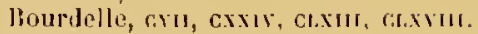

bour.I ne, Lxir.

Bourdon, cximr.

Bourgenis Charles), $\mathrm{cx}$.

lorurgeois Paul, Cu., crul, ixusul,

Bourgeois lioile, laxil, chll.

lbomgronis leéon, cxxrtr.

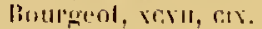

liomiger, rxi.

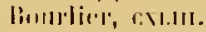

linutuel-Iulmilul, ax.

liousfyet diu, coris.

lisularel time, roxumt.

lioulroux, cixn.

Bis)urard, xivif.

Bonvar.l Roger, Lxxu, cur.

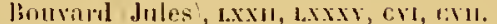

bouwens vilu der Boycur, ratl, rast.

liovy l. A itr.

lioger Pitul, crut.

Blich Arhiblel. c.s.

lirack Georges', cr.

Biriçuemomi, Lxill.

bramit, r.s.

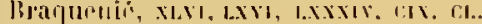

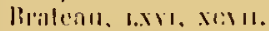

linalull, I.xistr.

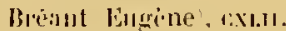

Bacer, ratis.

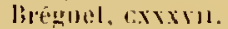

lipillot, cxisl.

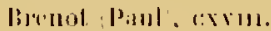

lireyans Ealunamal de ret.

Hirialal, cxilal.

hirientel.

Bricumnet lieves, II.

lirillat Silvarin, is.

lirocherie cxitu.

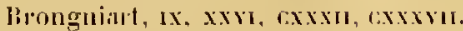

linoquelle, xxitl.

limssard, $c x$

lirossy-billumat. xas.

Brot. crin.

linonckiche de cxxxy.

lironilliud (L.), cxill.

binnet J.-L.), cinl.

limet, caxxinur.

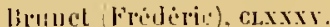

Bums, Iv.

linequel (Hanrice), cxistr.

Bugnot, cis.

liuisson Fevdinand, ccull. 
Bussot, cx.

Bulitul, cxxrouit.

Burette, ix.

Burger, cxir.

limine-Jones, Lixin.

IBurly, xxisix.

liussive, cxilt.

B:'ssy (Ch. de), cxı.

\section{C}

Cabiuct drs monailles, m.

Gaen Gustave), dxuyul

Cahies, xiv.

caillul, cxxxult.

Ciili (Georges, xcrist, cxisi.

Cain (lleni), xrilr, cxlrt.

Callol (scurs), xcr.

Camp) (Maxime du', Xxim.

Campana Collection', xws.

Callu (T.), cxl.1I.

Giapé, cxist.

Carpue, xw, xy, xxxs.

Conalsin (Rupert), xcu, cxvis.

Carayou, xr.

Giucente, cxis.

Cardaillar we', xxxix.

Gardeilhac, xcr, r.x.

Caressa, crin.

Curelte, cri.

Carez, cxxxil.

Carissimo, ex.

Calhian f, cxxxull, cxi.

Carmiclnäl, cx.

Carnot le Prosidenl), t.xu.

Canol fiancolst, xevil, cxis, rxxy, cxxy,

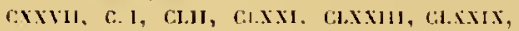

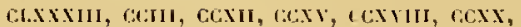
cexxri, coxisil, rexi.t.

Carol, cxxxini.

Caron-Langlois, xxvit.

Carot, xcili.

Carpeaus, xivi

Carré (Alberl), Lxil, crilt.

Carré (Georges), cx.

Carrier-Bellemse, xxxи, хxхи.

Carrière Emi'e cxisurs.

Carricie, s.xw, xr.

Carlhian, cxL.

Calribs, xcis, xirvin.

Cirterel, cxill.

Casier, crum.

Cilsse, cxxxyir.

Cassien-Bernard. I.xxxr.

Castellani, cxxxis.

Castiglione comlessa de , six.

Cilnile. $x$

Cammont de', cxxis.
Caussen, $x y$.

Gavelier, xx, xxxis, xxxy

Civillou, CL.

Caviole, crit, cxirin.

Cazin, Lxvi, xcill.

Celle, cxuIIt.

Cellini (Benvenulo), xxil, xxxil, xxтri.

Gire Etnila!, Gis.

Chabil Dussirgey. xxryt.

Chilbanue, cx.

Chabran, cxitit.

Chnbricres (lug.), cxis.

(:)aguon, cxtul.

Chnise Jules), x:iv.

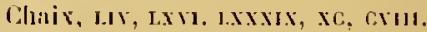

Clistain L.j, rixi.I, CxiıI.

Clinlamel, cxixix.

(ihambon, cxirus.

Chambre de Commerie di: lyon, xxx.

Chamhre de Commere de Paris, xxxu.

Chambre syndicale ile I Ebenisierie, ccrvil.

Chambre syadicale le la Bijoutere, Joaillurie, Orfeverie, ccrini.

Chambre syndicale the l'llorlogerie, sr.

Champagny (de), :xxx.

Champ de llars, IY, xxxix, LI, LY, LxIII.

Champenois, Lxis, Ixxxix, cril, cxLIs.

Champtleury, xxxix

Chanpier ('ictor), xix, I.xi, Lxxil, Ixxur, Lxxit, Lxxis, xc, cxxi.

Chanée, cix.

C:hanoine Beusens, cxult.

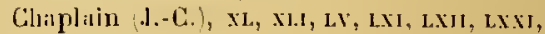
Lxxivir, cris.

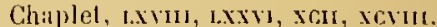

c:loplin, xws.

Chapon, crits.

Chapsal (liernand), Lxxir, cr, cri, cxirr, cxwill.

Clmptal (comle), v, cxis.

Chapu Il.), xxxix, cxhi.

Charbin (Etienne), cxuvis.

Challes X $(\cdots i)$, xi, xхті.

Charlel (11.) cxiri, cxliI.

Charpenticr Alexandrel, Ixxr, xcu, xcrus. Chartron, xxvir.

Charvet, cx

Chassiligne-Goyon, clxxil.

Chassaing. Ixxi.

Chalel, xar, cix. cxi.

Chaudelon, caxsurr.

Cillaulnes (duc de), Lx.

Chamnes (Geull'oy de), xx, sxxis.

chaumel, xavi, axi.

Chaumié, เxxu.

Chavะs?, cLxxxy.

('lauvin (Mlexis, cxisut, ।..

(:Jebeaux, xxxis.

iliclann', cril, CxNor, Clxil. 
Chenavaru, xum, xix, xx, xхи.

Chennevicles ide, Lix, Lxul, Lxxr.

Cilı̈ret Jules, hxir, Lxxi, I.xxxix, xe, xaı, xerr.

Cherfils (Christian), cxirs, cixu.

Clièruit, cx.

Chéry, caliry.

Chesneau Ernest, xxm, cxxxul,

Chevalier Michel xxro, xrxur, xu, xurr, cxxif, cxxxul, cxxxs, cxxis, cxxwo.

Chevalies, crull.

Cheveran L.), cx, cxisul.

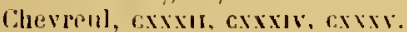

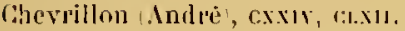

Cheveron, cx.

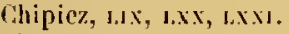

rhiquet, ext.y.

Chocrqued, sxxum, cxxiols.

Choiselit, xxir.

Chorpet, cxis.

Choulens, Lxxix.

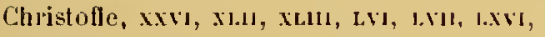
Lxxi, xcy, cx, cxxxy, cxxiry.

Guard, xis.

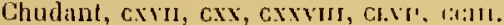

Cicéri, $N$.

Cirey (Cristalliries da) . xy.

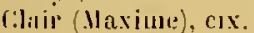

C'arelie (Jules', xcini, cxus.

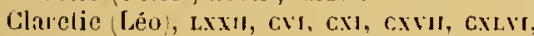
i.s..

Climandot, cxis.

Clnẻat, critur.

('nchin (Denys), crus.

Cuchin (1.), cxisurs.

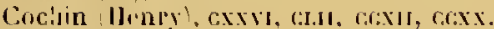

fereumbrey, coms.

Cognact. cx.

Colien-Stuart, $\mathrm{cx}$ u.

Coignet (11.), ,xxxix.

Colcombet (.1)ex.), cxis.

Colin (E.), I.xxxu, cxis:

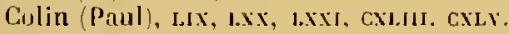

Collas (delitle), xxro.

(collin (Raphaël), ixxxr.

Colmont (delille dw), xv, xx, cxxrx.

Colonna, Lxxre, xch, xar, xстr.

Comité lrancitis des Exposiliuns al l'Etralu-

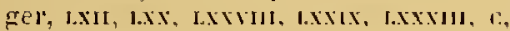
cul, CXI, CXI1.

Conte (Iules), Lxiu.

Comte (dirguste), cis, caxir.

Congres des dils dicorotifs ts69). xixux.

Congles diss lits decoratifs (1894), Lxx. IXXY, IXXY.

Congrès des Arts industriels (1978', Lrm.

ronquet-Carteret, r.xixix.

Cunservatoire des dits et lieiers, ur.

Constin'-'Bernard, crir, cix.
Conli, vi.

Copenhague Manufacture de, Lxim, xas.

Corłbière (conte de', xr, cxxxr.

Corderier, xw.

Cormon, crir.

Cornil Georges), ctl.

Comille, Lxxir, scrv, crx, cxlyis, ca.

Cornwallis (Lord), vil.

Corroyer, xcy.

Costaz (haron), vi, vi, vil, xif, xur, cxxx.

Cotlier Mauric:! cri.

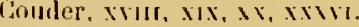

Coudlyesp, cax, cox.

Contuin Clatude? cxx.

Cusulon, xcru, Cxr.

Coulon aini), cxxxs.

Cumpit, crxivil.

Courcier Alex.l, cr.

Courlet, cixist.

Cousin. Lxxxr.

Couly (Edme), xa, xar, (n.

Convreur (Lonis), t.xxix.

Conyba Charles-Maurice), Lxxı, Lxxin,

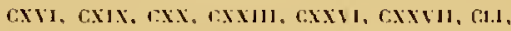

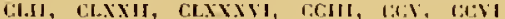
ccxxif, cexxint

Cox, cxisul.

Cralse (Wallor, txxir, caxisu.

Greil biëences de), xw.

Crespel, cx.

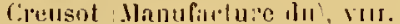

(itillet. xivir.

(Gochet Ach. cxxriul.

Cros (Ilempi), xem.

Cro-ville. cxixix.

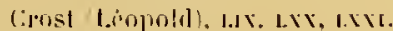

Comolé (11.), cxi.l.

Crozier, xivis.

(implui (Jeau), txxil, Ixxill, cxst, cxx.

(Cicluelet, cxis:

(anil' al timoire, cxxxix.

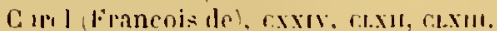

Curnicr, xwrul.

\section{D}

Dafripue, xxit.

Disuel "t Cie,

Daiber (1I.), cxxsix.

Dililancourt, cxxхгк.

Dalluz Pilll, xxxix.

D unez (C!I.), cxilı.

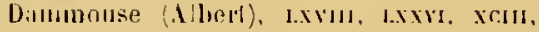
Xivill, CH, CIX, CCIV.

Dithol, raxxis, Xch, t:19.

mampit J. , xcril, cox.

Dituliunt, cix.

Dorilenur, cxisu. 
Darintom. exxitt.

Dirroux V.), cxxxim.

Daubergne, xxr.

Daum, Lxxxi, Lxixis, cx, c.lm.

Daumont-Tournel (L.), scrir, cxist.

Dauphinot. Cri.

Dausset (Lonis), LxxI, Cxil, cxxil, Cl.xxxi, ccxinif, ccxxil, ccrxxix.

Daulel (Pierre), crir, cxirr. cxil.

Dauze (Pierre), cvir.

Javanne, cril, cxxirit, cxi cxli, cxlur.

David, $\mathrm{Ir}, \mathrm{v}, \mathrm{x}$,

David (A.), CIL.

David Felnand, cxrvir.

David d'Angers, $x$.

bavid-Ilennel, ixxu, xry, $r$.

Davioul, xrmut, I.I, I.Ix.

Daroust, cxi.ut.

Jawant, cirl.

Debain, loxix, Lxxiv, xas,

Debès, crur.

Uebon (Ant.) crxxix.

Decazes (lue), xu, cxxx.

béchelette, xcrr, cxiru.

Dete, xxix, Lri.

Déclosieres R.), cIL.

Decorir, сан, слх.

leenrchemont, cix.

Dedel (Panl), Lrin. crxrir.

Defour, CXL11.

Defrasse, cril.

Deglane, Lxxxy.

Degrand (E.), cxxxir.

Dehesdin (Georges). cx. LIL.

Delaeroix (Eug.), xir, xim.

Dolagrave, xxxix, ixxxy, Lxxxix, crü.

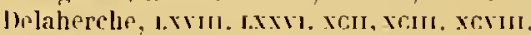
cix.

Vlelalajn, cvisu.

Delamoriniere. rasul.

Delard Engènel. cal.

Delaroche Philippe', cxixru.

Dulaunay-Belleville, Lxxrm, Lxxx.

Délégations ouvriéres aux Expositions :

Amsteriam (1983), cxir.

Anvers (188:5), cxuli, cxilur.

Chicngo (1893), Lxixts.

Londres 1851 ef 18503$)$, xхxй.

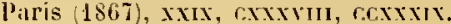

Paris (1878). cxis.

Philarlelplite (1876), I.

Vieme (1873), xlı, coxxxux.

Delessert les (rères), ir.

Delesserl (Benj.), cxixit.

Dellitye, cxxirit, cxi.

Delicourt (Elienne), rxis, xxy, sxiv.

Midieux, cxir, ccrir.

bellepiane. rour.
Dellerba, cxir.

Deluias, crin.

Delombre (Paul, Lxirit.

Demachy (Roberi), crir.

bemar, cxt.

Deuay, cxxruir.

Demaria (Jules), crmi, cxlvir.

Demessirejean, crxxr.

Deneirousse, $x y$, xxir, $x x x$, cxisil.

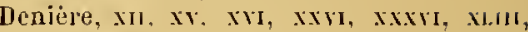
cxxxil.

Denis (Mlaurice), Lxxxy, xcm, cxxir, chxul, clxvilt.

Denis-Dosen, cxlil.

Denlroux (J.), cxi.rt.

Depaulis, xix.

Depouilly, xr, sil.

lerville (Slóphanc), I.xxm, I.xxvir, Ixxxy. cr, cur, crrit.

Desbazeille, xisu.

Desbois, Lxiri, xcm, cxxxru.

Descubes (Amédée". I.xx.

Deslosse E. E. Cxunu.

Desfosse (Jules) axivi, cax.

leshatrs, Cls.

I). sjardins (Panl), crxis, cuxu, lixur.

Desuaisons, cxlm.

Despres (Felix), cxi.

bespret (Georges), cx.

Destrées, cxxIr, CLY, cl.xH.

Destrés, cxxix.

Desvillicres Georges'. criv.

Delaille, crir.

Deflomas llax , fis.

Devambez. xc.

levilwril, cll.

d)repia, xx+11.

Deviz", xwrl.

Deville. exxiry.

Derille-Ciarollin. cxisı.

Devais, $x$.

Dezermeaux, cirt.

Didot Jules), xir.

Dillot Pierr, v. vir. vir, xvi.

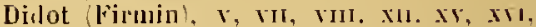

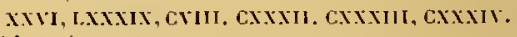
Didot jeune? Ir.

Dirlron, XIII, LIY, CXLI.

Diélerle, xxxix, cxximr, cxxirr.

Dielz-Ilonin, cxi.

lieubuné. cxxrum.

Dighy-Wyalt. cxixiul.

Diomede, Lxil.

Dill et Guéral'd. ハ, vir.

Dout Taxile, xcmr.

I) euillel (G.), scr, cx.

Doignoll, cxills.

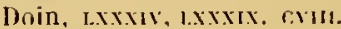

Duiziry (P.). co. 
Doll, ex.

Dollfus-Jlicg, mu, , w.

Dollfus (E.), Cxxin, crxil.

Domange, Lxxil, crx, cxisu.

Domby (P.-C.), cxxxix.

Domergue 'J.), cxis.

Dommarlin, cxrsurl.

Donckile, cx.

Dorval, cxxxyur.

Dosburg (E.), crxxun.

Uouay, CXLII.

Doudeanville (Iuc de), crix.

Doumerc, cxrrvir.

Doumergue, txxrm, xсти, cxx.

Dreyfus (Gustave), cru.

Dreyfurs F.), r...

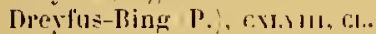

Driron, r.xxus.

Drom, rixs.

D'Il Léon), Ixx.

Diucsne, cxral, crimu.

Duban, xist.

Dubief, I.xxwit, cxis

Duboe (llenri), a.

bubois, cxxwal, cxtoll.

luhuis (Ilen:i', rax.

I) muldé, LxI.

Imbriuluz, rxix, crum.

Jubret (II, , cryi, cax, ccry.

l) bule (finillame), си, сти, схи.

Duché, xxrit.

linchel (1.), xcril, r.xivi.

IHclair, cxlut.

Mutuing (N), cxxxvu.

l)ıfaul, cxis.

lufourny, cxlis.

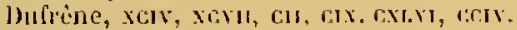

Duliayon, cxir.

Wuhem (Henri), cxxi, (:1.

buillon 1.-B.), (:xxxir.

Mujarlia, t.xxxix.

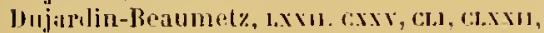

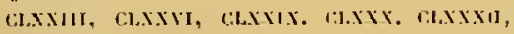

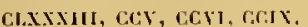

Dulong, זxxxi.

Dumarest, ix.

Dumas, xcif, cxut.

Dumas, cxxxı, cxxx11, cxxxul,

Jumas (Juslin), cxxim.

bumns-Descoumb's, xvi.

Dumout (Challes), cxxv, cr.m, roxu, coxx.

Duminthier, cxiru.

1) upagny. c.xi., cxilu.

Dupard, CL.

Dupin (baron Charles), xwm, xxx, cxxy, cxisiy.

Duplan, xcr.

Duponchel, xrit, xum.

Dupunt (Pne1), xxis.
Dupont Emile, 1.xx, Lxxix, Lxxxy, cr,

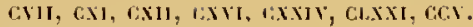

buprat llite, xcry.

bupré (Viclor), ccrs.

Duj)ré, CXLt.

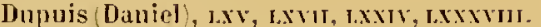

Iupuy (Jean), cxx.

Dupuy (Ch.), ci.

Durand (J.), cxxxix.

Duraud, x.riv.

Durand Amedé, cxxxu.

Durind, cxxis.

Duruy Victor, xus.

Dusautog (dug.), cxxirul.

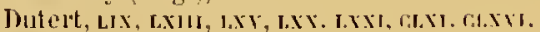

Dulleih G. . cxirnu.

Dity C.-L. , (xi.).

Duval, xrill, rixt.

Dıvivier Benjamiı, ı, ハ, Мı, хи.

Durelleroy, list, cx, cxrritl, cxi..

\section{$\mathbf{E}$}

Ehelumen, cxxim, cxxxm.

Eralle, схи.

Ecole d'apprenlissage de Touroing, cxur. licole d'At decoratif the Limoges, t.Ix, cxx.

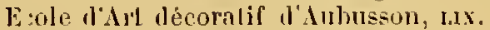

Erole des Beaux-Alts de Paris, l.1x, ccru.

Erole nationale des dils industriels ile koubaix, Lx, cxir.

Ecole de lit lsijonterie-Jnaillerie-Orfivrer"a", xi.tI, L.15, cxxi.

Ecole de la Bijoulerie fantaisir, cxxr.

Erote de Bijouteric et d'llorlogerie de lyon, cxis.

Ecole de Ja Chambre syndicale de l'llorlugerie, LII, axxi.

Erole du Bronze, cxir.

Ecole de dessin de lomilres an sumld fiensington, xxxilir.

Ecole de Dessin ct de Malhematiques, 1.1x.

Eeule de l't bénisleric, l.r. cxxı.

Ecule de la Ilenuiserie, cxxi.

Ecole municipale Bernard-Paljss, LXXI.

Ecole municipale fermain-Pilon, ו.x, וxx.

Ecole de Dentrlle dissoire, cxxi.

Ecole Nitinnale il's Arts Deromilils, I.1. I.xx, I.xxi.

Eck, xxw.

Fogly ul lioux, xxin.

Egrpte vice roi d ${ }^{\prime \prime}, \mathrm{xl.}$

Eiffel, txill, Lxy.

Elkington, xix.

Engel, Lxxis.

Fngelmann, xix, xxil, Ixxyx.

Engisin, croxuru! 
Enoch, Lxxxix, crilt.

Epeaux, xсы.

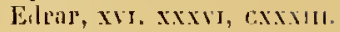

Erazzu (IImc), xis:

Estrault, nit.

Esncult-Pelterie, $c x$.

Espinouse, rxum.

Estien llanrice, Lxx, t.xxrit, I.xxix, crt.

D'Estomelles ile Constiul, cxrvir.

Elllinger, cxi.

Eugénie iunpéralrice, xur.

Evetic, cru, cr.

Exuer C.-F. , CNI.I.

\section{Expositions :}

Imien:, xxint.

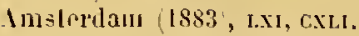

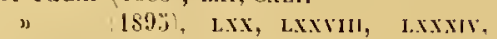

cxise.

Anvers 18Sä, LX1, LXII, Cxvil.

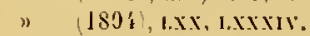

Bircelone, xxrit.

Bertill, xxis:

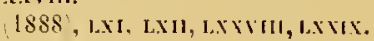

Berne, xxril.

Borifoanx, xxvm.

$$
1 \text { 18?2, L.I. }
$$

" 1907 , cix.

buselles, xxrm.

"1888!, LXI.

" libre estheliq.1e, 189' . Lxrul.

"1897, Lxx, Lxix, Lxxx.1, Lxxy.

1) $1910, \mathrm{c}, \mathrm{CI}, \mathrm{Cr}, \mathrm{CXI1}, \mathrm{CXI}, \mathrm{CXY}$

coxix, coxis. coxis.

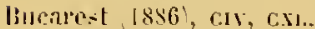

buenos-dires : 1910, cav.

Cacell 1803', xxrmr.

Clicago 1893 , Lxx, Lxxym ì Lxxx, t.xxxw C:XIIN.

Cuprullugue (Irl décomatif francais, J909? c., GI, CXII, CIL, CGXXII.

Dijoll, xxrur.

Dublia (1997), cre, chl.

filurence, xxims.

Gand, xivill.

G'asgow 1901), cxixix, cill.

Gremoble, xxrint.

J):กnï (992-1903), c1v, cxLII.

Lillsinne, xirml,

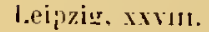

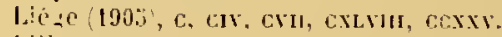

l.illin, xxvils.

Lishoune, xxru.

Lontles imnivisollis et iusermationale,

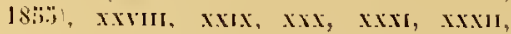

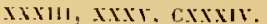

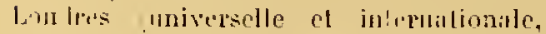

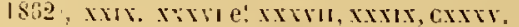

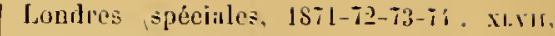
xlyII, cxxix el xi.

Londres (francaise, 1890/, Lxx, Lxxvur.

" (rianco-britannipue, 1908), c, crs, Ca, CXI, CXII, LCXXXII.

Lyon $1872 \%$, XL1II.

" (159i), Lxxis.

.lladrid, xxril.

Melbourue 1880 , เxт.

Netz, xxini.

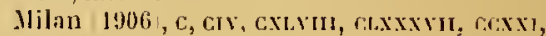
ccxist.

Moscou, xxvmu.

" francilise, 1891, I.xx, t.xxvil ol ix. Inuiıh, xxrull.

" (anl molerne), cxir, caxisur, cras. Niney (1909), cxill.

Vinles, xxim.

New-lork, xwm.

Paris: 1. - Exporilims nalionales industrielles.

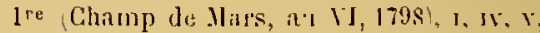
xxy, cxxis.

20 (L) Lovre, an IX, 180 /, I, v, xxv, cxxix.

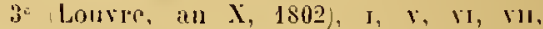
xix, cxxx.

fe (Esplanate des lnvalides, 1S06), I, III, $1 \mathrm{x}, \mathrm{xi}, \mathrm{x} \mathrm{xv}, \mathrm{cxxx}$.

5e Lonver, 1919', xit, xull, xxw, cxxx.

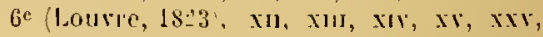
crix.

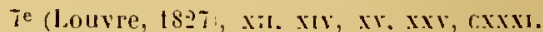
se (Place de la Concorile, 1si34, xvm, xix, xxi, xxi, xxy, cxxxi.

9. (Caryé Marigny anx Champs-Elysies,

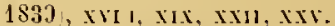

10e (Carré Marigny alx C'Lanps-Ely'sécs, 18'f), xver, xix, xxur, xxy, exxis.

lle Carré Marigny a'x Champs-Flysees,

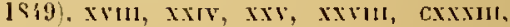
cxisis.

\section{I'aris: B. - Ermosilions universelles el intronationates.}

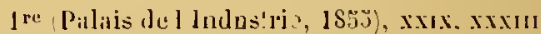
i VI, Cxxx's:

ge Chitwp de.Mn's, 1S67), xxix, xxx x, xil it VII, LI, Cxxxvi.

8e Chimps-lilysies, Champ de Mirs el Paca res invalide-, 1878 , xhra, 1 i I.NII, CXis.

40 Champs-lilysies, Champ de Mars el

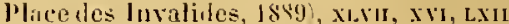

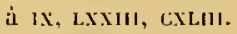

"שe Champs-Elysées, (hamp de Nils's il Place des Invali jes, 1!900 , I.xx, I.xxy it NCI, CXLY. 
Paris : C. - Exposilions ditersos.

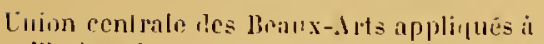
Inuluslrie $1863,69,6 \%, 69,74,76,80$. xitx, xxxix, xist, t.x.

Union centrale des Arts Decoritif's $18 \mathrm{~s} 0$,

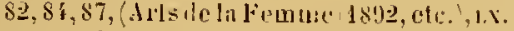
Musée Galliera, L 1 , cxxx.

Silons des Arlistes lécorileul's, $1: 11$.

Exposition de lil leur legi), Lxxir.

Prujet al'Exposiliun de la Plante, txx, lxxir. Salons du Mobilier $(1902,6,8,11)$, cxiv.

lixposition internationale des Arls deco-

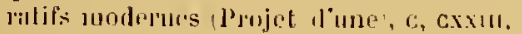

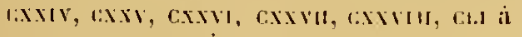
1:1.X, Ci.XI, CLXIX il ci:Xul.

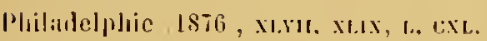

honse, cicxis.

linubaix 1911 , ces.

liown $1896,1 . x \times x y$ :

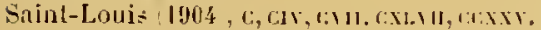
Silint-Petershour: .xim.

$$
\text { - } \quad 1899, \text { Lxxy cxis. }
$$

Lxxis, chis.

lits decoralifs, 1931-?

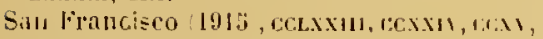
cexl.

Saragnsse (1908, cir, cxul, kil.

Slockliolm, xхvin. cixisine

Irls decolal lis, 1909, cxur,

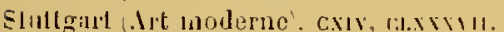

Silniay $(1879)$. Lxi.

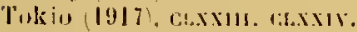

Touluase, xxiur.

Toutcoing 1906 , cvil, atx.

Triestr, xivilı.

Tu:in, xxym.

- Mrls décomitils modernes, 1902. cui, civiu, ci.xxxy, ccxxi.

Turin (IJ1), c, CJy, cxm, (xvil, cl., cixlx,

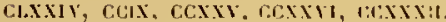

Valenciennes, xwill.

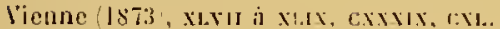

Vi.mn e crxixin.

Washingion, xirati.

Zuricl, xirul,

\section{F}

Failliot, ixxm.

falguice, вxv.

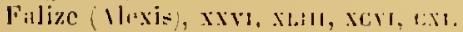

lialize (Indlio). Cr.

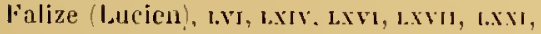

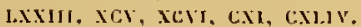

lialliares (le président), cxxur.

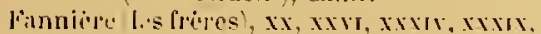
XI.11.
Falleher E. . xGe

Findela J. Dr, cxisuta,

Parcheur (Ell.), cxist.

liu:duied-Delivigne, c..

Falleunnice, xis, xiv.

faulex cxxis, caxivi, cxisul,

fialde Maldice, cxvi.

lane lean', l.xin.

faute Le Page, laxix.

Favolte, coris.

Fivie-lleinlich, cxi.

Fĕau, cxi.

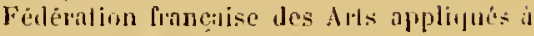

l'Industrie pojel, axxrut.

Fiilix, xcy.

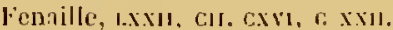

Feria (1.), cxis.

Felis E. Exוt.

lecroud, txxxix.

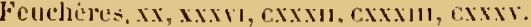

licuillalle, cxx.

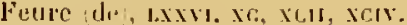

lijphter .l. , citil.

Findierit, l:xxilt.

Pilliul. vin.

Fillot, cx.

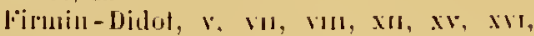

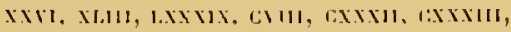
cxxis,

lij\%:ill, xxw.

Fichal stéphanc, xvm, xx, taxis.

lila ssien liemes. xxw.

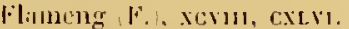

lifertiot Pand, elxxix.

l'obitu les flepes, Lxxux.

frlıury, Lxixid, crin, cxis.

fucillon, M.tul, cxxisix.

lioires, 1,11 .

Fio: In chatles, $x \div$ cix.

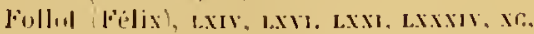

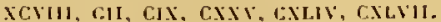

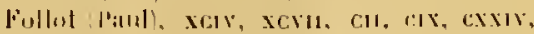

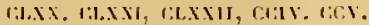

lomein, x.

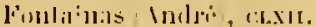

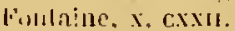

funlenily, XluI, NIIS, CXI.,

Forilin, Evil.

finfuentin, exrm, cu.

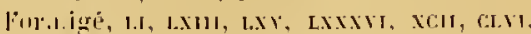
bisi, risivi

Fornet, Lxxily, cxi.

Fols"er louis), cxxis.

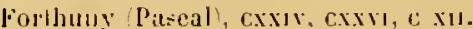

Forticz, w.

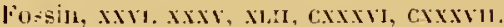

linai lée, coxis.

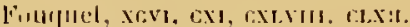

lonulua.! de. corvi. 


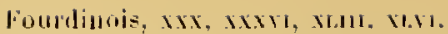

fouret (R. , crill, cxi, cxLIx.

Founel, cxisix.

Fournel, cxlits.

Foumier, xcrs.

Finnier. rxillu.

Fox, vir.

l'raenckel, cx.

Frapont G. I. Lxxru.

Frantz-tourditin, Lxy, Lxxy, IXxxi, cVir,

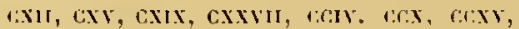
corvi, cexvit, coxiri.

frémiet, xcry.

liemy (E), cxxxus.

linichot, $15, x+1, x+1$.

lilitsele-Estrongin, crin.

Froment-sleurier, vill, vil, xill, xitr, ivi, xखm.

Finment-llentice Emil, xxy. M.ıI, m.1. I.Xivi, xcy.

Fuchs Ed, ), cxxxyוt, cxyxyur.

fillon. 1.xuा.

\section{G}

Riabel, cxisti.

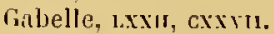

Galorelle, cxxxix.

Gagnenu (Georges), Lxxxu, xcrul.

Gaillard Lucien), xtirt, CXI.

Gaillard Eugine, Jasir. xc. xcu, cir, cox, ex:xxys.

Gidillard, cxis.

Galichm, xxxix.

Gallonil, xxxix, I.xy.

Gillle, N.

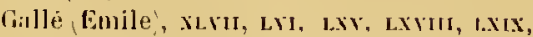

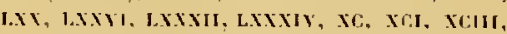

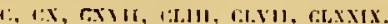

Gialles (Pritue de), swor.

(iil!i Ilenrj), cxyII, raxxx.

Gallicio (lusée), git, fxvin, coxxs.

Gisllot, cix.

Gaune, xir.

Gitnue J.-.l. , crovull

fiartet, tril.

dimpiel Paul, cxlis.

Garn er (C..), xњ.

Garnier, xcm.

Gilsquet, cerr.

Gastimne-Renetle, I.xxu.

Ciiston, CXLY.

Gaulin, xcm, cIx, Cxisul

Ginumont, crisr.

Gounin, cxxxix.

Giussen, lo'l1, cxxx11, cxxxi, cxxxy, cxxxy, CXLI.

Gilulhiep-Villars, I.xxxix, riuls.
Gautier Ch.-1., LXy, Lxxxy.

baulier Theoplile), xxm, xxm.

Gaulhiez (pierre), cxxr, caxur.

Givarn;, xirl, xxirl.

Gaveau, crilt.

Gay, cxliII.

Gilyet, sxilr.

Gaviard, ril1.

Gazet te des Beaux-dits, cxxy, cux,

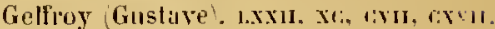

Ge'ger, xxrs.

Geiger (le), CL.

Geisler, wxil.

Genty, oxxxy, cxu.

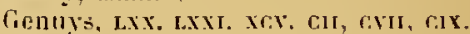

Gollias, risiol.

licoffroy do Chamenos, $\mathrm{xy}$, vivis.

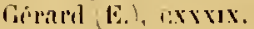

Geriult-fillon, sxy.

Gericault, xrll.

Geruain, txis:

Germain (Mphonse), rixur, rixur.

Gionme, xxxix.

Gerschel, crill.

Cierson Davil), crrxull.

Gervais, cxcim.

fieismar, cx.

(iissé, xxill.

Gide (Andrè), cxrr.

Girle Charles, cxxir, cisy, fisx, coxul, ixcrili.

Gillet, $\mathbf{x} 1 \mathrm{x}$.

(iillot (Charles), wxxix.

Gillon, crirr.

Ginisty Pilul, cxxir, Gixu..

Giraldou. I.xxwix, cix.

(iilitrd. xxwir.

(ijmal lime), cxxyra, axxis.

diirardin .llm"de〉, xwו1.

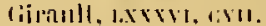

Giboulon, ixxxim.

Girod, $1: x 1,11$

Glatstone, xuru.

Gleize (Jules), crill.

Glorieux, c:x, cxıvut.

Guhelins Manufachure des, III. YII, Ix, xcu.

Guhert, 11.

(ioleete, cxxrim.

Gorlefroy. xxyr.

Gody, cxit.

Goldeubers, crixir.

Gorce (Pierra de la) xur.

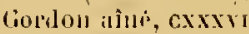

Goltvilles, Ixxu.

Goujon (Jean), cxrı.

Grunouilhou, crutr.

Gourlé (11.), cxirir.

Goniard, cxxxrx.

Gionthière. nu. 
Gouttiene, crits.

Grandhoune, xust, cı, cix.

Grundigneaux, cxvi, cxx, cxxк, cxху, CI.XII, CCIV, ccxisiv.

Grant (Président), xux.

Grisset, Ixy, Jxx, Lxx, Lxil, Lxxit,

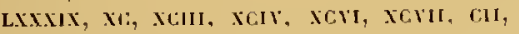
cix, clxix.

Greaard, Lxxy.

Greffuhle contesse, , ixul.

Grésoire, ir, vir.

Gremer, cxis.

Grémeret, cxxsix.

Grémustud, $\mathrm{x}$.

Grenier, cxis.

Grevedun, xxvill.

Groltier, cxumi.

(iros (Barou), cxsxu,

Gros (Lucien), txxxw.

Ciros-Davilliers, xvi.

Gros-Jeitu, xiriti.

Gruel, Lxit, xi, critr.

Goruhier Cla., tist.r.

Ginyer, xisul, fixsix.

givẻbin, rixill.

Goerind, 11, vir.

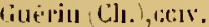

(iuériu, Lxxi.

liuer's, r:SLIII.

liuesdon, i:xLIs.

Giveyton (A.), xxi, axx.

Guibal-Anne-Veaule, cxixu.

Guiclard, xxxym, xı.и, cxxтин.

Guiffrey (Jean), Lxil, cxit, cxxis, cll, ctxx.

Cinilfrey (Jules), u, Lxil, Xit, crit.

liuignaid, $\mathrm{tx}$.

Ciuilbett, isn.

Guillaume (therl), Lxisi, (:ill,

Guillaume (Eugine), xxxix, XLII, LIII, I.Ix,

t.xx, Lxxi, LXSY, HXXY, CH.

Guillaume (Andre), t.xsi, LxxIY.

Guillaunout, cxxix.

Guillaumot, Ix.

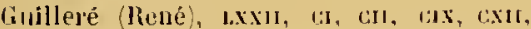

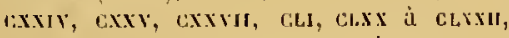

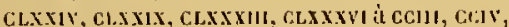

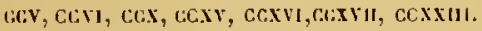

diuillol, Lxxry.

Guimari, cil, crit, sxi, ceis.

Ginimet, xy, xxin, xxx.

Guinet (J.), cxis:

Guinier, xcril.

Ciuinon, xivir.

Guisl'hau, ccxis.

Guizol, xxiu.

Guyill, r:Ly, Co,xır.

Guvot, ax.

Gilyot (lvest ixst ril.

(iinlon. llorveill, is.
Hache, Lxxxiv, cx, cxuy.

Ilache-Trest, cxilII.

IJachelte, Lxxix, crild, Lxix.

llidrot-Bilınul, $\mathrm{cx}$.

llaires, cix.

llalbout, $x$.

Ilalimbourg, A., : 11..

llallays André xrxur.

llamelle (Henry), cxisu.

llamm llemri, cıx, ccs.

IIamot, xLI, LXY, LXXXIY, dIx, cxis.

IIauali Cls. , ce.

llanser, cxulI.

IJant Lotis', Lxx, Lxxxis, cx, cxis, cow

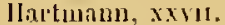

Ilaphann Geopresi, Lxix.

Ilartmanu, Ixxxis.

IIAllugr, (:Xte.

Ilaussmann, vill.

Hausswaml, xxxix.

Ilavird Henry' I.xsi.

llisiland, txinis.

lliven, bis, cxiry.

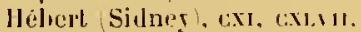

llübert, xivil.

Ileckld, ix.

Ileller, isis.

llénin, i:xisc.

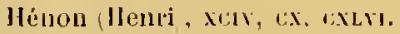

llenry (1). xistr.

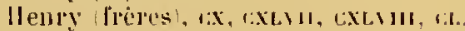

llepp Pieme, cxir, cuxl.

Ilerlıan, $\mathrm{r}$

Mericart de Thury vicomte, xa, cxrx. cxxxi, cxxxi, axxill.

llérissey, txxis, arll.

llermann, xxxvil.

llerman, ixxryti.

Ilerman (Jacques), Lxxir, ‘:ı).

lléron, cxisl.

llèron de Villefosse, cxxxi.

Ilerz, xis.

l]etzel, Lxir, Lxxxiy, Lxxxix, cy, cyil,

Jugel, s.xxis. wul,

lleurgon, crxisul.

llirseh, cxirl.

Iliptz, xint, xerti, a:s.

llittorf, xin.

IJoden, cxLII.

Iloulschel Georges, xi, cu, cxisu.

IJoganïs, ccxxrul.

Hollaude, lxxi.

Honuré, cax.

Horric de Beaucaire comle, rxu.

llorteloup. crir.

Jothot, Ixxxil, Lxxxil.

Ilutulajlle, cs, $a$. 
Houdon. cesir.

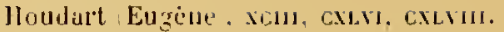

Itour, cxi.

llubert (luseph), xxin.

tlubert (Lucieu), xcrur.

llubert de Vaulicr (D.), coxisir.

Huet, $1 x$.

llugo lictor , xre xxil1.

llumbert. cxi.III.

lluret dules, cavit, CLVir.

lluskissen, xxtx.

llyde James-II.). Lxxil.

\section{I}

llock Lxixit, xchl.

|mills. $6 x$.

ludy Viucent d, ccxul.

Ingres, xill.

Isibey. $x$.

\section{$\mathbf{J}$}

Jabiul J. . cxill.

Jalsuuf, cxi.

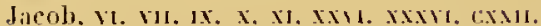
cixix.

Jacob-Desmilter franeols, $x$, xu.

Jacolsi de cxxilu.

daequard, xill, xr, Lillt. txilt.

Jieipuemind P.), corint.

Jacqueuart, vi, vm, Ixv.

Jilcquemart i3.), Lxis.

Jacquemin, CXLV.

Jiscifuemont Pilul cxis.

Jacquot (Albell', cxisl.

Jacta, Xсvi, cxis.

Jilla, Lxxi, cx.

Jaumes trancis , cril, ax 1 .

Janin Clement, ixy, oxrm, cxis.

Janin E. . cxxivin.

danisset IIac', xxy

Jansen. Lxir. XCII.

danvier. CxI.

Japuis. xroul.

Jillute 1. cistax.

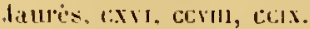

Jatrilus. I.xxit,

Jaliey louis. Gx.

deanest. $x$, xxxir. xxxis.

Jean Geol'ges! xchi.

deandyety. vir.

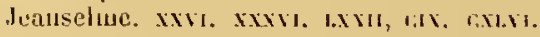
i.IL.

Jentoll, xall, cix.

Jotipe, cxis.

Joindy, Lxi, xas.

Jomes dobu-fo.) naxum.
Jolut-Desclosieres, crim

Jorranil, xcir.

Joséphine (impéralrice), и

Jouanny, Lxi, Lxxiv, xc, $\mathrm{CIX}$

Jouberi, vi, vill.

Jougla, crill.

Jourdain (lerant\%, t.xxy, txxry, crit, cxit,

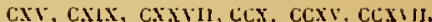

Jourdain (Fred), cxxxrir.

Jourdain (Eug.), cxLs.

Jomrdaiu (Fancis), Lxxxir.

Jourdan, xxis.

Jonveuel IJenry de). Cxiri, CLr, chrxill.

Jouvet, vi, rII.

Jonvil, xxir.

Jouy (Manufacture de', vin.

Jovidoux, citil.

Jozuu (Marecl), Lxin. cr.

Jutard, GXL.HI.

\section{K}

kaln Guslave, cxwh, cL.x.

liahn Paul, cx.

karbowsky, xar.

Keittinger, cxixul.

lieller frejes: $\mathrm{xer}, \mathrm{i}$.

liester. rir.

Kessler comle, cixni.

kielfer. cix.

Kinsbourg, $\mathrm{cx}$.

Klagmanı, xx, xxxi, xxxull.

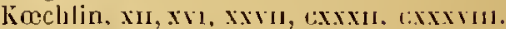

kechlin (hayuond), all, crx, cxir, cxryu,

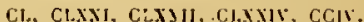

Kachlin-S.hwarly, cxtı.

kuller. crixs.

líantz C. . L. LI, LXXX. LXXX11. GXLt. GXLN.

Kriegck. cis.

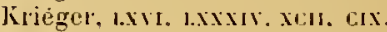

krog. IxiIII.

\section{L}

Labare, exxivut.

lahorde, ixxirir.

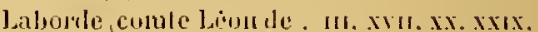

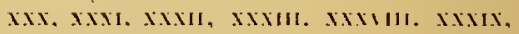

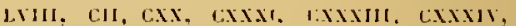
cxi.J. Gix, Clxy.

labouigue, cxi.1.

Labonlaye, cxirint.

Labusquiere JolıI . I.X.

Lacariere, .xw.

Lactoix, cx.

Lateruix 1. coxxax.

Iarpix 0 . . fixxus 


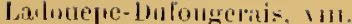

Latuderich (René), CL.

Lilleupstre, xxxix, r:xt.

Laferriore, xar.

Laflille, $x$.

Lalfilla (Pielw), crmt.

ling che, cximu.

bilgonlle. cxxis

Lilgl'ile (.Michel), Lxis, Cr. con.

Lilguionit, I.xx, cx, ci..

lahor (teat), cxrm, chm, cLx.

balute (dexis), wxir, Lxxxix, cvm, cxtı.

Lifine (Lou:s) xxxit.

Lilinel, cxxiy.

Lajolais (Louvriel de: Viil Ionvrier de Lijolais.

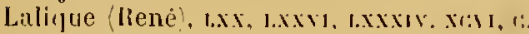

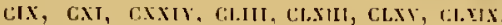

I.iluux, irn.

Lamaille Géo, Lxxиm, I.xxix, lixı.

litubelin (Roger), rixxx:

Litribert, call, rix, cxilt.

l.ami Eugene), xur.

Lamolbe Giol, ccir.

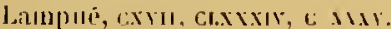

Li Ilisugrie, xilr.

Lin, exxitr.

Landier, tax.

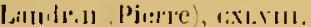

lanessith (de), Lxxt.

Lilluy, cix.

Lillerevill, xxim.

Linglois. caxxix.

Lannes, cIL.

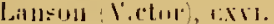

Laprorte-B!airsy, xcrir.

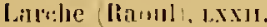

Lilliviere P./, xcitr, r:xtw

Lituche, xx, xxxy.

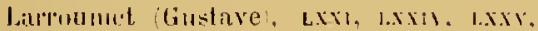
ivil, cris.

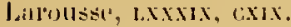

Lalloux, xes.

lisonuer, cxxirat

Lils:tus ide , xxul.

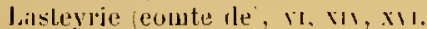

bitloniche G. , cxisin.

Lantrier. axxxy.

linily (ue), cxxwit.

latiretenl, xit.

Liturens Iein-Paul, xcis.

liturems, ixxxix, crut.

Lillth, xст5.

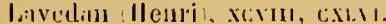

l.avollee 1.l, cxles.

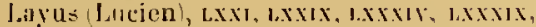

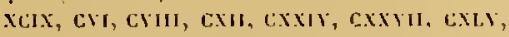

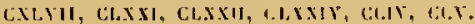

lianlle, וxxxix, xi: crit.
Lebailly, axil1.

Lebasteur, cxis.

Lebeiut, 1Y.

Lebea!1, c.xlin

Le Blan (f.), cxit, cXLIY.

Leblanc Léonide, xis.

Lehlinc-Burbedicnue, cxi.

Leba:uf, xxvi.

Lebon (Audlè), Lxxu, txxvm.

Lejorgne $F$.), xс1, xc1v, cxli.

Le Bourgeois, crx.

Lebouvier, xcr.

Jehrun, xxvi.

Le Chatellier, cxxis, coxilı, coxvm.

Lechesne, cxxxr.

Lecherallier-Cherignarl, crir.

Leclerc, xciv.

I.eclere, cxi.IIt.

l.ecomle. crisix.

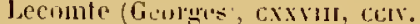

lecog de lini-lonudian, colv.

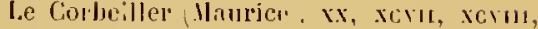
cxil, CXIII.

lecreux (Giasion, cax.

Ledilgre, xxry.

Le llue, rxull.

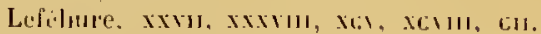
GXIIS, CXLY, CLIS.

d.elehisis, cxis.

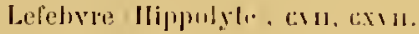

Lufere Cituille. scr, dis.

Jutivie, grim.

leferre el lils, vil.

l.efort C., cxist.

l.ege, cxxis.

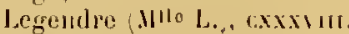

Legenlil, cxxil, cxxxiy, cxxxy, cxxily,

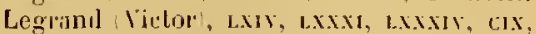
CXLIV, GXXX.

Legrand Chasle- , cxxк, Ixxx, c x.

Lemrand llthur crxy.

Legliel, cri, cxlır.

Legros. cхxхus.

Lelaile .1. , cxxxm.

Leli'vie freres, xar, crx.

Leloil et cie, xxri.

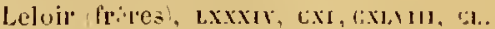

lefoir Il, xovil, GaLl.

J.enaire, vा, m, xrm, cxL.

lembitre, cximi.

lemercier. xivi.

l.enice, xri.

Lume illhi coxv.

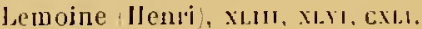

l.emoine. Lxxix.

l.enunnier. xxx.

Le'ufaul, sxxill,

Lumulile, cix.

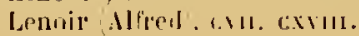


bexul Juseph, t:xir, cioxll.

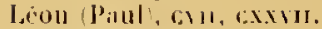

leènarıl, xск.

Lepage-llartiu, cxitr.

Lepire (Auguste), wxxix.

Le play, xix, sxxy, xxxy, xixs, x..

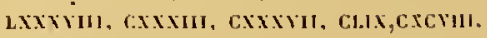

leprevost, xcill.

Jeprince, $\mathrm{cx}$.

lerolle. xxirit.

loe Rosey, l.xxixis.

Le Roux (Alired), cxixv.

Leroy, cxi。

Leloy (Isidole), Lxw, 1.xxr, I.xxxis, xc, cax, CXlit.

Leroy (llaurice), cix.

Leroy (Molesle) cxx.

Lescure. cx. cxil.

Lescur. Lixll.

lesient, cxxх1.

Le suddier, cxur, cxlyll.

Leture. xcrit.

Levallois Eroest, l.xxu, cx.

levallois (A.), cxisint.

l.e Vasseur, Lxir, Lxxix, Lxxxix, Gol.

lerejle, Lxixul, xen1.

Levent Charles', cx.

Levois, cxit.

Levraull. rill.

Levy (Emile), Lxxix.

Lery (Ilichel), cxlv1.

lexy (l'aul, ixl.

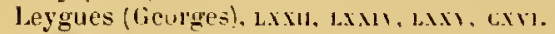
thermille, cvis, сxтын, сск.

Liard, txw, cxvi:

liberty, txxil.

lienald, xx. xix, xsxt.

liènard (Paul), xcru.

liesse (.), cxis, chur.

lieven-Delhaye, cxixu.

Lievie, xxxix.

ligncreux, vr, rit.

Linke (l.). cix, cruvit.

lipmann, csi.

lix G.), c.xi.

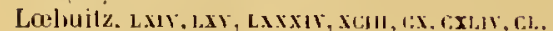

Loizel, cxxirut.

Luliée (Frélérie!, xtrs.

Lolliot, $\mathrm{cx}$.

Longperrier (de), cxirvi.

Lorain (Paul), xxix.

Lorfal-Jacob, critr, CL.

Lorthiois, ci, ct.

Loruchet-Bernaul (G.), CxLı.

lutichel (P'iul), cxi.

Louis XI roi), Ir.

louis XVl (rui), I, nu.

louis Xill] (roi), 11.

loui-plailiple (roi), xis, xw11.
Lourdalel linesl . Ixxint.

lourties (Virtur), Lxxint.

Lotvel. CxIxpH.

louvel, Lxxiri.

Louve Palais dı', II, r, vi, xil, xis, xir, xy, XXY, xLI, LXXy, cur, cxxix, cxxx, cxxy.

Lompier de Laljolais, xxxix, wil, Lx, txx. LXXI.

luens \{léou\}, cxxxuı.

Lucet. $\mathrm{cx}$.

Luciphar, cxis.

Lucy-Sédillol, cxxry.

Lunet (Louis), crrmi.

Lumiere. crill, cxiv.

Luynes (duc ale xxir, xxx, xxxint, xLrı,

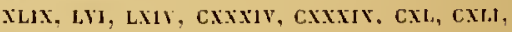
CXIK.

Luze (lleuri de), cxllill.

Lyon Gus!ave, crin.

\section{M}

Machault. «.

Maricl (Jules), Lxxir, cu, cix.

.lar-.llahon (matéclal de), I.I.

dlackintosch, croxull.

Macght (Ch.), Cxitr.

Milïs, xxx.

Mil̈s (lieorges), cx.

Materlinck (.laurice), cxxir, cixil, cLxil, Nigne (Emile), cix.

Magne (Il.-M).), xim.

Milgne (Lucien), Lxixr, xcrul, cril, call, CXXI, CXLI, cXLII.

Maguin Alfred), Lxil, cri.

Maillard. cxis.

Itillet, $\mathrm{xr}$.

Inillet Arthur, Lxir.

Mainguet, Lxxxıx, cru, cxır.

Mainie, cxx.

Maison (Louis), cxism.

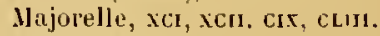

Malherbe (ic), xc.

Ilallel, xev.

Ila!lel (Etwuard). cxxxr.

Millié, xir, xv.

Maloye, cxxxul.

Iristère, cxisti.

Mame, xxvi, xiollt, Lxx

Manaul Fréléric, csxı. cro.

Mandard Victor). $c x$.

Mansarel (G.). cx, CuL.

Mantz Paul, xxxix.

Man\%i, rxxis.

Miple, Lxxill.

Marais, cxull.

Marcadel, cxxis.

Mared. $1 x$. 


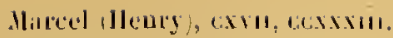

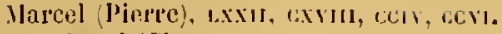

Matrchand (Cll.), Litl.

Marconx-Chateameuf. xcr.

Malpescot, cx.

Maret Jleury, Lxx.

Margaiue-Lacruix, xw, cx.

IIrgutrille, x.

Marie Joulso (imperatrice . $x$.

Marje (Cluarles), xcrut.

Marin, cxxivi.

Maruuse (C. ', CxLYu.

Malolte, Lxit, I.xxxix, cril,

Margue (Hbcrl), cciv.

Marran (Ch.), xcry.

Hariel, xix.

Marrel, Lxiv, Xcti, cXi, cXis.

Marrou, Lxir, xcvir.

Marteau (Ch.), ixır, cxist.

Ilattelel, cxxivi.

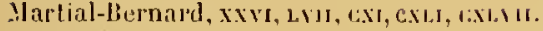

Jarlin Georges), $\mathrm{Cx}, \mathrm{cx}$, y.

Martin tJenrj, cxxis.

Martio, 11.

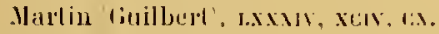

Martin Fernated cxi,

Mirtin liene? ex; cxisul,

Martin Irl]ur', èr.

Martinet, ciss.r.

IIarty, LXXYII, CXL1I, CXLIII.

Marvejouls, Lxivir.

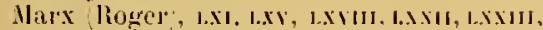

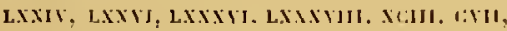
cxil, cxvit, cxix, cximl, cxxis, ixxylt,

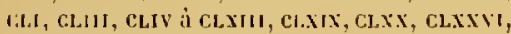
cerv. rese, coxisi.

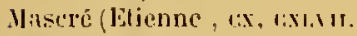

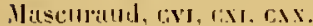

Masquelier, vil, vill.

Masse P. , t:xL11.

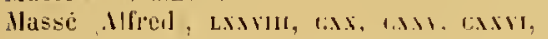
LLI, CIII, CLXXY, GIXYY, ta:XII, CH:XY.

Massine 1 , (.xis.

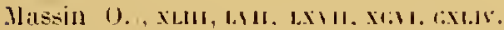

Masson, Lxxxw, bxxxix, crill, crixtx, cis.

Masson, cxixym, iximl.

Mittlie aìne, cxi.r.

Malhovel, xxill.

Ilalliell, cxxxin.

Mathice. ixxxt.

. Mallion Eugane. ex.

Mannoury, $\mathrm{cx}$.

Niarey-Deschamps, Lxxix, CxI.

Maurice, xxis.

Maussilo, cxxxrut.

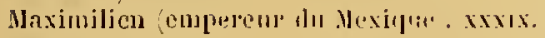
Jazaroz. xxxvil.

Jegnie\%, 1.xxul.

Vellerio. xiv.
Ménitrd liche, sisis.

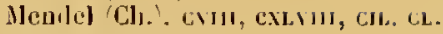

Menier Gastou, Lxxi.

Menu, xcrit.

Melié, evil.

Mercier, Lxw, xсп, :н, си.

Mercier, cxillI.

Mercier (Etnest), CxLr, cxist.

Merier (11.). crrmin.

Mère (Clèmenl), cix.

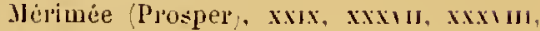
cxxil, cxxxy, CI.

Nerlat, cxirt,

Ilevin, r:xxiv.

Jermilliod (Eug.), cx, cxistr.

Merson (Juc-0livier), Lxxi, Lxxxix.

Mesuil, t.xxu.

Jesureur, Lxxinu.

Mithey, cux.

Métivel (Luciun), Lxxur

Jetulu, ci, cisxil, cossy.

Wellerujeh (princeser de, ilur.

IIelz (Arthur), cx.

Hever (dllied), xams.

Huger (Georges), cxi, di..

Meres, exximin.

lleyuad, xxvi, cisil, cxist

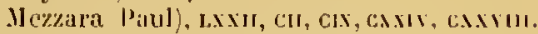

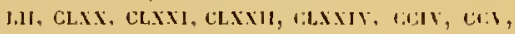

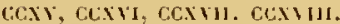

Michilux, cxl.

Micled (Marius), Lxv, Lxxxr. cix.

llicluel, xxir.

Miclel (Gustave), staluaire, cxxry.

Nichel (Is.), CxuIl.

Jiclel (Marius), cir.

Ilichel Victur), I.sxis.

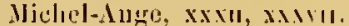

Miclıel-Cóte. $\mathrm{x} x$.

Ilicluelel, mxxra, cixml, 1.,y.

Migeol, cxtsl.

Mirneron. $\backslash 11$, las

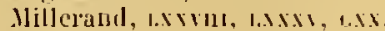

Villet (Pial), cxLII.

llilset ('l\%.), cxLIII.

llillet (Nime), xxxr.

slmcrel, cxixu, cxxin, crxxis.

Minet, cxxsis.

Hinosel, xixix.

Minot. Ixxxis.

Mirabeau. xhru.

Holl, cxxryil.

Monduit, LxII, Cxit, Ccxivi.

Jonge, vi, vis.

Jonmeja (Ferdinand), cxvir.

Jounet (1.), cxxxiur.

Jonnies, cxilu.

Noutaillé, xcv.

Jlonlirmal (Eag. de), Lxil, cri, cril, cax. 
Montesquieu, cxxi.

Montgolfier, vi, $1 . x ו 1$.

Muntherué (cristallipies lie, ar.

Monthiers (Maurice), l.xi.

lloreau (Gustave). Lxi, xcu.

Horeau-Nélaton (Etienne!, xciı.

Morel, c.scur.

Mlorel, xxvi, xxxi.

Moreno llemiqués, cxaxvil.

Morice (Ch.), cLx.

Morın (général), xxxs, xxxyı.

Morin (Ilarius), cxLIs.

Marin 1. GxL1.

Morin, Lxxxix.

Moriquand. cix.

Norny (alie de s. xxis.

Muruy (duchesse de), xl.u.

Moroge, rist.y.

Morris (W:Ilian, Lxix, Ixxy, ck. daxiva.

Mortier (1.), crur, cxur.

Molte, cx.

Hotteroz, ixxix.

Muscliel. cxixit.

Mouchy ducliesse de, vill.

Mouilbart, cx.

Mloulin (P.), c.st.H.

Mouliuet, csxix.

Mourcean II.). I.Y. Cxu.

Monrey Pl.! xysul.

llucha, xcis.

Mïlılbacher Guslave, IXxı.

Ilulari, cxcy.

iluller, ixy, xcill.

lluller, cix.

Mulleret, xisi.

Muntz (Eugine), xxxix.

Nurat, Lxxxib, cri.

Musild (Miice), xı.ly.

Musée Galliéra, cu, cxru, chı.

Musèe du Costume (projel), cur.

Musce Vicloria-Albert de l.ondr's, cir.

Ilusée d'Art et d'Industrie de Lyon, i. I.x. Musée des Arts decoratils. xxxix, Ix. Lxxu, xc, c, cill.

Musèe du Loxemboum. Lxxy.

Mustel, crill.

Nluzel Ilexist, wr.

\section{$\mathbf{N}$}

Sitdal, crrrs.

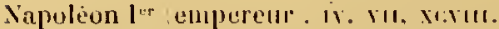

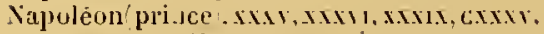

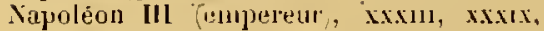
cxxxi, cxsxy.

Narjoux, cvu, c...

Natalis-liondul. I.1\%; wIt, ix. cxxxul. cxxxis, cxxxy, cxxxy, cxi, c.xi.i.

Parmat, i:xum, c:xis.
Tavale, cxlum.

Néron (Ellouilrd), cets.

Neufehateau (Francois de, I, I, I, I.

Neumout Maurice), וxxxix, cru.

Ney (souts), xcr.

Viclituse, Ixxu, cri.

Nicolle, cxxru.

Nilol, x.

Nivellier C. Cxxinur.

Nocq (Ilenri), xevu, cxill.

Noilot-Biais, ıxxx, xcy, cxth, cx, cxts.

Nollet. cxum.

Normand. cxxxir.

Noulens, cxxy. cuI, coxtl, cuxx.

Nozal, criv.

Nisssbauni, c.xi.

\section{o}

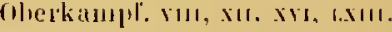

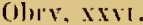

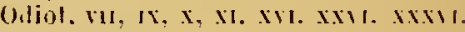

Ollenlsach, x!.:.

(Miriel, vil.

(d)iat, xiril.

Orleans (lue d". xxill.

olto, cillt.

Ousline, l.1t, I.I11, G., t.rit.

Oudry, cxxrrit.

Ozinine (Ch.), cxulı.

ozeniz: d.? cxi.

\section{$\mathbf{P}$}

Pagilled J. cxul.

lagé C.). crisi.

Paguel, calli.

Pilhols, cxllis.

Paillited (V.) cxxivi.

Paillielle (11.), cxivin.

Païva (a), xw.

Pijou, $x$.

Palais des llawufattures, xy.

Palilis des Sciences el des Arls le lonver) $r$.

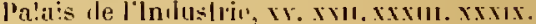

Palais de loll. cur.

Palais Glant, Ixxxy.

Paliis Pelil, t.xxxi.

Palinis des Valion: I.xxmu.

Panis, croxr.

Pilpst, Ix.

Pilquin. dit, cx.

Paquolle, cxtill.

Pal'ent, ci.

Parlot-Lamenl, cirl.

Purison II.). cxisulu.

Pirrisot, cxtr. 
Partuentice, 1 .

Parvillee, Lit, I.xT.

Pascal, coll.

Pasquier, cxliti.

Patey (A.), Lxxxi.

Patoulel, Ir.

Patriarche, criti.

Paul-Boucunr, cxx, cxxt, cxir. Ch, Clit,

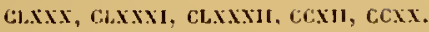

Paulint, sxi, cxis.

Paxton (Joseph), xxix.

payen, cxxre, cxxis, cxxxy, txxxit, crxirill.

Piagen (Inselure), cxxxrit.

Pearl (Curis), six.

Peel (thobert). xxix.

leert, cxull.

Pègard (IIne), Lxxxy, cxis.

l'eigue, crill.

Peiguot, Lxxis.

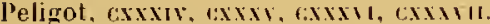

Pellat (11.) cxis.

Pelieria de Lalonche de', cro.

pelletan, Lxixix, crul.

Pelletier (A.), critl.

Pellissier, cix.

Pelouze, cxixvi.

Peltereas Plicide! cixisi.

Percier, $x$, cxxul.

Perloux (L.) 1.xxu, xcs; cx.

Pidrer (.lugustia), vit,

l'eried (Ferdinanit, I.xx.

P'ericel (Scipion), TI.

l'érol, LxxxIy, sci1, I:x, exw.

Perrichon, ccw

Perrier (Jile, t:xint

Perrigot-llisur" ' t.t.

lervin (Pinul), cisin.

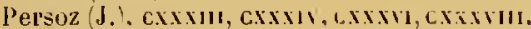

Petit (ricorgus), wxil.

Petileau, xxir.

Petiljean, cxir, cloxxy.

Peliljean (J.) xc, cxist.

l'cupin, cxxxur.

Peycelon. civis.

Perrot, carmil.

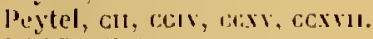

pieiller ili. cxurn.

liall, VIl, rill.

Piat, xxxix, Laxxul.

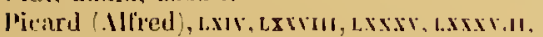
cxix, CXLII, CXIYY.

l'jeard, cis.

l'icard (Edwond), txxil, cxxIs, cLy, cr.xil.

Pichon, cxly.

Pichot (II.), crin, cxlyIt.

Picot, crisir.

Piel, cxxst, cxi, cxisul, cl.

pierj, corr. liverom, Lxxt.

Pierrul, cxull.

Pillel, xis.

Pillet (Charles), crir, cxI.

Pinard (A.), Lxsi, cr, cxlou.

Pinier, cxi.

Piot, xxill.

Piotet (J.-.J.), xcir, cxcri.

Pipel, cxilli.

Piranesi (les frẻres), ril, vil.

Pirolı, crulr.

Piver, t.xsivi.

Planche (Gustave; xxis.

Planclion (Mathieu), scroli, Extr.

Ples:ior (E.), crixis.

Plevel, xit.

Pliclioll, cxuls.

Plon-Nourrit, xxi1, lxxxis.

Plouin, xxy.

Plumel Charles', Lxsir, Lxxr, cril, cxill,

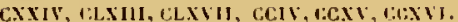

Poidebard, xis.

Poincare (Raymond), Lxxil.

Poirjer (E.), crxirut.

Polienac Mis de! crut.

lollen, cxxrif.

Bulfel, $c x$.

Pol Noveux, xc, cril. cxist.

Pompee (Phil.), cxxxvil.

Ponscamur, xist.

Porcalueul', crims.

Portes, txxi.

Porticz, i.l.:

boteau, sxixi, cix, cil.

Poterbet, xxxit.

Pottecher (Inurice), cxxir, I:ı, cosu, clivi:

linller, Ix.

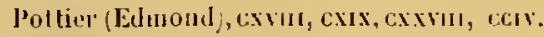

pollon, xxvis.

l'oulhin (Cli.), cxLIs, ct.

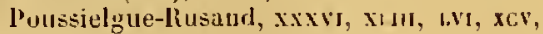
ex.

Poux, xxy.

Pradier, sx, xix.

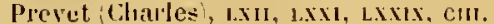

Irevosi, cxixis.

Prevolean. cxxisur.

Prince (Amèdé), cxi.

prince Jinjerial, xxxix, xt.m, xis:

Pruflit, cxi.

Proudhon, GLY, cLXI1.

proust (Antonin), LIX, LX, LXI1, Clt.

Prouve ! lictor), txxix, x., cxvir, cxx. cxxvill, ceIr, cex.

Prourost, cx.

Prulliun. x.

Ptolemice-Philométur, I.

Puech (Bengs), cru, coxil, acxi. 
P'lech. cxxy, chis, ciall, ticxs.

Pruel de lubel. cinti.

J'utois Georges c. c..

Puyis de Clatannes, Lxw.

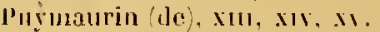

\section{Q}

Quenious liastun, crrm, cxs, cxmm, cor, (Iuennessen, cxi.

Quentin-Batuclanl. cxir. clxxir.

(Uuigusn (dilstare), cxur.

(Uiguon (J.-A.), xxrvi.

\section{$\mathbf{R}$}

bisbeault, cissorit.

lialutean, cxims.

liallinel, xxxix.

liatlius, cxt.

liamberl (dule-) ciximu.

liaimon, cx, ctl.

liaingo, xcri, ext.

liamogé, cxum.

Hintloing, cxxsix.

liann:z li. extroll.

linphitei, sxxrit.

liapin, cox.

Rau, Ixxis.

liaulnilz, $\mathrm{xar}, \mathrm{cx}$.

hault, l.vir.

Rault (.11!lo), xes.

liausse, cxill.

litrio. $1 \mathrm{x}, \mathrm{x}, \mathrm{x}$, cisll.

Rébeillillil. cxin, exxm.

licbour (Ch. cistr.

lieclus (Inurice), cirmi.

liedfern, xcr. ci.

Redonl, crit.

liegis, dxtIl!.

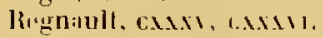

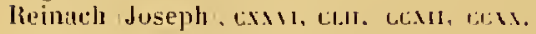

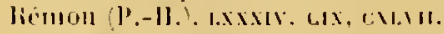

bemou deurges, Lanis.

liemquel. cxis.

liéviusal, $1 x$.

Heuarl Cianille, c.roli.

liendu (Ambroise), asxxr.

lienoldald. ixxrix.

Riesal, ixxit.

Réunien des Cunités el Jurys dus Expuzi-

tions unirerselles, txix, enlr.

liéveillon, vIl, r:ll.

levenu, cxxix.

leverolion, хxis, cxisit.

lieverdol, cs.

lievillon, txxit, ci..

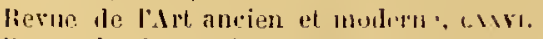

liave ales beaux-114, crxw.
Hevue des lots dicuratifs, Lxi, l.Axul.

Reymont, ixxxix.

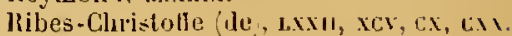

licbourg (1. , txLrut.

Richard E. , cr.

lichard dules, crut.

licois. 1.xu, cx, cxtoul,

Riel (L.) CXLII.

Riesier, xrxix.

lioudez, crun.

Ringel d Jllyach, xulr.

liotor (Lén), cix, cxix, cxsill.

Risler et Care, cr.

livaud, cix.

livet (Gustave), cxve.

Rivière (Tliéulore), Lxxxh, xcı,

Rivière, Lxxix.

Robaglia, cixxrs.

lloberl (Elias), xxxiv.

Robert (Eug.) crxxr.

liobert Emile, xim, oix.

livbert Clatrles', cxxrut.

Rohin (Jean-Paul), xxvi.

liobill Panl , xitrit.

lisbiquet J , xcrin, cxws.

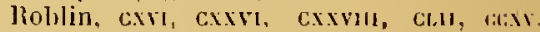

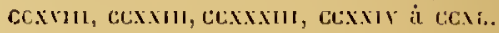
lioly.r.

lloby-] icul, cxu11.

Ruchambeau Jis A. lle, cxe.

lioche pierre/, cxxir, sxxix, xcil, cix.

loch. girosec, txxix.

Rodus (Fermind). cxrit.

Rodanet, hr, c.xı.ı.

lodenbaclı. xenı.

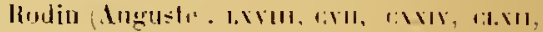
Cl.XY, Ccrili.

lioederer, $x$.

liogier, vı, , 1 .

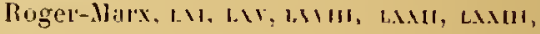

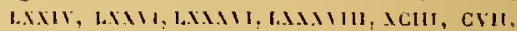

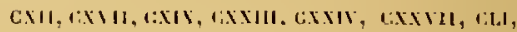

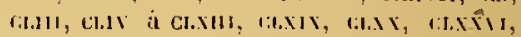
cest, cite, gexsur.

lingrnon Elienne cxrl, cxx, cxxy, aLt,

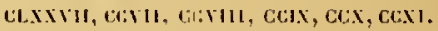

liniticl's, t.xir.

liolland gencint] axis.

lisllin, claxxy.

fiunle roi dle, $x$

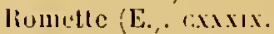

Rondelet (S. . cxixiti, cixl.

lionilot (Natillis, LIV, w1l, I.X, cisxim, cxxxw, cxxxy, cxxxt, cxi, cxi.

Roosen, cximu.

Roques linnerist, arr.

liosis, CXlt.

Rossigneux filıales xux, cu..

hossolitr, cxis. 


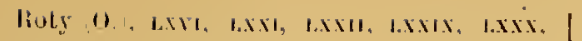

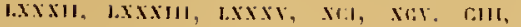
crils.

liotalt, ris.

Joubatali, ex.

Rouclue ,Jicejut:-, exit,

Roulf, xer.

Rouflaril, xv.

Rimhler, ixis.

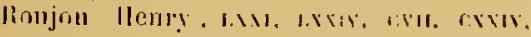

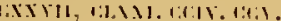

lioulliac, risium.

liomlleamx-1)ugage, fix..

liunssean, 3x, 3xi.

lionsseau (lulex), CI.

linusseall (Theolore), xis.

lintesent1-Idveilli, l.xyu

lioussel, xxix.

liousel Geo!, crit.

lioussel (Paul, xciY.

linussel Finncuis?. A.

linuset (P. cilu.

lionserl, veIt.

liolvenat, xiv, xis, rixl.

lionverer, fist,

linux íhaı"la-?, Jxxu.

linnx, xisti.

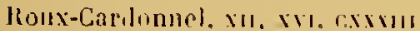

linuzi:, cri.

liny, cx.

Roy (1.), cxirinu.

lloze-Cinllier, xu, xw.

linzet, xer, r.si.

liurlient, Lxxis.

limle, xin, xxu.

liudolphi, xive, xis.

linepp, xi:,

lindz, rixts.

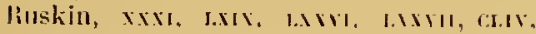
Cl.VI.

limsinger, w

liuln:ilu, lixi.

linty (Ilircel), xc.

linz: I. - li. , i:11.

\section{$\mathbf{S}$}

Sabran el Gersi, xirn.

sachot (limes', cxitur.

Siaget, $1 \mathrm{~N}$.

Siaglio, cris.

Silnsere (Olivier). cr, acur.

saint-Amant, xxis.

saint-Andre de Lignereux, cxivus.

sainte-Claite-Torjle, xxy coxxy, cxxxw. c.xxxyu.

Silint-Cricg (enute le), oxxxt.

Sitint-Louis (vemeries ds). xry.

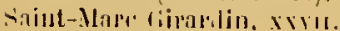

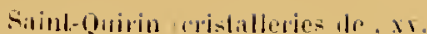

Sainl-siüls, cxrıll.

Sniut-Simoln, call, GLY.

saint-lves, livxrytr.

Saintin, exr.

Sijou, xxхтиt.

Salin 'Palrice', xxxix.

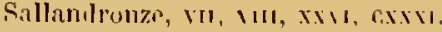

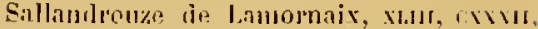
cxixill.

Sillons, 1, 11, 11, xv11, I.xxill, 1:т.х1. 1:сxи1.

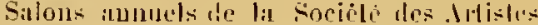
Decoratenrs, cis.

Silons ditulonne, r, cxr, cxxy, t:r, tatil.

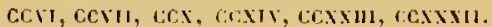

salons du Wobilier. Paris 1909. 1!01:3. 19018. 1!)! cxI1.

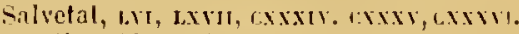

simblier llexamle xcm, an, crus.

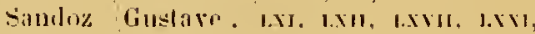
I.XXVI, LXXYIIs.

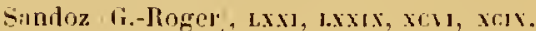

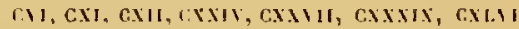

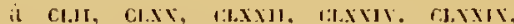

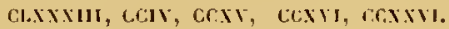

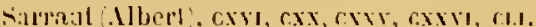

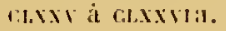

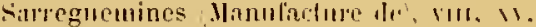
xivi.

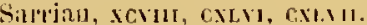

Saunier Charlest. kxwi.

saunier Claulius, cour.

Saurel, vark.

Simet l. . cxxis

Salrage llouri, t.xxxy, ros.

Salwageol, xrutx, xcr.

Gavali, dxy, lxwr, Ixxxir, I:y,

Savall, cxixir.

Savonnerie Manufacture do la . vilı, $\mathbf{x}$.

Savore (le), cxult.

Scholfer-Esadrl, xxxym.

Scheller (Aly), xir.

Scheilecker, cox.

Scheurer, xciv.

Schey, vill, xim.

Sehlimblerger, xy, xxrus, crivu.

Sibunit, xcm, cox.

Schneicled Hottense xis.

Schonacrs-llilleresu, crul.

schuri. cuxll.

schulzenberger, ixi.r.

sichwillty, xxพ11.

suoll Walter, xit.

Séhastien G. , xiw, axive.

Sébille, crxvis.

Sedan tissus de), xxvu.

Sedille Panl, xxxix, tax, wxyl.

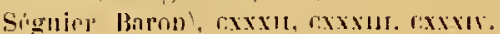


Seguin, xim.

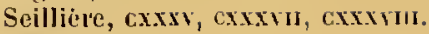

Seirulez, CXLY.

Sellier, xxw.

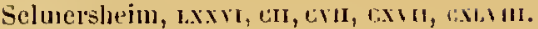

Sembat, cxxy, cl.11, ccxil, cсxх.

Senefelder, xir.

Senegas, cxilt.

Serre Telmon ilu , cil..

Sert (Josi-llariil), xc,

Sérusier, xсы.

Servant (G), t.й, cxis.

Soutiu (Em.), cxist.

Sevin (Constan!), xxxu, wur.

Sivpes (Manufacture de), $1, x x x, 1,1,1 . x+11$, xciv.

Seydoux (1.), cxivi.

Serrig, $\mathrm{GX}$.

Sézille, crxiv, rixur.

Silsille, cxxi, cus, cixı, coxx.

Silney-ltebert, cxs.

Siegfried (lules), wxxи, rxx.

Silbermann, xxvı.

Silvestre (C.), cxxxrm.

Simas, xciv.

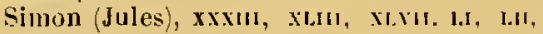
I.II, l.IN, LVIII, cxxtx, Gxi.r.

Simon, vir.

Simon (L.), CxLII.

Simon (Piul), i.xxu, Lxxix, c.x.

Simon (Eug.), cxly.

Simon (1R.), Gxxxvil.

Simonil, cxis

Simonin (L.), CXL.

Simonnot, cx, cle.

Simonnot-Godard, I.xisy.

Simynn, cxvi, cxrill.

Sius (E.), cx, cxuyu.

Siot-Decauville, txxxiv, cxt.

Sirveu, Lxixix.

Socièté des Artistes lécorateurs, a, $\mathrm{cr}, \mathrm{ct}$, cxi, cxvI, cxxis, Gxxy, GI, cLxx, CLxxI,

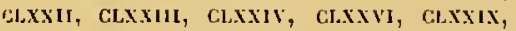

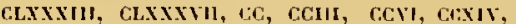
ccxil, ccxxil, corxxir.

Socicte des Arlistes francais, Lxx, I.xxIr,

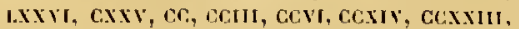
coximit.

Sociétè arcononie Inulustrielle et Conmerciale, txxwur.

Société a’lincouragement pour l'Iulustrie nitionale, I, VI, vir.

Srovide al'Encouragement a l'Arl et i lindustrip, laxy, I.xxı, Lxxi, Lxxxul, c, cxi, cxxis, cxxy, Gli, Goxix á coxxu, cl.xxur, Clxxiy, clxxix, cl.xxyil, clxxxwi, foc, ccur, cev, ccri, r.cxiv, coxxu, coxsur, ccxixil.

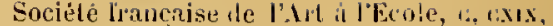

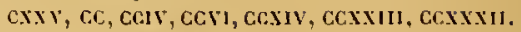
Societé du llusée des Aits llécoratifs, xivi.

Societi Nillionale des Beaux-Arts, Lxx, txxm, Lxxy, Lxxy, cxxy, gC, (coll, Ceyt, ccxis, ccxiru, ccxixu.

Societé logale des Ails, dis Manufacluris, et du Commerce (Lonllest, xxix, xxwr.

Solas (F.), crxxvilt.

Soleat, l.xxxiy, xcril, ixr, cxiy.

Soleil, cxxsix.

Sommerard (du), xxxv, xxxix, xt.th, xเ.1s, cxxxy, cxxxy, cxxxyi, cxi.

Somonny, cxur.

Son $(\mathbf{l}$.), cxxxym.

Sorel, Lxxxit, crut.

Soubrier, Lxxxi, Cix, CXLYI, CI..

Soufflot, $\mathrm{xCr}, \mathrm{cxur}$.

South-Kensington lluseun le Lombles: xxivi, xxxill, xisu, ly, tis.

Sollza (11. de), cix.

Soyer (Cli.), cxi.

Spoetler, cxrxis.

Spuller, txxy.

Staël (IIme de), xir.

Steck (Paul), crvı, cxrvi.

Steeg, cxxy, cxxil, cli, clxxx, cixxxı.

Steinlen, Ixxxvi, Ixxxis.

Steru, xa, crirt.

Stern (Charles), crrr.

Stetten (J.), Cul.

Stettiner (I), cxiv.

Stoerkel, cxxix.

Stopch (lejon), xcr, cx, cxur.

Suë (Eugène), xim.

Susse (Alberl), Ixxu, Lxxxiy, cxi, cxIr, cxisix.

Susse (Jacques), cxi, cxur, cl.

Szabo. crx.

\section{$\mathbf{T}$}

Taburt, txxu, txxxty, ycy.

Taffonneau, cx.

Taigny (Ediuond), x.I, cxxxym.

Taillandier, cL.

Talleyrand, xciul.

Tarbes (Igr tle', xar.

Tartart (E.). Exxint.

Tassimari, scriv, cix, ei.

Tavernier (Cli.), cxxxy.

'Teisserenc de Burf, I, vill.

Templier (Paul), xcrif, cxi, caxvis.

Tenicheff (princesse Mirlip), cxxis, caxil.

Ternaux, vi, xir.

Ternisien, Lxxxiv, crx, axi.vut.

T'ernynck, xxwm, cx.

Terquem, c:tı. 
Terren, cxrsu.

Testard Mauricej for.

Téterrger, cxi, cu.

Thénard baron), xxir.

Thenard (baron Loujs), crur.

Thèrésa, xi.v.

Thesmar (l'eluand), хсын, cor.

Thibault, xxve, cxxiut, cxxxis.

Thibonville-Lany, ı.xх, t.xхти.

Thięhaut-Sisson, rxiv, Lxxu, cxist.

Thiebaut (Clı. , cat.

Thierly (Gilstive?, textr.

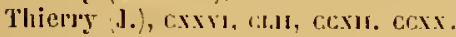

thiers, xrut.

Thiévet, $x$.

Thomas, cxulur.

Thomas, Lxxry, cxil.

Thowire, Ix, $x, x I, x y, x y, x x y$, xxxy.

Tiffany Louis), l.xvi, I.xxwy, sc.11r.

Tiliet, cXLs.

Tillier, rxwr.

Tipman (Alhert), crivir.

Tissie (Lucien), cax.

Tissot (E. Ch.), cXLN.

Tortoni, xxvis.

Toubin, cxxxitu.

Toudoure, cris.

Toulouse-Lautrec, ı.xxxy, xisı.

Tourrelte, cri, cix.

Touref, xxw.

Tournade, ci.xinr.

Trabuchi frères, ru.

Trélal, Lrus.

Tresea, xxxul, cxxirt.

'rézel, crx, clt, ci.

Triruels, xx.:

Trocadero (Palinis dıI, LI, LYT, LxuI.

Tronchet, Lxxirt, cril.

Tronquois, cxis.

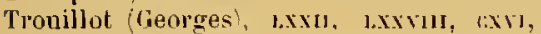
cisxis.

Troyet, xсr.

Truchet, crit.

l'urck (Georges), cax.

Turfuetil, xxrum.

Uubdenstork, ciu.

Union centrile des Arts decoralils, scou,

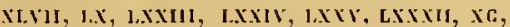
c, GII, GXI, CXXV, ClI, CLII, CIXXx, CLXXI,

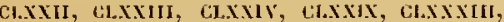

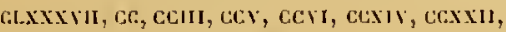
ccxill, ccxivi, clixxill.

Union centrale des Beaux-drts app'iqués a l'Judusirie, xxxyIl, XLvl, Lx.

Union provinciale des Arts decoratif:, c, cxr, axy, cxxy, re, fritr, gext, ersil, ccximi, cr.xxiI.

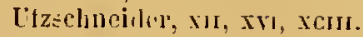

\section{V}

Vachier, cxt.11.

Vachon (Mariusj, Lxxr, Lxxry.

Vagurer (lien), cxi.

Vaillantet, crun.

Valencienues flenlelles de , xxrr.

Valeulino, ıxми, cru, сxит.

Vallet, cat.ı, cxill1,

Valloton, 1.xxxix, xem.

Valler (N.), cxxis.

Valton, cxi.

Vall di:ker (P.), cxist.

Van lBlarenberghe, cxxxiu.

Van lipock (Gaston), txxi, cxix, rxxum, cLxil, ceul, cexr, ccxis, cexril.

Vial Calster (A.), cxiı.

Yin der Stoppen (Ch.), cxlir.

Vian de Velde, s.xini, coxvir.

Vaucanson, t.xin.

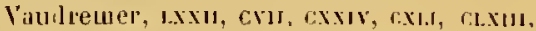
cLXYI.

Vaunois (Albert), cxilr, cxx, cxxyll, colv.

Viauquelin, $\mathrm{VI}, \mathrm{Ix}$.

Vilutier, cxws.

Vaut:er Galle, XLF,

Vauxcelles, cixty, cxirı, t:1.xu.

Vehel (Jein), Lxxxir.

Veclite, xx, хххи, хxхıу.

Vennenberg, ccxrour.

Venzel, rII.

Verbockhoven (S.-B.). cxLII.

Verger, csinu.

Verhaeren (Emile), cxxis, cixu, cLxis.

Vernègéol, cxisur.

Vernet (Ilorace), xxvir.

Vernet-Parmenties, cxirn.

Vermeuil, xcur.

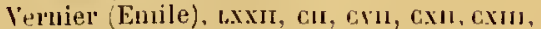
cary, ccxxriII,

V'eruon (Frẻdéric Je), xacr, xcrur, cu, crı, cr, cril.

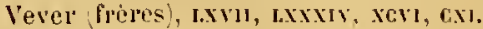

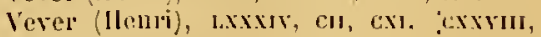
cxis, cels.

Veyral, xxxilus.

Viallar, cx.

Vian, xcill, cxI, cxly.

Viald (L. L.), cxxxix.

Vidal (Leon), cxls, crist, r.xryu.

Vidie (Jamres), cxi.rv.

Vierge (Daniel), Lxxix.

Vieules, cxisn.

liger, cri. 
Vignon $\left.(.1]^{\mathrm{m}}\right)$. Xis $\mathrm{x}$.

Vigomeux, cxxxis.

Villeminot, $\mathrm{cx}$.

Villeneuve, cxxxrx.

Villeroy, iv.

Villette, cxLIII.

Vilmorin, vi.

limont (Léon), cx.

linant (Georges), crx.

lincent $(\Lambda$. , , sir.

Vinci (Leonard ale), s.xxxix.

Yinet (A.), cxuvis.

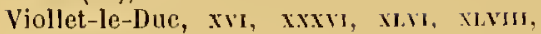
cxxxix.

Vitu (Aug.), cxxxvi.

Vogt (G.), xci, Cxivi.

Voguë (vicomte E. -M. de), xLıH, I.xur, Lxiv,

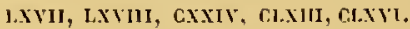

Voirin, crill, crswrit.

Vo!ta, txir.

\section{W}

Wibout, cxum.

Waddington (E.), cxir.

Wagner, xxu, xrvi.

Wagner (Ch.), cxxa:

Walewska (.lme), xi.u.

Wallander, ccxivur.

Walter, wxis

Walonquier (le), cus, ces.
Warée, Ixv, xel, cxil.

Warwick, Ir.

Walteau, cixxur, ccxils.

Weber (C.), cxirr.

Weill (Elie), GXuII.

Weill, xc, crim.

Wibaux-Florin, cx, cal.

Iickham, Lxx.

Willette, Ixvi, дxхуг, xr.

Winterhalter, xur, sivi.

Wittmann, crur.

Wolff (Louis), cx.

Wolonski, sxul, xxx, cxxint, cxixis, cxxxy'1.

Worms de liomilly, crivin.

Worth, rcr, cx.

Willemolte (1.), cxxxix.

Wumderly, Ixxi.

\section{$\mathbf{Y}$}

Yencesse (Ovide), cri, crit, cxiv, cхr.

Ives Guyot, Ixxi, cir.

Yvon, CXXIN, CLXU

Z

Zeiller (R.), cxiı.

Keller (Ch.), cxi.u.

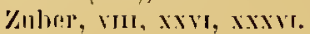




\section{ARTS APPLIQUEES ET INDUSTRIES D'ART AUX EXPOSITIONS}

\section{TABLE DES ILLUSTRATIONS}

Médailles et Plaquettes françaises des principales Expositions.

\section{8-1912}

l el II. - Ineuxieme et troisiome Expositions de Paris, an $1 \mathrm{X}$ el an $\mathbf{X}$. Midaille grave par Benjamin Duvivier. (Il nen avait pas élé dé-

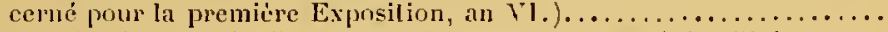

111 et 11 . - Projel de médaille, par Andrien, n’avant pas élé utilisc........

Y el VI. - Médaille de la Société d'Encouragement ponr l'Industrie nalionale, fondée en 1802 , qui pril une grande part à l'organisaliun de la

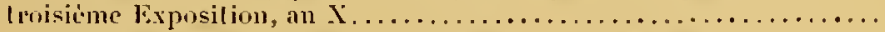

Vil el Vill. - Qualrième Exposition de Paris, 1 So6. Nédaille gravide pa.

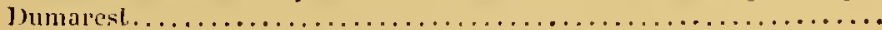

IX. - Face des Médailes des cinquiène el sixiène Expositions de l’aris,

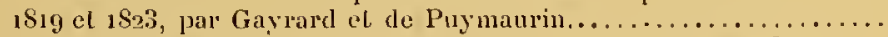

X. - Revers de la Médaille de la cinquiène Exposiljon de Paris, $1 \$_{19} \ldots . . .$.

Xl el Xll. - Premier el deuxiène élal dı rever's de la Nédaille de la sixiène

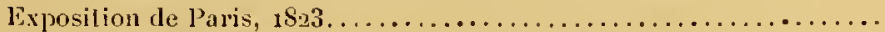

XIII. - Face de la Mlédaille de la seplieme Exposilion de Paris, 1s\%, par

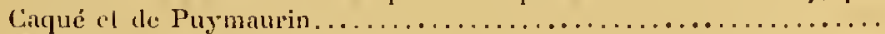

XIV. - Revers de la Nédaille de la seplieme lixposition de Paris, $18 ? 7$. sem-

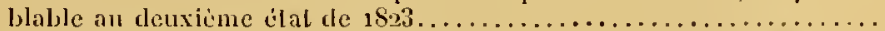

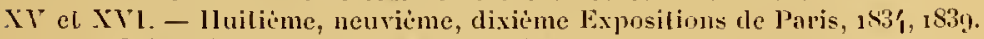

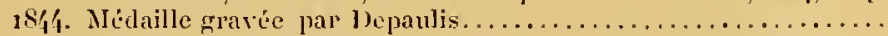

XVII. - Petile médaille frappée à l'oecasion de la dixieme lixposilion de

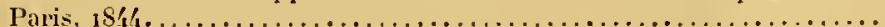

XYll el Xix. - Onzième el dernitre lixposilion nationale de Paris, 1849.

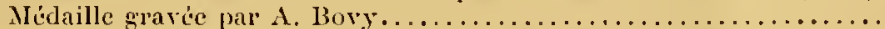

XX et XXI. - lixposition universelle el inlernationale de Paris, 1\$5. Mé-

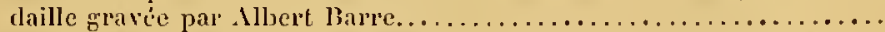

xxil et XxIlI. - Médaille comménoralive du palnis de l'lndustrie, gravéc

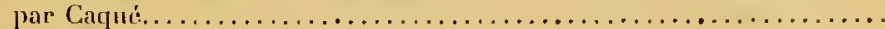

Xxlv. - Exposilion unireselle el inlemalionale de Paris, 1867. Grande

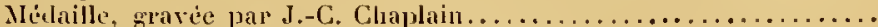

$\mathrm{XXY}$. Exposition miverselle el inlernatiunale de Paris, 1867 . Revers de la

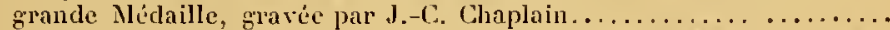

XXY1. - Exposition universelle el internationale de Paris, istiz. Face de la Médaille des récompenses, gravée par ll. J'onscarme.............

xxyll, - Exposition universelle el interutionale de Paris, 1867. Jace gravéc

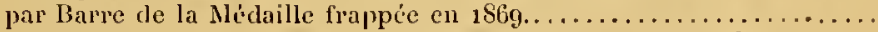

XXYlll. - Exposition universelle et internationale de Paris, 1867. Revers

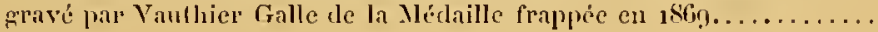


XXIX. - Face de la Platuetle des Exposilions organisées a Paris en 186.5, $1869,1874,1876,1880,1882,188 \%, 1887,1892$, par l'Lnion centrale des

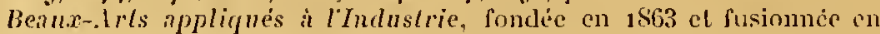
1883 avec la Socielé dn .Insée drs. Irls décoralifs sous le nom aclucl d'Union centrale des $\mathbf{I} \mathrm{rls}$ décoratifs........................

x.x. - Exposilion universelle et inlemalionale de Paris, 1878 . Face de la

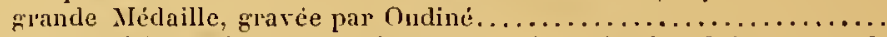

xxxl. - Exposition universelle el internationale de Paris, $18-8$. Revers de

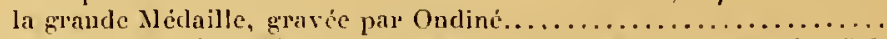

XXx11 el XXX111. - Exposilion universelle el internalionale de Paris, 18-8. Médaille des récompenses, gravée par J.-C. Claplain. ............

xxxys. - Exposition universelle el internationale de Paris, 18-8. Face des Médailles, gravées par Oudiné, l'une pour la construction lu l'alais: dı Trocadéro, l'autre en souvenir des Palais du Champ-dle-Mar's....

XXYT. - Exposition universelle el internatinnale de Paris, is gs. Revers de la Mlédaille du Palais du Trocadéro, gravée par Oudine............

IXXY. - Exposition universelle el internationale cle Paris, 1878. Rever's de la Nédaille des Palais du Champ-de-1Jars, gravée par Ondinc.......

X.XXT11. - Exposition inlernalionale d'ślectricilé de Paris, 1881 . Face de li

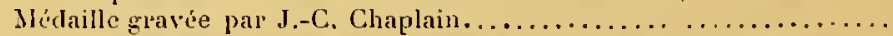

Xxxvll. - Treizieme Exposition oryaniste a Bordeaux, en 1882, par ha Sriciete philomallique. Vace de lit Médaille (reduite d'un quarl)......

IxxIx. - Exposilion universelle el internationale d'Anvers, 1855 . Face de Ia Médaille de la Section française, gravéc par J.-C. Chaplain.......

XL. - Exposition universelle et internationale de Barceloue, 1888 . Face de lit

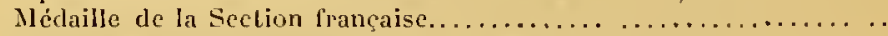

XLl et XLII, - Exposition universelle el inlernationale de Paris, ISS(1. ML:daille des réeompenses, gravée par Louis Bollé...............

XLull el XLIV. - Exposition universelle el intemationale de Paris, 1884. Médaille commenoralive, gravic par Daniel Dupuis..............

XIV el XLVI. - Fxposition universelle et inlernationale de Paris, 1880 . Medaille de la Tour Eillel el des Palais du Champ-de-Mlars, gravie

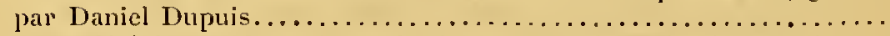

XLYII. - Sociélé des lrlistes français, fondée en 1882 . Iédaille gravéc pal

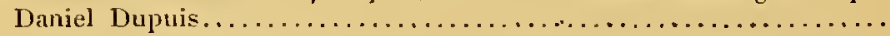

II.VIII. - Socièté nationale des Beaux irts, fondéc en 18 o. Plaquelle gravéc

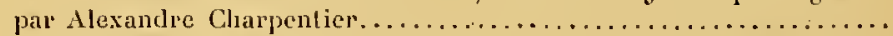

XLIX, - Exposition lrançaise de Londres, 1890 . Nédaille dessine par

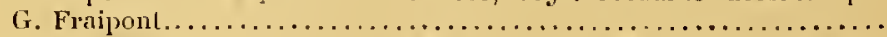

L. et LI. - Exposition liangaise de Moscon, 18!1. Mledaille daclmission

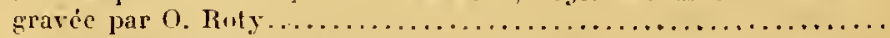

Lll et LilI. - Exposition niverselle el internationale de Chicago, 1893 . Plaquelte de la Seclion française gravée par O. Roty .................

LIV et LV. - Exposition universelle de Lyon, ISý. Médaille grave par

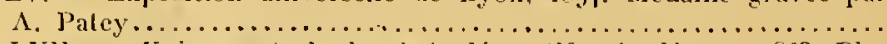

LYl el LVII. - Union centrale des Irts decoralifs, fonde en 1Se.3. Pla-

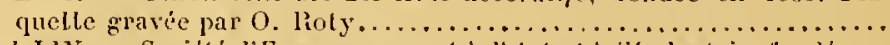

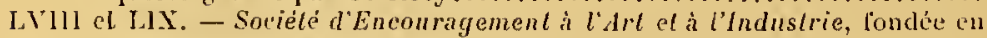

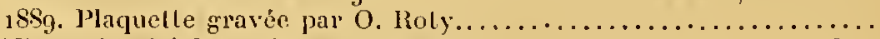

LX el LXl. - Comilé français des Exposilions à l'etranger, londe en 18 yo. Plaquelte gravéc par Louis Bollće.........................

L.Xll el Lxıll. - Exposition nationale el coloniale de Rouen, 1896 . Médaille

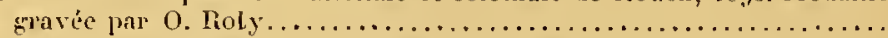

LXIV el LXV. - Exposition universelle el internationale de Paris, 1 . $\ldots$.

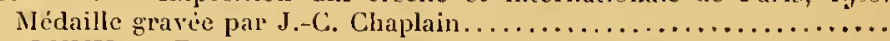

LXVI el I.XYII. - Exposition universelle el inlernalionale de Paris, 1gu.

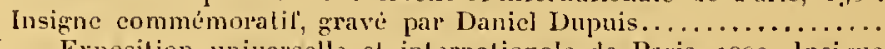

Lxv1lI. - Exposition universelle el internationale de Paris, 1900 . Insigne

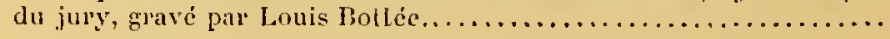

WI.YI

LII

1.111

I.

WI

LII

I.T'II

IXI

I. I I

1.XII

LXI

I.XIII

I.XY

1.xin

Lxis

IXxy

I.xxy

LXXTX

LAXX

IXXXI

I.XXxา

เ.xxxแ1

เ.хxบั1

I.xxxy

Exxity

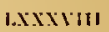

ז.x 
LXIX et LXX. - Exposition universelle et internationale de Paris. 1gor. Pla-

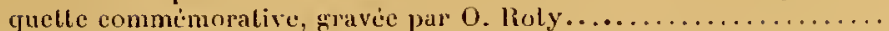

L.XXl et LXXII. - Exposition internationale de Glasgow, 1go1. I'aquelte de

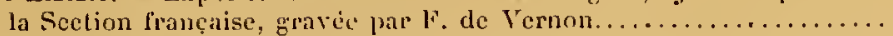

lXxill et LXXlV. - Exposition d'llamo:̈, 1902-1903. Medaille comménuma-

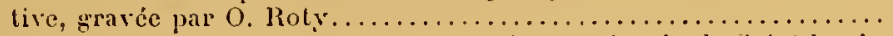

IXXY et LXXVI. - Exposition universelle el intermationale de Saiut-louis, 190\%. Plaquelte de la Seclion hrançaise, wravée par Louis Botté....

L.XXYl el IXXVIII. - Médailte commemorative du Lausfert au Louve dh

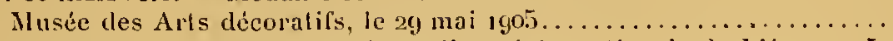

LXXIX et LXXX, - Exposition universelle el internationale de liége, Igph. Plaquelle de la Section l'rançaise, gravic par fi. de Vernon.........

1.XXXl et LXXX11. - Exposition internationale des Transports et des Aits dícoratifs de Nilan, 19o6. Plaquette de la Section française, gravio

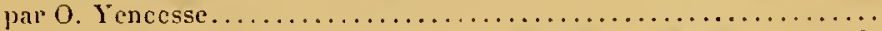

L.XXIll el Lxxiv. - Exposition intemationale des lndustries textiles de Tourcoing, 1,jo6. Plaquelle glavé par llippolyte Lefebrre........

LXXXY. - Exposition coloniale de Ilarseille, 1906. Face de la plaquelle, gravec par L. Palriarche, dapress le tableau de D. Dellepiane.......

1.Xxxy et LXXXil. - Exposition martime internationale de Bordeau,

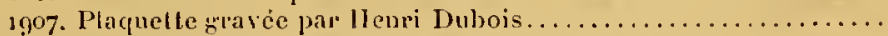

1.XXXvili et LXXXIX. - Exposition franeo-britannique de Londees, 1 gus. Plaquelle de la Section française, gravéc par Ch. Pillet............

XC et XLI.- - Exposition hispano franęaise de Saragosse, 19n8. Plaquelle de

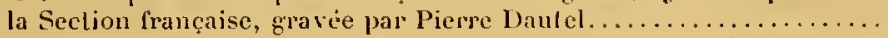

XCH el XCIII. - Exposition française d'Art decoratit de Copenhaģue, Igog).

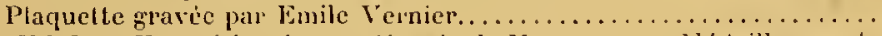

XCIV et XCV. - Exposition internationale de Xancy, 1!gog. Médaille gavide

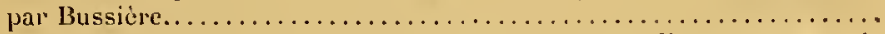

XCY1. - Exposition universelle el interuationale de Bruxelles, 1yio. Faec de la plaquette de la Section trançaise, gravéc par O. Yencesse........

ICV11. - Exposition miverselle el interuationale de Bruxelles, 1910. Revers de la Plaquetle de la Section française, grave par O. Yencesse....

XCVIIl el XCIX. - Expositions internationales de Buenos-Aires, 1 gro. Plaquette des Sections françaises. garave par l'rançois Roques....

$\mathrm{C}$ et $\mathrm{CI}$ - Exposition interuationale de lionbaix, 1011. Plaquette gravée par

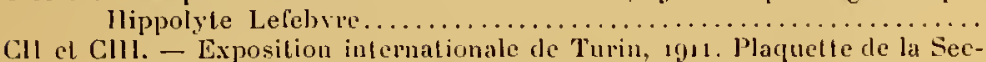
lion française, d'apuès l'ébauche de Pierre biutel............... 



\title{
ARTS APPLIQUES ET INDUSTRIES D'ART AUX EXPOSITIONS
}

\section{TABLE DES MATIÉRES}

\author{
I. - Le Directoire, le Consulat, l'Enpire (1798-1815).
}

Urigine les Exposilions. - Les vieilles Foires. - Salons des peiulres al seulpteurs. - Arts libiraux el Arts uliles. - Corporations, Mail rises el Jurandes. - Louis XVI foude une niedaille d'or annuelle de IIndustrie. - Francois de Neul'chiteau organise la premiere "Expusition publique des produits de l'Industrie française " en Ian VL 1795$)$ - Expusilions de

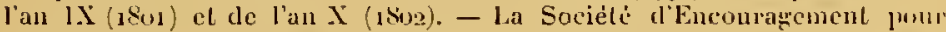
l'Industric nalionale. - Ce que comprement les beant-.trts i celle ípoque. - Suceís des ludustries d'Art ì l'Exposition de 1806 . Style

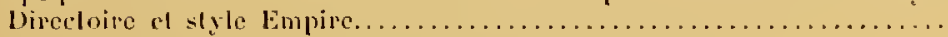

\section{II. - La Re:tauration (1815-1830).}

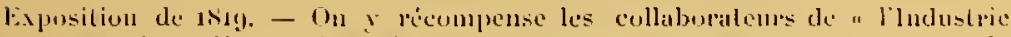
manufacturière " française. - l.e rapport du baron Cusla\% reste le

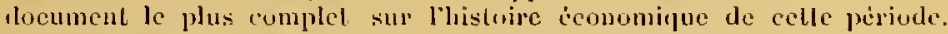
- Insueres relatil des Expusilions de 1823 el de 1827 , quoique cetl.

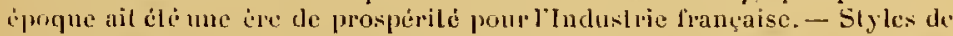
la Restauration. - Ie brie ì brae gollique el " moven ineux " simpose

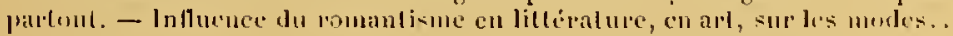

\section{III. - La Monarchie da Juillet et la deuxième République}

(1830-1851).

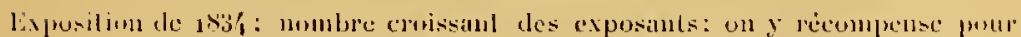
fa premien lais leurs collaborateurs, - Confusion des slyles el dispersion

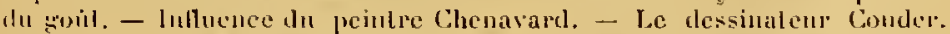
- Osinion de Stéphane Flachat sur les causes du maurais goul de

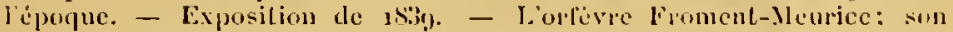
intluence: son projel darl populiare. - Exposilion de 1słi. - Besuin

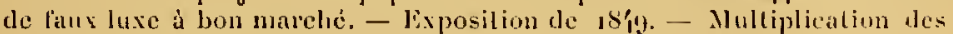
ricompenses depuis cincuante ans. - La gramle luduslice. - l.il mode

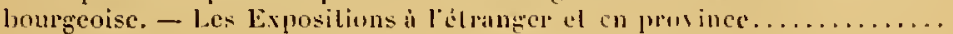

\section{IV. - La Second Empire (1851-1870).}

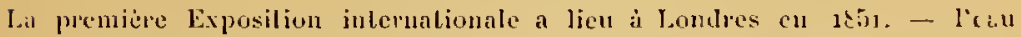
lapport du conte de Laborde sur l'application des Arts i l'Iedustrie. - L'Anerletere nous cnleve nos meilleurs arlistes industriels: Vechle. Iorel, ele. - Exposilion miverselle et inlernationale de Paris, 15i5; principans lauríat: récompenses aux collibomatcurs. - Expusition 
universelle el internationale de Londres 1862. - Lapport de 1'. Mérimác. - Fondation. cu 1863 , de lUnion centrale des Iscaux-Arts appliqués á Iindustrie; son prouramme, ses Expositions. - Exposition universelle et intemationale de Paris, 1867 ; classilication de Le Play; les ropports: les délégations ouvricues. - Slyle, modes el société du second Empire.

\section{V. - Les premières annèes de la Troisième République (1870-1889).}

Expositions de Londres, 1871-72-73-7'1; de Vienne, 1873 : de l'hiladelplice, 1876. - Exposition de Paris, $18-8$. - Son succés el son importance. - Belle introduction au Rapport général par Jules Simon; ses criliques du faux luxe et du manque doriginalité de nos objets usucls. - Nécessilé de créer d'urgence des écoles. - Trés intíressant rapport ale E. Didron sur les Arts décomatifs. - Réformes dans l'Euscinnement du Dessin suivant la méthode d'Eugène Guillaume. - L'Eecule nationale des Arts décoratil's et les Ecoles similaires de province, - L'Luion centrale des Arts decoratifs; son roule el son action. - La France aux Exposilions universelles de l'étranger, de 1878 ì 1889 . - Exposition de Paris, 1889. Son succès malgré l'abstentiou des grandes nations. - Le fer détròne le bris et la pierre. - Les Industries d'Ath commeneent à manifester un riel hesoin d'innover el une tendance plus saine ver's me ornementation moderne, interprétant la nature. - Le maitre Entile Galle.............

\section{VI. - La Fin du XIXe siècle (1890-1900).}

1.'Enseignement du Dessin : l'Eeole natiunale des Arts décoratifs: Grasset et licole de la rue Vavin: les Eeoles de provinee. - La Sociélé d'Encouramément à l'Art et à l'industrie. - Campazne pour l'adinission aux Salons des "Ourricrs d'alt industriel ": elte aboulit en 1 Sar a la Socicte nationale des Beanx-Arts el particllement en 18 , a la Sociélé des Artistes français. - Projet d'une Fxposilion de la Planle. - L'Exposition

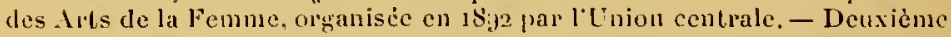

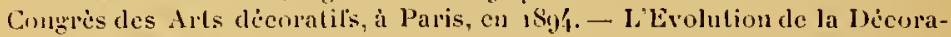
tion el des Arls appliquess accentue de plus en plus. - L' "Art nowveau". cu France el à létranger. - Le Connité français des Expositions i l'étrang'cl el la transformation des Expositions. - Exposilions françaises de Londres, 18.jo, et de Moscon, 1891 - Expositions universelles el internationales de Chicago, 18y3: Anvers, 1894 : Amsterdam. 18y5. - La Scclion française à l'Exposition de Bruxclles, $18 \% 7$. - Exposition universelle

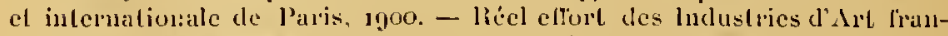
çaises pon se disager des furmes conventionnelles : Emile Galle, lienc Lalique. - Les Musces pétrospectils montrent Vérolution de la mode el du

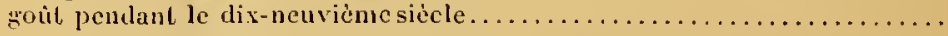

\section{VII. - L'Aurore du XX' ${ }^{\circ}$ siècle (1901-1912).}

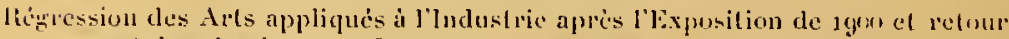
aux styles classiques. - I a mode et le suobisme. - La Socicté des drtistes dícoralcurs et ses Salons annuels. - L'Union centrale installe délinitirement le Musie des Arts decomalirs au Pavillon de Marsan. - Le Cumite français des Expositions à l'étrantere et la Société d'Encouragement ì l'Art el d l'Industrie soutiennent les Artistes décorateurs aux Expositions de Sant-Louis, 190': Liige, 1905; Milah, 1906; Londres, 190S. - L'Expo-

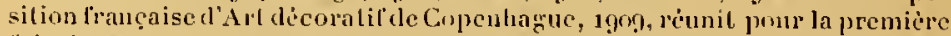
lois dans une aclion conmune artistes et industricls. - Expositions de

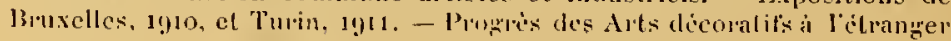


it notamneut en Allemagne, en Angleterle. - Le Salou dAulomne invile les Artistes décorateurs munichois à son Exposition anuclle de 1yjo. - L'Union provinciale des Arts décoralil's. - liéforme de l'Ensciguement du Dessin. - Société française de l'Art à l'Ecole. - Nouvel eflout pour la críation d'un style français contemporain. - La Socialisation de l'Art. - Nécessilé de coordonner les efforts de l'artiste, de l'industriel, de l'artisan, de l'ourrier d'arl. - Projet d'une Exposition internationale des Arts décoratil's modernes à Paris. - Pour réussir il faut unir les Associations intéressées, les Sýndicats et loutes les bonnes rolontés en une vaste Fédération francaise des Arts appliques a l'Tuclustric, qui dev'a rouloir et arvir, d'accord avec l'Etat........................

Liste sommaire des Rapports officiels français consacrés aux Industries d'Art dans les Expositions (1798-1911)

Documents concernaut l'Exposition internationale des Arts décoratifs modernes projetée à Paris.

1" Lixtrat du Rapport sur le Service des Benux-Arts, par MI. Ch. Couyba, chépula:

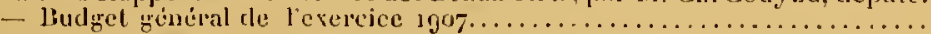

$2^{0}$ " the l'Art social el de la necessité den assurer le progrés par une

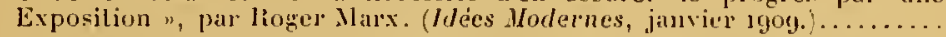

$3^{0}$ "L'Art décoratil s'alroplaie en lirance. Pour le vivifier, il faut faire ume Exposition inlemalionale des Arts décoralif's a Paris", par lloger Marx.

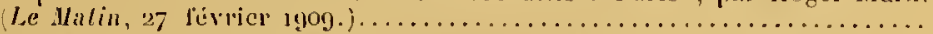

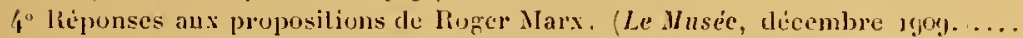

5" Société d'Encouragement à l'Arl et à l'Industric. Extrait du rapporl annucl á l'Assemblée géncirale du 16 novembre $1910 \ldots \ldots \ldots \ldots \ldots \ldots \ldots \ldots$.

6. Société d'Encouräement à l'Art et a l'Industric. - lixlrait du procís-revbal de la séance du Conseil ile direction du 28 mars 1911 .

7" Letlre de G,-Ruger Sandoz, secrétaire fréneral de la Societé d'Encuranement

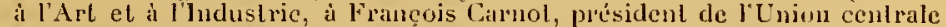

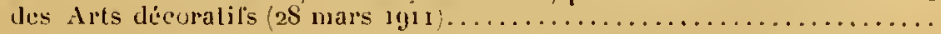

s" "Une Exposition en 1913 ", par Emile Berr. L.c F̈̈garo, 27 mals 1,j1.).... ๒" l'njet d'Exposition internationale des Arts décoralil's moternes. - Réunion des diléguís de l'Union centrale des Arts dicoratils, de la Socicté d"lencouracenent à l'Arl el it l'Industrie et de la Société des Artistes

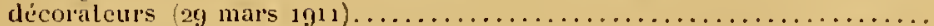

$10^{\circ}$ Chambre des Dépulés. - 1' séance du 30 mars 19n. Discussion ménínle du budget des Beaux-Arts. Discours de Albert Sarraut, I'apporteur.

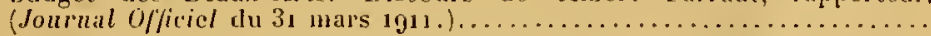

11" Lettre adresséc à Xl. Dujardin-beaumet\%, sous-secétaire d'Elat des beauxArts, par lUnion centrale des Arts dicoratifs, par la Socieli d'licoura-

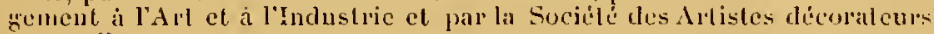

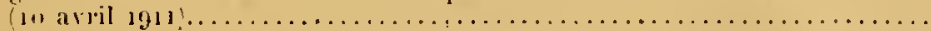

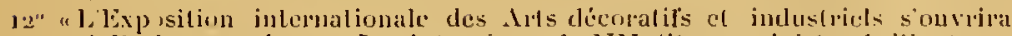

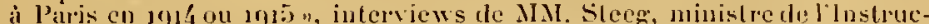
Liun publique; Massé, ministre du Cosnmeres: Paul-Boneutr, minstre

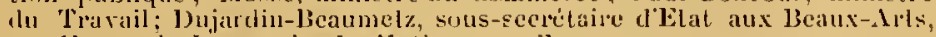

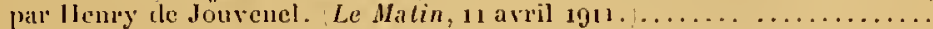

$13^{\circ}$ Conseil municipal de Paris. - Siance du 13 avril $19 n$ : adoption diun veu de Xl. Lampué en l'aveur de l'ormanisation d dune lixposition interuationale

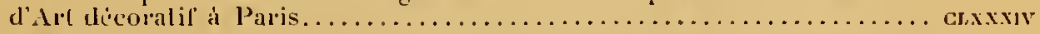

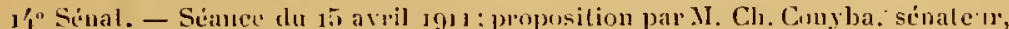
d'un projel de résolution, en vue de lorganisation d'une Exposition internationale des Arts décoratifs el industricls it Paris en 191'.

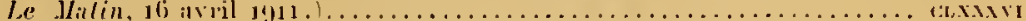




\section{- coliti -}

15. Commission detude composéte des déligués des Associations artistiejues francaises el présidéc par l'rancois Carnol. - Rapporl sur ure Érposilion internalionale des Arts décoratifs modernes it Paris en 1915 (vedige

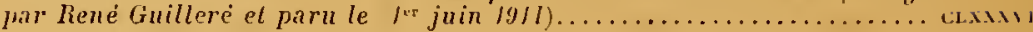

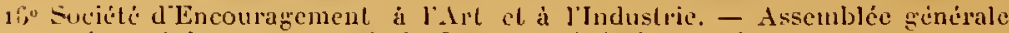
du 20 juin 1911 : extrait du lapporl général amuel..................

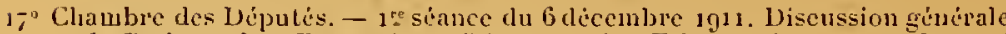
du Bulget des Beaux-Ajts. Niscours de Elienue Rognon. Journal

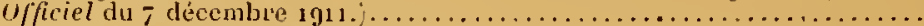

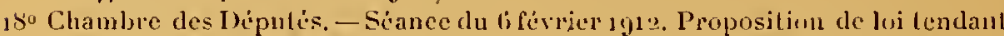
à organiser i Palis, en 1015, une Expositim internationale des Arts décoralit's modernes, présentie par l'rançois Carnol, Paul-boncour. IIenry Cochn (Nord, Charles Dumunt Jura. Massć, Toulens, Pucch, Toseph lieinach, Sembal, Sibille, J. Thierry, dyuard...............

14. Commission d'étude; sous-commission financiére présicléc par G.-liuger

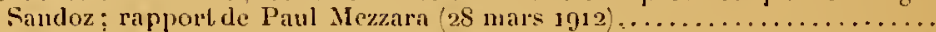

20" Conseil municipal de Paris. - seanec du a av'il 1012. I riscours de Louis

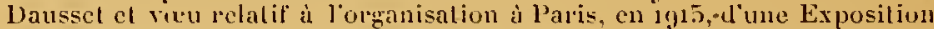

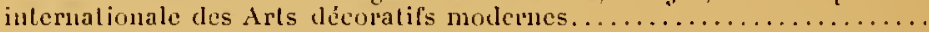

21" Union cent lale des Arts d ícuralifs. - Assembléc grincrale du 30 arril 1912 Extrail du lapport annuel de François Carnol, president.............

22" Chambre des Députér. - Tésumé du rapport de M. liublin, sur la proposilion de lui presentéc en rue d'une Exposition internationale des Arts dicu-

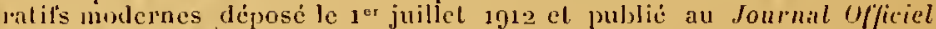

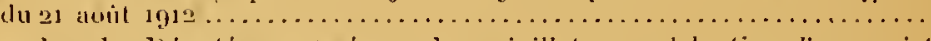

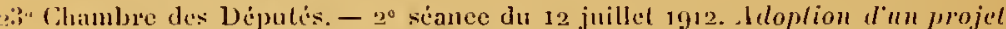
de résolution lendant à organiser en im/6 il Paris une lixposilion inter-

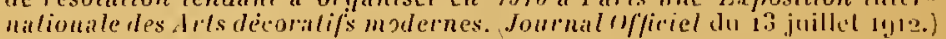

Index alphabétique des noms cités.

Table des Illustrations : Mèdailles et Plaquattes françaises des

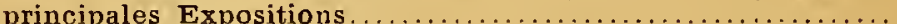

CILXY

Table dos Matières. 






BOUNDB 
